This report was prepared as an account of work sponsored by an agency of the United States Government. Neither the United States Government nor any agency thereof, nor any of their employees, makes any warranty, express or implied, or assumes any legal liability or responsibility for the accuracy, completeness, or usefulness of any information, apparatus, product, process disclosed, or represents that its use would not inferes, or service by trade name, trademark, ence herein to any specific commercial product, process, or service by its endorsement, iecommanufacturer, or otherwise does not necessarily constitute or imply its endorsem the views mendation, or favoring by the United States Governmentsarily state or reflect those of the and opinions of authes; expressed herein do nter
(General Energy Research -

DOE/OSTI-4500-INTERIM 2)

BNL -52131

DE89 000408

\title{
National Synchrotron Light Source Annual Report 1987
}

(For the period of October 1, 1986 through September 30, 1987)

Editors:

S. White-DePace, N.F. Gmur, and W. Thomlinson

October 1987

The National Synchrotron Light Source Department

is supported by the

Office of Basic Energy Sciences

United States Department of Energy

Washington, D.C.

Brookhaven National Laboratory

Associated Universities, Inc.

Upton, New York 11973

Under Contract No. DE-AC02-76CH00016 with the

United States Department of Energy 
Synchrotron radiation is being used at UII to induce and to study chemical reactions in molecular complexes. In one series of experiments, the energetics reactions involving 1,3-butadiene-SO $\mathrm{S}_{2}$ was elucidated, using a photoionization mass spectroneter. In oiher experiments, dissociative photoionization processes in Van der Waals dimers and trimers were studied. These processes involve the transfer of atoms from one moiety to another.

The use of visible fluorescence to vibrationally resolve autoionization of core hole resonances was demonstrated by a research tean from Boston University for nitrogen. By monitoring the $B \rightarrow X$ transitions in $N_{2}^{+}$it was shown that the cross section for the $v^{\prime}=1$ vibrational levc! increases relative to that of the $v^{\prime}=0$ level for resonant core hole excitation compared to photoionization at $\mathbf{S 0} \mathrm{eV}$. In other experiments, a research team from the Statc University of New York and Stony Brook luminescence from $\mathrm{O}_{2}^{++}$ions was discovered, demonstrating that ficiorescence detection will allow characterization of the final state of Auger decay with the high resolution of an optical specusmeter.

A research program on U15 is directed at learning about the chemical consequences of core electron excitation in molecules. The techniques of photoelectron, mass, and fluorescence spectroscopy are being used to reveal how and why unimolecular decay of the core hole varies with molecular structure, and depends upon the nature of the excited state of the core hole. Results for nitrous oxide indicate the importance of molecular orbital atomic populations and overlap populations. A theory, based on the concept of orbital force, is being developed to explain or predict fragmentation patterns of polyatomic molecules following the multiple electron excitation and ionization that accompanies decay of a core hole.

$\mathrm{X}$-ray fluorescence is being used on X24A to probe the properties of atoms and molecules. Progress was made in eliminating well-known problems with this technique and in opening new areas for study. Multiple vacancy effects were revealed, resonance fluorescence (scattering) was shown to avoid lifetime broadening, and energy selective excitation and polatization analysis were used to provide information about the spatial configuration of various orbitals.

$X$-ray reflectivity, scattering, and induced fluorescence is being used on several beam lines (X22, X18B, X3) to provide structural information about molecular monolayers, films, and interfaces, and about liquid crystals, polymers, polymerization kinetics, sol-gel transitions, and protein dynamics.

David Hanson

Subgroup Representative

\section{X-Ray Crystallography}

$\mathrm{X}$-ray crystallegraphic experiments on powders or single-crystal samples were performed at nine or more beam lines aroind the $\mathrm{X}$-ray ring during 1987. Additional stations are now being implemented and markedly increased activity in this field is expected in the future. The experimental problems have ranged from diffuse scattering experiments to complete data collections frem biological macromolecules. A few areas of research will be exemplified below; powder diffraction studies are covered in a separate summary.

Macromolecules. Complete collection of data using rotation photography techniques in the energy range 8-12 keV were performed at several experimental stations during 1987. The dedicated protein crystallography station X12C was particularly active, and high-resolution data sets to $1.9 \mathrm{~A}$ or better were conveniently obtained in less than two days. A total of well over 135 eight-hour shifts of data-collection time was allocated to protein crystallographic work. Major users were visitors to Brookhaven and the PRTs and groups from NASA, Oxford University, the University of California, MIT, Johns Hopkins, and the University of Pittsburgh.

Microcrystals. The high intensity of monochromatic X-rays was used to collect intensity data from microcrystals too small to be studied by conventional X-ray sources. Interest was focused on studies of catelytically important zeolite crystals, and initial studies of crystals in the $10 \mu \mathrm{m}$ diameter range verify the potential for single-crystal studies of crystals down to a few $\mu \mathrm{m}$ on edge. Groups from Exxon (X10A), the BNL Chemistry Department and iriobil (X13B) developed microcrystal diffraction techniques for future use.

Multiple Scattering. Multiple scattering techniques were employed in pilot experiments aimed at the direct-phase determination of crystallographic structure. The excellent colìmation and tunability of the radiation to long wavelengths allowed direct observaion of phases in systems such as $\mathrm{Si}$ and $\mathrm{Ge}_{38} \mathrm{As}_{8} \mathrm{I}_{8}$ [Polytechnic University of New York, BNL Chemistry Department (X13B)] and $\mathrm{V}_{3} \mathrm{Si}$ and benzil [Purdue University (X18A)].

Diffuse Scattering. An important area of research was the use of diffuse scattering, notably on the Oak Ridge X14A and on the SUNY X21 beam lines. The study of the material $\mathrm{Ni}(75+\mathrm{x}) \mathrm{Fe}(25-\mathrm{x})$ around the different absorption edges revealed surprising differences in size of the two different atoms in the crystal lattice. Other interesting studies include 


\section{CONTENTS}

SECTION 1

PAGE

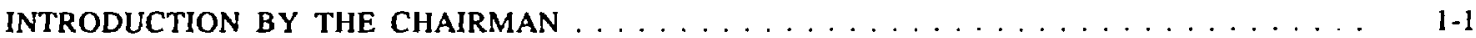

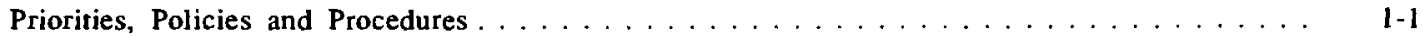

Phase II Shutdowns .................................1 $\ldots$

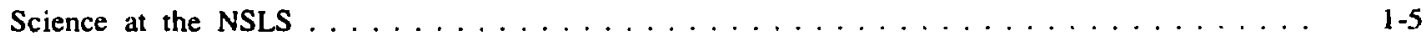

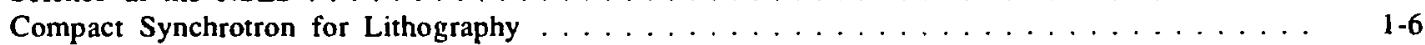

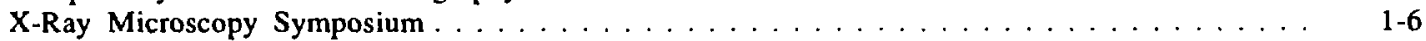

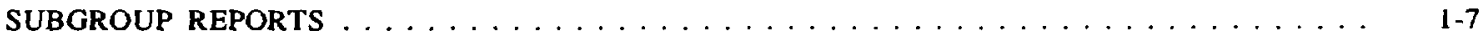

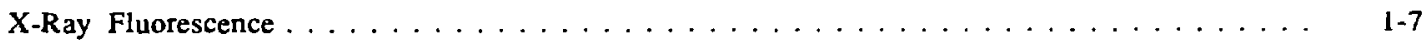

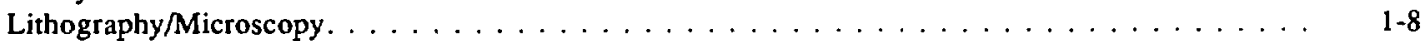

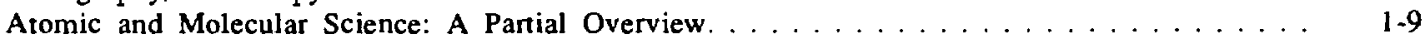

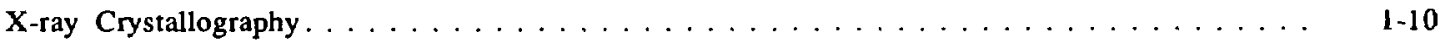

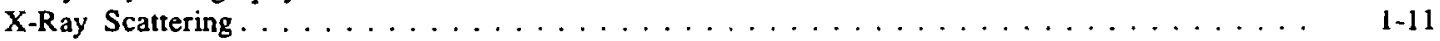

Topography ....................................12

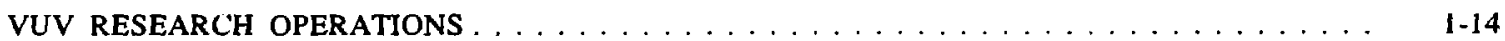

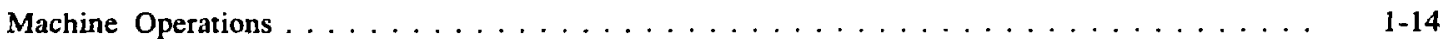

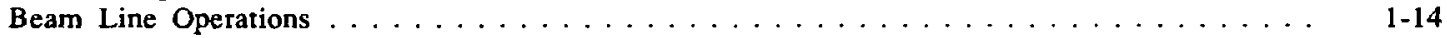

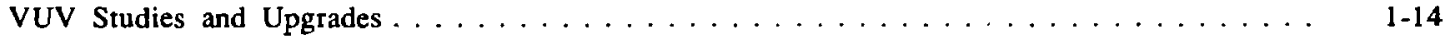

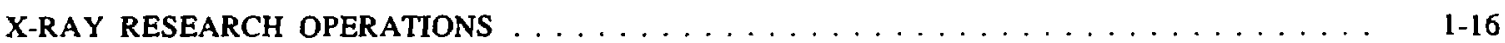

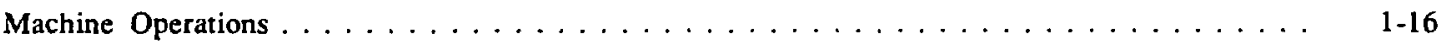

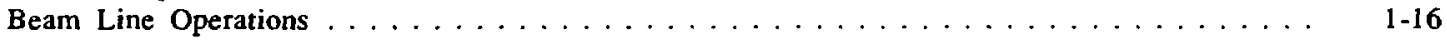

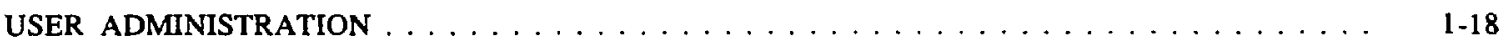

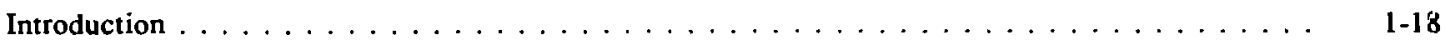

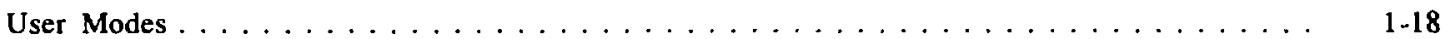

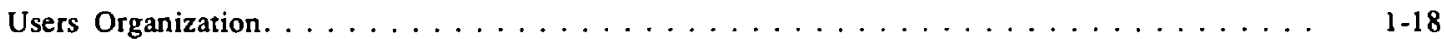

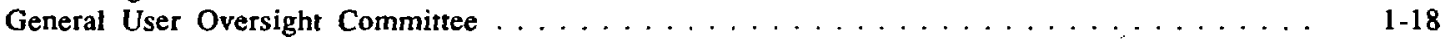

NSLS/HFBR Faculty Student Support Program . . . . . . . . . . . . . . . . . . . . 19

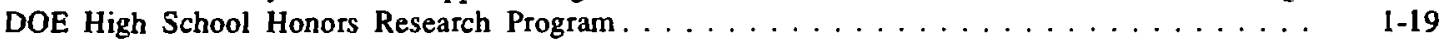

Informational Guide to the NSLS VUV Beam Lines . . . . . . . . . . . . . . . . . . . . $_{\ldots}$

Informational Guide to the NSLS X-Ray Beam Lines . . . . . . . . . . . . . . . . .

\section{SECTION 2}

REPORTS OF THE VUV RESEARCH AT THE NSLS . . . . . . . . . . . . . . . . $2-1$

\section{SECTION 3}

REPORTS OF THE X-RAY RESEARCH AT THE NSLS .................... . . . .

\section{SECTION 4}

USER PUBLICATIONS BASED ONI WORK AT THE NSLS DURING FISCAL YEAR 1987 . . . 4-1

PUBLICATIONS OF THE NSLS STAFF DURING FISCAL YEAR $1987 \ldots \ldots . \ldots$

\section{TABLES}

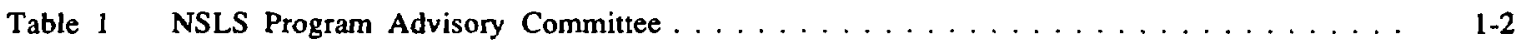

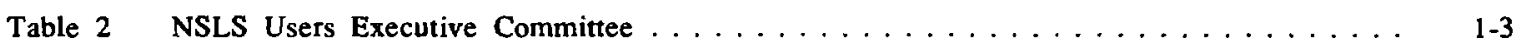

Table 3 NSLS General User Oversight Committee and NSLS Scientific Program Support Committee . . $1-4$

FIGURES

Figure 1 Total Monthly Amp Hours on the NSLS VUV Ring During FY 1987.......... 1-15

Figure 2 Utilization of the VUV Ring for FY 1987 by Percentage in Time . . . . . . . . .15

Figure 3 Total Monthly A.H./High Energy A.H. on the NSLS X-ray Ring During 1 Y 1987. . . 1-17

Figure 4 Utilization of the X-ray Ring by Percentage in Time. . . . . . . . . . . . .17 


\section{SECTION 1}

\section{INTRODUCTION BY THE CHAIRMAN}

Last year was a busy and productive year at the NSLS. The Users and the staff were all serving multiple duties: building and commissioning the rings and the beam lines; operating the facility and conducting scientific programs; installing upgrades and Phase $\Pi$ insertion device capabilities; and expanding the building. All this activity stretched us a little, but we saw improvements in the performance and understanding of the storage rings, and the establishment of an extremely broad and productive beam line inventory and experimental program. We made an aggressive step into the next generation of capabilities with installation of a full spectrum of insertion devices on our high brightness storage rings. Next year, 1988, will find us with over 90 experimental stations on the two storage rings, and a dozen insertion device stations on seven insertion devices. We worked hard to bring the storage rings as near as possible to their "final" configurations in coincidence with the Phase II installation, so that we will have uninterrupted operations well into the future. The unprecedented size and breadth of the capabilities of the NSLS, the number and complexity of the institutional and disciplinary involvements and commitments, and the size of the User community we seek to serve will provide us with scientific and management challenges for many years.

\section{Priorities, Policies and Procedures}

The various groups which provide advice and counsel to the NSLS management and the User community have been active this year.

The Program Advisory Committee (PAC, see Table 1) dealt with the allocation of the resources of the bending magnet and insertion devices with the approval of five new Insertion Device Teams and four new Participating Research Teams. The Advisory Committee continually examines the philosophy and methodology that is evolving to deal with the crush of Users and equipment that we have, and help the management of the NSLS and Useis set priorities for the allocation of resources.

Over the past year the Users Executive Committee (UEC, see Table 2) provided a clear picture of the needs of the User community. The UEC subcommittees on housing, space, parameters, laboratories, and scheduling had an important impact! on NSLS priorities and operating procedures, and pointed the way for needed changes in many areas.

The General User Oversight Committee (see Table 3) took on the job of assuring that the beam time available to the "General User" is efficiently and equitably allocated, and that, ultimately, the best science gets done. The General User program at the NSLS is critical in fostering wide involvement by the scientific community and in providing open access to all NSLS resources.

The PRT/IDT Council is made up of the principal investigators of the PRTs and IDTs and provides a direct link between NSLS management and the management of these important partners in the facility (see Informational Guides in User Administration section). The Council will provide a forum for the PRT/IDT community to establish its agenda and to provide advice and guidance to the NSLS in setting the policy and priorities dealing with the PRTs and IDTs, and in establishing our Jong-term goals and priorities. The Council is in its formative stages, but promises to develop a strong voice commensurate with its importance at the NSLS.

Finally, we recently formed The Scientific Program Support Committee (Table 3) which has the charge of taking a broad look at the operations of the facility to define ways in which the NSLS can be better and more smoothly utilized. They will identify any existing problems and weaknesses and find ways to deal with them. One lesson we have learned is that the system must be open, communications must be good, and people must work together.

\section{Phase II Shutdowns}

The shutdowns of the VUV and X-ray Rings for upgrades and installation of Phase II insertion devices and beam lines are well along, but have not been without problems. The VUV shutdown went close to schedule and included the installation of an Infrared beam line, the Transverse Optical Klystron (TOK), and provision for a spectroscopy beam line utilizing the TOK wiggler. New power supplies and a revamped RF system, together with an improved operating configuration, led to improved stability and reliability. The VUV ring now is in full, routine operations, and has two functioning insertion devices.

The X-ray shutdown is a more demanding project. The installation of new injection hardware and the Laser Electron Gamma Spectroscopy (LEGS) project went well and both were successfully commissioned. Subsequent problems with the new insertion device chambers were a serious setback, which cost us a few months, and moved our date for recommissioning from November 1987 to March 1988. The new power supplies were installed and successfully tested and the RF cavities were upgraded. A total of 22 insertion device and bending magnet beam lines are being added as part of the shutdown. Reestablishing the X-ray experimental program will be the first priority of the NSLS for FY 1988. 


\section{CHAIRMAN}

Dr. Michael L. Knotek - (516) 282-4966

National Synchrotron Light Source

Brookhaven National Laboratory

Bullding 725B

Upton, NY 11973

BI TNET : KNOTEK@BNL

NSLSFAX: (516) 282-4745

BNLFAX: (516) 282-3000 - ETS 666-3000

TELEX: 685216 BNL DOE

TWX: $510-228-1291$

Dr. Dale Sayers- (919) 737-3482

North Carolina State University

Department of Physics

Raleigh, NC 27695 (9/89)

BITNET: SAYERSENCSUPHYS

DECNET: PYVAX: :SAYERS

Dr. David J. Nagel - (202) 767-2931

Superintendent Condensed Matter

and Radiation Sciences Division

Nava 1 Research Laboratory

4555 Overlook Avenue, SW

Code 6600 (or 4600)

Room 300, Bldg. 75

Washingt on, DC 20375-5000 (1/89)

Prof. Robert Siemann - (607) 255-4882

Cornell University

Laboratory of Nuclear Studies

Wilson Synchrotron

Dryden Road

Ithaca, NY 14853 (1/90)

BITNET: SI emannCCRNLNS

DECNET: LNS61::Siemann

FAX: $607-255-8062$

Dr. Kenneth Kllewer - (317) 494-1730

Dean of the School of sclence

Purdue University

West Lafayet te, IN $47907(1 / 88)$

BITNET : KLIEWER @P URCCVM. BITNET

ARPANET : KLIEWER (PPURDUE. EDU

FAX: (317) 494-6609

\section{BX-OPFICIO}

Dr. Martin Blume - (516) 282-3735

Deputy Director

Brookhaven National Laboratory

Directors Office, Bullding 460

Upton, NY 11973

BITNET: BLUMECBNL. BITNET

DECNET: BNLCL2 : : BLUME

\section{DEPUTY CHAIRMAN}

Dr. Sam Krinsky - (516)282-4740

National Synchrotron Light Source Brookhaven National Laboratory Bullding 725B

Upton, NY 11973

Dr. Paul Horn - (914) 945-2445

IBM Research Center

P.0. Box 218

Yorktown Heights, NY 10598 (1/88)

BI TNET : PMHORNOYKTVMX

Dr. Richard P. Messmer - (518) 387-6257

General Electric

Corporate Research and Development

P.O. Box 8

B1dg. $\mathrm{K}-1$, Room 2A30

Schenectady, NY $12301(1 / 90)$

Dr. Albert Narath - (201) 386-5445

Vice President

AT \& T Bell Laboratories

Government Systems

Room WH4-A353

Whippany, NJ 07981

$(1 / 89)$

TEJ.EX: 219482

FAX: (201) 386-6260

TWX: $710-986-8230$

\section{EX-OF FICIO}

Dr. Paul Mart1n - (617) 495-5829

Harvard University

Division of Applied Sclence

Pierce Hall 217A, 29 Oxford Street

Cambridge, MA 02138

BITNET: martintharvard.bitnet

ARPANET: martineharvard.harvard.edu TELEX: 9102502591

\section{EX-OFFICIO}

Dr. Nicholas P. Samtos - (516) 282-2772

Director

Brookhaven National Laboratory

Directors office, Bullding 460

Upton, NY 11973 


\section{NSLS USERS EXECUTIVE COMITTEE}

Dr. Dale Sayers - (919) 737-3482

North Carolina State University

Department of Physics

Raleigh, NC 27695

Dr. Jack Rowe - (201) 582-5878

AT\&T Bell Labs

Room 1C-323

Mutray HI11, NJ 07974 (9/87-9/89)

Dr. Janos Kirz - (516) 632-8106

State University of New Yo:k

Department of Physics

Stony Brook, NY 11790

$(6 / 82-9 / 87)$
CHAIRPERSON

VICE CHAIRPERSON

PAST CHAIRPERSON
Dr. Denis Mclhan - (516) 282-3927

AT\&T Bell Labs

c/o Brookhaven National Laboratory

Buflding 510E

Upton, NY 11973 (9/87-6/89)

Wolfgang Eberhardt - (201) 730-2567

EXXON Research and Engineering Company

Corporate Research Sclence Laboratory

Clinton Township

Annandale, NJ $08801 \quad(6 / 86-6 / 88)$

Mr. Richard Hewitt - (201) 730-2832

EXXON Research and Engineering Company

Clinton Township

Annandale, NJ $08801 \quad(6 / 86-6 / 88)$
Dr. Kelth Jones - (516) 282-4588

Brookhaven National Laboratory

Department of Applied Science

Building 816

Upton, NY 11973 (9/87-6/89)

Dr. Gene Ice - (516) 282-5614

Oak Ridge National Laboratory

c/o Brookhaven National Laboratory Building 725A-X14

Upton, NY $11973 \cdot(6 / 85-6 / 89)$

Dr. Peter Johnson - (516) 282-3705

Brookhaven National Laboratory

Department of Physics, Building 510B

Upton, NY 11973 (9/87-6/89)

\section{NSLS SUBGROUP REPRESENTATIVES}

\section{TOPOGRAPHY}

Dr. Masao Kuriyama - (301) 975-5974

National Bureau of standards

Buflding 223, Room A-163

Gaithersburg, MD 20899

\section{X-RAY FLUORESCEHCE}

Dr. Mark Rivers - (516) 282-7708

Brookhaven National Laboratory

Department of Applied Sclence

Bullding 901A

Upton, NY 11973

EXAFS

Dr. Pedro Montano - (718) 780-5270

Brooklyn College of CUNY

Department of Physics

Brooklyn, NY 11210

\section{LITHOGRAPHY /MICROSCOPY}

Dr. Christopher Buckley - (516) 282-4723

State University of New York

Department of Physics

Stony Brook, NY 11794

\section{ENERGY DISPERSIVES DIFERACTION}

Dr. Michael Bennett - (914) 789-3604

Union Carbide Corporation

Tarrytown, NY 10591
ATOMTC \& MOLECULAR SCLENCE

Dr. David Hanson - (516) 632-7917

State University of New York

Department of Cheristry

Stony Brook, NY 11790-3400

\section{X-RAY GRYSTALLOGRAPHY}

Dr. Hubert KIng - (201) 730-2888

Exxon Research and Engineering

Corporate Research Sclence Laboratory

Clinton Township

Annandale, NJ 08801

\section{X-RAY SCATTERING}

Dr. Gerald L. Lied1 - (317) 494-4095

Purdue University

School of Materials Sclence

West Lafayette, IN 47907

UV PHOTOEIISSION \& SURFACE SCIENCES

Dr. Thor Rhodin - (607) 255-4068

Cornell University

School of Applied Physic

Clark Hall 217

Ithaca, NY 14753 


\section{ISLS GENERAL USER OVERSIGHT COYAITTEE}

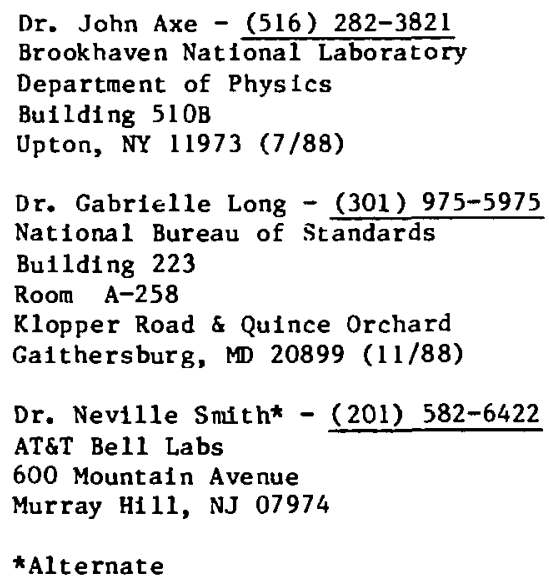

*Alternate

ISLS SCIENTIFIC PROGRAY SUPPORT COHAITIEE

\section{Organization}

Chat rperson:

Vice-Cha1rperson:

Secretary:

\section{ISLS Representation}

User Administrator:

X-ray Experimental

Operations:

VUV Experimental

Operations:

R1ng 0perations:

\section{Sclentific Conunity}

BNL-Chemist ry (U9):

Hunter College:

IBM (X20):

SUNY (X3):

U. of Penn. (X9):
W1111am Thomlinson

Denis McWhan

Nicholas Gmur

Susan White-DePace

(516) 282-7114

Roger Klaffky

(516) 282-4974

R1chard Garrett

Vinnie Racaniello

(516) $282-4245$

(516) 282-7336

Jack Preses

Martin Den Boer

Jean Jordan-Sweet

James Phtllips

Gerd Rosenbaun
(516) 282-3937

(5i6) 282-3927

(516) 282-2490
(516) 282-5509/4371

(212) 772-5258

(91.4) 945-3322

(516) 246-3478

(215) 386-1912 
This report contains summary discussions of the scientific areas represented by the Users Executive Committee Subgroups, and individual reports by the Users, arranged by beam line. Throughout the past year many advances were made in capabilities and significant results were obtained. Some examples of particular note are the following

Imaging techniques are among those which take greatest advantage of the high brightness of the NSLS storage rings. Imaging efforts at the NSLS include soft X-ray microscopy and holography, microtomography, microprobe, microbeam analysis, lithography, topography, and angiography. The X-ray microscopy and holography effort at U15 was given a gain of over two orders of magnitude in coherent power when it moved to the test bei miniundulator at XI7T. New zone plates allowed experimenters to push microscope resolution to the $75 \mathrm{~nm}$ range, and Gabor holograms demonstrated transverse resolution better than $40 \mathrm{~nm}$, an order of magnitude improvement over previous results. The X-ray microscopy and holography effort will now move to the full undulator at X1. Microtomography was carried out at X10, X14, X23, and X26. The X10 group employed sophisticated phosphors and CCD detectors, coupled with impressive sata reduction codes to push resolution to better than 2.5 microns, with the promise of 1 micron in the near future. Exxon is building a new beam line dedicated to microtomography based on these results. High intensity microbeams at X10, X13, X14, and X26 pushed single-crystal diffraction studies to crystals of the order of 10 microns, and microprobe resolutions to less than 25 microns with ppm sensitivities, opening many new areas of study. Topography, using both white and monochromatic beams at X19 and X23 showed high contrast and strain sensitivity down to 25 micron resolution. The X-ray lithography program at the IBM U6 line has been successful to the point that IBM has purchased a synchrotron to be dedicated to manufacturing development, and IBM was approved by the PAC for the installation of a second lithography beam line on the VUV ring. Soon to be brought on line will be the Coronary Angiography program on the X17 superconducting wiggler beam line.

Soft X-ray science saw some important advances in coincidence studies, spin-resolved spectroscopy, photonstimulated desorption, molecular dissociation and excitation, and electronic structure of clusters and high-temperature superconducting materials. Measurements of electron-ion coincidence on the X17T spectroscopy line directly linked Auger final states and specific fragmentation events. Electron-electron coincidence measurements on U12 allowed state specific Auger and photoemission measurements on surfaces. The spin-resolved photoemission beam line on the US undulator demonstrated spin-sensitive photoemission results for magnetic overlayers. Photon-stimulated desorption work on U8 and U1 demonstrated state-specific desorption on surfaces and also that state-specific chemical and structural information can be obtained. State-selective core level excitations are being employed on U15 to understand Auger-induced fragmentation. At U1, Fluorescence Yield Near Edge Spectroscopy was used to study surface chemistry in a high pressure environment, opening a new area for in-situ research on surface chemistry. Work at U7 on matrix-isolated clusters shows that coupling of the cluster to a sarface is critical to its chemistry and can be precisely controlled with rare gas adlayers. L9A has coupled lasers and synchrotron radiation to study photoionization of laser excited atoms. Numerous beam lines were used to study electronic structure and chemistry of high temperature superconductors. The new "Dragon" spherical element monochromator on (SEM) U4B produced a resolving power of better than 1000 and a high angular acceptance, and appears to be the instrument of choice in the soft X-ray region. Three additional SEMs are in various stages of construction or design.

Scattering measurements at X20 and X14 on quasicrystalline materials showed that symmetric peak shifts are associated with a linear phason strain, rather than with Paulings icosatwin model. Diffuse scattering measurements at X14 used anomalous dispersion to highlight size differences and short range order in crystalline FeNi alloys, information that will be valuable in many important materials.

Time-resolved scattering was used to observe hot phonons in quartz (X18), protein unfolding (X21), and crystallization behavior (X21). Surface scattering is now widely used to study surface ordering, melting and roughening, adlayer and adsorbate structure, and liquid crystals. Particularly important work on surface roughening has come out of X10, X16B, and X20. Magnetic scattering has gone from a hope a couple of years ago, to an important and rapidly growing area. Work as $\mathrm{X22}, \mathrm{X20}$, and X16 looked at several rare earths, critical scattering in $\mathrm{MnF}_{2}$, and separation of orbit and spin in holmium, respectively. An exciting step toward a new generation of scattering was accomplished in the study of nuclear Bragg scattering from nearly perfect ${ }^{57} \mathrm{Fe}_{2} \mathrm{O}_{3}$ crystals using an ultra high resolution $(5 \mathrm{meV}) 4$ crystal premonochromator on $\mathrm{X} 12 \mathrm{~A}$.

We are seeing greater use of lasers as pumps for time-resolved measurements such as the work at U9 (photoionization), X18 (hot phonons), X24 (electron-hole plasma on $\mathrm{Si}$ ), and X14 (laser melting of $\mathrm{Si}$ ). Many more such experiments are planned and several substantial laser installations are being made.

Finally, X-ray absorption measurements, which have formed the bedrock of synchrotron X-ray science since its inception, are being used at two dozen experimental stations around the facility. Current efforts are focused on examining buried interfaces using glancing angle techniques, and a variety of in-situ measurements of chemical and electrochemical systems. Recent advances in the understanding of near edge X-ray absorption fine structure made NEXAFS a widely used surface technique. 


\section{Compact Synchrotron For Lithography}

The NSLS progressed in its progran. to assist U. S. industry in the manufacture of high density chips, using X-ray lithography. At a meeting held November 17-18, 1986 (see BNL Report 52046) a detailed plan was drafted which described a project totalling $\$ 394.8$ million, broken into five areas.

1. Build an $X$-ray source within 30 months.

2. Start $R \& D$ design and build a superconducting source.

3. Provide a controlled environment building for semiconductor processing.

4. Develop masks and aligners for lithography.

5. Start R\&D to demonstrate 0.25 micron resolution, and leading-edge dynamic random access memory.

Funding was received in April 1987 which enabled a program to be started whose first mandate was to prepare a conceptual design report involving the first three items.

Working with BNL's Technology Transfer Office, a fourth workshop was held on July 8,1987 to develop plans for transferring X-ray lithography synchrotron (XLS) technology to industry (see BNL 52096). It is important to involve industry in the construction phase so that the technology base is developed there as early as possible.

\section{X-Ray Microscopy Symposium}

The Light Source was a co-sponsor of the Second International Symposium on X-ray Microscopy at Brookhaven from August 31 to September 4, 1987 . Approximately 100 persons from eight countries participated and about 80 papers were presented. This represented a substantial growth over previous symposia on the subject held in 1979 in New York and 1983 in Göttingen.

The symposium was sponsored by the NSLS, The Center for X-ray Optics at Lawrence Berkeley Laboratory, the Stony Brook Physics Department, and the National Science Foundation. The proceedings of the symposium will be published by Springer early in 1988.

Progress in Fresnel zone plate fabrication was reported by several researchers who indicated that resolution in imaging microscopes may be improved to $20 \mathrm{~nm}$ in the next several years. Scanning microscopes with zone-plate optics and high brightness synchrotron radiatic.1 sources are operating at the NSLS, Daresbury, and BESSY.

Phase contrast imaging microscopy was recently demonstrated by the Göttingen microscopy group.

Sourcce development has been rapid with soft X-ray undulators that now illuminate the microscopes at the NSLS, Daresbury, and the Photon Factory. The hligh coherent power available from the NSLS "mini-undulater" made it possible to obtain and reconstruct holograms of biological specimens with about $40 \mathrm{~m}$ resolution.

Applications were extensively reported in biological and materials sciences. Contact microradiography is the most frequently used technique, but results were presented from high-sensitivity fluorescent imaging and three-dimensional tomographic imaging that are used at the Light Source.

Michael Knotek

Chairman 


\section{SUBGROUP REPORTS}

The NSLS Users Organization provides for organized discussions among users of the NSLS facility as well as between the user community and the laboratory administration. Working in concen with this group are nine Subgroup Representatives representing different disciplines at the Light Source. The past and present Subgroup Representatives are listed below. Subgroup reports providing an overview of the science in these disciplines during the past year are also included below.

Subgroup

X-ray Fluorescence

Lithography/Microscopy

Atomic \& Molecular Science

X-ray Crystallography

$\mathrm{X}$-ray Scattering

Topography

EXAFS

Energy Dispersives

Diffraction

UV Photoemission \&

Surface Science
Past Representative

Mark Rivers

Jerry Silverman

David Hanson

Áke Kvick

Gerald LiedI

John Billelo

Pedro Montano

Michael Bennelı

Peter Johnson
Present Representative

Mark Rivers

Chris Buckley

David Hanson

Hubert King

Gerald Liedl

Masao Kuriyama

Pedro Montano

Michael Bennetl

Thor Rhodin

\section{$X$-Ray Fluorescence}

The Fluorescence Analysis Subgroup worked exclusively on beam line X26C during FY 1987. The members of the subgroup represent three disciplines: 1) analytical technique development, 2) biomedical applications, and 3) geochemical and cosmochemical applications.

Analytical Technique Development. The X26C fluorescence microprobe was commissioned in April 1986, and was in constant use during FY 1987. It consists of a white light beam line with adjustable slits $20 \mathrm{~m}$ from the source, a $\mathrm{Si}(\mathrm{Li})$ detector, X-Y-Z sample stage, visible light microscope and multichannel analyzer. Spot sizes as small as 25 microns and detection limits below $1 \mathrm{ppm}$ have been achieved in biomedical and geochemical specimens.

Developments in software and hardware allowed the collection of 2-D trace element scanning images. Images with 10 ppm elemental sensitivity and 30 micron spatial resolution were made for both geological and biomedical samples.

A microprobe which uses multilayer Kirkpatrick-Baez optics was tested on the beam line in collaboration with visitors from the Lawrence Berkeley Laboratory. This microprobe achieved a spot size of 10 microns at $10 \mathrm{keV}$ with a bandwidth of $1 \mathrm{keV}$.

One advantage of using synchrotron radiation for X-ray fluorescence is that the polarization of the incident beam can be used to reduce the background in the fluorescence spectra. This reduction then translates into improved minimum detectable limits (MDLs). However, alignment of the detector-sample-beam then becomes more crucial than in conventional XRF measurements. We developed procedures for rapid alignment of the sample within the beam and for the angle between the incident beam and the detector. The backgrounds are measurably higher (because of poorer polarization) if the sample is more than 10 micro-radians from the vertical center of the beam. It is likely that the vertical beam position is fluctuating more than this, so potentially the MDL may be improved by installing a beam position feedback on X26.

One of the main goals of the fluorescence microprobe is to obtain quantitative analyses in the absence of standards which are very similar to the unknowns. We now can measure the concentration of trace elements using a single major element as an internal standard. The accuracy of the technique generally is better than $\pm 20 \%$.

Cosmochemistry. Analyses of trace elements using synchrotron-induced X-ray emission were obtained on a variety of extraterrestrial materials including iron meteorites, micrometeorites from the stratosphere, ablation spheres from Greenland melt lakes and deep-sea sediments, lunar rocks, and refractory inclusions from carbonaceous chondrites. The most significant finding was the observation of $\mathrm{Cu}$ distribution coefficients $(\mathrm{Cu}$ in troilite/ $\mathrm{Cu}$ in metal) less than 1 for $\mathrm{Ni}$-rich iron meteorites suggesting that subsolidus re-equilibration was an important process in producing the trace element groupings. Stratospheric micrometeorites (about 10 micrometers in size) showed compositions near those of carbonaceous meteorites for most detected elements but were greatly enriched in $\mathrm{Br}$ by factors of 8 to 37. Since $\mathrm{Br}$ is detrimental to the Earth's ozone layer, the high content in these particles may have important implications to atmospheric chemistry. The trace-element signatures of meteoritic ablation spheres (about 100 micrometers in size) extracted mechanically from Greenland melt-lakes and magnetically from deep-sea sediments were depleted relative to carbonaceous meteorites for all detected elements with the exception of $\mathrm{Pb}$, suggesting that ablation/melting significantly modified the chemical composi- 
tion of the parent material. Compositional clustering observed for the deep-sea particles may be useful in identifying the parental objects. Analyses on igneous meteorites and lunar rocks show that $\mathrm{Ba}, \mathrm{Ti}$, and $\mathrm{Sr}$ contents and the element ratios $\mathrm{Sr} / \mathrm{Ba}$ and $\mathrm{Fe} / \mathrm{Mn}$ are useful parental fingerprints. $\mathrm{Sr} / \mathrm{Ba}$ was distinct for plagioclase from each of the meteorite and lunar samples. The initial research on refractory inclusions from primitive meteorites determined the melilite/liquid partition coefficients for refractory lithophiles in synthetic melts, which were between 0.2 and 0.1 for three rare earth elements ( $\mathrm{Sm}$, $\mathrm{Y}$, and $\mathrm{Yb}$ ), unity for $\mathrm{Sr}$, and less than .002 for $\mathrm{Zr}$. The values for rare earth elements are slightly less than rough estimates based on neutron activation analyses of mineral separates.

Geochemistry. The X-ray fluorescence microprobe enables geochemists to study concentrations of the elements of individual minerals, or within a single mineral grain. A variety of projects were carried out on the X26C beam line. Two representative studies were:

1. Concentrations of precious metals in common sulphide materials. These studies are important economically and also important for the information they provide on processes of ore deposition.

2. The diffusion rates of trace elements in rhyolite glasses was measured by comparing the concentration element profiles at 10 micron intervals across the interface between two glasses of different composition after they had been in contact at high temperature and pressure for different times. The results suggest that the trace element diffusion is strongly controlled by the major elements, with rates much lower than "tracer diffusion" studies would suggest.

Biomedical. Experiments were conducted to develop thin target standards within a biological matrix, refine methods for preparing specimens for SRIXE analysis, and to characterize the distribution of various trace elements in brain, liver, kidney, and bone.

Gelatin solutions containing trace elements of biological interest were frozen, cryosectioned at $20 \mu \mathrm{m}$, and freeze-dried to make thin standards of known low $\mathrm{Z}$ matrix. This approach circumvented the necessity of extrapolating from thick Standard Reference Materials to thin unknowns.

Several biological experiments were done by PRT members and by outside users of the X26 beam line: these fall under three general categories:

1. Distribution of essential trace elements: The microscopic distributions of $\mathrm{K}, \mathrm{Ca}, \mathrm{Cu}, \mathrm{Fe}, \mathrm{Zn}$, and $\mathrm{Br}$ were evaluated in biological structures which were too small or too complex in shape to dissect for conventional chemical analyses. The organs or tissues examined included cerebrum, cerebellum, kidney, and liver. The trace element content of the microscopic structure is correlated with the biochemical function of the elements in that structure.

2. Localization of toxic elements: Understanding the microscopic distribution of toxic metals is important to provide better indices of exposure and toxicity. Experiments measured and related the microscopic distribution of lead in bone and cerebrum to the metaholism and toxicity of lead in these tissues.

3. Localization of metal-containing drugs: Several drugs contain metals such as $\mathrm{Pt}, \mathrm{Cu}$, and $\mathrm{Fe}$. Experiments were conducted to investigate the localization of the metal moiety of two antitumor drugs, cis-platin and gallium nitrate, in normal and tumorous tissue. The localization of these drugs in the target cell is important to optimize dose for delivery of the drugs, and to evaluate the potential for improved drug delivery with different derivatives of the drug.

Mark L. Rivers

Subgroup Representative

\section{Lithography/Microscopy}

The past year was marked by continuing advances in X-ray lithography and new developments for soft X-ray microscopy and holography.

In lithography, the IBM group working at U6 continued its work in sral areas. The size of the group increased significantly, as researchers from the IBM East Fishkill manufacturing site joined those from IBM Research.

Radiation damage to the thin membranes used for mask substrates recently received a lot of attention. It was learned that boron nitride membranes, once considered a leading material for such substrates, are susceptible to radiation damage which may cause distortion that is unacceptable for high-resolution lithography. Studies were performed to learn more about the mechanism of damage and its dependence on other properties of the material. Since the membranes can be made under a variety of conditions, which permits the tailoring of some of their properties, such experiments may be useful in determining what other materials are less sensitive to radiation damage. 
The IBM stepper was used to learn more about making working devices using X-ray lithography. The stepper was modified and upgraded; it is heavily used for experiments in device-making, with studies underway to determine overlay and linewidth control capability. A significant effort went into developing a resist technology with the resolution and linewidth control necessary to make sub-micron devices. Meanwhile, work is in progress to develop new resist systems for future use, with the goal of finding ones with better sensitivity, in addition to improved characteristics of resolution and linewidth. A group from Rensselaer Polytechnic Institute continued their study of the exposure chemistry of resists, working primarily with PMMA.

Perhaps the most significant and exciting news came in June when it was announced that IBM contracted with Oxford Instruments to purchase a compact, superconducting storage ring to be installed in East Fishkill for $X$-ray lithography. The encouraging work done at beam line U6 at the NSLS over the last several years was an important consideration in reaching this decision.

It also has been a particularly exciting year for microscopy. As part of Phase II, beam line X1A has been designed to use an undulator for soft $\mathrm{X}$-ray imaging experiments, primarily of biological objects. The beam line will be the world's brightest continuous source of soft $X$-rays and thus will produce the highest, spatially coherent, soft $X$-ray power. This coherent power is necessary for imaging modes such as $\mathrm{X}$-ray holography and scanning transmission $\mathrm{X}$-ray microscopy.

The installation of a mini-undulator as a test bed on beam line X17T was a major advance. The undulator for beam line $\mathrm{Xl}$ will be a 37-period device (now being fabricated). Since it was considered very important to test high-brightness sources before the full Phase II installation, the Light Source installed a ten-period soft $X$-ray undulator in the existing straight section which illuminates beam line $X 17$. This test bed was operational for nine months. Three experiments were run on the beam line: undulator characterization, scanning microscopy, and holography.

Undulator characterization studies measured the absolute spectral intensity of the device. The results agreed well with theory and indicated an increase in brightness of two orders of magnitude compared to a bending magnet source on the YUV ring, where previous scanning microscopy and holography experiments were done. Operation of the undulator did not interfere with normal operations of the $X$-ray ring.

The scanning $\mathrm{X}$-ray microscope benefitted from the increased throughput. Images that took over 30 minutes at beam line U15 were made in less than a minute. Microscope hardware and software were rebuilt to allow for the higher throughput. The collaboration of the Center for $X$-ray Optics and IBM on the manufacture of high resolution zone plates continued, and with the aid of the latest generation of zone plates, a resolution of $75 \mathrm{~nm}$ was measured. Images of biological specimens in their natural environment were made. In particular, a collaboration with the Center for $\mathrm{X}$-ray Optics and University of California at San Francisco, provided images of the internal structure of wet, unstained, unfixed zymogen granules from the pancreas of a rat. Such structures are extremely hard to see by any other technique.

Gabor holograms of these zymogen granules were also made possible by the increased coherent flux of the beam line. Holograms of many biological specimens were exposed in PMMA resist, then read out in a transmission electron microscope and digitized. Computer reconstructions of these holograms demonstrated a transverse resolution of better than $40 \mathrm{~nm}$, an increase of over an order of magnitude from the best holograms obtained previously.

The microscopy and holography programs made good progress in 1986 and 1987 toward their goal of high resolution (about $10 \mathrm{~nm}$ ) imaging of natural, perhaps living, biological specimens.

Jerome Silverman

Past Subgroup

Representative

\section{Atomic and Molecular Science: A Partial Overview}

A study of molecular reaction dynamics involving mixtures of rare gases and halogen-containing molecules activated by VUV light was conducted on U9A by scientists from LANL: the motivation is the current interest in high power excimer lasers.

Cross sections of ground and excited-state atomic photoionization are being determined on U9A. This research uses a laser source to prepare a high concentration of excited state atoms, and the synchrotron source to provide the tunable radiation for making cross-sectional measurements over a wide range of wavelengths.

The VUV circular-dichroism studies of nucleic acids are being conducted in U9B to determine the origin of the large positive $C D$ bands around $185 \mathrm{~nm}$. Base pairing rather than the base sequence appears to be important. 
experiments on $\mathrm{Al}-\mathrm{Mn}$ quasicrystals, $\mathrm{Ni}$ on sapphire surfaces, $\mathrm{KMgF}_{3}$ at several temperatures, and the modulated phase of TTF-TCNQ at $15 \mathrm{~K}$.

Electric-field Experiments. Experiments performed at beam line X13B looked at the structural changes as a function of high-yoltage external electric field in technically important materials. The high resolution enabled very small changes in the unit cell to be studied as a function of the applied field, and changes in the Bragg intensities between + and polarization make detailed studies of the atomic and electronic redistribution possible. Materials such as lithium miobate, potassium titanyl phosphate and 2-methyl-4-nitroaniline were investigated by researchers from the BNL Chemistry Department. SUNY at Buffalo, University of Lund, and the University of California. These experiments of structure modulation promise to open up a new area of crystallographic research at the synchrotron.

\author{
Åke Kvick \\ Past Subgroup \\ Representative
}

\title{
X-Ray Scattering
}

Since 1985 when the first X-ray scattering experiment was performed at the NSLS, the X-ray scattering community at NSLS has been a growing and dynamic group. In the past year more beam lines designed around scattering capabilities became operational, with additional beam lines coming under development for operations after the X-ray Phase II shut down. Upon completion of the new scattering beam lines, the full set of capabilities for X-ray scattering at the NSLS will be unparalleled. In the early stages of operations, a significant amount of effort went into the development of projects for these beam lines. Problems with the beam line and instability of the source have been a factor. However, in spite of these problems and the short operational period of the X-ray ring this year (Phase II shutdown staned in March 1987), a wide range of experiments were conducted. Short summaries of these experiments are given elsewhere in this report.

The spectrum of experiments covers a wide range of $X$-ray scattering techniques and illustrates the capabilities of the scattering lines at the NSLS. The techniques encompass wide-angle scattering, small-angle scattering, high and low Qresolution scattering, diffuse scantering, magnetic scattering, time-resolved scattering, and surface scattering. The experiments focussed on all types of phenomena in liquids, monolayers, thin films, artificial superlattices, polymers, ceramics, and metals.

Surface scattering is one class of experiments which utilizes the full range of the synchrotron source. Eight beam lines (X15A, X16A, X16B, X18A, X20A, X20C, X21B, and X22C) were used for this new and exciting technique. (One should note that some of these beam lines are changing to new ports as part of the Phase II effort). The work of researchers from MIT and IBM on X20A and C illustrates the surface scattering work. In one experiment, they clarified the phase diagram of high density xenon-on-graphite to elucidate the essential features of this model system. Their results show that over a broad range of coverage that xenon exhibits a sequence of structures with decreasing temperature. Other experiments on these beam lines include the study of the structure and transition of hydrogen on tungsten, as well as an investigation of a liquid crystal system with a tuneable dimensionality. Other surface studies made use of the $X$-ray Standing Wave technique, the work by the AT\&T Bell Laboratories group on X15A being an excellent example. This investigation considered monolayers of $\mathrm{As}$ on $\mathrm{Si}(100)$ and found the results in good agreement with a model of symmetric As dimers on the surface. This small example of the surface studies conducted at the NSLS during the past year illustrates the powerful capabilities to undertake studies not previously possible.

Another area where the source characteristics are of critical importance is magnetic $X$-ray scattering. The new phenomena observed using X22B for the determination of the magnetic structure of erbium (including the discovery of three ferrimagnetic phases) is an outstanding example of how magnetic $\mathrm{X}$-ray scattering can be utilized. The rapid progress in the study of magnetic structures also was shown by the BNL-IBM-MIT collaboration on the study of $\mathbf{M n F}_{2}$.

An emerging area is time-resolved X-ray scattering experiments that are made possible by the high flux and timing of the source. A recent experiment by NSLS researchers utilized the time-resolving data acquisition of X18A to study hot photons in quartz arising from a laser pulse. A feasibility study also was recently completed on X21B by researchers from the State University of New York on protein folding. Further, time-resolved small angle scattering was shown to be a real asset. Recent work also by researchers from the State University of New York on X21B illustrated the unique information that could be obtained on a study of crystallization behavior of blends of high and low density polyethylene.

Another aspect of X-ray scattering at the NSLS is the multitude of studies involving diffuse scattering. A group from Oak Ridge National Laboratory (X14) conducted some interesting work on cobalt precipitates in copper, while another group from Northwestern (X18) used diffuse scattering to understand aspects of the precipitation in $\mathrm{Cu}-\mathrm{Be}$ and $\mathrm{Al}-\mathrm{Zn}$ alloys. 
Finally, the explosion of effort on high $T_{c}$ superconductors has used the unique characteristics of the source. The work of researchers from the University of Houston on X22 observed a spontaneous monoclinic distortion that may be relevant to the superconducting properties.

These studies provide a brief summary of the many exciting new techniques and experiments that have been conducted at the NSLS. The X-ray scattering community at the NSLS has shown its enormous potential and we look forward to the expansion of this effort with the completion of the Phase II construction.

Gerald L. LiedI

Subgroup Representative

\section{Topography}

Introduction. The following are brief summaries of major experiments performed at the synchrotron topography station, on beam line X19C at the NSLS. They were mainly performed on the white beam camera, although the capability for monochromatic topography is also available. The capability for dedicated white beam topography is unique in the United States.

An Experimental Study of the Critical Factors Controlling the Mechanical Properties of Molybdenum and of the Interaction of Interstituals with Body-Centered-Cubic Transition Metals. This work encompassed the theoretical and experimental development of a new high-sensitivity method for the determination of strain fields in perfect to highly deformed crystals with a strain sensitivity of one part in $10^{4}$ and a spatial resolution of 25 micrometers. The technique was implemented by studies of the strain field in the proximity of a stress raisor in Mo single crysials. Variations in the lattice spacing as high as $300 \%$ and angular misalignments of $100 \%$ over 25 micrometers from a cracktip were detected.

A Theoretical Study of the Critical Factors Controlling the Mechanical Properties of Molybdenum and of the Interaction of Interstituals with Body-Centered-Cubic Transition Metals. This work introduces a modification in the Finnis-Sinclair potentials as a guide to interpreting strain field measurements in synchrotron X-ray topography, with special reference to interactions of interstituals and vacancies. With this modification, good results are obtained for the energetics of instability. Excellent agreement also is found between the lattice parameter dependence of the cohesive energy of Mo as obtained using the modified potentials and via calculations of self-consistent augmented-spherical-waves.

Beam-Line Development for Topography, Tomography, and Microradiography on a Seven GeV Synchrotron Source. Preliminary studies of special interest are focused on those problems where deep penetration of the radiation, energy tunability over a broad range, and/or high speed real-time experiments are essential. To cite a few examples: studies of voids in sintered ceramics, void formation in the bulk during high-temperature creep, dynamics of plastic flow, high resolution strain studies in thin-film integrated circuits, and in situ studies of crystal growth. Design factors necessary for constructing an optimum beam line to effectively utilize $7 \mathrm{GeV}$ radiation, from both the cost and scientific perspective, are in progress. X19C at the NSLS and the white beam station at SSRL will be used as a test bed for carrying out ideas to be incorporated in the proposed new synchrotron facilities.

White Beam Fractography of Mo and Nb Crystals. There were several experimental and theoretical studies using white beam techniques for assessing the fracture behavior of $\mathrm{Mo}$ and $\mathrm{Nb}$ crystals. Factors of interest included the size of the plastic relaxed zone, the dislocation density, and the interpretation of the image contrast.

Synchrotron X-Ray Topography Observations of Fatigue and Fracture Behavior in Zinc Bicrystals. Crack propagation at $77 \mathrm{~K}$ and $298 \mathrm{~K}$ was studied for low-cycle prefatigues zinc bicrystals. Synchrotron X-ray Fractography ( SXRF) and monochromatic Bragg Angle Strain Contour Mapping (BACM) were used to examine the strain field of the crack in relation to the bicrystal boundary plane. The BACM method has been developed as a powerful tool to study in detail the strain field of a relaxed crack in the bulk of a crystal. The results showed that pure tilt boundaries were several times tougher than single crystals: the method may be extended to technical alloys.

Microstructure Development in Thin Films During Deposition from the Vapor Phase. It is well recognized that the structure of a thin metallic film can be amorphous, polycrystalline or single crystal (epitaxial), depending upon the deposition process. In particular, the rate of deposition and the temperature of the substrate have important influences on the structure. It has been suggested that the grain structure of a polycrystalline film is determined by the nucleation density or by recrystallization effects, both of which are temperature-dependent.

In metal films made by thermal vapor deposition or by ion sputtering, we found that the grain size of the material, as deposited, depends linearly upon the film thickness when cold substrates are used. The results clearly indicate that grain growth occurs during the deposition process itself. The necessary thermal activation for recrystallization appears to derive 
from the latent heat of solidification from the vapor phase. The occurrence of continuous recrystallization during film growth raises some interesting questions about the origins of grown-in film stresses.

Identification of the Failure Mechanism of a Compressively Loaded Thin Film on a Thick Substrate by Means of Synchrotron X-ray Topography Combined with Transmission Electron Microscopy. A compressively loaded thin film on a substrate is theoretically very stable, and its failure by delamination requires the existence of some form of stress concentration in order to nucleate a buckle. This failure mude is more common than would be expected on the basis of the theory. Using polycrystalline films on single crystal silicon wafers, we were able to measure the elastic deformation of the substrates with extreme accuracy using Synchrotron X-ray Topography (SXRT), and we also imaged the formation of localized deformation lines characteristic of film delamination when a certain film thickness is achieved. Electron microscopy of the same specimens reveals that the deformation is associated with bands of slip in the substrates, presumably generated by the stresses deriving from the overlayer film: the bands cause surface steps on the substrate, which provide the necessary stress concentration for delamination of the film by buckling.

Development of Grazing B ragg-Laue Synchrotron Topographic Techniques. White-beam synchrotron topographic techniques were developed in grazing Bragg-Laue geometries. These techniques examine the evolution of strain in the near-surface regions of single crystals undergoing phase transformations, in particular, for metal single crystals undergoing hydridation. Analysis of the projected lengths of dislocation images on topographs recorded by these techniques, incorporating the exploitation of the projective properties of the topographs, enabled the direct determination of X-ray penetration depths in single crystals diffracting in this geometry. The depth of penetration varied according to the distribution of localized strain fields in the crystal. In the regions immediately surrounding dislocation lines, penetration depths agreed with values predicted from kinematical theory. For regions of crystal where the local distortion field produces effective misorientations smaller than the rocking curve width of the perfect crystal, dynamical considerations are expected to be operative.

Synchrotron X-ray Topographic Studies of Electronic Materials. Synchrotron radiation was used to monitor the quality of single crystals of zinc cadmium telluride, quartz and gallium arsenide as a function of processing conditions. The technique was shown to be a powerful tool for such characterizations, giving unique insights as to how processing might be improved in these materials.

Synchrotron Topographic Studies of Nickel Base Alloy Jet Turbine Blades. Both reflection ACT and synchrotron white beam topographs of single crystal nickel base alloy jet engine turbine blades reveal that topography is far superior to previously used $\mathrm{X}$-ray diffraction techniques for quality control of such blades. The use of white beam synchrotron X-ray topography should permit optimization of growth, annealing, and other processing of the materials of the blades in order to improve crystal perfection and hence improve mechanical and thermal properties.

Synchrotron X-ray Probing of Acoustic Waves. Transmission synchrotron X-ray topographs recorded from 0.5 inch diameter single crystals of aluminum which had been insonated with $20 \mathrm{kHz}$ high power ultrasound revealed marked plastic deformation throughout the entire volume of the crystal that was caused by the ultrasound. This study provides direct evidence, for the first time, that high power ultrasound can move dislocations over large distances in metals.

Synchrotron X-ray Topographic Studies of Defects and Strain Fields in Metal-Semiconductor (Pd, Si) Interfaced Materials. A series of in sin absorption edge contour mapping experiments were carried out on metal-silicide specimens in the past year. A miniature fabrication chamber was constructed to enable in situ observations of the evolution of film stresses to be made during the deposition of the metal films, and during the subsequent annealing to allow the growth of silicides at the interfaces. Results obtained show that the residual film stress can be tailored by controlling the annealing process.

A Study of Creep Damage Using Synchrotron Microradiography. Synchrotron micro-radiographic techniques have been developed which can be used to quickly and reliably measure the amount of distribution of creep damage in a sample. This technique is made possible by the high brightness of the synchrotron source.

John Bilello

Past Subgroup

Representative 


\section{VUV RESEARCH OPERATIONS}

\section{Machine Operations}

The UV ring was relurned to operation from the Phase II shutdown essentially on schedule, with the first experiments being performed in late January. In addition to installing the Transverse Optical Klystron (TOK) and Infra-red bearn lines, four of the eight dipole chambers were replaced, and new distributed ion pump elements, and clearing electrodes were installed. Also, a number of power supplies were replaced.

Unfortunately there were unplanned shutdowns during the remainder of 1987. A leak developed in the U2 front-end valve which necessitated venting the ring in May, in the time set aside for the installation of the TOK magnet. Problems were also experienced with the TOK water-cooled aperture, which required extra time to rectify. Subsequently, in late June, the aperture developed a leak from the cooling pipe to the ring and had to be removed. The following conditioning period was complicated by the fact that a considerable quantity of water had entered the ring. A new aperture was designed and installed in September, which was followed by the most successful conditioning of the UV ring to date. An integrated current of 43 Amp-hours was injected over four days including a peak current of 1.03 Amp.

Operations resumed with 5 bunch fills and injection over $700 \mathrm{~mA}$. This conditioning performance was a great credit to the Vacuum and Operations Groups.

In September and October reliable high current operations were achieved with typical fills to $750 \mathrm{~mA}$ lasting about 5 hours with lifetimes of 150 minutes at $200 \mathrm{~mA}$. Figure 1 shows graphically the total amp hours during FY 1987 . Figure 2 shows the percentage breakdown of operations, studies, downtime (which includes injections/ramping time), maintenance, and conditioning.

\section{Beam Line Operations}

The past year saw a number of beam line developments on the UV floor. As mentioned, the TOK and IR beam lines were instalied in the Phase II shutdown and are nearing operation. Radiation has been observed from both beam lines and characterization of the two sources has begun.

- The prototype spherical grating monochromator, dubbed the "Dragon," was installed in record time on U4 and has given indications of spectacular resolution at full aperture, in excess of 1000 at the oxygen $\mathrm{K}$-edge.

Other notable developments were the installation of a white light branch line on $\mathrm{U} 3$ and the addition of a transmission grating monochromator on U10A.

The second genetation TGMs on U7 and U12 are nearing completion and work has begun on the ERG and TGM lines on Ui6. Also, the U8C zone plate moriochromator is fully operational.

Finally, the University of Minnesota/ Argonne National Laboratory PRT vacated the U2 beamport in 1987.

\section{VUV Studies and Upgrades}

During the Phase II shutdown the following hardware was installed in the ring:

- the TOK wiggler,

- new quadrupole power supplies,

- new loop tuner for the main RF system, and

- a $200 \mathrm{MHz}$, 4th harmonic prototype RF system.

The TOK wiggler was successfully commissioned and the perturbation on the electron beam during normal operation, has been minimized.

The new loop tuners provide easier and more reliable control of the coupled bunch longitudinal instability.

The prototype 4th harmonic RF system, by lengthening the bunch and thereby reducing the Touschek scattering, improves the beam lifetime by $20-40 \%$. A final system is now under design.

The construction of a resonant closed-orbit feedback system is being planned. This system should reduce by a factor of about 5 the low frequency orbit movements due to mechanical vibrations, and temperature variations. The magnitude of the present orbit movements is about $100 \mu \mathrm{m}$.

A low emittance configuration $\left(5 \times 10^{-8}\right) \mathrm{m}$-rad at $750 \mathrm{MeV}$ ) was also successfully tested. The lifetime of the stored beam is severely limited by the Touschek effect. 


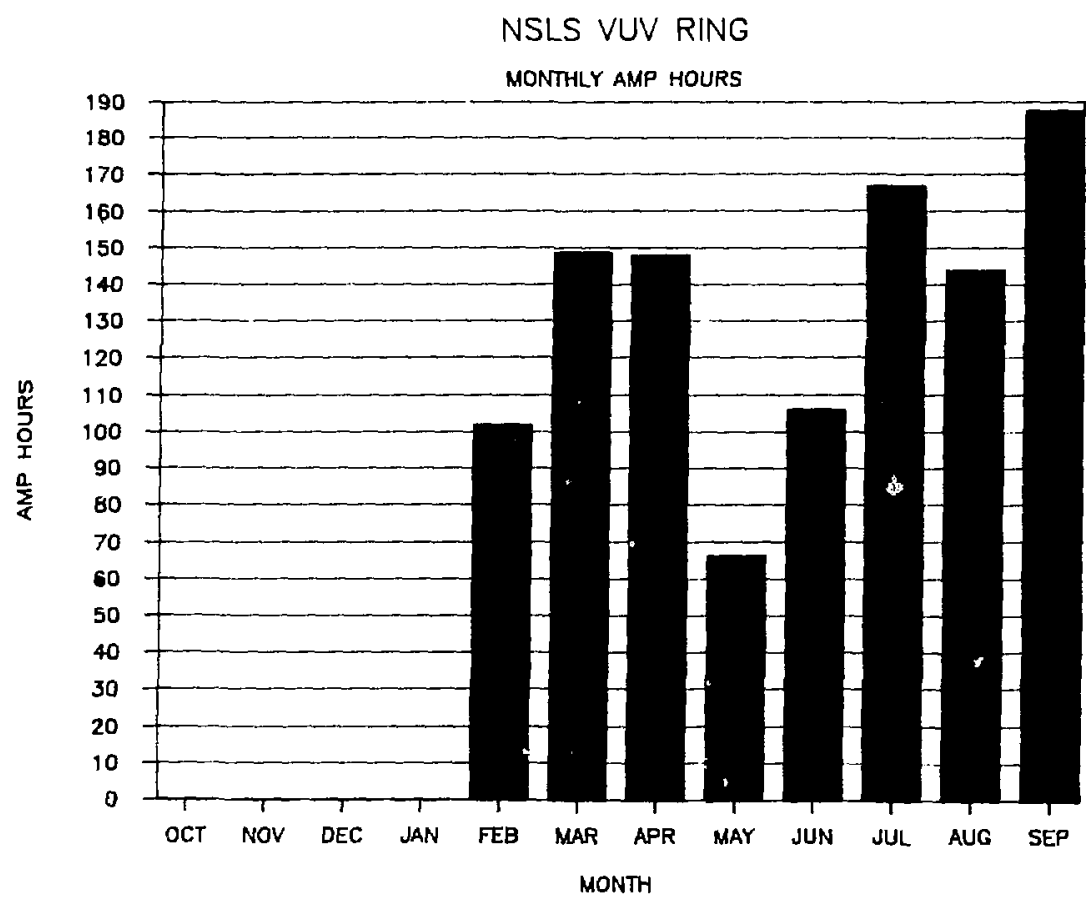

Figure I Total Monthly Amp Hours on the NSLS VUV Ring During FY 1987.

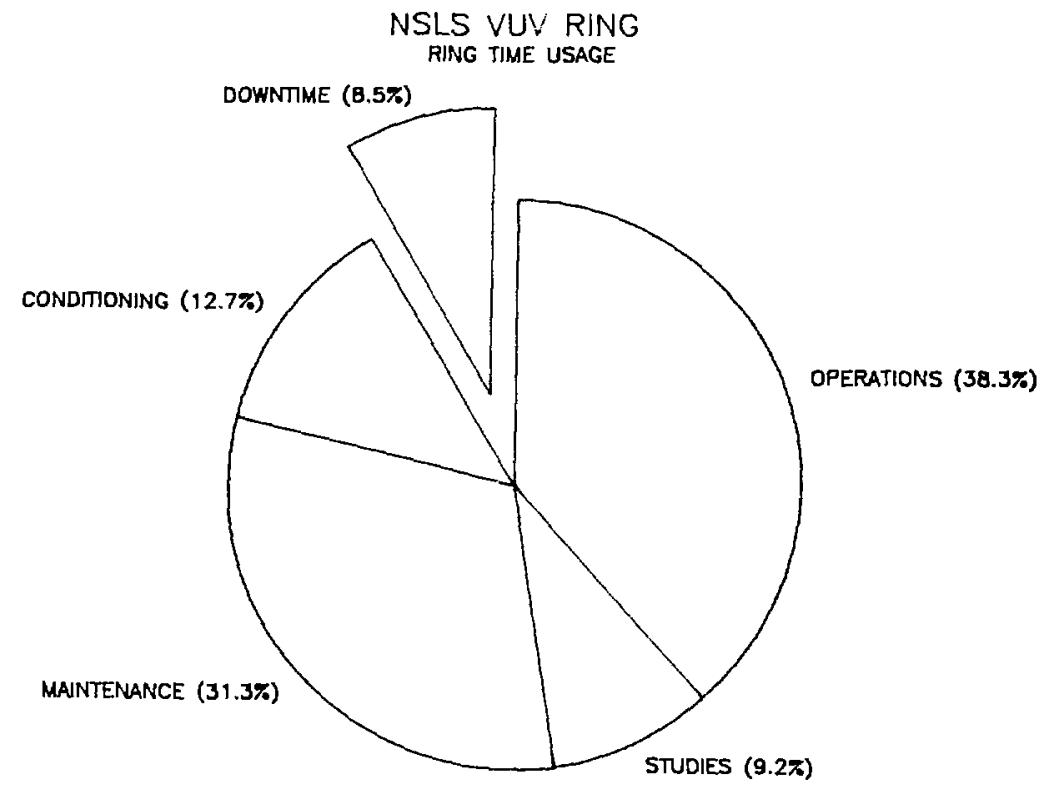

Figure 2 Utilization of the VUV Ring for FY 1987 by Percentage in Time. 


\section{X-RAY RESEARCH OPERATIONS}

\section{Machine Operations}

During the 1987 fiscal year there were five months of X-ray operations before the Phase II shutdown early in March 1987. During these five months, there were steady improvements in the amp hours of beam as displayed in Fig. 3 (which shows the total amp hours and the high energy amp hours). These improvements largely resulted from the installation of a third $52 \mathrm{MHz}$ RF cavity' in June 1986 which improved the ring vacuum by decreasing the required power levels in each of the cavities. Improvements also were made in the software ramp to avoid beam instabilities, thereby enabling higher current fills. The breakdown of the fiscal year into percentages of operations, studies, downtime (which includes injection/ramping time), maintenance and conditioning is shown in Fig. 4. The large percentage of time devoted to maintenance reflects seven months of Phase II shutdown work.

\section{Beam Line Operations}

The number of operating beam lines increased from 29 in FY 86 to 34 by March 1987, with the commissioning of the $\mathrm{X} 10 \mathrm{~B}, \mathrm{X} 10 \mathrm{C}$ (beam position monitor), X11B, X12B, X17T beam lines. The safety systems on beam line X21B and X23A3 were modified to allow different operating modes for new experiments.

Several changes were made to improve beam line operating conditions, which included changes in the procedures for the beain line vacuum so that the need for RGA scans is eliminated when front end pressure or beam line pressures fall below certain values. Several dedicated si.ngle-bunch shifts were scheduled for X18A and X24C and timing signals were provided. The unattended mode of $\mathrm{X}$-ray operation was continued as was the parasitic use of studies shifis during periods when there are no injection/ramping studies.

In the area of user support an improved gas cylinder system was put into effect so that there would be a permanent stock of cylinders available on a sign-out basis. The BNL Ethernet system was made available to users. Also, by using a voice synthesizer the instantaneous X-ray and UV beam currents and messages displayed on channels 6 and 7 of the TV monitor were made available to users by dialing 282-5700. The poor quality of these messages will be upgraded in FY 88 in conjunction with other improvements in user communications. Towards the end of FY 87, the procedure for entering a user ILR (Intra-Laboratory Request) into the BNL system was greatly streamlined by directing work requests to the User Secretary. Also, a permanent, large (6000 liter), self-pressurizing, liquid nitrogen system was scheduled for installation in FY 88.

In July 1987 a major effor was made to render the X-ray floor and entire NSLS, clean and safe. The NSLS Housekeeping and Safery Committees will maintain these conditions in future. The additional storage and set-up space in the basement of Building 535 provided by the Phase II building expansion will facilitate this effor. An 80' $\times 40^{\prime}$ trailer also was assigned to the storage of user's packing boxes and 1.5 smail trailers were assigned for the storage of user's equipment.

Before she shutdown, a number of modifications were made to the $X$-ray ring which provided crucial information. The first of these was the implementation of a prototype closed-orbit local feedback system on the X17T undulator beam line. Studies shifts were used to debug the system, and users observed negligible orbit shifts on their beam lines when the feedback was turned on and off. The feedback system stabilized the vertical and horizontal beam position to within $\pm 15 \mu \mathrm{m}$ $(<20 \mu$ radians of angle). A similar local feedback system will be employed on the Phase II insertion devices. In anticipation of the installation of the X5 LEGS chamber and magnets, the LEGS sextupole was installed in October 1986 to ensure that its effect on the X-ray orbit could be corrected.

In the fall of 1986, members of the Experimental Program Support Section met with each X-ray user group to determine what new beam lines, hutches, safety systems and utilities would be installed during the Phase II shutdown and what modifications would be required for existing beam lines. The extensive amount of work was needed. Ultimately an additional 27 beam lines would have to be installed, 9 of which would be on operating front ends (X9B, X10C, X15B, $\mathrm{X} 20 \mathrm{~B}, \mathrm{X} 23 \mathrm{~A} 2$ and $\mathrm{X} 26 \mathrm{~A}$ ), and 6 of which would result from moving the X13 and X21 beam lines to X7 and X3, respectively, to make room for new insertion device lines. When ihese new lines are completed, most of which are on bending magnets, the number of operating $\mathrm{X}$-ray beam lines will almost double. With the assignment of an electrical engineer to the Experimental Program Support Section, it became possible to design an upgrade to the NSLS interlock system for installation on these new beam lines. The new design makes use of more compact, high reliability relays, of printed circuit boards to minimize wiring errors and facilitate maintenance, and of modularity to permit disconnection of the beam line safety system from the main interlock iystem for testing during normal operations. In FY87 the major prototype logic units were bench-tested and the prototype system will be installed on X7 in early FY88. 
NSLS $X$-RAY RING

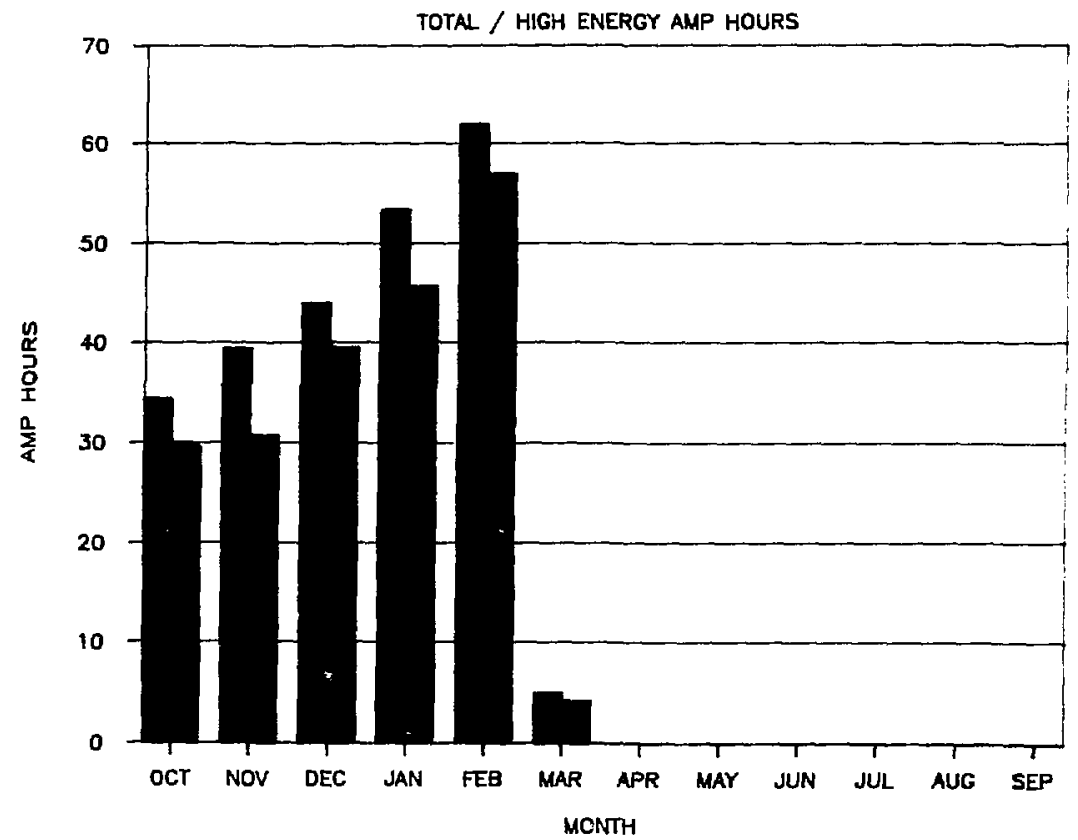

Figure 3 Total Monthly A.H./High Energy A.H. onthe NSL3 X-ray Ring During FY 1987.

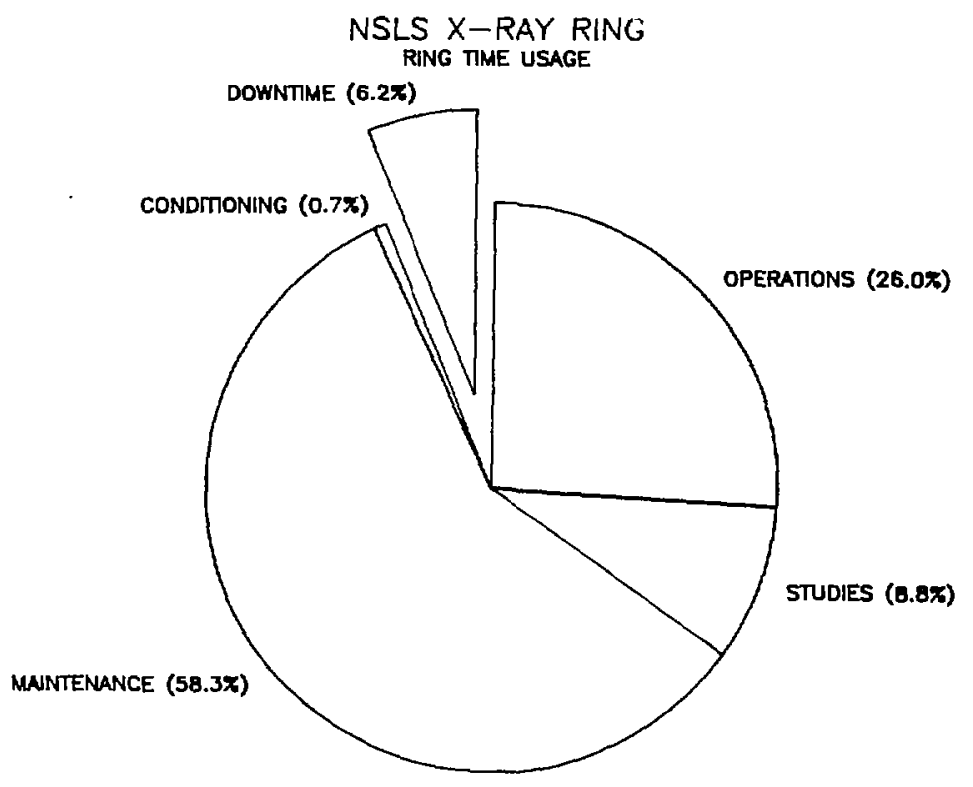

Figure 4 Utilization of the X-ray Ring by Percentage in Time. 


\section{LSER ADMINISTRATION}

\section{Introduction}

Last year was a busy and productive one for the NSLS user community. This Section provides a brief overview of the events that occurred during the past year. The Informational Guides at the end of this Section outline the operational status, experimental capabilities available at each beam port/line, and contact personnel for those beam lines.

iser Modes

The policy for experimental utilization of the NSLS is designed to enable the scientific community to cooperate in establishing comprehensive long-range experimertal programs. Approximately 99 universities, 25 corporations, and 19 government institutions participate in research at the facility.

In addition to the beam lines constructed by the NSLS staff for general usage, a large number of beam lines were designed and instrumented by Participating Research Teams (PRTs). The PRTs are entitled to up to 75\% of the operational time on their beam line(s) for a three-year term.

Insertion Device Teams (IDTs) were formed to design, fabricate, commission, and use wiggler and undulator beam lines. The conditions and terms are similar to those of the PRTs.

General users :-e scientists interested in using beam time at the NSLS facilities for experimental programs. They are scheduled by an i. sependent allocation committee for a percentage of operating time for each beam line. Liaison and utilization support is provided to the General User by the cognizant beam line.

Proprietary research can be performed at the NSLS. The DOE granted the NSLS a Class Waiver, under whose terms the Proprietary User is obligated to pay the full cost recovery rate for using the NSLS. In return, the user has the option to take title to any inventions made during the research program and to treat as proprietary all technical data generated during that program.

\section{Users Organization}

The Users Organization met five times during FY $19: 7$ to discuss various user-related issues such as housing, user support space, Phase II space allocation, Phase II shutdown scheduling, and the development of the General User scheduling and PRT tenure reviews.

Six subcommittees were appointed to address items of particular concern to the users. They were: 1) Phase Il space allocation, 2) VUV ring scheduling, 3) X-ray ring scheduling, 4) orbit stability, 5) housing, office, and laboratory space, and 6) user accounting. Subcommittee reports are available upon request from the User Administration Office.

During the Annual Meeting, new members were elected to the Users Executive Committee (UEC) and to represent the Subgroups. These members are listed in Table 2

Approximately 250 people attended the annual meeting on September $21-22$. The program was dominated by scientific results germane to programs at the NSLS. Six keynote speakers and six plenary talks were presented during this meeting. Held in conjunction with the Users Meeting was the dedication ceremonies for the Phase II construction project. Foliowing the dedication ceremony the PRTs displayed posters of work conducted at their beam line. In all, 145 posters were displayed.

In an effort to improve communications with the user community, a forum was held in the last session. between more than 60 users and a panel of UEC, NSLS staff, and lab management. From the level of interest shown, this type of forum will be continued at future meetings.

\section{General liser Oversight Committee}

The NSLS General User Oversight Committee (GUOC) was formed by the NSLS and the Users Executive Committee (UEC) to recommend allocations of beam time to the NSLS Chairman and to resolve conflicts that may arise between General Users, PRTs, IDTs, and NSLS staff. The Committee consists of five members; one NSLS scientist and two representatives from both the UV and X-ray community (see Table 3 ).

Thirty proposals were submitted for allocation of beam time by the GUOC for the May through August scheduling cycle on the UV ring. Twenty-four of these proposals were allocated beam time. Of the remaining six, three proposals were held pending completion of the beam lines requested, and for other reasons, three proposals were left for the subsequent scheduling cycle. Approximately ten General User proposals were allocated beam time on the X-ray ring before to the Phase II shutdown. 
Although the present system is working well, during the past year it became apparent that scientific peer review will be necessary for certain disciplines. A The formation of a Proposal Study Panel is being discussed.

\section{NSLS/HFBR Faculty Student Support Program}

This program funded by the Department of Energy provides support for faculty/student research groups performing experiments at the NSLS as General Users, or neutron experiments at the BNL High Flux Beam Reactor (HFBR). The program is designed to encourage new users to these facilities and defray expenses incurred during exploratory visits to BNL, and during initial experiments at the NSLS and HFBR. It is aimed at university users having only limited grant support.

A three-member committee, consisting of one representative form the NSLS staff, one from the HFBR staff, and one designee of the NSLS Users Executive Committee, reviews applications and selects participants for the program.

Fifty-four faculty members and students participated in research on the X-ray and VUV rings at the NSLS and at the HFBR during FY 1987 with the help of this funding. Application forms or further information can be obtained from Susan White-DePace.

\section{DOE High School Honors Research Program}

For the second year in a row, Brookhaven hosted 56 high school students in the DOE High School Honors Research Program. The program was designed to encourage the development of scientific and technical talent in energy-related areas, emphasizing the type of research conducted at the NSLS. One outstanding student was chosen from each state, plus one each from the District of Columbia and Puerto Rico. In addition, students from Canada, Italy, Japan, and Mexico participated for the first time.

During the first three days of the program the students : "ended lectures on the nature of synchrotron radiation and its scientific applications, machine physics, operations, and procedures at the NSLS, and on the experiments which the students would be conducting. The weekend was devoted to calculations aimed at an understanding of the machine and its applications.

The second week was devoted to experiments at the NSLS facility. These experiments involved optical diffraction techniques for measuring laser light wavelengths, use of the photoelectric effect for determining the composition of a metal alloy (U7B and U14A), fluorescence spectrum of cyclohexane normalized by sodium salicylate fluorescence spectrum (U9A), photoionization yields of gaseous molecules (U1I) and reflectivity of multilayer mirrors (U15). Tours also were provided by the Applied Science, Biology, Chemistry, HFBR, Medical, and Physics Departments.

The students used the final days of the program to prepare reports and present their experimental results and conclusions to the group as a whole. Copies of the program report are available from Don Metz, Office of Educational Programs.

All correspondence and inquiries regarding the NSLS facility should be addressed to:

Susan White-DePace, User Administrator

National Synchrotron Light Source Department

Building 725B

Brookhaven National Laboratory

Upton, NY 11973

(516) $282-7114$ 


\begin{tabular}{|c|c|c|c|c|c|c|c|}
\hline \multicolumn{8}{|c|}{ INFORATIONAL GUTDE TO THE NSLS VUV BFAM LINES } \\
\hline $\begin{array}{l}\text { Beam } \\
\text { Port }\end{array}$ & $\begin{array}{l}\text { Beam } \\
\text { Live }\end{array}$ & $\begin{array}{l}\text { Operational } \\
\text { Status }\end{array}$ & Affulation & Research Progran & $\begin{array}{l}\text { Muioctr } \\
\text { mator }\end{array}$ & ro- $\begin{array}{c}\text { Local } \\
\text { Contact }\end{array}$ & Spokesperson2 \\
\hline \multirow[t]{2}{*}{ U } & A & 0 & $\begin{array}{l}\text { Exxon Research \& } \\
\text { Eighineeriıg }\end{array}$ & SEXAFS, ARUPS, XPS & ERG & $\begin{array}{l}\text { Dale Soinderidker } \\
\text { (516)282-5501 } \\
\text { (516) 282-4983 }\end{array}$ & $\begin{array}{l}\text { Wblfgaing Eberhardt } \\
\text { (516)282-4983 } \\
(201) 730-2567\end{array}$ \\
\hline & B & $\mathrm{N}$ & $\begin{array}{l}\text { Exxon Research \& } \\
\text { Englineering }\end{array}$ & - & TOM & $\begin{array}{l}\text { Iffee Sansone } \\
\qquad \begin{array}{l}(516) 282-5759 \\
(516) 282-5501 \\
(201) 730-3388\end{array}\end{array}$ & $\begin{array}{l}\text { Wolfgaig Tberhandt } \\
\text { (516)282-4983 } \\
\text { (201) } 730-2567\end{array}$ \\
\hline U2 & OIEN & & & & & & \\
\hline \multirow[t]{3}{*}{ U3 } & A & 0 & $\begin{array}{l}\text { LANL/Sandial } \\
\text { U. of CA/LIL. }\end{array}$ & Detector Calibration & ERG & $\begin{array}{l}\text { Pandy Alldre } \\
\text { (516)282-5503 }\end{array}$ & $\begin{array}{l}\text { Walt Trela } \\
\text { (505) } 667-1674\end{array}$ \\
\hline & B & $\mathbf{N}$ & $\begin{array}{l}\text { LANL/Santial } \\
\text { U. of CA/ILL }\end{array}$ & Radicuetry & - & $\begin{array}{l}\text { Randy Alkc1 re } \\
\text { (516)282-5503 }\end{array}$ & $\begin{array}{l}\text { Walt Trela } \\
3 \quad(505) 667-1674\end{array}$ \\
\hline & $c$ & 0 & $\begin{array}{l}\text { LANL/Sandilal } \\
\text { U. of CA/LLL }\end{array}$ & Saft X-ray Spectroscopy & - & $\begin{array}{l}\text { Randy Alkd re } \\
\qquad(516) 282-5503\end{array}$ & $\begin{array}{l}\text { Whlt Trela } \\
3 \quad \text { (505) } 667-1674\end{array}$ \\
\hline \multirow[t]{2}{*}{$\mathrm{U} / 4$} & A & 0 & AT\&T Bell Labs & ARJPS & $\mathrm{TOM}$ & $\begin{array}{l}\text { Jadk Rowe } \\
\text { (201)582-5878 } \\
(516) 282-5504\end{array}$ & $\begin{array}{l}\text { Jadk Rowe } \\
\quad \text { (201)582-\$878 }\end{array}$ \\
\hline & B & $\mathbf{C}$ & AT\&T Bell Labs & URS, SEXAFS, NEXAFS & SEM & $\begin{array}{l}\text { Fraucesco Sette } \\
\text { (516)282-5504 } \\
\text { (201) 582-3351 } \\
\text { c.T. Ohen } \\
\text { (201) } 582-6030 \\
\text { (516)282-5504 }\end{array}$ & $\begin{array}{l}\text { Francesco Sette } \\
\text { (201)582-3351 } \\
\text { C.T. Chen } \\
\text { (201)582-6030 }\end{array}$ \\
\hline U4IR & & $\mathbf{M}$ & $\begin{array}{l}\text { NSLS/AT\&T Re11 Labs/ } \\
\text { Fairleigh } \\
\text { Dfodıson U./Exoon }\end{array}$ & $\begin{array}{l}\text { Vibrat:onal Sectroscopy } \\
\text { of Moleailes on Surfaces, } \\
\text { Absorption, Fast Detectors }\end{array}$ & IR & $\begin{array}{l}\text { Gy: Willamb } \\
\text { (516) 282-3634 }\end{array}$ & $\begin{array}{l}\text { Gyn williams } \\
\text { (516) 282-7529 }\end{array}$ \\
\hline \multirow[t]{2}{*}{45} & & 0 & NSLS & Dagrostics & - & $\begin{array}{l}\text { Ron Nawro cky } \\
(516) 282-4449\end{array}$ & $\begin{array}{l}\text { John Galayda } \\
\text { (516) 282-4593 }\end{array}$ \\
\hline & $\mathrm{U}$ & 0 & ENL-Ptysics & $\begin{array}{l}\text { Spln Polarized Agle } \\
\text { Resolved UV Photoenl ssion }\end{array}$ & $\mathrm{TCH}$ & $\begin{array}{l}\text { Peter Johuson } \\
\text { (516) 282-3705 }\end{array}$ & $\begin{array}{l}\text { Peter Johiboil } \\
\text { (516)282-3705 }\end{array}$ \\
\hline 166 & & 0 & IBM & Lithography & White & $\begin{array}{c}\text { Jerry Silveman } \\
\text { (516)282-5506 } \\
(914) 945-2099 \\
\text { John Werlaurmit } \\
\text { (914)945-1819 }\end{array}$ & $\begin{array}{l}\text { Alan Hilsoil } \\
\text { (914)945-2759 }\end{array}$ \\
\hline \multirow[t]{2}{*}{ U7 } & A & $M$ & $\begin{array}{l}\text { ENLFHysics/ } \\
\text { NSIS/EOODil }\end{array}$ & XIS, SEXAFS & TOM & $\begin{array}{l}\text { Fraucls Loeb } \\
\text { (516)282-5507 } \\
\text { (516)282-2092 }\end{array}$ & $\begin{array}{l}\text { Myron Stroughil } \\
\text { (516)282-3763 }\end{array}$ \\
\hline & B & 0 & $\begin{array}{l}\text { ENL-Physios } \\
\text { SWY/C } \\
\text { Staybrodk }\end{array}$ & ARUPS, SEXAFS & $P O M$ & $\begin{array}{l}\text { Francls Loeb } \\
\text { (516) } 282-5507 \\
\text { (516) } 282-2092\end{array}$ & $\begin{array}{l}\text { Myron Strangun } \\
\quad(516) 282-3763\end{array}$ \\
\hline & & & & & & & $10 / 22 / 87$ \\
\hline
\end{tabular}




\begin{tabular}{|c|c|c|c|c|c|c|c|}
\hline $\begin{array}{l}\text { Beam } \\
\text { Port }\end{array}$ & $\begin{array}{l}\text { Beam } \\
\text { Live }\end{array}$ & $\begin{array}{l}\text { Operational } \\
\text { Status }\end{array}$ & Affiliation & Research Progran & $\begin{array}{l}\text { Ionochro- } \\
\text { metor }\end{array}$ & o- $\begin{array}{c}\text { Local } \\
\text { Contact }\end{array}$ & Spokesperson \\
\hline \multirow[t]{4}{*}{ UB } & $\mathbf{A}$ & 0 & IBM & ARUPS, NESEFS & TOM & $\begin{array}{l}\text { Arfua } \\
\text { Taleb-Ibrahtai } \\
\text { (516)282-5508 } \\
\text { (516) } 282-5303\end{array}$ & $\begin{array}{l}\text { Pead McFeely } \\
\text { (914)945-2068 }\end{array}$ \\
\hline & B & 0 & IBM & ARUPS, NEXAFS & TQM & $\begin{array}{l}\text { Andua } \\
\text { Taleb-Tbrahiml } \\
\text { (516)282-5508 } \\
\text { (516)282-5303 }\end{array}$ & $\begin{array}{l}\text { Read McFeely } \\
\text { (914)945-2068 }\end{array}$ \\
\hline & C & 0 & IBM & $\begin{array}{l}\text { Evaluation of a dine } \\
\text { Plate Monochromator, } \\
\text { PeflectIvity Masurents } \\
\text { of Thin FIl ins and } \\
\text { Milt llayers }\end{array}$ & $\begin{array}{l}\text { Zme } \\
\text { Plate }\end{array}$ & $\begin{array}{l}\text { Shertard Splller } \\
\text { (914)945-2447 }\end{array}$ & $\begin{array}{l}\text { Ebertard \$piller } \\
7 \begin{array}{ll}(914) 945-2447\end{array}\end{array}$ \\
\hline & D & 0 & IBM & $\begin{array}{l}\text { Scanuiling Soft X-ray } \\
\text { Meroscopy }\end{array}$ & $\begin{array}{l}\text { Mcro- } \\
\text { scope }\end{array}$ & $\begin{array}{r}\text { Eberhard 9uller } \\
\text { (914)945-244 }\end{array}$ & $\begin{array}{l}\text { r Bhertard Splller } \\
47 \quad \text { (914) } 945-2447\end{array}$ \\
\hline \multirow[t]{2}{*}{ U9 } & $\mathbf{A}$ & 0 & $\begin{array}{l}\text { NSLS/ENL- } \\
\text { Chentstry }\end{array}$ & $\begin{array}{l}\text { Flworesceince Iffettes } \\
\text { Photoconduct Ivity, } \\
\text { Photolanizatian }\end{array}$ & $S-N$ & $\begin{array}{l}\text { Jadk Preses } \\
\text { (516)282-55u9 } \\
\text { (516) 282-4371 }\end{array}$ & $\begin{array}{l}\text { Palph Nestan } \\
\text { (516)282-4373 }\end{array}$ \\
\hline & B & 0 & $\begin{array}{l}\text { NSTS/BNL- } \\
\text { Hology }\end{array}$ & $\begin{array}{l}\text { CD, NOD, Fluorescence } \\
\text { Iffetines }\end{array}$ & $C-T$ & $\begin{array}{l}\text { John Sutherland } \\
\text { (516)282-5509 } \\
(516) 282-3406\end{array}$ & $\begin{array}{l}\text { Johul Sutherland } \\
\text { (516)282-3406 }\end{array}$ \\
\hline \multirow[t]{2}{*}{ บ10 } & $\mathbf{A}$ & 0 & $\begin{array}{l}\mathrm{U}_{\text {, of }} \mathrm{TN} / \mathrm{ORN} / \mathrm{l} \\
\mathrm{NBS}\end{array}$ & $\begin{array}{l}\text { X-ray Fluoreacence, } \\
\text { Soft X-ray Emlosion, } \\
\text { Soft X-ray Absorption, } \\
\text { Electron Spectrosccpy }\end{array}$ & SXES & $\begin{array}{l}\text { KA'B Tsarg } \\
\text { (516)282-5510 }\end{array}$ & $\begin{array}{l}\text { Tam Call.cott } \\
(615) 974-7848\end{array}$ \\
\hline & B & 0 & $\begin{array}{l}\text { NSIS/Spercmintuttug } \\
\text { Super Collider }\end{array}$ & $\begin{array}{l}\text { Stimilated } \\
\text { Desorptian }\end{array}$ & Wite & $\begin{array}{l}\text { Joe Schucham } \\
\text { (516)282-4630 }\end{array}$ & $\begin{array}{l}\text { Joe Schuchan } \\
\text { (j16) } 282-4630\end{array}$ \\
\hline v11 & & 0 & 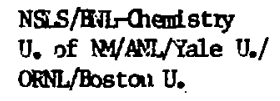 & $\begin{array}{l}\text { Gas Phase } \\
\text { Photoiontation }\end{array}$ & NM & $\begin{array}{l}\text { Mike White } \\
\text { (516)282-5511 } \\
(516) 282-4345\end{array}$ & $\begin{array}{l}\text { J. Robb Grover } \\
\text { (516)282-5511 } \\
\text { (516) } 282-4348\end{array}$ \\
\hline \multirow[t]{3}{*}{$\mathbf{v 1 2}$} & $\mathbf{A}$ & C & U. of $\mathrm{PA} / \mathrm{ORNL}$ & $\begin{array}{l}\text { High Tesolution Core } \\
\text { Level Pectroscopy }\end{array}$ & $\mathbf{T a M}$ & $\begin{array}{l}\text { Xiache Pan } \\
\text { (516) } 282-5512 \\
\text { (516) } 282-5210\end{array}$ & $\begin{array}{l}\text { Hard Dhwer } \\
\text { (215)890-8157 } \\
\text { Movid Zehuer } \\
\text { (615)574-6291 }\end{array}$ \\
\hline & B & 0 & U. of EA/ORNL & ARJPS & TQM & $\begin{array}{l}\text { Xlache Pau } \\
\text { (516) 282-5512 } \\
\text { (516)282-5210 }\end{array}$ & $\begin{array}{l}\text { Hard Plumer } \\
\text { (215)898-8157 } \\
\text { David Leher } \\
\text { (615)574-6241 }\end{array}$ \\
\hline & C & C & U. of $\mathrm{EA} / \mathrm{OPNL}$ & $\begin{array}{l}\text { Lifrared Vibration } \\
\text { quectroscopy }\end{array}$ & $C-T$ & $\begin{array}{l}\text { Devid Heskett } \\
(215) 898-7987\end{array}$ & $\begin{array}{l}\text { Wand Phorer } \\
\qquad(215) 896-8157\end{array}$ \\
\hline \multirow[t]{2}{*}{ I13 } & $\mathbf{T a k}$ & M & NSLS/ATKT Bell Labs & Tak Higgler & & $\begin{array}{l}\text { Ame Vrie } \\
\text { Fauchet } \\
\text { (516)282-5028 }\end{array}$ & $\begin{array}{l}\text { Anve Kirle } \\
\text { Fauchet } \\
\text { (516)282-5028 }\end{array}$ \\
\hline & $\mathbf{v}$ & C & $\begin{array}{l}\text { NSTS/Dresel U./ } \\
\text { U. of Wisconsin Q } \\
\text { Mlravlee/Rbutana } \\
\text { St. U./Brandels U./ } \\
\text { ATET Bell Iabs }\end{array}$ & $\begin{array}{l}\text { High Resolition VW/ } \\
\text { Soft X-ray Electron } \\
\text { and Ion qectroscoiles }\end{array}$ & SOM & $\begin{array}{l}\text { Steve hibert } \\
\text { (516)282-7570 }\end{array}$ & $\begin{array}{l}\text { Waye Bord } \\
\text { (406)994-6156 } \\
\text { Seve thibert } \\
\text { (516)282-7570 }\end{array}$ \\
\hline
\end{tabular}




\begin{tabular}{|c|c|c|c|c|c|c|c|}
\hline $\begin{array}{l}\text { Beam } \\
\text { Port }\end{array}$ & $\begin{array}{l}\text { Beam } \\
\text { Ifire }\end{array}$ & $\begin{array}{l}\text { Operattonal } \\
\text { Status }\end{array}$ & Affulation & Research Program & $\begin{array}{l}\text { Wroctro- } \\
\text { mator }\end{array}$ & Local & Spokesperson \\
\hline 114 & A & 0 & NSLS & $\begin{array}{l}\text { Solid state Photoemissions } \\
\text { Studies }\end{array}$ & $P Q M$ & $\begin{array}{l}\text { Garol Hirschmgel } \\
\text { (516)282-5514 } \\
(516) 282-7253\end{array}$ & $\begin{array}{l}\text { I Ruchard Garrett } \\
\text { (516) } 282-4245\end{array}$ \\
\hline थ5 & & 0 & $\begin{array}{l}\text { NSLS/SNY @ } \\
\text { Stonybrodk/ } \\
\text { IBU/LEL }\end{array}$ & $\begin{array}{l}\text { Soft X-ray Spectroscopy, } \\
\text { Contact Milcroscopy }\end{array}$ & TOM & $\begin{array}{l}\text { Waimen } \\
\qquad 516) 282-5515\end{array}$ & $\begin{array}{l}\text { Jancs KArz } \\
(516) 632-8106 \\
(516) 282-4723\end{array}$ \\
\hline \multirow[t]{3}{*}{ U16 } & A & C & $\begin{array}{l}\text { Conell } U_{0} / \\
U_{*} \text { of } T_{\lambda} \text {, entila }\end{array}$ & $\begin{array}{l}\text { AFIPS, SEXAFS, XPS, NEXAFS, } \\
\text { Stimulated Degorption }\end{array}$ & EFG & $\begin{array}{l}\text { Thor Frodty } \\
\text { (607) } 255-4068\end{array}$ & $\begin{array}{l}\text { Thor Prodtu } \\
\text { (607) } 255-4068\end{array}$ \\
\hline & B & $\mathbf{P}$ & $\begin{array}{l}\text { Corwell U./ } \\
\mathrm{U} \text {. of } \mathrm{TX} / \text { Sandia }\end{array}$ & $\begin{array}{l}\text { Woledilar Beam Scatterlig } \\
\text { Solid tate Photoenission } \\
\text { Soft X-ray Spectroscopy }\end{array}$ & $\mathbf{S}-\mathbf{N}$ & $\begin{array}{l}\text { Robert Merrill } \\
\qquad(607) 255-7504\end{array}$ & $\begin{array}{l}\text { Robert Merrill } \\
\qquad(607) 255-7504\end{array}$ \\
\hline & c & $\mathrm{c}$ & U. of TX/Sarktia & $\begin{array}{l}\text { Angle-resolved Photo- } \\
\text { electron Enission, \$111- } \\
\text { Polarized Fhotoelectrai } \\
\text { Emission, Bitaxdal Mtal } \\
\text { FIlms }\end{array}$ & $\operatorname{TaM}$ & $\begin{array}{l}\text { Janes Ersldive } \\
\text { (512)471-1464 }\end{array}$ & $\begin{array}{l}\text { Janes Erskive } \\
\qquad(512) 471-1464\end{array}$ \\
\hline
\end{tabular}


INFOPMATIONAL GUIDE TO THE NSLS X-RAY FAM LINES

\begin{tabular}{|c|c|c|c|c|c|c|}
\hline $\begin{array}{l}\text { Beam } \\
\text { Port }\end{array}$ & $\begin{array}{l}\text { Beam } \\
\text { Line }\end{array}$ & $\begin{array}{l}\text { Operational } \\
\text { Status }\end{array}$ & Af fillation & Research Program & $\begin{array}{l}\text { Lacal } \\
\text { Contact }\end{array}$ & Spokesperson \\
\hline \multirow[t]{2}{*}{$\overline{X I}$} & $\bar{A}$ & $\mathrm{C}$ & $\begin{array}{l}\text { NSLS/SWNY (d Stony Brodk } \\
\text { IBM/LKL. }\end{array}$ & Soft X-ray Imaging & $\begin{array}{l}\text { Farvey Rarbadk } \\
\text { (516)282-3758 } \\
(516) 282-5601\end{array}$ & $\begin{array}{l}\text { Harvey Rarbadk } \\
(516) 282-3758\end{array}$ \\
\hline & B & $M$ & Exxon Research \& Engl neering & Spectroscopy & $\begin{array}{l}\text { Wolfgang Eberhard: } \\
\qquad \begin{array}{l}\text { (201)730-2567 } \\
\text { (516) 282-4983 } \\
(516) 282-5701\end{array}\end{array}$ & $\begin{array}{l}\text { Wolfgang Eberhard } \\
\text { (516)282-4983 } \\
(201) 730-2567 \\
(516) 282-5701\end{array}$ \\
\hline \multirow[t]{2}{*}{$x^{2}$} & A & $P$ & $\begin{array}{l}\text { ANL/NSLS/Arooklyn College } \\
\text { @ aNY/NC State U./ } \\
\text { Northestern U./Standard } \\
\text { Oil/U. of MI }\end{array}$ & $\begin{array}{l}\text { Scattering, Small Angle } \\
\text { Scattering, Diffraction }\end{array}$ & $\begin{array}{l}\text { Mat1 Bloch } \\
\text { (516) } 282-3641\end{array}$ & $\begin{array}{l}\text { Gopal Shenoy } \\
\text { (312)972-5537 }\end{array}$ \\
\hline & B & $\mathbf{P}$ & $\begin{array}{l}\text { ANL/NSLS/Brodklyn College } \\
\text { a aNY/NC gtate } \mathrm{U}_{0} / \\
\text { Northwest:em U./Standard } \\
\text { OII/U. ci MI }\end{array}$ & $\begin{array}{l}\text { TIme \& Space Resolved } \\
\text { Dispersive X-ray } \\
\text { Spectroseopy }\end{array}$ & $\begin{array}{l}\text { Tim Morrison } \\
\quad(0 ! 2,972-5539\end{array}$ & $\begin{array}{l}\text { Gopal Shenoy } \\
\text { (312)972-5537 }\end{array}$ \\
\hline \multirow[t]{3}{*}{$\times 3$} & Al & $\mathbf{P}$ & State $\mathrm{U}$. of $\mathrm{NY}$ & $\begin{array}{l}\text { Short Wavelength } \\
\text { Crystallography, } \\
\text { Diffraction, and } \\
\text { Scattering }\end{array}$ & $\begin{array}{l}\mathrm{JIm} \text { Phtllips } \\
(516) 282-5603 \\
(516) 282-3770\end{array}$ & $\begin{array}{l}\text { Ph11 Coppens } \\
\text { (716)831-3911 }\end{array}$ \\
\hline & A2 & 0 & State $\mathrm{U}$. of $\mathrm{NY}$ & $\begin{array}{l}\text { Diffractoretry, X-ray } \\
\text { Spectroscopy, Crystallo- } \\
\text { graphy, Scattering, } \\
\text { Small-angle Scattering }\end{array}$ & $\begin{array}{l}\text { Jm Phillips } \\
(516) 282-5603 \\
(516) 282-3770\end{array}$ & $\begin{array}{l}\text { Phtl coppens } \\
\text { (716)831-3911 }\end{array}$ \\
\hline & B & 0 & State $U_{0}$ of $N Y$ & $\begin{array}{l}\text { X-ray Spectroscipy, } \\
\text { Surface Physics }\end{array}$ & $\begin{array}{l}\text { Jim Phillips } \\
(516) 282-5603 \\
(516) 282-3770\end{array}$ & $\begin{array}{l}\text { 1 Coppens } \\
\quad-16) 831-3911\end{array}$ \\
\hline \multirow[t]{2}{*}{$x_{4}$} & A & $\mathrm{N}$ & $\begin{array}{l}\text { Howard Hughes Medical } \\
\text { Institute (Columbia } U_{.} \text {) }\end{array}$ & $\begin{array}{l}\text { Mult iwavelength anona- } \\
\text { laus Diffraction Analysis } \\
\text { of Crystalline Eclog- } \\
\text { cal Macromoleales }\end{array}$ & $\begin{array}{l}\text { Jean-Lauls } \\
\text { s Staudermann } \\
(212) 305-1846 \\
(516) 282-3132\end{array}$ & $\begin{array}{l}\text { Wayne Hendrikson } \\
\text { (212)305-3456 }\end{array}$ \\
\hline & C & $\mathrm{N}$ & $\begin{array}{l}\text { Howard Fughes Medical } \\
\left.\text { Institute (Columbla } U_{6}\right)\end{array}$ & $\begin{array}{l}\text { Diffraction Measurements } \\
\text { Eron Blological Macro- } \\
\text { miearles }\end{array}$ & $\begin{array}{l}\text { Jeantauis } \\
\text { Staudemann } \\
\text { (212) } 305-1846 \\
\text { (516)282-3132 }\end{array}$ & $\begin{array}{l}\text { Wayne Hendrikson } \\
\text { (212)305-3456 }\end{array}$ \\
\hline$\times 5$ & A & $\mathrm{N}$ & BNL-Physies & $\begin{array}{l}\text { LECS, Nedfum Energ" } \\
\text { Nuclear Physics }\end{array}$ & $\begin{array}{l}\text { Andy Sandorf } 1 \\
\text { (516)282-7951 }\end{array}$ & $\begin{array}{l}\text { Andy Sandorf } 1 \\
\text { (516)282-7951 }\end{array}$ \\
\hline$x 6$ & A & $\mathrm{N}$ & Exxon Research \& Eng. & X-ray Tamography & $\begin{array}{l}\text { Kevin D'Amico } \\
(516) 282-2065 \\
(201) 730-2891\end{array}$ & $\begin{array}{l}\text { Kevin D'Amico } \\
(516) 282-2065 \\
(201) 730-2891\end{array}$ \\
\hline $\mathrm{x} 7$ & A & 0 & $\begin{array}{l}\text { NSLS/BNL-Physiog/U. of PA/ } \\
\text { State U. of NY/Allied/Sigmal/ } \\
\text { Dupont/Carmegle Inst of WA/ } \\
\text { Union Grbide/Alfred U./ } \\
\text { Mobil/U. of CA C Santa Barbara }\end{array}$ & Powder Diffraction & $\begin{array}{l}\text { Dave Cox } \\
\quad(516) 282-5607 \\
(516) 282-3818\end{array}$ & $\begin{array}{l}\text { Dave Cox } \\
\quad(516) 282-3818 \\
(516) 282-5607\end{array}$ \\
\hline
\end{tabular}




\begin{tabular}{|c|c|c|c|c|c|c|}
\hline $\begin{array}{l}\text { Bean } \\
\text { Port }\end{array}$ & $\begin{array}{l}\text { Beam } \\
\text { Line }\end{array}$ & $\begin{array}{l}\text { Operational } \\
\text { Status }\end{array}$ & Affillation & Research Program & $\begin{array}{l}\text { Local } \\
\text { Contact }\end{array}$ & Spokesperson \\
\hline$x$ & $B$ & 0 & $\begin{array}{l}\text { NSSS/ENL-Chenistry/ } \\
\text { U. of Pittsburgh/ } \\
\text { Stedish Research Council/ } \\
\text { Ibbil Pesearch \& Develop- } \\
\text { ment Corp. }\end{array}$ & $\begin{array}{l}\text { Crystallography, wide } \\
\text { Angle Scattering }\end{array}$ & $\begin{array}{l}\text { Ake Kvidk } \\
(516) 282-5707 \\
(516) 282-4381\end{array}$ & $\begin{array}{l}\text { Ake Kvidk } \\
(516) 282-5707 \\
(516) 282-4381\end{array}$ \\
\hline \multirow[t]{2}{*}{$x 8$} & A & $\mathbf{M}$ & $\begin{array}{l}\text { LANL/Sandia/LNL/ } \\
\mathrm{U} \text {. of CA }\end{array}$ & $\begin{array}{l}\text { Photoelect man and } \\
\text { Photoion Spectro } \\
\text { scopy }\end{array}$ & $\begin{array}{l}\text { Randy Alkire } \\
\text { (516)282-5503 } \\
(516) 282-5520\end{array}$ & $\begin{array}{l}\text { Roger Bartlett } \\
(505 \times 667-5923\end{array}$ \\
\hline & $c$ & $M$ & $\begin{array}{l}\text { LANL/Sandia/LNL/ } \\
\text { U. of CA }\end{array}$ & EXAFS, Diffraction & $\begin{array}{l}\text { Randy Alki re } \\
\text { (516)282-5503 } \\
(516) 282-5520\end{array}$ & $\begin{array}{l}\text { Halt Trela } \\
\qquad 505 \times 667-1674\end{array}$ \\
\hline \multirow[t]{2}{*}{$x$} & $\mathbf{A}$ & 0 & $\begin{array}{l}\text { National Biostuxtures } \\
\text { Pesearch Pesource }\end{array}$ & EXAFS & $\begin{array}{l}\text { Syed Khalld } \\
(516) 282-5609\end{array}$ & $\begin{array}{l}\text { Grant Bukiker } \\
\text { (215)386-1912 }\end{array}$ \\
\hline & B & $\mathbf{P}$ & $\begin{array}{l}\text { National Bostructures } \\
\text { Research Resaurce }\end{array}$ & $\begin{array}{l}\text { Scattering, } \\
\text { Diffraction }\end{array}$ & $\begin{array}{l}\text { Syed Whalid } \\
\text { (516)282-5609 }\end{array}$ & $\begin{array}{l}\text { Kent Blasie } \\
\text { (215)898-6208 }\end{array}$ \\
\hline \multirow[t]{3}{*}{$\mathrm{x} 10$} & $A$ & 0 & $\begin{array}{l}\text { Exxon Pesearch \& } \\
\text { Englineering }\end{array}$ & $\begin{array}{l}\text { Scattering, Small Angle } \\
\text { Scattering, Diffraction, } \\
\text { Crystallography }\end{array}$ & $\begin{array}{l}\text { Kevin D'Anico } \\
\text { (516)282-2065 } \\
(516) 282-5610 \\
(201) 730-2891\end{array}$ & $\begin{array}{l}\text { Dave Mbnctron } \\
\begin{array}{l}(516) 282-2741 \\
(201) 730-2334\end{array}\end{array}$ \\
\hline & $\mathbf{B}$ & 0 & $\begin{array}{l}\text { Exoon Research \& } \\
\text { Engineerirg }\end{array}$ & $\begin{array}{l}\text { Crystallography, } \\
\text { Scattering }\end{array}$ & $\begin{array}{l}\text { Kevin D'Amico } \\
\text { (516)282-5610 } \\
(516) 282-2065 \\
(201) 730-2891\end{array}$ & $\begin{array}{l}\text { Dave Ibncton } \\
(516) 282-2741 \\
(201) 730-2384\end{array}$ \\
\hline & C & c & $\begin{array}{l}\text { Exxon Research \& } \\
\text { Ingineering }\end{array}$ & EXAFS & $\begin{array}{l}\text { Kevin D'Amico } \\
\text { (516)282-2065 } \\
(516) 282-5610 \\
(201) 730-2891\end{array}$ & $\begin{array}{l}\text { Dave Moncton } \\
\text { (516)282-2741 } \\
(201) 730-2384\end{array}$ \\
\hline \multirow[t]{2}{*}{$\mathrm{x} 11$} & $\mathbf{A}$ & 0 & 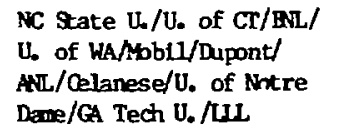 & EAFS & $\begin{array}{l}\text { Stewe Heald } \\
(516) 282-5611 \\
(516) 282-2861\end{array}$ & $\begin{array}{l}\text { Dale Sayers } \\
\text { (919)737-3482 }\end{array}$ \\
\hline & B & $\mathrm{c}$ & $\begin{array}{l}\text { NC State U./L. of CT/BNL/ } \\
\text { U. of WA/Lbil/Dupont/ } \\
\text { ANL/Celanese/U. of Notre } \\
\text { Dame/CA Tech U./LLL }\end{array}$ & EXAFS & $\begin{array}{l}\text { Steve Heald } \\
(516) 282-5611 \\
(516) 282-2861\end{array}$ & $\begin{array}{l}\text { Dale Sayers } \\
\qquad(919) 737-3482\end{array}$ \\
\hline \multirow[t]{3}{*}{$\mathrm{X} 12$} & $\mathbf{A}$ & 0 & NSLS & Diagnostics & $\begin{array}{l}\text { Peter Siddons } \\
\text { (516)282-2738 }\end{array}$ & $\begin{array}{l}\text { Peter Siddons } \\
\quad(516) 282-2738\end{array}$ \\
\hline & B & $M$ & NSSS/ENL-Biology & Suall Angle Scattering & $\begin{array}{l}\text { Malcoln Capel } \\
(516) 282-5712 \\
(516) 282-2792\end{array}$ & $\begin{array}{l}\text { Malcolm Capel } \\
\qquad(516) 282-2792\end{array}$ \\
\hline & $\mathrm{C}$ & 0 & ENL-Biolog & Protein Crystallography & $\begin{array}{l}\text { Bob Sweet } \\
(516) 282-5712 \\
(516) 282-3401 \\
(516) 282-5642\end{array}$ & $\begin{array}{l}\text { Bob Street } \\
(516) 282-3401 \\
(516) 282-5642\end{array}$ \\
\hline $\mathrm{x} 13$ & & & NSTS & $\begin{array}{l}\text { RED optics Developuent } \\
\text { Soft X } \mathrm{r} \text {-ry Utlization }\end{array}$ & $\begin{array}{l}\text { Erlk Johnson } \\
\text { (516)282-4603 }\end{array}$ & $\begin{array}{l}\text { Erik Johnson } \\
\text { (516)282-4603 }\end{array}$ \\
\hline Pooton & & & & & & $10 / 22 / 87$ \\
\hline
\end{tabular}




\begin{tabular}{|c|c|c|c|c|c|c|}
\hline $\begin{array}{l}\text { Bean } \\
\text { Port }\end{array}$ & $\begin{array}{l}\text { Bean } \\
\text { Line }\end{array}$ & $\begin{array}{l}\text { Opentional } \\
\text { Status }\end{array}$ & Af fillation & Research Program & $\begin{array}{l}\text { Local } \\
\text { Contact }\end{array}$ & Spokesperson \\
\hline $\mathrm{X} 14$ & A & 0 & $\begin{array}{l}\text { ORNL/Cak Ridge Associated } \\
\text { Universities Users } \\
\text { Association }\end{array}$ & $\begin{array}{l}\text { Scatteritg, Crystallo- } \\
\text { graphy, Spectroscopy }\end{array}$ & $\begin{array}{l}\text { Gene Ice } \\
\quad(516) 282-5614\end{array}$ & $\begin{array}{l}\text { Cullie Spadks } \\
\quad(615 \$ 574-6996\end{array}$ \\
\hline \multirow[t]{2}{*}{$\mathrm{X} 15$} & A & 0 & ATß́T Bell Labs & $\begin{array}{l}\text { X-ray Standing have, } \\
\text { Soft X-ray Spectroscopy, } \\
\text { X-ray Lfthograpty' }\end{array}$ & $\begin{array}{l}\text { Brian Kincaid } \\
(516) 282-5615\end{array}$ & $\begin{array}{l}\text { Brian Kincaid } \\
\quad(516) 282-5615\end{array}$ \\
\hline & B & $M$ & AT\&T Bell Labs & SEXAFS, EXAFS & $\begin{array}{l}\text { Alastair MacDowe11 } \\
\text { (516)282-3565 }\end{array}$ & $\begin{array}{l}\text { Paul cltrin } \\
\text { (201) } 582-5275\end{array}$ \\
\hline \multirow[t]{3}{*}{$\mathrm{X} 16$} & A & 0 & AT\&T Bell Labs & Surface Diffraction & $\begin{array}{l}\text { Alastair MacDowell } \\
\text { (516)282-3565 } \\
(516) 282-5716\end{array}$ & $\begin{array}{l}\text { Paul Fuoss } \\
\text { (201)949-3581 } \\
\text { Ian Pobinson } \\
\text { (201)582-6056 }\end{array}$ \\
\hline & B & 0 & AT\&T Bell Labs & Diffraction & $\begin{array}{l}\text { Alastair MacDowe11 } \\
\text { (516)282-3565 } \\
(516) 282-5716\end{array}$ & $\begin{array}{l}\text { Denis Mcthan } \\
\text { (516)282-5716 } \\
(516) 282-3927 \\
\text { (201) } 582-4557\end{array}$ \\
\hline & C & 0 & AT\&T Bell Labs & Diffraction & $\begin{array}{l}\text { Alastalr MeDowell } \\
(516) 282-3565 \\
(516) 282-5716\end{array}$ & $\begin{array}{l}\text { Denis Mchan } \\
(516) 282-5716 \\
(516) 282-3927 \\
\text { (201)582-4557 }\end{array}$ \\
\hline \multirow[t]{3}{*}{$\mathrm{x} 17$} & Bl & $c$ & NSLS & $\begin{array}{l}\text { Materials Sciences } \\
\text { Chemlcal Crystallo- } \\
\text { graphy, EXAFS, High } \\
\text { Pressire Physios, } \\
\text { Topography, X-ray } \\
\text { Scattering }\end{array}$ & $\begin{array}{l}\text { Dean Ohapran } \\
(516) 282-5617 \\
(516) 282-4744\end{array}$ & $\begin{array}{l}\text { Bill Thomlingon } \\
\text { (516)282-3937 }\end{array}$ \\
\hline & B2 & 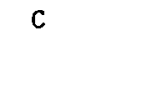 & $\begin{array}{l}\text { NSS/SSR/Stanford U./ } \\
\text { LE/ INL-HEdical }\end{array}$ & $\begin{array}{l}\text { Angiography, } \\
\text { Ratiotherapy }\end{array}$ & $\begin{array}{l}\text { H11 Thanlinsan } \\
\text { (516)282-5617 } \\
\text { (516)282-3937 }\end{array}$ & $\begin{array}{l}\text { Bill Thamlineon } \\
\text { (516)282-3937 }\end{array}$ \\
\hline & C & $\mathrm{C}$ & $\begin{array}{l}\text { NRL/LUL/L6 of WA/ } \\
\text { U. of CA C Berkeley/ } \\
\text { Eoron'U. of HI/ } \\
\text { Carnegle Inst of WA/ } \\
\text { ATsT Bell Labs/SUN C } \\
\text { Stony Ben/k/Comell U./LANL }\end{array}$ & Hitgh Pressure & $\begin{array}{l}\text { Denis Mclhan } \\
\quad(516) 282-3927\end{array}$ & $\begin{array}{l}\text { Earl Skelton } \\
\text { (202) }) 67-3014\end{array}$ \\
\hline \multirow[t]{2}{*}{$\mathrm{x} 18$} & $\mathbf{A}$ & 0 & Matrix & $\begin{array}{l}\text { Diffuse \& Surface } \\
\text { Scatterirg }\end{array}$ & $\begin{array}{l}\text { Steve Errlich } \\
\text { (516)282-5618 } \\
(516) 282-7862\end{array}$ & $\begin{array}{l}\text { Cerry Liedl } \\
\qquad(317) 494-4095\end{array}$ \\
\hline & B & 0 & $\begin{array}{l}\text { Hest Virginia U./ } \\
\text { U. of PIttsburgh/Chevron' } \\
\text { Alled-Stgral Research } \\
\text { GTE/Brodklyn College } \\
\text { of aNY }\end{array}$ & EAFS & $\begin{array}{l}\text { Mohan Raranathan } \\
(516) 282-5718 \\
(516) 282-7860\end{array}$ & $\begin{array}{l}\text { Pedro Pntano } \\
\text { (304)293-3422 } \\
(718) 780-5779\end{array}$ \\
\hline$\times 19$ & A & $M$ & NSLS & $\begin{array}{l}\text { X-xay spectrosecpy, } \\
\text { EXAFS }\end{array}$ & $\begin{array}{l}\text { Peter Stefan } \\
\quad(516) 282-5619 \\
(516) 282-2117\end{array}$ & $\begin{array}{l}\text { Peter Stefan } \\
\quad(516) 282-2117\end{array}$ \\
\hline
\end{tabular}




\begin{tabular}{|c|c|c|c|c|c|c|}
\hline $\begin{array}{l}\text { Bean } \\
\text { Port }\end{array}$ & $\begin{array}{l}\text { Beam } \\
\text { Line }\end{array}$ & $\begin{array}{l}\text { Operational } \\
\text { Status }\end{array}$ & Af flliation & Research Program & $\begin{array}{l}\text { Local } \\
\text { Contact }\end{array}$ & Spokesperson \\
\hline $\mathrm{x} 19$ & $\mathrm{C}$ & 0 & $\begin{array}{l}\text { NSIS/Synchrotron } \\
\text { Topography Project } \\
\text { Consortín }\end{array}$ & Topography & $\begin{array}{l}\text { Tony thelo } \\
(516) 282-5719 \\
(516) 632-8500\end{array}$ & $\begin{array}{l}\text { Michael Dudley } \\
\text { (516)632-8500 }\end{array}$ \\
\hline \multirow[t]{3}{*}{$\times 20$} & $A$ & 0 & $\mathrm{IBM} / \mathrm{MIT}$ & Scattering, EXAFS & $\begin{array}{l}\text { Jean Jordan-swet } \\
\text { (516)282-5720 }\end{array}$ & $\begin{array}{l}\text { Paul Horn } \\
\text { (914)945-2445 }\end{array}$ \\
\hline & B & C & IBMMIT & $\begin{array}{l}\text { Scattering at Fixed } \\
\text { Energy }\end{array}$ & $\begin{array}{l}\text { Jean Jordan-Sweet } \\
\text { (516)282-5720 }\end{array}$ & $\begin{array}{l}\text { Paul Horn } \\
\text { (914)945-2445 }\end{array}$ \\
\hline & $\mathrm{C}$ & 0 & $\mathrm{BBM} / \mathbf{M T}$ & Scattering, EXAFS & $\begin{array}{l}\text { Jean Jordan-Sweet } \\
\text { (516)282-5720 }\end{array}$ & $\begin{array}{l}\text { Paul Horn } \\
\text { (914)945-2445 }\end{array}$ \\
\hline$x 21$ & & $N$ & NSLS & $\begin{array}{l}\text { High Enengy Resolution } \\
\text { Inelastic Scattering }\end{array}$ & $\begin{array}{l}\text { Jerry Hastings } \\
\text { (516)282-3930 }\end{array}$ & $\begin{array}{l}\text { Jerry Hastings } \\
\text { (516)282-3930 }\end{array}$ \\
\hline \multirow[t]{2}{*}{$X 22$} & B & 0 & $\begin{array}{l}\text { ENL-Physics/ } \\
\text { Harvard U. }\end{array}$ & $\begin{array}{l}\text { High Pesohition } \\
\text { X-ray Diffraction }\end{array}$ & $\begin{array}{l}\text { Ben Ocko } \\
\begin{array}{l}(516) 282-5622 \\
(516) 282-4299\end{array}\end{array}$ & $\begin{array}{l}\text { John Axe } \\
\quad(516) 282-3821\end{array}$ \\
\hline & C & 0 & BNL-Physics & $\begin{array}{l}\text { Diffraction Studles } \\
\text { of !hgnetic and } \\
\text { St nuctural Fhase Trans- } \\
\text { formtions, Surface } \\
\text { Scattering }\end{array}$ & $\begin{array}{l}\text { Doon Gibbs } \\
(516) 282-5622 \\
(516) 282-4608\end{array}$ & $\begin{array}{l}\text { John Axe } \\
\quad(516) 282-3821\end{array}$ \\
\hline \multirow[t]{3}{*}{$\times 23$} & A2 & M & $\begin{array}{l}\text { National Breau of } \\
\text { Standards }\end{array}$ & $\begin{array}{l}\text { EXFS, SEAFS, wh } \\
\text { Standing Wave \& Photo- } \\
\text { Electron Detection, } \\
\text { Spearlar X-ray Reflection }\end{array}$ & $\begin{array}{l}\text { Richard Spal } \\
\text { (516)282-5623 } \\
(516) 282-2279 \\
\end{array}$ & $\begin{array}{l}\text { Masao Kurfyama } \\
\text { (301)975-5974 }\end{array}$ \\
\hline & $A^{3}$ & 0 & $\begin{array}{l}\text { National Bureau of } \\
\text { Standar ds }\end{array}$ & $\begin{array}{l}\text { Real Time Topography, } \\
\text { Mcroratiography, } \\
\text { Energy Dispersive } \\
\text { Diffraction, White Beam } \\
\text { Experiments, EXAFS }\end{array}$ & $\begin{array}{l}\text { Rd chard Spal } \\
\text { (516)282-5623 } \\
\text { (516)282-2279 }\end{array}$ & $\begin{array}{l}\text { Masao Kurfyama } \\
\text { (301 } 975-5974\end{array}$ \\
\hline & $B$ & 0 & Nav1 Pesearch Lab & $\begin{array}{l}\text { Scattering, Crystallo } \\
\text { graphy, EXAFS }\end{array}$ & $\begin{array}{l}\text { John K1 rkland } \\
\text { (516)632-8515 } \\
\text { Richard Nelser } \\
\text { (516)282-5723 } \\
\text { (516)282-2258 }\end{array}$ & $\begin{array}{l}\text { W. T. Elam } \\
\text { (202)767-3014 }\end{array}$ \\
\hline \multirow[t]{2}{*}{$x 24$} & A & 0 & $\begin{array}{l}\text { National Bureau of } \\
\text { Standands }\end{array}$ & $\begin{array}{l}X \text {-ray Spectroscopy, } \\
\text { Ataulc \& Mbleoular } \\
\text { Physlcs }\end{array}$ & $\begin{array}{l}\text { Berry Karlin } \\
(516) 282-5624 \\
\text { Paul Cowan } \\
\text { (301)975-4846 }\end{array}$ & $\begin{array}{l}\text { Ptchard Deslattes } \\
\text { (301)975-4841 }\end{array}$ \\
\hline & $\mathrm{c}$ & 0 & Nava1 Research Lab & $\begin{array}{l}\text { Photoemission and } \\
\text { Reflectance Spectroscopy }\end{array}$ & $\begin{array}{l}\text { Jack Rife } \\
(516) 282-5624 \\
(202) 767-4654\end{array}$ & $\begin{array}{l}\text { Milton Kabler } \\
\quad(202 \nabla 67-2223\end{array}$ \\
\hline $\mathrm{x} 25$ & & $\mathrm{C}$ & $\begin{array}{l}\text { NSIS/AT\&T Bell Labs/IBM/ } \\
\text { Haruard U./BNL-Physics/ } \\
\text { Exoon }\end{array}$ & $\begin{array}{l}\text { High-? Resolution } \\
\text { Elastic Scattering }\end{array}$ & $\begin{array}{l}\text { Lomy Bemen } \\
\quad(516) 282-5625\end{array}$ & $\begin{array}{l}\text { Lomy Beman } \\
\qquad(516) 282-5625\end{array}$ \\
\hline Footno & appe & n last prepe & Inforational Guide. & & & $10 / 22 / 87$ \\
\hline
\end{tabular}




\begin{tabular}{|c|c|c|c|c|c|c|}
\hline $\begin{array}{l}\text { Bean } \\
\text { Port }\end{array}$ & $\begin{array}{l}\text { Bean } \\
\text { Wine }\end{array}$ & $\begin{array}{l}\text { Operational } \\
\text { Status }\end{array}$ & Affillatiat & Researdh Program & $\begin{array}{l}\text { Local } \\
\text { Contact }\end{array}$ & Spokespersoll \\
\hline \multirow[t]{2}{*}{$x 26$} & $\mathbf{A}$ & $\mathbf{P}$ & $\begin{array}{l}\text { BNL-DAS/U. of Chicago/DOE/ } \\
\text { NLH Blotechnology Pesearch/ } \\
\text { Cornell U./Texas ASM/ } \\
\text { U. of TN }\end{array}$ & Milcroprobe & $\begin{array}{l}\text { Keith Jo1es } \\
\begin{array}{l}(516) 282-5626 \\
(516) 282-4588 \\
(516) 282-5726\end{array}\end{array}$ & $\begin{array}{l}\text { Keith Joies } \\
\text { (516)282-4588 }\end{array}$ \\
\hline & C & 0 & 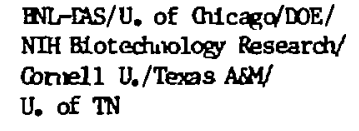 & Atondc Prysics & $\begin{array}{l}\text { Keith Joues } \\
\text { (516) } 282-5626 \\
(516) 282-4588 \\
(516) 282-5726\end{array}$ & $\begin{array}{l}\text { Keith Jares } \\
\text { (516) } 282-4588\end{array}$ \\
\hline X27 & & c & NSS & $\begin{array}{l}\text { Instrument \& Daguastic } \\
\text { Development }\end{array}$ & $\begin{array}{l}\text { Peter Siddons } \\
\quad(516) 282-2738\end{array}$ & $\begin{array}{l}\text { Peter Siddous } \\
\quad(516) 282-2738\end{array}$ \\
\hline$X 28$ & & C & NSLS & $\begin{array}{l}\text { Instrument \& Dilaphostic } \\
\text { Development }\end{array}$ & $\begin{array}{l}\text { Peter Stddons } \\
\text { (516) } 282-2733\end{array}$ & $\begin{array}{l}\text { Peter Siddous } \\
\text { (516) 282-2738 }\end{array}$ \\
\hline \multicolumn{7}{|c|}{ 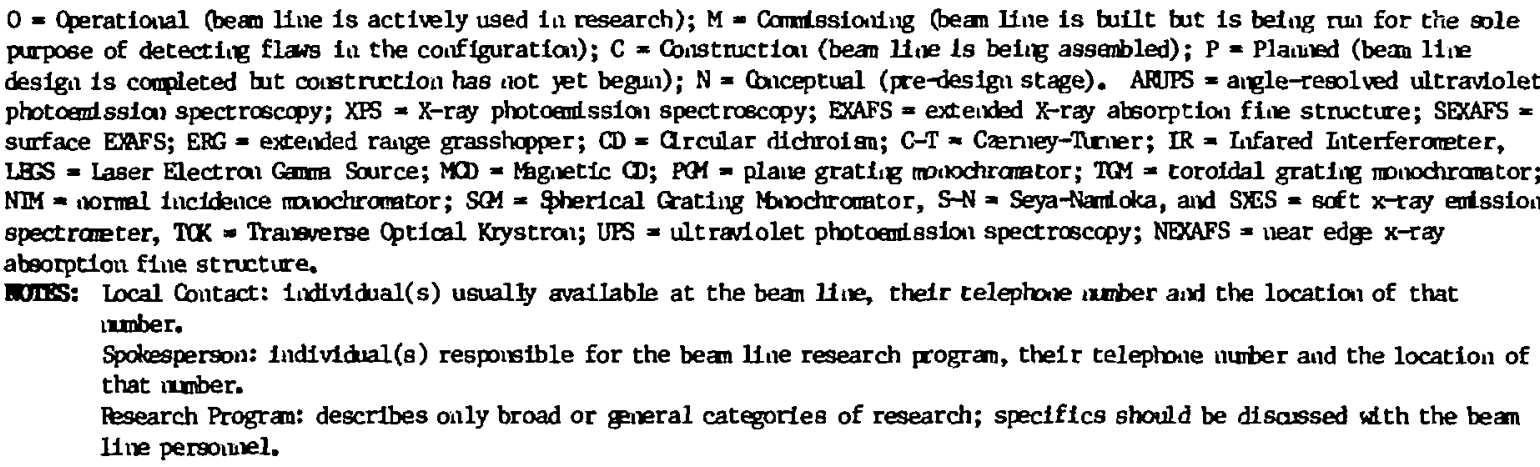 } \\
\hline
\end{tabular}




\section{REPORTS OF THE VUV RESEARCH AT THE NSLS}

This section contains the reports of research carried out at the NSLS VUV storage ring during the 1987 fiscal year. Most of the contributions have been specifically written for this annual report by the experimenters. Their efforts are greatly appreciated by the annual report staff. The repons are presented by beam line and are arranged alphabetically by first author (except where a specific order was requested.) The Table of Contents that follows is also arranged by beam line and first author.

\section{VUV Storage Ring Parameters as of June 1987}

\begin{tabular}{|c|c|}
\hline Parameters & VUV Storage Ring \\
\hline Normal Operating Energy & $0.750 \mathrm{GeV}$ \\
\hline Design Current (multibunch operation) & $1.0 \operatorname{amp}\left(1.1 \times 10^{12} \mathrm{e}^{-}\right)$ \\
\hline Circumference & 51.0 meters \\
\hline Number of Beam Ports on Dipoles & 17 \\
\hline Number of Insertion Devices & 2 \\
\hline Maximum Length of Insertion Devices & $\sim 3.00$ meters \\
\hline$\lambda_{c}\left(E_{c}\right)$ & $25.3 \mathrm{~A}(486 \mathrm{eV})$ \\
\hline$B(p) c^{\prime}$ & 1.28 Tesla (1.91 meters) \\
\hline Electron Orbital Period & 170.2 nanoseconds \\
\hline Damping Times & $\tau_{x} \simeq \tau_{y} \simeq 17 \mathrm{msec} ; \tau_{\epsilon} \simeq 9 \mathrm{msec}$ \\
\hline $\begin{array}{l}\text { Touschek lifetime dependent on current } \\
\text { and vertical emittance }\end{array}$ & \\
\hline Lattice Structure (Chasman-Green) & Separated Function, Quad, Doublets \\
\hline Number of Superperiods & 4 \\
\hline Magnet Complement & $\begin{array}{l}8 \text { Bending ( } 1.5 \text { meters each) } \\
24 \text { Quadrupole ( } 0.3 \text { meters each) } \\
12 \text { Sextupole ( } 0.2 \text { meters each) }\end{array}$ \\
\hline Nominal Tunes $\nu_{\mathrm{x}}, \nu_{\mathrm{y}}$ & $3.12,1.17$ \\
\hline Momentum Compaction & 0.023 \\
\hline R.F. Frequency & $52.887 \mathrm{MHz}$ \\
\hline Radiated Power & $14.7 \mathrm{~kW} / \mathrm{amp}$ of Beam \\
\hline R.F. Peak Voltage & $100 \mathrm{kV}$ \\
\hline Design R.F. Power & $50 \mathrm{~kW}$ \\
\hline$\nu_{\mathrm{s}}$ (Synchrotron Tune) & 0.002 \\
\hline Natural Energy Spread $\left(\sigma_{\epsilon} / \mathrm{E}\right)$ & $4.5 \times 10^{-4}$ \\
\hline 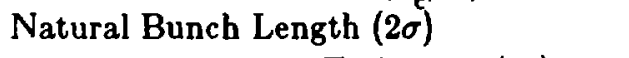 & $7.6 \mathrm{~cm}(\mathrm{I}<20 \mathrm{~mA})$ \\
\hline Horizontal Damped Emittance $\left(\epsilon_{x}\right)$ & $\begin{array}{l}1.5 \times 10^{-7} \text { meter-radian } \\
>28 \times 10^{-10}\end{array}$ \\
\hline $\begin{array}{l}\text { Vertical Damped Emittance }(\epsilon y) \\
\text { Power per Horizontal milliradian, } 1 \mathrm{~A}\end{array}$ & $\begin{array}{l}\geq 2.8 \times 10 \text { meter-radian (adjust.) } \\
2.3 \text { Watts }\end{array}$ \\
\hline Source Size: $\sigma_{\mathrm{h}}, \sigma_{\mathrm{v}}$ & $0.5 \mathrm{~mm},>0.06 \mathrm{~mm}$ \\
\hline
\end{tabular}

Source of Data: NSLS Parameters, January 1983, compiled by A. van Steenbergen; updated values provided by Gaetano Vignola (NSLS).

$$
2-1 \mid 2-2
$$




\section{CONTENTS}

\section{RESEARCH REPORTS FOR THE VUV BEAM LINES}

Beam Line U1

W. Eberhardt, and R. Murphy

J. Gland, D. Fischer, and S. Shen

D. Sondericker, Z. Fu, D.C. Johnston, and W. Eberhardt

D. Sondericker, Z. Fu, D.C. Johnston, and W. Eberhardt

L. Yang, B. Abeles, W. Eberhardt, D. Sondericker, H. Stasiewski, and Z. Fu

Beam Line U3

E.D. Poliakoff, L. Kelly, L. Duffy, B. Space, P. Roy, S.H. Southworth, and M.G. White

Beam Line U4A

R.H. Gaylord and S.D. Kevan

R.H. Gaylord and S.D. Kevan

A.L.D. Kilcoyne, D.P. Woodruff, R.H. Gaylord, S.D. Kevan, and J.E. Rowe

Beam Line U4B

C.T. Chen and F. Sette

Beam Line U4IR

G.P. Williams, E. Kneedler, C. Hirschmugl, M. Shleifer, P.Z. Takacs, Y. Chabal, F. Hoffmann, and K.D. Moller

Beam Line U5

P.D. Johnson, S.L. Qiu, L. Jiang, M. W. Ruckman, M. Strongin, S.L.

Hulbert, R.F. Garrett, B. Sinković, N. V. Smith, R.J. Cava, C.S. Jee, D. Nichols, E. Kaczanowicz, R.E.

Salomon, and J.E. Crow

\section{Beam Line U6}

J.O. Choi, J.A. Moore, J.C. Corelli, and J.P Silverman

S.S. Dana, J.R. Maldonado, J. Batey, and $J$. Silverman
Auger-Electron Ion Coincidence Studies on Small Molecules.

Fluorescence Yield Near Edge Spectroscopy (FYNES): A Novel Technique for In-Situ Surface Chemistry ...........

Resonant Photoemission of $\mathrm{La}_{2} \mathrm{CuO}_{4}$

Valence Band Photemission of $\mathrm{La}_{2} \mathrm{CuO}_{4}$

Photoemission Study of a-Si:H/a-SiN ${ }_{x}: H$ Interface Formation

Vibrationally Resolved Electronic Autoionization of CoreHole Resonances.

Spin-Orbit Interaction Induced Surface Resonance on $\mathbf{W}(110)$

Surface States and Reconstruction on W(110)

Electronic Structure of $\mathbf{C}, \mathbf{N}$ and $\mathrm{O}$ Adsorption Structures on $\mathrm{Ni}(100)$

A Preliminary Report on "Dragon" Monochromator: the Spherical Version of the Cylindrical Element Monochromator.

The Infra-Red Beam Line IR4

Photoemission Studies of the High $\mathrm{T}_{c}$ Superconductor $\mathrm{YBa}_{2} \mathrm{Cu}_{3} \mathrm{O}_{9}-\delta$

Degradation of Poly(Methyl Methacrylate) by X-rays...

Effects of X-ray Radiation on the Physical Properties of Boro-Hydro-Nitride Films 
J. Hrbek, T.K. Sham, and M.L. Shek

S.H. Lu, Z.Q. Wang, S.C. Wu, C.K.C. Lok, J. Quinn, Y.S. Li, D. Tian, and F. Jona

S.L. Qiu, J. Chen, and M. Strongin

S.L. Qiu, V. Murgai, and M. Strongin

S.L. Qiu, M.W. Ruckman, J. Chen, and $M$. Strongin

S.L. Qiu, M.W. Ruckman, P.D. Johnson, J. Chen, L. Jiang, M. Strongin, B. Sinkovic, and N. Brookes

S.L. Qiu, M.W. Ruckman, P.D. Johnson, J. Chen, C.L. Lin, M. Strongin, B. Sinković, and N. Brookes

S.L. Qiu, M.W. Ruckman, M. Strongin, and $J$. Chen

M.W. Ruckman, S.L. Qiu, S. Heald, and $H$. Chen

M.W. Ruckman, S.L. Qiu, M. Strongin, and $J$. Chen

Beam Line U8B

F.J. Himpsel and J.A. Yarmoff

G. Jezequel, A. Taleb-Ibrahimi, and R. Ludeke

J.R. Lince, T.B. Stewart, M.H. Hills, P.D. Fleischauer, J.A. Yarmoff, and $A$ Taleb-Ibrahimi

F.R. McFeely, J.A. Yarmoff, A. TalebIbrahimi, and D.B. Beach

A. Taleb-Ibrahimi, G. Jezequel, and R. Ludeke

J.A. Yarmoff, D.R. Clarke, W. Drube, U.O. Karlsson, A. Taleb-Ibrahimi, and F.J. Himpsel

J.A. Yarmoff and F.R. McFeely

J.A. Yamnoff, A. Taleb-Ibrahimi, F.R McFeely, and Ph. Avouris

Beam Line U8C\&D

E. Spiller

E. Spiller
Mn Overlayers On Ru(00) Surface

$\mathrm{Cu} / 001 / \mathrm{c}(2 \times 2)$-Pd: A Surface Alloy Atomic Artangement and Electronic Structure

Studies of Potassium with Solid Ammonia

Growth of Yb Films on $\mathrm{Ta}$

The Nature of the Interface for Pd Overlayers on Ta.

Resonant and X-ray Photoemission Studies of the $\mathrm{YBa}_{2} \mathrm{Cu}_{3} \mathrm{O}_{7}$ Valence $\mathrm{B}$ and Above and Below the Superconducting Transition Temperature.

Interaction of Oxygen with a High $\mathrm{T}_{\mathrm{c}}$ Superconducting Oxide at Low Temperature

Formation of Al/Ta(110) Interfaces and Their Mudification by $O x i d a t i o n$

Room Temperature Intermixing at Cu-Al Interfaces....

Morphology, Bonding and Thermal Stability of $\mathrm{Cu} /$ $\mathrm{Ta}(100) \mathrm{Au} / \mathrm{Ta}(110)$ Overlayers

Microscopic Sinucture of the $\mathrm{SiO}_{2} / \mathrm{Si}$ Interface............

Interface States and Schottky Behavior

Photoelectron Spectroscopic Study of the Effect of NobleGas Ion Bombardment on the $\mathrm{MoS}_{2}(000 \mathrm{I})$ Surface .....

Interaction of Pyrolized Hexafluoroazomethane with SI(11)

On the Effects of $\mathrm{Ga}$ in the Formation of Reactive Interfaces.

Electronic Structure of $\mathrm{Y}_{1} \mathrm{Ba}_{2} \mathrm{Cu}_{3} \mathrm{O}_{7}$.

Chemical Vapor Deposition of Tungsten on Silicon Oxides

Chemical Selectivity in Photon Stimulated Desorption of Fluorine from Silicon

Resolution Test of the Zoneplate Monochromator at Beamline U8

Refractive Index Measurements of Amorphous Carbon Near Its $K$ Edge. 
Beam Line U9A

R.A. Holroyd and K. Nakagawa

J.M. Preses

J.M. Preses

J.J. Tiee, C.R. Quick, and D. Hof

Beam Line U9B

K.H. Johnson. D.M. Gray, P. Morris, and J.C. Sutherland

S-K. Kim, N.E. Geacintov, D. Zinger, and J.C. Sutherland

K. Polewski, D. Zinger, J. Trunk, and J.C. Sutherland

\section{Beam Line U10}

D.L. Ederer, R. Schaefer, K.-L. Tsang, C.H. Zhang, T.A. Callcott, and E.T. Arakawa

K.-L. Tsang, T.A. Callcott, J.E. Rowe, R.A. Logan, D.L. Ederer, and E.T.

Arakawa

K.-L. Tsang, C.H. Zhang, T.A.

Callcott, L.R. CanfieId, D.L. Ederer, J.

E. Blendell, C.W. Clark, N. Wassdahl,

J.E. Rubensson, G. Bray, N.

Mortensson, J. Nordgren, R. Nyholm, and $\mathbf{S}$. Cramm

C.H. Zhang, K.L. Tsang, and T.A.

Callcott, D.L. Ederer, and E.T.

Arakawa

\section{Beam Line U10B}

D. Bintinger, P. Limon, J. Tompkins,

H. Jostlein, and D. Trojevic

Beam Line U11

J.R. Grover, E.A. Walters, J.K.

Newman, and M.G. White

J.R. Grover, E.A. Walters, and M.G. White

\section{Beam Line U12}

E. Jensen, R. Bartynski, S. Hulbert, and E. Johnson

S.-C. Lui, B.S. Itchkawitz, E.W. Plummer, and D.M. Zehner
Photodesorption from LHe Temperature Beam Tube Surfaces.

Photoionization of Anthracene

Fluorescence from Cyclohexane lsolated in an Argon Matrix.

Photoionization of Laser-Excited Atoms

Time-Resolved Fluorescence Study of VUV Light Induced Reactions of Chlorine or Cyanogen Containing Molecules/

Rare-Gas Mixtures

Circular Dichroism of Synthetic RNAs in the Vacuum Ultraviolet

Fluorescence Decay Profiles of Covalent Ennzo(A)Pyrene Diol Epoxide Enantiomer-DNA Adducts

Argon Matrix Isolation Fluorometer

Electronic Structure of the Icosahedral and Other Phases of Aluminum-Manganese Alloys Studied by Soft X-ray Emission Spectroscopy

Soft X-ray Emission Studies of $\mathrm{Al}_{x} \mathrm{Ga}_{1-\mathrm{x}} \mathrm{As}$ Compounds.

Soft X-ray Absorption and Emission Spectra and the Electronic Structure of the $\mathrm{Ba}_{2} \mathrm{YCu}_{3} \mathrm{O}_{7-x}$ Superconductor....

The $\mathrm{AL}_{2,3}$ and $\mathrm{MG}$ Double Ionization Emission Spectra of Dilute $\mathrm{AL}$ in $\mathrm{MG}$ Alloys

Photoionization Studies of a Self-Reactive Van Der Waals Complex: 1,3-Butadiene-Sulfur Dioxide

Dissociative Rearrangement in the Photoionization of Weak Molecular Complexes

Auger Photoelectron Coincidence Spectroscopy of Al $(100)+0$.

Angle-Resolved Photoemission Determination of the NiAl Band Structure and Fermi Surface 
J.M. Bloch, M. Sagurton, G.P. Williams, I. Jacob, and C. Binns

R. Garrett, E. Johnson, E. Kneedler, G. Williams, and J. Tranquada

L. Golub and E. Spiller

R.J. Lad and V.E. Henrich

M. Sagurton and G.P. Williams

K.E. Smith and V.E. Henrich

G.P. Williams, M. Sagurton, P. Xu, R. F. Garrett, E. Kneedler, W. Braun, G. Tourillon, E. Dartyge, and A. Fontaine

Beam Line U15

D.M. Hanson, S.L. Anderson, K. Wu, D. Lapiano, and C.I. Ma

A. Reisman, C.K. Williams, P.K. Bhattacharya, and $W . N g$

S.C. Woronick, W. Ng, A. Krol, B.X. Yang, and Y.H. Kao

S.C. Woronick, B.X. Yang, A. Krol, Y.H. Kao, H. Munekata, and L.L. Chang
Photoelectron Diffraction from Langmuir-Blodgett Films ..

Photoemission Investigation of the $\mathrm{La}_{2-x} \mathrm{Sr}_{x} \mathrm{CuO}_{4}$ High

Temperature Superconductors..............................

Large Area X-ray Multilayer Mirror Calibration ..........

Angle-Resolved and Resonant Photoemission Studies of $\mathrm{MnO}$ and $\mathrm{Fe}_{3} \mathrm{O}_{4}$

Energy-Dependent Photoelectron Diffraction from GaAs(110)

Resonant Photoemission Effects and Bulk Band Disper-

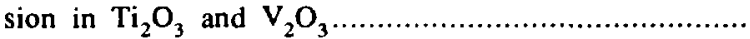

Near-Edge X-ray Absorption Fine-Structure Observations of Ordering and Metallic-like Behavior in Organic Conducting Polymers on $\mathrm{Pt}$

Core Electron Excitation and Relaxation in Molecules.....

Defect Generation in Silicon Dioxide from Soft X-ray Synchrotron Radiation

Temperature Dependence of Local Environment Surrounding Oxygen Atoms in $\mathrm{Y}-\mathrm{Ba}-\mathrm{Cu}-\mathrm{O}$ Compounds.

Interfacial Roughness of InAs/GaAs Heterostructures Determined by $\mathrm{X}$-ray Reflectivity 
W. Eberhardt

EXXON Researr.h and Englneering Co., Route 22 East, Annandale, NJ 08801

R. Murphy

Physics Dept., Univ. of Pennsylvania, Philadelphia, PA 19104

The absorption of a soft x-ray photon by an 1solated molecule leads to a chain of events the ultimate result of which is the fragmentation of the molecule. Initially a highly excitea core hole state is created. This state decays via a radiationless two electron transition. The final state of this transition has multiple holes in the valance shell and these are the unstable configurations that lead to the production of lonic and neutral fragments. In order to 1dentify the pathways of the soft $x-r a y$ induced fragmentation one has to characterize the final electronic configurations of the molesule after the core hole decay by measuring the kinetic energy of the ejected Auger electron. The 1ons are then recorded in coincidence with the varlous final states of the core hole decay.

Using the quasimonochromatic undulator beam at the X17T spertroscopy beamline we have studied these processes for various molecules Including $\mathrm{N}_{2}, \mathrm{~N}_{2} \mathrm{O}$, and $\mathrm{C}_{2}$. Here we want to just give an example by showing the ion spectra of $\mathrm{N}_{2} \mathrm{O}$ in $\mathrm{F} 1 \mathrm{~g}$. l, taken in colncidence with the Auger deray of an $0-c o r e$ hole. The mass to charge ratio of the lons is measured by the t1me of flight of the produrt and the most likely asstgnment is indicated above each peak.

The Ion spectra in the top panel of $\mathrm{Fig} .1$ are taken in coIncidence with the leading Auger peak of the 0 -Auger decay of $\mathrm{N}_{2}$, which is assigned to a $\left[2 \pi^{-2}\right]$ double hole configuration. The ion spectra show that this electronic final state of the core hole decay results in the production of $\mathrm{N}^{+}$and $\mathrm{NO}^{+}$as the major decay channel. This is not unexpected because the $2 \pi$ orbital is bonding between the two Nitrogen atoms in the linear NNO molecule.

In the next panel (B) of $\mathrm{F} 1 \mathrm{~g} .1$ we see not only $\mathrm{N}^{+}$and $\mathrm{NO}^{+}$ but also the complementary channel of $\mathrm{O}^{+}$and $\mathrm{N}_{2}{ }^{+}$. The hole configurations we are taking these lons in colncidence with ace $\left[1 \pi^{-1}, 2 \pi^{-1}\right]$ and $\left[6 \sigma^{-1}, 2 \pi^{-1}\right]$.

In panels $\mathrm{C}$ and $\mathrm{D}$ we do not observe any $\mathrm{N}_{2}^{+}$and Not anymore. Now the molecule falls apart completely and in some of the events a neutral third fragment has to be produced. The hole configurations are $\left[6 \sigma^{-1}, 1 \pi^{-1}\right]$ for panel $c$ and $\left[5 \sigma^{-1}, 6 \sigma^{-1}\right]$ as well as $\left[4 \sigma^{-1}, 5 \sigma^{-1}\right]$ for panel $D$. The $4 \sigma$ and $5 \sigma$ orbitals are bonding throughout the molecule and therefore it is not surprising to find the molecule completely fragmented upon removal of these electrons.

Auger-electron Ion coincidence studies like the ones presented here reveal the involvement of Individual valence electrons into the formation of the molecular bond. Measuring also the kinetic energy distribution of the lonic fragments observed, In some cases we can even directly determine the potential energy surfaces of the lighly excited states populated in the decay of the initial core hole excitation.

These experiments were carried out on $X 17 \mathrm{~T}$ at the NSLS. This program was partially supported by NSF under contract No. NSFDMR-851919.

\section{$\mathrm{N}_{2} \mathrm{O}$ Auger Electron Ion Coincidences}

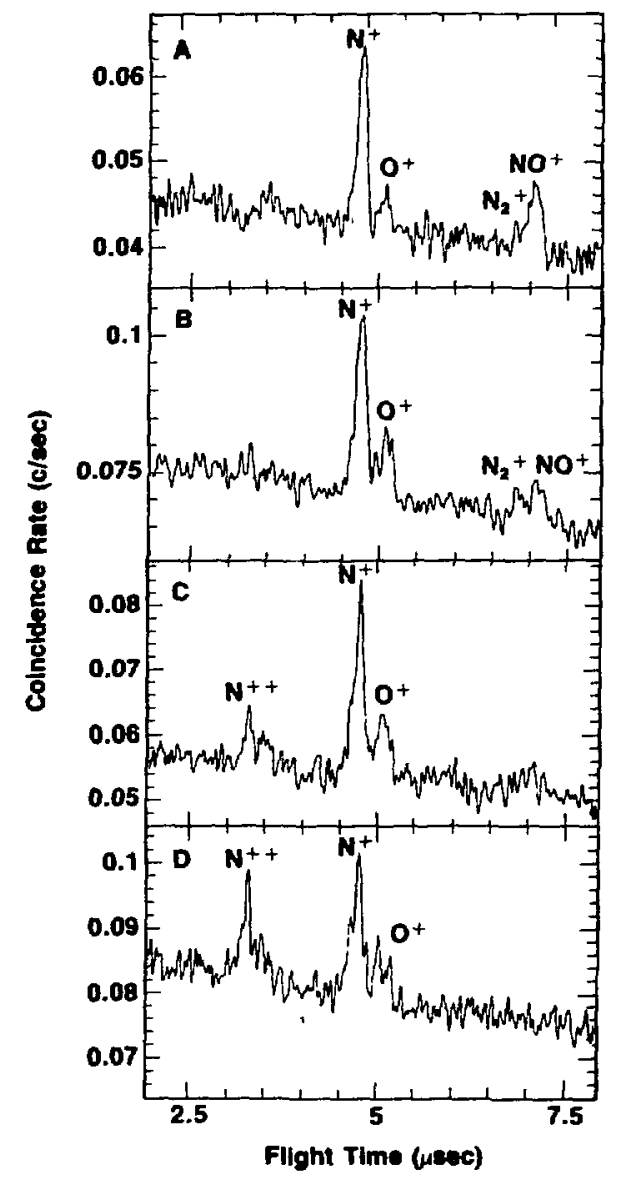


J. Gland, D. Fischer, * and S. Shen**

EXXON Research and Englneering Co., Route 22 East, Annandale, NJ 08801

*NSLS, Brookhaven National Laboratory, Upton, NY; *kChinese Arad. of Sri, , Dalian, China

Our Fluorescence Yield Near Edge Spertroscopy (FYNES) program has been forussed on a detalled study of the Interaction of coadsorbed $\mathrm{CO}$ and hydrogen on the $\mathrm{Ni}(100)$ surface for hydrogen pressures up to 10 torr. During these studies, we discovered that chemisorbed $C O$ is displaced by more weakly adsorbed hydrogen for hydrogen pressures above $10^{-4}$ Torr in a matter of minutes in the 290 to $330 \mathrm{~K}$ temperature range. The discovery of this unexpected surface reaction highlights the importance of surface methods which allow adsorbed monolayers to be characterized in the presence of reactive environments.

Detalled spectroscopic, examination of coadsorbed $\mathrm{CO}$ and hydrogen using FYNES indicates that no detectable changes of elther the orientation or bonding of chemisorbed co are caused by coadsorbed hydrogen over a wide range of temperatures and hydrogen pressures. These high pressure experiments were performed with dilute mixtures of $C 0$ in hydrogen (1-100 ppm) so that large Co coverages could be ma1nrained in the presence of hydrogen pressures above $10^{-4}$ torr.

Several series of experiments were performed to characterize the kinetics and mechanism of hydrogen displacement of chemisorbed $\mathrm{C} 0$. As indicated in Fig. 1 , the Fluorescence Yield intensity of the $\pi$ resonance of adsorbed $C O$ was used to monitor the displacement of $c 0$ in real time in the presence of gaseous $\mathrm{H}_{2}$. A serles of in-situ transient Fluorescence Yield Near Edge Spectroscopy experiments have been performed over the $10^{-4}$ to 1 torr pressure range to characterize the kinetics of the displacement reaction illustrated in Fig. 2. The reaction is first order in co coverage with an abrupt decrease in rate with derreasing co coverage. The activation energy of the displacement reaction is $8 \mathrm{kcal} / \mathrm{mole}$ in the high coverage region and $12 \mathrm{kcal} / \mathrm{mole}$ for low coverages. The reaction $\mathrm{kinetics}$ are 0.4 order in hydrogen pressure over the $10^{-5}$ to $10^{-2}$ torr range.

A series of thermal desorption experiments were performed to confirm that displacement occurs and to check the validity of the FYNES kinetic results. Rapid displacement of adsorbed co by hydrogen was observed. The kinetic results obtained using the thermal desorption method agree with the more complete kinetic results obtained with FYNES. In addition, the thermal desorption results suggest that the abrupt decrease in displacement rate is correlated with the increase in heat of adsorption observed with derreasing Co coverages. A series of displacement experiments were performed in order to characterize the mechanism of the displacement reaction. No displacement is observed with He, Ne, $\mathrm{Ar} \mathrm{Ch}_{4}$, and $\mathrm{N}_{2}$ for pressure up to $10^{-3}$ torr. $\mathrm{D}_{2}$ gives displacement rates within $5 \%$ of those observed for $\mathrm{H}_{2}$. Taken together these results suggest that direct energy transfer between "hot" recently formed hydrogen atoms and chemisorbed $C 0$ is furnishing part of the energy required for displacement. Thermal energy from the surface is furnishing the remainder of the energy required to desorb co from the surface.

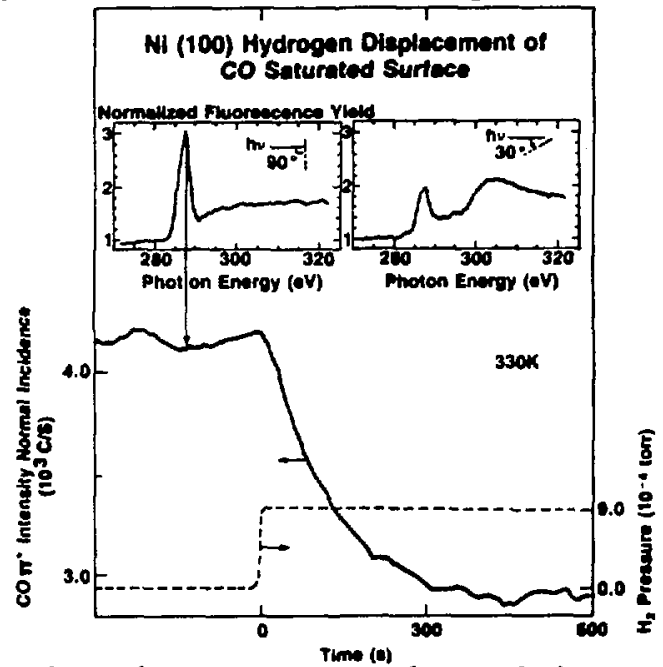

Fig. I Disptacement of a monolayer of chemisorbed CO by $9 \times 10^{-4}$ torr of hydrogen occurs in less than. $600 \mathrm{sec}$ at $300 \mathrm{~K}$. The inset spectra 11lustrate normalized CO spectra with normal and glancing Incidence $1 \mathrm{ight}$ for a co saturated surface at $100 \mathrm{~K}$.

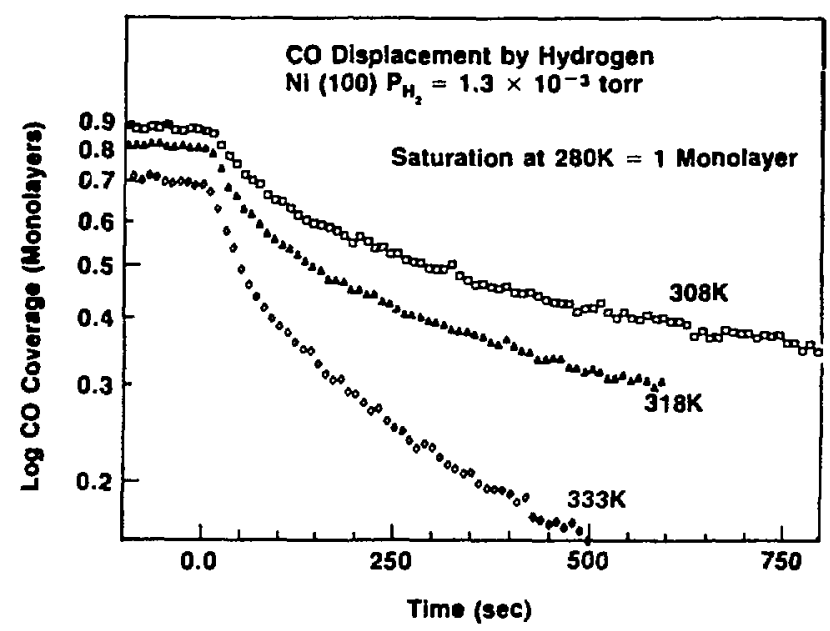

Fig. 2 The logarithm of co coverage taken from transient FYNES experiments, as a function of displacement time for several temperatures. Reaction rates in the $10^{-2}$ monolayer/sec to $10^{-5}$ monolayer/ sec can be characterized using this in-situ techn ique. 
RESONANT PHOTOEMISSION OF $\mathrm{La}_{2} \mathrm{CuO}_{4}$

D. Sondericker, * Z. Fu, ** D. Johnston, and W. Eberhardt

EXXON Research and Englneering Co., Route 22 East, Annandale, NJ 08801

We have used total electron yield to study the near edge $x$-ray absorption fine structure (NEXAFS) of

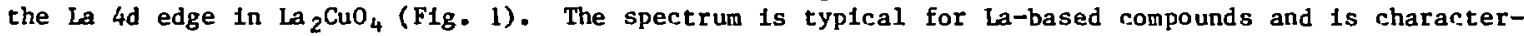
ized by two sharp peaks below the $4 \mathrm{~d}$ threshold and giant resonance peak with a maximum at about 25 eV above threshold. The decay of these $4 \mathrm{~d}$ core electron excitations causes resonant enhancement of the La photoemission features, which will be used to Identify the La contribution to the valence band photoemission. To observe which channels are activated in the deexcitation of the La core to bound transition, photoemission spectra with incident photon energies indicated by the arrows in Fig. 1 were collected and normalized to the incident photon flux. As can easily be seen, the photoemission spectrum "e" taken w1th hy=l18 eV, the maximum in the giant absorption peak, shows enhancement of the La 5s, $5 \mathrm{P}_{1 / 2}$, and $5 \mathrm{P}_{3} / 2$ emission and in the La-Auger $\mathrm{N}_{4}, 5 \mathrm{O}_{2}, 3 \mathrm{~V}$ channels. Not so obvious, but nevertheless more interesting to the problen of high- $T_{c}$ superconductors, is what is occuring in the valence band. The cross sections for $\mathrm{Cu}$ and 0 are lower for an incident photon energy of hv = $118 \mathrm{eV}$ than for $113.5 \mathrm{eV}$. Therefore the enhancement in the difference spectra "e-d" of Fig. 2 at $3.5 \mathrm{eV}$ below $\mathrm{E}_{\mathrm{F}}$ is a La-derived feature.

The peaks at 9.5 and $11.5 \mathrm{eV}$ do not exhibit any comparable resonant enhancement. Relative to the $\mathrm{Cu}$ and $\mathrm{O}$ emission the $\mathrm{La}$ derived states are located near the top of the strongest valence band peak whereas Mattheis ${ }^{3}$ calculates the La features to contribute mostly to the high energy side of the peak. However the density of states calculations do not represent the valence band photoemission in general, due to hole localization. Therefore any comparison with these calculations has to be viewed with caution. If, for example, the la states are more delocalized than the 0 and $\mathrm{Cu}$ states, then the relative shift between the calculated and experimental valence bands could be explained. The resonant photoemission from the spike at $h_{v=10} .5 \mathrm{eV}$ depicted in curve " $b$ " of F1g. 2 shows enchancement of the La $5 s$ and 5p1/2 emission but not of the $5_{3} / 2$. This work was performed at the EXXON $U-1$ beamline at the NSLS which is supported by the DOE.

*NSLS, Brookhaven National Laboratory, Upton, NY 11973 **Dalian Inst. of Cher. Phys., Chinese Academy of Sc1., Dalian, People's Republic of ChIna

1 L. F. Mattheis, Phys. Rev. Lett. 58, 1028 (1987).

Fig. 2 Normalized photoemission spectra of $\mathrm{La}_{2} \mathrm{CuO}_{4}$ taken at the photon energies indicated by the arrows in $\mathrm{F} 1 \mathrm{~g}$. 1. The arrows mark the Auger $\mathrm{N}_{4}, 5^{\circ}, 3 \mathrm{~V}$ enission.

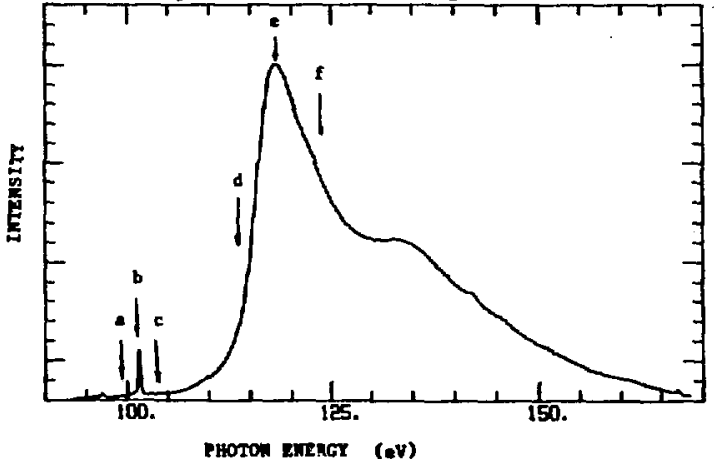

F1g. 1 La $4 d$ absorption edge in $\mathrm{La}_{2} \mathrm{CuO}_{4}$.

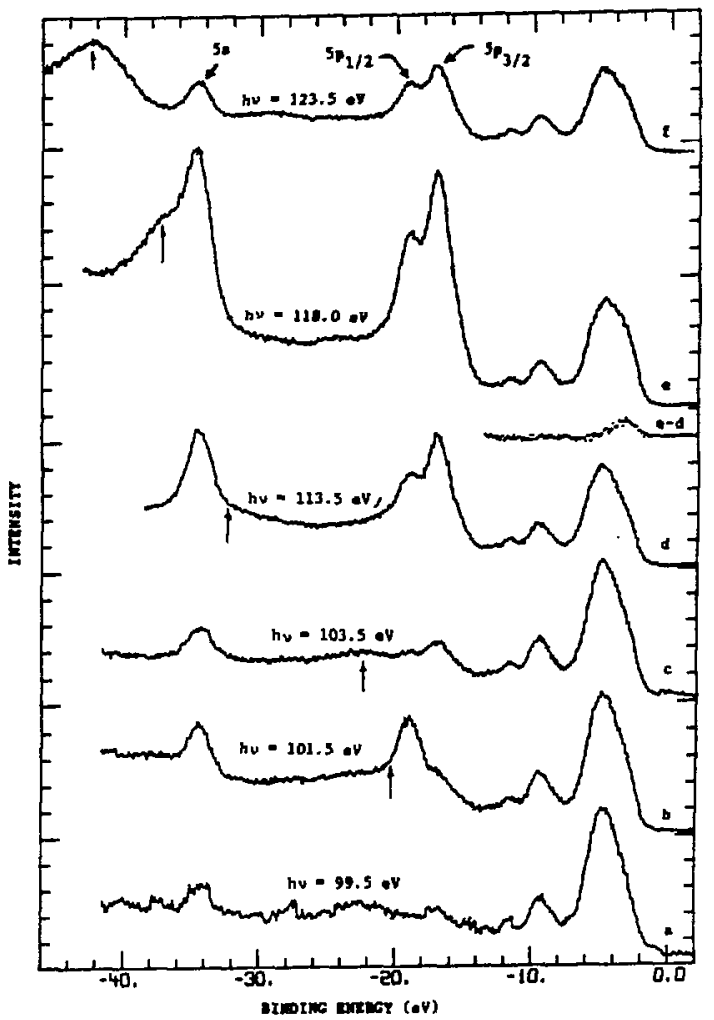


VALENCE BAND PHOTOEMISSION OF $\mathrm{L}_{2} \mathrm{CuO}_{4}$

D. Sonderfcker, * Z. Fu, ** D. C. Johnston, and W. Eberhardt

EXXON Research and Engineering Co., Route 22 East, Annandale, NJ 0880!

Valence band photoemission spectra of superconducting, Sr-doped La $1.8 \mathrm{Sr}_{0.2} \mathrm{CuO}_{4-\mathrm{y}}$ and of the base oxide $\mathrm{La}_{2} \mathrm{CuO}_{4-\mathrm{y}}$ have been studied on the EXXON beamline Ul. The samples were introduced Into the UHV chamber by means of a transfer 11ne. Cleaning was done by Ar and 0 lon sputtering or by scraping with a tungsten carbide file. All data were collected at room temperature and no changes in the data were observed as a function of time.

Photoemission measurements of the valence bands of $\mathrm{La}_{2} \mathrm{CuO}_{4}$ and $\mathrm{La}_{1.8} \mathrm{Sr}_{0 .} \mathrm{CuO}_{4}$ taken at photon energies of $h_{v}=100 \mathrm{eV}$ and $50 \mathrm{eV}$ are shown $\mathrm{in} \mathrm{FIg}$. 1. The curves are comprised of three peaks. The large peak with its maximum at $4.8 \mathrm{eV}$ is mainly conposed of an overlap of the $\mathrm{Cu} 3 \mathrm{~d}\left(\mathrm{x}^{2}-\mathrm{y}^{2}\right)$ and $02 \mathrm{p}$ bands. The peak at $9.5 \mathrm{eV}$ is probably due to $\mathrm{C}$ contamination and the peak at $11.5 \mathrm{eV}$ is a shake up satellite. As can be seen, there is very little difference between the superconductor and the base oxide. The Inset of Fig. 1 shows the Ferml level of $\mathrm{La}_{2} \mathrm{CuO}_{4}$ multiplied times 50 compared to a Pt foil. From this we conclude that there is a very low but measurable density of states at the Fermi level. The Fermi level shifted by $<100 \mathrm{meV}$ upon doping in the superconducting sample relative to the base oxide.
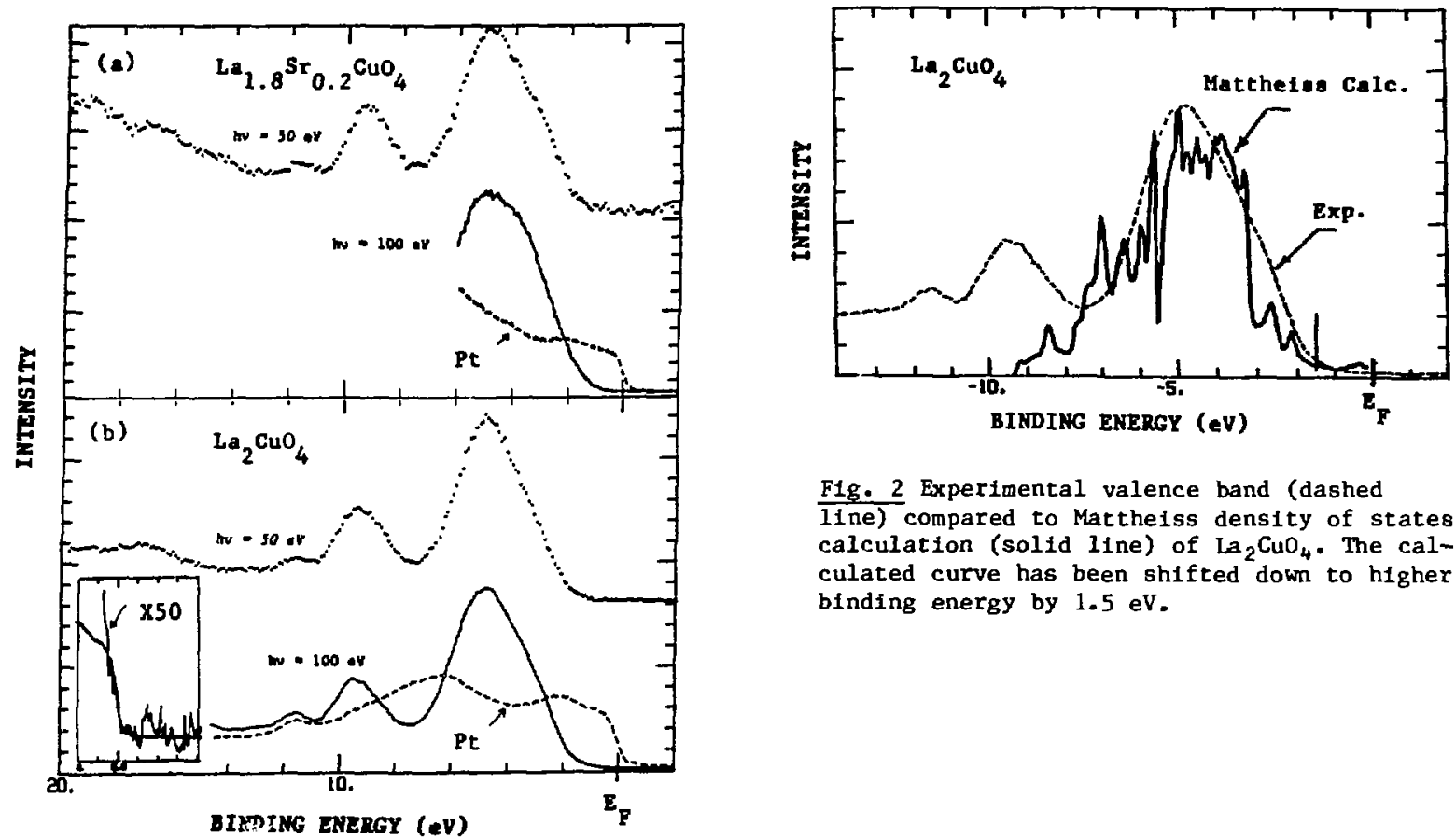

F1g. 2 Experimental valence band (dashed IIne) compared to Mattheiss density of states calculation (solid Iine) of $\mathrm{La}_{2} \mathrm{CuO}_{4}$. The calculated curve has been shifted down to higher binding energy by $1.5 \mathrm{eV}$.

F1g. 1 Photoemission spectra of (a) $\mathrm{La}_{1} \mathrm{Sr}_{0}{ }_{2} \mathrm{CuO}_{4}$ and (b) $\mathrm{La}_{2} \mathrm{CuO}_{4}$ at $\mathrm{h} v=100 \mathrm{eV}$ and $\mathrm{h} v=50 \mathrm{eV}$. The dashed line is from a Pt standard. The inset shows the Fermi level of $\mathrm{La}_{2} \mathrm{CuO}_{4} \times 50$ compared to Pt.

Fig. 2 shows the experimental valence band compared to the density of states calculation of Mattheiss. 1 Lining up the center of gravity of the largest valence band peak, we find a shift of 1.5 $\mathrm{eV}$ between the experfmental and theoretical curves. This discrepancy could be due to a localization of the final state hole, which is not correctly described in the delocallzed band picture. The presence of the shake up peak in the valence band as well as the core level photoemission satellites Indicates the importance of hole localization and screening in these materials. These experiments were performed at beamline $\mathrm{Ul}$ at the NSLS, which is supported by the DOE.

*NSLS, Brookhaven National Laboratory, Uptan, NY 11973.

**Dalian Inst. of Chemical Physics, Chinese Academy of Sciences, Dalian, People's Republic of China

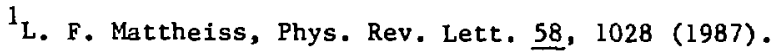


L. Yang,* B. Abeles,* W. Eberhardt,* D. Sondericker,** H. Stäsiewski,* and Z. Fut $\star$ EXXON Research and Engineering Co., Annandaie, NJ 08801

**NSLS, Brookhaven National Laboratory, Upton, NY 11973

$\dagger$ Dalian Institute of Chemical Physics, Academia Sinica, China

Interface Structure can be studied on an atomic scale by growing the interface, monolayer by monolayer, and observing the evolution of the electronic structure as a function of layer thickness. Here we report such a study using photoemission spectroscopy on hydrogenated amorphous silicon (a-Si:H) and silicon nitride $\left(\mathrm{a}-\mathrm{S}_{1} \mathrm{~N}_{\mathrm{X}}: \mathrm{H}, \mathrm{X} * 1.33\right)$ heterojunctions made by plasma assisted CVD. The experimental techniques for heterojunction fabrication, in-situ sample transfer and photoemission measurements are the same as in our previously reported work on amorphous silicon and silicon oxide interfaces.

Figure $1(a)-(d)$ shows the $\mathrm{Si}-2 \mathrm{p}$ core level spectra measured at photon energy $\mathrm{hv}=120 \mathrm{eV}$ for a a-Si:H overlayers deposited on $\mathrm{a}-\mathrm{SiN}_{\mathrm{X}}: \mathrm{H}$. The photoemission intensity of the $\mathrm{Si}$ overlayer is given by the peak centered at binding energy of $99.6 \mathrm{eV}$. It was obtained by subtracting from the measured photoemission intensity (full curve) the contribution due to the SiN $\mathrm{N}_{\mathrm{x}}$ underlayer given by the peak centered at $101.2 \mathrm{eV}$. We find that the S1 overlayer peak coincides with the peak corresponding to Si coordinated with four $S 1$ atoms even for the first few monolayers. This indicates that the $S i$ atoms in the overlayer are bonded predominantly to the $S 1$ atoms in the $a-S 1 N_{x}: H$ substrate forming an atomically abrupt interface. Similar bonding of the S1 atoms was also observed in the case of a-Si:H overlayers on $\mathrm{a}-\mathrm{S}_{1} \mathrm{O}_{\mathrm{x}}: \mathrm{H}$. 1 Unlike SiO $\mathrm{O}_{x}$ on $\mathrm{SI}$ interface where significant plasma oxidation was observed causing a graded region over $\simeq 5 \AA, S 1 N_{X}$ on $S 1$ interface was found also atomically abrupt indicating that nitridation is rather weak.

Valence band photoemission on heterojunctions was measured and gave a value of $1.2 \pm 0.2 \mathrm{eV}$ for the band offset between a-S1:H and $\mathrm{a}-\mathrm{SIN}_{\mathrm{K}}: \mathrm{H}$ which is in agreement with previous measurement6. ${ }^{2}$ Other important information obtained from the valence band EDC's and $\mathrm{Si} \mathrm{I}_{2,3}$ absorption edge measured by yield spectroscopy as a

function of overlayer thickness for both $\mathrm{a}-\mathrm{S} 1: \mathrm{H}$ and $\mathrm{a}-\mathrm{S} 1 \mathrm{~N}_{\mathrm{x}}: \mathrm{H}$ are discussed in detall elsewhere. ${ }^{3}$

The photoemission experiments were performed at beamline U1 at the NSLS, which is supported by the DOE.

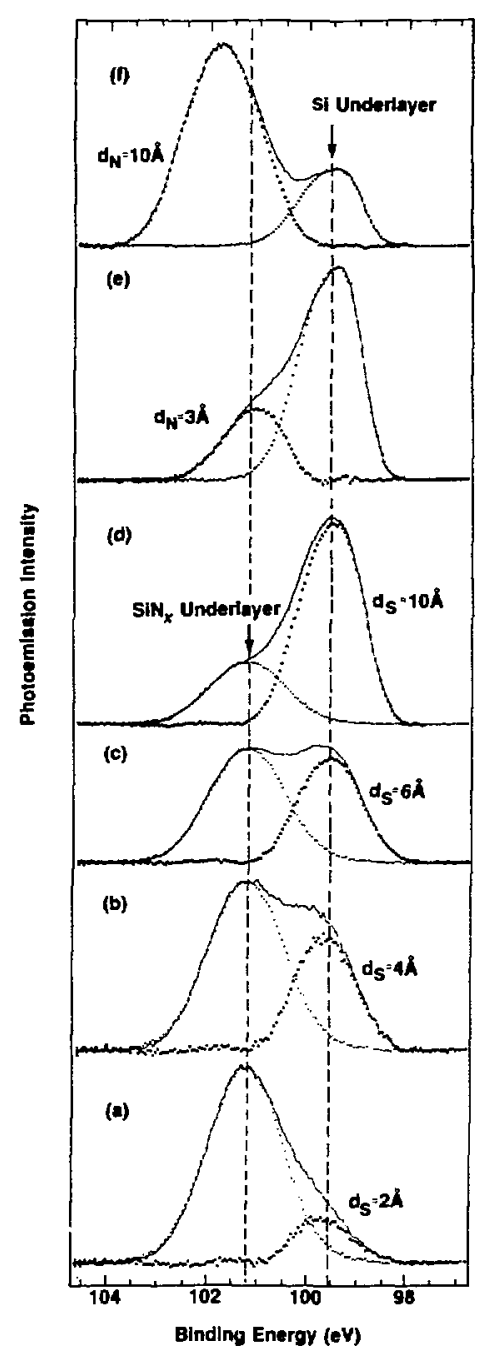

Fig. 1 Si-2p core level spectra for a-S $1: H$ overlayers grown on a $\mathrm{a}-\mathrm{S} 1 \mathrm{~N}_{\mathrm{k}}: \mathrm{H}$. Overlayer thicknesses are indicated. 
VIBRATIONALLY RESOLVED ELECTRONIC AUTOIONTZATION OF CORE-HOLE RESONANCES

E.D. Poliakoff*, L. Kelly, L. Duffy, and B, Space (Boston Univ.)

P. Roy and S.H. Southworth (Los Alamos), and M.f. White (BNL)

Vibrational motions of molecular ions are influenced by resonant excitation, and conversely, fundamental aspects of resonant molecular ionization are 1lluminated by probing the vibrational motion of molecular ions. However, vibrationally resolved studies following resonant excitation of core electrons have been beyond the reach of traditional photolonization studies. Using $N_{2}$ as an example, we demonstrate that dispersed fluorescence measurements from electronically excited valence hole state ions circumvent limitations imposed by alternative methods, and in so dofpg, provide completely vibrationaliy resolved data. Recent theoretical studies and experiments have investigated the decay of molecular core-hole resonances into the (single) valence hole states of the molecular ions. A novel aspect of autoionization for core hole resonances is that lifetime broadening results in overlapping vibrational levels of the core-excited state. The studies presented here demonstrate that dispersed fluorescence measurements provide an excellent means of investigating such effects.

The excitation-fluoresience sequence used for the present studles is represented schematically by the following equation.

$$
\begin{aligned}
& \mathrm{N}_{2}\left(\mathrm{X}_{\mathrm{I}}^{\mathrm{I}}{ }_{\mathrm{g}}^{+}, \mathrm{v}=0\right)+\mathrm{h} v_{\text {exc }} \rightarrow \mathrm{N}_{2} *\left(1 \mathrm{~s}^{-1}, 1 \pi *,[\mathrm{v} * *\}\right) \\
& \mathrm{N}_{2}+\left(\mathrm{B}^{2} \Sigma_{\mathrm{u}}+\mathrm{v}^{\prime}\right)+\mathrm{e}^{-} \\
& \dot{\mathrm{N}}_{2}{ }^{+}\left(\mathrm{X}^{2} \Sigma_{\mathrm{g}}{ }^{\mathrm{u}}+\mathrm{v}^{\prime \prime}\right)+\mathrm{h} \mathrm{v}_{\mathrm{v}} \mathrm{v}^{-}
\end{aligned}
$$

where $v^{-}$and $v^{-\infty}$ are the vibrational levels for the ion in the excited $\left(B^{2} \Sigma^{+}\right)$and ground $\left(x^{2} \Sigma_{g}{ }^{+}\right)$ valence-hole states, respectively, and hy $v^{\prime} v^{\prime}$ is the energy separation between these levels. $g$

Figure 1 shows two fluorescence spectra. The spectrum obtained at $h v=50$ eV 1 s a nonresonant spectrum, and $h^{\prime}=401$ eV corresponds to the peak of the $1 \mathrm{~s}+1 \pi^{*}$ resonance. These spectra cover the reglon of the $v^{\prime}=0 \rightarrow v^{\prime \prime}=1$ and $v^{\prime}=1 \rightarrow v^{\prime \prime}=2(B \rightarrow X)$ fluorescence transitions, and they demonstrate that the cross section for the $v^{*}=1$ level increases relative to that of $v^{*}=0$ for resonant excitation. These results are currently being analyzed to assess the importance of 1 ifetime induced vibrational interference, and the key point is that these results give completely vibrationally resolved data, thereby permitting quantitative comparison with theory.

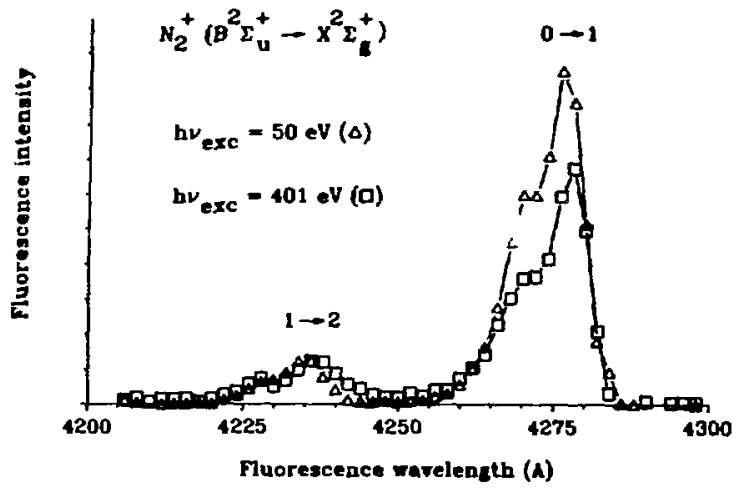

Figure 1. Fluorescence spectrum of $N_{2}{ }^{+}\left(B^{2} \Sigma^{+} \rightarrow x^{2} \Sigma^{+}\right)$ showing $v^{\prime}=0 \rightarrow v^{-\prime}=1$ and $v^{\prime}=1 \rightarrow v^{\prime}=2^{g}$

transitions following nonresonant excitation $\left(h \nu=50 \mathrm{eV}\right.$ ), and resonant excitation (hv=401 eV, $1 \mathrm{~s} \rightarrow 1 \pi_{g}{ }^{*}$ ).

\section{References}

1. N. Correia, A. Flotes-Riveros, H. Agren, K. Helenelund, L. Asplund, and U. Gellus, J. Chem. Phys. 83, 2035 (1985)

2. T.X. Carrol1, S.E. Anderson, L. Ungler, and T.D. Thomas, Phys. Rev. Lett. 58, 867 (1987)

* Research sponsored by the National Science Foundation and the Air Force Office of Scientific Research, Air Force Systems Command, USAF, under grant number AFOSR-84-0261.

+ Supported by the US Department of Energy through its division of Chemical Sciences, Office of Basic Energy Sciences. 
R.H Gaylord and S.D. Kevan: University of Oregon. Physics Department

To date, there exists no general procedure to predict when a surface resonace might occur and what its properties might be. This is unfortunate since resonant states enable "communication" between surface and bulk layers, and thus might be important in determining such phenomena as surface reconstructions and electric dipole layer formation. The difficulty in predicting the occurance of a surface resonance arises from the uncertainty of how strongly it will couple to the bulk states with which it is degenerate. If the coupling is to strong, the resonance will be broadened to such an extent that it becomes too diffuse to observe. In the case of coupling to the bulk through the spin-orbit interaction. the coupling will usually be weak and characterization will be possible.

A surface resonance has been observed on the (110) surface of tungsten using angle-resolved photoemission. The resonance is located near the center of the surface Brillouin zone in a pseudo gap opened by the spin-orbit interaction and lies at a binding energy of $1.18 \mathrm{eV}$ at $\bar{\Gamma}$. It is degenerate with a bulk band which, in the absence of the spin-orbit interaction, would have a different symmetry than a state in the gap. The resultant weak coupling leads to formation of a well-defined surface resonance. This state is extremely sensitive to contamination, and is attenuated rapidly in the ambient vacuum of $0.8-1.5 \times 10^{-10}$ torr obtained in these experiments. This combined with it lack of dispersion with $k_{1}$ (the $\Sigma$ direction) and the dependence of its intensity on photon energy confirms its ident ification as a surface resonance.

The $\Sigma$ direction in the bulk system is composed of bands of $\Sigma_{5}$ symmetry in accord with double group representation. No gap exists in the binding energy range of the observed feature. In fact. the resonance lies in a "pseudogap" between the $\Gamma_{8+}$ and $\Gamma_{7^{+}}$bands at $\bar{\Gamma}$. We refer to this as a pseudogap Decause the only degenerate bulk band is of $\Sigma_{5}{ }^{1}$ symmetry. The superscript in this designation refers to the symmetry of the band prior to doubling the group as required upon introduction of the spin-orbit interaction. An electronic energy level having substantially different single-group character will be coupled only weakly by the spin-orbit interaction to the $\Sigma_{5}{ }^{\prime}$ continuum, and thus a well defined surface resonance may exist. We interpret the surface resonance in this context.

Support for this interpretation comes from the fact that the intensity of the surface resonance is maximized when the final state momentum probes the vicinity of the bulk band edges. This is in accord with the expectation for a surface localized state'. In addition the polar ization dependence of the intensity of the state is in accord with the expectations for a surface resonance as def ined in the previous paragraph.

I. S.D. Kevan, N.G. Storfel, N.V. Smith: phys. Rev. B 31 (1985) 3348

ACknowledgement: USDOE grant DE-FG06-86ER45275 and Am. Chem. Soc. Petroleum Res. Fund 


\section{R.H Gaylord and S.D. Kevan; University of Oregon, Physics Department}

Surface reconstructions have been observed in a variety of metal and semiconductor systems. Adsorbate-induced reconstructions are of particular interest since this class of reconstructive behavior has direct implications for questions related to the bonding of atoms and molecules to surfaces. This is because the perterbations of the substrate electronic structure induced by adsorbate bonding are directly responsible for the geometric rearrangement of the substrate; i.e., a new ground electronic state is induced which requires a new geometric configuration. At a very fundamental level, concepts such as stress, strain, and force constant softening, which are of ten invoked to explain reconstruction, are determined by the electronic structure.

Most reconstructions involve an enlargement of the unit cell of the surface layer. However, Chung. et. al., have recently observed that $W(110)$ undergoes a hydrogen-induced reconstruction which can be described as a unidirectional displacement of tha top layer with respect to the second layer'. Since the unit cell size remains unchanged, the reconstruction was detected by observing the loss of the (110) mirror plane of the surface. A simple model which accounted qualitatively for this reconstruction was introduced. A translation of the first layer relative to the second indicates that the balance between first to second layer bonds projected onto the [ 110$]$ and [001] directions has been altered as a result of hydrogen adsorption. In the interest of characterizing such changes, we have measured the modifications of the electronic structure upon adsorbing hydrogen on both surfaces using high-resolution angle-resolved photoemission.

On clean $W(110)$, a variety of surface electronic states were observed which had not been previously detected due to the poorer resolution available in earlier studies 2,3 . Most of these features are exceedingly sensitive to hydrogen adsorption, being quenched by less than 0.1 monolayers. Since the $W(110)$ surface is reconstructed only after adsorbing in excess of 0.5 monolayers, we conclude that these ultrasensitive states are not directly related to the reconstruction. The most interesting features we have observed exist in surface projected band gaps near the Fermi level $\left(E_{F}\right)$ which are opened by very strong bulk band hybridization. For example, in the vicinity of $k_{\|}=0.6 \AA^{-2}$ along $\bar{\Sigma}$, two bands near the Fermi level which are nearly degenerate for the clean surface, are observed to split upon hydrogen exposure. The higher binding energy feature shifts by as much as $0.6 \mathrm{eV}$, enough to traverse the entire gap. Adsorption of axygen destroys this feature altogether, implying that it is indeed a surface localized state. The different behavior of this band toward the two adsorbates implies that it may be related to the tendency to reconstruct, since oxygen does not induce the structural modification. More detailed studies indicate that the band forms a narrow segment of the Fermi surface near the $\bar{\Sigma}$ line which expands dramatically in the direction normal to $\bar{\Sigma}$ as hydrogen is added. In addition to the large energetic changes implied by these data, there must be significant rehybridization of the electronic levels in the vicinity of the surface: On the clean (covered) surface, the surface state will resemble the bulk states at the top (bottom) of the gap. Since the gap is opened by hybridization. these levels are quite different in their bonding/antibonding character. The observed change then presumably leads to a renormalization of the force constants near the surface. possibly to a softening of a surface phonon mode, and consequently to the reconstruction.

1. J.W. Chung, S.C. Ying, P.J. Estrup; Phys. Rev. Lett. 56 (1986) 749

2. M.W. Holmes, D.A. King; Surf. Sci. 110 (1981) 120

3. G.B. Blanchet. N.J. DiNardo, E.W. Plummer; Surr. Sci. 118 (1982) 496

Acknowledgement: USDOE grant DE-FG06-86ER45275 and Am. Chem. Soc. Petroleum Res. Fund 
ELECTRONIC STRUCTURE OF $C$, N AND O ADSORPTION STRUCTURES ON Ni(100)

A.L.D. Kilcoyne and D.P. Woodruff

Physics Department, University of warwick, Coventry CVA 7AI, England

R.H. Gaylord and S.D. Kevan

Physics Department, University of Oregon, Eugene, OR 97403

J.E. Rowe

A.T. and T. Bell Laboratories, Murray Hill, NJ 07974

Adsorption of oxygen on $\mathrm{Ni}(100)$ is well-known to produce, at a nominal half-monolayer coverage, a $c(2 \times 2)$ chemisorbed phase in which the oxygen atoms lie slightly above (0.9A) an unreconstructed metal surface. A similar coverage of carbon or nitrogen, however, leads to the adsorbate atoms adopting almost coplanar site within the top metal layer leading to a surface metal layer distortion to accommodate these atoms with a $\mathrm{p}(2 \times 2) \mathrm{p} 4 \mathrm{~g}$ meshand space group[1]. In an earlier study of the surface carbide phase we compared the results of an ARUPS band mapping of the adsorbate-induced features with ARUPS from the clean surface and the results of a FLAPW calculation of the electronic structure of an unreconstructed surface structure[2]. This revealed generally good agreement for the main $\mathrm{C} 2 \mathrm{~s}$ and $2 \mathrm{p}$ induced features but also indicated changes in the metal d-band region which might be involved in driving the reconstruction. Comparison of similar data for graphitic overlayers on this surface also indicated the strength of the $\mathrm{C}-\mathrm{C}$ and $\mathrm{C}-\mathrm{Ni}$ interaction [3].

In a new series of experiments we have extended this ARUPS band mapping to the $N$ and $O$ adsorption structures with the object of further clarifying the difference between the electronic structures of the reconstructed and unreconstructed surfaces. Full analysis of the data is not yet complete and further related slab calculations are also in progress. The data do show, however, that the trend in the $C$ adsorption structure ARUPS to show the strongest C-induced features in higher surface Brillouin zones is reproduced for the $\mathrm{N}$-induced structure. One particular problem in studying the $\mathrm{Ni}(100) \mathrm{c}(2 \mathrm{x} 2)-0$ structure which is widely recognised is that islands of Nio start to nucleate on the surface at average coverages below one half of a monolayer. We have therefore also collected ARups spectra for the higher coverage, oxide-dominated phase. These clearly allow the chemisorption features to be distinguished from those associated with surface oxide formation.

References

I. J.H. Onuferko, D.P. Woodruff and B.W. Hollend, Surface Sci. 87, 357 (1979)

2. C.F. McConville, D.P. Woodruff, S.D. Kevan, M. Weinart and J.W. Davenport, Phys. Rev. B 34 , 2199 (1986)

3. C.F. McConville, D.P. Woodruff and S.D. Kevan, Surface Sci. 171, L447 (1986)

4. D.W. Bullett and W.G. Dawson, Vacuum, submitted.

A.L.D.K. and D.P.W. acknowledge the financial support of the Science and Engineering Research Council of the U.K. for this work. 
AT\&T Bell Laboratorics

600 Mountain Avenue

Murray Hill, New Jersey 07974

Tunability, high resolution and high flux in the soft $x$-ray region is highly demanded by spectroscopists and is a great challenge to synchrotron radiation machine physicists and monochronator designers. Monochromatization of synchrotron radiation in the photon energy 300 eV $101000 \mathrm{eV}$ range has been a very difficult lask, because crystal monochromators are inapplicable and grating monochromators must work at every grazing angle (2-4 degree) and so suffer seriously from aberration and figure error of the optical elements. To meet this challenge, a new cylindrical element monochromator (CEM) design for soft $x$-ray synchrotron radiation has been proposed. 'Design and construction of such a nonochromator (which is dubbed "Dragon" and is the spherical version of the CEM design) has been carried out in its entirety in the period October 1985 to July 1987. During the UV-ring 1986 fall shutdown, the existing U4 PGM was removed and the installation of Dragon was started. On July 13, 1987. Dragon delivered its first monochromatized photon beam.

Figure 1 displays the conceptual layout of the CEM design. At the left of the figure there are two mirrors, the one closer to the source is the horizontal focusing mirror (HFM), and the other is the vertical focusing mirror (VFM). These two mirrors are close to each other and each one focuses in only one direction. Therefore the optical functions are decoupled. The top view shows the HFM focusing the source inside the storage ring onto the sample position while the side view shows the VFM focusing the source into the entrance slit. Behind the entrance slit, the grating diffracts and focuses the bean vertically into the exit slit. The exit slit is made movable to follow the focal position for different wavelengths. The wavelength scanning mechanism is a simple sine-drive for the grating and a linear stage for the exit slit. The coupling between these two motions is nut demanding, because the tolerance of the exit slit position for a given grating scanning angle is few centimeters. Although the ideal surface tigure for all these optical elements is elliptic cylinder, the replacement by circular cylinder or even sphere will not degrade the CEM performance.

Recently, we have utilized the $\mathrm{Ca}_{2,3}$ and $\mathrm{F} \mathrm{K}$ absorption edges of $\mathrm{CaF}$, erystal to align and characterize the Dragon inonochromator. Figure 2 shows a set of spectra with both slits set at $10 \mu \mathrm{m}$ and angular acceptance set at $12 \mathrm{mrd} \times 1 \mathrm{mrd}$. The $0.25 \mathrm{eV}$ and $0.66 \mathrm{eV}$ FWHM measured in peaks at photon energies $351 \mathrm{eV}$ and $688 \mathrm{eV}$ respectively, demonstrate the resolving power of the Dragon (better than $10^{3}$ ). The ultimate monochromator resolution as well as photon flux of the Dragon will be exploited in the near future.

Various ideas of the CEM design, which contain important advantages over existing soft $x$-ray monochromators, have been realized in the Dragon monochromator. They include: (1) Promise of high resolution and high transmission. (2) Energy resolution being independent of horizontal angular acceptance. (3) Movable exit slit eliminating defocal aberration. (4) HFM serving as a heat and radiation protector for the VFM and the grating. (5) Due to the decoupled nature, the whole beamline being easy to align and operate. Further commissioning and studies are in progress in order to reach the ultimate performance.

1. C.T. Chen, Nucl. Inst. Meth. A256 (1987) 595.

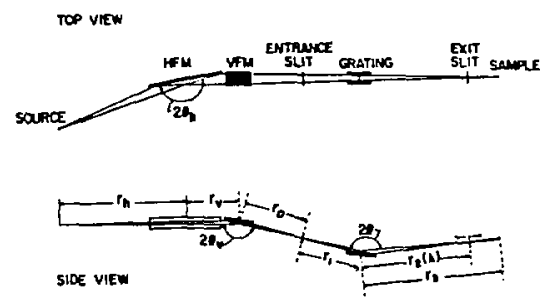

Fig. 1. Conceptual layout of the cylindrical element monochromator design.

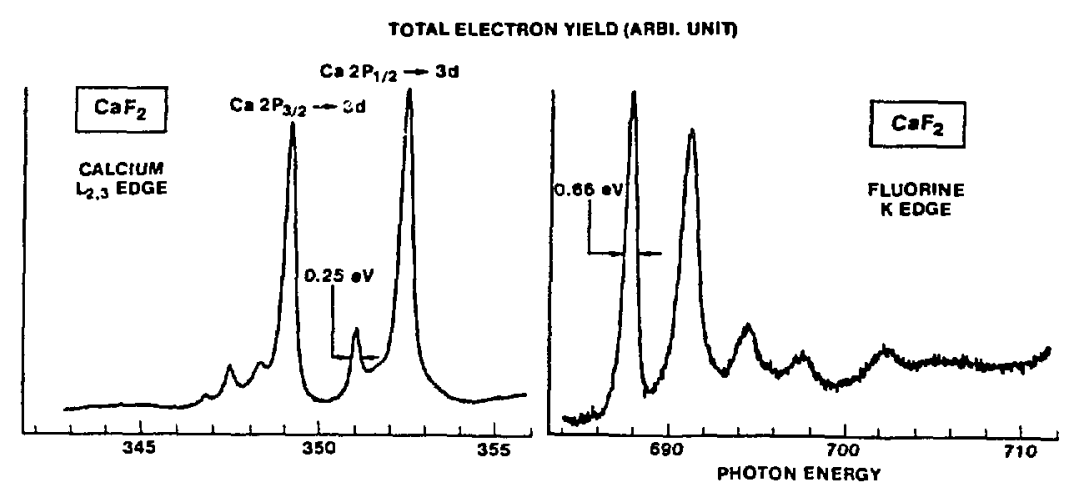

Fig. 2. $\mathrm{Ca} \mathrm{L}_{2.3}$ and $\mathrm{F} \mathrm{K}$ edge absorption spectra of $\mathrm{CaF}_{2}$ crystal taken with the Diagon monuchromator with $10 \mu \mathrm{m}-10 \mu \mathrm{m}$ slits and $12 \mathrm{mrd} \times 1$ mrd angular acceptance. 


\section{THE INFRA-RED BEAM LINE IRA}

G.P. Williams, E. Kneedler, C. Hirschmugl, M. Shleifer, P.Z. Takacs

NSLS, Brookhaven National Lab, Upton, NY 11973

Y. Chabal, AT\&T Bell Labs, Murray Hill, N.J. 07974

F. Hoffmann, Exxon, Annandale, N.J. 08801

K.D. Moller, Fairleigh Dickinson University, Teaneck, N.J. 07666

During the last year, the infra-red beamline front end components were installed. Mirrors 1-5 were installed and aligned, thus enabling the beam to be transported to the secondary focus at a quartz window. The latter is located on a platform above the VUV floor.

The beamline was first opened to the ring, and first light extracted on May 4th, 1987. Since that time, most of the components shown in the figure, which is a plan view of the platform layout, have been installed.

In July the first spectrum was measured using the Michelson interferometer. This instrument allows the NSLS to be compared with a black-body source. Using a quartz window, at a wavelength of 100 microns, (100 wave numbers or $10 \mathrm{meV}$ ), the NSLS at $500 \mathrm{~m}$ amps was found to be around 500 times brighter than the black body source. This result agrees well with theoretical predictions. Immediate plans call for the installation of the diamond window. Careful NSLS source characterization measurements will then be made.

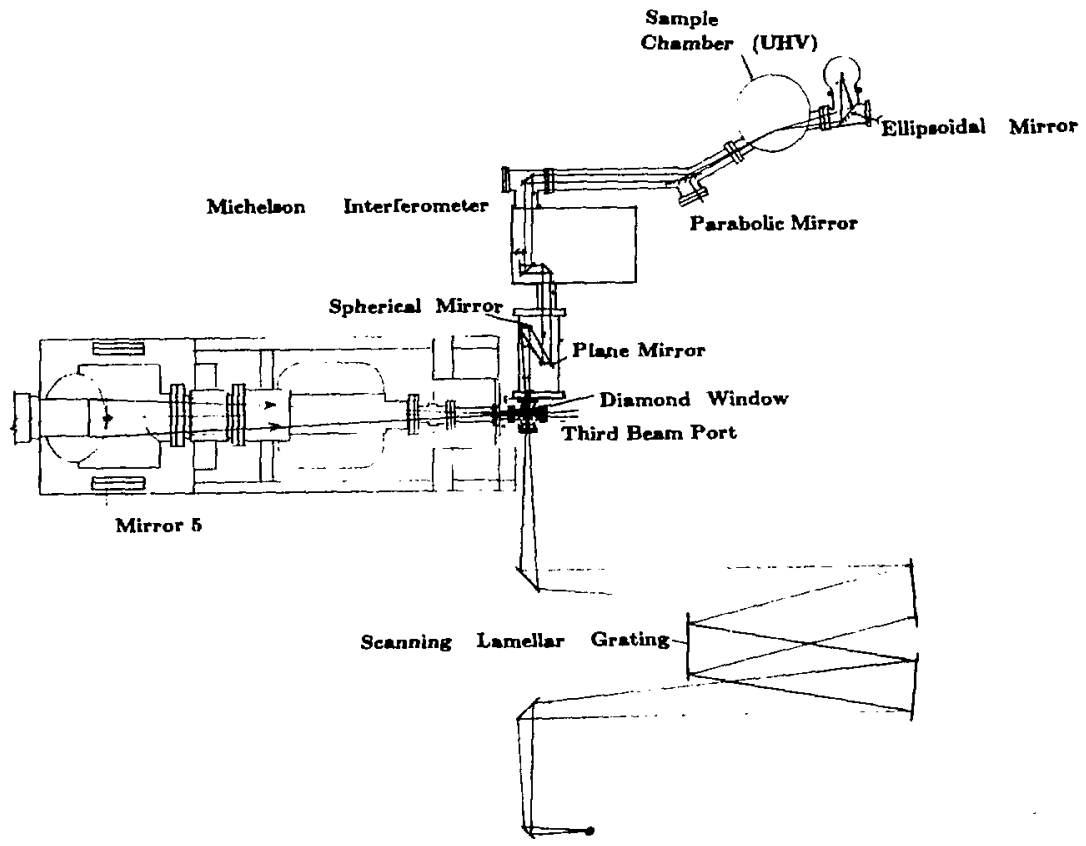

NSLS INFRA-RED BEAMTIME

BEAMLINE LAYOUT 
P. D. Johnson (BNL), S. L. Q1u (BNL) L. Jiang (BNL) M. W. Ruckman (BNL) Myron Strongin (BNL)

S. L. Hulbert (NSLS), R. F. (Garrett) (NSLS), B. Sinkovic'(AT\&T Bell Labs),

N. V. Smith (AT\&T Bell Labs), R. J. Cava (AT\&T Bell Labs), C. S. Jee (Temple U.)

D. Nichols (Temple U.), E. Kaczanowicz (Temple U.), R. E. Salomon (Temple U.) and J. E. Crow (Temple U.)

We have recorded photoemission spectra from the high $T_{c}$ superconductor $\mathrm{YBa}_{2} \mathrm{Cu}_{3} \mathrm{O}_{7}$ as a function of photon energy. The samples were cleaned by scraping the surface under UHV conditions. By examining the spectra as a function of photon energy 1 t was possible to determine the copper and oxygen components in the density of states from their different cross-sectional behavior. Thus at low energies one observes emission from both the copper and oxygen components whereas at higher energies the density of states is dominated by emission from the copper 3d states. It was further observed that at the Ferml level the measured density of states was extremely low.

In Fig. I we show a comparison of our measured density of states with a theoretical calculation due to Mattreiss and Hamann. [I] It will be seen that both components in the experimental spectrum, copper at $4.3 \mathrm{eV}$ and oxygen at $2.3 \mathrm{eV}$ wth respect to the Fermi level, are shifted to higher binding energies when compared with the theoretical calculation. The origin of this shift probably reflects in part the presence of the photo hole and in part the fact that the calculation employs the local density approximation (LDA). It is well established that LDA tends to underestimate the binding energy of more localised orbitals.

Finally we note that the experiment was carried out on a liquid helfum crystat. Measurements above and below $T_{c}$ showed no change in the spectra.

1. L. F. Matthelss and D. R. Hamann, Sol. Stat. Comm. 65, 395 (1987).

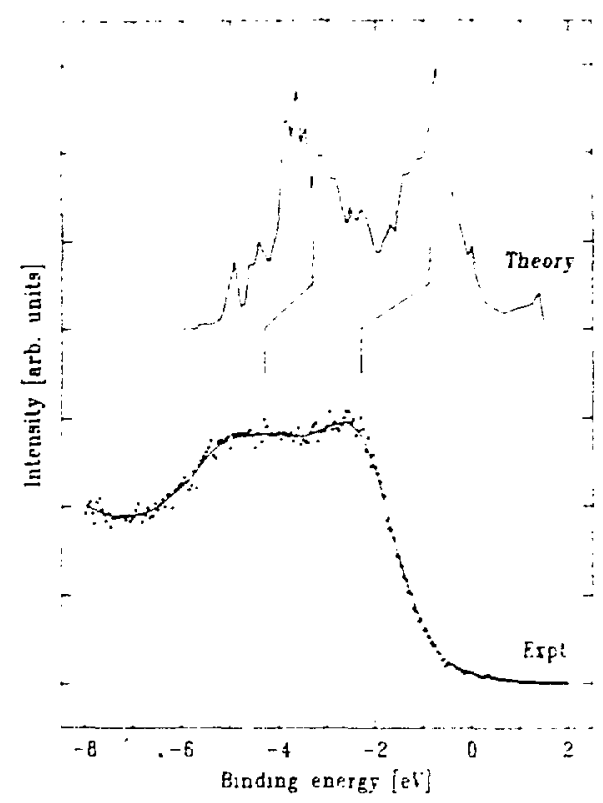

Fig. 1. Comparison of the measured density

of states with the calculated density

of states from Matthesis and Hamann

(Ref. 1).

hork partially supported by the Division of Materials sciences l. S. Department of Energy under Contract : 0 . DE-ACO2-CHOOO16. 
J.0. Choi, J.A. Moore and J.C. Corelli (Center for Integrated Electronics, Rensselaer Polytechnic Inst., Troy, NY I 2180 ) and J.P. Silverman (IBM, Thomas J. Watson Research Center, Yorktown Heights, NY lo598).

Poly (methyl methacrylate) PMMA, widely used as an electron beam resist, has also been used as an X-ray resist. An inherent part of the lithographic process in the fabrication of microcircuits is the degradation of PMMA caused by deep UV, $X-r a y$, electron beam or ion beam irradiation. The enhanced dissolution rate resulting from this degradation permits images to be developed in polymer films. The purpose of this effort was to study the degradation mechanismof PMMA caused by synchrotron $x-r a y s$ and to compare the results with $v v$, e-beam and ion beam irradiations. PMMA undergoes loss of ester side groups and scission of the main chain as a result of irradiation.

In this work, Fourrier transform infrared (FTIR) difference spectrometry and uv difference spectrometry are used to measuredirectly the changes in PMMA films upon $x$-ray irradiation. The observed changes are related to the decrease of specific functional groups and to the generation of new functional groups.

The decrease of the carbonyl ( $C=0)$ stretching band at $1730 \mathrm{~cm}^{-1}$ was found to be proportional to the incident dose of x-rays. The increase of the 195 nm absorption (caused by generation of $c=c$ ) in the uv spectrum was also proportional to the incident dose. The number of main chain scissions of pMma was similarly proportional to the incident dose.

The removal of ester groups was calculated from the FTI difference spectrum using standard and well known procedures relating absorbance, film thickness and concentration.

The number of $\mathrm{C}=\mathrm{C}$ bonds generated was close to the number $\mathrm{C}=0$ groups removed by $\mathrm{x}-$ irradiation to a dose of $1 \mathrm{~J} / \mathrm{cm}^{2}$. In other words each removal of an ester group generates $\mathrm{C}=\mathrm{C}$ bond by main chain scission or abstraction of hydrogen from the main chain.

The ratio of main chain scission to the change of specific functional groups depends on the type of radiation. Table l shows a comparison of the results obtained with different radiations. It is apparent that the $x-r a y s$ were the best at causing main chain scission with high efficiency and less removal of ester groups.

Table I

Degradation of Poly(methyl methacrylate) by Uv, E-beam, X-ray and Proton beam (main chain scission, ester group removal and carbon carbon double bond generation per 100 monomer units in PMMA).

\begin{tabular}{|c|c|c|c|c|}
\hline & $\begin{array}{l}\text { DUV } \\
4.6 \mathrm{eV} \\
0.6 \mathrm{~J} / \mathrm{cm}^{2}\end{array}$ & $\begin{array}{c}25 \mathrm{KeV} \\
20 \mu \mathrm{C} / \mathrm{cm}^{2}\left(0.5 \mathrm{~J} / \mathrm{cm}^{2}\right)\end{array}$ & $\begin{array}{c}\text { X-Ray } \\
0.8 \sim 1.8 \mathrm{KeV} \\
1 \mathrm{~J} / \mathrm{cm}^{2}\end{array}$ & $\begin{array}{c}\text { Proton-Beam } \\
300 \mathrm{KeV} \\
1 \times 10^{13} \mathrm{H} / \mathrm{cm}^{2} \\
\left(0.48 \mathrm{~J} / \mathrm{cm}^{2}\right)\end{array}$ \\
\hline $\begin{array}{l}\text { Main Chain } \\
\text { Scission (MCS) }\end{array}$ & 0.22 & 0.46 & 1.08 & 0.75 \\
\hline $\begin{array}{l}\text { Ester Removal } \\
(\mathrm{C}=0)\end{array}$ & 8.53 & 2.59 & 3.68 & 3.22 \\
\hline Rat io $\left(\frac{M C S}{C=0}\right)$ & 0.026 & 0.178 & 0.293 & 0.233 \\
\hline $\begin{array}{l}\mathrm{C}=\mathrm{C} \text { generation } \\
(\mathrm{C}=\mathrm{C})\end{array}$ & 7.06 & 2.24 & 3.72 & 2.83 \\
\hline Ratio $\left(\frac{M C S}{C=C}\right)$ & 0.031 & 0.205 & 0.290 & 0.265 \\
\hline
\end{tabular}


S.S. Dana. I.R. Maldonado, J. Batley and I. Sillerman II3M Researeh Division. T.J. Walson Research Center

The effects of $X$-ray radiation on the physical properties of Low Pressure Chemical Vapor Deposited "horo-hydronitride" tilms' have been studied using "white light" synchrotron radiation at the U-6 heamline at the National Synchrotron 1 ight Souree. The purpose of this study was to shed some light on the mask radiation dimage, an issue of great importance and concern in X-ray lithography. Radiation effects relevant to X-ray lithography include mechanical distortion and optical darkening of mask membranes prepared from such films.

Our results indicate that such films show a reduction in optical transparency on the order of $10 \%$ for an incident dose of $700 \mathrm{~J} / \mathrm{cm}^{2}$. with no significant additional reduetion oceurring when exposed to an additional $400 \mathrm{~J} / \mathrm{cm}^{2}$. Following irradiation, the boron to nitrogen ratio and hydrogen content were analyzed respectively by electron microprobe and resonant nuctear reaction techniques; no change in themical composition upon irradiation was detected.

The DC electrical resistivity of L.PCVD horo-hydro-nitride films was measured for various film deposition parameters and found to be directly related to both the optical transparency and the mechanieal stress of the $x$-ray mask membranes prepared from these films. The influence of the film's hydrogen and horon content on electrical resistivity is also being reported. The clectrical resistivity was observed to decrease after irradiation, as shown in Fig. 1 for successise exposures, for various values of the deposition parameter $R$. which is the incident gas ratio of ammonia to diborane. The rate of ehange of the electrical resistivity with dose increases with the film's initial (measured hefore irradiation) resistivity. Experimental results (shown in Fig. 2) suggest that the radiation danage relevant to $x$-ray lithos raphy in the mask membranes is directy related to their initial electrical resistivity and is most pronounced for films with the highest as-deposited initial resistivity.

\section{Roference}

1. "Low pressure chemical vapor deposition of boro-hydro-nitride films and their use in $x$-ray masks", S. S. Dana and J. R. Maldonado, J. Vac. Sci. Technol. B4 (1), 235. Jan/Feb 1986.

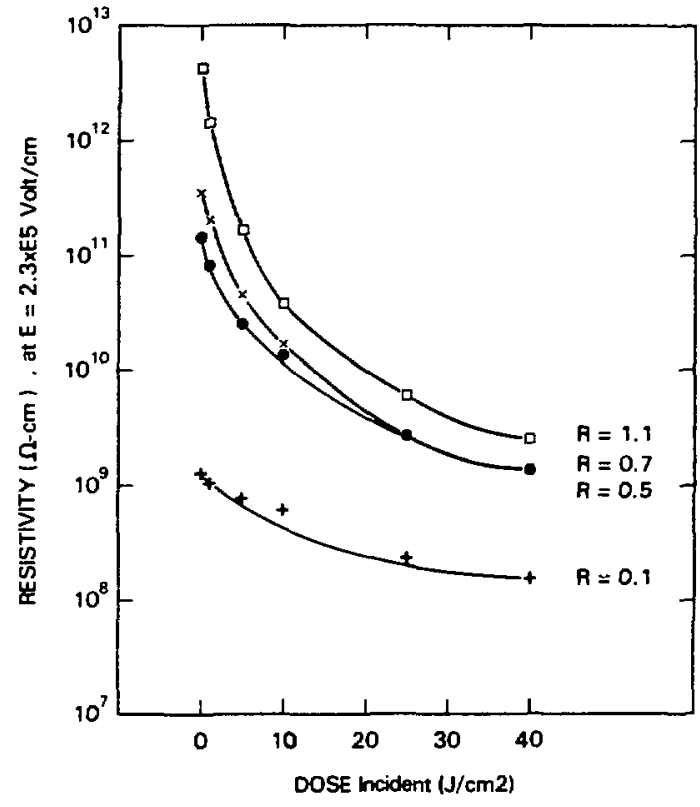

Fig. I. Effect of radiation on films deposited under different conditions (at $400^{\circ} \mathrm{C}$ )

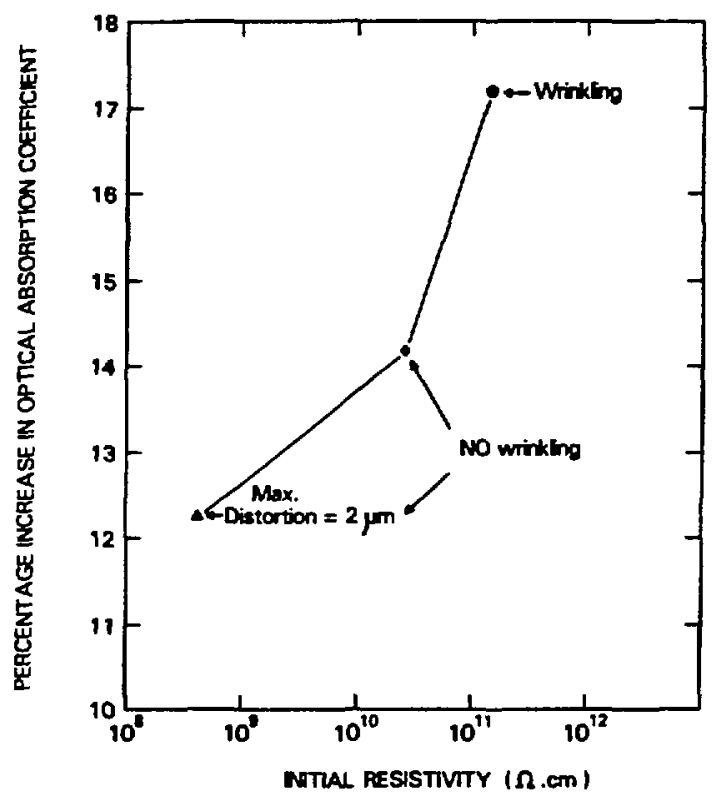

Fig. 2. Optical damage as a function of initial film resistivity after exposure to $1100 \mathrm{~J} / \mathrm{cm}^{2}$ 


\section{Hn OVRRLAYERS ON Ru(001) SURFACE}

Jan Hrbek, T. K. Sham* and M. L. Shek**

Departments of Chemistry and Physics, Brookhaven National Laboratory, Upton, NY 11973

Manganese overlayers have interesting chemisorption propertles ${ }^{l}$ and Mn metal is used as a catalyst in several Industrial processes; 11 ttle is known about the electronic and geometric structure of Mn promoted systems.

We have studied the valence band of the Mn/Ru(001) system using several photon energles at fixed sample geometry. Synchrotron experiment confirmed previous results obtained with Hel photons, namely, that the pseudomorphic Mn layer has a valence band similar to that of clean Ru even for the multilayer coverages. Using various photon energies we can conclude that the peaks in the spectra of Fig. 1 are due to initial states.

Carbon monoxide adsorbed on a pseudomorphic Mn layer shows typlcal $4 \sigma$ and $5 \sigma / 1 \pi$ orbitals. The shape, intensity and position of co derived peaks are identical to what is observed for co adsorbed on a Ru(001) surface. This, observation is paradoxical in view of complementary surface experiment carried out on the same system : Co bonding should be severaly perturbed on the Mn layer. We will investigate the system in greater detall with synchrotron radiation in the near future.

Pseudomorphic Mn overlayer on Ru is in an expanded lattice and magnetic properties of such a system were studied recently. ${ }^{3}$ In Fig. 2 we show that the splitting of the Mn 3 s core level of pseudomorphic ( 1 and 2 if) Mn overlayers is $5.7 \mathrm{eV}$. Such a large splitting is typical for Mn with magnetic moment close to $5 \mu_{B}$. For thicker Mn layers ( 5 and 10 ML) the Mn 3s peaks broaden and shift to higher binding energy. A possible explanation is the presence of $\mathrm{Mn}$ atoms in nonequivalent positions in the lattice.

1 I. Hrbek, J. Vac. Sc1. Technol. A5 (1987)

$$
864 \text {. }
$$

2 J. Hrbek, T. K. Sham and M. L. Shek, Surf.

Sc1., accepted.

3 B. Heinrich, C. Liu and A. S. Arrott, J. Vac. Sci. Technol. B3 (1985) 766.

* Present address: Synchrotron Radiation Center, 3731 Schneider Drive, Stoughton, WI.

** Present address: Dept. of Physics and Ast ronomy, Hunter College, New York, NY.

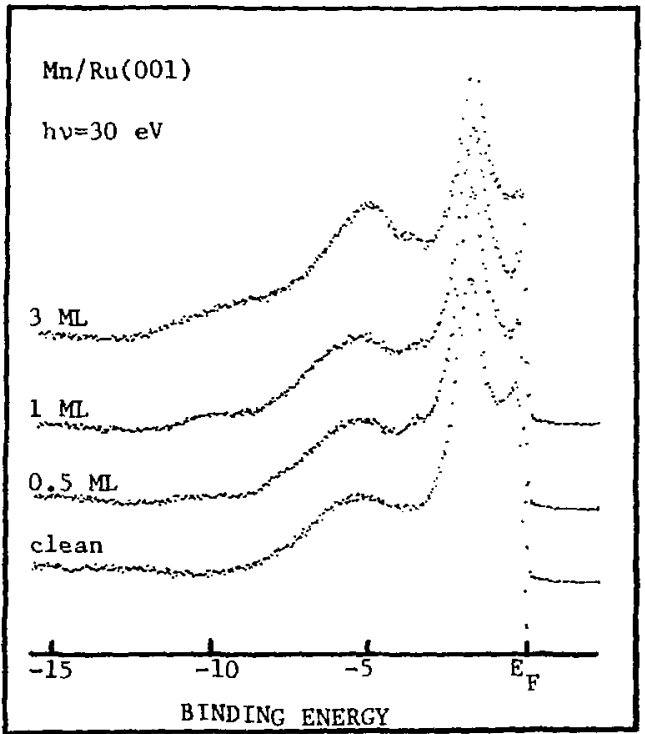

F1g. 1. Valence band spectra of pseudomorphic $\mathrm{Mn}$.

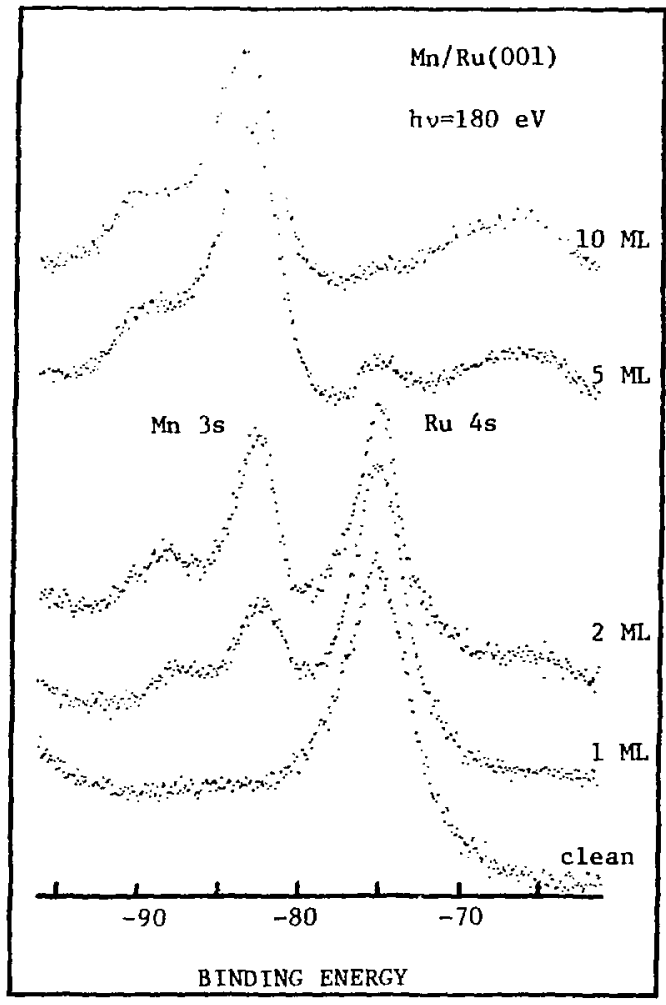

F1g. 2. 3s splitting in Mn overlayer.

This research was carried out at Brookhaven National Laboratory under contract. DE-ACO2-76CHO0016 with the U.S. Department of Energy and supported by its Division of Chemical Sclences, office of Basic Energy Sciences. 
Cu\{001\}c(2x2).Pd: a surface alloy

alonic arrangenent and electronic structure

S.H. Lu, Z.Q. Wang, S.C. Wu. C.K.C. Lıs, J. Quinu, Y.S. Li, D. Tian and F. Jona

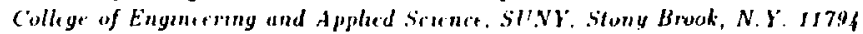

There is, tu date, only one reported cast of surface-alloy formation that was quantitatively proven and adequately documented by both experimental $\left.\right|^{1.2}$ and theoretical ${ }^{3}$ studies tlie case of $(u\{001\}<(2 \times 2)$-Au. A second case, zceorted here, is the one obtained from the room-temperature praction of a clean ('u\{001\} surface with less than one monolayer of $P d$. 'The resulting phase is an ordered $c(2 \times 2)$ layer, denoted C $u\{U(1]\} c(2 \times 2)-P d$. We summarize here the reults of LEED and UPS studies of this phase.

The LEED st udy involved a quantitative intensity analysis of data collected both at normal and off-normal incidence. Four independent sets of intensity data were uned, including a total of 26 beaus at normal and 22 besums at non-normal incidence. The analysis showed that the tup atomic layer was a mixed layer in which every other C'u atom had becn replaced by a Pd atom, with no ordered Pd content hevend the first layer, which is what we eall a surface alloy. The mixed layer is aluost planar, with the Pd atonis only slightly outward of the ('u atoms by $0.02 \pm 0.03 \mathrm{~A}$ (in contrast to the $A \mathrm{u}-\mathrm{C}^{\prime} \mathrm{u}$ surfare alloy, which is markedly buckled ${ }^{2}$. High background in the LEED pattern of the P'd-C'u phase suggested that some Pd atoms may possibly reside either above or below the first layer, although not with lung-range order. This possibility is further supported by the fact that the "best" LEED patterns (sharp spots and high contrast) were consistently obsepved only after deposition of $0.7-0.8$ monolayer equivalents of Pd (ideally, only 0.5 monolayer-equivalents are required to form a perfert $c(2 \times 2)$ structure). Nevertheless, the LEED analysis established unambiguously that the predominantly ordered product of the (u-Pd reaction was inderd a surface allov.

The l'PS study, carried out on beanline UTB with photon energies varying between 12.5 and $\mathbf{i} 30 \mathrm{eV}$, confirmed the alloy character of thr. surfare phase and revealed an interesting splitting of the Pd $d$ states. We show in the figure, as an example, the valence bands (after

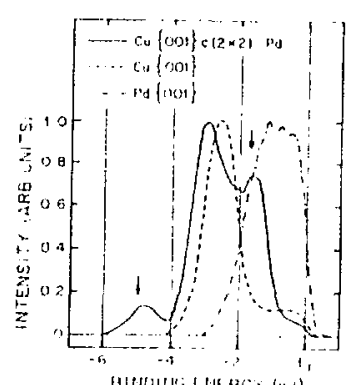
background subtraction) of clean (u\{001\} (dashed), of clean Pd\{001\} (dash-dotted) and of the ( $u\{001\}<(2 \times 2)$-Pd surface alloy (solid). In the latter spectrum we identify the features at -1.7 and 4.8.V with Pd-derived bands and the peak at $-3.0 \mathrm{eV}$ with the Cin-derived band. This assignment stems from a series of observations. Electron distribution curves (EDC) obtained with photon energies ranging from 12.5 to $130 \mathrm{eV}$ showed that, while the intensities of the Pd-derived peaks varied substantially with photon energy, their energy dispersion was almost nil. The intensity and the dispersion of the cia-derived feature resembled closely those of ckan $\mathrm{Cu}\{001\}$, exrept for a shift of about $0.4 \mathrm{eV}$ toward larger binding energy. At a photon energy of $130 \mathrm{eV}$, where the photoionization cross section of Pd is a minimum. the EDC of C $" 1001\}<(2 \times 2)-P d$ was equal to that of $C u\{001\}$ except for a shift of about 0.6 eV toward lower binding energies. Thus, the spectra of the surface alloy are characterized by the presence of two well-separated Pd-derived bands about $3.1 \mathrm{eV}$ apart. This phenomenon was observed before on single crystals of bull: ( $\mathrm{u}$-rich ('u-Pd alloys and was confirmed theoretically by calculations of complex-energy bands and average densities of states by Rao $c t$ al. ${ }^{4}$ The calculated positions of the Pd-derived features are shown with arrows in the figure. Physically, the phenomenon has its origin in the large-crystal-field splitting associated with the Pd muffin tin postential in the alloy, and also in the particular circumstance that the Cu $d$ band lies roughly in the middle of the substantially brow er Pd $d$ band. The Pd $d$ states then tend to get excluded from the middle region and give rise to at two-peaked structure in the density of states on the Pd site. Thus, the UPS results are consistent with the LEED results in confiming the alloy nature of the surface phase and in showing that the Pd-derived feat ures behave indeed like surface states.

This work was sponsored in part by the Department of Energy with Grant DE-FG02-86ER45239A001.

1. Z.Q. Wang ft al., Solid State C'ommun. 62.181 (1987).

2. J.C. Hansen el al. preprint (Surface Sri., in press).

3. S.M Foiles, preprint (Surface Sci., in press).

4. R.S. Ruo et al., Phys. Rev. B29, 1713 (1984). 
S. L. Qiu (BNL), J. Chen (BNL) ${ }^{\dagger}$ and Myron Strongin (BNL)

Alkali metal-ammonia solutions are model systems for studying Metal-Nonmetal transftions and potassium is of particular interest since it plays a catalytic role in the process of producing ammonia. We have studied this system by depositing different thicknesses of potassium on a Ta substrate and then condensing solid ammonia on the surface of the sample at liquid nitrogen temperature. The first spectrum at the botton of Fig. I shows the $3 p$ core level characteristic of metallic $\mathrm{K}$ ( 18 eV), and the $4 \mathrm{f}$ levels of $\mathrm{Ta}(\sim 22-25 \mathrm{eV})$. The thickness of $\mathrm{K}$ in Fig. $\mathrm{l}$ is $0.76 \mathrm{ML}$. At $0.2 \mathrm{ML}$ coverage of $\mathrm{NH}_{3}$, a high binding energy feature of the $3 p$ core level of $\mathrm{K}$ shows up and the intensity of this feature increases with increasing $\mathrm{NH}_{3}$ coverage. We have previously shown in studies of Na on solid ammonia that thishigh binding energy feature is due to non-metallic or "solvated alkali metal". For a smaller $K$ coverage of (0.23 ML) there is no such high binding energy feature at any coverage of $\mathrm{NH}_{3}$. We interpret this to mean that the $K$ does not solvate in the solid ammonia in this case. We have also deposited $\mathrm{K}$ on a thick layer (about 30 A) of solid $\mathrm{NH}_{3}$ (Fig. 3). At low $\mathrm{K}$ coverage, only the high binding, ęnergy feature of the $3 p$ core level appears, but at a certain coverage of $K$, the metallic $3 p$ peak $10^{15}$ starts to develop as in the case of $\mathrm{Na}$ on solid ammonia[l]. This is possibly related to the Metal-Nonmental transition or the formation of large metal clusters. At high coverage of $K$ (about $5.6 \times 10^{-15}$ atoms $\left(\mathrm{cm}^{2}\right.$ ) the metallic $3 \mathrm{p}$ peak dominates while the high binding energy feature becomes a shoulder. At this point by condensing solld ammonia on the top of $K$, the lnverse process can be seen, as shown $1 \mathrm{n}$ Fig. 3 (the top there spectra). With increasing exposure of $\mathrm{NH}_{3}$ the intensity of the high binding energy feature increases, and finally the metallic peak disappears and the high binding energy feature dominates.

1. S. L. Qiu, L. Jiang, M. W. Ruckman and Myron Strongin, "Studies of Na Solid Ammonia", to be published.

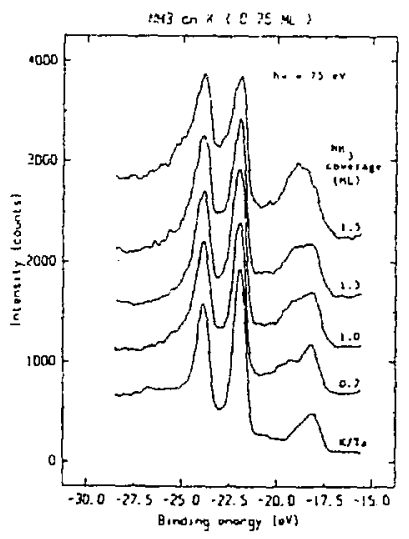

Fig.1 Solid ammonia on porassium (0.76 ML). At 0.2 $\mathrm{ML}$ coverage of $\mathrm{NH}_{3}$ the feature of the "solvated powssium" appears.

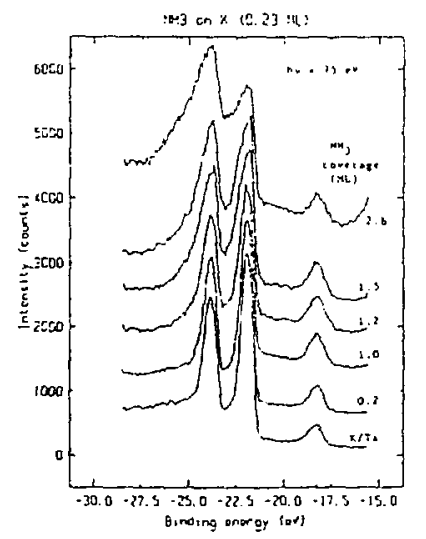

Fig. 2 Solid ammonia on polassium $(0.23 \mathrm{ML})$. There is no the feature of the "solvated poussium" at any coverage of $\mathrm{NH}_{3}$.

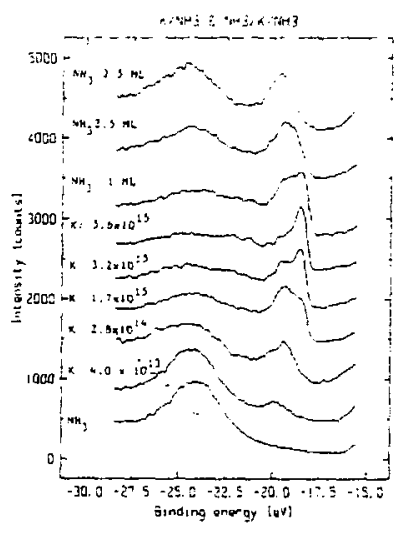

Fig.3 The change from the "solvated $\mathrm{K}$ " to the "inevallic $K^{-}$and is inverse process.

Work supported by the Division of Materials Sciences U. S. Department of Energy under Contract No. DE-ACO2-76CHOOO16.

talso at Huncer College of CUNY 


\section{S. L. Qiu (BNL), V. Murgal (BNL) ${ }^{\dagger}$, Myron Strongin (BNL)}

We have studied the growth of Yb films on a recrystallized Ta(110) surface with photoemission. From the electron energy distribuion curves (EDCs) of the core levels and the valence band, we $f 1$ nd that the $\mathrm{Yb}$ appears to grow layer-by-layer for the first two to three layers. Represntative valence band spectra can be seen in Fig. 1 and core level spectra can be seen 1n Fig. 2 . All the sites occupied by the $\mathrm{Yb}$ Initially are equivalent as seen from the $\mathrm{Yb} 4 \mathrm{f}$ and $5 \mathrm{p}$ core level peaks measured. In the submonolayer regime, $\mathrm{Yb}$ is divalent as is the case for $\mathrm{Yb}$ atoms on the surface of $\mathrm{Yb}$ metal or compounds including intermetalilc compounds where the $\mathrm{Yb}$ in the bulk may be mixed valent or trivalent. The Yb $4 \mathrm{f}$ peaks and the $5 p$ peaks are uniformly shifted towards lower binding energy than those of $\mathrm{Yb}$ atoms on an Yb substrate suggesting that the Ta substrate provides more effective screening for the emitted electrons. Another effect of the $\mathrm{Yb}$ layer is to reduce the width of the Ta $4 \mathrm{f} 7 / 2$ peak; an indication that the Ta surface shifted peak has been eliminated due to screening provided by the Yb. As the amount of $\mathrm{Yb}$ is increased further so that the second layer of $\mathrm{Yb}$ begins to grow, the outermost $\mathrm{Yb}$ layer sees an $\mathrm{Yb}$ substrate giving a doublet of $4 \mathrm{f}$ enission whose position is consistent with surface Yb atoms on an Yb substrate. The emission from the $\mathrm{Yb}$ at the Yb-Ta interface shifts to lower binding energy with the addition of a second layer of $\mathrm{Yb}$ due to fewer "dangling" bonds. This is also reflected in the $\mathrm{Yb} 5 \mathrm{p}$ emission where one sees two peaks due to $5 \mathrm{P}_{3 / 2}$ emission. These can be seen more clearly on substraction of the Ta contribution to the signal. With the evaporation of enough $\mathrm{Yb}$, bulk $\mathrm{Yb}$ spectre are recovered.

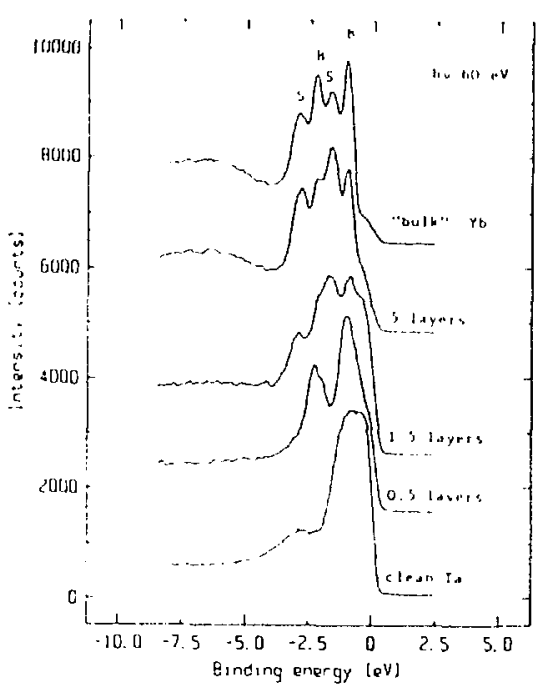

Fig.l Valence band of Yb On Ta.

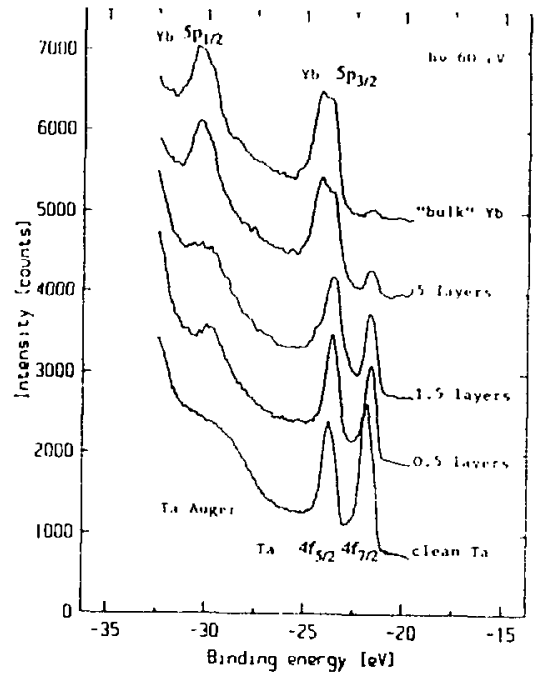

Fig. 2 Core levels of $Y_{b} 5 p$ and $T a d f$ as a function of the coverage of $\mathrm{Yb}$.

Work supported by the Division of Materials Sciences U. S. Department of Energy under Contract No. $\mathrm{DE}-\mathrm{ACO} 2-76 \mathrm{CH} 00016$

+Boston University, Boston, MA 02215 
THE NATURE OF THE INTERFACE FOR Pd OVERLAYERS ON Ta

S. L. Q1u (BNL), M. W. Ruckman (BNL), J. Chen (BNL) ${ }^{\dagger}$ and Myron Strongin (BNL)

The properties of bimelallic systems are of great interest for obtalning surfaces with greatly modifled properties. Pd on $\mathrm{Nb}$ or $\mathrm{Ta}$ is such a case where there is a considerable modification of the properties of the Pd overlayers. The overlayer system has been made in two different ways. First, by depositing a monolayer of $\mathrm{Pd}$ on $\mathrm{Ta}$ and second by depositing a thick Pd layer then heating to $800^{\circ} \mathrm{C}$ in which case only about one monolayer remains on the surface. In both cases the LEED pattern indicates that the Pd "layer" has the Ta(110) structure, and the electronic properties show that the d bands are similar in these two cases and are significantly below $E_{f}$, when compared to opposed to bulk Pd.

In this work, we have studied the behavior Ta $4 \mathrm{f}$ level to see $1 \mathrm{f}$ the Pd*(Jl0) overlayers made by these different methods are actually the same. In Fig. 1, the development of the interface compound is studied as Pd is deposited without heating. The first spectrum from the bottom shows the clean bulk Ta $4 \mathrm{f}$ levels, and upward from the second spectrum the evolution as a function of $P d$ coverage of the shifted feature due to bonding at the interface is seen. At about one monolayer of Pd, the 1ntensity of the interface feature becomes comparable to that of the bulk $\mathrm{Ta} 4 \mathrm{f}$ feature. Above monolayer coverage, the intensities of both features decrease with increasing Pd coverage. Figure 2 shows the development of the interface compound produced by heating a thick layer of Pd on Ta. From about 700 to $900^{\circ} \mathrm{C}$. the compound is stable, and at $800^{\circ} \mathrm{C}$ the shifted feature was heated for one hour and no change in the compound was observed. It is also seen that the interface feature is significantly higher than the bulk Ta feature, which tndicates that the interface must extend over several layers. Apparently the configuration formed by depositing a monolayer of $P d$ is not equivalent to that formed by heating a thIck Pd layer; even though the LEED patterns and the chemical properties of the layers are similar. This system will be looked at again with higher resolution on the U7A TGM.

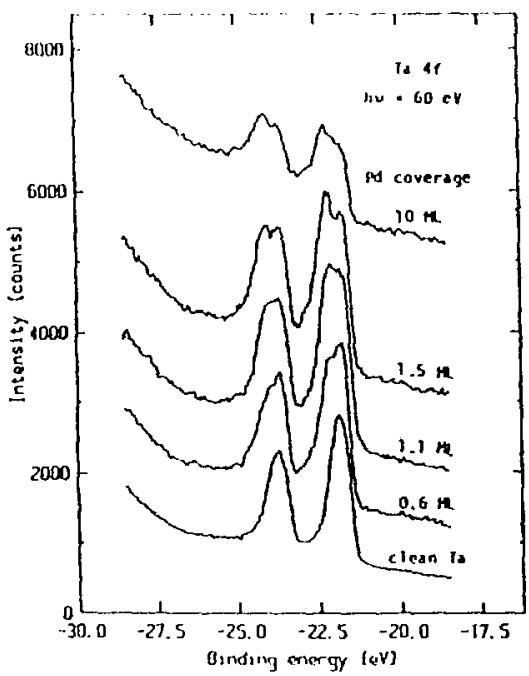

Fig.1 The interface compound of Pd/Ta as a function of the coverage of $\mathrm{Pd}$. The Ta Af levels were used as a probe.

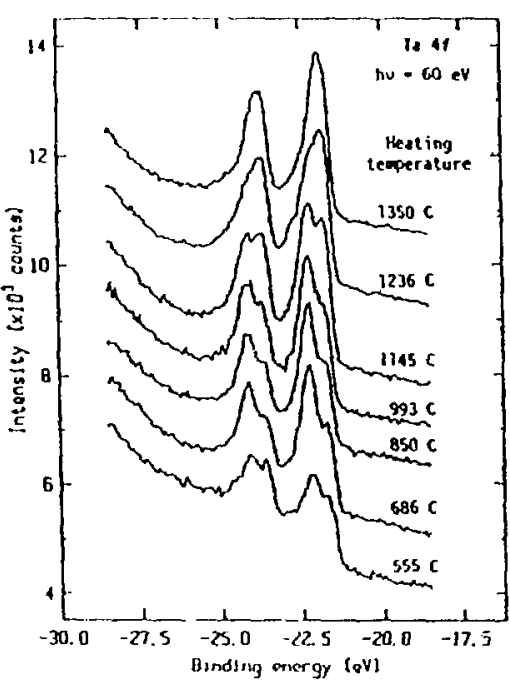

Fig. 2 The evolution of the interface compound by heating a thick layer of Pd on Ta. The Ta $4 \mathrm{f}$ levels were used as a probe.

Work supported by the Division of Materials Sciences U. S. Department of Energy under Contract No. DE-ACO2-76CH0O016.

also at Hunter College of CUNY 
RESONANT AND X-RAY PHOTOEMISSION STUDIES OF THE YBa $\mathrm{Cu}_{3} \mathrm{O}_{7}$, VALENCE BAND ABOVE AND BELOW THE SUPERCONDUCTIMG TRANSITION TEMPERATURE

S. L. Qiu (BNL), M. W. Ruckman (BNL), P. D. Johnson (BNL), J. Chen (BNL) ${ }^{\dagger}$, L. Jiang (BNL) ${ }^{\dagger}$, Myron Strongin (BNL), B. Sinkovic'(AT\&T Bell Labs) and N. Brookes (U. of TX, Austin)

A description of the electronic structure of high $T_{c}$ superconductors is essential, if an understanding of the superconducting mechanism is to be achieved. A number of theoretical models have been advanced co explain the high transition temperatures. Some of these models invoke charge fluctuations on the $\mathrm{Cu}$ tons between $a 2^{+}$and $3^{+}$state. other models suggest that holes become localized on the oxygen $0^{2}$ ions. Resonant valence band photoemission spectra and photoemission core level spectra along with other complimentary techniques should be able to detect changes in the charge state of $\mathrm{Y}, \mathrm{Ba}, \mathrm{Cu}$ or $\mathrm{O}$ ions and show changes in the degree of screening of the photon produced holes. photoemission spectra from freshly scraped surfaces at room temperature ( $300^{\circ} \mathrm{K}$ ) and for surfaces scraped at room temperature but cooled to $20 \mathrm{~K}$ for the superconducting compound, YBa. $\mathrm{Cu}_{3} \mathrm{O}_{7}$ using photon energies ranging from 50 to $150 \mathrm{eV}$. Valience band spectra (Fig. l) for room temperature YBa Cu $0_{7}$ shows resonant photoemission which permits the identification of the chemical origin of the peaks in the valence region, an extremely low density of states at the Fermi level and a Cu3d satelite (about 13 eV binding energy) seen near the $74 \mathrm{eV}$ Cu $3 \mathrm{p}$ photoadsorption threshold. The appearance of this satellite in the spectra is consistent with a $\mathrm{Cu}^{2+}$ valence. In spectra, recorded at temperatures below $T_{\text {c }}$, photoemission from the cu3d satellite becomes less intense suggesting possible electron delocalization. Otherwise the valence band shows little or no change between 300 and $20 \mathrm{~K}$. A conventional $x-r a y$ source was attached to the U7-B experimental chamber to permit studies of the valence charge state in the surface layer by XPS. Examination of the Cu $2 \mathrm{p}_{3 / 2}, 2 \mathrm{pl} / 2$ core level (Fig. 2 ) suggests that the copper valence is $2^{+}$because the poorly screened "satellite" peak, seen in Cu0, is present. The 0 Is (Fig. 2) show principle components at 529 and 531 eV binding energy and a much weaker component at 533 $\mathrm{eV}^{\mathrm{V}}$. observation of several oxygen species suggests that the surface layer is multi-phase in regards to oxygen concentration or suggests that significant impurity phases (e.g., $\mathrm{BaCO}_{3}$ or $\mathrm{Ba}(\mathrm{OH})_{2}$ ) may be present. Like the valence band, the core level spectra show little change in either binding energy or shape upon cooling below the superconducting transition temperature. This also suggests little or no change occurs in the chemical state of the surface layer, or in the screening of the final state hole.

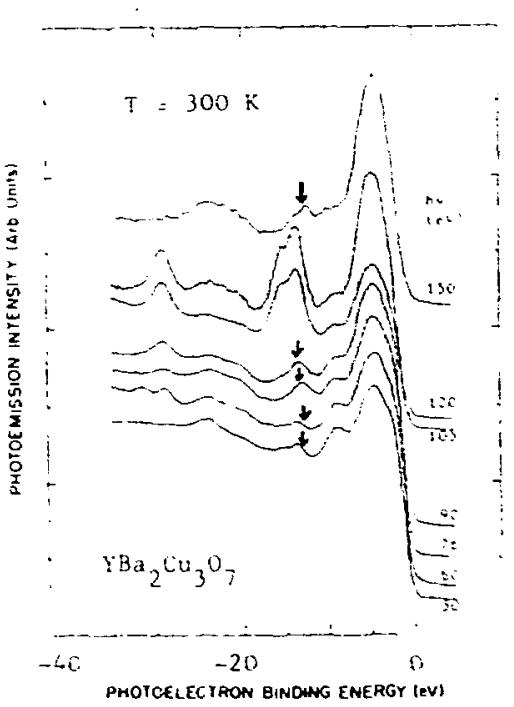

Fig. 1. Valence band spectra

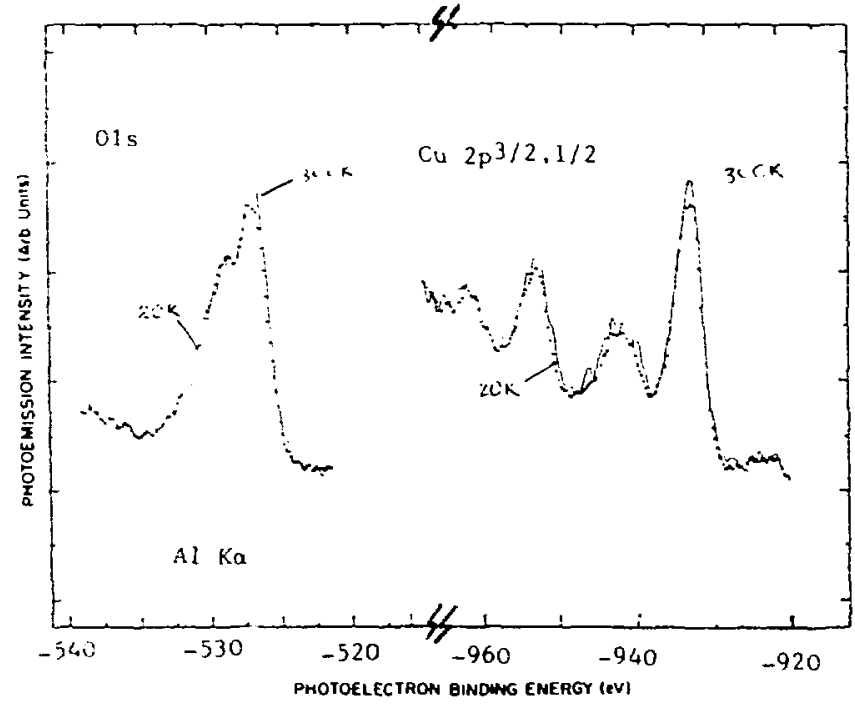

Fig. 2. Corelevel spectra

Work supported by the Division of Materials Sciences U. S. Department of Energy under Contract No. DE-ACO2-CHOOO16.

talso at Hunter College of CUNY

++ also at queens College of CUNY 
INTERACTION OF OXYGEN WITH A HIGH $\mathrm{T}_{\mathrm{C}}$ SUPERCONDUCTING

OXIDE AT LOW TEMPERATURE

S. L. Q1u (BNL), M. W. Ruckman (BNL), P. D. Johnson (BNL), J. Chen (BNL) ${ }^{\dagger}$, C. L. LIn (BNL), Myron Strongin (BNL), B. Sinkovic' (AT\&T Bell Labs), and N. Broukes (U. of TX, Austin)

Molecular oxygen was adsorbed on a freshly scraped $\mathrm{YBa}_{2} \mathrm{Cu}_{3} \mathrm{O}_{7}$ surface and its interaction with the substrate was probed using synchrotron radiation and $x$-ray photoemission. No significant amount of oxygen appeared to absorb at $300^{\circ} \mathrm{K}$ and subsequent gas exposures where performed on a surface cooled to $-20^{\circ} \mathrm{K}$. Valence band spectra (F1g. la) taken at $150 \mathrm{eV}$ show additional photoemission peaks (Fig. Ib) characterist $1 \mathrm{c}$ of physisorbed molecular oxygen after several small exposures. 0 ls core level spectra also show a peak at $538 \mathrm{eV}$ characteristic of molecular oxygen. An additional peak at 533 eV 1 s observed to grow with increasing oxygen exposure. Reduction in surface $\mathrm{O}_{2}$ coverage occurs and might be attibuted to either gradual desorption or diffusion into the bulk. The physisorbed oxygen could be removed by warming the sample to $50^{\circ} \mathrm{K}$. At this temperature the $538 \mathrm{eV} 0$ is feature disapppears, but the 533 peak retains its intensity. The valence band shows radical changes when compared to elther the spectrum taken at $20^{\circ} \mathrm{K}$ with no oxygen adsorbed or a spectrum taken at room temperature. Intense new valence band states are seen near $-7,-12$, and $-27 \mathrm{eV}$ binding energy. The valence band spectrum reverts to the room temperature spectrum when heated above $200^{\circ} \mathrm{K}$. Examination of $\mathrm{Ba}$, $Y$ or $\mathrm{Cu}$ core levels indicates 11ttle modification of the electronic structure. Reversion of the valence band back to its initial configuration suggests that the underlying atomic structure is unchanged and that additional physisorbed oxygen causes little chemical break down of the material. The nature of the modifled valence band and its connection with surface layer oxygen concentration is under investigation.

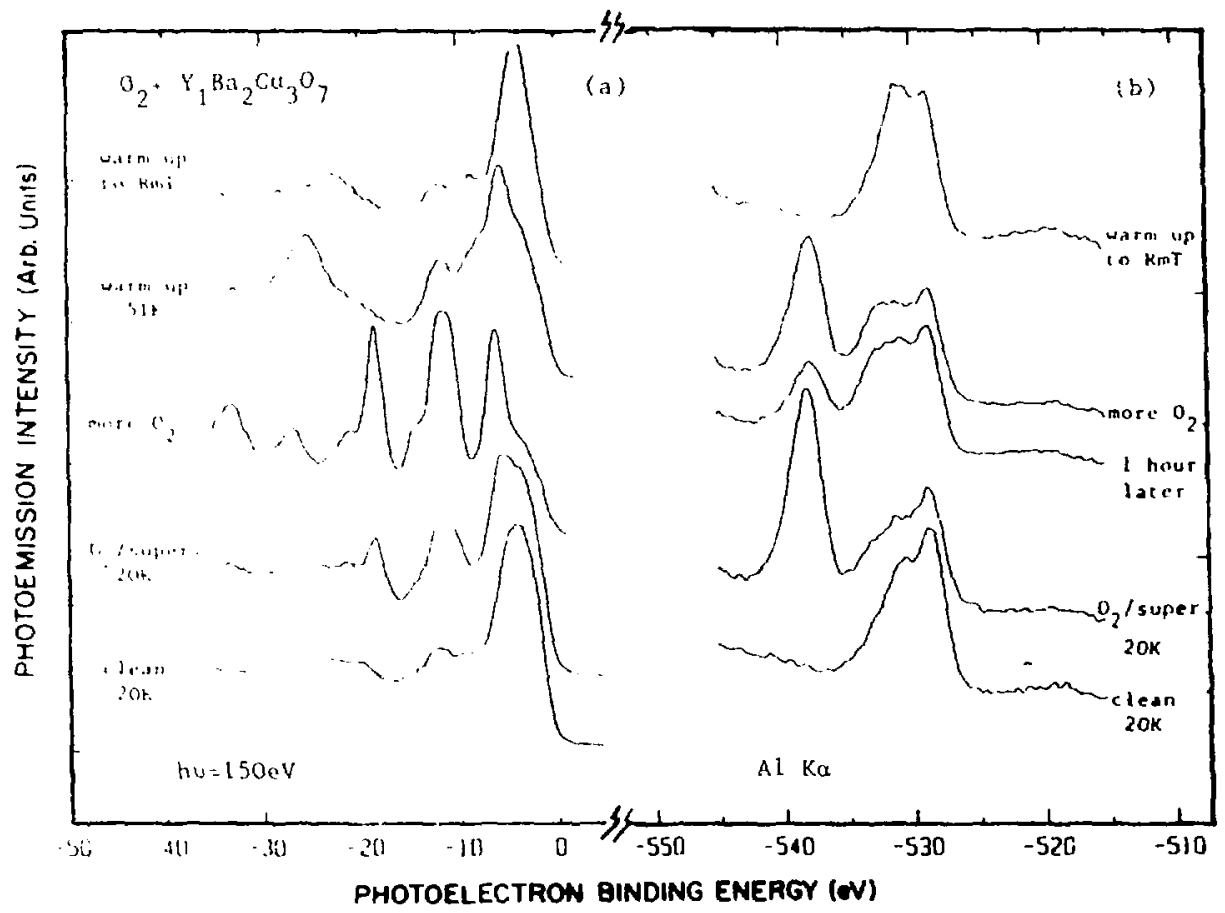

Fig. 1(a). Valence band spectra taken using $150 \mathrm{eV}$ photons (b). Ots corelevel spectra taken using Al K-a $\mathrm{x}$-rays

Work supported by the Division of Materials Sciences U.S. Department of Energy under Contract No. DE-ACO2-76CHOOO16.

talso at Hunter College of CUNY 
FORMATION OF A1/Ta(110) INTERFACES AND TULIR MOIJIFICATION BY OXIDATION

\author{
S. L. Q1u (BNL), M. W. Ruckman (BNI), Myron strungin (BNL) and J. Chen (BNL) ${ }^{\dagger}$
}

Interactions between $A J$ and a refractory metal were examined to gain insight Into the chemical and physical processes Important in making saphire-Nb thin film superconducting devices. To facilitate the experiment, Ta was substituted for $\mathrm{Nb}$ and functions between $\Lambda \mathrm{l}$ and $\mathrm{Ta}$ were made by vapor deposition of $\mathrm{Al}$ on a Ta substrate in ultrahigh vacuum $\left(-5 \times 10^{-10}\right.$ Torr). No evidence of intermixing between $\Lambda$ l and $\mathrm{Ta}$ below $1 \mathrm{~nm}$ thickness was detected and intensity variation of the Ta $4 \mathrm{f}$ core level suggests that Al inftially goes down layer-by-layer. Possible clustering and surface roughening are detected for Al coverages exceeding $1 \mathrm{~nm}$. No shifted $\mathrm{Ta} 4 \mathrm{f}$ core level component $1 \mathrm{~s}$ seen but modification of the Ta valence band suggeste that sufficlent bonding to account for the formation of a uniform flat Al overlayer at monolayer coverages exists. Heat treatments $\left(\sim 700^{\circ} \mathrm{C}\right)$ trigger interdiffusion and reaction to form a stable Ta-Al intermetallic compound. Further mixing of Ta and Al did not occur unt 11 temperatures exceeded $900^{\circ} \mathrm{C}$ and small amounts of $\mathrm{Al}$ were present at $1100-1200^{\circ} \mathrm{C}$. The observation of $\mathrm{Al}$ on the surface at these high temperatures suggests that the surface Al-Ta bond is stronger than the $\Lambda|-\Lambda|$ hond. We have also studied the oxidation of one and two monolayers of $A 1$ on Ta to see how the oxtde develops at the $\mathrm{Al}-\mathrm{Ta}$ interface. One pronounced feature is the enormous increase in the number of langmulrs of oxygen exposure necessary for the formation of the Ta. $\mathrm{O}_{3}$ features (about 1 eV deeper than the main $4 \mathrm{f}$ peaks) with increasing thickness of $\mathrm{Al} f \mathrm{flm}$. For clean.Ta about $1 \mathrm{~L}$ oxygen exposure shows well developed features, whereas for one layer of Al simllar features are seen at about 20-50 L exposure and for two layers of Al these features are seen above 1000L exposure. The 5 eV deeper peaks of $\mathrm{Ta}_{2} \mathrm{O}_{3}$ are seen at above $500 \mathrm{~L}$ for clean $\mathrm{Ta}$, at about 5000-50000L for one layer of Al, and there $f_{B}$ no indication of this oxide for 2 layers of Al at an exposure of 50000L. Figure la shows the features of $\mathrm{Al} 2 \mathrm{P}$ core level as a function of the oxygen exposure for one layer of Al. The feature at -1.4 eV relative to the clean peak shifts to high binding energy with increasing oxygen exposure and stays at $-2.6 \mathrm{eV}$ after 500L oxygen exposure. For two layers of $\mathrm{Al}$ (F1g. $1 \mathrm{~b}$ ) at about 50L oxygen exposure the feature of bulk $\mathrm{Al}_{2} \mathrm{O}_{3}$ at -2.6 eV starts to develop and shifts to -3.2 eV with 1 ncreasing the oxygen exposure, while after 5000L it shifts back to $-2.6 \mathrm{eV}$. This can be 1 nterpreted as the formation of the $\mathrm{Ta}_{2} \mathrm{O}_{3}$ layer underneath which causes the shift of the substrate vacuum level.

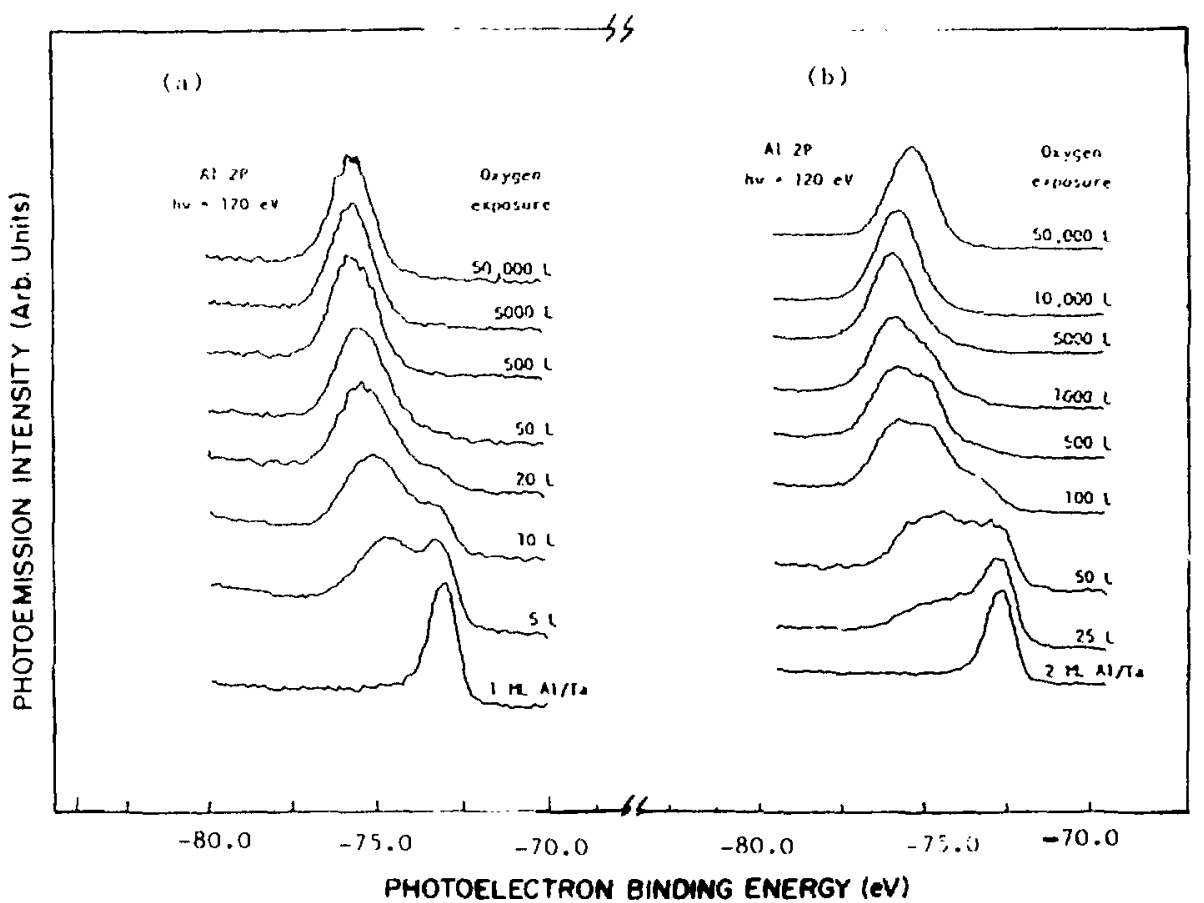

Fig. I(a). Oxygen on a Al/Ta(110) monolayer

(b). Oxygen on two Al layers supported on $\mathrm{Ta}(110)$

Work supported by the Division of Materials Sciences U. S. Department of Energy under Contract No. DE-ACO2-76CHOOOI6.

talso at Hunter College of CUNY 
M. W. Ruckman (BNL), S. L. Qiu (BNL), S, Heald (BNL) and

H. Chen (Queens-CUNY)

Synchrotron radiation photoemission was used to study room temperature interface formation between Cu and $\mathrm{Al}$. The experiment observed small scale $(1-2 \mathrm{~nm})$ intermixing at $300 \mathrm{~K}$ for both Cu/Al and the Inverted $\mathrm{Al} / \mathrm{Cu}$ junctions. The $\mathrm{Cu}$ or $\mathrm{Al} f \mathrm{flms}$ were deposfted on an inert substrate in ultrahigh vacuum to minimize impurities in the thin films or at the interface. $60 \mathrm{eV}$ photoemission spectra for the $\mathrm{Cu}-\mathrm{Al}$ are shown in Fig. 1(a). Modification of the Cu 3d-states suggests that $\mathrm{Cu}$ and Al have either alloyed or intermixed. Clustering of the $C u$ film can be ruled out because the "atomic-like" $C_{4}$ states are observed even after five Cu monolayers are deposited. Slow attenuation of the Al $2 \mathrm{p}$ core level during the early states of Al overlayer formation is consistent with significant surface alloying. More rapid attenuation of the $\mathrm{Al} 2 \mathrm{p}$ core level seen at later stages of interface formation can be explained by the burlal of the extended interface by metallic Cu. Comparable intermixing is also seen for Al-Cu because the high Al coverage spectra show Cu photoemission features suggestive of the presence of an atomic-like Cu species Fig. l(b).

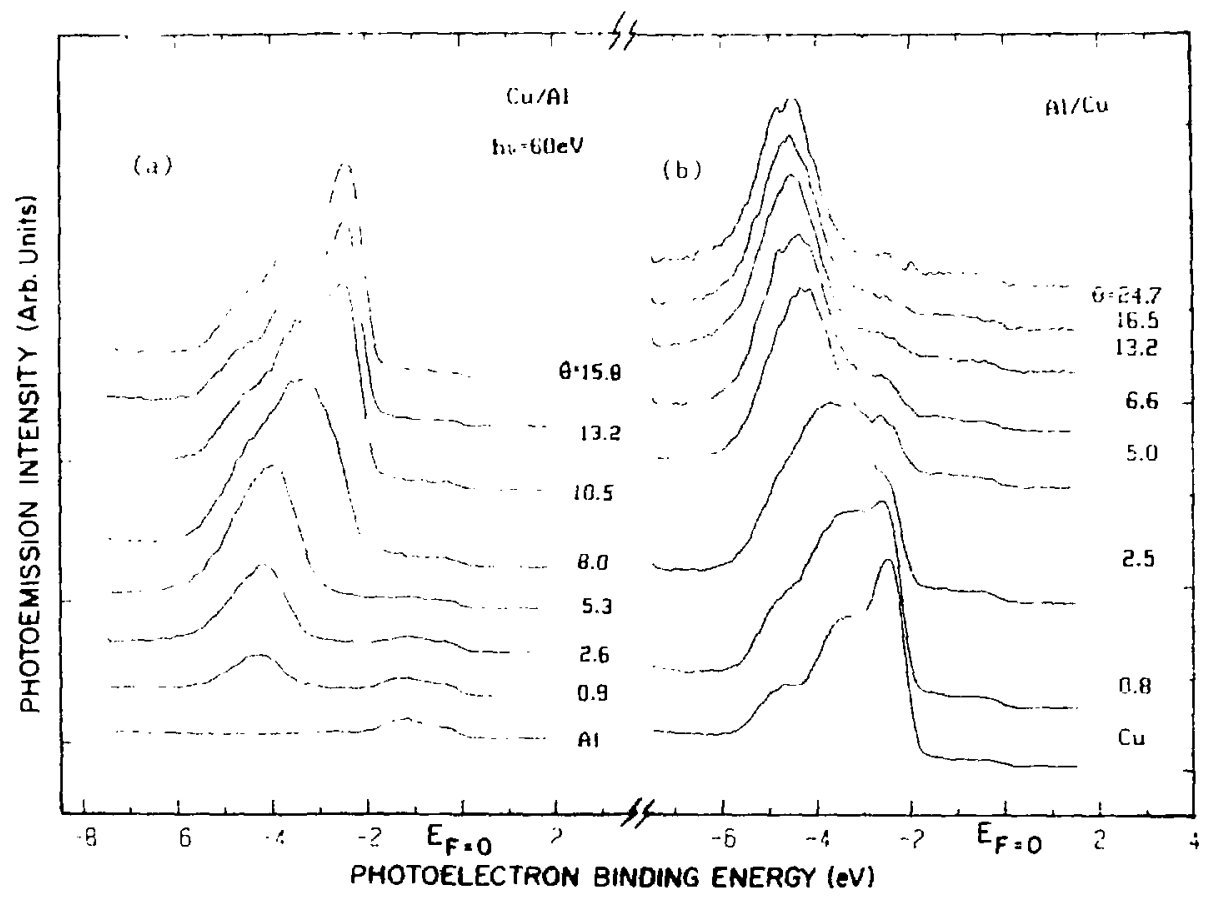

Fig. 1. 60 eV valence band photoemission spectra for the Cu-Al and Al-Cu intertaces, $\theta$ is the overlayer coverage in monolayers

Work supported by the Division of Materials Sciences U. S. Department of Energy under Contract No. $D E-A C O 2-76 C H 00016$. 
MORPHOLOGY, BONDING AND THERMAL STABILITY OF Cu/Ta(110) Au/Ta(110) OVERLAYERS

M. W. Ruckman (BNL), S. L. Q1u (BNL), Myron Strong1n (BNL) and J. Chen (BNL) ${ }^{\dagger}$

The structure, electronic properties and thermal modiflcation of Cu/Ta(110 and Au/Ta(1l0) were stidied using synchrotron radiation photoemission. The Ilnearity of the attenuation curve of the Ta $4 \mathrm{f}$ core level, Fig. I(a) Indicates that the growth of $\mathrm{Cu}$ on $\mathrm{Ta}(110)$ occurs $1 \mathrm{n}$ a layer-by-layer fashion. From LEED data and similar attenuation trends for the $T a$ ff core level, $1 t$ is also concluded the Au overlayers undergo epitaxial layer-by-layer growth. Modifications of the Au valence band states and core level binding energy shifts for both the Au $4 \mathrm{~F}$ and $\mathrm{Ta} 4 \mathrm{f}$ states suggest that some bonding occurs between $\mathrm{Au}$ and $\mathrm{Ta}$. However, the lack of change in the Ta d-band states or Au-d states when observed near the Cooper minimum for Au suggests little direct involvement of the Au metal d-states in forming bonds. A shift to lower binding energy (1.e., towards the metallic Au position) by the Au $4 f$ level occurs near the coverage required to cause the Au overlayer to revert to the close packed fcc structure. For $\mathrm{Cu} / \mathrm{Ta}(110)$, (Fig. 2) "atomic-like" Cu states can be seen below 2 monolayers (ML) Cu. Metallic Cu states are evident after $4 \mathrm{ML}$. No shift of the Ta $4 \mathrm{f}$ core level is seen when Cu is deposited. This suggests that the bonding between $\mathrm{Cu}$ and $\mathrm{Ta}$ is less than that which occurs between Au and Ta. A thick layer of $\mathrm{Cu}$ was heated up to $900^{\circ} \mathrm{C}$. The relative intenalty of Ta $4 \mathrm{f}$ core level versus temperature is shown in Fig. 1(b). During this process no shifted Ta $4 \mathrm{f}$ core level is observed and the valence band states of $\mathrm{Cu}$ shifted to the "atomic-like" postition and this suggests that the interaction between $\mathrm{Cu}$ and $\mathrm{Ta}$ is small. The data for $\mathrm{Cu} / \mathrm{Ta}(1 \mathrm{l})$ is consistent with thermally induced clustering. Heating above $800^{\circ} \mathrm{C}$ triggers significant mixing of Au and $T a$ which leads to the formation of a stable surface compound. The lack of a bulk metallic Ta $4 \mathrm{f}$ core level component suggests that the intermixed Au-Ta layer is thicker than the proting depth of the photoelectrons. Changes in the Au valence band and binding energy shifts of the $A u$ and $T a$ core levels are similar to those seen for chemisorbed $\mathrm{Au} / \mathrm{Ta}(110)$. Further heating, In excess of $1000^{\circ} \mathrm{C}$ destroys the Au/Ta surface and recovers the clean Ta surface.

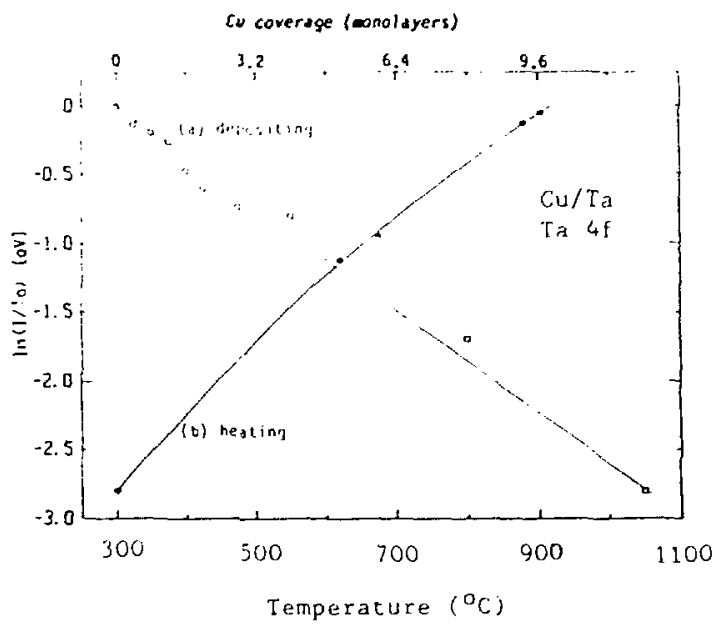

$\mathrm{Fig.} \mathrm{1.} \mathrm{Ia} 4 \mathrm{f}$ corelevel intensities for Cu/Ta(110)

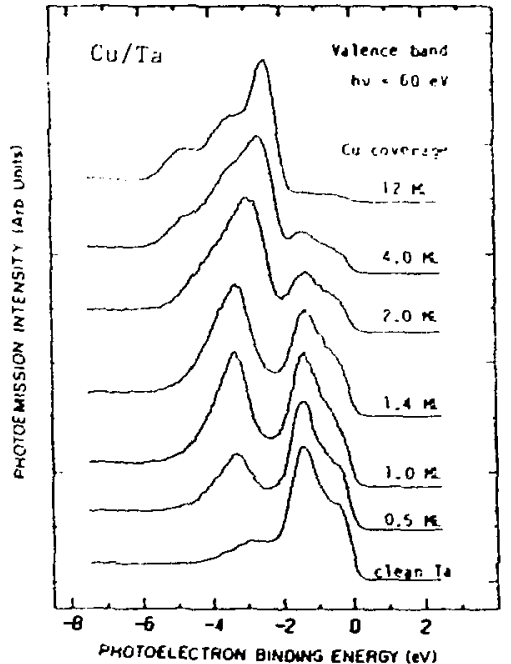

Fig. 2. EDCs for Cu/Ta(110) filins

Work supported by the Division of Materials Sciences U. S. Department of Energy under Contract No. $D E-A C 02-76 C H 00016$.

talso at Hunter College of CUNY 
IBM Research Division, IBM T. J. Watson Research Center

Box 218

Yorktown Heights, NY 10598

A variety of techniques has been used to study the structure of the $\mathrm{SiO}_{2} / \mathrm{Si}$ interface. The high electronic quality of this interface is the key to todays silicon technology. Many models have been proposed for the atomic arrangement at the interface. In a previous study ${ }^{(1)}$, we ruled out atomically abrupt models. Such models would predict only one intermediate oxidation state, i.e. $\mathrm{Si}^{2+}$, for the $\mathrm{SiO}_{2} / \mathrm{Si}(100)$ interface, whereas all three intermediate oxidation states (i.e. $\mathrm{Si}^{1+}, \mathrm{Si}^{2+}, \mathrm{Si}^{3+}$ ) are observed (see Fig. 1). In this work ${ }^{(2)}$, we propose a structural model (Fig. 2) which gives the correct intensity and distribution of oxidation states. The interfaces of $\mathrm{Si}(100)$ and $\mathrm{Si}(111)$ with $\mathrm{SiO}_{2}$ are studied for a wide range of preparation conditions including high pressure reactions as used in device processing. As an example, we show the effect of hydrogen annealing $\left(1\right.$ atmosphere, 1 min at $850^{\circ} \mathrm{C}$ ). Annealing the $\mathrm{SiO}_{2} / \mathrm{Si}$ interface in $\mathrm{H}_{2}$ is $\mathrm{known}$ to reduce the density of interface states. Essentially, the hydrogen saturates free Si bonds $\left(P_{b}\right.$ centers $^{(3)}$ ) at the interface. There is no detectable influence of $\mathrm{H}_{2}$ annealing on the distribution of oxidation states. This is understandable since the number of $\mathrm{P}_{\mathrm{b}}$ centers reaches at most about $10^{92} \mathrm{~cm}^{-2}$, i.e. $1 / 1000$ of a monolayer. Such small changes are not detectable with our technique. However, we do see an effect of $\mathrm{H}_{2}$ annealing on the electrical properties. The Fermi level moves to an unpinned position, which confirms the removal of interface states by hydrogen. This Fermi level movement shows up as an overall shift of the core level spectrum in Fig. 1 . The shift reverses after annealing in vacuum, whereby the $H$ is driven out.

\section{References}

1. G. Hollinger and F. J. Himpsel, Appl. Phys. Lett. 44, 93 (1984).

2. F. J. Himpsel, J. A. Yarmoff and G. Hollinger, Phys. Rev. B, in preparation.

3. N. M. Johnson, D. K. Biegelsen, M. D. Moyer, S. T. Chang, E. H. Poindexter, and P. J. Caplan, Appl. Phys. Lett. 43, 563 (1983).

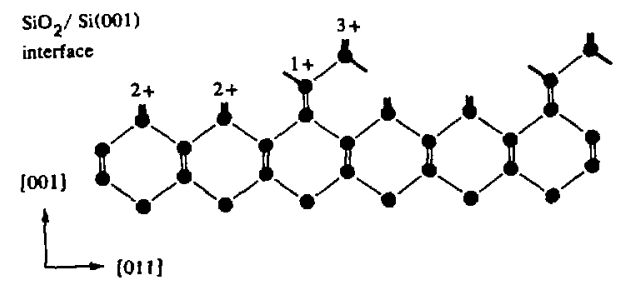

Figure 1. Structural model for the $\mathrm{SiO}_{2} / \mathrm{Si}(001)$ interface derived from core level spectroscopy. The amorphous $\mathrm{SiO}_{2}$ network (not shown) connects to the broken bonds.

Figure 2. Distribution of oxidation states at the $\mathrm{SiO}_{2} / \mathrm{Si}(100)$ interface. Annealing in hydrogen does not change the distribution but moves the Fermi level to an unpinned position.

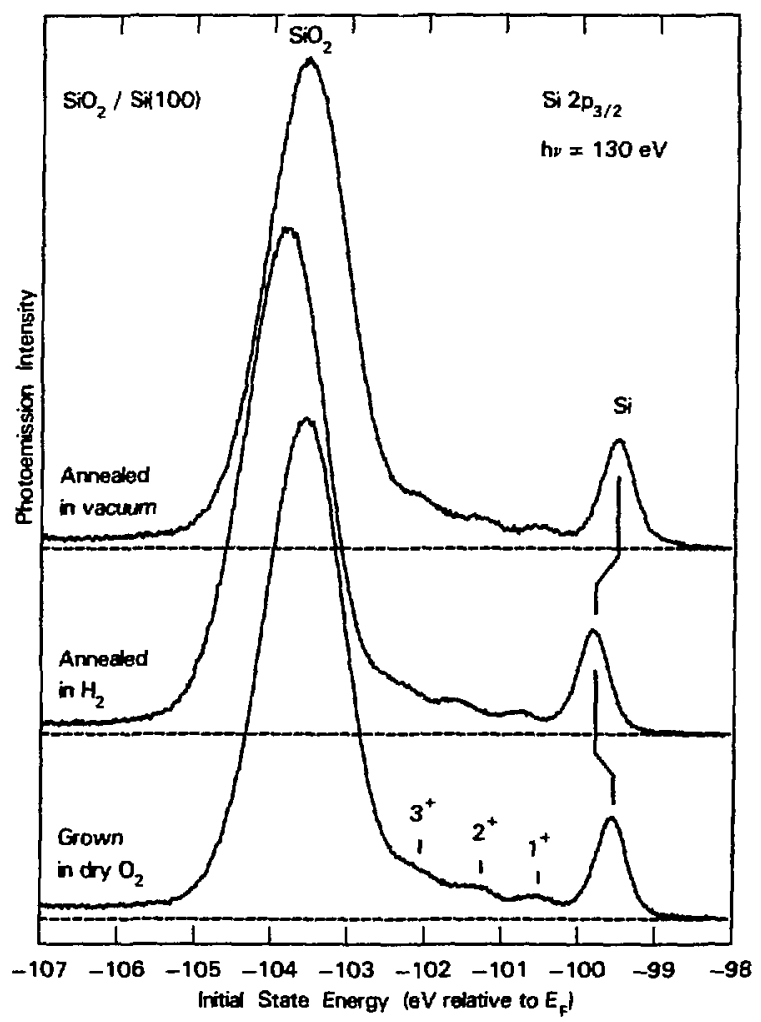




\title{
INTERFACE STATES AND SCHOTTKY BEHAVIOR
}

\author{
G. Jezequel, A. Taleb-Ibrahimi and R. Ludeke \\ IBM T.J. Watson Research Center, \\ P.O.Box 218, Yorktown Heights, N.Y. 10598
}

The role of interface states on the electronic Schottky barrier has now been recognized. However, the origin of these states as well as their density are still controversal. Metal induced gap states ${ }^{1}$ and/or defects ${ }^{2}$ and impurities ${ }^{3,4}$ have often been implicated. The role of the metal, or more specifically its metallic character received but seant attention; in particular, only its role in altering the net interface charge was considered.

We set out to investigate the effect of the metal by exposing the clean cleaved GaAs surface to two different metals. The first metal, a reactive one, $V$ or $P d$ was used to generate interface states of varying densities and energetic positions in the gap. The second metal a non-reactive one, $\mathrm{Ag}$, was then deposited to thicknesses as high as $30 \AA$ A to monitor the effects of metallic behavior. The band bending shifts as a function of Ag coverage for various thicknesses of $V$ interlayers are shown in fig. $1-a$ and $1-b$. Our results show that the Fermi level approaches the valence band edge closer than either of the two metals alone. These observations are interpreted as being predominantly the effect of metallic screening. ${ }^{5}$

The experiments were performed at the U8 beamline, we acknowledge the technical assistance of M.Prikas and D.Costas and the co-operation of the NSLS staff.

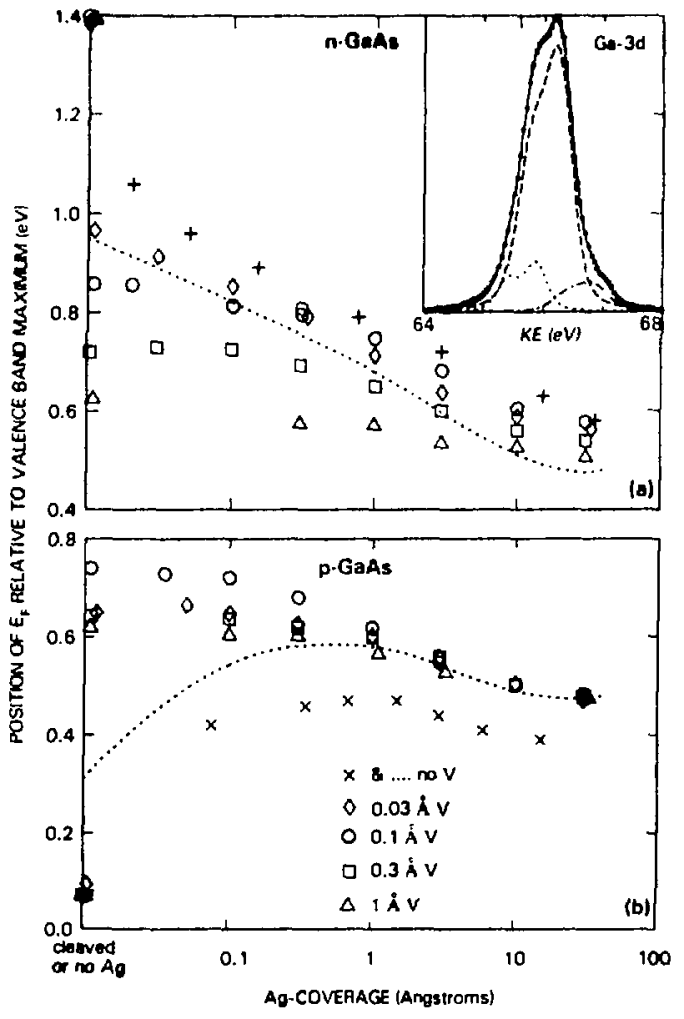

\section{REFERENCES}

1. V. Heine, Phys. Rev. A 138, 1689 (1985): C. Tejedor, F. Flores and E. Louis, J. Phys. C 10, 2163 (1977); J. Tersoff, Phys. Rev. lett. 57, 465 (1984).

2. W.E. Spicer, P.W. Chye, P.R Skeath, C.Y. Su and I. Lindau, J. Vac. sci. Technol. 16, 1422 (1979); S.F. Ren and R.E. Allen, Surf. Sci. 148, L637 (1984).

3. R. Ludeke, F. Schäffler and D. Rieger, J. Vac. Sci. Techol., B4, 924 (1986).

4. R. Ludeke, D. Straub, F.J. Himpsel and G. Landgren, J.Vac. Sci. Technol. A4, 874 (1986).

5. R. Ludeke, G. Jezequel and A. Taleb-Ibrahimi, to be published.

Figure 1. The evolution of the position of the Fermi level at the interface of $\mathrm{GaAs}$ with $\mathrm{Ag}$ coverage for various $\mathrm{V}$ interlayer thicknesses on n-type (a) and p-type GaAs (b) The insert shows a Ga-3d core level spectrum for a surface exposed to $\simeq 0.02 \mathrm{ML} V$ and covered with $3 \AA \mathrm{Ag}$ : the dots are the experimental points and the solid line is the sum of the bulk substrate component (dashed curve) which is used to monitor band bending shifts, the surface component (dotted curve on the low kinetic energy side) and a third component on the high KE side which is due to metallic Ga which has been replaced by $V$. 


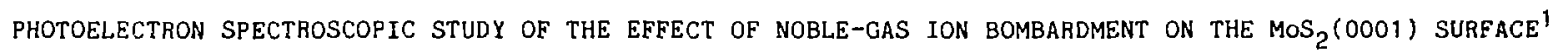

J. R. Lince, T. B. Stewart, M. H. Hills, P. D. Fleischauer (Aerospacé2),

J. A. Yarmoft, and A. Taleb-Ibrahimi (IBM)

The chemical state of the $\operatorname{MoS}_{2}(0001)$ surface after bombardment with low-energy, noble-gas ions was analyzed by high-resolution core-level and valence-band photoelectron spectroscopies (CLPS and VBPS, respectively) on beam line U8-B. All samples were naturally occurring molybdenite crystals that were initially prepared by cleavage in air. The samples were mounted in vacuum, after which they were resistively heated to $>550^{\circ} \mathrm{C}$. That treatment produced a ( $1 \times 1$ ) low-energy electron diffraction (LEED) pattern; no evidence of carbon, oxygen, or other contaminants was detected by $\mathrm{CLPS}_{\text {. MoS }}(0001)$ surfaces were bombarded with varying dosages of neon and argon lons with an energy of 1 keV.

Curve fitting of the Mo-3d doublet clearly indicates the formation of molybdenum metal after bombardment. Whereas previous studies ${ }^{1-4}$ concluded molybdenum-metal formation of the basis of indirect information, the superior resolution $(-0.35 \mathrm{eV})$ in this study enables the contribution of the Mo(IV) in the $\mathrm{MoS}_{2}$ to be separated from that of the metallic Mo (see Fig. 1b). The metallic contribution increases with ion dosage until, at a dosage of $2 \times 10^{16} \mathrm{~cm}^{-2} \mathrm{Ne}^{+}, 85 \%$ of the surface Mo (i.e.., in the top - 15 A) is in metallic form (see Fig. 1c). After annealing the bombarded sample to - $700^{\circ} \mathrm{C}$, no LEED pattern was observed. The Mo(IV) and metallic Mo peaks of the Mo-3d spectra shifted farther apart in binding energy (see Fig. 1d). This observation, in addition to the lack of change of the peaks' relative heights as the photon energy is changed, suggests the existence, after annealing, of unconnected Mo metal islands on the surface that are thicker than - 15 A.

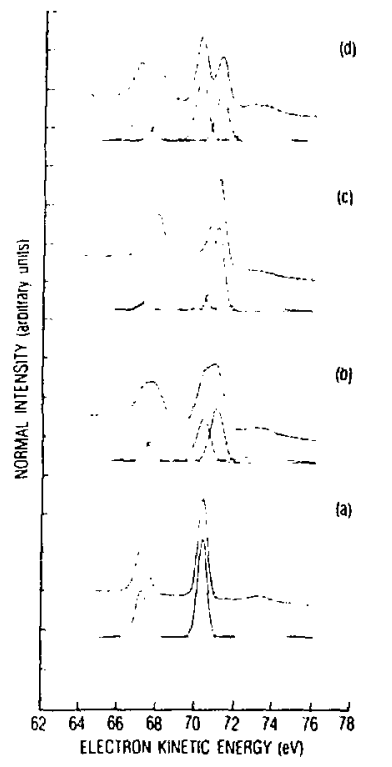

Fig. 1. CLPS of the Mo-3d doublet for (a) the clean $\mathrm{MoS}_{2}(0001)$ surface, and after $1 \mathrm{keV} \mathrm{Ne}$

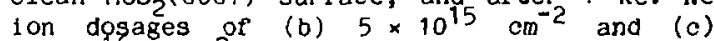

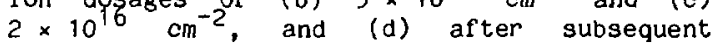
annealing. A photon energy of $300 \mathrm{eV}$ was used.

Extensive chemical modification is also exhibited by the sulfur in the bombarded-surface region. Curve fitting of the S-2p doublet (not shown) after ion Dombardment indicates the presence of elemental sulfur in addition to a surface $\mathrm{MOS}_{2}$ sulfur species shifted to lower binding energy as a result of sulfur vacancy formation at the surface.

Finally, VBPS of $\operatorname{MoS}_{2}(0001)$ during bombardment (not shown) revealed movement of the Fermi level consistent with metalific character at the surface. Also, changes in the relative helghts of the valence band peaks imply that sulfur vacancy formation during bombardment causes a decrease of the electron density in the Mo-4d areas of the valence band.

\section{References}

1. J. R. Lince, D. J. Carre, and P. D. Eleischauer, Langmuir 2, 805 (1986).

2. J. R. Lince and P. D. Fleischauer, J. Vac. Scl. Technol. A 5,1312 (1987).

3. M. Kamaratos and C. A. Papageorgopoulos, Surf. Sc1. 178, $86 \frac{5}{5}(1986)$.

4. H. C. Feng and J. M. Chen, J. Phys. C I, L75 (1974).

\footnotetext{
This work was supported by the Air Force Space Division under contract number F04701-85-C-0086-P00016 and by DOE, Dept. of Materials Science.

The Aerospace Corporation, P. 0. Box 92957, Los Angeles, CA 90009.
} 


\title{
INTERACTION OF PYROLIZED HEXAFLUOROAZOMETHANE WITH SI (111)
}

\author{
F.R. McFeely, J.A. Yarmoff, A. Taleb-Ibrahimi and D.B. Beach \\ IBM T.J. Watson Research Center, Box 218, Yorktown Heights, NY 10598
}

One of the more interesting and important aspects of the halocarbon-based plasma etching of silicon is the control of shemical specificity. In practice, specificity in the $\mathrm{SiO}_{2} / \mathrm{Si}$ system can be achieved by the addition of hydrogen or oxygen to a $\mathrm{CF}_{4}$ plasma. These additions react with the plasma species to alter the nature of the reactants incident upon the substrate surface. Oxygen increases the density of free fluorine atoms in the plasma, and favors the etching of silicon. Hydrogen, on the contrary, reacts with free fluorine atoms in the discharge to produce HF, thus producing a fluorine deficient distribution of reactants and altering the relative etching rates so as to favor the etching of $\mathrm{SiO}_{2}$. On this basis it has been suggested that while fluorine atoms are the primary etchants for $\mathrm{Si}, \mathrm{CF}_{\mathrm{x}}$ species $(x=1,3)$ are responsible for $\mathrm{SiO}_{2}$ etching.

If this hypothesis is correct, the understanding of the microscopic mechanism for chemical selectivity in the $\mathrm{SiO}_{2} / \mathrm{Si}$ system can be gained only by understanding the reactivities of each of the $\mathrm{CF}_{\mathrm{x}}$ molecules with $\mathrm{Si}$ and $\mathrm{SiO} 2$ surfaces. Experimentally this is a daunting task. As a possible answer to this problem, we report in this paper experiments on the interaction between clean Si (111) surfaces and hexafluoroazomethane (HFAM). The virtue of this molecule is revealed by the pyrolysis reaction: ${ }^{1}$

$$
\mathrm{CF}_{3} \mathrm{~N}_{2} \mathrm{CF}_{3} \rightarrow 2 \mathrm{CF}_{3}+\mathrm{N}_{2}
$$

The only significant side reaction in the pyrolysis of HFAM is the recombination of the $\mathrm{CF}_{3}$ radicals to form $\mathrm{C}_{2} \mathrm{~F}_{6}$. However $\mathrm{C}_{2} \mathrm{~F}_{6}$ is a fully saturated molecule known to be unreactive towards silicon. Since the pyrolysis can be carried out almost quantitatively, this scheme offers the possibility of producing only $\mathrm{CF}_{3}$ radicals and the inert molecules $\mathrm{N}_{2}$ and $\mathrm{C}_{2} \mathrm{~F}_{6}$.

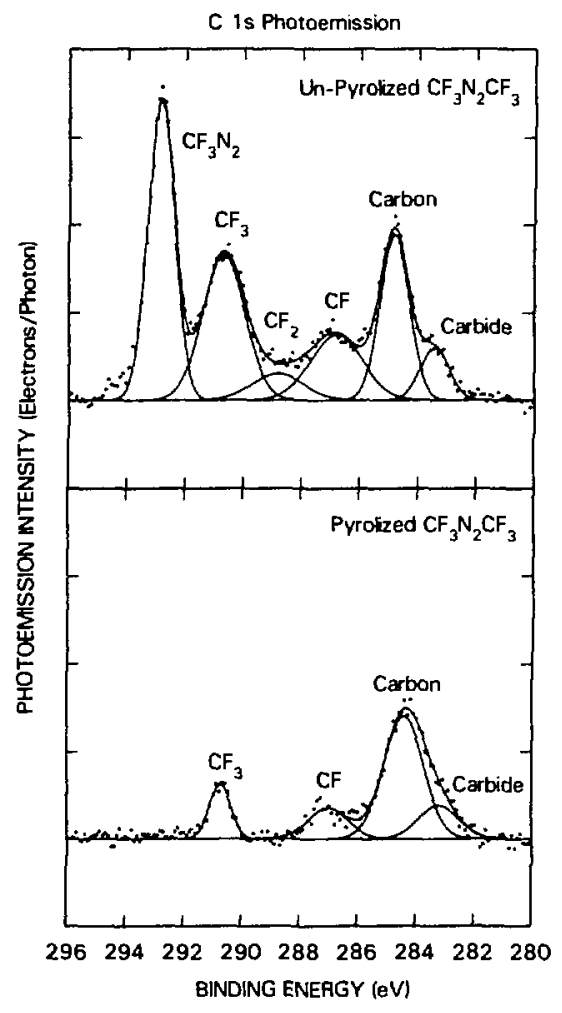

Figure 1 shows the $\mathrm{C}$ Is photemission spectra of a clean $\mathrm{Si}$ surface after exposure to un-pyrolized HFAM and after a dose of pyrolized HFAM. While the un-pyrolized HFAM shows the chemisorption of a $\mathrm{CF}_{3} \mathrm{~N}_{2}$ fragment, it is entirely absent in the case of pyrolized HFAM. In addition, the un-pyrolized HFAM showed dissociative nitrogen adsorption, while there was no detectable $\mathbf{N}$ $1 \mathrm{~s}$ peak after exposure to pyrolized HFAM. This indicates that the pyrolysis was indeed complete.

The effect of incresing the dose of pyrolized HFAM was to intiate the build-up of more graphitic and carbidic carbon. Examination of these spectra in conjunction with $F$ Is spectra showed that upon additional exposure, $\mathrm{F}$ atoms were removed from the $\mathrm{CF}_{3}$ radicals and transfered directly to silicon. This results in the formation of a passivating carbon layer on top of the clean $\mathrm{Si}$. It is therefore suggested that the buildup of such a passivating layer is responsible for the failure of $\mathrm{CF}_{3}$ radicals to effectively etch $\mathrm{Si}$, thereby increasing the selectivity of $\mathrm{SiO}_{2}$ over $\mathrm{Si}$ in the absence of $\mathrm{F}$ atoms.

\section{REFERENCES}

1. M. Rossi and D.M. Golden, Int. J. Chem. Kinet. 11, 775 (1979).

Figure 1. Carbon 1s photoemission spectra collected with $350 \mathrm{eV}$ photons. a) $\mathrm{Si}(111)$ exposed to $10 \mathrm{~L}$ of $\mathrm{CF}_{3} \mathrm{~N}_{2} \mathrm{CF}_{3}$. b) $\mathrm{Si}$ (111) exposed to pyrolized $\mathrm{CF}_{3} \mathrm{~N}_{2} \mathrm{CF}_{3}$. 


\title{
ON THE EFFECTS OF Ga IN THE FORMATION OF REACTIVE INTERFACES
}

\author{
A. Taleb-Ibrahimi, G. Jezequel and R. Ludeke \\ IBM T.J. Watson Research Center, \\ P.O. Box 218 Yorktown Heights, N.Y. 10598.
}

Metal adsorption studies on semiconductors at low coverages offer the possibility of identifying precursor states which evolve into interface states that determine the Schottky barrier. An interesting class of metal adsorbates are the transition metals, which are known to form deep levels in bulk semiconductors, and which also have been intimated by us as important in the formation process of Schottky barriers. Although very reactive even at room temperature, a stable configuration is not expected. Annealing the surface, on the other hand, may reduce inhomogeneities. Such effects have indeed been observed by annealing GaAs cleaved surfaces exposed to $\mathrm{V}$ and Pd for coverage ranges of 0.01 to 2 monolayers (ML). A Jrastic enhancement in the line shape of the Ga $3 \mathrm{~d}$ core level spectrum to that of the clean surface ensues on both $\mathrm{n}$ and p-type GaAs. Whereas the Fermi level position on n-type GaAs decreases slightly relative to the valence band maximum (VBM) with anncaling, on p-type GaAs decreases exceeding $300 \mathrm{meV}$ are observed for coverages below 0.1 ML. Smaller changes are obsarved for larger coverages. These observation are inconsistent with a single intrinsic defect. They rather indicate the presence of acceptor and clonor levels of different origin. Upon annealing the donor levels either evolve into levels lower in the band gap or they disappear as new donor states begin to dominate. A possible source for these states are reaction products of the metallization.

Elemental $\mathrm{Ga}$ is essentially the only biproduct observed during the metallization of GaAs with reactive metals, which include most of the metals studied thus far. Since Ga itself has been reported to form a Schottky barrier, the role of the two metals in the barrier formation process cannot be separated a priori without additional experiments. To understand the role of elemental $\mathrm{Ga}$, we have reexamined the $\mathrm{Ga} / \mathrm{GaAs}(110)$ interface. On n-type surfaces an initially slow, nearly logarithmic decrease in the position of the Fermi level is observed to a coverage of about $0.5 \AA$ of Ga, after which a rapid decrease occurs which subsequently levels off to a value $0.6 \mathrm{eV}$ above the VBM. The behavior on p-type is similar, with the exception that the band bending is constant at a value of $250 \mathrm{meV}$ above the VBM over the range 0 f 0.005 to $0.5 \AA$, before rapidly rising to a value near $0.6 \mathrm{eV}$ above the VBM. The onset of the rapid changes in the Fermi level positions on both conductivity types coincides with the formation of metallic Ga islands. This unusual behavior suggests that a unique donor level $\simeq 250 \mathrm{meV}$ above the VBM is formed by the non-metallic Ga. We do not know however, if the $\mathrm{Ga}$ is atomic or in clusters consisting of a few atoms, although the data appears to support the former. The estimated Schottky barrier height for n-type GaAs ol $0.60 \pm 0.040 \mathrm{eV}$ is in considerable disagreement with previous determinations.

The low value of the Ga donor level is consistent with the annealing experiments, provided that this treatment reduces the donor levels induced by the transition metals- a possibility since the position of the donor level for the bulk substitutional impurities lie generally near or below the VBM. However, it is generally observed that the Fermi level position during metallization on p-lype GaAs far exceeds the Ga donor level, from which we conclude that Ga does not play a major role in the Schottky barrier formation process of reacting metals on GaAs. Furthermore, its low miscibility at room temperature with many metals suggests that the exchanged $\mathrm{Ga}$ is swept away from the interface as the metal grows, a phenomenon already observed for $\mathrm{Ag}$ grown on a GaAs surface with dispersed $\mathrm{Ga}$ atoms. 


\title{
ELECTRONIC STRUCTURE OF $\mathrm{Y}_{1} \mathrm{Ba}_{2} \mathrm{C}_{\mathrm{U}_{7}} \mathrm{O}_{7}$
}

\author{
J.A. Yarmoff, D.R. Clarke, W. Drube, U.(). Karlsson, A. Talch-lbrahimi, and F.J. Ilimpsel \\ IBM lhomas J. Watson Rescarch Center, P.O. Box 218. Yorktown Heights, NY 10598
}

The electronic structure of the copper oxide-hased supercend ectors ${ }^{1.2}$ is of considerable interest for understanding the

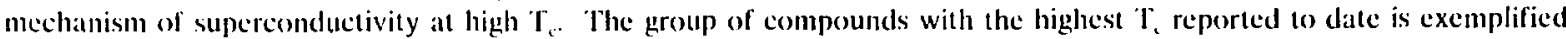
hy $\mathrm{Y}_{1} \mathrm{Ba}_{2}, \mathrm{C}_{7} \mathrm{O}_{7}$. We are using a combination of state-of-the-art lechniques such as photoemission, inverse photoenuission, and near edge $X$-ray absorption fine structure (NEXXAS) in order to oblain the salient features of the Cu-and $\mathrm{O}$ - derived statcs.

From the photoemission data, we observe a significant contribution from a thin carbonate overlayer (typically $5 \AA$ ) which was identilied by its $C$. Is signal. Carbonate gives rise to a peak at $-9.3 \mathrm{eV}$ and comtributes to the $-4.7 \mathrm{eV}$ peak." The carbonate ion is mostly associated with Ba since a high binding energy componeat of the Ba 4 d eore level inereases with higher carbonate concentration. The NEXAFS data are unaflected by the presence of carbonate since secondary electrons with acro kinctic encrgy (i.e. long mean frec path) are detected. We note that carbonate films may cause the weak links that linit the current carrying capacity of high $T$, supereonductors.

From our NI:XAFS results at the Cu and O core edges we obtain the oxidation states of Cu and $O$, which have been observed to play a critical role for the occurrence of supereondetivity. We find that Cu is in the $2+$ oxidation state and that the $2 p$ shell of the oxygen atoms is not filled completely. In a simplified picture, there are two ways to distribute the available electrons among $\mathrm{Cu}$ and $\mathrm{O}$, always assuming fully-oxidized $1 \mathrm{Y}^{3+}$ and $2 \mathrm{Ba}^{2+}$. One needs $2 \mathrm{Cu}^{2+}+1 \mathrm{Cu}^{3+} \mathrm{per}$ unit eell in order to have $70^{2}$. Alternatively, having all $\mathrm{Cu}$ atoms in the $2+$ oxidation state would require one oxygen in the 1-oxidation state. Our NliXAFS data favor the second picture. The ( 3 p edge hats atn energy position identical to that in ('uO) without additional structures. The Cu $2 p$ edge hehatves likewise (Fig. I). The O Is edge is characterized hy a spike at threshold (arrow in Fig. 2) which indicates transitions froin O1s into unoccupied $02 p$ states.

\section{REFERENCES}

1. J. G. Bednor\% and K. A. Müller, Z Phys. B 64, 189-193 (1986).

2. M. K. Wu, J. R. Ashburn, C. J. Torng, P. H. Hor, R. I. Meng, I. Gao, Z. J. Huang, Y. Z. Wang, and C. W. Chu, Phys. Rev. l.ctl. 58, $908(1987)$.

3. I.A. Yarnoff, D.R. Clarke, W. Drube, U.O. Karlsson, A. Taleh-Ibrahimi, and F.J. Himpsel, Phys. Rev. B36. 3967 (1087).

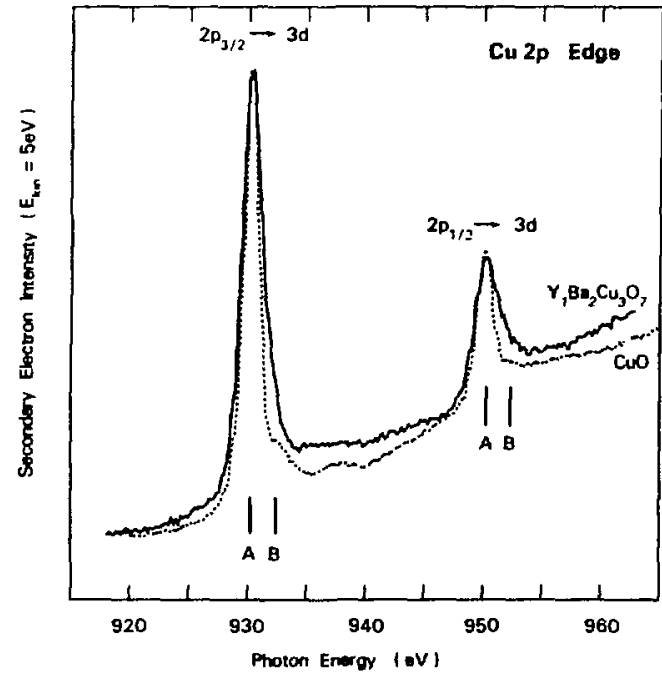

Figure 1. Near edge $\mathrm{X}$-ray absorption spectra of the $\mathrm{Cu}$ $2 p$ edge measured via the yicld of secondary electrons. The $\mathrm{Cu} 2 \mathrm{p}$ edge is very similar to $\mathrm{CuO}$, indicating $\mathrm{Cu}^{2+}$

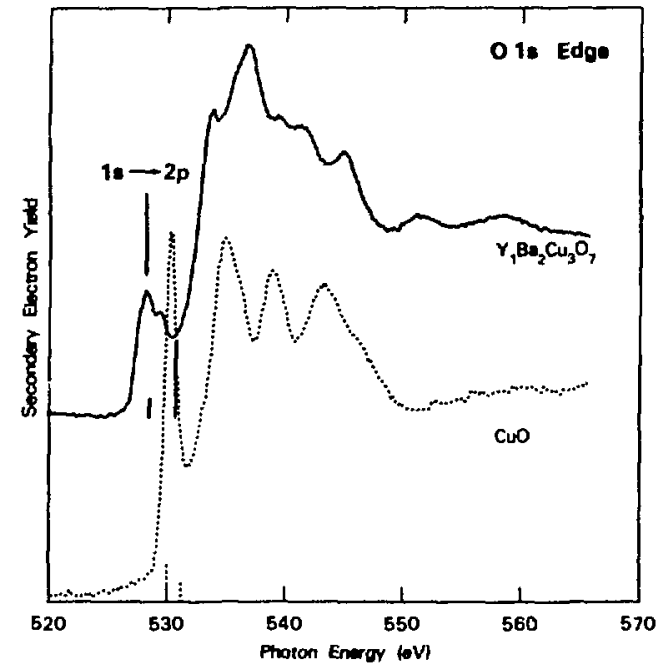

Figure 2. Near edge $X$-ray absorption spectra of the $\mathbf{O}$ Is edge measured via the yicld of secondary electrons. The $O$ is edge has a spike at threshold indicating unoccupied 0 2p states. 


\title{
CHEMICAL VAPOR DEPOSITION OF TUNGSTEN ON SILICON OXIDES
}

\author{
J.A. Yarmoff and F.R. McFeely \\ IBM T.J. Watson Research Center, Box 21:, Yorktown Heights, NY 10598
}

The growth of metallic films on semiconductors via Low Pressure Chemical Vapor Deposition (LPCVD) has many advantages over traditional methods, such as evaporation or sputter deposition. One of the major advantages of LPCVD is that the chemical nature of the process allows for the ability to produce spatially selective deposits. In the present case, tungsten films are grown on silicon by exposure of silicon wafers to tungsten hexalluoride. This process is seleetive in that a tungsten film will grow on a bare Si substrate, but no growth will take place on silicon oxide. ${ }^{1.2}$ The growth of a $W$ film on clean Si proceeds via Si diffusion through the growing $W$ layer to the surface, so that Si can chemically reduce incoming $W_{6}$, molecules. ${ }^{3}$ As no growth will occur on a thin (11 $\AA$ ) thermally annealed oxide layer, it is suggested that this oxide layer forms a barrier to silicon atom diffusion.

To more fully understand the nature of the chemical sclectivity and the role of a thin oxide layer in inhibiting the $\mathrm{W}$ growth, exposures were made on silicon surfaces that were only partially oxidized. A partial oxide layer was grown by exposure of a clean $\mathrm{Si}(1 \mathrm{~J})$ ) wafer to $200 \mathrm{~L}$ of $\mathrm{O}_{2}$ at room temperature. The $\mathrm{Si} 2 \mathrm{p}$ spectrum of this sample showed only a small amount of $\mathrm{Si}^{4+}$ (i.e. fully formed $\mathrm{SiO}_{2}$ ) and mostly partially oxidized $\mathrm{Si}$ atoms on the surface. Exposure of this sample to $1000 \mathrm{~L}$ of $\mathrm{WF}_{6}$ at room temperature resulted in a distribution of tungsten oxidation states which indicated an incomplete dissociation of the chemisorbed $W F_{b}$ molecules.

The $\mathrm{W}$ 4f distribution of this sample can be seen in the photoemission spectrum of Fig. 1 . A small amount of metallic $W$ is visible and a large amount of $W 4 f$ intensity shifted towards higher binding energy from the metallic $W$ 4f. The shifted W $4 \mathrm{f}$ intensity was divided into two separate peaks for the numerical fitting shown in Fig. 1 . One of these regions was shifted $3.3 \mathrm{eV}$ from the metallic $W 4 f$ and the other was shifted $6.8 \mathrm{eV}$. It is likely that some of the species seen in the shifted $\mathrm{W} 4 \mathrm{f}$ levels of Fig. I are $\mathrm{W}$ atoms bound both to fluorine and oxygen, for example an $W_{\mathrm{\gamma}} \mathrm{O}$ unit which is bound to Si through the $\mathrm{O}$ atom.

\section{REFERENCES}

1. E.K. Broadbent and C.L. Ramiller, J. Electrochem. Soc. 131, 1427 (1984).

2. E.K. Broadbent and W.T. Stacy, Solid State Tech. 28, 51 (December 1985).

3. J.A. Yarmoff and F.R. McFecly, J. Appl. Phys., submitted.

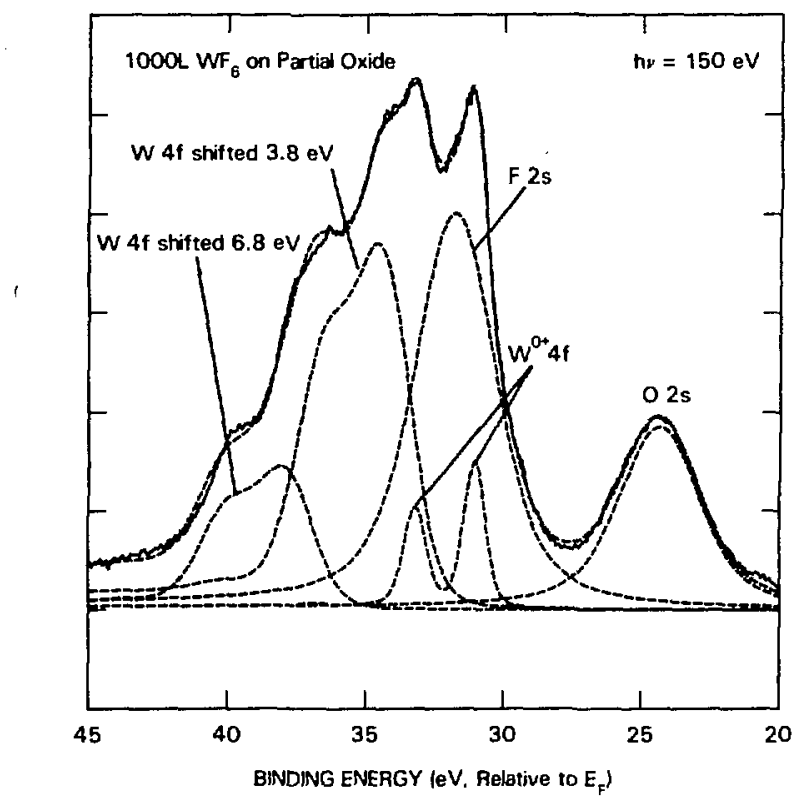

Figure 1. Photoemission spectrun of a $\mathrm{Si}(111)$ wafer exposed to $200 \mathrm{~L}$ of $\mathrm{O}_{2}$ at room temperature followed by exposure to $1000 \mathrm{~L}$ of $W^{6}$ at room temperature. The solid line is the raw data and the dashed lines are a numerical tit to the data. 


\title{
CHEMICAL SELECTIVITY IN PHOTON STIMULATED DESORPTION OF FLUORINE FROM SILICON
}

\author{
J.A. Yarmoff, A. Taleb-Ibrahimi, F.R. McFecly and Ph. Avouris \\ IBM T.J. Watson Research Center, Box 218. Yorktown Heights, NY 10598
}

The process of stimulated desorption of positive ions from surfaces has been used extensively as a means for understanding the localized bonding states and geometries of adsorbed species, We report here results from the study of $F^{+}$ desorption from $\mathrm{Si}(111)$ in which desorption occurred as a direct result of ionizing the $2 \mathrm{p}$ core level of the Si atom to which the fluorine was bonded. It was observed that the desorption yicld vs. photon energy was dependant on the oxidation state of the bonding atom in that the desorption threshold at the $2 p$ core level was shifted by chemical shift of the $2 p$ level that was observed with photoemission. Because of this strong dependence of the PSD on the oxidation state of the bonding Si atom. the possibility exists for synchrotron-driven selective chemistry. By tuning the radiation to the core level binding energy of a species in a specific state, that species can be selectively desorbed from the sample.

The PSD yield vs. photon energy for these surfaces is in essence the local absorption spectrum of the bonding $\mathrm{Si}$ atom. Due to the different bond angles for the various types of silicon fluoride species, the ions were emitted from the sample along different directions for each of the chemically distinct species. In particular, desorption of $\mathrm{F}^{+}$from $\mathrm{Si}$ atoms in the $1^{+}$state was observed in the normal direction from the sample, while $\mathrm{F}^{+}$from the $2^{+}$and the $3^{+}$oxidation states desorbed at a more grazing angle. Because of this angular dependence to the PSD, the absorption spectra of Si atoms at different surface sites can be easily separated.

A surface containing a mixture of silicon fluorides can be prepared by exposure to $50 \mathrm{~L}$ of $\mathrm{XeF}_{2}{ }^{1}$ The $\mathrm{Si} 2 \mathrm{p}$ photoemission spectrum of such a surface is shown in the bottom panel of fig. 1 . The top panel of fig. 1 shows the absorption spectrum of this surface, obtained by monitoring the yield of $25 \mathrm{eV}$ electrons, along with the PSD obtained with the sample normal facing the analyzer and with the sample rotated $65^{\prime \prime}$ from that position. Note that the onset for the absorption spectrum correlates with bulk photoemission, since the main absorption feature is the transition from a bulk Si $2 \mathrm{p}$ level tw ihe conduction band minimum (CBM). The normally directed PSD signal, however, is shifted approximately $1 \mathrm{eV}$ from the absorption onset, and correlates well with the position of the $2 p$ level shifted due to bonding with a single $F$ atom. This indicates that the PSD occurs as the $2 \mathrm{p}$ electron in the bonding Si atom becomes ionized.

Also shown in fig. 1 is the PSD obtained at a grazing exit an-
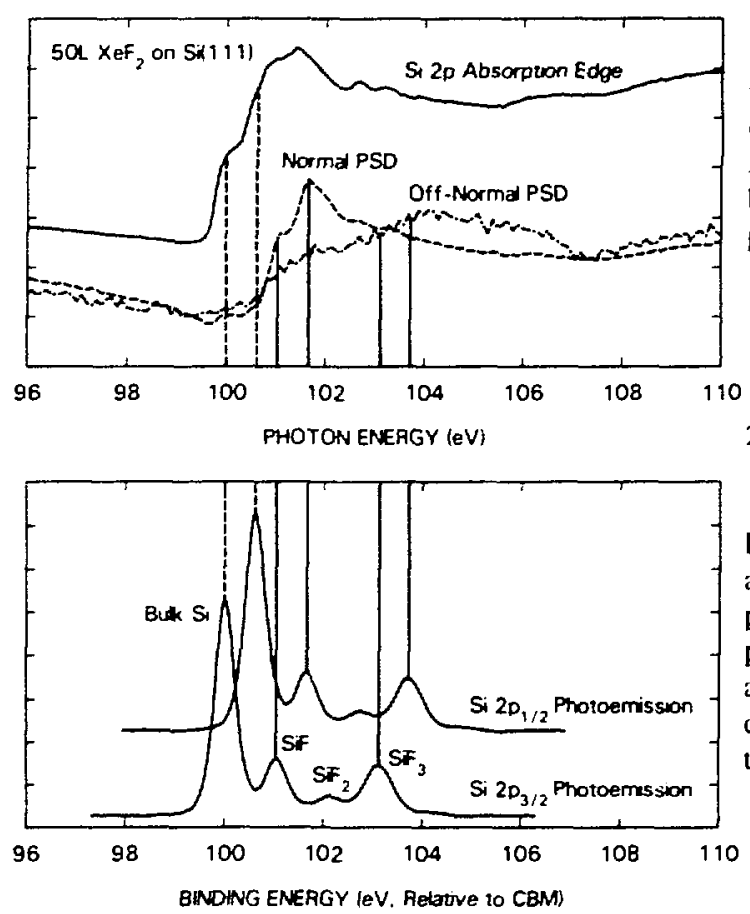
gle. In this case, the peak near $102 \mathrm{eV}$ is greatly attenuated, and a new peak begins to appear near $104 \mathrm{eV}$. This new peak is the PSD resulting from fluorine bonded in an $\mathrm{SiF}_{3}$ group. Note that the off-normal PSD shows additional structure not present in the SiF PSD. This additional structure is assigned to transitions from the bonding $\mathrm{SiF}_{3} \mathrm{Si} 2 \mathrm{p}$ level to Rydberg-like $3 \mathrm{~s}$ and $3 \mathrm{p}$ states that are present in the quasj-molecular $\mathrm{SiF}_{3}$ unit. $^{2}$

\section{REFERENCES}

1. F.R. McFeely, J.F. Morar, N.D. Shinn, G. Landgren and F.J. Himpsel, Phys. Rev. B30, 764 (1984).

2. H. Friedrich, B. Pittel, P. Rabe, W.H.E. Schwarz and B. Sontag, J. Phys. B 13, 25 (1980).

Figure 1. The upper panel shows the photoabsorption spectrum and normal and off-normal PSD spectra for a Si (111) surface exposed to $50 \mathrm{~L}$ of $\mathrm{XeF}_{2}$ The bottom panel shows the $\mathrm{Si} 2 \mathrm{p}$ photoemission spectrum, resolved into its spin-orbit components and shown with respect to the CBM in order to appropriately demonstrate the correlation between the photoemission and features in the PSD and absorption spectra. 


\section{Eberhard Spiller}

IBM T. J. Watson Research Center

Yorktown Heights, NY 10598, USA

Figure 1 gives the geometry of the zoncplate monochromator at beam line U8. The monochromator contains only one optical element, a free-standjng zoneplate of $1000-2000 \AA$ thick gold. There is no entrance slit. The exit slit is at a distance of $15700 \mathrm{~mm}$ from the source and wavelengths are tuned by a linear translation of the zoneplate.

\section{ZONE PLATE}

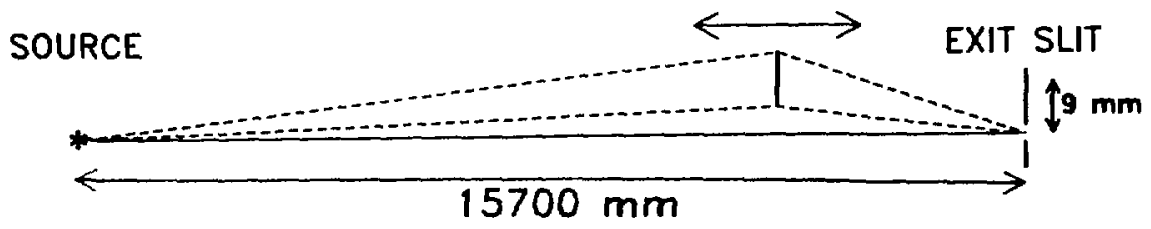

Fig.1. Geometry of the monochromator.

The translation range of $1800 \mathrm{~mm}$ corresponds to tuning of about a factor 2 in wavelength or energy. There are positions to mount 5 different zoneplates; two are presently mounted and cover the range from $\lambda=20-35$ and $\lambda=32-59 \AA$. The zoneplates were fabricated' for a resolution $\mathrm{E} / \Delta \mathrm{E}>2000$; however, this resolution requires a source size below $0.1 \mathrm{~mm}$. $^{2}$ Values around 200 are obtained with the present beam. The circles in Fig. 2 show the measured photocurrent from a graphite sample as a function of photon energy. For comparison, we show the graphite spectrum as published by Morar et al. ${ }^{3}$ convolved with a Gaussian of $1.4 \mathrm{eV}$ halfwidth (full curve). The Gaussian alone is also plotted (dashed) in the Figure and represents the present resolution of the monochromator. We hope that a better resolution will be obtained with a smaller source size.

\section{References}

1. Y. Vladimirsky, E. Källne and E. Spiller, Proc. SPIE 448, 25, (1984).

2. E. Spiller, SSRL report 78/04, VI-44, (1978).

3.J.F. Morar, F.J. Himpsel, G. Hollinger, J.J. Jordan, G. Hughes and F.R. McFeely, Phys. Rev. B 33, 1346, (1986).

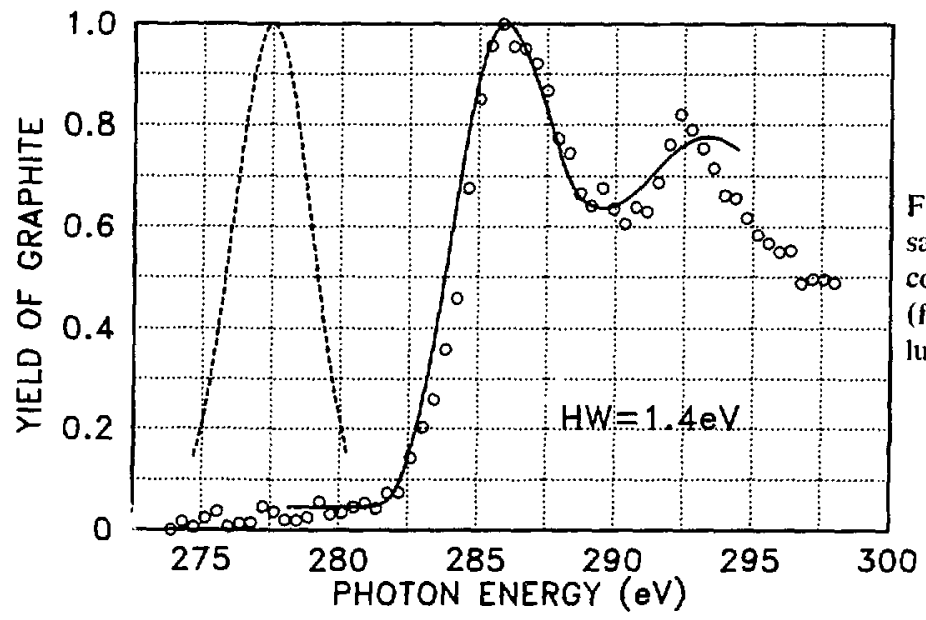

Fig. 2. Measured photocurrent from a graphite sample (circles), Graphite spectrum from Ref. 3 convolved with a gaussian of $1.4 \mathrm{eV}$ halfwidth (full curve) and gaussian used for the convolution (dashed). 


\section{Refractive Index Measurements of Amorphous Carbon Near its K Edge}

\section{Eberharć Spiller}

IBM T. J. Watson Research Center

Yorktown Heights, NY 10598 , USA

Direct measurements of the refractive index for soft $x-$ ays from reflectivity data has been hampered by weak signals and surface contamination problems. Around the carbon K-edge contanination of the monochromator optics by carbon caused additional difficulties. The carbon contamination problem of the optics can be eliminated by using a zone plate monochromator with a free-standing zone plate as the only optical element for monochromatization. Reflectivity meas.rement from a multilayer instead from a single film increases the signal and replaces the external surface with a large number of better defined internal surfaces. Such measurements using multilayers have been previously reported at the Ti $\mathrm{K}$ edge $(4.9 \mathrm{keV})^{1}$ and $\mathrm{Ni} \mathrm{L}$ edge $(850 \mathrm{eV})^{2}$. We report here the first measurements around the $\mathrm{C} \mathrm{k}$ edge at $284 \mathrm{eV}$.

The position of the reflectivity maximum of a multilayer is slightly shifted from the position defined by the Bragg condition due to refraction and this shift can be used to deternine the effective index of a nultilayer which is defined as

$$
\delta_{\text {iff }}=\beta \delta_{1}+(1-\beta) \delta_{2}
$$

where $\beta$ is the fraction of the multilayer occupied by material $I$ and $\delta_{1}=1-n_{i}, \delta_{2}=1-n_{2}$ are the refractive indices of the two components of the multilayer. The effective index is obtaincd from the wavelength $\lambda$ and grazing angle $\Theta$ of the reflectivity maximum of a first ordu: peak:

$$
\delta_{\mathrm{cff}}=\sin \Theta(\sin \Theta-\lambda / 2 \mathrm{p})
$$

We used a 140-layer Co-C multilayer with a period $\mathrm{p}=32.1 \AA$ and a $\beta$ value of 0.66 for the carbon layers and obtained $\delta_{\text {eff }}$ from measured reflectivity curves $R(\theta)$ as shown in Fig. 1 . The refractive index of carbon is obtained from eq. 1 using published values ${ }^{3}$ for the index $\delta_{2}$ of cobalt. The results are given in Fig. 2 and are in reasonable agreement with the data of Henke et al. ${ }^{3}$. We used an adjustment in the zero of the $\Theta$-scale to produce agreement between our measurments and Henke's data for $\lambda=55 \AA$.

1. W.K. Warburton, K.F. Ludwig. Jr., T.W, Barbee, Jr., J. Opt. Soc. Am. B 2.565, (1985).

2. H. van Brug, M.P. Bruijn, R. van der Pol, M.J. van der Wiel, Appl. Phys. Lett. 49, 914 (1986).

3. B.L. Henke, P. Lee, T. J. Tanaka. R. L. Shimabukuro and B. K. Fujikawa, AlP Proc. 75, 340, (1981), Atomic Data and Nuci. Tables 27,1.(1982).
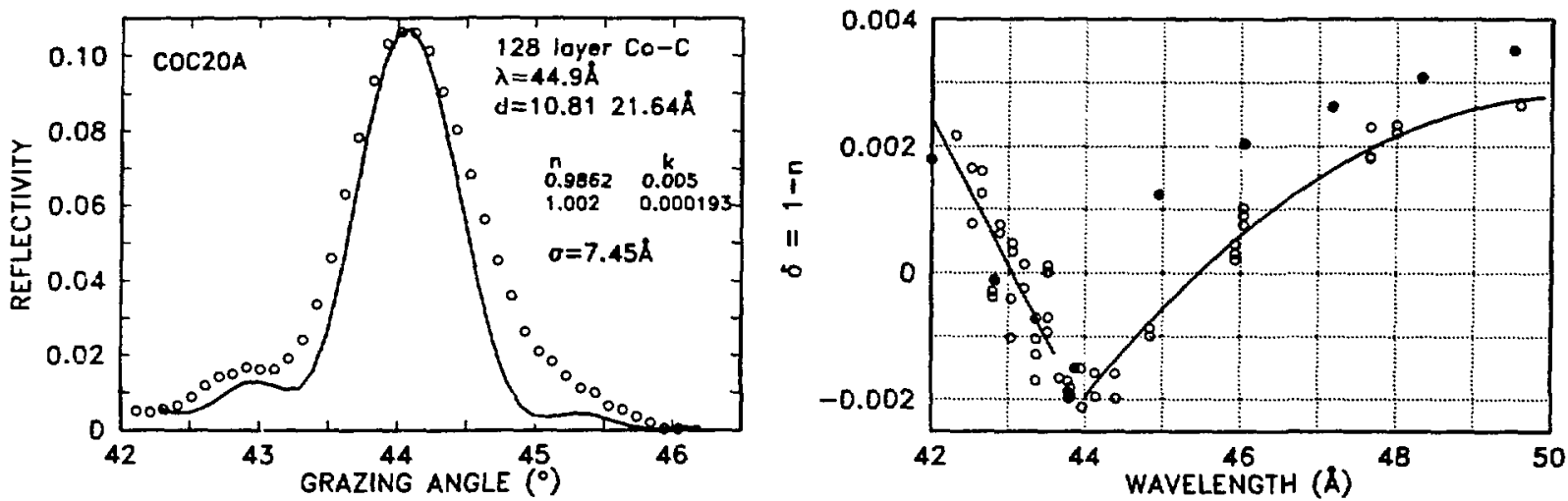

Fig. 1. Measured reflectivity $R$ versus grazing angle $\Theta$ for a 140 layer $C o-C$ multilayer mirror (circles). The full curve is calculated with the parameters given. The larger width of the measured curve is due to slight deviations from strict periodicity and the limited resolution of the zone plate monochronator.

Fig.2. Refractive indcx of amorphous carbon near the carbon edge. Each point (open circle) is obtained from a reflectivity curve as that in Fig. 1. The full circles are from Ref. 3. 
PHOTOIONIZATION OF ANTHRACENE

R1chard A. Holroyd and Kazumichi Nakagawa, BNL

The photolonization of anthracene dissolved In liquld alkane solvents was studied at the NSLS, beam 1 ine U9A. The purpose of the study being to investigate further the mechanism of photolonization in solution.

The observed thresholds in cyclohexane, 2,2-dimethyltutane and neopentane are $6.13,6.12$ and 6.10 eV, respectively. The photoconductivity spectrum (FIg. 1) of anthracene in cyclohexane showed a broad peak at $6.4 \mathrm{ev}$. Thus, cyclohexane is similar to neopentane and 2,2-dimethylbutane which also exhibit peaks in the photoconductivity at this energy attributed to the presence of Rydberg states. Previously it was thought that such states were not formed in liquids in which the electron mobility is low, 1 and cyclohexane is such a liquid.

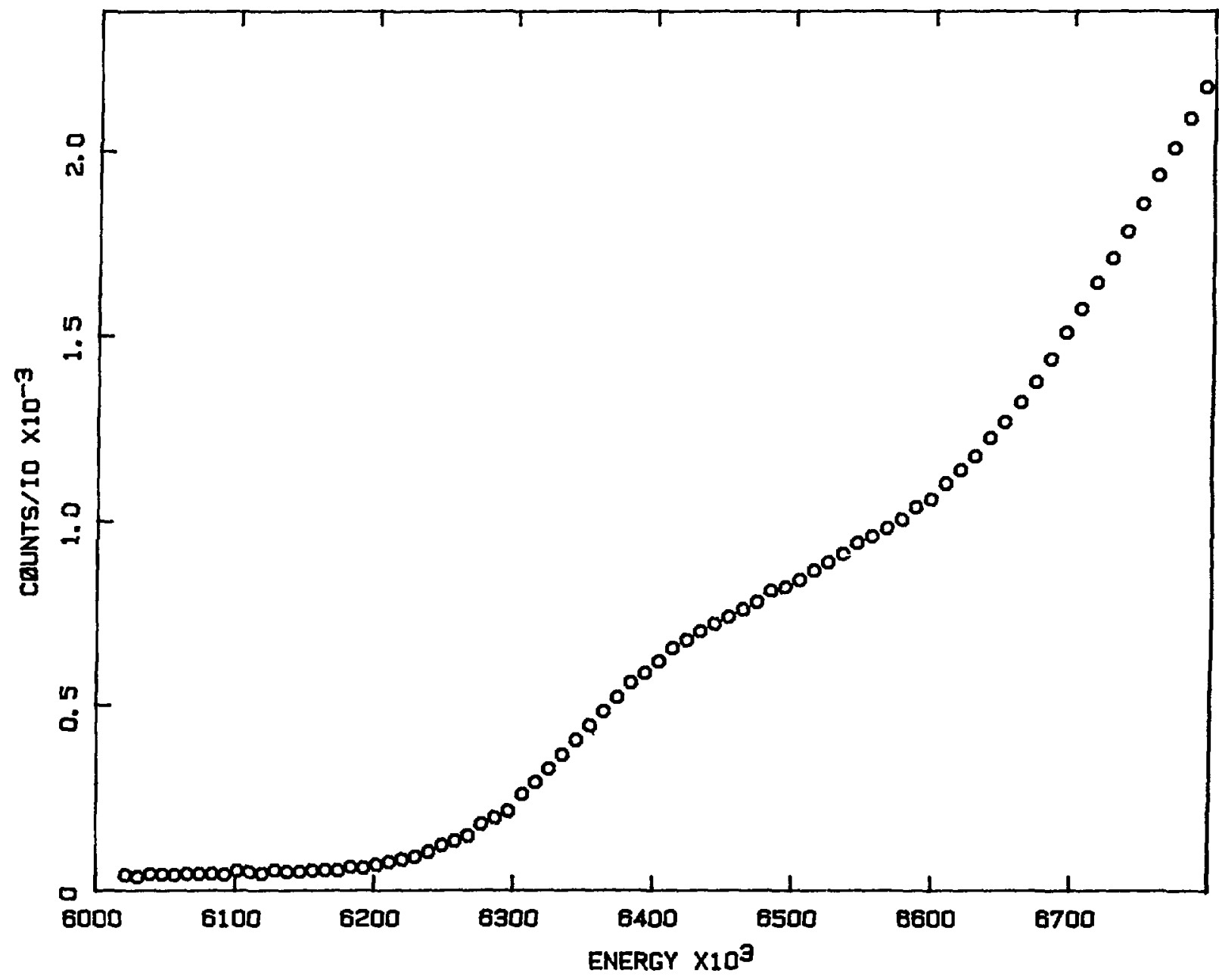

Fig. 1. Yield of photolonization vs photon energy (in mev) for $5 \mathrm{mM}$ anthracene in cyclohexane.

TR. A. Holroyd, J. M. Preses, E. H. Böttcher and W. F. Schm1dt, J. Phys. Chem. 1984, 88, 744. Acknowledgment

This research was carried out at Brookhaven National Laboratory under contract DE-AC02-76CH00016 with the U. S. Department of Energy and supported by its Division of Chemical Sciences, office of Basic Energy Sciences. 
Jack M. Preses

Chemistry Department, Brookhaven National Laboratory, Upton, NY 11973

Previous work in this program has produced detalled information about relaxation of electronic/rovibrational energy transfer $1 \mathrm{n}$ gas, liquid, and solid saturated and unsaturated hydrocarbons. 1-3 By studying the behavior of fiuorescence lifetimes and excitation spectra as functions of pressure, excitation wavelength, and quenching gas concentration, we have developed a siaple model for the decay of excess energy in these systems. The smallest saturated hydrocarbons from which fluorescence has been observed contaln five carbon atoms. In order to develop a detalled model for electronlc energy trangfer, data are needed about fluorescence from smaller, more easily described molecules. Therefore, methods must be used which may permit observation of fluorescence from these molecules. Isolation of hydrocarbon molecules in a cryogenic rare-gas matrix may achieve this goal for the following reasons. First, the molecular environment in a rare-gas matrix $1 \mathrm{~s}$ relatively non-1nteracting. Th1s permits control of hydrocarbon concentration while reducing the deactivation present in the neat liquid or solid. In fact, control of hydrocarbon concentration peralts studies of monower-monomer, and oligomer-oligomer interactions. Second, the relatively dilute concentration of hydrocarbon moiecules in a rare gas matrix allows penetration of UV/VUV radiation Into the bulk of the matrix; the high extinction coefficient of neat liquid or solid hydrocarbons for absorption of UV/VUV radiation causes surface or near-surface fluorescence, only. Also, the fluorescence quantum yleld in saturated hydrocarbons is enhanced at low temperature. Therefore studies at cryogenic temperatures may permit observation of fluorescence hitherto too weak to be studied.

We have observed fluorescence from a few percent of cyclohexane $\mathrm{in}$ an Ar matrix in the range 14-30 $\mathrm{K}$. The fluorescence lifetime is near $2.4 \mathrm{nsec}$, with an excitation wavelength near $155-165 \mathrm{~nm}$. The lifetime is a weak function of temperature in the range studied. The form of the excitation spectrum is simllar to that observed in the neat solid or liquid near room temperature, but 18 wider, so that some fluorescence may be observed with excltation whose wavelength is as short as $145 \mathrm{~nm}$.

\section{Deferences}

1. M. A. Wickramaaratch1, J. M, Preses, R. A. Holroyd, and R. E. Weston, Jr., J. Chem. Phys. 82 (1985) 4745 .

2. M. A. Wickramaratch1, J. M. Preses, and Ralph E. Weston, Jr., J. Chem. Phys. 85 (1986) 2445.

3. M. A. Wickramaaratch1, J. M. Preses, and Ralph E. Weston, Jr., J. Chem. Phys. Lett. $120(1985) 491$.

\section{scknomledgenent}

This research was carried out at Brookhaven Nat1onal Laboratory under Contract DE-AC02-76CH00016 with the U.S. Department of Energy and supported by Its division of Chemical Sclences, office of Basic Energy Sclences. 
J. M. Preses

Chemistry Department, Brookhaven National Laboratory, Upton, NY 11973

C. E. Burkhardt, W. P. Garver, and J. J. Leventhal

Department of Physics, University of Missour1-St. Louls, St. Louis, MO 63121

In the past several years, we have undertaken a program of determining ground and excited state atomic photolonization cross sections using laser and synchrotron radiation. "2 Measurement of photoionization cross sections over reasonably wide wavelength ranges requires the tunability of synchrotron radiation. Generation of large concentrations of excited-state atoms requires an intense source of pumping radiation within a narrow bandwidth, such as that available from an etalon-equipped argon-ion pumped dye laser. The use of laser and synchrotron sources, together, therefore, in a synergistic manner, exploits the benefits of both devices.

We have measured photolonization cross sections of ground state Mg atoms, and excited state Na(3p) atoms. The next logical step in the measurement of the photolonization cross section of an excited atom such as $\mathrm{Ba}(6 \mathrm{p})$. The photoionization spectrum of this species will exhybit resonances from two-electron autoionizing states embedded in the continuum, following excitation of ground state Ba by green light. Last year, detection of ground and excited state Ba photoionization was demonstrated, but only weakly. Evidence was also obtained for Ba ionization from "energy pooling", collisional ladder-climbing processes. This year's experiments were performed using a modified apparatus, which eliminated mass selection, and a better detector. Photoion signals we re obtained from ground state $\mathrm{Ba}$, and evidence was obtained for at least six autolonizing resonances, in the ground state spectrum. Exclted state signals were still too weak for rellable observation. The most important reason for the weak $\mathrm{Ba}(6 \mathrm{p})$ signal appears to be the relatively low photon flux from beam 11ne U9A. Another attempt will be made to measure the Ba(6p) photoionization cross section, using the greater flux available from beam line Ull.

\section{References}

1. J. M. Preses, C. E. Burkhardt, W. P. Garver and J. J. Leventhal, Phys. Rev. A 29, 985 (1984).

2. J. M. Preses, C. E. Burkhardt, R. L. Corey, D. L. Earsom, T. L. Daulton, W. P. Garver, J. J. Leventhal, A. Z. Msezane, and S. T. Manson, Phys. Rev. A 32, 1264 (1985).

This research was carried out at Brookhaven National Laboratory under Contract DE-AC02-76CH00016 with the U.S. Department of Energy and supported by Its division of Chemical Sciences, office of Basic Energy Sclences. 
During FY 1987, a one-week (June 1 . June 5) experiment on gas-phase vuv photochemistry was conducted at the U9B beamline. This work was done in collaboration with Jack Preses and Ralpl yeston of the Chemistry Department at BNL. The main thrust of the experiment was to investigate the reaction dynamics of vuv light activated reactive mixtures. Specifically, fluorescence excitation spectra and some time-resolved fluorescence measurements on mixtures of Xe or kr $\forall i t$. $\mathrm{Cl}_{2}, \mathrm{HCl}, \mathrm{CCl}_{4}, \mathrm{COCl}_{2}, \mathrm{COClF}$, and $\mathrm{C}_{2} \mathrm{~N}_{2}$ were made.

Interest in high power excimer lasers in recent years has prompted several studies of $l i g h t$ induced reactions between rare gas atoms and halogen containing molecules. 1 Much of this worl was aitned at understanding the kinetic processes that are relevant to excimer laser systems, namely, reactive mixtures of $\mathrm{Cl}_{2}$ and $\mathrm{HCl}$ with $\mathrm{Ar}, \mathrm{Kr}$, and $\mathrm{Xe}{ }^{2}$ In this work, we intend tr examine the chemical dynamics of highly excited polyatomics colliding with inert gases such as $\mathrm{Xe}$ and $\mathrm{Kr}$. Particular emphasis is directed at investigating the importance of electronic statespecificicy in the molecular precursor and its relation to pertinent issues such as the branching ratio, quantum efficiency, and internal energy contents of the resultant excites: proclucts. This would provide new insight to the reaction mechanism for producing excited exciners and answer questions such as whether differences exist in transitions involving valence, Rydberg, or ion-pair states, and perhaps provide useful information related to thephotodissociation dynamics of the parent species. Furthermore, it is intended that the vuy excitation technique be used as a selective means for producing new excimers, allowing their identification and characterization.

In the first set of experiments, it was determined that excimer emission was detected only wher: the vuv light excitation involves relatively long lived (on the orders of ns) upper electronic states of the mixture species. This was illustrated in the fluorescence excitation spectrum of $\mathrm{Kr}^{-C_{2}}$ in the 110 to $145 \mathrm{~nm}$ region obtained by monitoring KrCl C-X emission. The spectrum: mimics the fluorescence excitation spectrum of $\mathrm{Cl}_{2}$ emission. Since in the case of $\mathrm{Cl}_{2}$, the reduction in fluorescence quantum efficiency in these states is believed to be due primarily to predissociation. The quantur $y$ ield of the $\mathrm{KrCl}^{*}$ is, therefore, a mere reflection of the efficiency of how the reaction rate at the operating pressure competes with the fluorescence lifetime of the states. This is also indicative that weak XeCl emission was detected when $\mathrm{HCl} / \mathrm{Xe}$ mixtures were excited in the spectral region where $\mathrm{HCl}$ is highly predissociative. A high spectral resolution experiment which can resolve rotational structures will be of particular value to further verify this conclusion. Unfortunately, the needed spectral resolution is unattainable with the current apparatus. In experiments that involved mixtures of $\mathrm{Kr}$ or $\mathrm{Xe}$ with $C 1$ containing polyatomics ( $\mathrm{CCl}_{4}, \mathrm{COCl}_{2}$, and $\mathrm{COClF}$ ), preliminary results indicate higher fluorescence quantum efficiencies were obtained based on their absorption cross sections and estimated lifetimes. It appears that there is also a distinct drop off in fluorescence intensity going from $\mathrm{Xe}$ to $\mathrm{Kr}$ mixtures, which is not observed in the similar mixtures involving $\mathrm{Cl}_{2}$ with comparable amount of photoexcitation. This may simply be due to a significant difference in the energetics for breaking a $\mathrm{Cl}-\mathrm{Cl}$ and $\mathrm{C}-\mathrm{Cl}$ bond, and for forming an excited excimer complex. This suggests that either different reactive pathways or species (or same species, but different energy levels) are at work. One possibility could be that, in the excitation of $\mathrm{COCl}_{2}$ mixtures, for example, $\mathrm{Cl}_{2}$ in a lower electronic state than can be generated by directly excited $\mathrm{Cl}_{2}$ is produced in the photolysis. Excited chlorine molecules in this lower electronic state can have a much longer lifetime than its parent precursor and therefore can react more effectively. Because of the lower excitation in the reactive species, it can generate only the lower energy products ( $\mathrm{XeCl}^{*}$, but not $\mathrm{KrCl}^{*}$ ). More detailed experimental measurements are necessary before this question can be resolved. One interesting observation was also made in the photoexcitation of $\mathrm{Kr}$ or $\mathrm{Xe} / \mathrm{C}_{2} \mathrm{~N}_{2}$ mixtures. Emission in the near ur and $v$ isible was detected when electronic resonances of $\mathrm{Xe}$ and $\mathrm{C}_{2} \mathrm{~N}_{2}$ (but not $\mathrm{Kr}$ ) were excited. Since only bandpass filters were used to sort out the emission bands, we were not able to unambiguously identify the emitting species. It is possible a lot of the emission is due to $E$ and $A$ states of $C N$ radicals. The emission observed when Ye is excited can be attributed to a photosensitizing process where the excited atom transferred its energy to the $\mathrm{C}_{2} \mathrm{~N}_{2}$ molecules and resulted in excited $\mathrm{CN}$ photofragments. However, the negative $\mathrm{Kr}$ result seems to rule out that emission was primarily from excited CN radicals, since in that case comparable emission would be expected for $\mathrm{Kr}$ excitation. It is conceivable that emission is indeed coming from an exciced Xe-CN complex. Additional measurements, emission spectra in particular, will be conducted to determine this observation.

$1_{J}$. K. Ku and D. W. Setser, Appl. Phys. Lett. 48,689 (1986)

${ }^{2}$ V. S. Zuev, A. V. Kanaev, and L. D. Mikheev, Sov. J. Quantum Electron. 14, 242 (1984)

NOTE: This work is sponsored by the Los Alamos National Laboratory 
Kenneth H. Johnson (UT-Dallas), Donald M, Gray (UT-Dallas), Patricia Morris (NSLS), and John C. Suther land (NSLS)

Double-stranded DNAs in the A conformation generally have large positive circular dichrolsm (CD) bands at or about $185 \mathrm{~nm}$, the magnitudes of which increase with G.C content. 1 We were interested in (a) whether large VUV CD spectral bands also generally appear upon base pairing of double-stranded RNAs and (b), if so, whether these bands depend simply on base composition or also depend on the sequence. Therefore, we measured the VUV CD of double- and single-stranded synthetic RNAs containing different nearest neighbors. The CD spectra of two additional single strands were estimated, using the nearestnelghbor approximation, from the measured spectra of oligomers. The RNAs measured were: poly $[r(A-U) \cdot r(A-U)]$, heat-denatured poly[r(A-U)], poly[r(A)・r(U)], poly[r(A)], poly[r(U)],

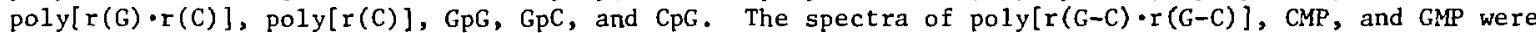
generously communicated by J. Rlazance and W. C. Johnson Jr. (OR State U.).

The VUV CD spectra of the double-stranded RNAs did have large positive bands. The main positive VuV band was centered at $185 \mathrm{~nm}$ for $(G \cdot C)$-containing RNAs and at $177 \mathrm{~nm}$ for $(A \cdot U)$-containing RNAs. Figure I shows difference spectra obtalned by subtracting spectra of the component single strands from the spectra of the double strands. Such difference spectra show the $C D$ changes induced by base pairing. For both the $(G \cdot C)$-containing and $(A \cdot U)$-containing polymers, the main positive VUV $C D$ bands were also present in the difference spectra and thus were due to base pairing. The similarities in the 174-220nm region between the difference spectra of the two (A.U)-containing polymers, and the similarities between the difference spectra of the two $(G \cdot C)$-containing polymers, indicated that nearest neighbors had $11 t t l e$ effect on the VUV bands induced by base pairing. These similarities were in marked contrast to differences in the longer wavelength region, where nearest-neighbor contributions dominate. Since $A \cdot U$ and $G \cdot C$ base pairs each make distinct contributions to the CD in the 174-220nm region, it may be possible to use this region of the spectrum to estimate the amount of $A \cdot U$ and $G \cdot C$ base pairs in a natural RNA.

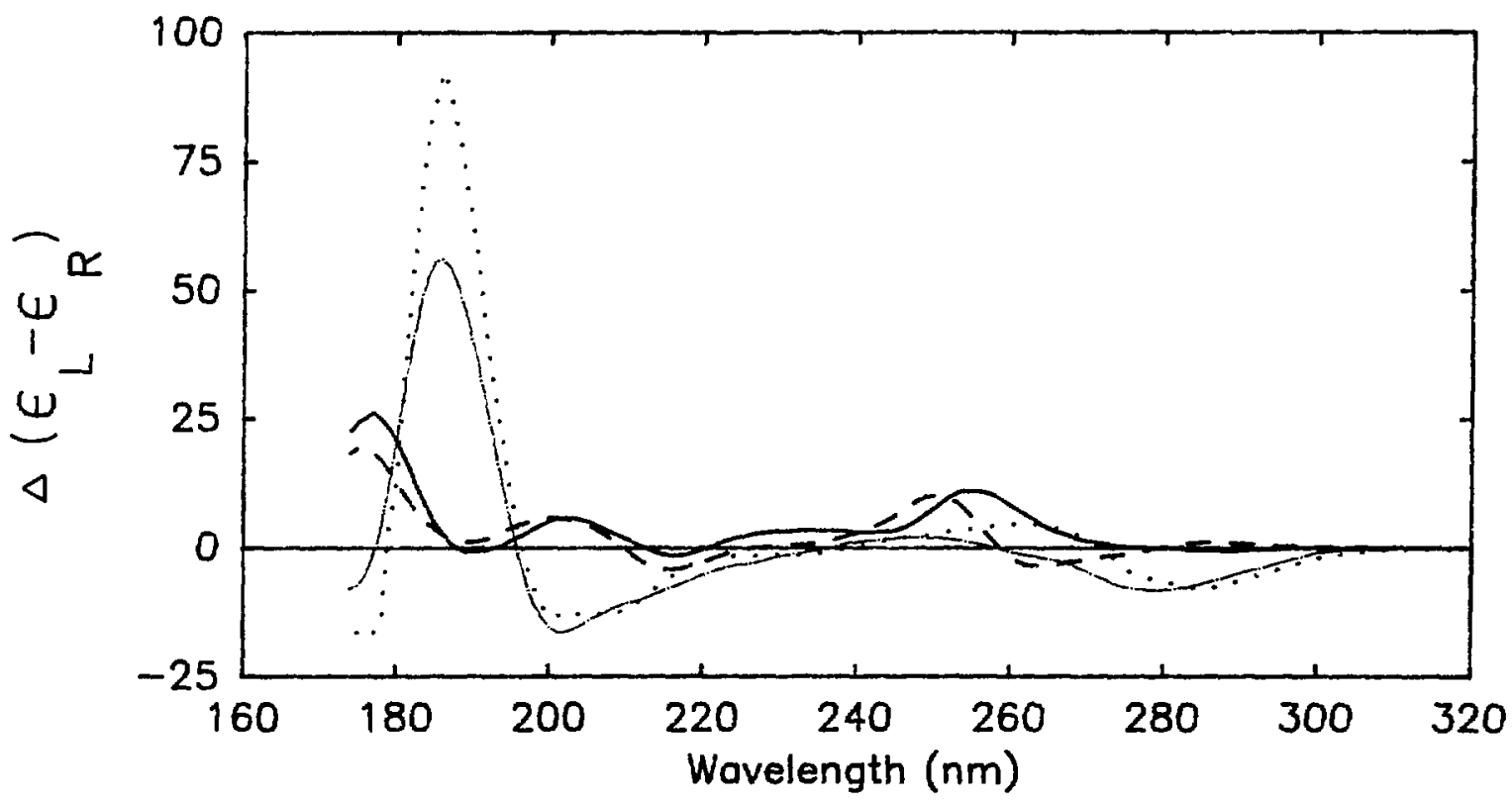

Fig. 1 CD spectra of double-stranded RNAs minus the CD spectra of the corresponding

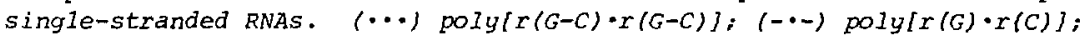

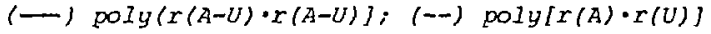

${ }^{1}$ Sprecher, C.A., Baase, W.A., and Johnson, W.C., Jr. (1979). Biopolymers 18, 1009-1019.

Th1s work was supported by NIH Research Grant GM 19060, by Grant AT-503 from the Robert A. Welch Foundation, and by the NSLS Faculty-Student Support Program. 
FLUORESCENCE DECAY PROFILES OF COVALENT ENNZO(A)PYRENE DIOL EPOXIDE ENANTIOMER - DNA ADDUCTS S-K. K1m, N. E. Geacintov (Cheristry Dept., New York University), D. Zinger and J. C. Sutherland (Biology Department, Brookhaven National Laboratory)

This investigation is a part of an ongoing study of the covalent adducts of the carcinogen benzo(a)pyrene diol epoxide (BaPDE) and DNA and their physical conformations [1]. In the past we have studied the adduct configurationg resulting from the addition of a racemic mixture of BaPDE to calf thymus DNA. The fluorescence decay profiles of these adducts are multiexponential, indicating heterogeneity of binding sites. In order to better understand this heterogeneity we have this time focused on the adducts of the pure $(+)$ and $(-)$ enantioners of the hydrocarbon. The study of the enantiomers is further interesting due to their radically different biological activities $((t))>(-))$. The narrow, high repetition, high intensicy pulse of the National Synchrotron Light Source was an ideal excication source in these measurements due to the rapid decay of the shortest lifetime components of the adducts, and due to the low concentrations of fluorophores in these samples (and consequently inherent low signal intensities).

Data with emission at $400 \mathrm{~nm}$ was collected at two different excitation wavelengths: 346 am, the absorption maximum of ( + ) BaPDE-DNA, and $352 \mathrm{~nm}$, the absorption maximum for (-) BaPDE-DNA; it should be noted however, that the adducts of each enantiomer exhibit some absorption at or around both wavelengths, (-) BaPDE-DNA being the more heterogeneous of the two. This data is summarized in Table 1. A broad excimer eraission band with a 472 nm maximum, but overlapping the 400 nn band, was found to contain 1.8 and 18 ns decay components.

Table 1. Fluorescence Lifetimes in Nanoseconds

Excitation Wavelengths (emission of $400 \mathrm{~nm}$ )

\begin{tabular}{|c|c|c|c|c|}
\hline & \multicolumn{2}{|c|}{$346 \mathrm{~nm}$} & \multicolumn{2}{|c|}{$352 \mathrm{~nm}$} \\
\hline$(+)$ BaPDE-DNA & $\begin{array}{l}a_{1}=0.45 \\
a_{2}=0.37 \\
a_{3}=0.13 \\
a_{4}=0.05\end{array}$ & $\begin{aligned} \tau_{1} & =1.4 \\
\tau_{2} & =5.0 \\
\tau_{3} & =19 \\
\tau_{4} & =130^{a}\end{aligned}$ & $\begin{array}{l}a_{1}=0.44 \\
a_{2}=0.41 \\
a_{3}=0.14\end{array}$ & $\begin{array}{l}\tau_{1}=0 . \overline{8} \\
\tau_{2}=2.7 \\
\tau_{3}=15\end{array}$ \\
\hline (-) BaPDE-DNA & $\begin{array}{l}a_{1}=0.69 \\
a_{2}=0.19 \\
a_{3}=0.11 \\
a_{4}=0.05\end{array}$ & $\begin{array}{l}\tau_{1}=0.8 \\
\tau_{2}=3.1 \\
\tau_{3}=22 \\
\tau_{4}=130^{a}\end{array}$ & $\begin{array}{l}a_{1}=0.37 \\
a_{2}=0.44 \\
a_{3}=0.19\end{array}$ & $\begin{aligned} \tau_{1} & =0.8 \\
\tau_{2} & =3.1 \\
\tau_{3} & =15\end{aligned}$ \\
\hline
\end{tabular}

The 130 ns lifetime component was determined independently, using a conventional flash lamp as a light source. This component was then held fixed in the analysis of the synchrotron data. It is attributed to dissociated adducts in the form of Bap tetraols which have an absorption maximum at 343 $\mathrm{nm}$ and almost no absorption at $352 \mathrm{~nm}$; thus no ${ }_{4}$ was fixed at $352 \mathrm{~nm}$.

The major difference between data for $(+)$ and $(-)$ BapDE-DNA lies in the overall slower decay of the $(+)$ BaPDE-DNA fluorescence in comparison to that of the (-) adducts. In addition, $\tau$, (which is longer than $T_{1}$ ) is more prevalent in the $(+)$ adduct than in the $(-)$ adduct solutions. The winor $\tau_{3}$ components are attributed to the broad emission excimer fluorescence.

Since the $\tau_{1}: \tau_{2}$ ratios ( $\tau_{1}$ and $\tau_{2}$ are the decay components attributed to covalent adducts) are not in accordance with the distribution of binding site types as known from absorption, linear dichrolsm [2] and HPLC [3] measurements ( (+) BaPDE-DNh, for example, appears to be about $94 \%$ homogeneous), it seens probable that the $\tau_{1}: \tau_{2}$ ratios are related in part to the base sequences of che DNA. To address this, we have begun fluorescence decay measurements using adducts of (+) and (-) BapDE with selected synthetic polynucleotides of known sequence.

[1] Geacintov, N. E., Zinger, D., Ibanez, V., Santella, R., Grunberger, D. and Harvey, R. G., Carcinogensis $8,925(1987)$.

[2] Geacintov, iv. E., in ACS Symposium Series Ho. 283, "Polycyclic Hydrocarbons and Carcinogenesis", 1985 , edited by R. G. Harvey.

[3] Osborne, M. R., Jacos, S., Harvey, R. G. and Brookes, P., Carcinogenesis 2, 553 (1981).

- This work was supported by U.S. DOE contract DE-ACO2-78EV04959, and by the O.H.E.R., U.S.D.O.E. 
ARGON MATRIX ISOLATION FLUOROMETER

K. Polewski (BNL and Agricultural University, Poznan, Poland), D. Z1nger, J. Trunk, and J. C. Sutherland (Blology Department, BNL)

A matrix isolation fluorometer was designed and built at beamline u9B, with the capability of sublimating solids into an inert gas matrix at cryogenic temperatures. This fluorometer will be utilized for the spectroscopic and time dependent study of nucleic acid bases in an argon matrix.

The excitation wavelength is selected by a vacuum monochromator. The emission is passed through an air monochromator or to a cooled photon counting side window photomultiplier tube. The sample holder is attached to a helium expansion cryotip, and is placed in a vacuum chamber. The solid state nucleic acids are placed in a tantalum boat in the same vacuum chamber, held by two copper electrodes, with an opening toward the sample holder. To form a matrix, the tantalum boat is heated by slowly increasing the current passed through $i t$, the nueleic acids are sublimated and deposited on the l3 $\mathrm{K}$ quartz or magnesium fluoride window on the sample holder. Argon is simultaneously introduced through thin copper tubing bent so that its opening is just above the tantalum boat opening and pointed toward the window. The flow of argon gas is controlled by an adjustable leak valve.

Detection of the absorption properties of a deposited matrix is made possible by a hole in the sample holder along the excitation light path.

The sample holder can be turned in different directions depending on whether a matrix is being deposited, an absorption spectrum recorded, or fluorescence properties investigated.

To date, an adenine-argon matrix has been successfully deposited, in a manner which proved to be reproducible. The absorption spectrut of this matrix is shown in fig. l; it corresponds to spectra of adenine in solutions. 1

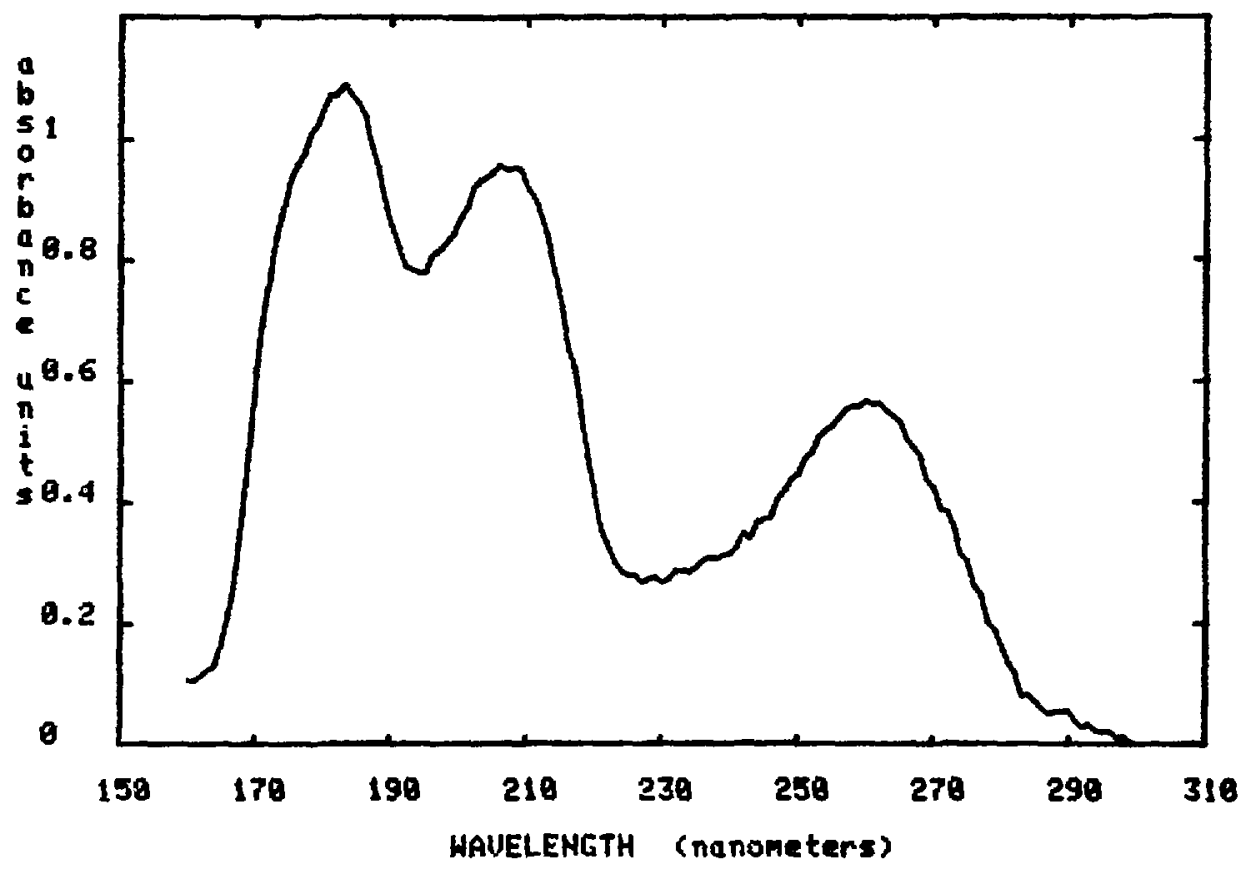

Fig. 1. Absorption spectrum of an adenine-argon matrix.

1 D. Voet, W. B. Gratzer, R. A. Cox, and P. Doty, Biopolymers 1, 193 (1963).

* This work was supported by the O.H.E.R. of the U.S. Department of Energy. 


\title{
Electronic Structure of the Icosahed ral and Other Phases of Aluminum - Manganese Alloys Studied by Soft X-Ray Emission Spectroscopy
}

\author{
D.L. Ederer and R. Schaefer \\ National Burcau of Standards, Gaithersburg, MD 20899
}

K.-L. Tsang, C.I1. Zhang, T.A. Callcott

University of Tennessee, Knoxville, TN 37966
E.T. Arakawa

Oak Ridge National Laboratory, Oak Ridge, $1 \mathrm{~N} 37930$

Intermetallic phases have been discovered" which exhibit icosahedral or decagonal ( $T$ phase) symmetries that are impossible for ordinary crystalline material. There have been many interpretations of the structure of this material. One would like to determine where the atoms are with respect to sites in the unit cell, the tiles, or the structural element. This important quantity has not been difinitively established. Furthermore the nonperiodic structure of these materials makes the calculation of the band structure a challenge. Several authors ${ }^{2-4}$ have modeled the electronic properties of these materials, but there has been almost no measurement of their band structure. Soft $x$-ray emission (SXE) yields valence band emission spectra proportional to the partial density of states (PDOS) localized at the emitting atom. We rcport the first measurement of the SXE spectra of the $\mathrm{L}_{2,3}$ emission bands in the icosahedral and decagonal ( $\mathrm{T}$ phase) and the related $\alpha$ cubic phase of Al-Mn-Si.

The measurements were made from a melt spun ribbon prepared at the NBS. Our ultra sensitive soft $x$-ray spectromete ${ }^{5}$ installed on U-10 was used to obtain the spectra, which were excited by an electron beam. The results are summarized in Figure 1. Fig. 1a) is an enlargement of the spectral range near the photon energy corresponding to transitions of the elecirons near the Fermi encry $\varepsilon_{F}$ to $2 p$ core holes. Fig. $1 \mathrm{~b}$ ) shows a comparison of the PDOS beiween 62 and $67 \mathrm{cV}$, corresponding to small values of the $k$ vector .

Figure 1:

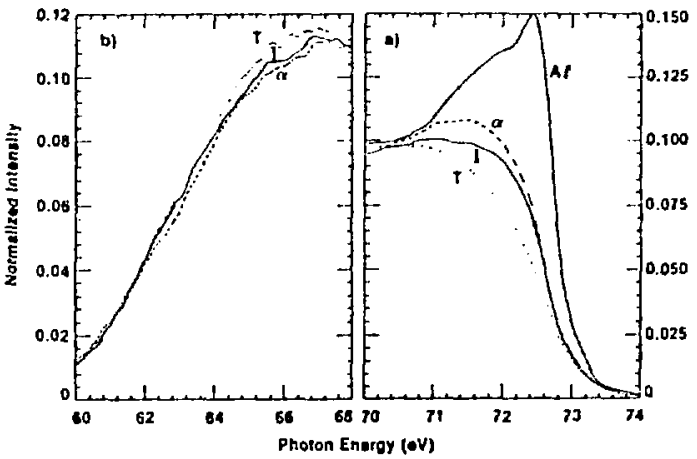

$\mathrm{L}_{2,3}$ spectra of aluminum.

a) Shows the spectra on an cxpanded scalc near $\varepsilon_{F}$.

b) Shows the spectra on an cxpanded scale for lower photon energies. Al. $T, \alpha$, and 1 identify the curves for purc aluminum, the $T$ phase, the $\alpha$ cubic phase and the icosidhedral phase of the mascrials, respectively.

In summary, we find the spectra of different alloy phases very similar. This observation suggests ilat the quasicrystalline phase produces a small perturbation of the electronic density of states. We observe a chemical shift of $0.2 \mathrm{eV}$ between the alloys and pure aluminum, which is consistant with the shift one would observe by accounting for the redistribution of the electrons localized at the aluminum and the change in the volume available to the electrons at the aluminum sites. We observe a chemical shift of less than $0.1 \mathrm{eV}$ between alloys of the crystalline phase and the quasicrystalline phase, which contradicts one model ${ }^{2}$ that predicted a $0.9 \mathrm{eV}$ shift. We also observe a diminution in the partial DOS near $\varepsilon_{F}$ of the quasicrystalline alloy compared to the crystalline alloy. Two theoretical models 2,3 predicte an enhancement of the DOS near $\varepsilon_{F}$ which was not observed. These results provide new information to guide the calculations of the electronic band structure of these materials.

\section{Acknowledgements:}

The authors are grateful to Mr. F. Biancaniello of the Metallurgy Division at the National Bureau of Srandards for providing the alloy samples used in this research. This research is supported by NSF grant DMR-8593541 (UT), by the Science Alliance grant from the state of Tennessee (UT), by USDOE contract DE-ACO5-840R21400 (ORNL), and by the U. S. Air Force Office of Scientific Research under contract ISSA87-0050 (NBS). The research was carried out in part at the National Synchrotron Light Source at Brookhaven National Laboratory, supported by USDOE contract DE-AC02-76CH0O016.

\section{References:}

1) D. Shecheman, I. Blech, D. Gratias, and J.W. Cahn, Phys. Rev. Let1. 53, 1951 (1984)

2) M. E. Mchenry, M. E. Eberhan, R. C. O'Handlcy and K. H. Johnson, Phys. Rev. L.elt. 56, 81 (1986)

3) T. C. Choy, Phys. Rev. Lett. 55, 2915 (1985)

4) J. B. Sokoloff, Phys. Rev. Lelt. 57, 2223 (1986)

5) T. A. Callcott. K. L. Tsang, C. H. Zhang, D. L. Ederer, and E. T. Arakawa, Rev. Sci. Inst. 57, 2680 (1986) 
SOFT $\mathrm{x}$-RAY EMISSION STUDIES OF $\Lambda_{\mathrm{x}^{\mathrm{Ga}}} \mathrm{G}-\mathrm{x}^{\mathrm{As}}$ COMPOUNDS

K. -L. Tsang, T. A. Callcott (U, of Tenn.)

J. E. Rowe, R. A. Logan (AT\&T), D. L. Ederer (NBS), and

E. T. Arakawa (ORNL)

The alloy semiconductor compounds, $A 1_{x} \mathrm{Ga}_{1-\mathrm{x}} \mathrm{As}$, have been extensively studied because of their importance in semiconductor technology. Most of the experimental data of these compounds are obtained by either optical measurement or photoemission spectroscopy, and the partial density of states have not been studied. The $\mathrm{A} 1 \mathrm{~L}_{2,3}$ emission spectra in $\mathrm{A} \mathrm{x}_{\mathrm{x}} \mathrm{Ga}_{1-\mathrm{x}} \mathrm{As}$ compouris have been systematically measured for the first time.,

Figure 1 shows $A 1 \mathrm{~L}_{2,3}$ emission spectra for $\mathrm{x}=0.05,0.1,0.2,0.3,0.4,0.6$, and 0.8 alloys with all spectra normalized to the P2 peak height. The qualitative changes we observe with increasing Al soncentration are the following: (1) No changes occur in peak P3 in either position or magnttude; (2) Peak P2 narrows and Increase in amplitude so that its area is nearly unchanged; and (3) The high energy shoulder is unchanged except that the position of the valence band maximum (VBM) decreases with increasing $A 1$ content.

There is almost no shift between peaks $\mathrm{P} 2$ and $\mathrm{P3}$ in SXE spectra, while there are more than 0.3 eV changed in PE data obtained by Ludeke et al. The observed change in the position of the VBM is plotted in Figure 2. A tocal shift of $0.75 \mathrm{eV}$ is observed that may be fitted by two straight line curves that intersect at about $x=0.38$ near the concentration of the fundamental bandgap transition. The inclusion of the cation d-orbitals as suggested by Wei $t t$ al. may partially explain the suppression of the top of the valence band. The observed nonlinear change in the VBM is probably a hybridization effect similar to fundamental bandgap observed in optical data.
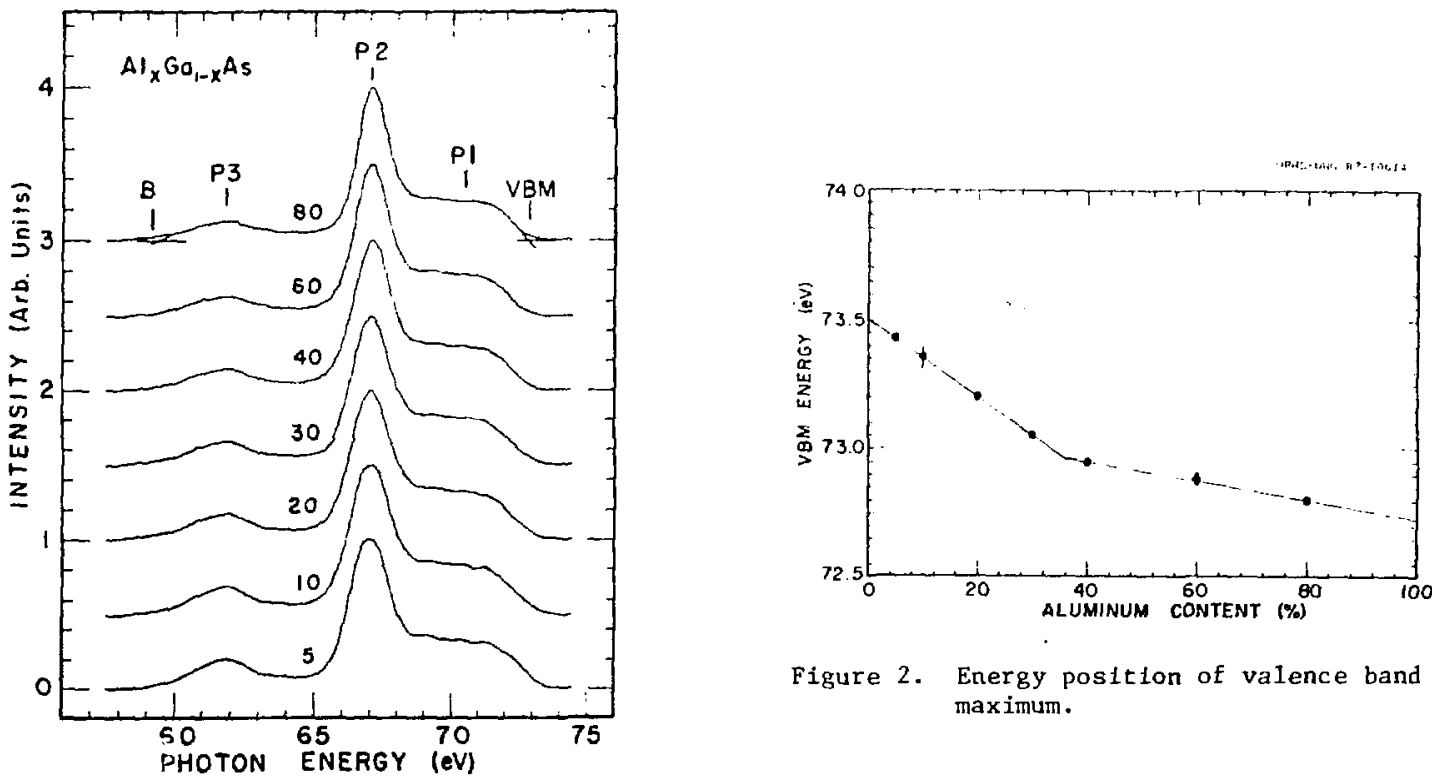

Figure 2. Energy posttion of valence band maximum.

Figure :. SXE $\mathrm{L}_{2,3}$ spectra of $\mathrm{A} 1$ in

$$
\mathrm{Al}_{x}^{\mathrm{Ga}}{ }_{1-\mathrm{x}}^{\mathrm{As}}
$$

References:

1. R. Luduke, L. Ley, and K. Ploog, Sol, State Commun. 28, 57 (1978).

2. S. $-\mathrm{H}$ Wei and A. Zunger, Phys. Rev. Lett. 59, 144 (1987).

\section{Acknowledgements:}

The research was supported by NSF grant DMR-8503541, by the Sc lence All lance grant from the state of Tennessee, and by the US DOE under contract DE-AC05-840R21400 with Martin Marletta Energy System. The research was carried in part at the Natlonal Synchrotron Light Source, which is supported by the US Department of Energy under contract DE-AC02-76CH00016. 


\title{
Soft $\mathrm{X}$-ray $\mathrm{Absorption}$ and Emission Spectra and the Electronic Structure of the $\mathrm{Ba}_{2} \mathrm{YCu}_{3} \mathrm{O}_{7-x}$
}

\author{
K.-L. Tsang, C.H. Zhang, T.A. Callcott \\ University of Tennessee, Knoxville TN, 37966 USA \\ L.R. Canfield, D.L. Ederer, J. E. Blendell, C. W. Clark \\ National Bureau of Standards, Gaithersburg, MD 20899 USA \\ N. Wassdahl, J. E. Rubensson, G. Bray, N. Mortensson, J. Nordgren
University of Uppsala, Uppsala, Sweden \\ $\begin{array}{ccc}\text { R. Nyholm } & \text { and } & \text { S. Cramm } \\ \text { University of Lund, Lund, Sweden } & \text { Universität Hamburg, Hamburg, West Germany }\end{array}$
}

We present measurements of soft $\mathrm{x}$-ray emission and total photoelectron yield of $\mathrm{Ba}_{2} \mathrm{YCu}_{3} \mathrm{O}_{7-\mathrm{x}}$. Our total photoelectron yield measurements near the $3 p$ ionization threshold in $\mathrm{Cu}$ support the contention that $\mathrm{Cu}$ is in the +2 valence state. 1.2 We have used electron-beam excited soft $x$-ray emission spectra to measure the p-type partial density of states $(p-P D O S)$ localized on $\mathrm{O}, \mathrm{Ba}$, and $\mathrm{Y}$ sites. For the elements $(\mathrm{Y}, \mathrm{Ba}$, and $\mathrm{O})$ the major peak in the soft $\mathrm{X}$-ray emission spectra lies about 3.4 to $4.0 \mathrm{eV}$ below $\varepsilon_{\mathrm{F}}$ rather than at the $\sim 2 \mathrm{eV}$ that would be expected from p-PDOS derived from ground state band structure calculations. 3.4. We have also observed the $L_{2,3}$ emission spectrum of $\mathrm{Cu}$ in $\mathrm{Ba}_{2} \mathrm{YCu}_{3} \mathrm{O}_{7, x}$, which maps out valence states of $d$ symmetry. The maximum in the PDOS lies about $2.5 \mathrm{eV}$. below $\varepsilon_{\mathrm{F}}$. These observations place the $\mathrm{d}$ and $\mathrm{p}$ bands about $2 \mathrm{eV}$. and $4 \mathrm{eV}$. below $\varepsilon_{\mathrm{F}}$ respectively. This evidence is supported more strongly by a tight binding calculation ${ }^{4}$ of the band structure and the DOS than by a highly precise local density band study ${ }^{3}$ where the O p states have a large DOS at $2 \mathrm{eV}$. BE and are embedded in the copper d bands which have the largest DOS at about $4 \mathrm{eV}$. The present measurements have been made both at room temperature and at $85 \mathrm{~K}$. No difference in the p-PDOS was observed at the two temperatures. This is consistent with observations that $\mathrm{Ba}_{2} \mathrm{YCu}_{3} \mathrm{O}_{7-x}$ does not undergo a structural phase change between $\mathrm{T}_{c}$ and room
temperature.

\section{Figure 1:}

a) Total quantum yield for superconducting $\mathrm{Ba}_{2} \mathrm{YCu}_{3} \mathrm{O}_{7-x}$ as a function of the photon encrgy. A defines the energy region corresponding to that required for the promotion of a $3 p$ core electron in $\mathrm{Cu}$ to the conduction band. The energy band denoted by $\mathrm{B}$ is the absorption by $4 \mathrm{~d}$ core electrons in $\mathrm{Ba}$.

b) Intensity of soft x-ray fluorescence excited by $2 \mathrm{keV}$ eitectons vs. photon energy. C denotes the encrgy position of the $\mathrm{N}_{2,3} \mathrm{M}_{4,5}$ transition in $\mathrm{Y}$ in second order reflection from the grating: $F$ is the first order signal of this transition. $D$ is the energy region comesponding to $\mathrm{Ba}$ inner sheil transitions $\mathrm{O}_{2,3} \mathrm{~N}_{4,5}$ and transitions between the valence electrons and the Ba 4 d hole states.

\section{Acknowledgements:}

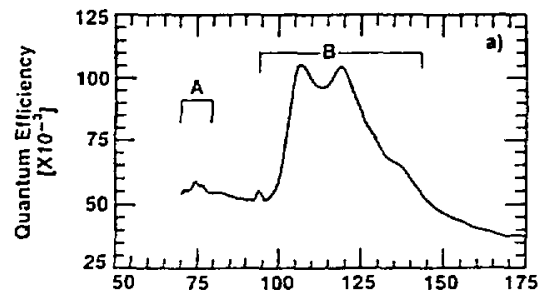

The authors are grateful to Dr. L. Bennett of the Alloy Physics Division at the National Bureau of Standards for verifying the superconducting nature of the samples. We also appreciate the hospitality shown us at the Hamburg Synchrotron radiation source, and we are grateful to $C$. Kunz for the use of his monochromator. Assistance from the operating staff of the NBS-SURF II synchrotron light source is gratefully acknowledged. This research is supported by NSF grant DMR-8593541 (UT), by the Science Alliance grant from the state of Tennessee (UT), by USDOE contract DE-AC05-840R21400 (ORNL), and by the U. S. Air Force Office of Scientific Research under contract ISSA87-0050 (NBS). The research was carried out in part at the National Synchrotron Light Source at Brookhaven National Laboratory, supported by USDOE contract DE-AC02-76CH00016.

\section{References:}

1) R. L. Kurtz, R. L. Stockbauer, D. Mueller, A. Shih, L. E. Toth, M. Osofsky, and S. A. Wolf, Phys. Rev. B 35, 8818 (1987)

2) M. Onellion, Y. Chang, D. W. Niles, R. Joynt, G. Margaritondo, N. J. Stoffel, and J. M. Tarascon, Phys, Rev. B 36, 819 (1987)

3) J. Redinger, A. J. Freeman, J. $Y_{\mathrm{u}}$, and S. Massida, preprint (1987)

4) B. A. Richert and R. E. Allen, preprint (1987) 
THE AL2.3 AND MG DOUBLE IONIZATION EMISSION SPECTRA OF

DILUTE AL IN MG ALLOYS

C. H. Zhang, K. L. Tsang, and T. A. Callcott

University of Tennessee, Knoxville, TN 37996

\author{
D. L. Ederer
}

National Bureau of Standards, Gaithersburg, MD 20899

E. T. Arakawa

Oak Ridge National laboratory, Oak Ridge, TN 37830

The Al2.3 spectra for dilute alloys of Al (0.5. 1.0.2.0 at. \%) in $\mathrm{Mg}$. and the $\mathrm{Mg}$ L satellite spectra produced in aloms with doubly ionized 2 p core levels has been measured. Two spectra can be viewed as isolated impurity atoms with a single excess charge in final state imbedded in a Mg host lattice. and expected 20 have similar features according to the equivalent core approximation (ECA)1. Under same assumption, the Auger KL $1 V$ spectrum of $\mathrm{Mg}$ with an excess core hole in the final state of the transition should give some information similar to SXF spectra, although $s$ and $p$ states with approximately equal probabisty in radiative transition

The spectra of the $\mathrm{Mg}$ satellite and $\mathrm{Al} \mathrm{L2,3}$ for $\mathrm{Al}$ in $\mathrm{Mg}$ alloys and pure $\mathrm{Mg}$ are $:$ hown in Figure 1 . We report for the first time observation of the $\mathrm{L}_{3}-\mathrm{L}_{1}$ intercore transition for the satellite spe:trum at $54.4 \geq 0.1 \mathrm{eV}$. The weaker high energy structure from about 67 to $74 \mathrm{eV}$ in pure $\mathrm{Mg}$ satellite we observe may result from the radiative decay of the previously unobserved 1 SO state.

In Figure 2, the spectra of the $A 1$ impurity, $\mathrm{Mg}$ satellite, and $\mathrm{Mg} K \mathrm{~L}_{1} \mathrm{~V}$ from Lasser et al. 2 are compared. Each is observed to have a prominent low energy peak associated with the screening charge, but the central peak in the $\mathrm{Mg}$ satellite spectrum. which corresponds to a band structure feature in pure Mg has no counterpart in the A impurity spectrum. A possible reason for the dissimilarity between Al impurity and $\mathrm{Mg}$ satellite spectra is the s-like valence orbitals penetrate inside the core level sphere. and thus see different potentials for the $\Lambda 1$ impurity and for $\mathrm{Mg}$ atoms with an extra $2 \mathrm{p}$ core hole. Clearly, a more sophisticated approach than the ECA is required for the interpretation of $\$ X E$ and other core level spectra.

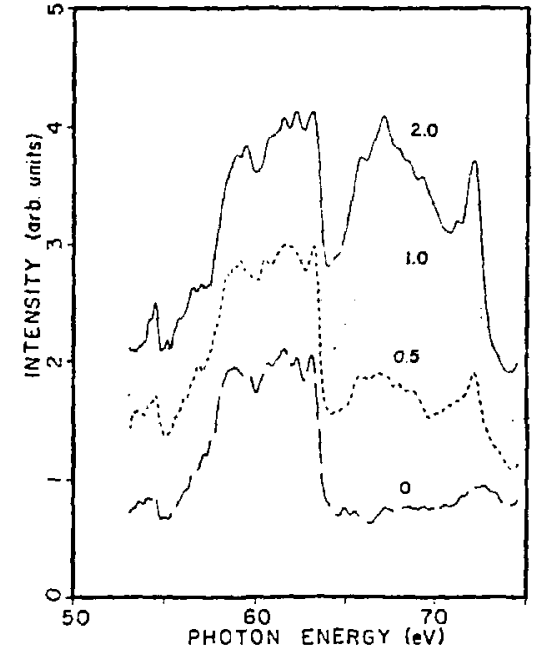

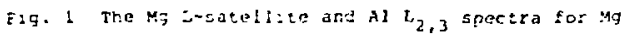

netal and al ir Ma aloys. Tho spectra are laboled

w:th it a cotwit it atomic parcent.

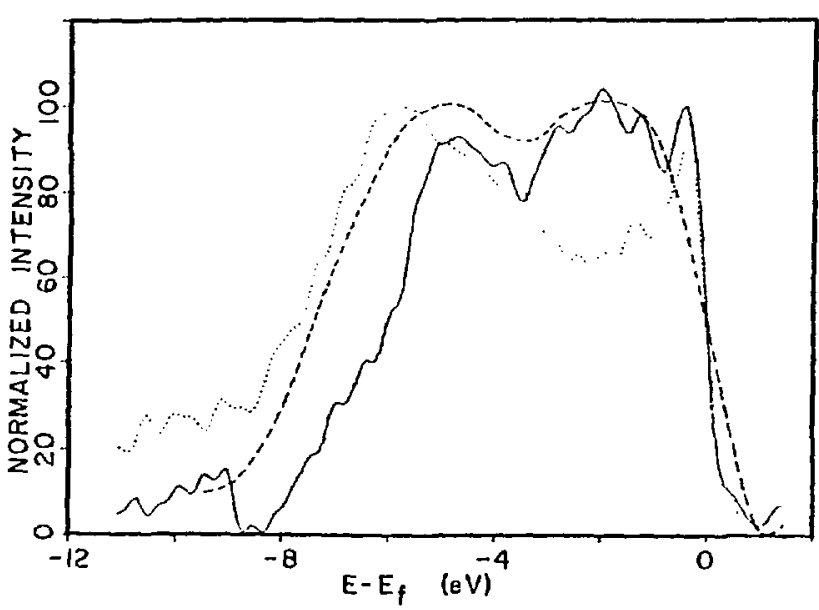

Fiq. 2 The $H q$ L satellite, the 1 at $M \mathrm{Al}_{2,3}$, and the $\mathrm{KL}_{1} \mathrm{~V}$ Auger spectro compared. $(\ldots)$ al impurity, $(-\ldots)$ $K_{2} \vee$ Auger, $\longrightarrow$ Mgsatellite. The Auger spectrum was taken from Ref. 5.

Supported in part by NSF grant DMR-8503541, DOE under contract DE-AC05-840R21400 with Martin Marietta Energy Systems, and the Science Alliance Center of Excellence grant from the state of Tennessee. The beamline U-10A at Brookhaven National Laboratory is supported by DOEDE-ACO2-76CH00016.

References:

1 U von Barth and G. Grossman. Physica Scripta, 28, 107 (1983).

2. R. Lasser and J C. Fuggle. Phys. Rey. B22. 2637 (1980). 
D. Bintinger, P. Limon, J. Tompkins (SSC-CDG)* H. Jostlein, D. Trojevic (Fermilab)*

Photodesorption from pure (4N) aluminum and stainless steel, both at LHe temperature, has been investigated. Photodesorption from pure aluminum was found to be approximately equal to photodesorption from stainless steel and copper whlch had been measured previously. The present measurements on stainless steel were made up to integrated photon doses four times that of the previous measurements. These measurements confirmed hints from the earlier data that the $\mathrm{H}_{3}$ pressure within the experimental beam tube rises with increasing photon dose. This is shown in Fig. 1. This rise is thought to be associated with the condensation of desorbed $\mathrm{H}_{2}$ on the inner surface of the cold beam tube. Fighre 1 also shows successive cool-downs of the beam tube. The beam tube was warmed above the condensation temperature of $\mathrm{H}_{2}$ between the cool-downs and the $\mathrm{H}_{2}$ pumped away. After 2 warm-up and recooldown the $\mathrm{H}_{2}$ pressure rise due to photodesorption decreased to approximately the initial level. It then began to increase again, achieving pressures at high dose slightly below the first cool-down pressures. This behevior is suggestive of the clean up process that is observed in electron storage rings, although this clean up requires warming the beam tube. During each warm-up, a measurement was made of the amount of $\mathrm{H}_{2}$ gas desorbed during the previous cool-down and exposure. This amount of $\mathrm{H}_{2}$ gas was significantly less than that expected form room temperature photodesorption measurements. This hint of a temperature effect for photodesorption will be followed up in future experiments.

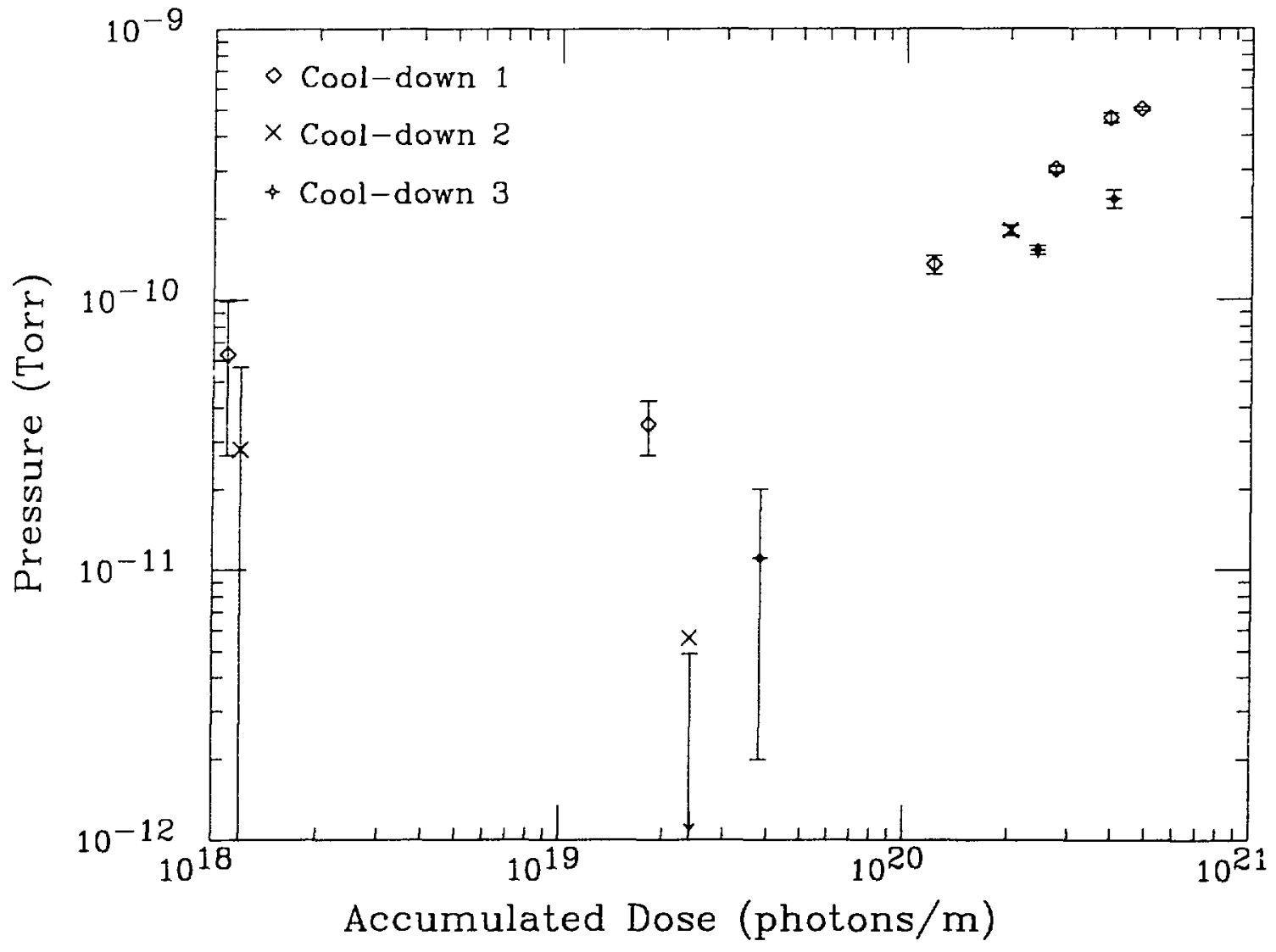

Pig. 1. Hydrogen pressure rise at the detector vs. photon dose.

* Operated by the Universities Research Association for the Department of Energy. 
J. R. Grover, $t$ E. A. Walters, $t \dagger$ J. K. Newman, $t \dagger$ and M. G. Whice $t$

tChemlstry Department, Brookhaven National Laboratory, Upton, NY 11973

ttchemistry Department, Universicy of New Mexico, Albuquerque, NM 87131

The existence of weak complexes of reactants prior to their transformation to products has long been studied in condensed phases, where such complexes often profoundly influence reaction pathways, yields and rates. It is to be anticipated that the additional detall obtainable in moleular beam studies will advance the understanding of these reactions. One such complex is $1,3-b u t a d i e n e \cdot \mathrm{SO}_{2}$, which undergoes an addition reaction to produce sulfolene, $\frac{W}{\mathrm{SO}_{2}}$, but does so slowly enough that 1 ts photolonization, as well as that of its reaction product, can be studied. Efficlency functions were measured using a photolonization mass spectrometer in which a molecular beam of target complexes, formed by a skimmed and recollimated free jet expansion of $1: 41,3$-butadiene $+\mathrm{SO}_{2}$, was made to intersect the tunable vUV beam from the monochromator on U-ll. The detector is a channeltron operated in the lon-counting mode. Careful analysis established the relative densities of dimers and trimers in the molecular beam, at nozzle pressures small enough that larger clusters are unimportant. The dissoclation energy at $0 \mathrm{~K}$ of $1,3-\mathrm{C}_{4} \mathrm{H}_{6} \cdot \mathrm{SO}_{2}$ was measured by the spectrum-stripping method (1984 NSLS Annual Report) to be $3.24 \pm 0.48 \mathrm{kcal} \operatorname{mol}^{-1}$, while the energy needed for the process $\left(1,3-\mathrm{C}_{4} \mathrm{H}_{6} \cdot \mathrm{SO}_{2}\right)^{+} \rightarrow$ $\mathrm{C}_{4} \mathrm{H}_{6}{ }^{+}+\mathrm{SO}_{2}$ was found to be $3.27 \pm 0.86 \mathrm{kcal}$ mol ${ }^{-1}$, much sualler than expected. Comaprisons of photolon efficlency functions and Ion yleld spectra established that $1,3-b u t a d i e n e \cdot \mathrm{SO}_{2}$ and sulfolene are different species. Sulfolene's Ionization potential was measured to be $9.80+0.05 \mathrm{eV}$, and the $\mathrm{C}_{4} \mathrm{H}_{6}{ }^{+}$appearance potential $10.10 \pm 0.03 \mathrm{eV}$. Thus, the Gulfolene ion is already unstable above $0.3 \mathrm{eV}$ of excitation, and this is reflected in its very small yield. Also, from Fig. 1 we see that the sulfolene ton is more stable than $\left(1,3-\mathrm{C}_{4} \mathrm{H}_{6} \cdot \mathrm{SO}_{2}\right)^{+}$, but only by $4 \mathrm{kcal}$ mol ${ }^{-1}$. We found that the reaction 1,3 -butadiene $+\mathrm{SO}_{2}+$ sulfolene $1 \mathrm{~s}$ exotheraic by $1.03 \mathrm{ev}\left(24 \mathrm{kcal}^{*} \mathrm{~mol}^{-1}\right)$, consistent with the 11terature value of $23 \pm 2 \mathrm{kcal} \mathrm{mol}^{-1}$ from bulk rate experiments. The rearrangement process $1,3-\mathrm{C}_{4} \mathrm{H}_{6} \cdot \mathrm{SO}_{2}+\mathrm{h \nu} \rightarrow \mathrm{C}_{4} \mathrm{H}_{6} \mathrm{SO}^{+}+0$ was discovered; it occurs in very low yleld. The observation of $\mathrm{C}_{4} \mathrm{H}_{6} \mathrm{SO}^{+}$reported earlier was shown to stem from the dissociative photolonization of trimers, the yield from which 10 much larger. Also, the efficlency functions for the two processes differ markedly. The close similarity in dissociation energy and in the efficiency function for producing $c_{4} H_{6}{ }^{+}$, to the corresponding properties for trans-2-butene- $\mathrm{SO}_{2}$ leads us to speculate that the $\mathrm{SO}_{2}$ molecule associates with only one of the two double bonds in butadiene, the ground state of which is transoid. The cisoid structure, more energetic by $2.5 \mathrm{kcal} \mathrm{mol}^{-1}$, must be achieved for addition to form sulfolene to occur.

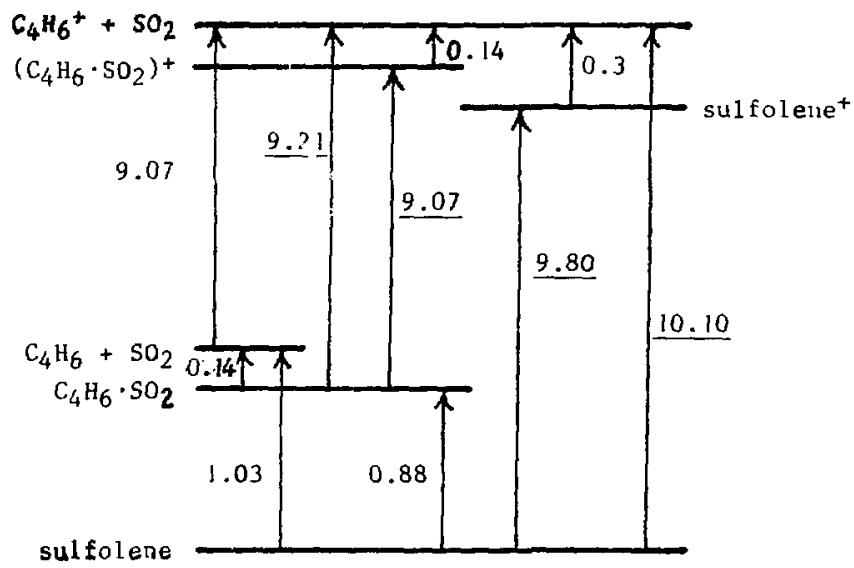

F1g. 1. Energy diagram for the system 1,3-butadiene $+\mathrm{SO}_{2}$. Transition energies are given $1 \mathrm{n}$ electron volts. Values measured in this work are underlined. Refinement of these numbers is still in progress.

This research was carried out at Brookhaven National Laboratory under Contract DE-ACO2-76Ch00016 with the U.S. Department of Energy and supported by its division of Chemical Sciences, office of Basic Energy Sciences. 
J.R. Grover ${ }^{\dagger}$, E.A. Walters ${ }^{\dagger \dagger}$, and M.G. White ${ }^{\dagger}$

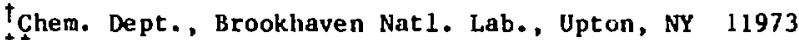

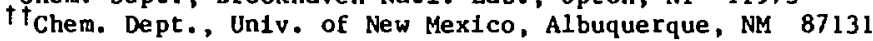

The special dissociative photolonization process in van der Waals dimers and trimers in which atoms transfer frcm one molety to another is being studied, and has revealed itself to be a rich and general new area for the investigation of chemical dynamics. In addition, this process provides an extremely promising way to prepare and study species that were previously unknown, or that are especially Interesting but difficult to make by other techniques. The target complexes are prepared in molecular beams by recollimation of skimmed free-jet expansions of gas mixtures, and made to undergo single-photon interactions with the tunable VUV beans from the monochromator of line U-!1. To measure photoefficiency functions a quadrupole mass spectrometer 1s used to select the photolons of interest, and detection is by means of a channeltron operated in the lon-counting mode. Studies to date have focused on the spectes $\mathrm{C}_{6} \mathrm{H}_{6} \mathrm{Cl}^{+}$from complexes of $\mathrm{C}_{6} \mathrm{H}_{6}$ and $\mathrm{HCl}, \mathrm{C}_{2} \mathrm{H}_{4} \mathrm{Cl}^{+}$from $\mathrm{C}_{2} \mathrm{H}_{4}$ and $\mathrm{HCl}_{4}$, $\mathrm{C}_{4} \mathrm{H}_{6} \mathrm{SO}^{+}$from 1,3-butadiene and $\mathrm{SO}_{2}, \mathrm{C}_{6} \mathrm{Hg}^{+}$and $\mathrm{HBr}_{2}$ from allyl bromide and argon, and $\mathrm{HClBr}^{+}$fron allyl bronide and HCl. The products from the heteroclusters, e.g. $\mathrm{C}_{6} \mathrm{H}_{6} \mathrm{Cl}^{+}, \mathrm{C}_{2} \mathrm{H}_{4} \mathrm{Cl}^{+}, \mathrm{C}_{4} \mathrm{H}_{6} \mathrm{SO}^{+}$, all display onsets that are markedly higher in energy than their true thresholds' (e.g. from 0.7 eV above for $\mathrm{C}_{2} \mathrm{H}_{4} \mathrm{Cl}^{+}$to $3.0 \mathrm{eV}$ above for $\mathrm{C}_{6} \mathrm{H}_{6} \mathrm{Cl}^{+}$). In addition, in each case the yleld from heterotrimers vastly exceeds that fron heterodimers, as lllustrated in Fig. 1 for the production of $\mathrm{C}_{2} \mathrm{H}_{4} \mathrm{Cl}^{+}$. Indeed, sometimes no yleld from dimers can be detected at all, as is the case with $\mathrm{C}_{6} \mathrm{H}_{6} \mathrm{Cl}^{+}$from $\mathrm{C}_{6} \mathrm{H}_{6} \cdot \mathrm{HCl}$. The photolonization efficiency function for production from dimers can display pronounced structure, as is detalled in FIg. 2 for the production of $\mathrm{C}_{2} \mathrm{H}_{4} \mathrm{Cl}^{+}$from $\mathrm{C}_{2} \mathrm{H}_{4} \cdot \mathrm{HCl}$. Thes results show that the products from heteroclusters are born with substantial excltation energies, which makes their efficlent survival dependent on the presence of a third "solvent" molecule whose excitation and ejection from the cluster serves as the necessary energy sink, hence the greatly enhanced ylelds from trimers relative to dimers. Also, since there are always lowenergy dissociative pathways avallable via the characteristic weak bonds of the complexes, these species can only be produced in highly nonstatistical processes. For the survivors of the production from dimers, one therefore expects the number of avallable pathways to be quite small, very likely only one, and this would allow the appearance of prominent structure, as exemplified by the peak at $15 \mathrm{eV}$ in $\mathrm{Fig} .2$.

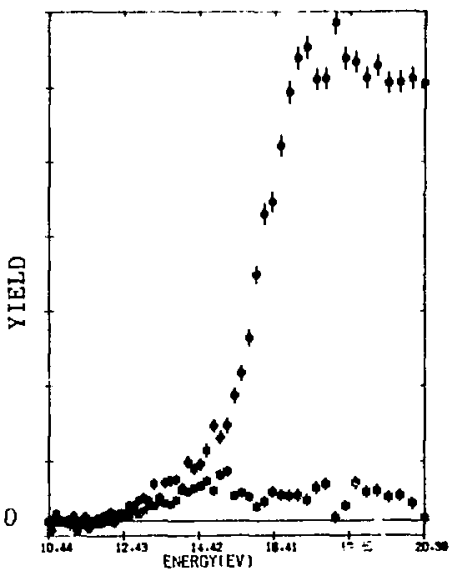

Fig. 1. Closed circles: yield of $\mathrm{C}_{2} \mathrm{H}_{4} \mathrm{Cl}^{+}$from the dissociative photolonization of trimers, 1.e. $\left(\mathrm{C}_{2} \mathrm{H}_{4}\right)_{2} \mathrm{HCl}$ plus $\mathrm{C}_{2} \mathrm{H}_{4}$ (HC1) 2 - Open squares: yle ld, on the same scale, of $\mathrm{C}_{2} \mathrm{H}_{4} \mathrm{Cl}^{+}$from the weak complex $\mathrm{C}_{2} \mathrm{H}_{4} \cdot \mathrm{HCl}$. Absclssa gives photon energy.

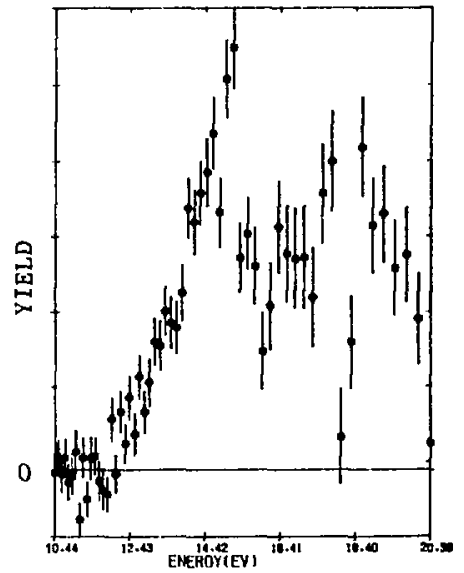

Fig. 2. Yleld of $\mathrm{C}_{2} \mathrm{H}_{4} \mathrm{Cl}^{+}$from the dissociative photolonization of the weak conplex $\mathrm{C}_{2} \mathrm{H}_{4} \cdot \mathrm{HCl}$, as a function of photon energy.

This research was carried out at Brookhaven National Laboratory under Contract DE-AC02-76CH00016 with the U.S. Department of Energy and supported $f_{y} 1$ ts division of Chemical Sciences, office of Basic Energy Sclences. 
AUGER PHOTOELECTRON COINCIDENCE SPECTROSCOPY OF Al(100)+0

E. Jensen (Brandeis U.), R. Bartyngk1 (Rutgers U.), and S. Hlulbert and E. Johnson (NSLS)

Auger Photoelectron Colncidence Spectroscopy (APECS) using a laboratory $x$-ray source was developed by Auger Photoelectron Colncidence Spectroscopy (APEcs) using a laboratory the the the tunability of synchrotron radiation. In the APECS technique two electron energy analyzers are used. One is tuned to the energy of photoelectron, and the other to an auger energy assoclated with the decay of the photohole. A colncidence is recorded if and only if an electron arrives in each analyzer simultaneously. One analyzer is swept in energy, and the other is kept fixed. Both cofncidence and aingles (ordinary photoemission) spectra are recorded simultaneously for comparison.

The purpose of this technique is the enhancement of ordinary photoemission techniques. The advantages are the following: All uncorrelaced background is removed; Overlapping spectra from alloys can be separated; Complex many body structure (magnetic effects, anitiplet and shakeup structure) can be untanglet; The coincidence cechntque has about twice the surface sensitivity of ordinary photoemission.

The first two points are 1llugtrated in the data below from Al(100) covered with $30 \mathrm{~L}$ oxygen. The top panel shows a full singles scan at a photon energy of $120 \mathrm{eV}$. The oxygen $2 \mathrm{p}$ level is at $108 \mathrm{eV}$, the aluminum and aluninum oxide LVV auger spectra overlap and stretch from 40 to $70 \mathrm{eV}$, the aluminum $2 \mathrm{p}$ level is at $42 \mathrm{eV}$ (arrow 2) and the aluminum oxide (aluminum 2p, arrow 1) is at $40 \mathrm{eV}$. The second panel compares a singles sweep through the core level region to the colncidence spectrum, with the fixed analyzer at $68 \mathrm{eV}$ (arrow 3), the high energy part of the auger spectrum. In the colncidence spectrum the oxide core is completely removed, Indicating that the oxide core does not decay via 68 eV auger electrons. In addition, the background under the singles spectrum is removed. The bottom two panels show sweeps through the auger region, and lilustrate how the complex overlapping aluminum and aluminum oxide spectra are completely separable by moving the fixed analyzer from the oxide core (3rd panel) to the metal core (bottom pane1). The removal of uncorrelated background is again seen.

1. H.W. Haak, G.A. Sawatzky, T.D. Thomas, Phys. Rev, Lett. 41, 1825 (1978).

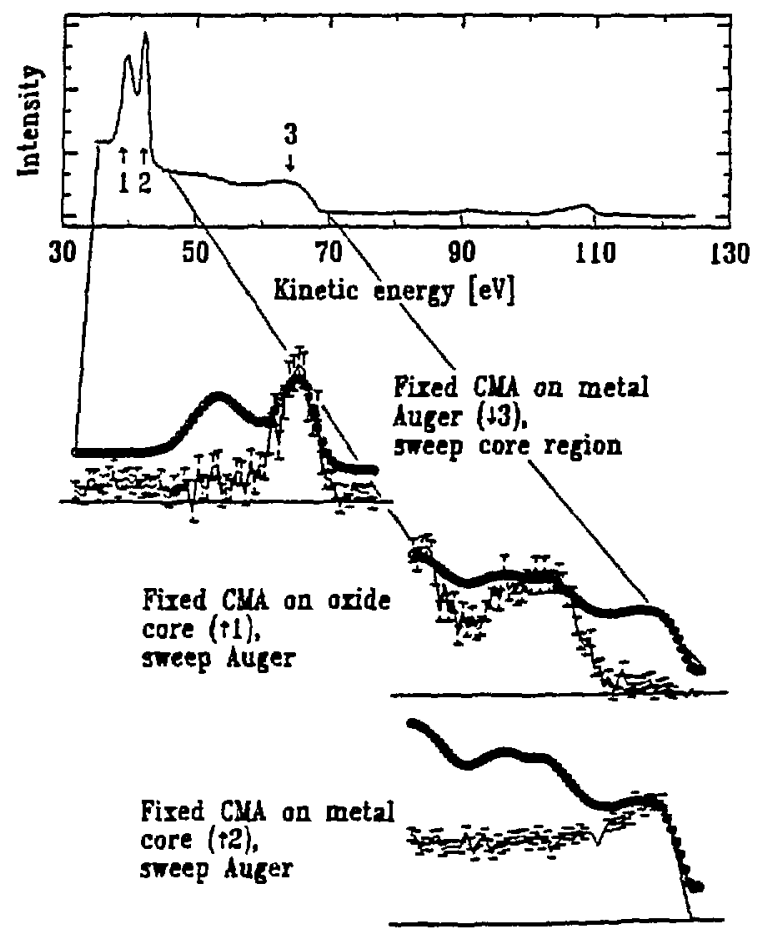

$\mathrm{Al}(100)+30 \mathrm{~L} \mathrm{O}_{2}$

Auger - Photoefectron caincidence

First data August 1987 
S.-C. Lui, B.S. Itchkawitz and E.W. Plummer

Liboratory lor Research on the Structure of Matler

University of Pensisylvania

Philadelphia, PA 19104-6396

David M. Zehner

Solid State Division

Oak Ridge National Laboralory

Oak Ridge, TN 37831-6024

We have carried out an extensive study of the experimental band structure of NiAl using the (100) face of this crystal. The crystal surface was cleaned in situ by Ne sputlering and subsequently annealed to $950-1000^{\circ} \mathrm{C}$, which produced a well ordered surface that exhibited a $(1 \times 1)$ LEED pattern. NiAl has a CsCl-type structure which has two atoms per unit cell. In k-space, the Brillouin zone is a simple cubic shown in Figure la. The simplicity of the cubic Brillouin zone makes it possible to measure the Fermi surface by photounission. The crystal was oriented such that $A \| l \mid \bar{r} \bar{\chi}$. Using s-polarized light and moving the analyzer to the zone boundary ( $\chi$ of the surface Brillouin zone), the transition of the $\Delta$, band (seventh band) was found to be very strong at $16 \mathrm{eV}$ photon energy (this photon energy was found to connect the initial state at $\chi_{1}$ to final state $x_{\text {s }}$ or $x^{\prime}$ ). Moving the analyzer collection angle back loward $\bar{\Gamma}$. Ilue Fenti level crossing the $\Delta_{1}$ band was observed at $k_{\mu}=0.74 \pm 0.02 \mathrm{~A}$. This detemined point $\mathrm{A}$ in the Fermi surface cross section shown in Figure Ib. Due to the high symmetry of the cubic Brillouin zone, we only need to detemine the Fermi susface in $1 / 8$ of the zone and the entire Femi surface can be generated by symmetry operation. Starting from point A in Figure $1 b$, we determine the Fermi surluce by changing $k$, i.e., by increasing photon energy from $16 \mathrm{eV}$ and by changing the analyzer collection angle slightly such that we can lollow the Fermi fevel crossing at a different $k$ as photon energy is increased. Point B in Figure $1 b$ was found at $h \omega=25 \mathrm{eV}$. The $k_{\text {perp }}$ at this point is obrained by the following simple relationship assuming a free electron final band

$$
h \omega-E_{i}=\left(h^{2} / 2 m\right) k_{l /}^{2}+\left(h^{2} / n\right)\left(k_{p \in T}+G\right)^{2}-V_{0}
$$

Since $E_{i}=0$ at the Fermi level, $k_{\text {perp }}$ was found to be $0.80 \pm 0.02 \mathrm{~A}$ which is equal to $k_{\text {, a }}$ at point $B$. The Fermi surface obtained in this experiment is found to be in agreement with those obtained graphically from the energy band plot of D.J. Nagel' using a self-consistent APW calculation with a Slater $\mathrm{X} \alpha$ exchange.

The high symmetry points in the NiAl band strueture were determined by measuring both normal and off-nomal emission. Figure 2 plots the variation between the experimeatally determined critical points $\left(E_{m}\right)$ and the self-consistent $A P W$ calculation by $N a g e l^{\prime}\left(E_{c}\right)$. The dotted line is the data from $\mathrm{Ni}$ (scaled down to half the values) taken from reference 2 where the comparison was made with calculation by Wang and Calliway. Figure 2 shows that the discrequency with theory follows the siume trend for both Ni and NiAl. If we Ireat Figure 2 as the self-energy correction, then it clearly indicates that the d hole is more localized in Ni then in NiAl. Upon alloying with Al, hybridization with Al s,p electrons make the $\mathrm{Ni} d$ electron orbitals in NiAl more delocalized as compared to Ni d orbitals in its elememal form. As a consequence, we could expect a larger self-energy correction for $\mathrm{Ni}$ due to d-hole localization. A more detailed discussion on the comparison to theory will be followed in our future publication."

\section{Acknowledgenients}

The synchrotron beam line was funded and supponed by NSF/MRL program DMR-8519059, and by the Division of Malerials Science, U.S. Department of Energy under contract DE-ACO5-840R21400 with Martin Marietta Energy Systems, Inc.

\section{References}

L. D.J. Nagel, Ph.D., thesis, University of Maryland, 1977.

2. W. Eberhardt and E.W. Plummer, Phys. Rev. B21, 3245 (1980).

3. C.S. Wang and J. Callaway, Phys. Rev. BIS, 298 (1977); 9, 4897 (1974).

4. S.C. Lui, B.S. ltchkawitz, E.W. Plummer and D.M. Zehoer, to be published.

(a)
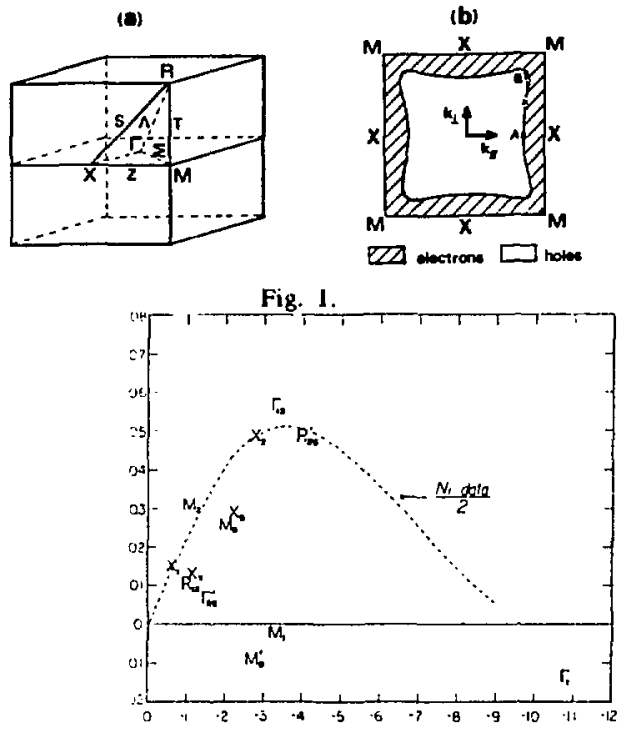

Fig. 2. $E_{\mathrm{e}}(\mathrm{w})$ 


\section{PHOTOELECTRON DIFRACTION FROM LANGMUIR-BLOMGIITJ FILMS*}

J.M. Bloch

Argonne National Laboratory, Division of Materials Research, Argonne, IL 60439

M. Sagurton and G.P. Willians

NSLS, Brookhaveri National Laboratory, Upton, NY 11973

I. Jacob

Ben Gurion University of the Negev, Israel

C. Binns

Department of Physics, University of Leicester, Leicester LEl 7RH, UK

In angle-scanned photoelectron diffraction (PD) from molecules adsorbed on surfaces, it is known that intra-molecular photoelectron forward scattering can produce peaks at angles which coincide with the orientations of axes connecting nearneighbor atoms. Thus, this technique has proven useful for determining the oricntation of simple molecular species adsurbed on surfaces, e.g. $\mathrm{CO} / \mathrm{Ni}(001){ }^{1}$ We have carried out a feasibility study in which we applied this technique for the first time to the study of Langmuir-Blodgett (LB) films on Si wafers. 1- and 3-layer Cd stearate and 1-layer Mn stearate samples were measured. The molecules comprising these films contain an 18 atom $\mathrm{C}$ 'zigzag' chain. Forward scattering along the chain axis and between nearest-neighbor $\mathrm{C}$ atoms is likely to produce PD peaks at angular positions which are directly related to the molecular tilt angle and the azimuthal orientation of the $\mathrm{C}$ zigzag.

The photoelectron diffraction function $\chi$, defined as

$$
\chi=\left(I-I_{0}\right) / I_{0} \text {, }
$$

was measured as a function of tle polar emission angle $\theta$ for a photon energy of $450 \mathrm{eV}$. I and $\mathrm{I}_{\mathrm{o}}$ represent the $\mathrm{C}(1 \mathrm{~s})$ angleresolved photoemission peak intensities from the LB film and from a powder reference sample, respectively. Count rates were adequate to perform the experiments in a reasonable time as, e.g., $5000 \mathrm{cps}$ were obtained on the $\mathrm{C}(1 \mathrm{~s})$ peak with a $=$ $3 \mathrm{eV}$ analyzer energy resolution. However, the uv beasn was found to degrade the LB films on the time scale of several hours, requiring frequent sample changes.

A strong $20 \%$ oscillation in $\chi$ was obtained from the 3-lajwr Cd stearate sample (Fig. 1). Peaks occur for $\chi$ approximately equal to $0^{\circ}, 40^{\circ}$, and $50^{\circ}$. The first may have a simple interpretation involving forward scattering along the axis of the LB molecule, while the peak at $40^{\circ}$ may be associated with forward scattering along nearest-neighbor $C$ atoms. Theoretical calculations of the polar PD pattern are planned to test this interpretation and to attempt to extract the molecular tilt angle with respect to the surface. We did not observe PD patterns from the 1-layer LB films, possibly due to sample quality.

We intend to extend this work involving systems with one or a small number of organic long chain layers to study different molecular species and the effect of different sample preparation conditions.

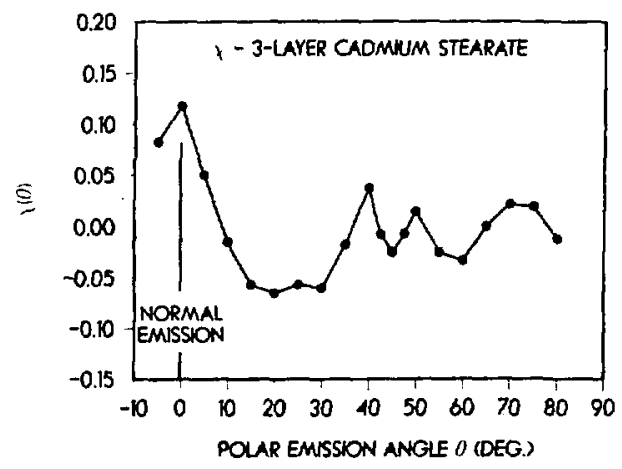

Fig. 1. C(Is) polar phoioelectron diffaction pattern obtained from a 3-layer Cd stearate LB film, for a photon energy of $450 \mathrm{eV}$.

\section{References}

1. L.-G. Petersion, S. Kono, N.F.T. Hall, C.S. Fadley, and J.B. Pendry, Phys. Rev, Lett. 42, 1545 (1979).

\footnotetext{
- Work perforned under the auspices of the U.S. Departmem of Entrgy, under conlaci No. DE-ACO2-76CHO0016.
} 


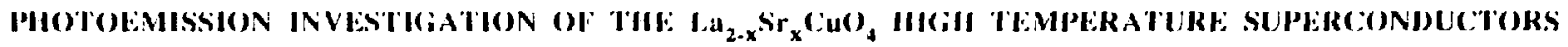

R. Garrett, E. Johnson, E. Kneedler and G. Williams

National Synchrotron Light Source, Brookhaven National Lab

\section{J. Tranquada}

Physics Deparment, Brookhaven National Lab, Upton, NY 11973

A series of resonance photoemission and photon stimulaced desorption measurements were made on the $\mathrm{La}_{-\mathrm{x}} \mathrm{Sr}_{\mathrm{x}} \mathrm{CuO}_{4}$ high temperature superconductors. Five samples were used, with $x=0,0.1,0.15,0.2$ and 0.3 . The best stoichiometry for high temperature superconductivity is $x=0.18$, which has a $\mathrm{Tc}$ of about $40 \mathrm{~K}$.

The experintents were performed at room temperature in UHV using beamline U14. The surfaces were prepared by scraping with a ruby stone rod. A typical valence band spectrum is shown in Figure 1 . A freshly scraped surface was found to degrade relatively yuickly in the UHV environment, with the valence band peak degradation intensity near the fermi level within 20-30 minutes. Calculations [1] indicate that the valence band peak is composed primarily of copper and oxygen contributions, with oxygen states dominating the lower binding energy region of the peak. Thus we attribute the degradation shown in Figure 1 to a loss of surface oxygen from the material. The peak below the valence band at about $10 \mathrm{eV}$ binding energy is a contamination peak due to surface oxygen and carbon.

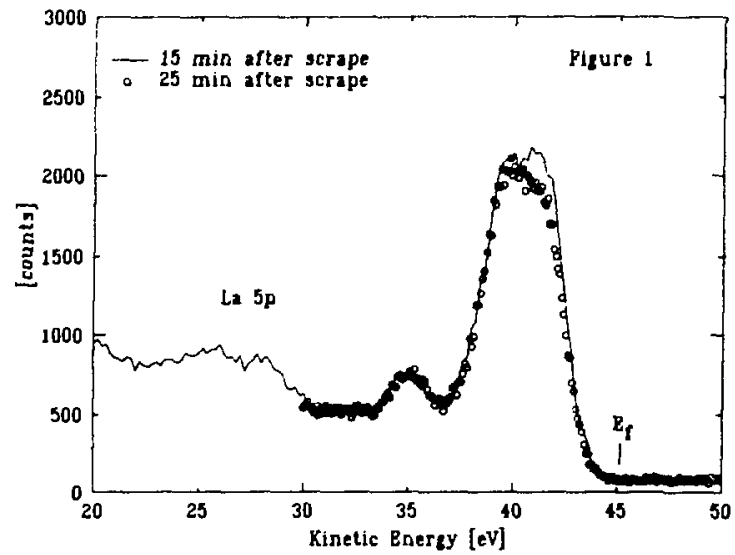

Figure l

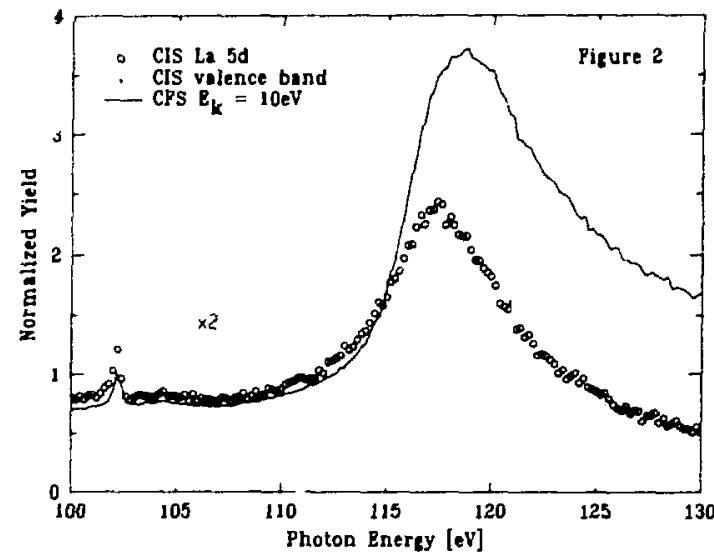

Figure 2.

A striking feature of photoemission from rare earth compounds is the resonance behavior at the $4 \mathrm{~d}$ threshold. Various CIS and CFS (constant initial state; constant final state) spectra from $\mathrm{La}_{2} \mathrm{CuO}_{4}$ are shown in Figure 2. Three resonance features are observed: two sharp peaks below the $4 \mathrm{~d}$ threshold at $97.8 \mathrm{eV}$ (not shown) and $102.2 \mathrm{eV}$ respectively, and a large feature centered at $118 \mathrm{eV}$. Listle variation in these spectra was observed between differing stuichiometries. The curves shown in Figure 2 are almost identical in form to those measured from LaB ${ }_{6}$ [2]. The resonances are attributed to transitions to empty $4 \mathrm{f}$ states: the strong exchange interaction between the excited $4 \mathrm{f}$ electron and the $4 \mathrm{~d}$ hole produces highly localized "atomic like" $4 f$ levels which give rise to the resonance feature: in Figure 2 [2].

Figure 2 shows CIS scans which illustrate the resonant enhancement of the La 5 p peak and the valence band due to a direct recombination decay of the excited 4 f electron. The 5 p emission shows a strong enhancement at $118 \mathrm{eV}$ (similar to the CFS) while the valence band is only weakly enhanced, also similar to the LiB6 data [2]. This indicates that while the major contributors to the valence band are $\mathrm{Cu}$ and $\mathrm{O}[1]$, lanthanum electrons contribute a small but significant intensity.

Photon stimulated desorption spectra were obtained via a time of flight technique. The only desorbing ionic species detected at the various $\mathrm{La}, \mathrm{Sr}, \mathrm{Cu}$ and $\mathrm{O}$ edges was $\mathrm{H}^{+}$. The lack of $\mathrm{O}^{+}$or $\mathrm{OH}^{+}$desorbing ions indicates that the loss of surface oxygen is not due to the impinging photon beam. Strong "prompt" fluorescence signals were also detected, presumably from desorbing excited hydrogen.

This work was sponsored by the DOE under contract DE-ACO2-76CHOOO16.

1. L.F. Mattheiss, Phys. Rev. Lett. 58, 1028 (1987)

2. M. Aono, T. Chiang, J. Knapp, T. Tanaka and D. Eastman, Phys. Rev. B21, 2661 (1980) 
TITLE OF EXPERIMENT: Large Area X-ray Multilayer Mirror Calibration

DATE: June $7-17,1987$

EXFERIMENTERS: Leon Golub (Harvard-Smithsonian Ctr. for Astrophys.) and Eberhard Spiller (IBM's Thomas J. Watson Research Center)

\section{ABSTRACT}

The soft $X$-ray reflectivity of a $25 \mathrm{~cm}$ diameter Ritchey-Chrétien telescope was measured, using the U14A monochromator. Both X-ray throughput and absolute wavelength of peak reflectivity were determined and compared with measurements performed on "witness" samples. The latter consisted of small Si wafer strips which were glued to the surface of the figured optics and coated at the same time.

The telescope is a two-mirror Cassegrain-type system, in which the overall performance depends upon the quality of the multilayer coating on each mirror (uniformity, boundary roughness, accuracy of 2d-spacing), as well as on the degree of overlap between the passbands of the two mirrors. Much of our testing has been done with the witness mirrors, and the primary purposes of the NSI.S tests were: i) to determine whether the telescope mirrors have on their surfaces the same coatings that were deposited onto the witness samples, i1) to establish that the optical system will transmit $X$-rays of the predicted wavelengths from the entrance aperture to the focal plane; and iif to determine the X-ray reflectivity and wavelength of peak throughpur of the telescope. All of the above measurements need to be accurate to $\ll 1.3 \%$, which is the multilayer passband; this translates to an absolute accuracy of $\ll 1.0 \mathrm{eV}$.

The major result is shown in the figure below, which indicates that the mirrors and the witness samples both received the same coating to within $\pm 0.2 \mathrm{eV}$. The absolute reflectivity is more difficult to determine due to enlargement of the transmitted lmage relative to the straight-through; however, we calculate that the U14 measurement agrees to within $25 \%$ with measurements performed on the samples.

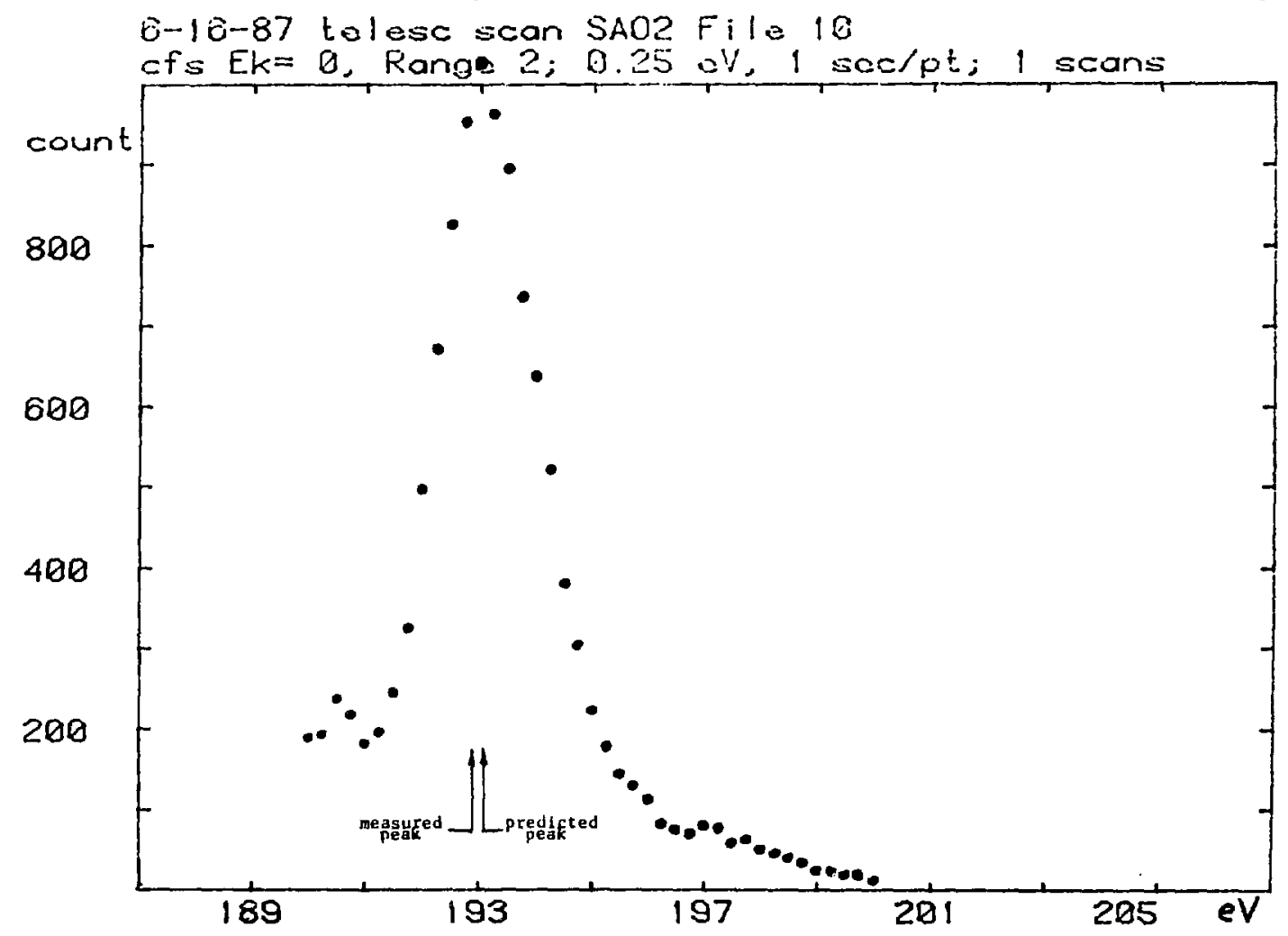

Fig. l. Measured throughput of the X-ray telescope at output of the UliA monochromator

This work was supported by the NSF under Grant DMR-8313070 to the Smithsonian Institution, 
Robert J. Lad and VIctor E. Henrich

App I led Physlcs, Yale University, New Haven, CT

Al though angle-resolved photoemission has proven to be a powerful technique for mapping out the bulk and surfacr. alectronlc structures of a large number of metals and semiconductors, very few angle-resol ved measurements have been performed on transition-metal oxides. This is partiy due to the fact that the valence band features of the oxldes are generally quite broad, making the determination of band dispersions difficult. Nonetheless, we have carried out angle-resolved normal emission experiments on cleaved single crystals of $\mathrm{MnO}$ and $\mathrm{Fe}_{3} \mathrm{O}_{4}$ and have qualitatively determined the energy dispersion of the valence band. In addition, the $3 d$ character has been distingulshed from $02 p$ derlved valence band features by using constant-Initial-state (CIS), constant-final-state (CFS), and total yield measurements, taken with photon energies at the $3 p-3 d$ resonance [1].

The photoemission spectra were acquired on beaml ine U14 at NSLS using photon energles between 30 and $120 \mathrm{eV}$. Normal emission spectra were measured with a hemispherlcal analyzer at $\pm 2^{\circ}$ angular resolution, and CIS and CFS spectra were taken in the angle-integrated mode using a cylindrical mirror analyzer. The single crystal swere oriented to expose $\mathrm{MnO}(100)$ and $\mathrm{Fe}_{3} \mathrm{O}_{4}(110) \mathrm{faces}$, and they were cleaved In situ at $<2 \times 10^{-10}$ Torr.

MnO is an insulating monoxide, in which the $30^{5}$ electrons are bel leved to be fairly localized on the $\mathrm{Mn}^{2+}$ lons due to electron correlation effects. Normal emission sfectra taken from MnO (100) for $30<h v<80$ ey exhlbit two peaks separated by 1.8 ev due to axcitation from the e $\mathrm{e}^{\uparrow}$ and $+{ }_{2}^{\uparrow} \mathrm{g}$ orbltals in the $\mathrm{Mn}^{2+}\left(+{ }^{3} \mathrm{~g}^{\top} e^{2} T_{i} \mathrm{C}_{\mathrm{A}_{1}}\right)$ ground state. A primarily $02 \mathrm{p}$ region is located between 1 and 5 el above the $t_{2} \uparrow$ peak, Ind a satellite feature appears near 7 eV; spectra are arbitrarlly referenced in energy to the $t^{\uparrow}$ peak because the location of the Fermi level within the bandgap could not be determined due fo surface charging. Of interest in a normal emission experiment are peak dispersions. Fitting Gausslans to the t $\uparrow$ and $e^{\uparrow}$ peaks, we find that these Mn $3 d$ derlved states do not disperse more than $\pm 0.1 \mathrm{eV}$ relafive to gach other. In contrast, features In the 0 $2 p$ resion do show some disperslon, although band mapping is tenuous because of the broad nature of the pears. These data support a locallzed $3 d$ electron view of the electronic structure [2,3], al though a one particle band theory [4] showing very little dispersion cannot be ruled out. 3p-3d resonance effects are visible in the normal emission data at photon energles between $48<$ hv $<52$ ev. The $t_{2} \uparrow$ and $e^{\uparrow}$ peaks undergo an antiresonance as the photon energy is swept through the Mn $3 p$ photomthreshold, whereas emission in the $02 p$ and satellite reglons exhlbits resonant behavlor. The assoclated Fano-like I ineshapes are clearly evident in CIS and CFS spectra. The antiresonance of the lowest binding energy Mn 3d features is attributed to screenling of the final states by I igand-tometal charge transfer [5]; the satel lite is belleved to correspond to an unscreened $3 d^{4}$ $f$ inal state. A resonant enhancement in the $02 \mathrm{p}$ reglon suggests some overlap of the Mn $3 \mathrm{~d}$ and 0 $2 p$ final states.

$\mathrm{Fe}_{3} \mathrm{O}_{4}$ crystal lizes in the spinel structure, which contalns $\mathrm{Fe}^{2+}$ and $\mathrm{Fe}^{3+}$ lons coordinated in ocfahedral and tetrahedral sites of an fcc lattlce of $0^{2-}$ lons. It exhibits metalilic conductivity at room temperature, and the electronic structure can more justifiably be descrlbed by itinerent electrons. Normal emission spectra measured from cleaved $\mathrm{Fe}_{3} \mathrm{O}_{4}(110)$ between $34<\mathrm{hv}<80$ eV are composed of many multiplet I Ines from the $\mathrm{Fe}^{2+}$ and $\mathrm{Fe}^{3+}$ ions, which are difficult to separate from the overlapplng $02 p$ band. CIS and CFS spectra at the $3 p-3 d$ resonance reveal that the main valence band emission is well screened by IIgand charge transfer; the Intensity of the unscreened satel I ite peak is very weak. An analysis of the data in terms of a strlctiy one electron band approach, and a comparison to band calculations [6], is in progress.

\section{References:}

[1] R.J. Lad and V.E. Henrich, submitted to Phys. Rev. B.

[2] A. Fujlmor I, M. Saekl, N. Kimlzuka, M. Taniguchi, and S. Suga, Phys. Rev. B 34, 7318 (1986).

[3] J. Zaanen, G.A. Sawatzky, and J.W. Al len, Phys. Rev. Lett. 25, 418 (1985); J. Magn. Magn. Mater. 24-57, 607 (1986).

[4] T. Oguchi, K. Terakura, and A.R. WIII I ams, Phys, Rev. B 28, 6443 (1983); K. Terakura, T. Oguch I, A.R. WI I l ans, and J. Kubler, Lbid. 30,4734 (1984).

[5] L.C. Davis, Phys. Rev. B 25, 2912 (1982); J. App I. Phys. 59, R25 (1986).

[6] A. Yanase and K, SIratori, J. Phys. Soc. Jpn. 53, 312 (1984).

Note: The authors gratefulity acknowledge assistance by K.E. Smith and the NSLS staff. Thls work was partial ly supported by NSF, Sol id State Chemistry Grant No. DMR-8202727. 


\section{ENERGY-DEPLNDLNT PIOTOLLLCTRON DIFRACTION FROM GAAS(MO)*}

M. Sagurton and G.P. Williams

NSLS, Brookhaven National Laboratory, Upton, NY 11973

Energy-dependent photoelectron diffraction (EDPD) has developed into a useful surface structural tool, so far employed primarily as a means of determining site types and $z$ displacements in ordered overlayer systems.' The present study was conducted to test whether EDPD could accurately determine the structural parameters associated with the GaAs(110) surface. This is a considerably more complex problem, first because the surface reconstructs, and second because atoms (either $\mathrm{Ga}$ or As) in many different local environments contribute simultaneously to the diffraction pattern. A further motivation for studying this system is the uncertainty which has existed in the exact nature of the reconstruction due to the inability of low energy electron diffraction (LEED) to accurately determine the displacements of atoms parallel to the surface. $^{2}$

The measurement of EDPD involves determining the function $\chi$ (hv) $=\left[I(h v)-l_{0}(h v)\right] / l_{0}(h v)$, where $h v$ is the photon energy, and $\mathrm{I}$ and $\mathrm{I}_{\mathrm{o}}$ represent core level angle-resolved photoemission peak intensities with lo corresponding in principle to the case where there is no scattering of the outgoing photoelectron wave from its neighbors following the initial excitation. In this study we measured the Ga(3d) core level for hv between approximately 100 and $280 \mathrm{eV}$ (for a photoelectron kinetic energy between approximately 77 and $257 \mathrm{eV}) . \mathrm{I}\left(\mathrm{I}_{\mathrm{o}}\right)$ is then the $\mathrm{Ga}(3 \mathrm{~d})$ peak area following subtraction of an integral background. $I_{0}$ was measured from a GaAs reference sample with a disordered surface showing no LEED pattern. Use of a reference sample also has the advantage that it normalizes out the dependence of the peak intensity on factors such as the monochromator function, beam current decay, beam movement (uii a long time scale), and analyzer transmission function. EDPD curves were obrained at eight near-grazing (within $20^{\circ}$ of the surface) emission angles to enhance surface sensitivity. The full range oscillarion in $\chi(\mathrm{hv})$ ranged from approximately $15 \%$ to $50 \%$. Figure 1 shows the results abtained at a polar emission angle (wr the surface) $\theta$ of $20^{\circ}$ and an azinuthal emission angle of $180^{\circ}$ $\left(90^{\circ}\right.$ from the mirror plane).

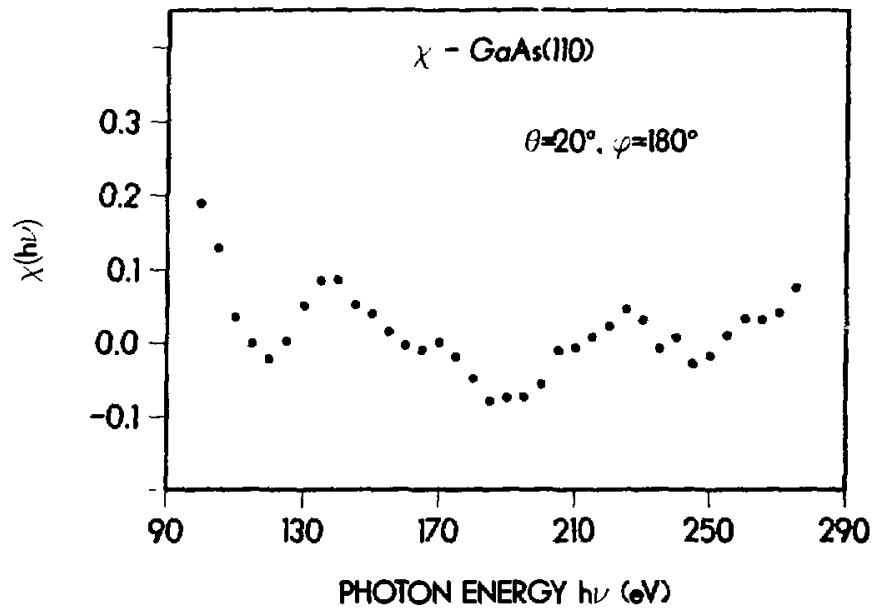

Fig. 1. Experimental energy-dependent photoelection diffraction curve obtained $20^{\circ}$ from the surface and $90^{\circ}$ from the surface mirror plane.

Structural information is derived from the experimental data through comparison with theoretical EDPD curves computed assuming different values for the various structural parameters. To date, we have carried out calculations in the somewhat crude plane wave (PW) and single scattering (SS) approximations. The results show both an encouraging level of agreement with experiment and a high degree of structural sensitivity, althougn the latter is strongly dependent on emission angle. It thus appears likely that in conjunction with more accurate calculations to be carried out, the EDPD results will provide an accurate structural determination of the GaAs(110) surface.

\section{References}

1. J.J. Barton, C.C. Bahr, Z. Hussain, S.W. Robey, J.G. Tobin, L.E. Klebanoff, and D.A. Shirley, Phys. Rev. Lett. 51,272 (1983).

2. C.B. Dike and A. Paton, J. Vac. Sci. Technol. B2, 327 (1984).

-Work performed under the auspices of the U.S. Department of Energy, under contract No. DE-ACO2-76CH00016. 


\section{RESONWT PAOTOEMISSION EFFECTS AND BULK BAND DISPERSION IN $\mathrm{TI}_{2} \mathrm{O}_{3}$ AND $\mathrm{V}_{2} \mathrm{O}_{3}$}

Kevin E. Smith and Victor E. Henrich

Applled Physlcs, Yale University, 15 Prospect St., New Haven, Cr 06520.

The bulk electronlc structure of $\mathrm{Tl}_{2} \mathrm{O}_{3}$ and $\mathrm{V}_{2} \mathrm{O}_{3}$ has been the subject of conslderable exper Imental and theoretical investigation over the last forty years, motivated primarliy by a desire to understand the nature of the metai-insulator transitions which these materlals undergo [1,2]. We report here results of a comprehensive study of the electronlc structure of $\mathrm{TI}_{2} \mathrm{O}_{3}$ and $\mathrm{V}_{2} \mathrm{O}_{3}$ using both angle integrated and angle resolved ultravlolet photoemission spectroscopy (AROPS) performed on NSLS beaml Ine U14A [3].

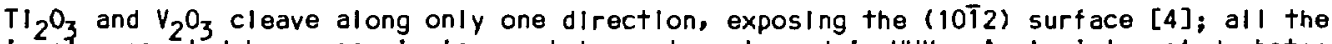
experiments reported here use single crystal samples cleaved in UHV. Angle integrated photoemission spectra were obtained from $\mathrm{V}_{2} \mathrm{O}_{3}$ at varlous photon energles. These spectra are $;$ imllar to those obtained prevlously using a he discharge lamp [4]; close to the Ferml level, $E_{F}$, emlssion from the $V$ 3d states is observed and below this lies the broad emisslon from the $02 p$ band. However there is a feature visible in the spectra which was not seen in the previous study [4]. The bindling energy of this feature, $10.8 \mathrm{eV}$, colncldes with a bulk energy loss observed in the electron energy loss spectrum of $\mathrm{V}_{2} \mathrm{O}_{3}$ [5] and thus we can identlfy this feature as a valence band satellite according to the exclton model of de Boer et al. [6]. The $v 3 d$ emission displays a resonance behavior close to the $V 3 p$ - 3d threshold [7]. However the onset of the resonance 15 delayed by 6 eV above the $V 3 p$ 3d separation; in $V$ metal the delay in resonance is almost $8 \mathrm{eV}$ [8].

Normal emission ARUPS spectra were taken from both the cleaved $\mathrm{T}_{2} \mathrm{O}_{3}\left(10 \overline{1}_{2}\right)$ and $\mathrm{V}_{2} \mathrm{O}_{3}(10 \overline{12})$ surfaces. In general the ARUPS spectra were quite similar to those obfained in an angle integrated mode [4,9]. The direction In k-space probed in a normal emIssion experiment from a (1012) surface In a corundum structured crystal is not of particularly high symmetry; none of the available band structure calculations provide dispersion curves for the direction studied in these experiments $[10,11]$. However, the directions alorig which the calculations were made do intersect the experimentally probed I ine at a number of polnts where comparison with the experiment can be made. The normal emission spectra obtalned from $\mathrm{Tl}_{2} \mathrm{O}_{3}(10 \overline{1} 2)$ show a small $(<0.4$ eV) but significant dispersion for the TI $3 d$ states near $E_{F}$. Similarly the $V 3 d$ emission in ARUPS spectra from $\mathrm{V}_{2} \mathrm{O}_{3}$ (10T2) shows a silght dispersion ( $<0.3 \mathrm{eV}$ ) [3]. The observed dispersion in both materials shows iftilie simliarlty to that expected from the calculations. However, this does not necessarlly Invalidate the calculations since the dispersion occurs in the photon range where resonant photoemission is the dominant contribution to the measured $3 \mathrm{~d}$ intensity. The onset of resonance is delayed in the case of $\mathrm{Ti}_{2} \mathrm{O}_{3}$ Just as it is in $\mathrm{V}_{2} \mathrm{O}_{3}$.

\section{Acknowledgements}

The authors wIsh to acknowledge the Invaluable assistance of R.J. Lad and the staft at NSLS, in partlcular R.F. Garret, E. Kneedler. M.J. Sagurton and G.P. Wllliams. ThIs work was partially supported by NSF Solld State Chemlstry Grant DMR 82-02727.

1. J.B. Goodenough, Prog. Solid State Chem. 5, 145 (1972), ed. by H. Relss (Pergamon, NY, 1972), and references therein.

2. J. Ashkenazl and M. Weger, Adv. Phys. 22, 207 (1973), and references therein.

3. K.E. Smith and V.E. Henrlch, submitted to Phys. Rev. B.

4. R.L. Kurtz and V.E. Henrlch, Phys. Rev B 28, 6699 (1983).

5. V.E. Henrich, H.J. Zeiger and G. Dressel haus, In "Electracatalysis on Non-Metallic Surfaces", Natlonal Bureau of Standards Special Publication 455, 133 (Nov.,1976).

6. D.K.G. de Boer, C. Haas and G.A. Sawatzky, Phys. Rev. B 29, 4401 (1984).

7. For a recent revlew of resonant photemission see L.C. Davis, J. Appl. Phy5. 29, R25 (1986).

8. J. Barth, F. Gerken and C. Kunz, Phys. Rev. B 31,2022 (1985).

9. R.L. Kurtz and V.E. Henrlch, Phys. Rev. B 25, 3563 (1982).

10. J. Ashkenazl and M. Weger, J. Phys. (ParIs) 37, C4-189 (1976).

11. J. AshkenazI and T. Chuchem, Phllos. Mag. 22.763 (1975). 


\title{
NEAR-EDGE X-RAY ABSORPTION FINE-STRUCTURE OBSERVATIONS OF ORDERING
}

\section{AND METALLIC-LIKE BELAVIOR IN ORGANIC CONDUCTING POLYMERS ON PI.}

\author{
G.P. Williams, M. Sagurton, P. Xu, R.F. Garrett, E. Kneedler, W. Braun $\dagger$
}

National Synchrotron Light Source, Brookhaven National Laboratory, Upton, NY 11973

G. Tourillon, E. Dartyge and A. Fontaine

LURE, Batiment 209D, 91405, Orsay, France

We observed a remarkable ordering of films of several layers thickness of poly(3-methylthiophene) electrochemically deposited on a Pt electrode, using NEXAFS. ${ }^{1}$

Polythiophene and its derivations represent a new class of organic conducring polymers which are of great interest for two reasons. First, their electrical conductivities can be varied by 12 orders of magnitude by doping, and secondly, they show great chemical and electrochemical stability against moisture and oxygen. ${ }^{2}$ Neither the conduction mechanisms or the morphology of these materials are known. Our NEXAFS measurements sought to address the unoccupied electronic structure questions from peak heights and positions and the physical structure issue from the polarization dependence.

The figure below shows polarization dependent data for undoped poly3methylthiophene. A strong transition at grazing incidence was observed for peak $A$ which we assign to a $2 \pi^{*}$ final state, which indicates that the thiophene ring is lying down on the surface.

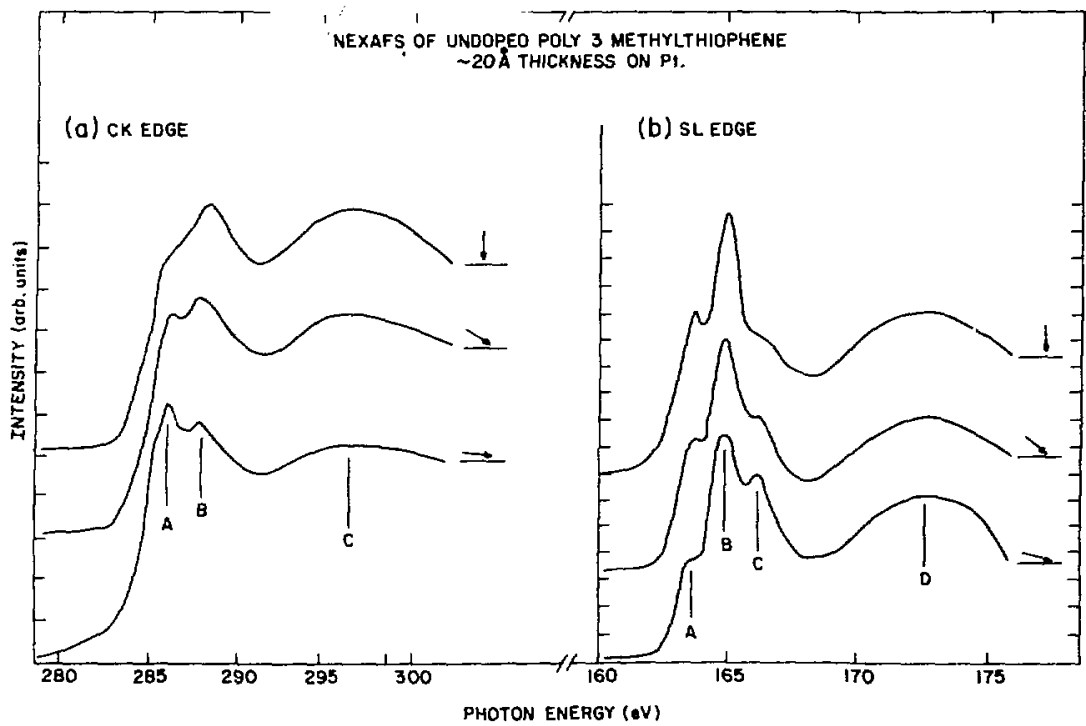

Polarization dependence of NEXAFS spectra obtained from a 20 -Å-thick film of undoped poly/3-methylthiophenel above (a) the $C K$ edge and (b) the $S L$ edge. The insets indicate the direction of poly(3-methylthiophene) film.

On doping with $\mathrm{ClO}_{4}$, we saw essentially the same features with no significant changes in the $\sigma$ resonances. This suggests that no modifications to the basic structural unit in this polymer took place juring the doping process. However, the $2 \pi$,* band was substantially affected with a decrease in intensity of the main Is $\rightarrow 2 \pi^{*}$ transition and the appearance of additional intensity at low energy $(282-284 \mathrm{eV})$ abeve the carbon edge. We associate these modifications with the formation of empty states in the gap which is consistant with UPS and XPS ${ }^{3}$ studies.

\section{References}

1. G. Tourillon, A. Fontaine, R. Garrett, M. Sagurton, P. Xu and G.P. Williams, Phys. Rev. B35 9863 (1987).

2. G. Tourillon, in Handbook of Conducting Polyers, edited by T. Skotheim (Marcel Delcher, New York, 1986) Vol 1., P. 294.

3. Y. Jugnet, G. Tourillon and Tran Minch Duc, Phys. Rev. Lett. 561862 (1986). 


\title{
CORE ELECTRON EXCITATION AND RELAXATION IN MOLECULES ${ }^{\star}$
}

\author{
D.M. Hanson, S.L. Anderson, K. Wu, D. Lapiano, and C.I. Ma \\ Department of Chemistry, State University of New York \\ Stony Brook, NY 11794-3400
}

\begin{abstract}
Our research program is directed at learning about the chemical consequences of core electron excitation in molecules. With tunable, monochromatic synchrotron radiation, it is possible to excite selectively not only core electrons of different elements, but also core electrons of the same element in different chemical environments in the molecule. In addition, different types of excited states can be prepared. The core electron can be excited to unoccupied valence orbitals, Rydberg orbitals, shape resonances, or the ionization continuum. Auger decay, accompanied by fragmentation of the molecule, usually occurs following such excitation in the gas phase. It is our objective to learn how and why the fragmentation varies with molecular structure and depends upon the nature of the core hole excited state. The techniques of photoelectron, mass, and fluorescence spectroscopy are being used in these studies. Analysis of data obtained for carbon monoxide and trifluorotoluene almost is completed. Recently data has been collected for water, methanol, propanol, diethylether, methane, and tetrafluoromethane. Dther results
\end{abstract} are summarized below.

For nitrous oxide, core holes were created selectively in either of the two nitrogen atoms or in the oxygen atom by exciting a $1 \mathrm{~s}$ electron to an unoccupied valence orbital. Time of flight mass spectroscopy was used to elucidate the chemical consequences of this excitation. Clear changes in the mass spectra with the atomic site of excitation were observed. These changes can be understood qualitatively in terms of the atomic populations, which govern the Auger decay channels, and the overlap populations, which determine the bond structure, of the valence molecular orbitals.

Mass spectra also were obtained to characterize the fragmentation of acetone folluwing excitation of an oxygen is electron to an unoccupied valence orbital, to a shape resonance, and to the ionization continuum. The production of methyl ion fragments was found to exhibit a marked enhancement that appears to be 1 inearly related to the oxygen $1 \mathrm{~s}$ partial absorption cross section. Neither carbon nor oxygen ions are significant products of oxygen $1 \mathrm{~s}$ excitation. These results are intriguing because while localized Auger decay and bond rupture around the site of the core hole would explain the formation of $\mathrm{C}^{+}$and $0^{+}$, the production of methyl ions may be consigtent with the molecular orbital population analysis used for the case of nitrous oxide.

Fluorescence spectra can be used to detect neutral fragments and ions produced in electronically excited states by Auger decay of core holes. The most interesting results have been obtained for the case of oxygen. The luminescence spectrum uhiained following excitation in the region of the oxygen $k$ edge consists of two series of bands, one in the blue region (400 to $500 \mathrm{~nm}$ ) and the other in the green region $(500$ to $700 \mathrm{~nm})$. It was found that ion yield spectra and the relative intensity of these bands vary with excitation energy through the pi and sigma resonances. The green bands clearly correspond to the first negative system of $\mathrm{O}_{2}{ }^{+}$. The blue bands, however, do not match known luminescence of this ion or other possibilities. Recent calculations, and data from electron impact and double charge transfer experiments indicate that there are two states of $\mathrm{O}_{2}^{++}$separated by $3 \mathrm{ev}$. The blue bands therefore may be due to $0_{2}^{++}$. This is an exciting result because there is only one previous report of dispersed luminegcence from $^{2}$ a doubly charged molecular cation in the literature. Probing the Auger final state by observing its fluorescence decay makes it possible to do Auger spectroscopy with the high resolution of an optical spectrometer. Such luminescence spectra with resolved rotational and vibrational structure can provide signiz-tant information about the energy spacing between electronic states, about the structure and bonding properties of ions in these states, and about the populations of rotational and vibrational levels, which can characterize the populating mechanisms.

A theory, based on the concept of orbital force, is being developed to explain or predict fragmentation patterns of polyatomic molecules following the multiple electron excitation and ionization that accompanies decay of a core hole. A change in the valence electron configuration produces a stress on the atoms in a molecule. This stress is relieved by changes in bond lengths and angles, by electronic relaxation, and by bond rupture. An analysis of this stress may serve to identfy the bonds that rupture. To date, this theory has been tested on diatomic molecules and ions. It has sugcessfully correlated bond lengths and vibrational force constants of different excited electronic states.

This research is supported by the National Science Foundatioa, Grant CHE 8703340.

1. J. Murakami, M.C. Nelson, S.L. Anderson, and D.M. Hanson, J. Chem. Phys. 85, 5755 (1986).

2. M.C. Nelson, J. Murakami, S.L. Anderson, and D.M. Hanson, J.Chem. Phys. $8 \overline{6}, 4442$ (1987).

3. K. Toh ji, D.M. Hanson, and B.X. Yang, J. Chem. Phys. 85,7492 (1987).

4. H. Yang, J.L. Whitten, and D.M. Hanson, manuscript in preparation.

5. Y. Zhang and D.M. Hanson, Chem. Phys. Letters 127,(1986); J. Chem. Phys. $\underline{86}, 347,666$ (1987). 
DEFECT GENERATION IN SILICON DIOXIDE FROM SOFT X-RAY SYNCHROTRON RADIATION

Principal Investigator, A. Reisman 1,2 Co-Principal Investigator, ${ }_{4}$.K. Williamis ${ }^{1}$ visiting scientist, P.K. Bhattacharya ${ }^{3}$ collaborating scientist, $W . N{ }^{4}$

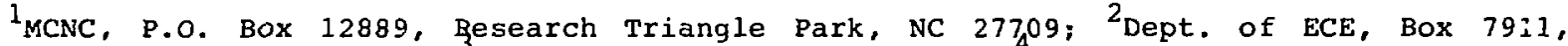
NCSU, Raleigh, NC 27695; 3 BARC, Bombay -400085 , India; 4 SLS, BNL, Upton, NY 11973

X-ray lithography is one method being investigated to pattern the next generation of semiconductor devices because of its high resolution capabilities, i.e. short wavelength. To take full advantage of this high resolution capability, the $x-r a y$ source must produce a very intense collimated beam. One such source is the vacuum ultraviolet (VUV) storage ring of the National Synchroton Light Source (NSLS) at Brookhaven National Laboratory. Such a ring provides a continuum of photon energies from less than $10 \mathrm{eV}$ to above $5000 \mathrm{eV}$. It has been reported that $\mathrm{x}$-ray radiation at energies above $1 \mathrm{KeV}$ produces fixed positive charge, fixed negative chafge, neutral electron traps in device gate insulators such as Sio, in large numbers. describes preliminary studies on defect generation in $\mathrm{SiO}_{2}$ from exposure to monochromatic $\mathrm{X}$-ray radiation in the energy range from 300 to $1000 \mathrm{eV}$. The purpcse of these studies was to determine if energy threshold(s) exist below which one or more of the three major electrically active defects (fixed positive charge, fixed negative charge, and neutral electron traps) are not generated, or where the number generated for a given number of rads begins to decrease monotonically with decreasing energy. If such a threshold exists, the energy used for $x$-ray lithography could be tailored such that little or no oxide damage occurs during the exposure. The alternative is to use energies that will generate the damage and 1) try to stop the X-rays from reaching the oxide by using a trilayer photoresist technology, or 2) attempt to anneal the damage after the exposure. The analyses are based on the results of experimental studies in which the gate insulators in insulated gate field effect transistors were exposed to the monochromatic X-rays at the NSLS U15 bgamline and then measured using an optically assisted hot electron injection technique. "The exposures were done for 1 ) a constant incident energy of $120 \mathrm{~mJ} / \mathrm{cm}^{2}$ to simulate an $\mathrm{X}$-ray lithographic step, and 2l constant absorbed dose of $2 \times 10$ rads $\left(\mathrm{SiO}_{2}\right)$ to determine the energy dependence of the defect generation. To uniformly expose a number of devices, the samples were scanned vertically through the $\mathrm{x}$-ray beam. Since the $\mathrm{X}$-ray beam has a near gaussian distribution in the horizontal direction, only devices at the same horizontal position (same column) receive the same dose. Devices on the sample that were to receive a different energy exposure, or that were to receive no radiation (controls) were shielded by stainless steel plates. In using the beamline, care must be taken in determining the actual exposure, because heating of the torodial grating monochromator by the incident "white" radiation from the synchrotron ring can reduce its efficiency, i.e. the actual photon flux incident on the sample may not be proportional to the beam current in the ring. The results indicate that the generation of fixed positive charge, fixed negative charge, and neutral electron traps remains approximately constant with decreasing $x-r a y$ energy. At $2 \times 10^{\circ}$ rads, using a special test device, the number of generated fixed postiye charges was approximately $9 \times 10^{11} \mathrm{~cm}^{-2}$, the number of fixed negative charges was $4 \times 10^{11} \mathrm{~cm}^{-2}$, and the number of neutral electron trus was $1.7 \times 10^{12} \mathrm{~cm}^{-2}$. If $\mathrm{x}-\mathrm{ray}$ lithography is used to pattern a metal layer, the maximum temperature that can be used subsequently to anneal the damage created is approximately $400^{\circ} \mathrm{C}$. The results obtained here indicate, that such annealing temperatures reduces the number of defects to approximately $3.5 \times 10^{1} \mathrm{~cm}^{-2}$ neutral electron traps, $1 \times 10^{1} \mathrm{~cm}^{-2}$ fixed positive charge, and less than $1 \times 10^{10} \mathrm{~cm}^{-2}$ fixed negative charge.

\section{References}

1. T.H. Ning, J. Appl. Phys. 49,4077 (1978).

2. J.M. Aitken and D.R. Young, J. Appl. Phys. 47, 1196 (1977).

3. J.M. Aitken, D.R. Young, and K, Pan, J. AppI. Phys. 49, 3386 (1978).

4. A. Reisman and C.J. Merz, J. Electrochemical Soc. $13 \overline{0,} 1384$ (1983).

5. A. Reisman, C.J. Merz, J.R. Maldonado, \& W.W. Molzen, Jr., J. Electrochem. Soc. 131,1404 (1984).

6. A. Reisman, C.K. Williams, and J.R. Maldonado, J. Appl. Phys, (to be published).

7. J.R. Maldonado, A. Reisman, H. Lezec, C.K. Williams, \& S.S. Iyer, J. Electrochem. Soc. $133,628(1986)$.

8. T.H. Ning and H.N. Yu, J. Appl. Phys. 44, 5373 (1974). 
TEMPERATURE DEPENDENCE OF LOCAL ENVIRONMENT SURROUNDING OXYGEN ATOHS IN $\mathrm{Y}-\mathrm{Ba}-\mathrm{Cu}-0$ COMPOUNDS

\author{
S.C. Woronick, W. Ng, A. Krol, B.X. Yang, and Y.H. Kao \\ Department of Physics \\ State University of New York at Stony Brook \\ Stony Brook, New York 11794-3800 \\ R.L. Meng, P.H. Hor, and C.W. Chu \\ Department of Physics, University of Houston \\ Houston, Texas 77004
}

The recent discovery of superconductivity in oxides with unprecedented high transition temperatures has stimulated enormous interest in the study of various physical properties of these materials. Although the underlying mechanism responsible for the high transition temperature remains unclear, it is conceivable that structural instabilities, lattice defects, oxygen vacancies, local atomic environment may play an important role in effecting the superconducting state. In the present work, we have investigated the local structure around the oxygen atoms in a high-T superconductor $\mathrm{YBa}_{2} \mathrm{Cu}_{3} \mathrm{O}_{7}-\delta$ by using the EXAFS technique, which provides information on the bond length and disorder between the oxygen and $\mathrm{Cu} / \mathrm{Ba}$ atoms. Our results indicate a structural instability transition around $161 \mathrm{k}$ not reported before.

Using the EXAFS spectra, we have extracted the effective Debye-Waller parameter $\sigma$ as a function of temperature, which is plotted in Fig. 1. An abrupt change in $\sigma$ was observed at a transition temperature around $161 \mathrm{~K}$. This can also be observed more directly by inspection of the k-value of the maximum amplitude of the backtransform oscillations, which shows an abrupt change at $16 \mathrm{lK}$. Other than this abrupt change, we see little variation in as a function of temperature. This suggests that cur sample most likely contains a large number of defects, and the static disorder in the system masks the usual temperature variation of $\sigma$ as predicted by the Einstein model of lattice vibration.

In sumary, we have investigated the local short-range-order structure around the oxygen atoms in the high-T cuperconductor $\mathrm{YBa}_{2} \mathrm{Cu}_{3} \mathrm{O}_{7-\delta}$ by using the EXAFs technique. Our findings indicate that ${ }^{c}$ the material contains a high degree of disorder and undergoes a structural transition as the temperature is lowered through $161 \mathrm{~K}$, seen as an increase in the effective Debye-Waller factor.

This work is supported in part by the Department of Energy.

\title{
References
}

1. M.K. Wu, J.R. Ashburn, C.J. Torng, P.H. Hor, R.I. Meng, I. Gao, Z.J. Huang, Y.Q. Wang, and C.W. Chu, Phys. Rev. Lett. $\underline{58}, 908$ (1987).

Figure Captions

Fig. 1 -- Temperature dependence of the effective Debye-Waller factor $\sigma$.

(a) $\mathrm{O}-\mathrm{Cu}$ bond, (b) 0-Ba Bond.
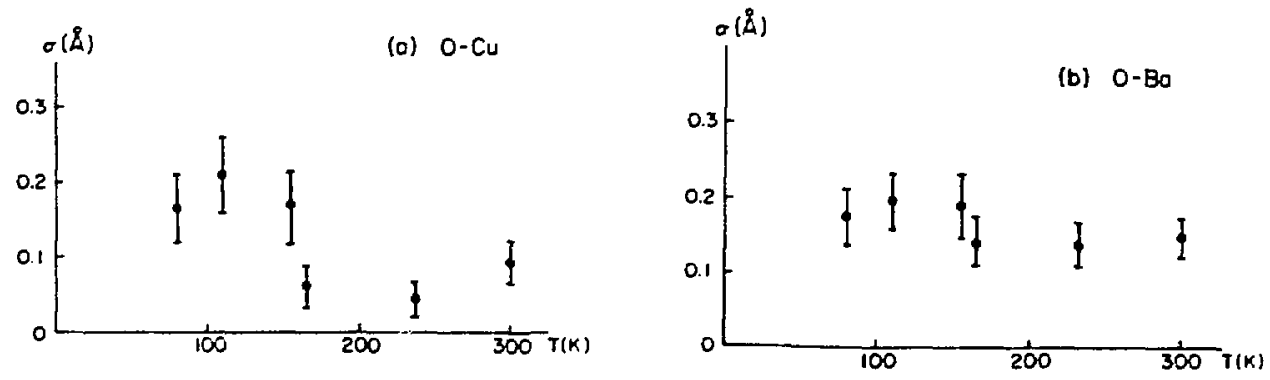


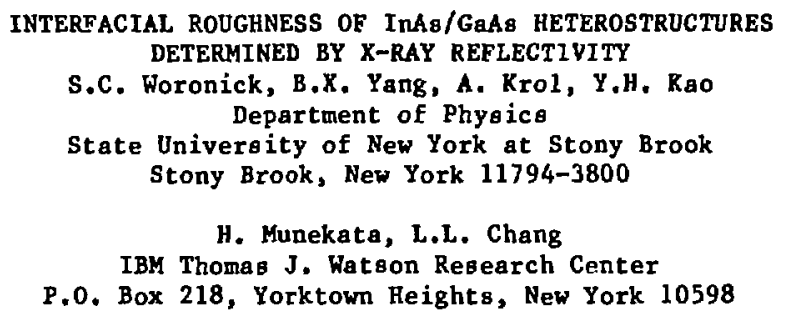

Many important physical properties of quantum-well systems are strongly related to the material structure at the boundary between different layers; the understanding and control of the interface appear to be essential for further development and device applications of the multilayer and single layer heterostructures. Despite extensive studies of the transport and optical properties of these layered structures, little is known at the present time about the interfacial roughness. This s low progress is due to lack of efficient experimental techniques for probing the interfacial structure, especially for nondestructive characterization of interfaces beneath the top surface of as-made samples.

We have measured the reflection of monochromatic x-rays by an InAs/GaAs heterostructure. The heterostructure was produced by growth of a thin layer of InAs on GaAs by) molecular beam epitaxy (MBE), with a nominal layer thickness of 250 \& estimated from growth time.

Our data show regular oscillations in both the reflectivity and wavelength-modulated reflectivity as a function of grazing angle. These oscillations are due to interfacial effects and contain information about the layer thickness and interfacial roughness. This information can be extracted by comparision of our data with a theoretical calculation based on the well-known Fresnel equations, modified to include surface roughness via a scalar scattering theory in the long wavelength regime. ${ }^{i 2,3}$ We have found good agreement between the theory and our data, as can be seen in Figure 1 . From the fit of the theory to our data, we have determined the thickness as $248 \pm 6 \&$, the InAs-GaAs interfacial roughness as $18 \pm 5 R$, and the top surface roughness as $1 R$ or less.

In conclusion, our results indicate that a layer of InAs on GaAs grown by GBE has started from a rough surface and ended with a smooth finish. In performing this experiment we have demonstrated the utility of this practical technique for nondestructive evaluation of the interfacial roughness in semiconductor heterostructures. This work is supported by ONR.

\section{References}

1. P. Beckmann and A. Spizzichino,

The Scattering of Electromagnetic

Waves from Rough Surfaces (Pergamon Press, New York, 1963).

2. C.K. Carniglia, Opt. Eng. 18, 104 (1979); and references cited therein.

3. S.C. Woronick, B.X. Yang, A. Rrol, Y.H. Kao, H. Munekata, I.L. Chang, and J.C. Phillips, Proceedings of the 3rd International Conference on Modulated Semiconductor Structure (to be published).

Figure Captions:

Fig. 1. - Reflectivity from an InAs/GaAs heterostructure for $442.1 \mathrm{eV} x$-rays, with the measured data plotted as points and a calculation plotted as a curve. The parameter values used for the calculation were:

$\mathrm{d}=255 \AA, \sigma_{1}=0.40 \AA, \sigma_{2}=17.5 \AA$.

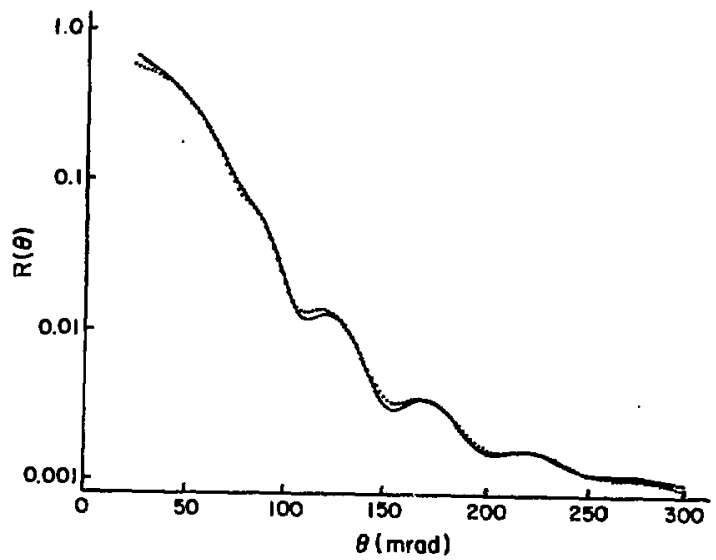




\section{REPORTS OF THE X-RAY RESEARCH AT THE NSLS}

This section contains the reports of research carried out at the NSLS X-ray storage ring during the 1987 fiscal year. Most of the contributions have been specifically written for this annual report by the experimenters. Their efforts are greatly appreciated by the annual report staff. The reports are presented by beam line and are arranged alphabetically by first author (except where a specific order was requested.) The Table of Contents that follows is also arranged by beam line and first author.

\section{X-Ray Storage Ring Parameters as of June 1987}

\begin{tabular}{|c|c|}
\hline Parameters & X-Ray Storage Ring \\
\hline Normal Operating Energy & $0.75-2.5 \mathrm{GeV}$ \\
\hline Design Current & $0.5 \operatorname{amp}\left(1.9 \times 10^{12} \mathrm{e}^{-}\right)$ \\
\hline Circumference & 170.1 meters \\
\hline Number of Beam Ports of Dipoles & 30 \\
\hline Number of Insertion Devices & 5 \\
\hline Maximum Length of Insertion Devices & $<4.50$ meters \\
\hline$\lambda_{c}\left(E_{c}\right)$ at $1.22 \mathrm{~T}(\mathrm{~B})$ & $2.48 \mathrm{~A}(5 \mathrm{keV})$ \\
\hline$\lambda_{c}^{c}\left(E_{c}^{c^{\prime}}\right)$ at $6.0 \mathrm{~T}(\mathrm{~W})$ & $0.50 \mathrm{~A}(25 \mathrm{keV})$ \\
\hline$B(\rho)$ & 1.22 Tesla (6.875 meters) \\
\hline Electron Orbital Period & 567.7 nanoseconds \\
\hline Damping Times $(0.7 \mathrm{GeV})$ & $\tau_{x}=\tau_{y}=6 \mathrm{msec} ; t_{\epsilon}=3 \mathrm{msec}$ \\
\hline Touschek $(0.7 \mathrm{GeV}, 1 \mathrm{~A})$ & $\geq 0.6 \mathrm{hrs}\left(\mathrm{v}_{\mathrm{RF}}=800 \mathrm{kV}\right)$ \\
\hline Touschek $(2.5 \mathrm{GeV}, 0.5 \mathrm{~A})$ & $\geq 8 \mathrm{hrs}($ same $)$ \\
\hline Lattice Structure (Chasman-Green) & Separated Function, Quad, Triplets \\
\hline Number of Superperiods & 8 \\
\hline Magnet Complement & $\begin{array}{l}16 \text { Bending ( } 2.7 \text { meters each) } \\
40 \text { Quadrupole ( } 0.45 \text { meters each) } \\
16 \text { Quadrupole ( } 0.80 \text { meters each) } \\
32 \text { Sextupole ( } 0.20 \text { meters each) }\end{array}$ \\
\hline Nominal Tunes $\nu_{\mathrm{x}}, \nu_{\mathrm{y}}$ & $9.15,6.20$ \\
\hline Momentum Compaction & 0.0065 \\
\hline R.F. Frequency & $52.88 \mathrm{MHz}$ \\
\hline Radiated Power for Bending Magnets & $252 \mathrm{~kW} / 0.5$ amp of Beam \\
\hline R.F. Peak Voltage & $800 \mathrm{kV}$ \\
\hline Design R.F. Power & $500 \mathrm{~kW}$ \\
\hline$\nu_{\mathrm{S}}$ (Synchrotron tune) & 0.002 \\
\hline Natural Energy Spread $\left(\sigma_{\epsilon} / \mathrm{E}\right)$ & $8.2 \times 10^{-4}$ \\
\hline Natural Bunch Length $(2 \sigma)$ & $10.5 \mathrm{~cm}$ \\
\hline Horizontal Damped Emittance $\left(\epsilon_{\mathrm{x}}\right)$ & $8.0 \times 10^{-8}$ meter-radian \\
\hline Vertical Damped Emittance $\left(\epsilon_{\mathrm{y}}\right)^{X^{2}}$ & $8.0 \times 10^{-10}$ meter-radian \\
\hline Power per Horizontal milliradian, $0.5 \mathrm{~A}$ & 40 watts \\
\hline Source Size: $\sigma_{\mathrm{h}}, \sigma_{\mathrm{v}}$ & $\sim 0.35 \mathrm{~mm}, \sim 0.15 \mathrm{~mm}$ \\
\hline
\end{tabular}

Source of Data: NSLS Parameters, January 1983, compiled by A. van Steenbergen; updated values provided by Beii Craft (NSLS).

$$
3-1 / 3.2
$$


Beam Line XIB

R. Murphy, I.-W. Lyo, and W. Eberhardt

Vibrational Structure in the Auger Decay of Core Excited

Beam Line $X 3$

B. Chu

B. Chu

B. Chu, C. $W_{u}$, and D.-Q. $W_{u}$

P. Coppens, D. Levendis, A. Paturle,

V. Petricek, G. Yan, and F.K. Larsen

K.-G. Huang, J. Zegenhagen, W.M.

Gibson, and J.C. Phillips

Y.H. Kao

B. Chu, D.-Q. Wu, C. Wu, W.J. MacKnight, C.W. Lantman, J.C. Phillips, A. LeGrand, and R.D. Lundberg

T.F. McNulty, J.C. Phillips, and P. Coppens

J.C. Phillips

C.T. Prewitt and D.J. Weidner

D.J. Weidner, A. Yeganeh-Haeri, D. Swanson, and C.T. Prewitt

Beam Line X5

O. Kistner, G. Matone, A. Sandorfi, C. Thorn, G. Giordano, C. Schaerf, M.

Blecker, C. Doss, B. Preedom, S.

Whisnant, K. Mize, M. Whitlow, S.

Thornton, and R. Sealock

Beam Line X7A

J.M. Bennett, R.M. Kirchner, and D.E. $\operatorname{Cox}$

M.M. Eddy, T.E. Gier, G.D. Stucky, J. Bierlein, and D.E. Cox

M.M. Eddy, J,E. MacDougall, G.D. Stucky, N. Herron, and D.E. Cox

T. Egami, W. Dmowski, D.D. Kofalt, I.A. Morrison, P.A. Heiney, P.A. Bancel, P.J. Steinhardt, S.J. Poon, Y. Shen, S. Preische, and G.J. Shiflet N

SAXS Studies of Sol-Gel Transition of Gelatin

Time-Resolved SAXS Study of Crystallization Behavior of Blends of High and Low Density Polyethylene.......

Fractal Geometry in Branched Epoxy Polymer Kinetics...

Synchrotron Radiation Study of the Five-Dimensional, Modulated Phase of TTF-TCNQ at $15 \mathrm{~K}$

$\mathrm{X}$-ray Standing Wave Measurements at Bragg Angles Close to 90 Degrees.

$\mathrm{X}$-ray Reflectivity and Interfacial Roughness

Small Angle $\mathrm{X}$-ray Scattering of Polystyrene lonomers....

Multi-Temperature EXAFS Spectroscopy of Six Coordinate, High Spin Meso-Tetraphenylporphinato-BISTetrahydrofuran Iron(II).

Protein Folding Observed by Time-Resolved Synchrotron $\mathrm{X}$-ray Scattering - A Feasibility Study

Perovskite

Thermal Diffuse Scattering in $\mathrm{KMgF}_{3}$ at Room Temperature and Elevated Temperatures.

The First Gamma-ray Beam at LEGS

The Crystal Structure of an As-Synthesized $\mathrm{ALPO}_{4}-16 \ldots$

Application of High Resolution Synchrotron Powder Xray Diffraction to the Structural Investigation of a New Non Linear Optical Material

Determination of the Structure of CdS/CdSe Clusters in Zeolite-Y by High Resolution Powder Synchrotron X-ray Diffraction

Atomic Structure of Quasicrystals (X7-A) 
H Gies, H. Strob!, C.A. Fyfe, G.T. Kokotailo, and D.E. Cox

R.J. Hemley, A.P. Jephcoat, H-k. Mao, C-s. Zha, L.W. Finger; and D.E. Cox

R.G. Hemley, A.P. Jephcoat, C-s. Zha, H-k. Mao, L.W. Finger, and D.E. Cox

S.J. Hibble, A.K. Cheetham, and D.E. $\operatorname{Cox}$

A.P. Jephcoat, R.J. Hemley, H-k. Mao, L.W. Finger, C-s. Zira, and D.E. Cox

A.P. Jephcoat, H-k. Mao, L.W. Finger, R.J. Hemley, C-s. Zha, and D.E. Cox

A.P. Jephcoat, H-k. Mao, R.J. Hemley, L.W. Finger, R.M. Hazen, C-s. Zha, and D.E. Cox

\section{L.B. McCusker}

L.M. Moroney, P. Thompson, and D.E. Cox

J.B. Parise, A.W. Sleight, H.S.

Horowitz, T. Egami, and W. Dmowski

S.B. Qadri, E.F. Skelton, C. Quinn, and C. Gilmore

S.B. Qadri, E.F. Skelton, M.W.

Schaefer, A.W. Webb, and L. Colombo

I. Sone and H. Herman

P. Suorti and D.E. Cox

Beam Line X7B

M.M. Eddy, G.D. Stucky, J.D.

Bierlein, and $\AA$. Kvick

R. Love, J. Grable, Y. Kim, and J.

Rosenberg

A. Paturle, V. Petricek, P. Coppens, R.

$M$. Wing, and $\AA$. Kvick

B. Post, E.M. Chen, and $\AA$. Kvick

C.Y. Yang, M.A. Paesler, D.E. Sayers, E.M. Chen, and $\AA$. Kvick

Beam Line $\mathrm{X} 9 \mathrm{~A}$

S.I. Ayene, A. Naqui, and B. Chance

W.F. Beyer Jr., J. Kitzler, and I.

Fridovich
High Resolution X-ray Powder Diffraction Studies of the Zeolites ZSM-11 and ZSM-5 Between $25-150^{\circ} \mathrm{C}$

Static Compression of $\mathrm{H}_{2}$ O-Jce To 128 GPA $(1.28$ MBAR)

Equation of State of Neon to $110 \mathrm{GPa}$

$\mathrm{Ca}_{0}{ }_{75} \mathrm{Nb}_{3} \mathrm{O}_{6}$ : A Novel Metal Oxide Containing NiobiumNiobium Bonds. Characterization and Structure Refinement from Synchrotron Powder X-ray Data ................

Static Compression of Corundum to 170 GPA (1.70 MBAR)

Pressure-Induced Structural Transitions in Condensed Gases

Single-Crystal X-ray Diffraction of Solid Hydrogen and Deuterium

Ab Initio Structure Determination from Powder Diffraction Data

Anomalous Dispersion and Shared-Site Problems in Crystallography

Diffraction Study of a Vanadium Phosphate Catalyst for the Oxidation of n-Butane to Maleic Anhydride ..........

Phase Stability of $\mathrm{ZrO}_{2}-\mathrm{Al}_{2} \mathrm{O}_{3}$ Films Grown by Magnetron Sputtering Under Application of Pressure ...................

High Pressure Studies of $\mathrm{HgMnTe}$

X-ray Analysis of Plasma-Sprayed Partially-Stabilized Zirconia.

Primary Extinction in Nickel Powder

Electric Field Induced Displacements in Potassium Titanyl Phosphate (KTP).

Data Collection from EcoRI Endonuclease-DNA Cocrystals at Crystallography Station X13B

Synchrotron X-ray Scattering in an External Electric Field.

Experimental Phase Determination of Crystallographic Structure Factors by Multiple Scattering Techniques....

Strucfural Srudies of Amorphous Chalcogenide Semiconductors

Sample Damage at BNL/NSLS on Beam Line X9-A ...

Comparison of the Active Site Manganese in Manganese Superoxide Dismutase and Manganese Catalase.... 
J.K. Blasie, J. Pachence, D. Pascolini, R. Fischetti, and F. Asturias

C. Bouldin, G. Bunker, D. Mckeown, and J.A. Ritter

G. Bunker, G. Rosenbaum, S. Khalid, B. Chance, J. Schug J. Schultz, L.

Thomas, and M. Sullivan

B. Chance, G. Zhang, K. Kozinski, S. Khalid, D. McKeown, and G. Bunker

P.A. Heiney, E. Fontes, and W.K. Lee

\section{S. Khalid and B. Chance}

S. Khalid, B. Chance, L. Thomas, and M. Zhang

C. Kim, G. Bunker, G. Zhang, A.

Yencha, B. Chance, and T. King

R. Korszun, G. Bunker, M.

Cusanovich, and R. Scheidt

D.A. McKeown and G.A. Waychunas

G. Rosenbaum, S. Khalid, and M.

Sullivan

G. Rosenbaum and G. Reed

G. Rosenbaum, L. Rock, J. Schultz, and $\mathrm{M}$. Sullivan

G. Rosenbaum, A. Simlyo, and A.

Somlyo

G. Zhang, K. Zhang, M.Z. Zhang, E. Gabiddon, and B. Chance

Beam Line $\times 10$

K.L. D'Amico, H.W. Deckman, and B. P. Flannery

K.S. Liang, G.J. Hughes, E.B. Sirota, K.L. D'Amico, J.M. Newsam, and P. Eisenberger

K.S. Liang, E.B. Sirota, K.L. D'Amico, G.J. Hughes, and S.K. Sinha

\section{Beam Line $X 11$}

E.E. Alp, G.K. Shenoy, L. Soderholm, D.G. Hinks, J. Guo, and D.E. Ellis

P. Bandyopadhyay and B.A. Bunker

J.I. Budnick, Z. Tan, and F. Sanchez
X-ray Diffraction Studies of Multilayer Films.

Studies of Multiple Scattering in XANES: Beam Line X9-A

Beam Line X9-A End Station Instrumentation: Spectroscopy

Rapid Flow Experimentation on Beam Line X9-A ......

Strong Incommensurate Fluctuations in a Smectic-A Phase

Large Area Rectangular Detectors for XAFS Spectroscopy

Elimination of X-ray Bearis Fluctuations for $\mathbf{X}$-ray $\mathbf{A b}$ sorption Studies

EXAFS Studies on Cardiac Cytochrome $c_{1} \ldots \ldots \ldots \ldots . . . .$.

X-ray Absorption Investigation of Stereochemistry of $\mathrm{Cy}$ tochrome $c^{\prime}$ on Beam Line X9-A

Titanium XANES and EXAFS of Some Silicate Minerals

Continuous Energy Scan of the Double Crystal Monochromator on Beam Line X9-A ............................

Vanadate Inhibition of 3-Phosphoglycerate Kinase .......

Precision Support Frame for Four-Circle Diffractometer on Beam Line X9-A

Feasibility of Diffraction from Thin Muscle Specimen with the Line Focused Beam

Development of a Flow Flash Apparatus for X-ray Absorption Studies of Carboxy Hemoglobin Photolysis ....

Microtomography at $\mathrm{X}-10$

$\mathrm{X}$-ray Study of the Structure of $\mathrm{Pb}-\mathrm{c}(5 \sqrt{2} \times \sqrt{2}) \mathrm{R} 45^{\circ}$ Overlayer on $\mathrm{Cu}(100)$ Surface.

The Step Roughening Transition of A Cu(113) Surface Studied by Surface $\mathrm{X}$-ray Scattering.

X-ray Absorption Studies at the M-Edge of Uranium and Neprunium Compounds

EXAFS Studies of Buried Interfaces: Al on GaAs......

EXAFS Study of Transition Metal Environments in Silicon Systens Prepared by High Dose Ion Implantation. 
D.C. Calabro and G.L. Woolery

H. Chen and S.M. Heald

T.W. Capehart, D.D. Beck, K.I.

Pandya, and R.W. Hoffman

D.A. Corrigan and T.W. Capehart, K.I. Pandya, and R.W. Hoffman

R.H. Felton, L.R. Furenlid, S.W. May, and J. Kaighobadi

L.R. Furenlid and R.H. Felton

S.M. Heald and J.M. Tranquada

S.M. Heald and J.M. Tranquada

H.S. Isaacs, S.M. Heald, J.M.

Tranquada, J.K. Hawkins, and G.E.

Thompson

Q.T. Islam and B.A. Bunker

S. Islam and B.A. Bunker

Y. Ma and E.A. Stern

J. McBreen, W. O'Grady D. Sayers, C. Yang, and K. Pandya

W.E. O'Grady, and D.E. Koningsberger

K. Pandya, R. Hoffman. W. O'Grady, J. McBreen, and D. Corrigan

D.M. Pease, D. Brewe, Z. Tan, M, Choi, and J.I. Budnick

W.-F. Pong, B.A. Bunker, U. Debska, and J.K. Furdyna

C.L. Spiro and J. Wong

E.A. Stern and K. Zhang

Z. Tan, J.I. Budnick, D. Pease, S.M. Heald, and J. Tranquada

E.C. Theil and D.E. Sayers

M.J. Weber and J. Wong

J. Wong and G.A. Slack

G.L. Woolery, A.A. Chin, G.W.

Kirker, and A. Huss, Jr.
X-ray Absorption Studies of $\mathrm{Cr}$ Oxide $/ \mathrm{SiO}_{2}$ Olefin Polymerization Catalysts

Glancing Angle EXAFS Studies on Al-Cu Interfaces..

Structure of Rhodium/Cerium $\gamma-\mathrm{Al}_{2} \mathrm{O}_{3}$ Catalyst with EXAFS

EXAFS Measurements of $\mathrm{Ni}(\mathrm{OH})_{2}$ with Coprecipirated $\mathrm{Co}$ and $\mathrm{Fe}$.

EXAFS of an Enzyme Transient: $\mathrm{ESO}_{2}$ of Protocatechuate 3,4-Dioxygenase (PCD)

Spherical Wave EXAFS Calculations of Transition Metal Complexes

EXAFS Studies of High $T_{c}$ Superconductors

Standing Wave Assisted EXAFS Study of a Ni-Ti Multilayer.

The Inhibition of Corrosion of Aluminum by Chromate Using Fluorescence Detection of Surface X-ray Absorption

Local Structure in Ferroelectric $\mathrm{Pb}_{1-\mathrm{x}} \mathrm{Ge}_{\mathrm{x}} \mathrm{Te}$

Site Correlations in Quaternary III-V Semiconductor Alloys

Short Range Order in the Icosahedral and Decagonal Phases.

An EXAFS Study of Pyrolyzed Metal Macrocyclic Electrocatalysts

Metal Support Bonds in Platinum-Carbon Catalysts Studied by EXAFS.

EXAFS Investigations of Nickel Hydroxides

Bonding and Coordination in Studies of Crystalline and Amorphous Transition Metal Alloy Systems

Bond Lengths in $\mathrm{Zn}_{1-\mathrm{x}} \mathrm{Mn}_{\mathrm{x}} \mathrm{Se}$

Metal Impurities in Coal and its Combustion Products....

Local Melting About Impurities.

Glancing Angle EXAFS Study of Al/Nb Interface Reactions Induced by Ion Beam Irradiation

The Oxidation of Fe(II) During Ferritin Formation: An Xray Absorption Study Leading to a Reevaluation of the Function and the Evolutionary Age of the Protein....... Rare Earth Ions in Fluoride Laser Glasses ............... 3-95 Metals in $\beta$-Boron ..................................... 3-96

$\mathrm{X}$-ray Absorption Studies of Vanadium in FCC Catalysts 
C.Y. Yang, J.M. Lee, M.A. Paesler, and D.E. Sayers

\section{Beam Line X12A}

D.P. Siddons, J.B. Hastings, G. Faigel, P.E. Haustein, and J.R. Grover

Beam Line X12C

R.M. Sweet and D.M. Cyr

Beam Line $\times 14$

J.D. Budai, J.Z. Tischler, A.

Habenschuss, G.E. Ice, and V. Elser

G.E. Ice, A.S. Bommannavar, C.J.

Sparks, and A. Habenschuss

G.E. Ice and C.J. Sparks

C.J. Sparks, M. Hasaka, D.S. Easton, S. Baik, T. Habenschuss, and G.E. Ice

J.Z. Tischler, J.D. Budai, G.E. Ice, and A. Habenschuss

Beam Line X15A

M. Marcus, B.M. Kincaid, and J. Mock

M. Marcus, B.M. Kincaid, and J. Mock

J. Zegenhagen, K.-G. Huang, W.M. Gibson, B.D. Hunt, and L.J.

Schowalter

J. Zegenhagen, K.-G. Huang, B.D. Hunt, and L.J. Schowalter

J. Zegenhagen, J.R. Patel, B.M.

Kincaid, J.A. Golovchenko, J.B. Mock, P.E. Freeland, R.J. Malik and K.-G.

Huang

Beam Line X15B

A.A. MacDowell, T. Hashizume, and

P.H. Citrin

Beam Line $\mathrm{X} 16 \mathrm{~A}$

P.H. Fuoss, L.J. Norton, and S.

Brennan

I.K. Robinson, R. Feidenhans'1, and $M$. Sauvage

I.K. Robinson, F. Sette, A.A.

MacDowell, and R. Feidenhans'l
Quantitative Measurement of Structural Changes Associated with Photo-Darkening In $\mathrm{a}-\mathrm{As}_{2} \mathrm{~S}_{3}$

The Use of an Ultra-High Resolution Monochromator for Nuclear Bragg Scattering.

A Brookhaven Biology Facility for Measurement of Single Crystal Diffraction Data from Protein Crystals.......

Phason Strain in Oriented Quasicrystals

ORNL X-ray Diffraction Beamline X14A

A Simple Cantilevered Mirror for Focusing Synchrotron Radiation

Structural Studies of Nickel Films and Their Interface with Sapphire Substrates

Multiple Scattering and the (200) Reflection in Silicon and Germanium

Development and Use of a Simple EXAFS System on a White Beamline (X-15A)

Development and Use of a Simple SAXS System on a White Beamline (X-15A)

Interface Structure of Epitaxial $\mathrm{NiSi}_{2}$ on $\mathrm{Si}(111)$

Interface Structure and Lattice Mismatch of Epitaxial $\mathrm{CoSi}_{2}$ On (111)

As On $\mathrm{Si}(100)$ Investigated with $X$-ray Standing Waves

A Soft-Hard X-ray Beamlir: for Photoabsorption, Photoemission, and Standing Wave Measurements in the Energy Range of 0.5-15 $\mathrm{keV}$

Direct Scattering Studies of the Melting of Lead Surfaces.

Vertical Structural Investigation of $\mathrm{Au}(110) 1 \times 2 \ldots \ldots$

Diffraction Studies of Te Overlayers on $\mathrm{Cu}(100) \ldots \ldots \ldots$. 
1.K. Robinson, W.K. Waskiewicz, P.H.

Fuoss, and L.J. Norton

\section{Beam Line $\mathrm{X} 16 \mathrm{~B}$}

D.R. Harshman, D.B. McWhan, and D. Gibbs

S.G.J. Mochrie

Beam Line X16C

F.S. Bates, H.D. Keith, and D.B

McWhan

\section{Beam Line X18A}

L.D. Chapman, S.N. Ehrlich, and N.M. Lazarz

J.R. Dennison, S.-K. Wang, J.C. Newton, H. Taub, E. Conrad, and $\mathrm{H}$.

Shechter

Q. Shen and R. Colella

W. Minor, L.D. Chapman, S.N.

Ehrlich, and R. Colella

P. Zschack, J.B. Cohen, and Y.W. Chung

Beam Line X18B

J.H. White, M.J. Albarelli, G.M. Bommarito and H.D. Abruña

W.B. Yun, J.M. Bloch, M.

Ramanathan, P.A. Montano, and C.

Capasso

W.B. Yun, J.M. Bloch, M.

Ramanatban, P.A. Montano, and C. Capasso

Beam Line X19A

P.Z. Takacs, W.-M. Liu, and E.L. Church

P.M. Stefan

Beam Line $\mathrm{X} 19 \mathrm{C}$

J.E. Benci and D.P. Pope

M. Dudley, J. Wu, and G.-D. Yao

A.B. Hmelo and J.C. Bilello

J.R. Laia, Jr, and P.J. Herley
Structural Analysis of $\operatorname{Si}(111) 7 \times 7$

$3-115$

Polarization Analysis of Magnetic X-ray Scattering.....

$3-116$

Thermal Roughening of the Copper (110) Surface......

Isotope Effect on the Meiting Temperature of Non-Polar Polymers

3-118

Hot Phonons in Quartz

$3-119$

Structure and Phase Transitions of Hexane Monolayers Adsorbed on Graphite

Solution of the Phase Problem in Crystallngraphy by Multiple Bragg Structure

Phason Dispersion Curves in Tantalum Disulphide by $\mathrm{X}$ ray Scattering

Stnuctural Determination of the $\mathrm{TiO}_{2}(100) 1 \times 3$ Reconstructed Surface

Molecularly Ordered Electropolymerized Films of [Ru(vbpy $\left.)_{3}\right]^{+2}$ : An $X$-ray Standing Wave Study

Near Total External Fluorescence from Mn-Stearate Monolayer

First Surface EXAFS from Surfactant Monolayer on Liquid

Scattering of $X$-rays from Smooth Surface - Theory Vs. Experiment

Studies and Commissioning on X-19A

A Study of Creep Damage Using Microradiography ....

Analysis of X-ray Penetration Depths on White Beam Topographs Recorded in Grazing Bragg-Laue Geometries

Characterization of Crack-Tip Microstructures Via Synchrotron Fractorgraphy in Mo and Mo-Nb Alloy Crystals.....

Crystalline Imperfections and Their Role in the Reactivity of $\mathrm{NaNO}_{3}$ and $\mathrm{NH}_{4} \mathrm{ClO}_{4}$ Single Crystals Studied by X-ray Diffraction Topography 
Y. Liu and A.H. King

R. Rebonato, G. íce, A. Habbenschuss, and J.C. Bilello

H.A. Schmitz and J.C. Bilello

V.S. Wakharkar and J.C. Bilello

J.M. Winter, Jr., R.E. Green, Jr., and W.S. Corak

\section{Beam Line X20}

K.F. Ludwig, G.B. Stephenson, J. Mainville, Y. Yang, M. Sutton, and J. L. Jordan-Sweet

Beam Line $\mathrm{X} 22$

A. Braslau, B. Ocko, P.S. Pershan, D. Schwartz, and G. Swislow

D. Gibbs, K.M. Mohanty, and J. Bohr

S.C. Moss, K. Forster, J.D. Axe, H. You, D. Hohlwein, D.E. Cox, P.H. Hor, R.L. Meng, and C.W. Chu

G. Swislow, A. Braslau, B. Ocko, P.S. Pershan, and D. Schwartz

H. You, J.D. Axe, D. Hohlwein, and J.

B. Hastings

I. Tidswell, B. Ocko, P.S. Pershan, S. Wasserman, G. Whitesides, and J.D.

Axe

Beam Line X23A

R.C. Dobbyn, M. Kuriyama, and S. Takagi

R.C. Dobbyn and P.A. Pella

R.C. Dobbyn, B. Steiner, and $M$. Kuriyama

M. Kuriyama, B. Steiner, and R.C.

Dobbyn

R. Spal, T. Jach, D. Novotny, G. Garver, and J. Geist

B. Steiner, U. Laor, M. Kuriyama, and R.C. Dobbyn
Stress Study of Nickel Silicide Thin Film on Silicon Wafer Via Synchrotron Topography.

An Experimental and Theoretical Study of the Critical Factors Controlling the Mechanical Properties of Molybdenum and of the Interaction of Interstitials with BodyCentered-Cubic Transition Metals

Transgranular Fracture in Zinc Bicrystals as Probed by Monochromatic and White Beam Synchrotron $\mathrm{X}$-rays...

An 'In-Situ' Investigation of the Deformation Behaviour of Molybdenum Crystals Via Synchrotron X-ray Topography

Gallium Arsenide Topography at Beamline X-19C......

Initial Stage Ordering Kinetics in $\mathrm{Cu}_{3} \mathrm{Au}$.

$\mathbf{X}$-ray Reflectivity Studies of the Surfaces of Liquid Crystals

High Resolution $\mathbf{X}$-ray Scattering Study of Charge Density Wave Modulation in Chromium.

High Resolution Synchrotron X-ray Study of the Structure of $\mathrm{La}_{1 \cdot 8} \mathrm{Ba}_{\cdot 2} \mathrm{CuO}_{4-y}$

X-ray Reflectivity and Critical Bulk Scattering from a Micellar Lyotropic Liquid Crystal.

Search for Charge Density Waves in a Single Crystal of Potassium by Synchrotron X-ray Diffraction

$X$-ray Reflectivity from Solid Surfaces

X-ray Imaging for Microtomography and Microradiography

Total Reflection EDXRF Using Monochromatic Synchrotron Radiation: Application to Selenium in Blood Serum

Angle-Resolved Imperfection Scattering in Diffraction Imaging .

Diffraction Images of Representative Optoelectronic Materials

An X-ray Monochromator Crystal with a Built-In Photodiode

Diffraction Imaging of High Quality BSO: Implications for Crystal Growth 
S. Shih, C. Hor, D. Mueller, C.R.K. Marrian, W.T. Elam, P. Wolf, J.P.

Kirkland, and R.A. Neiser

W.T. Elam, J.P. Kirkland, R.A. Neiser, and P.A. Wolf

E.F. Skelton, W.T. Elam, S.B. Qadri, and J.M. Pinneo

R.A. Neiser, J.P. Kirkland, W.T. Elam, J. Cocking, J. Sprague, S. Sampath, and $H$. Herman

P. Skeath, W..K. Bums, and W.T. Elam

S. Sampath, H. Herman, R.A. Neiser, J.P. Kirkland, W.T. Elam, and S.

Rangaswamy

J.P. Kirkland, J.V. Gilfrich, and W.T. Elam

X.Q. Yang, $M$. denBoer, T.A. Skotheim, P. Wolf, and J. Kirkland

\section{Beam Line X24A}

P.L. Cowan, S. Brennan, T. Jach, D.

W. Lindle, and B.A. Karlin

J.B. Kortright, P. Plag, R.C.C. Perera, P.L. Cowan, D.W. Lindie, and B.A.

\section{Karlin}

S. Brennan, P.l.. Cowan, R.D.

Deslatres, A. Henins, B.A. Karlin, R.E. LaVilla, and D.W. Lindle

P.L. Cowan, D.W. Lindle, B.A. Karlin, and $P$. Takacs

P.L. Cowan, S. Brennan, R.D.

Deslattes, T. Jach, R.E. LaVilla, D.W. Lindle, and B.A. Karlin

P.L. Cowan, R.D. Deslattes, T. Jach, R.E. LaVilla, D.W. Lindle, and B.A. Karlin

P.L. Cowan, T. Jach, F. Sette, J.

Rowe, and B.A. Karlin

S. Brennen, J. Cooper, P.L. Cowan, R.

D. Deslattes, T. Jach, R.E. LaVilla, and B.A. Karlin

P.L. Cowan, S. Brennan, T. Jach, R.E. LaVilla, and B.A. Karlin

R.E. LaVilla, S. Brennen, P.L. Cowan, T. Jach, and B. Karlin
Surface EXAFS Study of Surface BaO Layers on Tungsten Surfaces

Escape Depth of Electron-Detection EXAFS

Structural Studie: of Epitaxially Grown Polycrystalline Diamond.

Structural Analysis of Plasma Sprayed NiCrAlY Coatings

Relationship of the Concentration-Dependent Ti Center to the $\mathrm{LiNbO}_{3}$ Ordinary Optical Index

EXAFS Studies on Plasma Spray Quenched Materials.....

Appearance Potential X-ray Fluorescence Spectroscopy ....

XANES Study of Ion Conducting Polymers

$\mathrm{X}-24 \mathrm{~A}$ Instrumentation: Performance of a High Energy Resolution, Tender X-ray Synchrotron Radiation Beamline

X-24A Instnumentation: Performance of a Multilayer Mirror as a Pre-Filter for a Synchrotron X-radiation Beamline....

3-160

X-24A Instrumentation: Performance of a Tunable Secondary X-ray Spectrometer

X-24A Instrumentation: X-Ray Mirror Characterization for $X-24 A$

X-24A New Experimental Techniques: Energy Selective Excitation of X-ray Emission Spectroscopy

X-24A New Experimental Techniques: Polarization Analysis of $\mathbf{X}$-ray Emission Spectra

X-24A New Experimental Techniques: Developments in Back-Reflection $\mathbf{X}$-ray Standing Wave Analysis

X-24A Atomic Physics: Studies of Argon K-Edge Absorption

X-24A Atomic Physics: Resonant Inelastic X-ray Scattering from Argon Gas

$\mathrm{X}$-24A Atomic Physics: The Origin of the Argon KB" Satellite in the $\mathrm{KB}$ Emission Spectrum 
T. Jach, P.L. Cowan, S. Brennan, R.E. LaVilla, and R.D. Deslattes

T. Jach, P.L. Cowan, S. Brennan, R.E, LaVilla, and R.D. Deslattes

B.H. McQuaide, D.E. Jenkins, M.D. Hawkins, M.S. Banna, P.L. Cowan and B.A. Karlin

R.C.C. Perera, P.L. Cowan, T, Jach, R. E. Lavilla, D.W. Lindle, and B.A.

Karlin

D.W. Lindle, P.L. Cowan, R.E.

LaVilla, T. Jach, B. Karlin, and R.D.

Deslattes

D.W. Lindle, P.L. Cowan, T. Jach, R. E. LaVilla, B.A. Karlin, and R.C.C. Perera

P.L. Cowan, R.D. Deslattes, T. Jach, R.E. LaVilla, D.W. Lindle, and B.A. Karlin

R.E. LaVilla, P.L. Cowan, D.W.

Lindle, S. Brennan, B. Karlin, and R.

D. Deslattes

J. Rowe, F. Sette, P.L. Cowan, T. Jach, and B.A. Karlin

F. Sette, J. Rowe, P.L. Cowan, T. Jach, and B.A. Karlin

T. Jach, P.L. Cowan, F. Sette, J.

Rowe, and B.A. Karlin

Beam Line X24C

J.P. Long, J.C. Rife, H.R. Sadeghi, and M.N. Kabler

Beam Line X26

J. Chen, E.C.T. Chao, J. Minkin, J. Back, W. Bagby, A. Hanson, K. Jones, M. Rivers, and S. Sutton

K.W. Jones, B.M. Gordon, A.L. Hanson, B.M. Johnson, M. Meron, J.G. Pounds, J.V. Smith, M.L. Rivers, and S.R. Sutton

S.M. Lasley and J.G. Pounds
$X-24 A$ Atomic Physics: Energy Dependence of the $K \beta^{v}$ Satellite in Ar Gas

X-24A Atomic Physics: Unusual Threshold Behavior of the $K \beta^{\mathbf{V}}$ Fluorescence Satellite in Ar Gas.

3-170

X-24A Atomic Physics: Observation of Multivacancy Photoelectron Satellites from Argon Gas.

X-24A Chemical Physics: Sub-Threshold Excitation of C1 Fluoresence from Chloro-Fluoro-Methanes

X-24A Chemical Physics: Polarization of X-ray Fluorescence from $\mathrm{CH}_{3} \mathrm{Cl}$

X-24A Chemical Physics: Polarization of X-ray Fluorescence from Chloro-Fluoro-Methanes.

X-24A Chemical Physics: Near-Resonant Excitation of Sulfur X-ray Emission from Sulfur Hexafluoride .........

X-24A Solid State Science: Potassium and Chlorine KAbsorption and $K \boldsymbol{\beta}$ Fluorescence of $\mathrm{KCL}$

X-24A Surface Science: Structure of C1 Adsorbed on Cu(100) Determined by Back-Reflection X-ray Standing Waves

$X-24 A$ Surface Science: Structure of $S$ Adsorbed on $\mathrm{Cu}(100)$ Determined by SEXAFS and Back-Reflection Xray Standing Waves

X-24A Surface Science: Temperature Dependance of Sulfur Adsorption Site on $\mathrm{Cu}(100)$ Studied by BackReflection X-ray Standing Waves

Combined Laser-Synchrotron Photoemission Experiments on $\mathrm{X}-24 \mathrm{C}$

Synchrotron Microprobe and Micro-Optical Study of Gold in Carlin-Type Ores

FY 1987 Research Activities on the X-26 Beam Port.....

3-182

Regional Alterations in Trace Element Content in Brains of Lead-Exposed Rats 
R. Murphy, In-Whan Lyo

Physics Dept., Univ. of Pennsylvania, Philadelphia, PA 19104

W. Eberhardt

EXXON Research and Engineering Co., Route 22 East, Annandale, NJ 08801

We have studied the effects of nuclear motion on the Deexcitation electron spectrum of $\mathrm{N}_{2}$, $\mathrm{C}_{2} \mathrm{H}_{2}$, and $\mathrm{CO}_{2}$ resulting from the Auger-like decay of a neutral core to bound state excitation into single hole final states. Here we want to report the results for $N_{2}$. The initial $1 s+1 \pi_{g}$ core excitation of $\mathrm{N}_{2}$ was accomplished using quasi-monochromatic radiation from the soft $x-$ ray undulator on the X17T beamline. The $I \pi \mathrm{m}$ core excited state has a lifetime of $10^{-14} \mathrm{sec}$ which is comparable to the vibrational period of the $\mathrm{N}_{2}$ molesule. This state undergoes an Auger type deray to the $3 \sigma^{-1}$ and $1 \pi^{-1}$ single hole final states. The resulting spectrum is shown in Fig. 1 (labelled DES) with the $1 \pi_{u}$ single hole final state peaked at $17 \mathrm{eV}$ binding energy while the $3 \sigma_{\mathrm{g}}{ }^{-1}$ final state shows a broad vibrational sequence.

This deexcitation lineshape depends upon the electronic matrix elements for the excitation and decay process and the product of vibrational matrix elements from the initial state to the intermediate core excited vibrational states times the element from the intermediate state to the final vibrational state. The vibrational structure is modulated by the time evolution of the core excited state before It decays and interference effects result from the two step nature of the process. This is in contrast to a photoemission event which leads to the same single hole final states in a one-step process. The corresponding photoelectron spectrum is shown in the top part of Fig. 1 (PES).

Using a simple Franck Condon analysis ${ }^{1}, 2$ wth a complete decoupling of the Auger and vibrational matrix elements, we were able to reproduce the deexcitation spectrum very well. This leads to the conclusion that despite the short lifetime of the core excited state, the vibrational structure is dominated by the overlap between the core excited vibrational state and the final vibrational state. The $1 \pi_{\mathrm{u}}^{-1}$ intensity falls into one transition. Simllarly, the broad $3 \sigma_{\mathrm{g}}^{-1}$ vibrational structure can be explained by the large change in equilibrium nuclear sparing in this transition. We find that the interference ten for the two step deexcitation process plays a minor role in determining the vibrational substructure.

The deexcitation vibrational structure is compared to that seen in direct photoemission in Fig. 1. Here the rlassical argument for the large vibrational structure in the $1 \pi u^{-1}$ final state is simply that a large change in equi..ibrium bond length has occurred directly from the initial to the final 'state when the bonding $1 \pi_{u}$ electron is ejerted. The $3 \sigma_{g}$ photoemission hardly causes any bond length change and thus appears as nearly one peak. These type of experiments involving extremely shortlived intermediate states open up the possibility to study the dynamical processes and energy dissipation in a new, sub-picosecond time regime. The interference processes, which will be more prominent if the timescale gets even shorter, 1.e. for similar deray processes in molecules composed of atoms with a larger $Z$, allow for a test of quantum mechanics at a very fundamental level. These studies were carried out at the X17T spectroscopy beanline at the NSLS. This experimental program is partlally supported by NSF under grant *NSF-DMR-851919.

${ }^{1}$ N. Correla, A. Flores-Rtveros, H. Agren, K. Helenelund, L. Asplund, U. Gellus, J. Chem. Phys. 83, 2053 (1985). ${ }^{2}$. Murphy, In-Whan Lyo, W. Eberhardt, Phys. Rev. Letts., submitted.

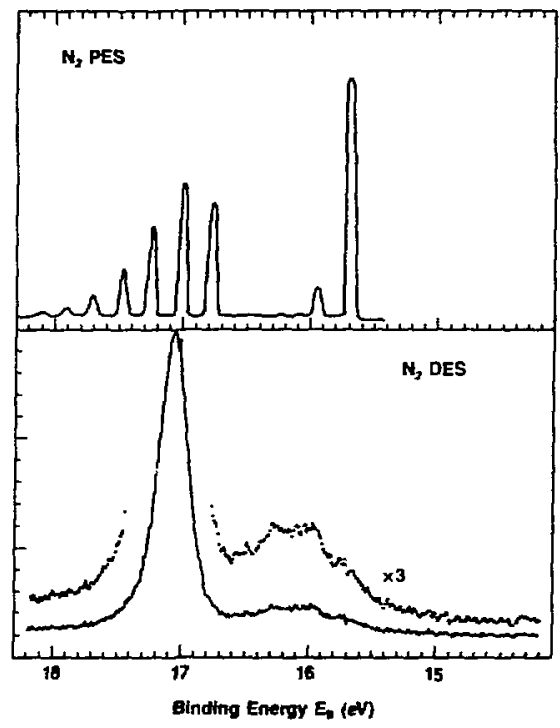

Fig. 1 Photoemission spectra (taken from A.L. Gardner and J.A.R. Samson, J. Chem. Phys. 62, 1447 (1975)) in top panel and Deexcitation Electron spectrum of $\mathrm{N}_{2}$ in the bottom panel. The electron spectra are shown on a binding energy scale and the emission observed corresponds to the creation of the $3 \sigma_{\mathrm{g}}^{-1}\left(\mathrm{X}^{2} \Sigma_{\mathrm{g}}{ }^{+}\right)$and $1 \pi_{\mathrm{u}}^{-1}$ $\left(\mathrm{A}^{2} \Pi_{\mathrm{u}}\right.$ ) states of $\mathrm{N}_{2}{ }^{+}$. 
Tre sol-gel transition of gelatin in solution $\left(0.1 \mathrm{M} \mathrm{NaCl}, \mathrm{PH}_{-} 7\right)$ with concentrations varying from $0.5 \%$ to $22 \%$ was investigated by means of small angle $X$-ray scattering (SAXS). Gelatin solutions were quenched from $50^{\circ} \mathrm{C}$ (sol) to $-11^{\circ} \mathrm{C}$ with the gelatin temperature measured at $30^{\circ} \mathrm{C}$

using optical rotary dispersion. Figure 1 shows typical time-resolved scattering patterns of the gelatin sol-gel transition using $0.5 \%$ gelatin in $0.1 \mathrm{M} \mathrm{NaCl}$ and a temperature jump fron $50^{\circ} \mathrm{C}$ to $10.9^{\circ} \mathrm{C}$. The scattering curves repiesent a growth of scattered intensity, especially at small scattering angles as a function $0:$ time. After quenching, the scattered intensity rimained relatively weak until the sample temperature reached about $30.7^{\circ} \mathrm{C}$. Each curve was measured for a period of 100 seconds. The bottom curve represents a composite scattering curve with temperatures varying from 30.7 to $13.6^{\circ} \mathrm{C}$. The next composite scattering curve from the bottom represents a temperature variation from $13.6^{\circ} \mathrm{C}$ to $11.4^{\circ} \mathrm{C}$ over the $100-s e c o n d$ period. The remaining curves (third curve from bottom to top curve) are at $10.9^{\circ} \mathrm{C}$. If we denote the bottom curve as the starting time, the time sequence for the eight representative curves (from a total of 30) is $0,100,400,900,1400,1900,2400,2900$ seconds.

The details of the scattering curves will be analyzed in terms of fractal dimension and in combination with $l$ igit scattering and small angle neutron scattering data.

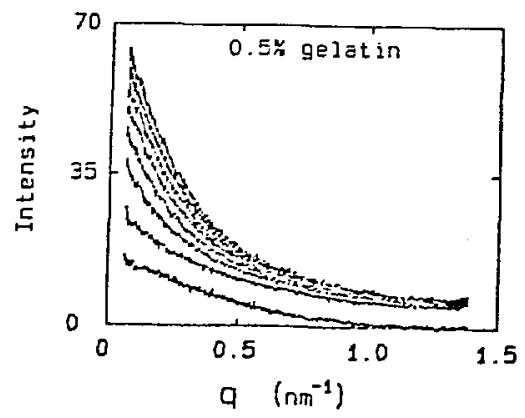

Figure 1. Sol Gel Transition of Gelatin. 
TIME-RESOLVED SAXS STUDY OF CRYSTALLIZATION BEHAVIOR OF BLENDS OF HIGH AND LOW DENSITY POLYETHYLENE. B. ChU (SUHY/STONY BroOK).

The crystallization behavior of blends of high and low density polyethylene (PE) was investigated using time-resolved small angle $x-r a y$ scattering (SAXS). Crystallization processes of high density PE, low density PE and 50:50 HD/LD PE were studied as follows: (1) slow cooling of the samples from the melts to near the crystallizarion temperatures, (2) isothermal crystallization using temperature jumps from $135^{\circ} \mathrm{C}$ to $110^{\circ} \mathrm{C}$ for HDPE, and from $109^{\circ} \mathrm{C}$ to $99^{\circ} \mathrm{C}$ for $L D P E$, and (3) quenching of samples from $T>T_{\mathbf{g}}$ to $T C C T_{\mathbf{g}}$. Separate crystallization phenogena were observed.

Figure 1 shows typical SAXS curves of siow cooling of 50:50 HD/LD PE (cooling rate $\approx 0.3^{\circ} / \mathrm{min}$ ). By comparing the scattering curves with those obtained from HDPE and LDPE, we can deduce the crystal growth process and its origin, which cannot be obtained by standard SAXS measurements.

The details of the crystallization process for HDPE/LDPE polymer blends will be studied using the existing HDPE, LDPE and 50:50 LDPE/HDPE blend samples at different temperature jump distances from the crystallization temperatures in order to reduce the rate of crystallization.

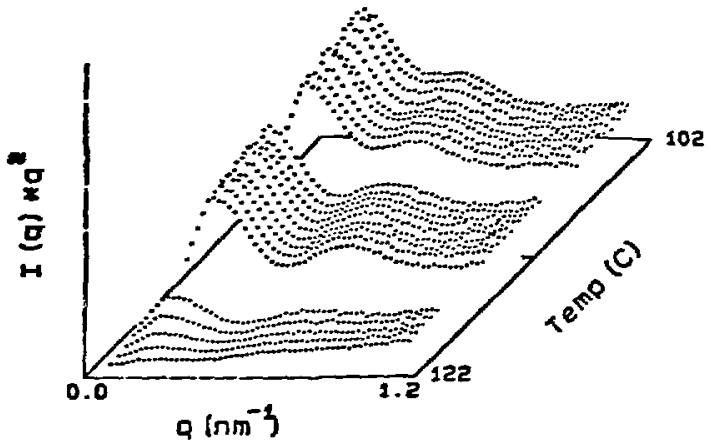

Figure 1. Typical SAXS curves of siow cooling of $50: 50$ HD/LD PE (cooling rate $=0.3^{\circ} / \mathrm{min}$ ). 
ERACTAL GEONETRY IN BRANCHED EPOXY POLYMER KIHETICS. B. CHU, O. WU, D. -Q. Wu (SUHY/StONY Brook).

The fractal dimension $d_{f}$ of a branched epoxy polymer (DGEe) before its gelation point has been measured by smell-angle $x$-ray scattering. The fractal dimension $\left(d_{f}=2.17\right.$ using a molar ratic of epoxy (LGEB):curing agert (CH):catalyst (CA) = $1: 2: 0.001$ at $30^{\circ} \mathrm{C}$ ) could be used to provide a new description of the structure of epoxy polymers as well as additional macromolecular information on the kinetic process.

From our SAXS results, we can draw the following conclusions:

1. We can use SAXS to determine $d_{f}$ which is related to the epoxy polymer structure.

2. Before the gel point, we can determine $M_{w},{ }_{g}$ using static scattering techniqueg. With $d_{f}$ the molecular weignt distribution at each stage of the polymerization process can be obtained experimentally from dynamic light gcattering, especially in view of the fact that the particle scattering factor in the visible range for guch epoxy systems is near unity.

3. Beyond the gel point, we can use fractal dimengion to investigate changes in epoxy structure.

A detailed study of the structure and dyramles of this epoxy model system using a combination of SAXS and 1 igit scattering is underway. 
SYNCHROTRON RADIATION STUDY OF THE FIVE-DIMENSIONAL, MODULATED PHASE OF TTE-TCNQ AT $15 K$. P. Coppens, D. Levendis, A. Paturle, V. Petricek, Gao Yan (SUNY/Buffalo) and F.K. Larsen (U. of Aarhus, Denmark).

The one-dimensional conductor TTF-TCNQ (tetracyanoquinodimethanide-tetrathiofulvalene) undergoes a Peierls transition at $53 \mathrm{~K}$ and further transiormations at 49 and $38 \mathrm{~K}$. Though the modulation vectors have been determined and the average structure is known at $45 \mathrm{~K}$ (1), detailed information on the molecular displacement has been lacking. The scarcity of experimental information is due to the weakness of the satellites which are typically $10^{-4}$ times the irtensities of the main reflections.

With the synchrotron source we have measured a total of 564 reflections, including 450 satellite reflections with $\sin \theta / \lambda$ in the range of $0.2-0.5 \mathrm{~A}^{-1}$. Satellite intensities on an absolute scale were obtained by scaling the main reflection intensities to $F^{2}$ values calculated from the $45 \mathrm{~K}$ parameters (1). 137 unique satellite intensities with $I>30$ were used in the least squares refinement in the five-dimensional centrosymmetric super-space group P:P2,/c:cmm.

Equations for the displacements of symmetry-related atoms in the five-dimensional case will be given elsewhere. A new computer program, JANA5, was used. We assumed, as in our previous work (2), that the molecules are displaced as rigid bodies by the modulation wave. This assumption greatly reduces the number of parameters to be determined.

The final R-value for 137 satellite reflections is 0.198 . The main feature of the $2 k$ modulation is a translational displacement of the TTF molecules. The largest magnılude, for the $\mathrm{q}_{2}$ translational wave of TTF is $0.0191(8)$ A (Figure 1). All other translations, though experimentaliy significant, are smaller than 0.01 月. The rotations are less than $0.2^{\circ}$. The direction of the main translational displacement is within experimental error along the long molecular axis of both molecules. The largest atomic displacement under these modes is only about $0.003 \mathrm{~A}$.

A most curious result is that different stacks distort in different ways, thus creating a band gap which is different for chemically equivalent columns.

References

1. A.J, Schultz, G.D. Stucky, R.H. Blessing and P. Coppens, J. Am. Chem. Soc. 98,3194 (1976).

2. V. Petricek, P. Coppens, and P.J. Becker, Acta Cryst. A41, 478-483 (1985).

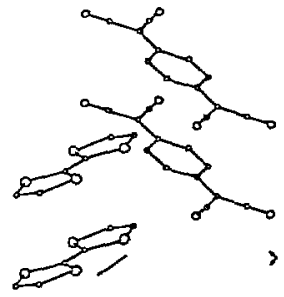

Figure 1. Relative arrangement of TTF and TCNQ molecules. Arrows represent the anplitudes of the main modulation waves enlarged by a factor 100. The TCNQ modulation has a component along the molecular normal, while the TTF modulation represents a slip along the long molecular axis. 
$X$-RAY STANDING WAVE MEASUREMENTS AT BRAgG ANGLES ClOSE TO 9O degreES. K.-G. HUang, J. Zegenhazen, W.M. Gibson (SUNY/Aibany) and J.C. Phillips (SUNY/Buffalo).

The $X$-ray standing wave (XSW) technique is a sensitive probe for investigating the structure of the surface and interface region of perfect single crystal substrates (1). With an (hkl) reflection the (hkl) Fourier component of the distroution function of atoms under consideration $1 \mathrm{~s}$ determined. XSw data are taken scanning in angle whin the range of total Bragg reflection. The reflection curves become very narrow for hign (hkl) indices. However, for Bragg reflections ciose to 90 degrees the rocking curve width $\Delta \theta$ increases drastically to $\left(\Delta \theta-\operatorname{Sin}^{-1}(2 \theta)\right)$. We performed XSW measurements for Nis 2 MBE produced epitaxial layers on Si(555), with Bragg angles up to 89.4 degrees. Higher order Fourier components could be determined. The wide rocking curves (32 sec of arc in our case) may allow use of less perfect sibstrates where commonly XSW measurements are not possible.

References

1. B.W. Batterman, Phys. Rev. Lett. 22, 703 (1969). 
X-RAY REFLECTIVITY AND INTERFACIAL ROUGHNESS. Y.H. KaO (SUNY/StonY Brook).

We have recently carried out extensive studies of $x$-ray reflectivity and developed a new method for determining the interfacial roughness between different materials in semiconductor heterostructures. By using grazing angle $x$-ray incident on semiconductor heterostructures, we have found pronounced oscillations in the reflectivity. These oscillations are later identified as the analogue of the Newton's ring effect in the $x$-ray wavelengths. The angular dependence of these oscillations is related to the thickness of the epilayer and the interfacial roughness. By a comparison between the experimental data and a theoretical model based on the Fresnel equations modified to include some roughness parameters, we were able to determine for the first time the interfacial roughness of a sub-surface interface between InAs and GaAs. Also, the thickness of the epilayer was accurately determined. These results have been submitted for publication. 
SMALL ANGLE X-RAY SCATTERING OF POLYSTYAENE IONOMERS. BEn ChU, D.-Q. WU, C. WU ISUNY/StONY Brooi), W.J. Macknight, C.W. Lantman (J. of Massachusetts), J.C. Phillips and A. LeCrand (Brookhaven National Laboratory and SUNY/Buffalo), R.D. Lundberg (Ex\%on).

Small angle X-ray scattering (SAXS) studies using a new modified Kratky block collimation system have teen made on polystyrene ionomers. The sulfonated polystyrene $\left(\mu_{\mathrm{w}}=1 . \mathrm{i}^{5 \times 10^{5}}\right)$ samples include both narrow and broad molecular weight distributions ( $\left.M_{w} / M_{n}=1.04,2.65\right)$ in acid form as well as sodium and zinc salis. The mole sulfur raries from 1.3 to 4.5 with the exception of sodium salt form to 7.5. We were able to achieve a q range between 0.1 and 7.5 $\mathrm{nm}^{-1}$ where $\mathrm{q}=(4 \pi / \lambda) \sin (\mathrm{g} / \lambda)$ with $\lambda=0.154 \mathrm{~nm}$ and $\mathrm{g}$ being the scattering angle.

we nave been able to measure the details of the statio structure factor including the temperature effects from $27^{\circ} \mathrm{C}$ to $250^{\circ} \mathrm{C}$. The nature of the ion clusters, including variations in action form, polydispersity and ior content bive information on inter- and intramolecular interference models. 
MULT I-TEMPERATURE EXAFS SPECTROSCOPY OF SIX COORDINATE, HIGH SPIN MESO-TETRAPHENYLPORPHINATOBIS-TETRAHYDROFURAN IRON(II). T. F. McNulty, J. C. Phillips, P.Coppens (SUNY/Buffalo).

The high spin, six coordinate iron porphyrin meso-tetraphenyl-porphinato-bis-tetrahydrofuran iron(II) (FeTTP(THF)2), has been studied using EXAFS spectroscopy. Our low-temperature crystallographic analysis, done at a conventional source, showed a large contraction of the axial Fe-O bond between room- and liquid-nitrogen temperatures. Magnetic measurements showed anomalies in the paramagnetism below the latter temperature. In order to investigate if a further contraction below liquid-nitrogen can explain the magnetic observations a series of EXAFS experiments were conducted at various temperatures down to $20 \mathrm{~K}$. The results convincingly show that no further contraction occurs. The observed increase in magnetic moment remains unexplained. 
PROTEIN FOLDING OBSERVED BY TIME-RESOLVED SYNCHROTRON X-RAY SCATTERING - A FEASIEILITY STULY. James C. Phillips (SUNY/Buffalo).

The ability to calculate the 3D structure of proteins from knowledge of treir sequence (or their gene seguence) would be a major advance in biology and biotechnology. The database for such calculations can be enhanced by knowledge of intermediate structures from time-resolved measurements of proteins folding and unfolding in solution. This project seeks to test the feasibility of using a powerful synchrotron radiation source, combined witn $t-j u m p$ and timeresolved X-ray scattering techniques to investigate pathways of protein folding. ile have used the SUNY X21 beamline, SAXS bench and time-resolved data acquisition system for initial studies in this area. A temperature jump apparatus was constructed to study thermally induced folding and unfolding. Scattering of solutions uf myogisbin in the angular range $20=1-50 \mathrm{mrad}$ was measured during temperature jumps cetween $25^{\prime}$ and $75^{\circ} \mathrm{C}$. T-raise data show clear signs of structural changes (Figure 1), however, the T-drop experiments show minimal changes. Moreover, the T-raise changes are reproducible only qualitatively, not quantitatively. A tentative interpretation of the observations is as follows: (1) heating to $55^{\circ} \mathrm{C}$, no big structural

change (2) by $55^{\circ} \mathrm{C}$ partial unfolding with increased radius of gyration foilowed by (3) mostiy unfolded followed by (4) irreversible aggregation.

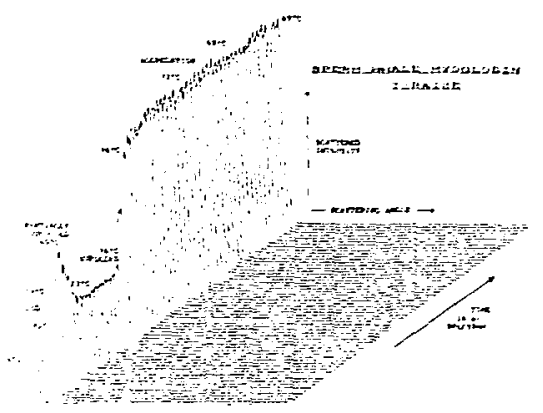

Fizure 1. Time-resolved keasurement of $x$-ray Scattering of a Solution of Sperm winale Myoglobin as the Temperature is Raised. 
PEROVSKITE. C.T. Prewitt (Geophysical Lab. Washington, DC) and D.J. Weidner (SUNY/Stony Brook).

The perovskite crystal structure is of interest because its derivatives constitute the high $T_{c}$ superconductors that have been the focus of widespread inquiry in the past few months. $(\mathrm{Mg}, \mathrm{Fe}) \mathrm{SiO}_{3}$ perovskite is thought to be the most abundant mineral in the earth, comprising the bulk of the lower mantle below $670 \mathrm{~km}$. The orthorhombic $\mathrm{MgSiO}_{3}$ perovskite structure has two crystallographic sites, one normally occupied by $S i$ in octahedral coordination and the other occupied by eight-coordinated $\mathrm{Mg}$. A recent EXAFS and XANES study at SSRL on (Mg.Fe)SiO, synthesized in a diamond-anvil cell indicated disorder between these two sites with Fe on the octahedral site and, presumably, Si on the eightfold position (1). This is an unexpected result that has important implications for the phase equilibria of the lower mantle and for silicate crystal chemistry. One problem with these experiments is that only a very small quantity of material can be made in the diamond cell, i.e., a disk-shaped polycrystalline sample about 80-100 microns in diameter and 20 microns thick. Our intention in this experiment was to obtain a powder diffraction pattern and to analyze the cation distribution through profile fitting of the pattern by the Rietveld technique. Figure 1 shows the observed pattern for $\left(\mathrm{Mg}_{0.9}, \mathrm{Fe}_{0.1}\right) \mathrm{SiO}_{3}$. However, because of the very high background, we have been unabie to verify $w^{2}$, ther disorder is present in the sample. Further experiments will have to be made after mu'. more effort has been made to reduce the background through the addition of slits and collimators to the diffractometer system on the beamline. Also, the X-ray wavelength used, 1.41 \& may be causing fluorescence in the sample.

\section{References}

1. W.E. Jackson, E. Knittle, G.E. Brown, Jr., and R. Jeanloz (1987). Partitioning of Fe within high-pressure silicate perovskite: Evidence for unusual geochemistry in the lower mantle. Geophys. Res. Letters 14, 224-226.

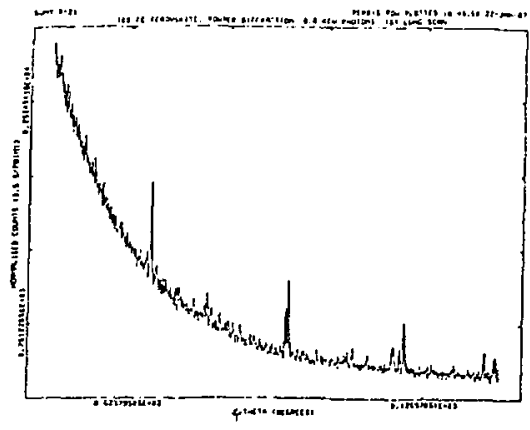

Figure 1. Powder diffraction pattern of $10 \%$ Fe perovskite, $8.8 \mathrm{keV}$ photons. 
THERMAL DIFFUSE SCATTERING IN $\mathrm{KMgF}_{3}$ AT ROOM TEMPERATURE AND ELEVATED TEMPERATURES. D.J WeidnER, Amir Yeganeh-Haeri (SUNY/Stony Brook), D. Swanson, (DuPont), and C.T. Prewitt, (Geophysical Lab., Washington, DC).

Previous attempts to isolate the thermal diffuse scattering contribution to the scattered $x$-ray intensities have proven unsuccessful. This experiment was designed to optimize the possibilities of observing such a signal by observing the $x$-ray scattering at elevated temperatures and at a higher scattering angle.

A 300 micron single crystal which was spherical in shape was used in the experiments. $X-r a y$ intensities were collected at the $(033)$ Bragg reflection. Intensities were measured along 3 perpendicular directions extending 0.08 reciprocal lattice vectors away from the Bragg $s p o t$ at intervals of 0.01 . The TDS intensities of these three lines should be proportional to: $1 /\left(q^{*} q^{*} C\right)$, where $q$ is the distance from the BragB position in reciprocal space and $C$ is the elastic modulus $\left(\mathrm{C}_{11}+\mathrm{C}_{12}+2 \mathrm{C}_{44}\right) / 2 \cdot \mathrm{C}_{44}$, or $\left(\mathrm{C}_{11}-\mathrm{C}_{12}\right) / 2$ depending on which 1 ine.

The slope of a straight line for I vs. $1 /\left(q^{*} q\right)$ should be proportional to $1 / C$. The data can thus be evaluated as to whether or not the ratios of slopes for two such lines agrees with the known ratios of elastic moduli.

The room temperature data are not consistent with the intensities observed in this region being of TDS origin. The intensities and slopes for the line parallel to ( 011 ) (which is the two theta-omega direction and corresponds to the longitudinal acoustic direction of the TDS) are both quite low. The two perpendicular lines by comparison yield slopes that are an order of magnitude too large. Thus, while the shape has the correct sign, the shape of the diffuse scattering intensity contour is too much like a pancake relative to that expected from TDS. These results were reproduced in two data sets and qualitatively in agreement with the previous experience.

The high temperature $(600 \mathrm{C})$ results are much more encouraging. The slopes are consistent with those expected from TDS with about a factor of two uncertainty. This uncertainty is a reflection of the reproducibility of the results.

We conclude that we have detected diffuse scattering that is dominated by TDS. However, it is still not usable to determine the single crystal elastic properties or their variation with pressure or temperature. Counting time can be extended to give a better statistical evaluation of the high temperature data. However, longer counting times would not qualitatively improve the room temperature data. The use of TDS as a means of exploring elastic properties using synchrotron radiation and smali samples probably awaits higher resolution of the energy of the detected $\mathrm{X}$-ray (perhaps $0.01 \mathrm{ev}$ ). 
o. Kistner, G. Matone, A. Sandorft, C. Thorn, (BNL)

G. Giordano, (INEN, Erascatti, Italy)

C. Schaerf, (Univ. II Rome, Italy)

M. Blecker, C. Does, (Virginia Polytechnic Inetitute)

B. Preedom, S. Whisnant, K. Mize, M. Whitlow (Univ. South Carolina)

S. Thornton, and R. Sealock (Univ. Virginia)

The first gama-ray beams from the Laser-Electron-Gama-Source (LEGS) were produced on Thursday, May 21, 1987 during a three week period of initial tests. Gammas were also successfully tagged in this test run. UV light at 351 nm from an Ar-ion laser was backscattered from $2.5 \mathrm{GeV}$ electrons circulating in the $X-$ ray ring to produce gamma-rays up to 300 MeV. The spectrum of gamma-rays, observed by a 10 by 14 inch MaI(Tl) detector, is shown at the top of the $f$ igure. The lower part of the figure is the epectrum of gamma-rays in coincicence with electrons detected at an intermediate point in the partially completed tagsing spectrometer. The measured rate of the gamma-ray beam, normalized to the etored beam current and laser power, was 35 per second-MeV-mA-Watt. Both the shape of the spectrum and the observed rata are in excellent agreement with calculated predictions. At the full ring current of $300 \mathrm{~mA}$ and with 3 watts of uv power, the backscattered gamma-ray beam rate will be 107 per second.

These tests followed a shutdown perlod in the spring during which a part of the LEGS equipment was installed in the $X$-ray ring tunnel. The principal items installed were the modified dipole vacuum chamber, one of the magnets for the tagging spectrometer, and a COz laser in the center of the injection straight section for measuring the energy of the stored beam. The Ar-ion laser was installed in the LEGS hutch prior to the beginning of the shutdown. During the test period the computer controlled aiming system for the laser demonstrated its capabilities both in finding the alignment of the laser beam with the electron beam in the injection straight section and in waintaining this alignment to produce a stable gamma-ray beam. The measured positioning accuracy of the laser optical system is 10 micrometers and 10 microradians. Definitive tests of the operation of the $\mathrm{CO}_{2}$ laser system were not possible because of the poor vacuum in the injection straight section.

The tagging spectrometer for LEGS consists of four dipole magnets, the first of which is the ring dipole X1BM1. The second dipole is a septum magnet with a gradient field which will operate with a field of $2 T$ at $3 \mathrm{~cm}$ from the stored beam. This magnet has been carefully designed to minimize the leagage fleld at the stored bean. It is made of Hiperco-50, an alloy of Iron and cobalt that has high permeability at high fields $(40,000$ at 1.9 T), and the current septum has been located outside the magnetic gap along the front face of the magnet in such a way as to cancel the gradient of the leakage field at the position of the stored beam. Three sets of trin colls wound on the front face of the magnet are used to further minimize the leakage field. This magnet was thoroughly tested before installation in the $X-r a y$ ring, and can produce fields in the working gap up to $2.2 \mathrm{~T}$ with leakage flelds less than $2.5 \times 10^{-5}$ $T$ at the stored beaw. During the test period with beam in the ring, repeatedly turning this magnet on and off produced no change in the orbit at $2.5 \mathrm{GeV}$ as determined by the $\mathrm{PUE}^{\circ} \mathrm{B}$.

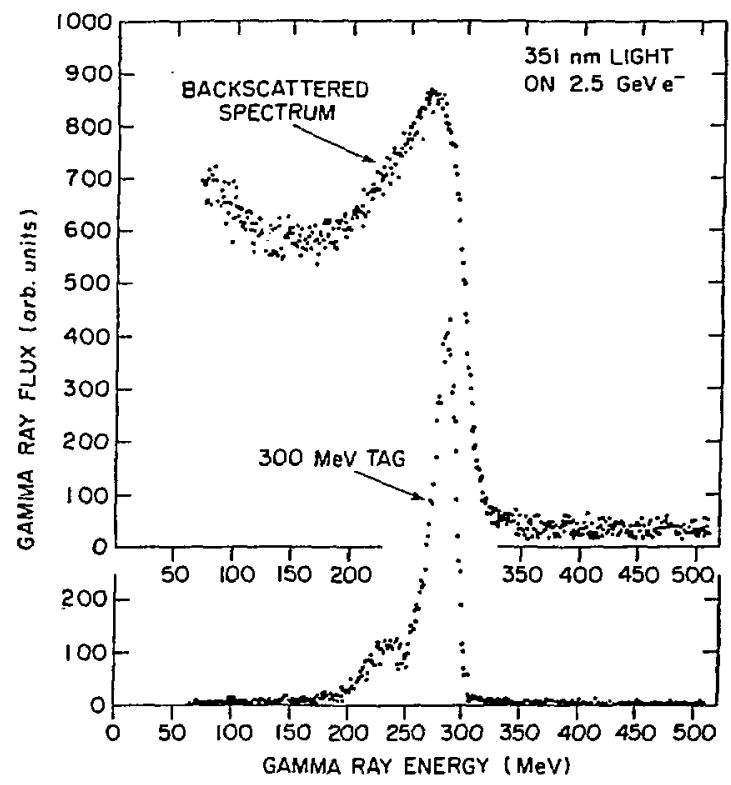

Spectrum of gamma-rays from Compton backscattering with no tagging, at top, and with energy defining electron tag at $300 \mathrm{MeV}$, at bottom. 


\section{THE CRYSTAL STRUCTURE OF AN AS-SYNTHESISED ALPO ${ }_{4}^{-16}$}

J. M. Bennett. Central Scientific Laboratory. Union Carbide Corporation. Tarrytown. N. Y. 10591 R. M. Kirchner. Manhaltan College. Riverdale, N. Y. 10471

D. E. Cox', Department of Physics. Brookhaven National Labatory. Upton. N. Y. $1 / 973$

$\mathrm{AIPO}_{4}-16$ is a member of the novel aluminophosphate-based families of molecular sieves which are an important new class of catalyst and adsorbent materials. Data were collected from a flat plate sample and indexed on a cubic cell with $a_{0}=13.384 \AA$. the space group was determined to the F23. The framework topology was determined using a modelling technique applicable to tetraheral framework structures. The data were refined using the DLS-Rietveld program of $\mathrm{Ch}$. Baerlocher. The framework topology consists of double four rings interconnected by single tetrahedra in an arrangement similar to that reported for the mineral Zunyite but with no tetrahedral vacancies. The organic template (quinuclidine) is disordered and has been sucessfully modelled in the center of the large cavity. The final positional parameters and the result of the Rietveld refinement are shown below, the differences in the tails of the peaks are cased by particle size broadening. The assistance of $\mathrm{Ch}$. Baerlocher and G. Harvey at ETH. Zürich. Switzerland during the final stages of this structure detemination is greatfully acknowledged.

\begin{tabular}{|c|c|c|c|c|c|c|c|c|c|}
\hline Atom & $x$ & $y$ & $z$ & mult. & Aton & $\mathrm{x}$ & $y$ & $\mathbf{z}$ & mult. \\
\hline A11 & 0.11547 & 0.11547 & 0.11547 & 0.3333 & P1 & -.11527 & 0.11527 & 0.11527 & 0.3333 \\
\hline A12 & 0.75 & 0.25 & 0.25 & 0.0833 & P2 & 0.25 & 0.25 & 0.25 & 0.0833 \\
\hline 01 & -.01384 & 0.13025 & 0.14632 & 1.0 & 02 & 0.18917 & 0.18913 & 0.18913 & 0.3333 \\
\hline 03 & -.17591 & 0.17591 & 0.17591 & 0.3333 & N1 & 0.0560 & 0.4329 & 0.0424 & 1.0 \\
\hline C1 & 0.0056 & 0.3916 & -.0462 & 1.0 & $c 2$ & -.0601 & 0.4680 & -.0973 & 1.0 \\
\hline C3 & 0.1159 & 0.5193 & 0.0103 & 1.0 & $C 4$ & 0.0529 & 0.5988 & -.0393 & 1.0 \\
\hline $\mathrm{c} 5$ & -.0214 & 0.4689 & 0.1118 & 1.0 & C6 & -.0878 & 0.5472 & 0.0646 & 1.0 \\
\hline $\mathrm{C} 7$ & -.0552 & 0.5662 & -.0418 & 1.0 & H7 & -.0978 & 0.6173 & -.0741 & 1.0 \\
\hline H11 & 0.0566 & 0.3668 & -.0939 & 1.0 & H12 & -.0351 & 0.3331 & -.0261 & 1.0 \\
\hline H21 & -.0382 & 0.4774 & -.1673 & 1.0 & H22 & -.1300 & 0.4437 & -.0995 & 1.0 \\
\hline H 31 & 0.1506 & 0.5481 & 0.0691 & 1.0 & H32 & 0.1686 & 0.4965 & -.0364 & 1.0 \\
\hline H41 & 0.0592 & 0.6627 & -.0025 & 1.0 & H42 & 0.0772 & 0.6110 & -.1081 & 1.0 \\
\hline H51 & -.0626 & 0.4116 & 0.1344 & 1.0 & H52 & 0.0112 & 0.4970 & 0.1722 & 1.0 \\
\hline H61 & -.1583 & 0.5246 & 0.0658 & 1.0 & H62 & -.0845 & 0.6099 & 0.1036 & 1.0 \\
\hline
\end{tabular}

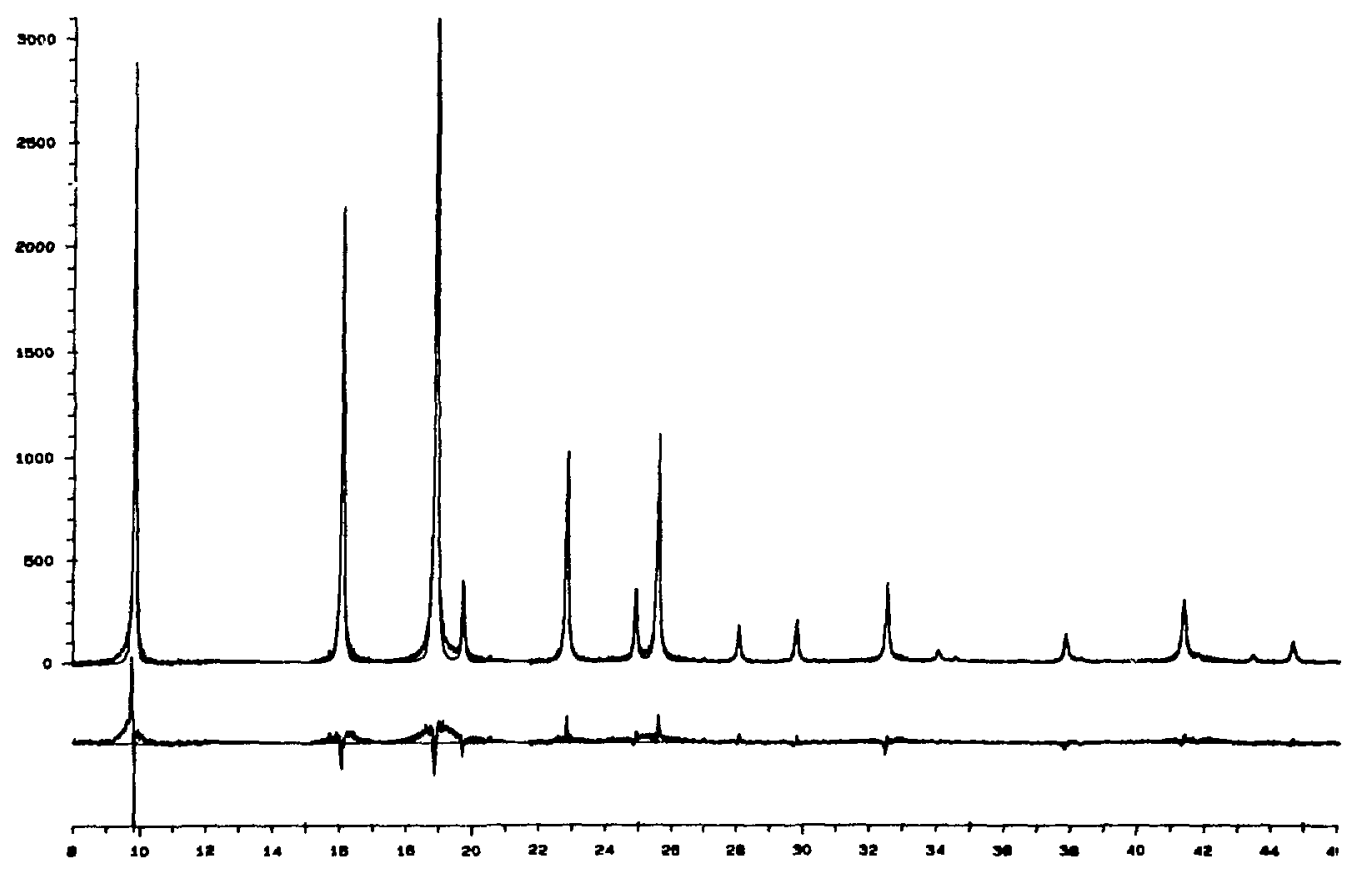

'Work was supported by the Division of Materials Sciences, U. S. Department of Energy, under contract DE-ACO2-76CHOOO16. 
APPLICATION OF IIGII RESOLUTION SYNCIIOTRON POWDER X-RAY DIFFRACTION TO TIE STRUCTURAL INUESTIGATION OF $\Lambda$ NEG NON LINEAR OPTICAL MATERIAL.

M.M.Eddy, T.E.Gler, G.D.Stucky

Dept. of Chemistry, UCSB, Santa Barbara, CA 93106.

$$
\text { J, Bierlein }
$$

E.I.Dupont de Nemours and Co.. Wilmington, DE 19898 .

$$
\text { D.E. } \operatorname{Cox} *
$$

Dept. of Physics, Brookhaven National Lab., Upton, NY 11973

Amonium titanyl phosphate (NTP) is a new non-1inear optical material which shows considerable pronise in waveguiding, electro-optic and second harnonic applications. The structure of NTP is analagous to the potassium derivative (KTP) which is the premier material used for second harmonic generation of the 1. 0 Ger YAG laser.

our structural studies lave shown that by using ion excluage or thermal. treatments the structure and non-1inear optical properties of NT can be altered considerably. However these procedures usually result in a loss of the single crystal integrity. Consequentiy powder methods are required for any structural. investigations.

The aim of our research in this area is to be able to manipulate the structure, and hence the non-linear optical properties by using simple chemical methods, such as lon-exchange or thermal treatments. To this end a sanple was prepared, designated NOTP, In which half of the ammonium had been calcined from the structure, and this had then been hydrated. This material exhibited a second hamonic signal equivalent to KTP or NTP and is the subject of this investigation.

In the early stages of data reduction it was clear that additional peiks, which could not be indexed using the orthorhomblc cell of Notp. were present. in the powder pattern. Consequently, these were excluded from the refinenent until the least squares had converged and all of the extra-framework material had been located by fourier techniques. The final results are given in table 1 . Then the calculated powder profile for NoTp was subtracted from the raw data and the structure of the inpurity phase refined using this difference data. The inpurity was found to be anatase, although the lines are substantiliy broadened. lits phase results fron partial collapse of the titanium phosphate framework.

Table 1. Final Atomic Positions for NoTP.

\begin{tabular}{|c|c|c|c|c|c|c|}
\hline Atom & site & $x / a$ & $y / b$ & $z / x$ & $B\left(\Lambda^{2}\right)$ & oce. \\
\hline Ti (1) & 10 & $0.3716(2)$ & $0.499(1)$ & 0.000 & 1. $29(6)$ & 1.0 \\
\hline $\operatorname{Ti}(2)$ & 10 & $0.2488(7)$ & $0.263(1)$ & $0.251(1)$ & 1.29 & 1.0 \\
\hline$p(i)$ & $4 a$ & $0.4976(9)$ & $0.339(1)$ & $0.255(2)$ & $1.12(8)$ & 1.0 \\
\hline$P(2)$ & 40 & $0.1830(1)$ & $0.506(2)$ & $0.509(1)$ & 1. 12 & 1.0 \\
\hline $0(1)$ & 40 & $0.490(2)$ & $0.486(3)$ & $0.115(1)$ & $0.86(8)$ & 1.0 \\
\hline $0(2)$ & $4 a$ & $0.519(2)$ & $0.160(3)$ & $0.380(1)$ & 0.86 & 1.0 \\
\hline$O(3)$ & ha & $0.400(1)$ & $0.181(3)$ & $0.290(2)$ & 0.86 & 1.0 \\
\hline$O(4)$ & $4 a$ & $0.594(1)$ & $0.213(2)$ & $0.216(1)$ & 0.86 & 1.0 \\
\hline$O(5)$ & $4 a$ & $0.116(1)$ & $0.310(3)$ & $0.51,2(2)$ & 0.86 & 1.0 \\
\hline$o(6)$ & ia & $0 . \operatorname{L16(1)}$ & $0.682(3)$ & $0.479(2)$ & 0.86 & 1.0 \\
\hline$o(7)$ & la & $0.247(2)$ & $0.560(3)$ & $0.62 / 4(2)$ & 0.86 & 1.0 \\
\hline$O(8)$ & $4 a$ & $0.260(2)$ & $0.458(3)$ & $0.385(2)$ & 0.86 & 1.0 \\
\hline $0(9)$ & ha & $0.219(1)$ & $0.034(3)$ & $0.650(1)$ & 0.86 & 1.0 \\
\hline $0(10)$ & $4 a$ & $0.231(1)$ & $0.050(3)$ & $0.391(2)$ & 0.86 & 1.0 \\
\hline$o(11)$ & $4 a$ & $0.385(1)$ & $0.786(2)$ & $0.327(1)$ & $1.04(9)$ & 1.0 \\
\hline \multirow[t]{2}{*}{$N(1)$} & $4 a$ & $0.394(1)$ & $0.193(2)$ & $0.576(2)$ & $1.0 \%$ & 1.0 \\
\hline & $\begin{array}{l}\mathbf{n} \\
\mathbf{b} \\
\mathbf{c}\end{array}$ & $\begin{array}{r}12.9154(1) A \\
6.1996(1) A \\
10.5886(1) \AA\end{array}$ & $\begin{array}{l}R_{I} \\
R_{w p r} \\
R_{e \times p}\end{array}$ & $\begin{array}{r}-6.08 \\
-19.58 \\
-14.78\end{array}$ & & \\
\hline
\end{tabular}

Space Group Pna21 (Int. Tables I No.33)

* Work supported by the Diviston of Materials Sclences, U.S. Dept. of Fnergy, under contract DE-AC02-76C1100016 
DETERMINATION OF TIIE STRUCTURE OF CdS/CdSE CLUSTERS

IN ZEOLITE-Y BY IIGI RESOLUTION POWDER SYNGIROTRON X-RAY DIFFRACTION

M.M.Eddy, J.E.MacDouga11, G.D.Stucky

Dept. of Chemistry, UCSB, Santa Barbara, CA 93106.

N.Ilerron
Nupont de Nemours and Co., Wilmington, DE 19898.
D.E.Cox*

Dept. of Physics, Building $510 \mathrm{~B}$, Brookhaven National Lab., Upton, NY 11973 .

Small wetal and seaiconductor particles, having hybrid molecular and bulk properties, represent a new class of materials and are presently under intensive investigation. Many approaches exist for preparing these small clusters. However in almost a 11 of the methods used to date the size of the cluster is not well defined. A new approach, which we have adopted, is to prepare the desired cluster inside an open framework host material. The host chosen for these studies was zeolite-Y which has the largest void volume of any zeolite.

The optical properties of zeolite-Y loaded with differing concentrations of $c$ as and cdSe have been monitored by diffuse reflectance vis/U.v. spectroscopy. In order to understand the unusual optical properties displayed by these materials a detailed knowledge of their structure is essential. Large single crystals of zeolite-Y are not available, so powder methods have dominated in the structural investigation of this aluminosilicate. The high resolution and intensity available at a synchrotron source are ideal for collecting data fron these large unit cell, weakly scattering materials.

The moisture sensitive samples were loaded into the aluninum containers and sealed with thin beryllium foil. Exposure to the afr causes migration of the scmiconductor to the zeolite surface. Beryliium forms a protective layer whicli is non-absorbing, and the small number of diffraction peaks are easily excluded from the data.

Figure 1 shows the observed, calculated and difference profiles for one of the samples studied (CdSe In zeolite-Y). It is quite apparent that the pattern calculated from the refined model is in excellent agreement with the data.

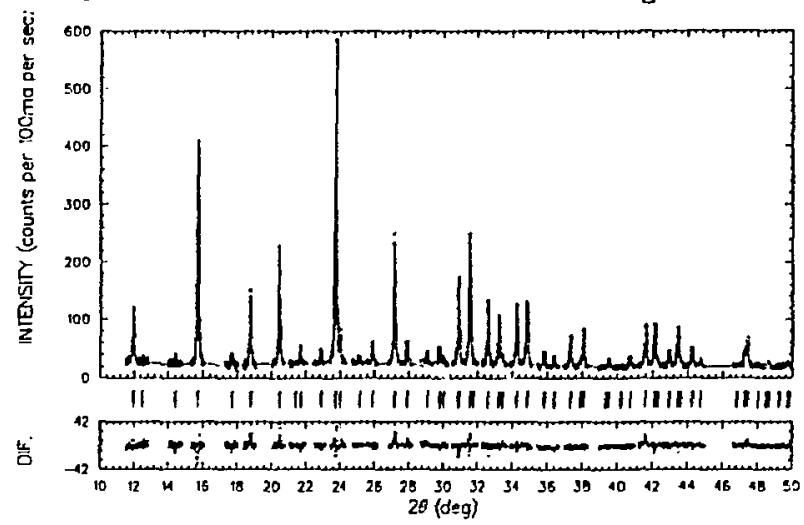

Figure 1. Observed (dots), calculated (solid line) and difference (sub-plot) profiles for cdse in zeolite-Y.

In a 11 cases the framework is essentially unchanged from that of the parent. zeolite-Y and the mean $T-O$ bond distances are in excejlent agreement with that calculated from the Si/Al ratio. Gadmiun occupies two sites, one in the sodalite six-ring, the other in the supercage twelve-ring, while the sodiur remaining after ion exchange is in the most favorable position, the six-ring window of the framework. The coordination complenent of the cadmium is mads up from framework oxygen, oxygen of hydroxide ions left after dehydration, and s or Se.

* Work supported by the Divfsion of Materials Sclences, U.S. Dept. of Energy, under contract DE-AC02-76C1100016.

1 Y. Wang. N.llerron, J.Phys.Chem..91, 257, (1987). 
T, Egani, W. Dnowski, D.D. Kofalt, I.A. Morrison, P.A. Heiney, P.A. Bancel, P.J. Steinhardt (U. of PA), S.J. Poon, Y. Shen, S. Preische, and G.J. Shiflet (U. of VA)

\section{Objective and Approach}

Extensive theoretical and experimental studies have been carried out on the structure of quasicrystals, however, wany fundamental questions renain unsolved. It is still actively debated whether the icosahedral solid is truly a quasicrystal described by a 3 -dinensional Penrose tiling (3-DPT) structure, or nerely an orientationally ordered glass. Furthermore the actual atomic structure has not been deternined. To address both of these problems we carried out differential anomalous-x-ray-scattering measurements to obtain the total and differential atomic pair distribution functions (PDF's), and compared the results with structural models.

\section{Results}

The scattering intensities fron the icosahedral (I) phase of $\mathrm{Al}_{5.5} \mathrm{II}_{3.3} \mathrm{Cu}$ were found to compare well with to the one calculated for a 3-DPT structure with $A 1$ and $C u$ atoms at the vertices and edge centers [1]. The total PDF of the I-phase and that of the Frank-Kasper (FK) phase of the same composition are very similar up to $20 \AA$ as shown in Fig. 1 [2], supporting the model by Henley and Elser, and small differences between these PDF's suggest that the I phase is not made of packed icosahedral clusters as the icosahedral glass (IG) nodel assumes. The uranium differential distribution function (DDF), which is the atomic distribution function with uraniun atons at origin, of icosahedral $\mathrm{Pd}_{58,8} \mathrm{U}_{20.6} \mathrm{SI}_{20.6}$ was determined by the differential anomalous-x-ray-scattering (DAS) [3]. The DDF agrees very well with the PDF calculated for a 3-DPT structure with the quasilattice constant of $5.14 A$ and with $U$ atoms placed at each vertex, in the range of 12 to $40 \mathrm{~A}$, as shown in Fig. 2 [4]. Also the physical density of the 3DPT model was in very good agreenent with the uranium density in the sample. The IG nodels (C and $\mathrm{D}$ in $\mathrm{Fig}$. 2) show less satisfactory agreement. The DAS measurement of $\mathrm{I}$-phase $\mathrm{Al} \mathrm{I}_{78} \mathrm{Ru}_{5} \mathrm{Mn}_{17}$ shows that Ru atoms occupy the vertex positions of a quasicrystalline sublattice [5]. These results demonstrate that sone icosahedral solids are indeed best described as decorated 3-DPT quasicrystals, and gave further insights regarding the mechanism of their stability.

\section{Ackouledgments}

The authors are grateful to the members of the PRT at X13-A (now X7-A), particularly to $D$. E. Cox. This work has been supported by the National Science Foundation through the Grants DRR8318816, DMR86-17950, DMR85-19059, DMR84-02642, and DMR82-16718.

\section{References}

[1] Y.Shen, S.J.Poon, W.Dmowski, T.Egami and G.J.Shiflet, Phys. Rev. Lett., 58, 1440 (1987).

[2] W.Dnowsk1, T.Egani, Y.Shen, S.J.Poon and G.J.Shiflet, Phil. Hag. Lett., 56, 63 (1987).

[3] D.D.Kofalt, S.Nanao, T.Egami, K.M.Wong and S.J.Poon, Phys. Rev. Lett., 57, 114 (1986).

[4] D.D.Kofalt, I.A.Morrison, T.Egami, S.P.eische, S.J.Poon and P.J.Steinhardt, Phys. Rev., B35, 4489 (1987).

[5] W.Dmowski, T.Egami, P.A.Bance1, P.A.Heiney, D.V.Baxter and J.A.Leake, Mater. Sc1. Eng., in press.

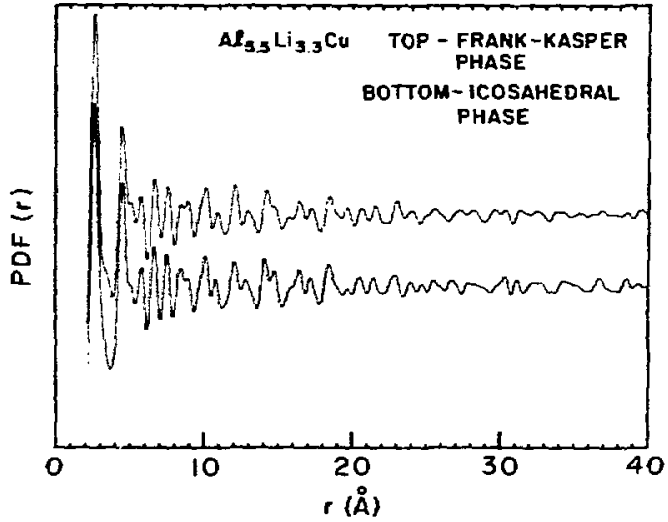

Fig. 1. Atomic pair distribution function of icosahedral and Frank-Rasper phases of $\mathrm{Al}_{5.5^{\mathrm{Li}}}{ }_{3.3}^{\mathrm{Cu}}[2]$.

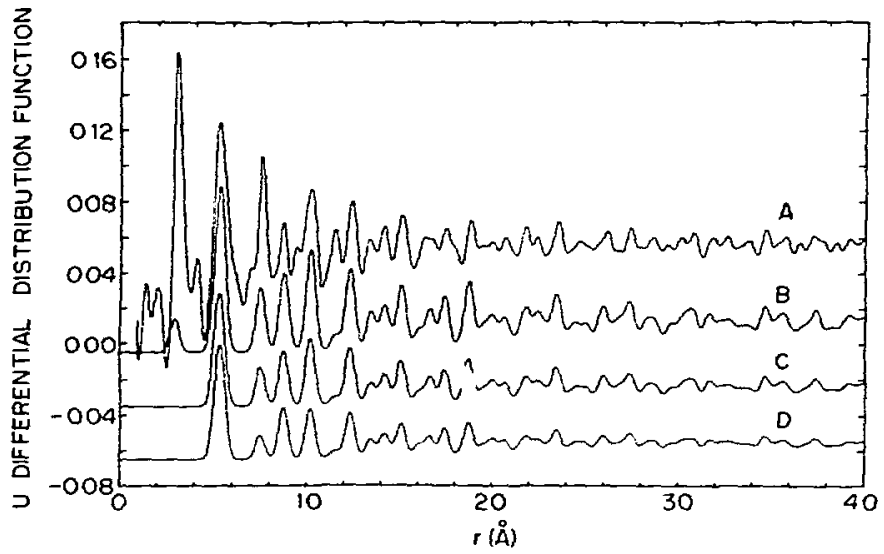

Fig. 2. Uranium DDF of $I-P_{58.8} \mathrm{U}_{20.6} \mathrm{SI}_{20.6}(\mathrm{~A})$, PDF's of 3-DPT(B), and icosahedral glass models (C and D) [4]. 
H. Gies, H. Strobl, C.A. Fyfe and G.T. Kokotailo, University of Guelph,* and D.E. Cox,t Brookhaven National Laboratory, Upton, New York 11973

ZSM-5 and ZSM-1I belong to a family of shape-selective catalysts which have important industrial applications. Their structures consist of open frameworks of essentially rigid Si0 $\mathrm{O}_{4}$ tetrahedra characterized by ten-membered ring apertures which can admit certain types of hydrocarbon molecules. As shown in Fig. 1 there are substantial differences in the magic angle spinning NMR spectra from $25 M-11$ at $25^{\circ} \mathrm{C}$ and $100^{\circ} \mathrm{C}$ indicative of some kind of symmetry change. High resolution synchrotron $x$-ray powder data have been collected at these temperatures from a Im diameter capillary specimen mounted in a furnace. A Ge(111) monochromator and a LiF(400) analyzer crystal were used, with $\lambda=1.315 A$. The use of a capillary specimen greatiy reduces preferred orientation effects, but does not lead to any loss of resolution in the diffraction pattern when the crystalana?yzer technique is used. Although no change in crystallographic symmetry can be detected at $25^{\circ} \mathrm{C}$, preliminary analysis indicates some significant changes in the environment of the Si atoms which might correspond to local symmetry changes. Full structure refinements, involving 76 structural parameters, are nearing completion.

Temperature dependence data have al so been collected from a Imm capillary sample of ZSM-5, which is known to undergo a trasition from monoclinic to orthorhombic symetry at about $100^{\circ} \mathrm{C}$, or as a function of absorbed hydrocarbon content. Some representative scans showing the splitting of the orthorhombic (133) peak are shown in Fig. 2. There is an appreciable range of coexistence of the two phases, and a build-up of some diffuse scattering between the monoclinic (133) and (133) peaks preceding the appearance of the orthorhombic phase. A structure refinement of the latter at $150^{\circ} \mathrm{C}$ is in progress.

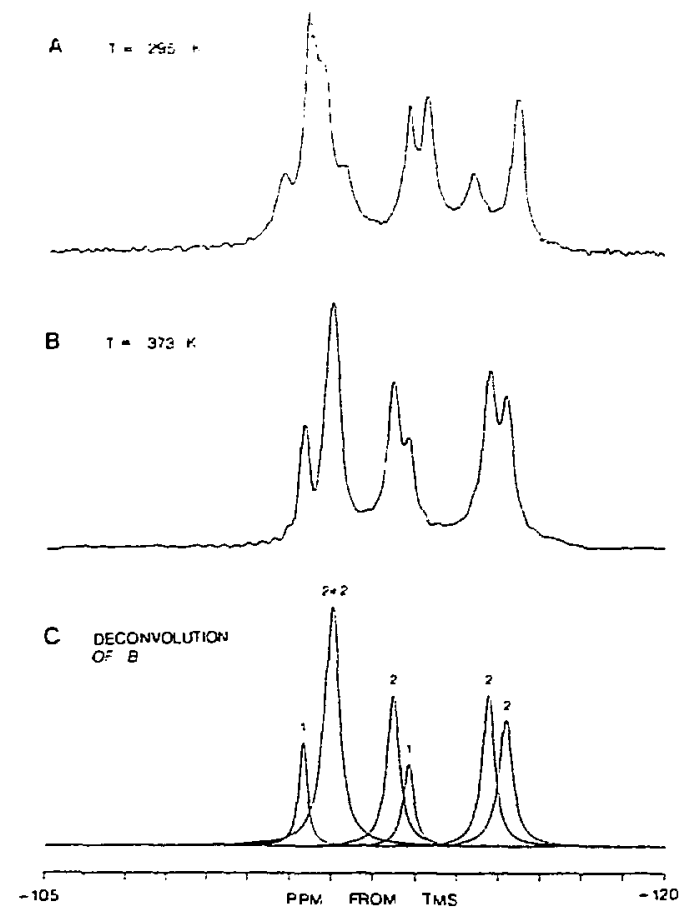

Fig. 1. ${ }^{29}$ Si MAS-NMR Spectra from ZSM-11.

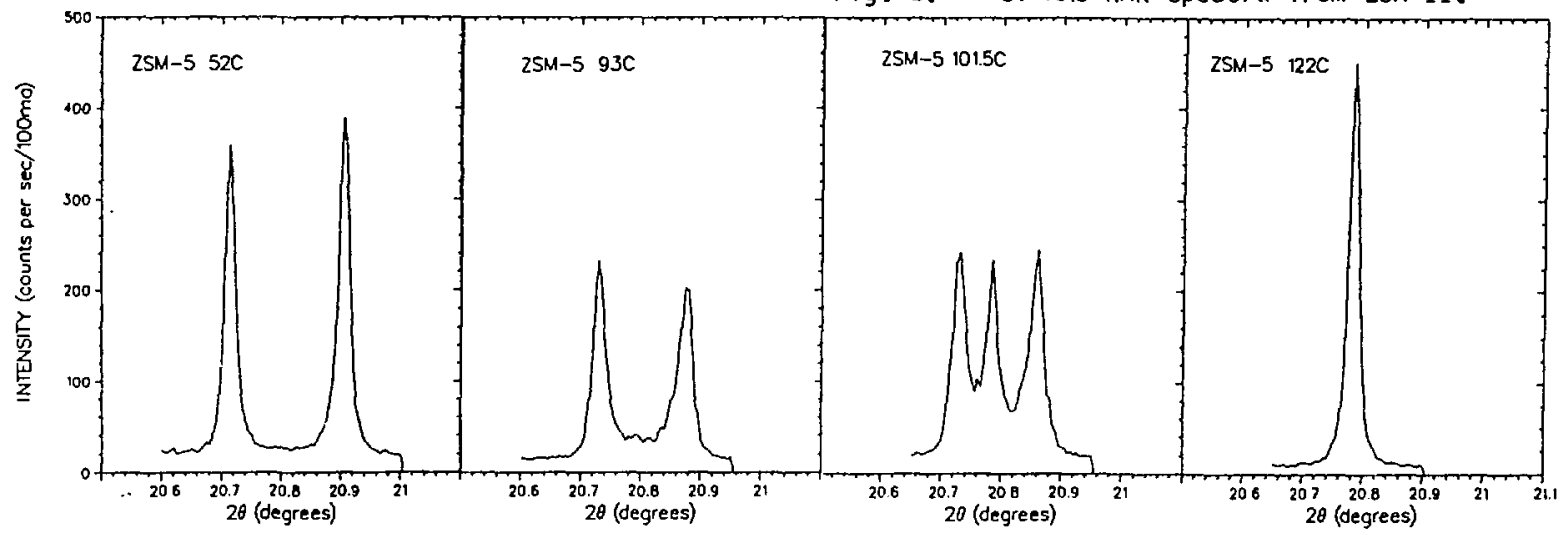

Fig. 2. Evolution of ZSM-5 Monoclinic (133) and (133) Peaks as a Function of Temperature.

* Current affiliation, University of British Coiumbia

+ Work supported by US DOE contract No. DE-ACO2-76CH0OO16. 
R.J. Hemley, A.P. Jephcoat, H-k. Maı, C-s. Zha, L.W. Finger (Geophysical Laboratory, Washington, D. C.), and D.E. Cox $\$$ (BNL).

The high-pressure behavior of $\mathrm{H}_{2} \mathrm{O}$ is of fundamental importance in both condensed matter and planetary physics. ${ }^{1,2}$ The hydrogen bonding in this system gives rise to a variety of phases at low pressures and temperatures (i.e., $<2 \mathrm{GPa}$ and $<300 \mathrm{~K}$ ), including the recently discovered high-density amorphous phases. ${ }^{3}$ Structural and equation of state and spectroscopic studies have been carried out in the 30-50 GPa range on the dense ices (ice VII and VIII), but no experimental data are available on the properties of solid $\mathrm{H}_{2} \mathrm{O}$ in the megabar pressure range ( $>100 \mathrm{GPa}$ ) where a variety of stable phases, including the metallic form, have been proposed. Information on the properties of $\mathrm{H}_{2} \mathrm{O}$ at these pressures has been limited to the results of shock-wave experiments, which probe the fluid phase at high pressures and temperatures, and to theoretical statistical electron calculations. In the present study, we have compressed ice in a diamond-anvil cell to $128 \mathrm{GPa}$ and measured the molar volume as a function of pressure by synchrotron $x$-ray diffraction techniques. The room-temperature equation of state is shown in Figure 1. The diffraction data are consistent with the body-centered cubic oxygen sublattice of ice VII persisting to the highest pressures of our measurements. The measured equation of state indicates that ice is less compressible at very high pressures than is suggested by recent experiments in the 30-50 GPa range, but more compressible than statistical electron and recent pair-potential models predict.

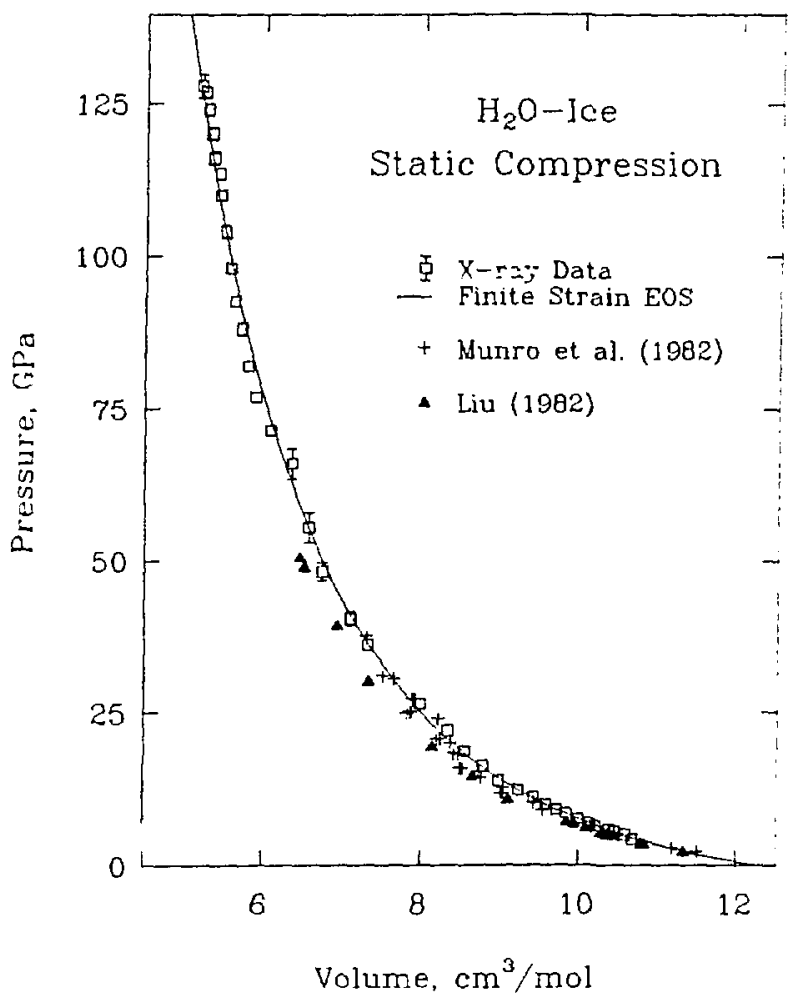

Fig. 1 Pressure-volume data and calculated roomtemperature equation of state for $\mathrm{H}_{2} \mathrm{O}$-ice.

\section{References}

'P.V. Hobbs, Ice Physics, (Clarendon, Oxford, 1974).

2W.B. Hubbard, Planetary Interiors, (Van Nostrand Reinhold, New York, 1984).

${ }^{3}$ O. Mishima, L.D. Calvert, and E. Whalley, Nature, 310, 393 (1984).

${ }^{4}$ Munro, R.G., Block, S., Mauer, F.A., and Piermarini, G., J. Appl. Phys., 53, 6174-6178 (1982).

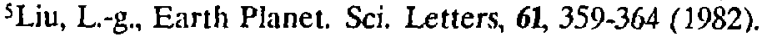

Acknowledgements

Work supported by the Carnegie Institution of Washington, the National Science Foundation (grants EAR8314064, EAR-8418706, EAR-8419982), and by NASA (contract NAGW214). \Work supported by The Division of Materials Sciences, U.S. Department of Energy, contract DE-AC02-76 CH00016. 


\section{EQUATION OF STATE OF NEON TO $110 \mathrm{GPa}$}

R.J. Hemley, A.P. Jephcoat, C-s. Zha, H-k. Mao, L.W. Finger (Geophysical Laboratory, Washington, D. C.), and D.E. Cox $\$$ (BNL).

The properties of condensed gases at ultrahigh pressures continue to attract much experimental and theoretical attention as these systems provide critical tests of theoretical models of bonding in solids ${ }^{1}$. Solid neon was compressed to $110 \mathrm{GPa}(1.1 \mathrm{Mbar})$ in a diamond-anvil cell to determine its structure and pressure-volume equation of state. Energy-dispersive and micro-collimation methods were employed to obtain diffraction data at ultrahigh pressure. The maximum compression, corresponding to a relative volume $\mathrm{V} / \mathrm{V}_{0}=0.28$ at 110 $\mathrm{GPa}$ is among the largest measured by $\mathrm{x}$-ray diffraction techniques. Neon remains an insulator witl the $f c c$ structure over this pressure interval. The measured P.V isotherm at high pressure is poorly described by the available pair potentials for neon (Fig. 1) but is in excellent agreement with the results of electronic structure calculations. The determination of an accurate Ne-Ne pair potential has has been the subject of much controversy in recent theoretical studies of rare-gas solids, and there is no consensus on the role of many-body forces in solid neon. The present data provide important constraints on the role of pair and many-body forces in this material at high compressions.

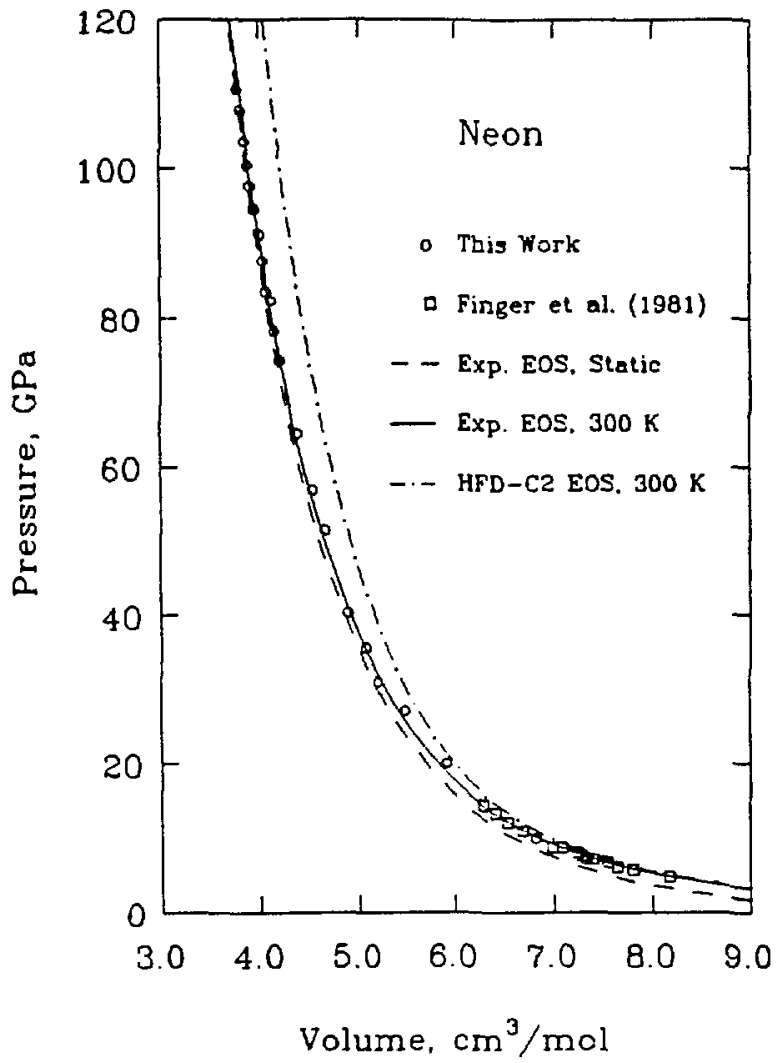

Fig. 1 Pressure-volume data and calculated equations of state for solid neon. The solid and dashed lines are fits of a Birch-Murnaghan equation of state to the experimental data. The dash-dot line was calculated from the HFD-C2 pair potential of Ref. 3, with the $P_{z e}$ and $P_{T H}$ contributions calculated from quasiharmonic lattice dynamics (see Ref. 1).

\section{References}

'M. Klein and J. Venables, Rare Gas Solids (Academic, New York, 1976).

${ }^{2}$ L.W. Finger, R.M. Hazen, G. Zou, H.K. Mao, and P.M. Bell, Appl. Phys. Lett. 39, 892 (1981).

${ }^{3}$ R.A. Aziz, J. Meath, and A.R. Allnatt, Chem. Phys. 78, 295 (1983).

Acknowledgements

Work supported by the Carnegie Institution of Washington, the National Science Foundation (grants EAR8314064, EAR-8418706, EAR-8419982), and by NASA (contract NAGW214). †Work supported by The Division of Materials Sciences, U.S. Department of Energy, contract DE-AC02-76CH00016. 
$\mathrm{Ca} 0_{0.75} \mathrm{Nb}_{3} \mathrm{O}_{6}$ : A NOVEL METAL OXIDE CONTAINING NIOBIUM-NIOBIUM BONDS. CHARACTERIZATION AND STRUCTURE REFINEMENT FROM SYNCHROTRON POWDER X-RAY DATA

S.J. Hibble and A.K. Cheetham, (Oxford University, England), and D.E. Cox* (Brookhaven National Laboratory)

High resolution synchrotron $x$-ray powder data collected at beam-line $X 13 A$ have been used to refine the structure of a novel mixed metal oxide $\mathrm{Ca}_{0} \cdot 75^{\mathrm{Nb}} \mathrm{O}_{6}$. The composition of the latter was determined by analytical electron microscopy. The unit cell is orthorhombic, space group Imm with lattice parameters $a=7.113 \AA, b=10.286 \AA, c=6.563 \AA$. The atomic coordinates are listed in Table $I$, selected bond angles and distances in Table II, and views of the structure in Figs. 1 and 2 . An interesting feature of the structure is the presence of an extremely short $\mathrm{Nb}-\mathrm{Nb}$ bond distance of $2.58 \mathrm{~B}$ within an $\mathrm{B}_{2} \mathrm{O}_{B}$ unit.

Table t. Profile and Siructural Parameters from the Rietveld Analysis of the Synchrotron Data

\begin{tabular}{|c|c|c|c|c|c|}
\hline \multicolumn{6}{|c|}{ 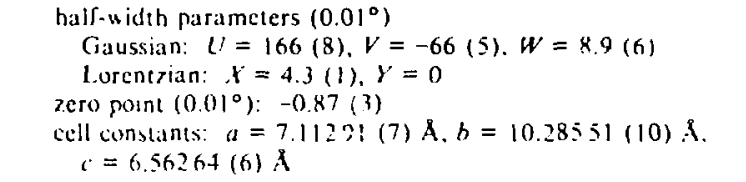 } \\
\hline \multicolumn{6}{|c|}{ Siructural Parameters } \\
\hline \multicolumn{6}{|c|}{ overall isotropic temperature factor: 0.20 (7) $A:$} \\
\hline \multicolumn{6}{|c|}{ Fractionial Atomic Coordinates in $/$ mmm (No. 71) } \\
\hline atom & $\begin{array}{c}\text { sym } \\
\text { position }\end{array}$ & $x$ & $y$ & $z$ & $\begin{array}{c}\text { atoms/ } \\
\text { unit cell }\end{array}$ \\
\hline $\mathrm{Nb}(1)$ & $4 j$ & 0.0000 & 0.5000 & $0.3036(5)$ & 4 \\
\hline $\mathrm{Nb}(2)$ & $8 n$ & $0.2278(3)$ & $0.2808(2)$ & 0.5000 & 8 \\
\hline $\mathrm{Ca}$ & $4 i$ & 0.5000 & 0.5000 & $0.238(2)$ & $3.03(6)$ \\
\hline$O(1)$ & $4 g$ & 0.5000 & $0.668(2)$ & 0.5000 & 4 \\
\hline$O(2)$ & th & 0.5000 & $0.678(2)$ & 0.0000 & 4 \\
\hline$O(3)$ & 160 & $0.820(2)$ & $0.366(1)$ & $0.232(1)$ & 16 \\
\hline
\end{tabular}

${ }^{a} R_{\text {nuc }}$ is the reliability factor based on approximate integrated intensities. ${ }^{15}$

Table II. Bond Angles ( $\AA$ ) and Distances (deg) for $\mathrm{CaNb}_{3} \mathrm{O}_{6}$

\begin{tabular}{llll}
\hline $\mathrm{Nb}(1)-\mathrm{Nb}(1)$ & $2.578(7)$ & $\mathrm{Nb}(2)-\mathrm{O}(2)$ & $1.930(20)$ \\
$\mathrm{Nb}(1)-\mathrm{Nb}(2)$ & $3.061(4)(\times 4)$ & $\mathrm{Nb}(2)-\mathrm{O}(3)$ & $1.992(20)(\times 2)$ \\
$\mathrm{Nb}(2)-\mathrm{Nb}(2)$ & $3.241(6)$ & $\mathrm{Nb}(2)-\mathrm{O}(3)$ & $2.240(20)(\times 2)$ \\
$\mathrm{Nb}(2)-\mathrm{Nb}(2)$ & $3.357(6)(\times 2)$ & $\mathrm{Ca}-\mathrm{O}(1)$ & $2.432(24)(\times 2)$ \\
$\mathrm{Nb}(1)-\mathrm{O}(3)$ & $1.941(20)(\times 4)$ & $\mathrm{Ca}-\mathrm{O}(2)$ & $2.415(24)(\times 2)$ \\
$\mathrm{Nb}(2)-\mathrm{O}(1)$ & $2.008(20)$ & $\mathrm{Ca}-\mathrm{O}(3)$ & $2.666(26)(\times 4)$ \\
$\mathrm{Nb}(1)-\mathrm{Nb}(2)-\mathrm{Nb}(1)$ & 49.8 & $\mathrm{O}(3)-\mathrm{Nb}(1)-\mathrm{O}(3)$ & 152.0 \\
$\mathrm{Nb}(2)-\mathrm{Nb}(1)-\mathrm{Nb}(2)$ & 63.9 & $\mathrm{Nb}(2)-\mathrm{O}(2)-\mathrm{Nb}(2)$ & 114.2 \\
$\mathrm{Nb}(2)-\mathrm{Nb}(1)-\mathrm{Nb}(2)$ & 94.9 & $\mathrm{Nb}(2)-\mathrm{O}(1)-\mathrm{Nb}(2)$ & 149.3
\end{tabular}

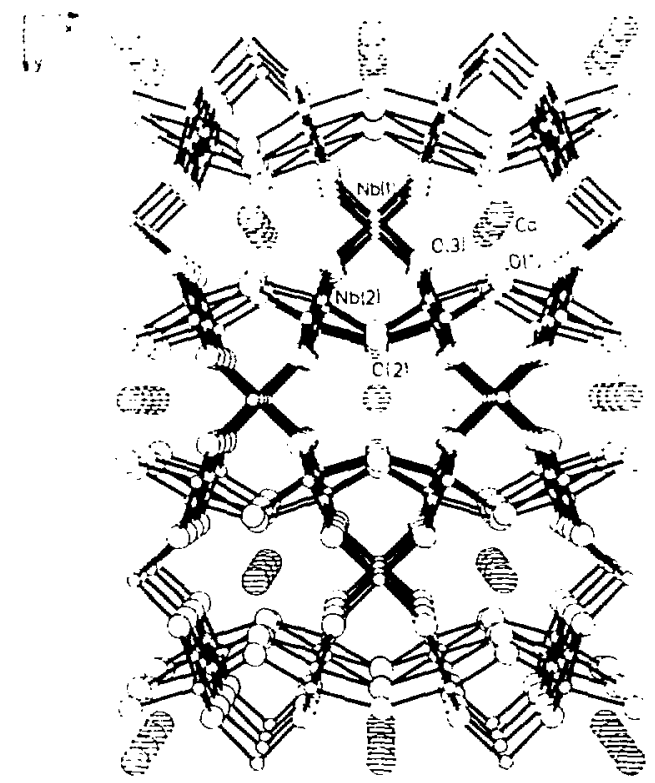

Figure 1. Structure of $\mathrm{Ca}_{075} \mathrm{Nb}_{3} \mathrm{O}_{6}$ viewed down $z$ ( $\mathrm{Ca}$. hatched circles: $\mathrm{Nb}$, small circles: $\mathrm{O}$. large open circles).

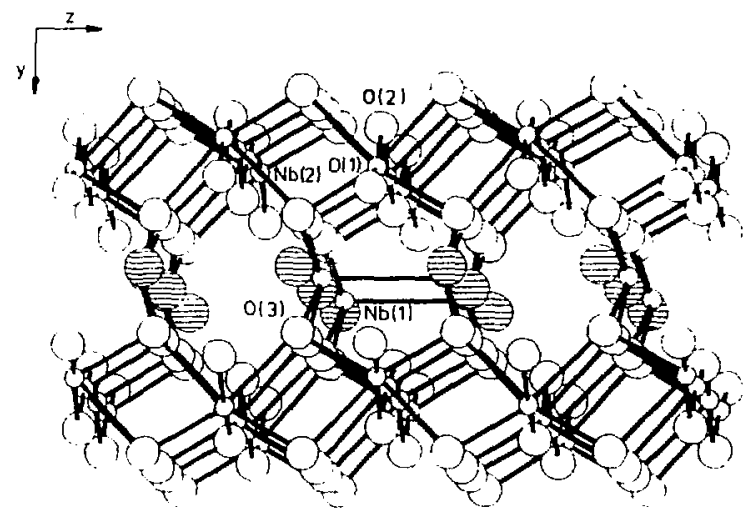

Figure 2. Structure of $\mathrm{Ca}_{0.75} \mathrm{Nb}_{3} \mathrm{O}_{6}$ viewed down $\mathrm{x}$

* Work supported by U.S. Department of Energy contract No. DE-ACO2-76CH00016. 
A.P. Jephcoat, R.J. Hemley, H-k. Mao, L.W Finger, C-s. Zha (Geophysical Laboratory, Washington, D.C.), and D.E Cox $\ddagger$ (BNL).

Compression data for ruby $\left(\mathrm{Al}_{2} \mathrm{O}_{3} \approx 0.05 \% \mathrm{Cr}^{3+}\right)$ have been obtained by energy-dispersive scattering in a diamond-anvil cell to $170 \mathrm{GPa}(1.7 \mathrm{Mbar})$. Diffraction was observed from ruby powder $(\leq 5 \mu \mathrm{m})$ included with the sample for calibration of the pressure in a static compression experiment at room temperature. Information on the structural behaviour of ruby to such pressures is useful because of its frequent usage as a secondary pressure calibrant in static compression studies and recent theoretical predictions of an instability in corundum at ultra high pressures. Results from the present work indicate that, within the comparatively large uncertainty in pressure due to the weakening and broadening of $R_{1}-R_{2}$ lines under nonhydrostatic compression, ruby does not undergo any reconstructive structural transition to at least $170 \mathrm{GPa}$. The large stress gradients that exist under nonhydrostatic compression also rule out the possibility that corundum is elastically unstable up to the pressures of this study. The unit-cell volumes are plotted as a function of pressure in Figure 1. At the highest pressure, the volume measured is consistent with both an extrapolated equation of state frorn ultrasonic measurements ${ }^{1}$ and one derived from single-crystal studies to $5 \mathrm{GPa}[2]$ with $\mathrm{K}_{0} \approx 254 \mathrm{GPa}, \mathrm{K}_{0}^{\prime} \approx 4.3$. There is alsu excellent agreement with a first-principles calculation of the equation of state using the potentialinduced breathing model ${ }^{3}$. The c/a ratio obtained from refinements of the strongest lines in the EDS spectrum (Fig. 2) remains constant throughout the pressure range at $2.73_{ \pm} .05$ and equals the value at zero pressure. A more sensitive indication of the onset of a possible structural distortion at high pressure, however, could be obtained by high-pressure vibrational spectroscopy. This work demonstrates that P-V studies can be carried out on low-Z materials in the megabar pressure range ( $>100 \mathrm{GPa})$.
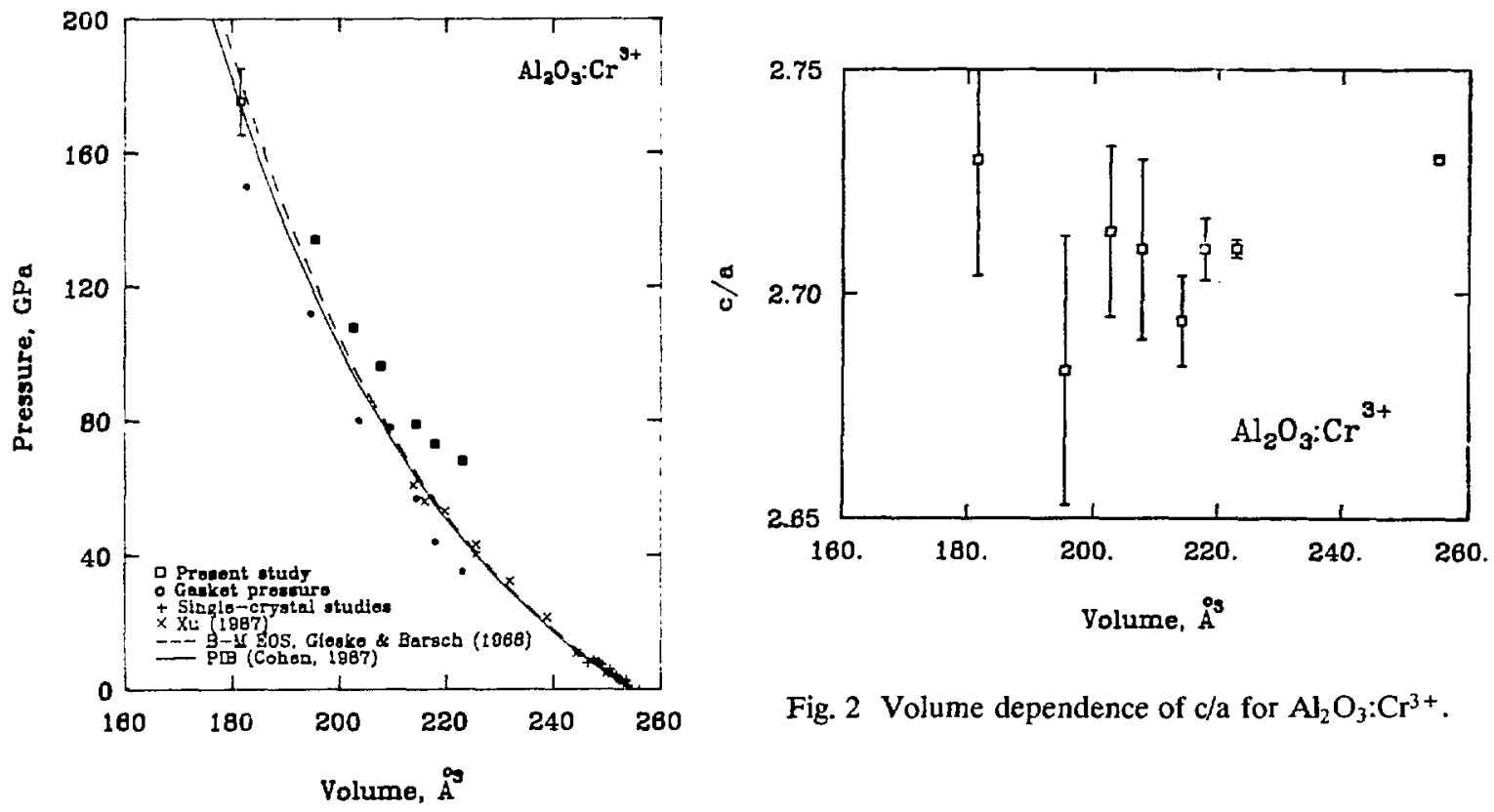

Fig. 1 Pressure-volume data for $\mathrm{Al}_{2} \mathrm{O}_{3}: \mathrm{Cr}^{3+}$ to $170 \mathrm{GPa}$.

\section{References}

1J.H. Gieske and G.R. Barsch, Phys. Status Solidi 29, 121 (1968).

${ }^{2}$ L.W. Finger, and R.M. Hazen, J. Appl. Phys. 49,5823 (1978).

${ }^{3}$ R.E. Cohen, L.L. Boyer, and M.J. Mehl, Phys. Chem. Min., in press (1987).

${ }^{4} \mathrm{~J}-\mathrm{a}$. Xu, unpublished data (1987).

\section{Acknowledgements}

Work supported by the Carnegie Institution of Washington, the National Science Foundation (grants EAR8314064, EAR-8418706, EAR-8419982), and by NASA (contract NAGW214). \&Work supported by The Division of Materials Sciences, U.S. Department of Energy, contract DE-AC02-76CH00016. 
A.P. Jephcoat, H-k. Mao, L.W. Finger, R.J. Hemley, C-s. Zha (Geophysical Laboratory, Washington, D. C.), and D.E Cox $\ddagger$ (BNL).

The properties of condensed gases as a function of pressure are of fundamental importance in condensedmatter physics. In particular, the relative stability of the crystal structures of the rare-gas solids has been the focus of many theoretical models ${ }^{1}$, as has the insulator-to-metal transition in atomic and molecular systems ${ }^{2}$. We report results of energy-dispersive $\mathrm{x}$-ray diffraction studies at high pressure on solid xenon and solid nitrogen performed with a tinely-collimated, white $\mathrm{x}$-ray beam at beamline X13A. Xenon was compressed to $137 \mathrm{GPa}$ (the highest pressure to be obtained with a soft sample) and nitrogen to $65 \mathrm{GPa}$. A synchrotron source was indispensable for both experiments in order to compensate for the effects of very small scattering volumes (Xe sample thickness at $137 \mathrm{GPa} \leq 10 \mu \mathrm{m}$ ) and the low intrinsic scattering cross section of $\mathrm{N}_{2}$.

Two structural transitions were observed in xenon (Fig. 1). The fcc phase is unstable above $14 \mathrm{GPa}$ and transforms to a phase that appears to be a close-packed polytype similar in structure to the rare-earth metals. Above $\sim 75 \mathrm{GPa}$ a transformation to the hicp structure takes place. The existence of the intermediate phase between $f c c$ and $h c p$ is important because structures with mixed cubic and hexagonal packing have not been considered in theoretical models of rare-gas solids.

The structural transitions observed in solid nitrogen are shown in Figure 2. The initial changes in the diffraction pattern to $16.4 \mathrm{GPa}$ result from the breakup of large crystallites in the sample chamber. The structural transitions at higher pressures can be correlated with branching of the low-frequency vibron in molecular nitrogen observed by spectroscopic methods.

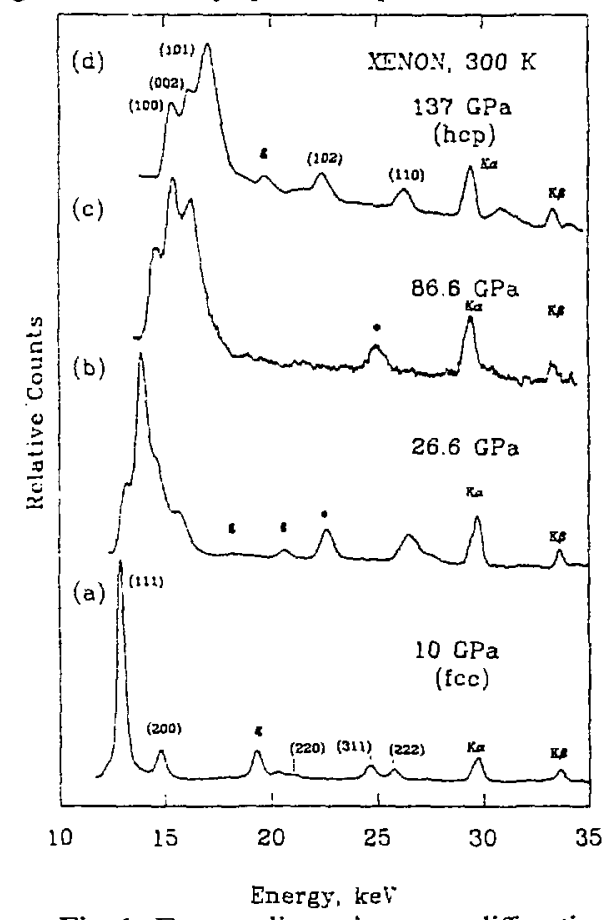

Fig. 1 Energy-dispersive x-ray diffraction spectra of solid xenon to $137 \mathrm{GPa}$.

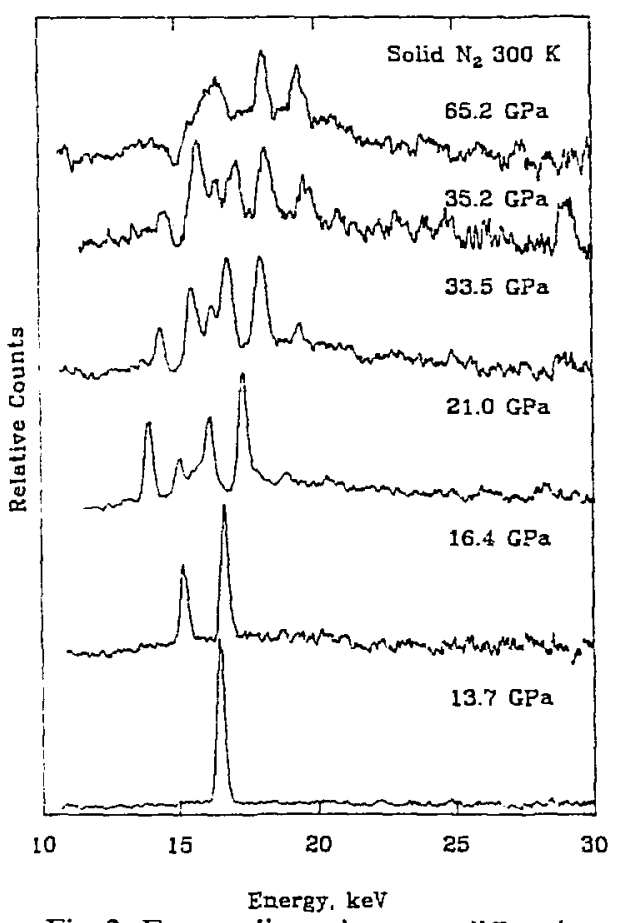

Fig. 2 Energy-dispersive $x$-ray diffraction spectra of solid nitrogen to $\sim 65 \mathrm{GPa}$.

References

${ }^{1}$ M.L. Klein and J.A. Venables, Rare Gas Solids, (Academic Press, London, 1976).

${ }^{2}$ M. Ross and A.K. McMahan, pp. 161-168 in Physics of Solids Under Pressure, eds. J.S. Schilling and R.N. Shelton (North Holland, Amsterdam, 1981).

Acknowledgements

Work supported by the Carnegie Institution of Washington, the National Science Foundation (grants EAR8314064, EAR-8418706, EAR-8419982) and NASA (contract NAGW214). tWork supported by the Division of Materials Sciences, U.S. Department of Energy, contract DE-AC02-76CH00016. 


\section{SINGLE-CRYSTAL X-RAY DIFFRACTION OF SOLID HYDROGEN AND DEUTERIUM}

A.P. Jephcoat, H-k. Mao, R.J. Hemley, L.W. Finger, R.M. Hazen, C-s. Zha (Geophysical Laboratory, Washington, D. C.), and D.E Cox (BNL).

The equations of state (EOS) of solidified $n-\mathrm{H}_{2}$ and $n-\mathrm{D}_{2}$ have been determined directly by $x$-ray scattering methods to pressures of $26 \mathrm{GPa}$ and $14 \mathrm{GPa}$, respectively (Figs. 1 and 2 ). A combination of single-crystal, diamond-anvil cell techniques a: energy-dispersive $x$-ray diffraction methods resulted in the successful determination of unit-cell volume at these high pressures and room temperature. Initial work at $5.4 \mathrm{GPa}$, just above the room-temperature freezing pressure, was performed with a conventional sealed $\mathrm{Mo}-\mathrm{K}_{\boldsymbol{\alpha}}$ source ${ }^{1}$ and a large sample volume. It was found that solid $\mathrm{H}_{2}$ adopts the hexagonal close-packed structure, $\mathrm{P}_{3} /$ minc, $\mathrm{Z}=2$. In order to extend the $\mathrm{P}-\mathrm{V}$ measurements to higher pressures, significantly smaller sample volumes were required with a consequent reduction in scattering intensity. The experiment was also made more difficult by the breakup and re-orientation of the hydrogen single crystals on compression. Such problems were again minimized by use of finely-collimated, intense x-ray beam.

These data provide, for the first time, unambiguous constraint on the room-temperature equations of state of these molecular solids - previous determinations of the hydrogen $\mathrm{EOS}^{2,3}$ were in notable disagreement with each other. A room-temperature EOS was derived from the data of Ref. 3 by Hemmes et al. ${ }^{4}$. The new data plot with intermediate volumes at all pressures (Fig. 1).

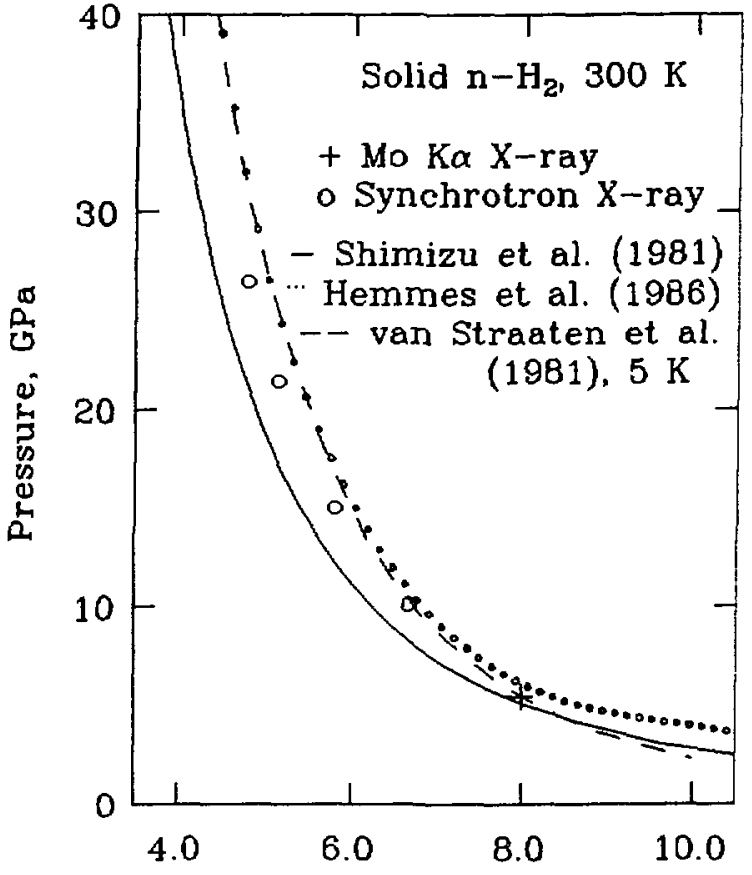

Volume, $\mathrm{cm}^{3} / \mathrm{mol}$

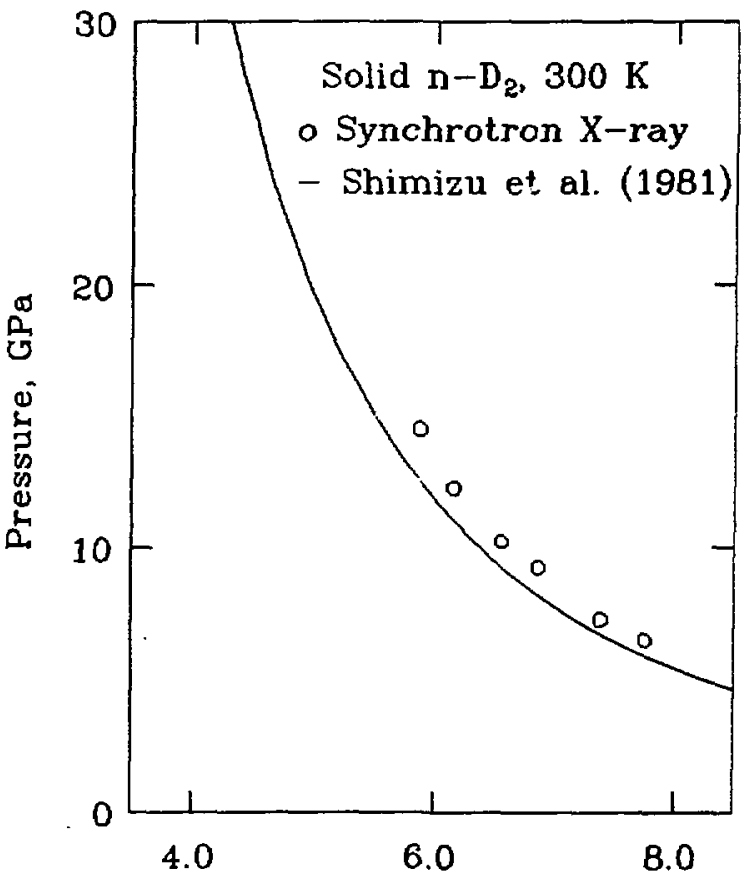

Volume, $\mathrm{cm}^{3} / \mathrm{mol}$

Fig. 1 Pressure-volume data for solid $n-\mathrm{H}_{2}$ to $26.6 \mathrm{GPa}$. Fig. 2 Pressure-volume data for solid $n-\mathrm{D}_{2}$ to $14.0 \mathrm{GPa}$.

\section{References}

${ }^{1}$ R.M. Hazen, H-k. Mao, L.W. Finger, and R.J. Hemley, Phys. Rev. B 36, 3944 (1987).

${ }^{2}$ H. Shimuzu, E.M. Brody, H-k. Mao, and P.M. Bell, Phys. Rev. Lett. 47 , 128 (1981).

${ }^{3}$ J. van Straaten, R.J. Wijngaarden, and I.F. Silvera, Phys. Rev. Lett. 48, 97 (1982).

${ }^{4} \mathrm{H}$. Hemmes, A. Driessen, and R. Griessen, J. Phys. C: Sol. St. Phys. 19, 3571 (1986).

Acknowledgements

Work supported by the Carnegie Institution of Washington, the National Science Foundation (grants EAR8314064, EAR-8418706, EAR-8419982) and NASA (contract NAGW214). ‡Work supported by the Division of Materials Sciences, U.S. Department of Energy, contract DE-AC02-76CH00016. 
Lynne B. McCusker (Oxford University, U.K.)

Knowledge of the aluminosilicate framework structure of zeolitic materials is essential to the understanding of their unique chemical and catalytic properties. Unfortunately, most new synthetic zeolites are only available in polycrystalline form, so single-crystal diffraction techniques cannot be applied. Since their structures are so important, a number of ingenious indirect methods have been developed over the years, but interpretation of the data is heavily dependent upon experience and intuition.

With the advent of synchrotron radiation, very high resolution $x$-ray powder diffraction has become possible and a crystallographic approach to the problem more feasible. The higher resolution a?.lows a much less ambiguous decomposition of the powder diffraction pattern than was previously possible. Although overlapping reflections are not eliminated, they are minimized. Once reliable integrated intensity values have been calculated, a single-crystal structure determination procedure can be followed.

In order to investigate the feasibility of this approach to zeolite structure solution, data on three samples (one with a known, one with a proposed and one with an unknown structure) were collected on beam line X13A at the NSLS. A series of computer programs for processing the data had already been assembled, modified and tested for this purpose using data from the SRS facility in Daresbury, U.K.

The highlight of this investigation has to be the solving of the previously unknown structure of Sigma-2 directly from the powder diffraction data. Sigma-2 is a new clathrasil phase and closely related to the zeolite family of materials. Data were collected with: $\lambda=1.5468 \mathrm{~A}, 0.01^{\circ} 2 \theta$ steps, 4-10 sec/step, $1 \mathrm{~mm}$ capil1ary, $\mathrm{Ge}$ (111) monochromator, and LiF (400) crystal analyzer. Peak positions were located (PEAKFIND), the pattern indexed (TREOR), systematic absences determined, individual reflection intensities extracted (ALLHKL), and direct methods applied (XTAL). The framework structure (right) has $4 \mathrm{si}$ and 70 atoms in the asymmetric unit, and 9 of these 11 positions appeared in the direct methods solution. Eight were used to generate a difference Fourier map, which clearly showed the remaining three oxygen positions.
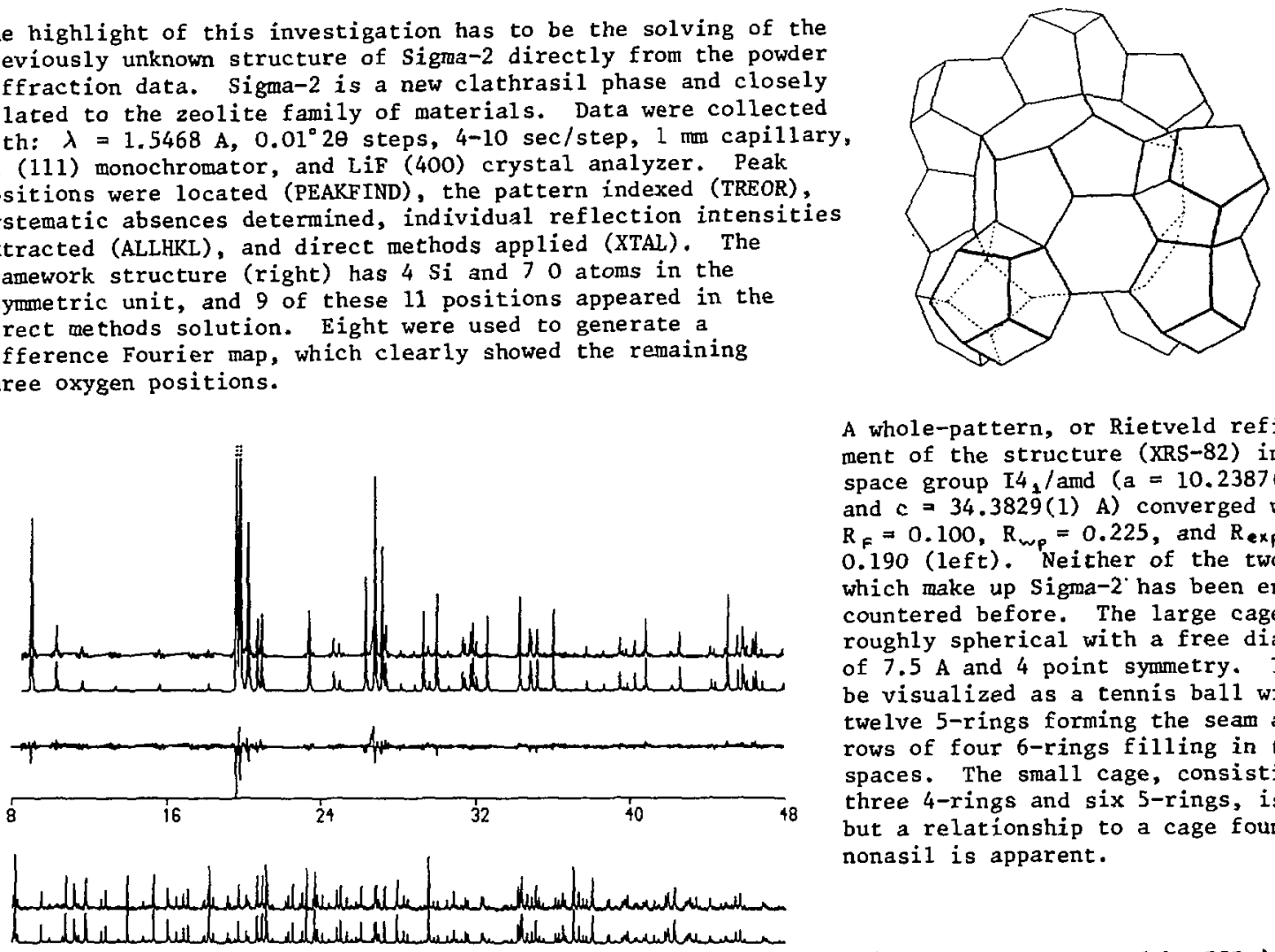

A whole-pattern, or Rietveld refinement of the structure (XRS-82) in the space group $\mathrm{I}_{4} /$ and $(\mathrm{a}=10.2387(1)$ and $c=34.3829$ (1) A) converged with $R_{F}=0.100, R_{w p}=0.225$, and $R_{\exp }=$ 0.190 (left). Neither of the two cages which make up Sigma-2 has been encountered before. The large cage is roughly spherical with a free diameter of $7.5 \mathrm{~A}$ and 4 point symmetry. It can be visualized as a tennis ball with twelve 5-rings forming the seam and rows of four 6-rings filling in the spaces. The small cage, consisting of three 4-rings and six 5-rings, is new, but a relationship to a cage found in nonasil is apparent.

This work was sponsored by ICI in the form of a JRS grant with Dr. A.M. Glazer.

I thank Drs. D.E. Cox and M.M. Eddy for their assistance during data collection at the NSLS. 
L. M. Moroney (NSLS), P. Thompson* (BNL), and D. E. Cox* (BNL)

By making use of the anomalous dispersion of $x$-rays close to the $Z r$ and $Y$ absorption edges we have found that individual cation $B$ factors can be determined independently in a refinement of the structure of yttria-stabilized zirconia ceramic material with composition $2 \mathrm{r}_{0.81} \mathrm{Y}_{0.19^{\circ}}{ }_{1.90}$. With $\mathrm{x}-\mathrm{ray}$ powder data collected at a single wavelength this is not possible because the two cations share the same set of sites and their B factors are highly correlated in any structure refinement. Normally only one average value can be determined. Simultaneous refinement of data collected at three different $x$-ray wavelengths $(0.7726(1) \AA, \quad 0.7283(1) \AA$ and $0.6892(1) \AA)$ has allowed the determination of separate mean square displacements for each atom, the respective values being $0.45(2)$ for $2 r^{4+}, 0.24(6)$ for $Y^{3+}$ and $0.098(2)$ $A^{2}$ for $0^{2-}$. The results indicate that the structural configuration of $2 r^{4+}$ is significantly different from that of $\mathrm{Y}^{3+}$.

Doping zirconia with allovalent oxides such as $\mathrm{Y}_{2} \mathrm{O}_{3}$ enables the 3 tabilization at room temperature of the cublc fluorite phase in which both the dopant and host cations occupy crystallographically equivalent sites. Electroneutrality is preserved by the creation of one anion vacancy in the lattice for every pair of dopant $y^{3+}$ ions. Existing crystallographic evidence indicates there is considerable static disorder in the material, partficularly on the anion sublattice, although smaller cation displacements have also been observed. $\left[{ }^{2}, 2,3\right]$ In the fluorite structure all atoms are on fixed positions and the specific structural parameters we wish to determine accurately are the effective Debye parameters ( $B$ ) for the individual atoms.

The refinement of the combined data sets was carried out simultaneously with a model (I) for the calculated structure factors, $F^{2} c a l c$, with three scale factors, $K_{A}, K_{B}, K_{C} ; \quad v i 2 ; F^{2}$ obs $(A)=K_{A} F^{2} c a l c(A)$, $F^{2}$ obs $(B)=K_{B} F^{2}$ calc $(B)$ and $F^{2}$ obs $(C)=K_{C} F^{2} c a l c(C)$. The variables in the fitting process were Debye parameters for $\mathrm{Zr}^{4+}, \mathrm{Y}^{3+}$ and $\mathrm{O}^{2}$ and three independent scale factors, one for each data set. The latter

Table 1. Debye-parameters and Scale Factors

Mode 1 I: Debye-parameters for $Z r$ and $Y$ individually refined.

Model II: Debye-parameters for $Z r$ and $Y$ constrained to be equal.

\begin{tabular}{|c|c|c|c|c|c|c|c|}
\hline \multicolumn{4}{|c|}{ Model I } & \multicolumn{4}{|c|}{ Model II } \\
\hline & $B\left(A^{2}\right)$ & Scale & Factors & & $B\left(A^{2}\right)$ & Scale & Factors \\
\hline $\begin{array}{l}7 x^{4+} \\
y^{3+} \\
0^{2-}\end{array}$ & $\begin{array}{l}1.18(4) \\
0.64(15) \\
2.57(4)\end{array}$ & $\begin{array}{l}\mathrm{K}_{\mathrm{A}} \\
\mathrm{K}_{\mathrm{B}} \\
\mathrm{K}_{\mathrm{C}}\end{array}$ & $\begin{array}{l}0.0717(1) \\
0.0758(1) \\
0.0458(2)\end{array}$ & $\begin{array}{l}2 r^{4+} \\
Y^{3+} \\
0^{2-}\end{array}$ & $\begin{array}{l}1.08(1) \\
1.08 \\
2.57(4)\end{array}$ & $\begin{array}{l}K_{A} \\
K_{B} \\
K_{C}\end{array}$ & $\begin{array}{l}0.0718(1) \\
0.0757(1) \\
0.0460(2)\end{array}$ \\
\hline
\end{tabular}

were necessary to account for the wavelength-dependent changes in the absolute intensities. Table 1 lists the refined values, their standard deviations and the estimates of the reliability of the fit. For comparison a model (II) with the cation Debye parameters constrained equal is also given. A Hamilton significance test [4] of the two refinements based on the welghted R-factors demonstrates that the inclusion of the extra parameter By $3+1$ s significant at the $99.5 \%$ confidence level.

This technique has clearly enabled us to distinguish between the two cations of the shared sites with a signiflcantly larger Debye parameter being obtalned for $2 \mathrm{r}^{4+}$ compared to $\mathrm{Y}^{3+}$. The excellence of the fit and the high quality data are indicated by the small $R$ factors obtained and the small ESDs. To illustrate the effect of using all three datasets simultaneously, we performed the same refinement on the Individual datasets. In this case, the correlation between the $B$ factors of the $\mathrm{Zr}^{4+}$ and $\mathrm{Y}^{3+}$ ions was $100 \%$, compared to $97 \%$ for the above refinement, and individual values could not be determined.

References

1. Steele, D. and Fender, B. E. F. (1974), J. Phys. C. 7, 1-11.

2. Morinaga, M., Cohen, J. B. and Faber J. (1979), Acta Cryst., A35, 789-95.

3. Horluchi, H., Schultz, A. J., Leuig, P. C. W. and Williams, J. M. (1984), Acte Cryst. B, B40, $367-72$.

4. Hamilton, W. C. (1965), Acta. Cryst., 18, 502-510.

Acknowledgment

Helpful discussions with D. P. Siddons and S. Heald are gratefully acknowledged. The sample of yttria-stabilized zirconia was kindly provided by Magnesium Elektron (U.K.).

This work was supported by the U.S. Department of Energy Division of Materials Sciences and Division of Chemical Sciences (Contract DE-ACO2-76CH00016) at Brookhaven National Laboratory. 


\section{DIFFRACTION STUDY OF A VANADIUM PHOSPHATE CATALYST FOR THE OXIDATION OF $n$-BUTANE TO MALEIC ANHYDRIDE.}

J.B. Parise (U. Sydney, Australia), A.W. Sleight, H.S. Horowitz (DuPont), T. Egami and W. Dmowski (U. Penn).

Mixed oxides of vanadium and phophorus are known to act as heterogeneous catalysts in the oxidation of $n$-butane and $n$-butene to maleic anhydride ${ }^{1}$. The catalyst is activated by exposing crystalline ( $\mathrm{VO})_{2} \mathrm{P}_{2} \mathrm{O}_{7}$, to which an excess of phosphate has been added, to a stream of $n$-butane above $400^{\circ} \mathrm{C}$. The resulting material is a mixture of crystalline (VO) $)_{2} \mathrm{P}_{2} \mathrm{O}_{7}$ and an amorphous phase (or phases) of unknown composition and topology. The crystal structure of the catalytically important conpound $(\mathrm{VO})_{2} \mathrm{P}_{2} \mathrm{O}_{7}$ has been reported ${ }^{2}$. More recently a study by Bergeret et al concluded that the amorphous phase resembles $\beta-\mathrm{VOPO}_{4}$. In order to test this conclusion, wide angle $X$-ray scatiering data were collected, for both the unactivated compound (totally crystalline) and working catalyst (mixed amorphous and crystalline), at the $\mathrm{X} 13 \mathrm{~A}$ beam-line.

A $\mathrm{Ge}(220)$ crystal was used to monochromate $X$-rays $(\lambda=0.6898 \AA)$. Samples were in the formof pressed discs, enclosed in a chamber filed with helium and mounted on a Huber 4-axis spectrometer. An intrinsic Ge detector was used to detect the scattered photons. The structure factors determined for both samples were scaled appropriately and subtracted to give $\Delta S(Q)$, the difference structure factor due to the amorphous material in the working catalyst (Fig, 1).

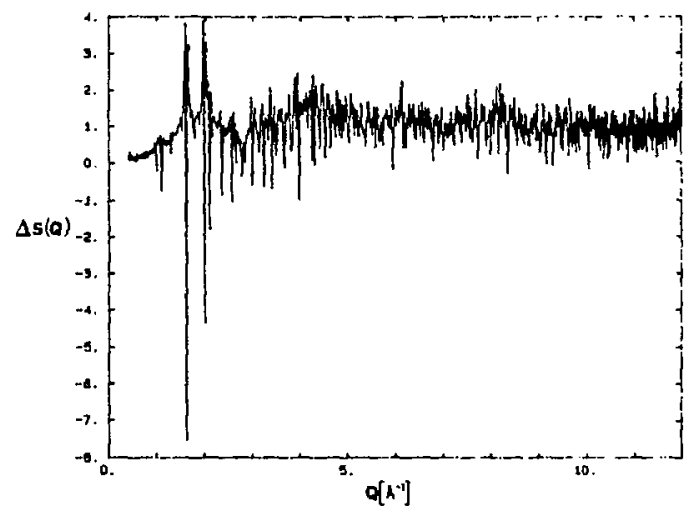

Fig. 1. The difference structure factor derived by subtracting the structure factors for the working catalyst from that for the crystalline (VO) ${ }_{2} \mathrm{P}_{2} \mathrm{O}_{7}$. The crystalline component of the working catalyst is broadened which results in the high frequency fluctuations.

The radial distribution function ( $R D F$ ) was calculated by the direct Fourier transformation of the structure factor (Fig. 2). Comparison of this function with that calculated for known topologies (Fig. 3) suggests some relationship to structures containing corner-linked $\mathrm{VO}_{6}$-octahedra. However, the best qualitative match is for the RDF calculated for $\mathrm{VO}\left(\mathrm{H}_{2} \mathrm{PO}_{4}\right)_{2}$ in which there is an excess of $\mathrm{PO}_{4}$-tetrahedra to $\mathrm{VO}_{6}$-octahedra over the $1: 1$ structures of $\alpha-$ and $\beta-\mathrm{VOPO}_{4}$; hardly surprising since the working calalyst is produced with a ratio of $P: V$ greater than $1: 1$.

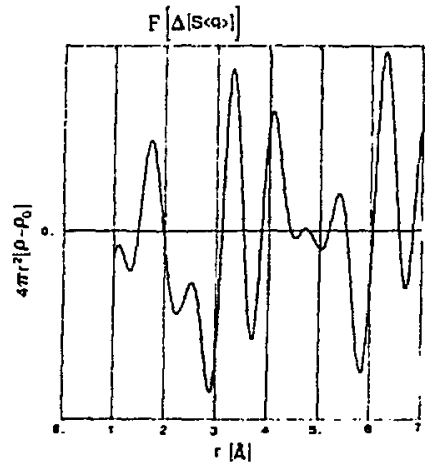

Fig. 2. RDF derived from Fig. 1 of the amorphous component.
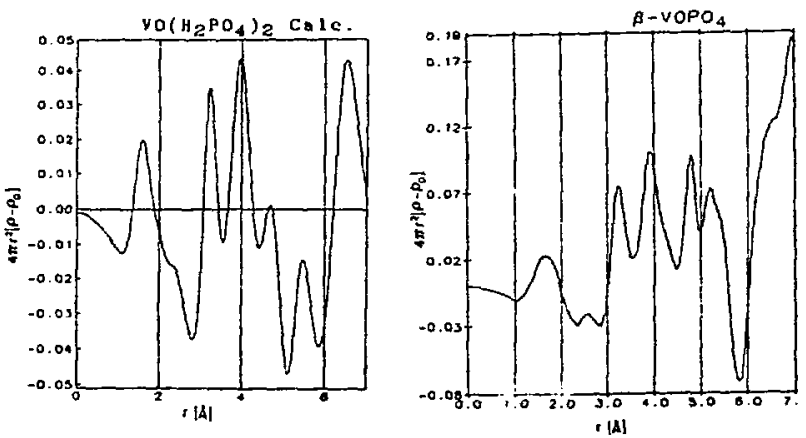

Fig. 3. RDF's calculated for the topologies of various vanadium phosphate compounds containing corner linked $\mathrm{VO}_{6}$-octahedra.

This work is in agreement pith that of Bergeret et $a l$ in as much as it indicates that the amorphous phase contains corner-linked $\mathrm{VO}_{6}$ octahedra as one of its structural elements. However, topologically and compositionally this material is more closely related to $\mathrm{VO}\left(\mathrm{H}_{2} \mathrm{PO}_{4}\right)_{2}$ than it is to $\beta-\mathrm{VOPO}_{4}$. Since these experiments do not allow us to extropolate from a similarity in structural topology to some chemical relationship, they say little of the changes in or the distribution of the oxidation states of vanadium.

1. E. Bordes and P. Courtine, J. Catal., 57, 236 (1979).

2. Yu.E. Gorbunova and S.A. Linde, Sov. Phys, Dokl., 24, 138 (1979).

3. G. Bergeret, J.P. Broyer, M. David, P. Gallezot, J.C. Volta and G. Hecquet, J. Chem. Soc. Chem. Comm., 825 (1986). 


\title{
PHASE STABILITY OF $\mathrm{ZHO}_{2} \cdot \mathrm{Al}_{2} \mathrm{O}_{3}$ FLLMS GROWN BY MAGNETRON SPUTTERING UNDER APPLICATION OF PRESSURE
}

\author{
S. B. Qadrit, E. F. Skelton, C. Quinn ${ }^{\dagger t}$, and C. Gilmoret† \\ Naval Research Laboratory, Washington, DC 20375-5000 \\ †Sachs/Freeman Associates, Inc., Bowie, MD 20715; ††George Washington Univ, Washington, DC 20052
}

Because of its high refractive index, high melting temperature, and corrosion resistant properties, zirconia, $\mathrm{ZrO}_{2}$, is a material with a wide vista of applications. Phase stablized $\mathrm{ZrO}_{2}$ has been used, inter alia, to prevent cracking in ceramics at elevated temperatures. The tetragonal phase of $\mathrm{ZrO}_{2}$, which can be formed at either high pressure or high temperature, can be retained by alloying with either $\mathrm{Y}_{2} \mathrm{O}_{3}$ or $\mathrm{CeO}_{2}$. Recently we have been successful in depositing $\mathrm{ZrO}_{2}-\mathrm{Al}_{2} \mathrm{O}_{3}$ films and stablizing the tetragonal phase of $\mathrm{ZrO}_{2}$ with $\mathrm{Zr}: \mathrm{Al}$ atomic ratios up to $0.76: 0.24$. For samples with higher $\mathrm{ZrO}_{2}$ content, only the monoclinic phase of $\mathrm{ZrO}_{2}$ was formed.

Standing films could be obtained by depositing the $\mathrm{ZrO}_{2}-\mathrm{Al}_{2} \mathrm{O}_{3}$ mixture on a substrate of $\mathrm{NaCl}$ and then dissolving the latter in distilled water. In our earlier studies, we demonstrated that as-deposited films were all initially amorphous, but that by annealing in air at $1000^{\circ} \mathrm{C}$, different polymorphs of $\mathrm{ZrO}_{2}$ emerged.[1-3] The rate of crystallization was also found to be dependent on the $\mathrm{ZrO}_{2}: \mathrm{Al}_{2} \mathrm{O}_{3}$ ratio; films with high $\mathrm{Zr}$ content crystallized in times as short as 2-h. In our earlier work, we noted that, in addition to particle size effects, a residual, internal compression was also possibly responsible for the stablization of the high temperature tetragonal phase of $\mathrm{ZrO}_{2}$.

At room temperature, $\mathrm{ZrO}_{2}$ has been found to transform from the room its normal monoclinic phase to a tetragonal phase at a pressure of about $5.0 \mathrm{GPa}$, and to an orthorhombic phase at about 15.0 Gpa. We have investigated the high pressure behavior of films of two compositions: 64:36 and 45:55. In the case of the 45:55-sample, the tetragonal-10-orthorhombic phase change appears to be at about $3.4 \mathrm{GPa}$. Two additional diffraction peaks with d-spacings of 3.344 and 2.12 A were tentatively identified as those of the orthorhombic phase with $(100)$ and $(112,022)$ Miller indices. In thecase of the 64:36-sample, the tetragonal phase remains stable even up to $15.0 \mathrm{GPa}$. In an effort to induce crystallization with pressure, we subjected an initially amorphous 64:36-sample to $25.0 \mathrm{GPa}$ pressure; there was no evidence of crysiallization. The stability of the tetragonal phase of the zirconia films under application of pressure appears to be dependent on the $\mathrm{Al}_{2} \mathrm{O}_{3}$ composition. The amorphous films of $\mathrm{ZrO}_{2}-\mathrm{Al}_{2} \mathrm{O}_{3}$ do not crystallize up to pressures of $25 \mathrm{GPa}$.

References:

1. C. M. Gilmore, C. Quinn, E. F. Skelton, C. R. Gossett, and S. B. Qadri, J. Vac. Sci. Technol. A4(6) 2598-2600 (1986).

2. C. M. Gilmore, S. B. Qadri, C. Quinn, C. R. Gossett, and E. F. Skelton, J. Vac. Sci. Technol. A5(4) 2085-2087 (1987). 1987

3. S. B. Qadri, C. M. Gilmore, C. Quinn, E. F. Skelton, C. R. Gossett, submitted to Phys. Rev. -B, 


\title{
HIGH PRESSURE STUDIES OF HgMnTe
}

\author{
S. B. Qadri", E. F. Skelton, M. W. Schaefert, A. W. Webb, and L. Colombott \\ Naval Research Laboratory, Washington, DC 20375-5000 \\ 'Sachs/Freeman Associates, Inc., Bowie, MD 20715 \\ tNational Research Council Posidorioral Associate; †tTexas Instrument, Dallas, TX
}

The ternary alloys $\mathrm{Hg}_{1-\mathrm{x}} \mathrm{M}_{\mathrm{x}} \mathrm{Te}$, where $\mathrm{M}=\mathrm{Cd}, \mathrm{Mn}$, or $\mathrm{Zn}$, are important materials for their application in electro-optic devices and magneto-optic devices in the infrared range. In our earlier high pressure investigations, we examined the elfects of alloying $\mathrm{HgTe}$ with $\mathrm{Cd}$ and $\mathrm{Zn.[1-2]} \mathrm{Interest} \mathrm{in} \mathrm{the} \mathrm{HgZnTe-system} \mathrm{arose} \mathrm{from} \mathrm{the} \mathrm{theoretical} \mathrm{prediction} \mathrm{that} \mathrm{adding} \mathrm{Cd}$ to $\mathrm{HgTe}$ would tend to destablize the already wgak $\mathrm{HgTe}$-bond, whereas the addition of $\mathrm{Zn}$ would have the opposite effect.[3] We found that, in addition to the difference in the pressure dependence of the atomic volume, the stability of the two phases were in fact different. In both cases, the B3-10-B9 structural transition pressure, $P_{t}$, increased from that of pure $\mathrm{Hg}$ Te. However, the effect of adding Cd was to increase the stability of the B1-phase, whereas the addition of $\mathrm{Zn}$ suppressed this phase.

Alloying with $\mathrm{Mn}$ is very appealing both because of its magnetic properties and the fact that it too will aiter the $\mathrm{HgTe}$ band gap. $\mathrm{Ho}$, rever, il was noi known whether Mn would stablize or destablize the HgTe bond and it is for this reason that high pressure experiments were performed on $\mathrm{Hg}_{0.91} \mathrm{Mn}_{0.09} \mathrm{Te}$ at NSLS on the white beam line (.X13-A) using standard energy dispersive diffraction and diamond-anvil cell techniques. [4]

The vo:ume compressibility of $\mathrm{Hg}_{0.91} \mathrm{Mn}_{0.09} \mathrm{Te}$ is, within the experimental uncertainty, equivalent to that of $\mathrm{HgTe}$ and $\mathrm{Hg}_{0.8} \mathrm{Cd}_{0.2} \mathrm{Te}$. The B3-to-B9 phase transformation was observed to occur at $2.3 \pm 0.1 \mathrm{GPa}$; no $\mathrm{Bg}$-to-B1 Iransition was observed up $1010.0 \mathrm{GPa}$, but a transition from the B9 to the A5 phase was seen at $11.5 \pm 0.5 \mathrm{GPa}$. Thus, the effect of alloying $\mathrm{HgTe}$ with $\mathrm{Mn}$ is similar to that of alloying with $\mathrm{Zn}$ in so far at the stability of the B1.phase is concerned, whereas the stability of the $\mathrm{B} 3$ phase is comparable with that of $\mathrm{Hg}_{0.8} \mathrm{Cd}_{0.2} \mathrm{Te}$. The volume compressibilities of all the materials, $\mathrm{HgTe}, \mathrm{Hg}_{0.8} \mathrm{Cd}_{0.2} \mathrm{Te}$, and $\mathrm{Hg}_{0.91} \mathrm{Mn}_{0.09} \mathrm{Te}$ are the same within the experimental uncertainty and the effect of adding $\mathrm{Mn}, \mathrm{Zn}$, and $\mathrm{Cd}$ to $\mathrm{HgTe}$ is to increase the stability of the zinc-blende structure under the application of pressure.

\section{References} (1986).

1. S. B. Qadri, E. F. Skelton, A. W. Webb, and J. Dinan, J. Vac. Sci. Technol. A4(4), 1974

2. S. B. Qadri, E. F. Skelton, A. W. Webb, M. W. Schaefer, J. H. Dinan, D. Chandra, and L. Colombo, J. Vac. Sci. Technol. A5. 3024(1987).

3. A Sher, A. B. Chen, W. E. Spicer, and C. K. Sheh, J. Vac. Sci. Technol. A3, $105 \mathrm{C}(1985)$.

4. E. F. Skelton, J. D. Ayers, W. T. Elam, T. L. Francavilla, S. B. Qadri, C. L. Vold, A. W. Webb, S. A. Wolf, C. Y. Huang, D. Schiferl, M. H. Manghnani, L. C. Ming, J. Balogh, and R. C. Lacoe, High Press.-High Temp. 16, 563-571 (1984); and references cited therein. 
I. Sone (SUNY-SB) and H. Herman (SUNY-SB)

Synchrotron $x$-ray radiation was employed on Beam Line $X-13 \mathrm{~A}$ to carry out a detailed analysis of the various phas.s (cubic, tetragonal and monoclinic) comprising a partlally-stabilized $\mathrm{zirconia} \mathrm{ZrO}_{2}-8 \% \mathrm{Y}_{2} \mathrm{O}_{3}$, which is used as a "thermal barrier coating". The analysis of this material was carried out on powders (40um obtained from mechanically reducing fused product) and 300um thick plasma-sprayed deposits. of special interest were the residual stresses thought to arise from the rapid solidification process inherent in plasma-spray deposition. In addition, specimens were thermally cycled and in some cases held sticically at high temperatures. Only the as-deposited coatings are discussed here. Diffraction peaks were analyzed using a least ch-square method by a random parameter fit. A modified Gaussian equation with three parameters was assumed for a diffraction peak, as glven in Fig. 1 . of special interest in this early period of study was the measurement of residual stress. The latter arises due to the difference in thermal expansion between the ceramic oxide coating and the metallic substrate. The failure of this system is generally believed partly due to stresses generated by expansion mismatch.

Residual Stress Measurements: The (620) reflection was chosen for precise residual stress measurements. There are three diffraction peaks overlapping in the (620) region: Tetragona1 (620); FCC (620); Tetragonal (602). X-ray scans were obtained in the (620) region. The first scan was performed with an inclined angle $\Omega=0.0$. For the second scan, the sample was inclined by $\Omega=45.0$. Diffracted intensity for the second scan decreased to $1 / 3$ of that of the first. The (620) and (602) tetragonal and the (620) FCC peaks were deconvoluted from the experimental data with a precise Bragg angle for all three peaks: Fig. 2. Conclusions: The residual stress in the tetragonal phase 45 degrees to the surface specimen is compressive $111 \mathrm{MPa}$. The residual stress in the cubic phase 45 degrees to the surface of the specimen is compressive $336 \mathrm{MPa}$.

Finally: $\quad$ FCC $\Delta \mathrm{d}=\mathrm{d} i-\mathrm{dn}=1.12 \times 10^{-3} \AA$; for cubic phase

Tet $(620) \Delta d=\mathrm{d} \mathbf{i}-\mathrm{dn}=3.7 \times 10^{-4} \AA$; tetragonal phase

Tet $(602) \Delta d=d i-d n=4.4 \times 10^{-4} \AA$; tetragonal phase

It can be concluded that synchrotron radiation is capable of determining the residual stresses within individual phases comprising the partially-stabilized $\mathrm{ZrO}_{2}$ ceramic. This is an extremely important result and will enable the determination of anisotropy factors in thermal expansion of a range of thermal barrier coatings.

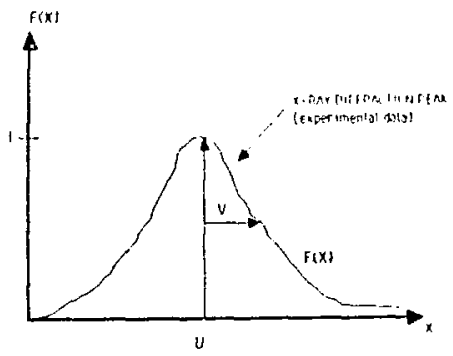

$$
F(X)=1^{*} \operatorname{EXP}^{\left.-1 / 21(X-U) / Y^{3}\right]}
$$

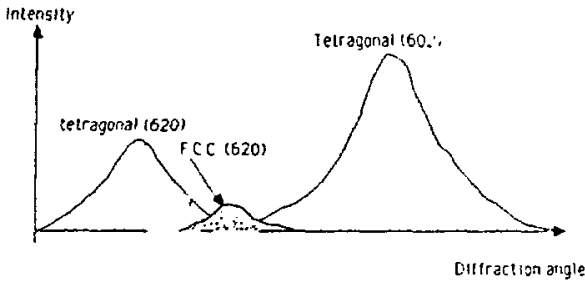

Fig. 2

Fig. 1 
P. Suortti* (Universty of Kelsinki, Finland), and D.E. Cox** (Brookhaven National Laboratory, Upton, N.Y. 11973

The powder diffraction beain line $x 13 \mathrm{~A}$ was used to study the effects of primary extinction in powder samples. The line profiles of the first three reflections of Ni were measured from a series of samples using the wavelength of the characteristic Cuka radiation, 1.5418A. The samples were made of the same powcer, but the compacting pressure varied from $6 \mathrm{MPa}$ to $480 \mathrm{MPa}$. Special emphasis was put on careful recording of the very long tails of the reflections, extending the measurements up to 3 degrees (in $2 \theta$ ) on both sides of the peaks. The contribution of the thermal diffuse scattering (TDS) was removed by subtracting from the measured intensities the intensities of a well annealed sample, where the tails of the Bragg reflections are neglegible. The intensities were brought to an absolute scale through a comparison with a standard sample (1).

The intensity in the tails is

$i(s)=N_{h k l} / 2 n s^{2} L$,

where $s=(\cos \theta / \lambda) \Delta 2 \theta$ is the distance from the peak, and

$N_{h k l}=\int i(s) d s$

For an analysis of the tails, another function is introduced (2),

$G(s)=2 \pi s^{2} i(s) / N_{h k l}$

so that the asymptotic value of $G$ is $G_{a s}=1 / L$. Here $L$ is the volume average of the size of the diffracting domains in the direction of the scattering vector. The value of $L$ was determined from the measured $\mathbf{i}(s)$ for the different $N i$ samples.

The absolute integrated intensities of the reflection were also measured using a conventional $x$-ray source. The results were corrected for the effects of porosity and preferred orientation, so that the remaining differences were due to primary extinction. The primary extinction factor can be written as

$y_{p}=\exp \left(-a^{2}(L / \Lambda)^{2}\right)$

where $A$ is the extinction length and $a$ is a constant that depends on the shape of the diffracting domains (3). There is a good agreement between the observed $y$ and $L$, if the domains are assumed to be plate-like. This is also the shape suggested by the electron micrographs.

1. P. Suortti, J.B. Hastings, D.E. Cox, Acta Cryst. A41, 413 (1985).

2. P. Suortti, L.D. Jennings, Acta Cryst. A33, 1012 ( $\overline{1977}$ ).

3. P. Suortti, Acta Cryst. A38, 642, 648 (1982).

* Work supported by the Academy of Finland, project $01 / 545$.

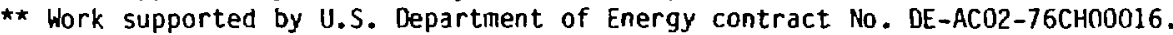




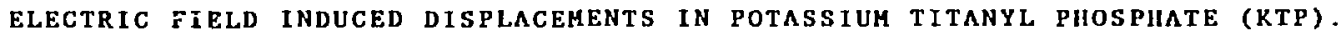

M.M.Eddy, G.D.stucky

Dept. of Chemistry, LicsB, Santa Barbara, CA 93106.

J. D. Bierlein

E.I.Dupont de Nemours and Co., Wilnington, DE 19898 .

A. Kvick*

Chenistry Dept., Brookhaven National Lab., Upton, NY 11973.

potassiua titanyl phosphate (KTP) is a relatively new non-linear optlcal material which has recently attracted considerable attention because of its high non-linear coefficient, high optical danage threshold and low phase watching, temperature sensitivity. These properties make kTP the premier material used for second harmonic generation of the $1.06 \mu$ YA laser. In addition, recent studies have shown that large single crystals may nake excellent wave guides and electro-optic modulators.

synchrotron radiation is an ideal probe for studying the effect of a polarizing field on the structure of these non-linear optical naterials. The high resolution enables very small distortions in the unit cell to be measured ( separations of cd/d less than 10-5 can be detected). In addition, because of the tuneable nature of synchrotron radiation the volume of the kTp crystal vhich is probed can be altered. Thus surface effects can be studied by using long wavelength $x$-rays.

The experinent undertaken on bean line $x 13 b$ was to apply an alternating square wave potential across a crystal of KTP, while simultaneously neasuring the peak profile of reflections along the polar axis. The potential and frequency could be altered and the counter was gated so that data for positive and negative polarization was collected.

Figure 1 illustrates the effect of altering the frequency of the alternating field on the intensity of the 080 reflection. The intensity difference decreases with increasing frequency. The cations find it more and more difficult to respond to the alternating voltage. At looliz, there is essentialiy no difference between the intensity of the 080 reflection when the finld is +1000v or -1000v. The inertia of the potassiun cations is such that liey cannot respond quickly enough to this rapidiy altering field.

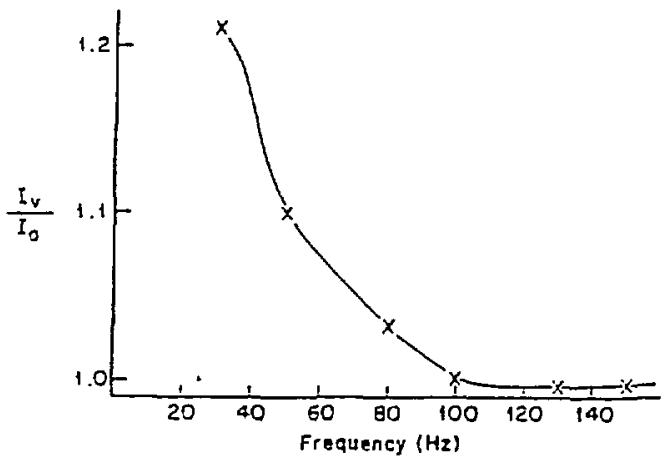

Figure 1. Efecet of Erequency on the

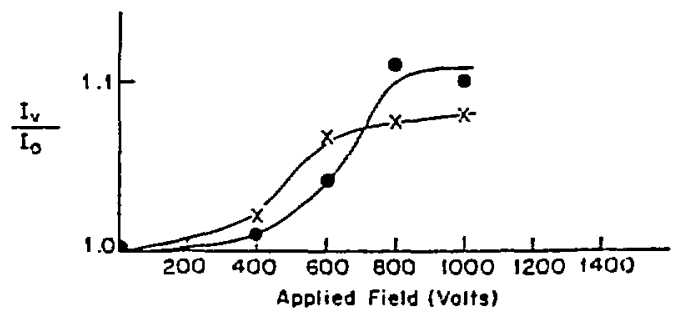

Figure 2. Effect of applied fleld on the 080 and 0120 reflections.

Figure 2 shows the effect of applied field on the intensity difference of the 040 and 080 reflections. In both cases alateau is reached vhich presumeably corresponds to a point where the attractive forces fron the titanyl phosphate frawework must be broken if the cations are to move further. slailar plots for the effect of increasing field and frequency on the unit cell parameters have been calculated.

Thus, fron these measurements, the displacenent of the cations (frou the intensity variation) and the extension of the franework (fron the unit cell distortions) can be nonitored.

* Work supported by the Division of Chenical sciences, U.s. Dept. of Energy, under contract DE- $\mathrm{CCO}-76 \mathrm{Cl} 100016$ 
DATA COLLECTION FROM ECORI ENDONUCLEASE-DNA COCRYSTALS AT CRYSTALLOGRAPHY STATION XI3B.

R. Love, J. Grable, Y. Kim, and J. Rosenberg (U, of Pittsburgh)

The enzyme EcoRI endonuclease $(\mathrm{Mr}=31,000)$ binds as a dimer to DNA at the sequence $5^{\prime}-\mathrm{GAATTC}-3^{\prime}$ and, in the presence of magnesium, hydrolyzes the phosphodiester bond between guanine and adenine on each strand. The crystal structure of the complex between endonuclease and a cognate oligonucleotide ( $5^{\prime}-$ TCGC-GAATTC-GCG-3') was solved previously to $3 A$ resolution (1). Cocrystals are obtained in the absence of magnesium, and are hexagonal plates with space group $P 321$ and unit cell $a=b=118.4 A, c=49.7 A$. The enzyme within these cocrystals can be activated by soaking them in a magnesium buffer: the DNA undergoes double-strand cleavage yet the crystals remain intact. In order to determine structural changes after DNA hydrolysis and to search for Mg sites, we collected a complete data set for Mg-soaked cocrystals. Average crystal size was .6 $.6 \times .2 \mathrm{~mm}$. An Enfraf-Nonius oscillation camera with a $0.2 \mathrm{~mm}$ collimator was used to collect 90 degrees of $\mathrm{fjlm}$ data at room temperature. Crystal to film distance was $100 \mathrm{~mm}$, and the wavelength was $1.576 \mathrm{~A}$. A 2 degree oscillation range was used (camera speed $=5 \mathrm{sec} / \mathrm{deg}$ ) with total exposure time of 20 min per film (see Fig. 1). Since a large number of crystals was available, each was used to generate only 3-4 films (or fewer if radiation damage became visiblel. Two Polaroid exposures of 3-5 min each were used to align each crystal. During data collection, the ring current was in the range 70-180 $\mathrm{mA}$.

We have recently grown cocrystals containing EcoRI endonuclease and longer DNA ( $5^{\prime}-$ TCGTG-GAATTC-CACG-3') with different base pairs flanking the recognition site. These crystals are triangular plates with space group $R 32$ and $a=b=127 A, c=146 A$. Complete data was collected for these "15-mer" cocrystals. The average crystal size was .4 $.4 \times .2 \mathrm{~mm}$ and collection parameters were simjlar to those already described (see Fig. 2). Also, partial data was collected for a gold derivative of this crystal form.

References:

(1) J. McClarin, C. Frederick, B.-C. Wang, P. Greene, H. Boyer, J. Grable, and J. Rosenberg. Science, $234: 1526$ (1986).

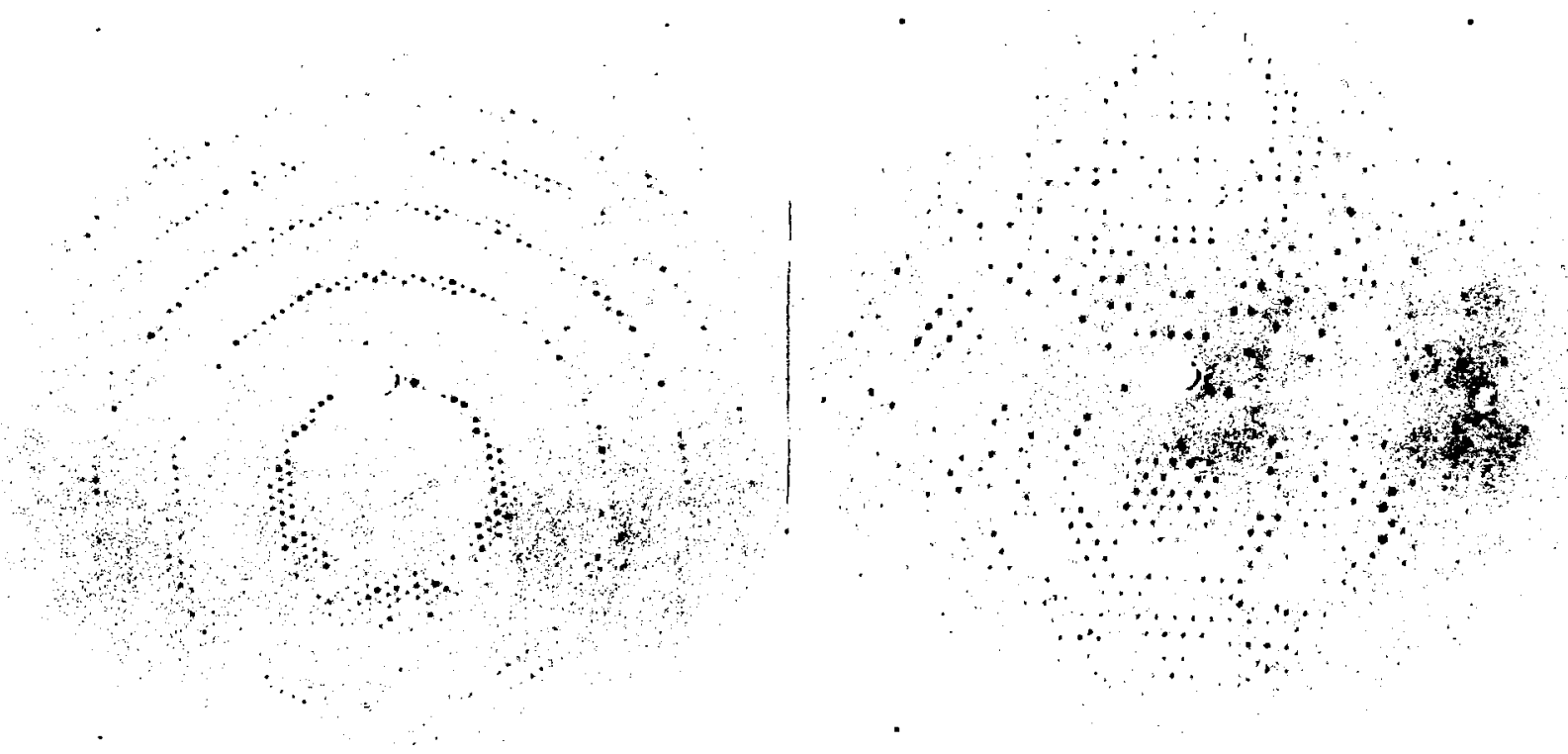

Fig. 1. $2^{\circ}$ oscillation photograph for an EcoRI endonuclease - tridecamer DNA cocrystal soaked in magnesium. Maximum resolution is about 2.9 A.
Fig. 2. $2^{\circ}$ oscillation photograph for an EcoRI endonuclease - 15mer DNA cocrystal. Maximum resolution is about $3 A$.

This work supported by NIH grant GM25671 to J.R. 
A. Paturle, V. Petricek, P. Coppens

Chemistry Department, State University of New York, Buffalo, NY

R. M. Wing

Chemistry Department, University of California at Riverside, Riverside, CA

A ke Kvick

Chem1stry Department, Brookhaven National Laboratory, Upton, NY 11973

The organic crystal :WA (2-Methyl-4-N1tro An111ne, non-centrosymmetric space group (Cc) is we $11 \mathrm{known}$

for 1 ts large non-linear optical properties (11near electro-opt1cal component $r_{11}=67 \times 10^{-12} \mathrm{~m} / \mathrm{V}$ ).

In order to better understand the microscopic origin of these effects, an X-ray scattering experiment has been performed at beamline $X 13 B$ of the National Synchrotron Light Source. The experiment gives, for the first time, information on molecular polarizability at the atomic level.

An alternating electric field ( $50 \mathrm{~Hz}, 10 \mathrm{kV} / \mathrm{cm}$ ) has been applied along the iNA polar axis. The counting signal was gated to separately record the "field up" and "fleld down" scattered intensity. 21 reflexions were collected with this "modulation method"."

Preliminary results show a significant change in the scattered intensity $\left((\Delta I / I)_{\text {max }} \times 3 \%\right)$. Two possible origins for the observed effect have been investigated. They are a molecular polarization and a piezoelectric effect which through a rotation of the molecule affects the unit cell constants. Refinements using newly modifled programs indicate that both effects may contribute. The induced dipole moment is about 0.1 D according to our present data, while the molecular rotation is only a few hundreds of a degree around an axis perpendicular to the long axis of the molecule.

This experiment is to be continued when NSLS resumes operation.

\section{Peferences}

1 G. T. Lipscomb, J. Chem. Phys 75(3), 1509-1516 (1981).

2 I. Fujimoto, Acta. Cryst. A38, 337-345 (1982).

This research was carried out at Brookhaven National Laboratory under Contract DE-ACO2-76CH000I6 with the $U . S$. Department of Energy and supported by its division of Chemical Sclences, Office of Basic Energy Sclences. 
EXPERIMENTAL PHASE DETERHINATION OF CRYSTALLOGRAPHIC STRUGTURE FACTORS BY MULTIPLE SCATTERIAG TECHNIQUES

B. Post

Physics Department, Polytechnic Institute of New York, New York, NY

E. M. Chen

Physics Department, Brookhaven National Laboratory, Upton, NY 11973

A. Kvick

Chemistry Department, Brookhaven National Laboratory, Upton, NY 11973

The solution to the "phase problem" in crystallography has been essential to the rapid growth of structural information. Presently this problem may be solved by statistical methods for structures involving < 150 atoms or by heavy-atom substitution methods for macromolecules. It has however long been realized that the details of the coherent interaction of the diffracted beams from several Bragg reflections simultaneously scattering contain phase information of the reflections involved. The inherent collimation and tunability to long wavelengths of synchrotron radiation suggest a possibility of convenient direct experimental determination of the phases. Initial studies of single crystals of S1 and Gegg Asg $I_{8}$ at the Crystallography Beam LIne X-13B clearly demonstrated the feasability for direct experimental phasing.

The experiments were performed at several wavelengths by recording the multiple diffraction peaks obtained by rotating around the (222)(S1) or $(022)\left(G_{38} A_{B} I_{B}\right)$ scattering vectors. The resolution $1 n$ the psi-scans were typically $0.005^{\circ}$ per step. The figure 11 lustrates the dynamicai three beam interaction in Si cisplaying the asymmetry around the central peak (truncated in the figure). The nature of the asymetry (dip and slow descent) yields the phasing information.

CoUnts

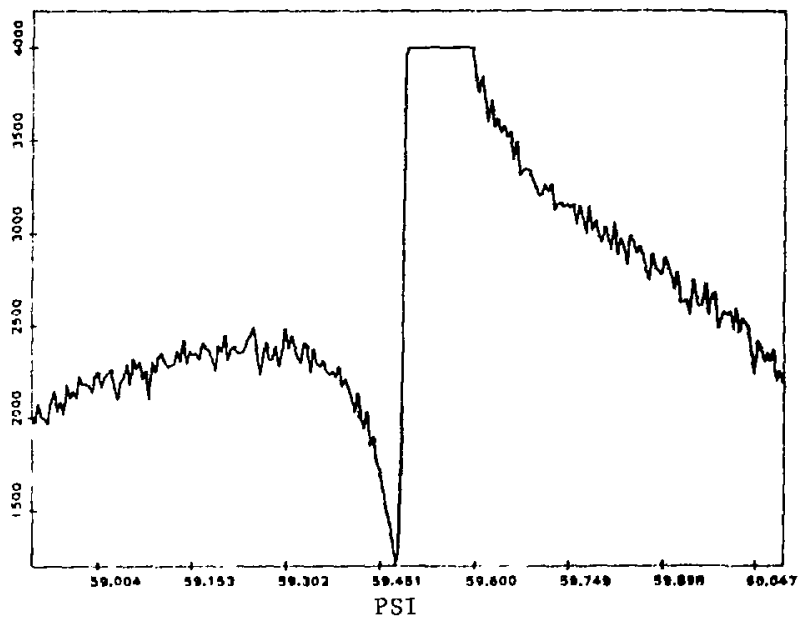

Details of a simultaneous reflection peak profile involving $\mathrm{Si}_{222}$. The peak intensity is 60000 counts and its FWHM $\leq$ $0.02^{\circ}, \lambda=1.325 \AA$.

This research was carried out at Brookhaven National Laboratory under Contract DE-AC02-76CH00016 with the U.S. Department of Energy and supported by its division of Chemical Sciences, office of Basic Energy Sciences. 
The determination of the atomic structure of amorphous (a-) semiconductors has long been a much sought after but seldom attained goal. For example, several models have been proposed for the structure of the well-characterized material a-As $\mathrm{S}_{3}$. An important factor which contributes to this lack of agreement among the proposed models is the method of preparation. Indeed our previous study of the effect of quenching temperature on the structure of stolchlometric bulk glasses has demonstrated that the structure of glasey $(\mathrm{g}-)_{A s} \mathrm{~S}_{3}$ is not unique. Preliminary $x$-ray diffraction measurements for a family of samples of bulk-quenched $\mathrm{B}-A s_{2} S_{3}$ were performed on beamline $X-13 B$ at the NSLS. In this work we focus on the flrst sharp $x$-ray diffraction peak at low scattering factor about $1.2 X^{-1}$. By coupling these results with structural models ${ }^{2}$, we hope to ascertain more completely the intermediate range structural modifications associated with the quenching temperature effect in $g-A_{2} S_{3}$.

References

1. C. Y. Yang, D. E. Sayers, and M. A. Paesler, Phys. Rev. B, In press.

2. G. Pfelffer, J. M. Lee, and M. A. Paesler, J. Non-Crys. Sollds, In press.

+ Deceased

NOTE: Th1s research was supported by the U.S. Department of Energy, Division of Materials Sciences, Office of Basic Energy Sciences under Contract Nis. DE-AC02-76CH00016 and DE-AS05-80-ER 10742 and by the National Science Foundation under Grant No. DMR-8407265. 
S. I. Ayene (1), A. Naqui (1), B. Chance $(1,2)$

(1)University of Pennsylvania, Department of Biochemistry/Biophysics, Philadelphia, PA 19104

(2) University City Science Center, Institute for Structural \& Functional Studies, Philadelphia, PA

Int roduction

Our aim was to study the structure of enzymes and their functional intermediates during turnover under physiological temperature using x-ray absorption spectroscopy. One problem that arises as a result of prolonged $x$-ray irradiation of biological samples is the sample damage (whether reduction by hydrated electrons or other damage). A systematic study of the sample damage is essential. our preliminary results are reported here:

We have performed two types of experiments: a) the sample was flowing through a sample chamber and its redox state was monitored optically using a simple single beam spectrometer, b) static samples were exposed to the $x$-ray beam for certain amounts of time, and later their optical and ligand binding properties were studied.

Results and Discussion

Experiment 1: The sample chamber was placed at $45^{\circ}$ with respect to the $x$-ray beam. The sample was circulated through the chamber from a reservoir at a rate of $10 \mathrm{ml} / \mathrm{min}$. using a peristaltic pump. Three proteins were used in this experiment: oxidized cytochrome $c$, met myoglobin and cytochrome $c$ oxidase. We monitored the redox state at the following wavelengths: cytochrome c-550 nm, met myoglobin-635 nm, cytochrome oxidase-445 nm. The results did not show any substantial change at 550 nm for about two hours. After exposure to radiation excess dithionite was added to fully reduce cytochrome $c$. The sample was frozen quickly at $-80^{\circ} \mathrm{C}$. Later, this $x$-ray irradiated sample was passed through a sephadex 625 column to remove excess dithionite, and its electron donating capability to cytochrome oxidase was measured. The maximum turnover number with respect to oxygen was found to be 39 sec $^{-1}$ as compared to $37 \mathrm{sec}^{-1}$ for a control sample. Thus, we conclude that no substantial damage of cytochrome $c$ was observed for about two hours of $x$-ray irradiation corresponding to $3.6 \mathrm{x} 10^{12}$ photons. Met myoglobin was similarly exposed to $x$-ray beam for about 1 hour. There was no observable reduction during this period. After completion of the experiment, excess dithionite was added and $f$ rozen at $-80^{\circ}$ C. The optical spectra of this deoxy state and later carbonmonoxy liganded state were identical to a control sample.

Cytochrome oxidase was also tested for $x$-ray induced damage. For about 2.5 hours, there was no substantial reduction, however some reduction was observed after 2.5 hours. When the beam was turned off, we noticed a partial reoxidation. But later testinq (Co binding capacity) suggests that cytochrome oxidase was damaged as it did not bind any $c 0$, as judged from the spectral changes in the alpha region.

Experiment 2: Two different systems were employed as follows:

A) Aqueous Samples: Cytochrome oxidase of different concentrations (80, $100 \mu \mathrm{m})$ in phosphate buffer $(0.1 \mathrm{M}$, pH 7.0) was exposed to synchrotron radiation (NSIS, BNL) for two and a half hours at $40-$ $45 \mathrm{~mA}$. The radiation damage was determined by measuring the ratio of the absorption at $605 / 655 \mathrm{~nm}$. The ratio was found to be increased after irradiation.

B) Dry Film Mounted Samples: The radiation damage of the enzyme was determined by measuring the absorption of $605 / 655 \mathrm{~nm}$. In dry PVA film mounted samples the ratio decreases after irradiation. The unusual behavior of the enzyme in dry film mounted samples cannot be easily explained. However, these results indicated that the redox effects of hydrated electrons is predominant in aqueous samples whereas no such effect is implicated in dry film mounted samples.

These results imply that prolonged exposure not only reduces (by hydrated electrons) but also damages the samples. Hence, further studies will be conducted to investigate the following:

1) Sample damage at sub-zero temperatures.

2) Protection of the sample by physical and chemical means.

\section{Physical}

a) changing dose-rate

b) changing the exposure time

c) limiting the number of scans for each sample

\section{Chemical}

a) scavenging of radicals by non-thiol compounds, e.g., formate, ethanol, DMSo, etc.

b) scavenging of radicals by thiol compounds

This work was carrled out on Beam LIne X9-A, supported by NIH Grant RR-01633, and this work was supported by Grants H1-18708, DMB-8414521, HL-31909, GM-31992 and GM-33165. 
COMPARISON OF THE ACTIVE SITE MANGANESE IN MANGANESE SUPEROXIDE DisMUTASE AND MANGANESE CATALASE

W. F. Beyer, Jr., J. Kitzler, I. Frtdovich

Duke University Medical Center, Department of Blochemistry, Durham, NC 27710

Organisms that proliferate in the presence of oxygen have developed a series of enzymes to deal with the deleterious effects of reduced oxygen species such as the superoxide radical anion ( $O_{2}-$ ) and hydrogen peroxide $\left(\mathrm{H}_{2} \mathrm{O}_{2}\right)$. The role of manganese in the biological detoxification of these species has been appreciated only in the last several yaars. Th1s laboratory has been interested in the role of manganese in catalytic dismutation of these reduced oxygen species since we reported the discovery of a manganese containing superoxide dismutase ( $T_{1.2 S O D)}$ in E. coli B in 1970 (1). Our continued interest in manganese containing enzymes resulted in the isolation and characterization of a novel manganese containing catalase (MnCAT) from $\mathrm{L}$. plantarum. The active site manganese in the MnSov has been studied using visible absorption spectroscopy and nuclear magnetfc resonance spectroscopy (2). The data is

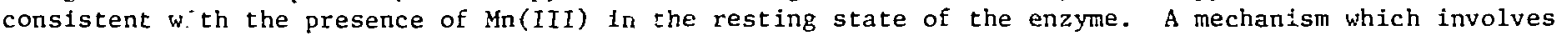
alternate oxidation and reduction of the manganese during the catalytic cycle was proposed:

$$
\underset{\text { NET: } 2 \mathrm{H}^{+}+2 \mathrm{O}_{2}-M \operatorname{Mn}(\mathrm{III})+\mathrm{O}_{2}-\rightarrow \mathrm{Mn}(\mathrm{II})+\mathrm{O}_{2}}{2 \mathrm{H}^{+}+\operatorname{Mn}(\mathrm{II})+\mathrm{O}_{2}+\mathrm{H}_{2} \mathrm{O}_{2}}
$$

The visible absorption spectrum of the MnCAT is similar to MnSoD suggesting that the MnCAT also contains Mn(III) at the active site of the enzyme. However, unlike the MnSoD which contains one Mn per subunit, the MnCAT contains two atoms of Mn per subunit (3). Recent studies using electron spin resonance, suggested the possibility of a binuclear manganese cluster as the active component of the MnCAT. EXAFS will allow us to determine if a binuclear cluster is present and to estimate a distance of separation between the two Mn atoms. In addition, we should be able to determine the oxidation state of the Mn atoms in the resting form of the enzyme. We have also been successful in obtaining an inactive form of the enzyme that is stable to the desired measurements. Similar measurements on this inactivated preparation will be important to understanding the catalytic cycle of the enzyme.

Although there is substantlal similarity in the visible absorption profiles of the two enzymes, there is no overlap in substrate specificity (4). Thus, the MnSOD is not a catalyst of hydrogen peroxide dismutation, nor is the MnCAT capable of dismuting superoxide. The information obtained from EXAFS measurements of these two enzymes will allow us to make a comparison of the active site manganese and perhaps provide some clue to a better understanding of the substrate specificity of these proteins.

\section{References}

(1) Keele, B.B., Mccord, J.M., Fridovich, I. (1970) J. Biol. Chem. 245, 6176-6181.

(2) Villafranca, J.J., Yost, F.J., Fridovich, I. (1974) J. Biol. Chem. 244, 3532-36.

(3) Beyer, W.F., Jr., Fridovich, I. (1985) Blochemistry, 24, 6460-67.

(4) Kono, Y., Fridovich, I. (1983) J. Biol, Chem. 258, 1364-48.

This work was supported by research grants from the Council for Tobacco Research, U.S.A., Inc.; the United States Army Research Office; the National Science Foundation; the Institute of General Medical Sciences of the National Institutes of Health; and the University City Sclence Center under the Biotechnology Resource Program of the Division of Research Resources of the National Institutes of Health. 
X-RAY DIFFRACTION STUDIES OF MULTILAYER FILMS

J. K. Blasie(1,2), J. Pachence (1), D. Pascolini (1), R. Fischetti(1,2), F. Asturias(1)

(1) University of Pennsylvania, Department of Chemistry, Philadelphia, PA

(2)University City Science Center, Institute for Structural \& Functional Studies, Philadelphia, PA

I. Meridional X-Ray Diffraction From Ultrathin Multilayer Films

Partially as a test of the photon flux density and focus produced by the current optics of Beam Line X9-A (Si(111) double-crystal monochromator and a variable, cylindrically-bent Al/Ni mirror), we have recorded (In November, 1986) the meridional x-ray diffraction from Langmuir-Blodgett multilayers containing from 1-10 bilayers deposited on flat, alkylated glass substrates ut1lizing multilayer oscillation and both one-dimensional and two-dimensional position-sengitive detectors. The photon flux density at $7605 \mathrm{eV}$ was measured (via extrapolation to zero attenuation of the integrated intensity of the (002) Bragg reflection from a flve-bilayer multilayer calibrated with a rotating-anode $x-r a y$ source and cylindrically-bent Ge(111) optics) to be $-5 \times 1010 / \mathrm{sec} / \mathrm{mm}^{2}$ within $0.1 \mathrm{~mm}$ of the vertical beam profile FWHM $\sim 0.5 \mathrm{~mm}$ for storage-ring parameters $2.5 \mathrm{GeV}, 105 \mathrm{~mA}$. The line-focused beam produces $\therefore Q_{\mathrm{Z}}$ resolution more than sufficient to resolve all subsidiary maxime about the (OCR) Bragg peaks for the ten-bilayer multilayers with a multilayer period along $z$ of $56 \AA$. Resonance $x-r a y$ diffraction effects from barium about the Ba LIII absorption edge on the meridional diffraction from five-bilayer multi-layers of barium arachidate have been utilized to determine the positions of the barium atoms within the multilayer profile to $\pm 1 \dot{A}$ accuracy. This work was spnsored by the NIH (Grants GM-33525 and HL-18708) and the NSF (MRL Program Grant DMR-8519059).

II. Non-Resonence and Resonance X-Ray Diffraction Studies on Protein Monolayers and Thick Membrane Multilayers

Two different experiments were performed (In February, 1987) on Beam Line X9-A employ1ng a S1(111) double-crystal monochromator, a variable, cylindrically-bent Al/Ni mirror, a Huber 4-circle diffractometer and a linear position-sensitive detector. The first investigated the resonance scattering effects from iron on the meridional diffraction from a single monolayer of cytochrome con the surface of a five-monolayer multilayer of arachidic acid on a flat, alkylated substrate over a \pm 100 eV energy renge about the $\mathrm{Fe} K$ absorption edge $(7110 \mathrm{eV})$ to a spatial resolution of $5 \dot{A}$. The second investigated the nature of the non-resonance meridional x-ray diffraction from thick multilayers of functional sarcoplasmic reticulum membranes over the energy range from $7000 \mathrm{eV}$ to $4000 \mathrm{eV}$. Results from the former experiment have been utilized to determine the profile structure of this non-periodic, ultrathin multilayer to $5 \dot{A}$ - resolution (previojsly determined to $10 \dot{A}$ - resolution employing a rotating-anode source) and the position of the cytochrome heme Iron atom within this profile structure to $\pm 1 \dot{A}$. Results from the latter experiment clearly demonstrated the feasibility of performing resonance $x-r a y$ diffraction on calcium bound to the two high-affinity binding sites of the Ca2t ATPase within the sarcoplesmic reticulum membrane profile structure. This work was sponsored by the NIH (Grants GM-33525 and Hi-18708).

The National Biostructures PRT and Beam Line X9-A are supported by NIH through the Biotechnology Resource Program of the D1vision of Research Resources under Grant RR-01633 and the NSF under the iNRL Program Grant DMR-8519059. 
STUDIES OF MULTIPLE SCATTERINC IN XAIES: BEAM LINE X9-A

C. Bouldin(1), G. Bunker(2), D. McKeown(2), J. A. Ritter (1)

(1) National Bureau of Standards, Galthersburg, itD

(2) University Cfty Science Center, Institute for Structural \& Functional Studies, Philadelphia, PA

In recent yeers it hes become apparent that the XANES is more sfmilar to EXAFS then was previously supposed. Of criticel importance in this connection is the dependence on energy of photoelectron multiple acattering (MS) relative to single scattering (SS). If US deceys rapidly enough with energy, EXAFS-I1ke analysis methods should be applicable in the low-k reglon. We have recently completed what we belleve is the first really "clean" experiment to address this issue. Previous studies have used condensed matter samples, and SS contributions from distant atoms are difficult to distingulsh from MS from near atoms. By using Germanium gases GeH4, GeH3Cl and GeCl4 we have been able to clearly separate these effects, and reaffirm previous conclusions of Bunker and Stern (from studies of kino4) that the "type 2 " iS dies away rapidly past the edge. We have also performed a series of multiple scattering computer calculations on these and other systems. Although these calculations are very interesting, in our opinion the theoretical results are too sensitive to the detalls of the constructed atomic potentials to be used for quantitative structure determination at this time. We believe that preY LOUsly reported XANES siqulations of hemoglobin have been overinterpreted. Nevertheless the calculations are of considerable heuristic value, and we are trying to improve the methods.
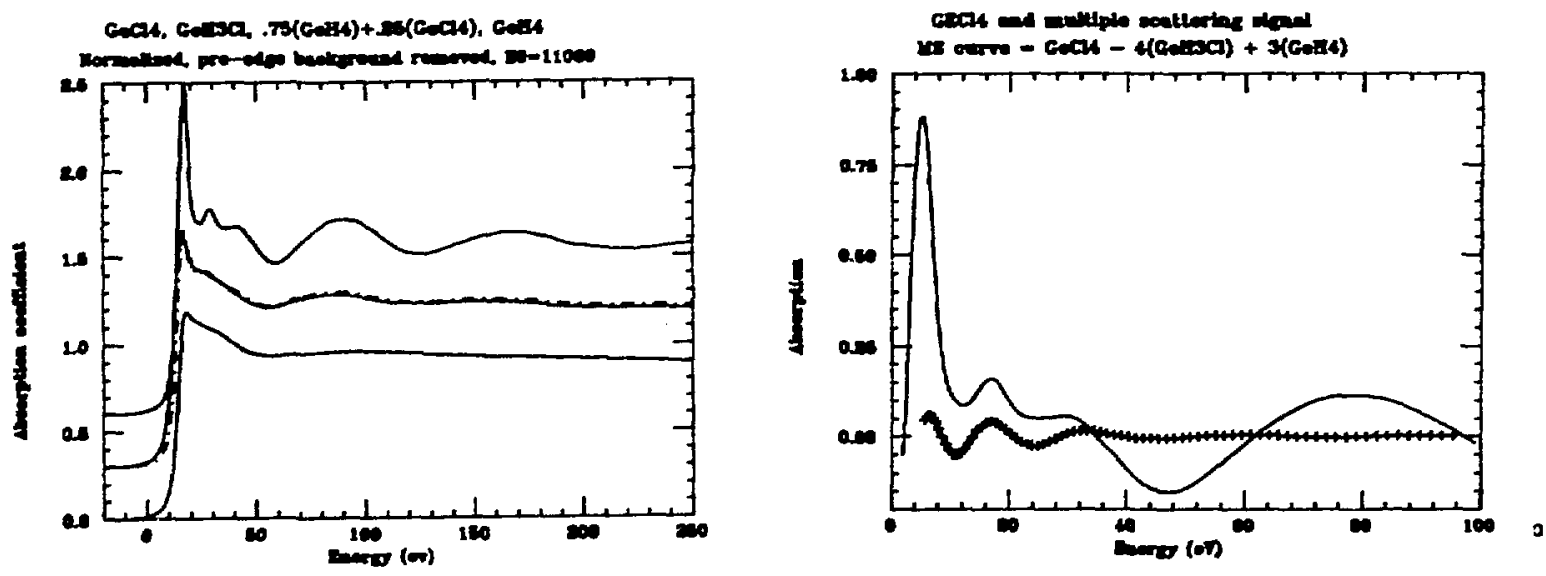

Supported by WIH through the Blotechnology Resource Progran of the Division of Research Resources under Grant RR-01633. 
BEAM LINE X9-A END STATION INSTRUMENTATION: SPECTRDSCOPY

G. Bunker (1), G. Rosenbaum(1), S. Khalld(1), B. Chance(1,2), J. Schug (1), J. Shultz(1), L. Thomas (1), M. Sullivan(1)

(1) Unfversity City Sclence Center, Institute for Structural \& Functional Studies, Philadelphia, PA

(2)University of Pennsylvania, Department of Biochemistry/Blophysics, Philadelphia, PA

The essential basic equipment is in place for conventional two channel fluorescence mode EXAFS/XANES experiments. Although initial testing of the instrumentation showed the equipment to be generally adequate, it also revealed some (usually minor) deficiencies and problems which we are now attempting to remedy. Precise manual and/or computer controlled apertures (slits) currently are provided to define $x$-ray beam dimensions. Incident intensity is monitored using a transmission type Ionization chamber, or a scatterer with a ZnS scintillator/phatamultiplier tube detector. For fluorescence detection the PRT owns one Stern/Jeald Type fluorescence ion chamber with Soller slits, low nolse preamp, amplifler, and V/F converter, Available gains are 1010, $10^{11}$ and $10^{12}$

volt/amp. Also present on the beam line are: 5 " diameter ZnS detectors, one Ke1thley 427 amplifier, dual channel $100 \mathrm{KHz} / \mathrm{V}$ voltage-to-frequency converter module, and $\mathrm{X}-\mathrm{Z}$ translation stages. One 6 channel scaler is installed in the computer interface, so that 5 detectors can be monitored at once when enough $V / F$ converter modules are bullt. "User friendly" data acquisition software for routine EXAFS experiments has been written and tested. A solenold driven attenuator has been built to help perform routine tests for nonlinear response of the whole detection system. A simple but general purpose "dual signal switcher box" was also constructed to interface an acbitrary "two state" experinent (e.g.. light on/light off for photosensitive materials) to the computer without reprograming. Construction of additional test and calibration equipment is planned.

Existing equipment is belng modified to improve its operating characteristics and reliability, and new equipment is being bullt to improve experimental flexibility and reduce down time on the beam line. Highest priority is given to constructing accuract, reliable, easy to use and documented equipment for the most common experiments. A separate core research project is devoted to pushing the state of the art in EXAFS instrumentation.

Supported by NIH thorugh the Blotechnology Resource Program of the Division of Research Resources under Grant RR-01633 also RR-05823 (Biomedical Research Support Grant). 
RAPID FLOW EXPERIMENTATION ON BEAM LINE X9-A

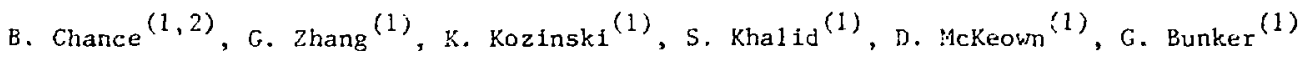

(1) University City Sclence Center, Institute for Structural \& Functional Studies, Philadelphia, PA

(2) University of Pennsylvania, Department of Btochemistry/Biophysics, Philadelphia, PA

The test program involves allgnment, signal acquisition effectiveness, interference of $x-r a y$ and optical signals, sample damage, sample flow rates, sample concentration evaluation. The regenerative flow apparatus was tested with Fe EDTA, metmyoglobin and horseradish peroxidase for an interval of four hours. In this interval of continuous running at $50 \mathrm{msec}$ times resolution, the protein was denatured by $10 \%$. Improved pistons are expected to give at least one shift of ruaning time at a time resolution of 100 msec and a concentration of $0.7 \mathrm{~m} \cdot \mathrm{r}$.

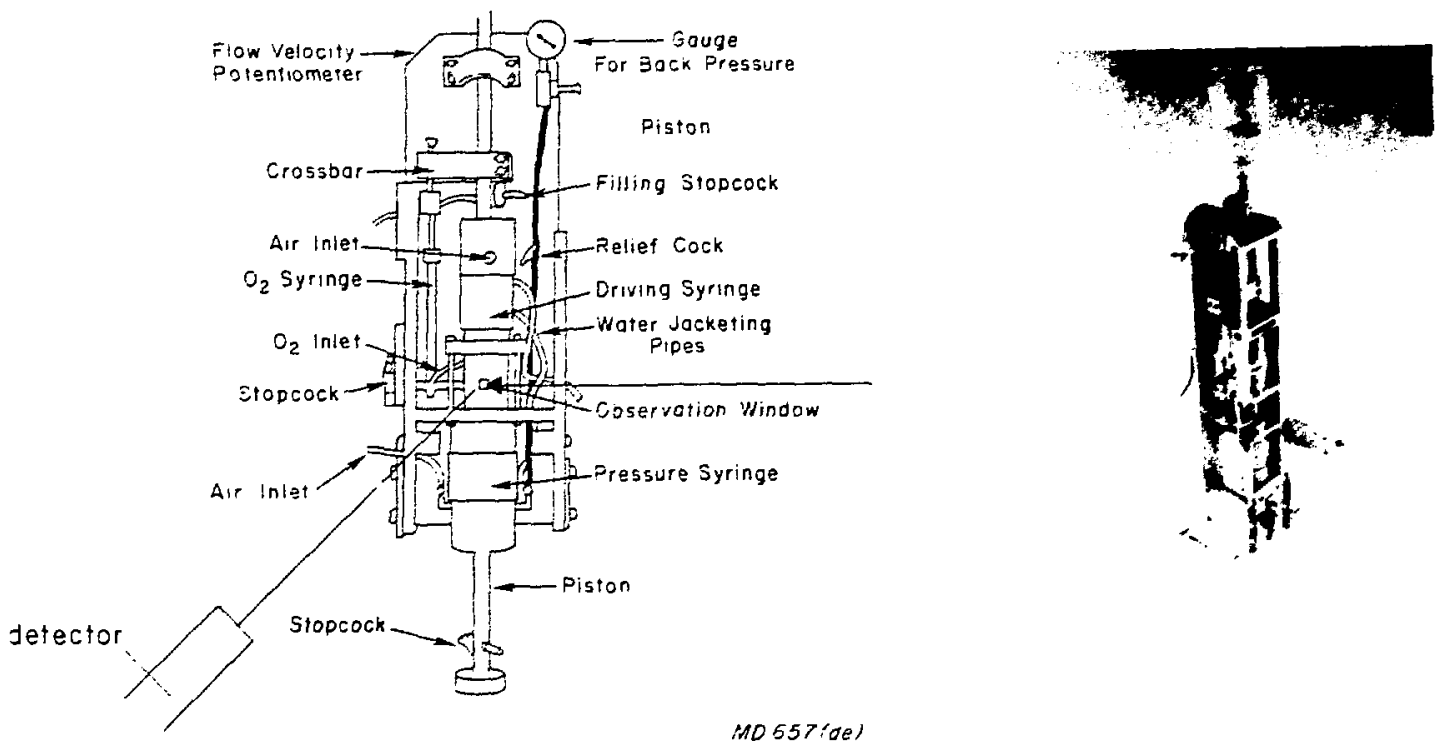

Drawing (right) and Photograph(left) of Regenerative Flow Apparatus for $X$-Ray Absorption Spectroscopy

This work was carried out on Beam line X9-A supported by XILI under Grant RR-01633, and this work was supported by Grants GM-31992, HL -18708 and MH-33165. 
STRONG INCOMMENSURATE FLUCTUATIONS IN A SMECTIC-A PHASE

P.A. Heiney, E. Fontes, and W.K. Lee (U. of Pennsylvania ${ }^{1}$ ).

The synthesis of rod-shaped organic molecules having fixed, permanent dipole moments has led to a rich variety of liquid crystal (LC) phases. Most polar smectic phase diagrams can be successfully interpreted in the frame of a phenomenological model ${ }^{2}$ for a frustrated smectic with two order parameters $\Psi_{1}(\vec{t})$ and $\Psi_{2}(\vec{F})$ (often identified as the dipole moment density and the center of mass density waves) that individually would condense at two incommensurate wayevectors $k_{1}$ and $k_{2}$ with $1<k_{2} / k_{1}<2$. Depending on the choice of parameters, this model can describe a monolayer $A_{1}$ phase, a bilayer $A_{2}$ phase ( in which $k_{1}=k_{2} / 2$, a partial bilayer $A_{d}$ phase, and twodimensional $\mathrm{A}$ and $\mathrm{C}$ phases in which two vectors of length $k_{1}>k_{2} / 2$ sum to form a vector of length $k_{2}$. Quite naturally, the theory also predicts a stable uniaxial incomm nsurate phase smectic- $A_{i}$, in which two colinear modulations of incommensurate wavelength are simultaneously condensed, producing sharp scattering peaks at $k_{1}$ and $k_{2}$.

In contrast with ordinary incommensurate systems, in an incommensurate $\mathrm{LC}$ it is difficult to distinguish between the "ordered" and "modulating" periodicities, since both potentials may be comparable in strength (i.e. $\Psi_{1}$ and $\Psi_{2}$ may be comparable in amplitude). However, there is still a distinction between weakly coupled phases, which presumably consist of interpenetrating density waves and yield Bragg peaks at $k_{1}$ and $t_{2}$ only, and strongly coupled phases, which may be considered as consisting of a periodic array of solitons, and will peaks at all sums $\mathrm{q}=\mathrm{nk}_{\mathbf{1}} \pm \mathrm{mk}_{2}$.

Weakly coupled incommensurate phases have previously been reported in smectic phases ${ }^{3}$. We have made high resolution $x$-ray scattering measurements on a liquid crystalline smectic- $A_{1}$ phase, which show two diffuse maxima at incommensurate wavevectors in addition to a fundamental quasi-Bragg peak. These diffuse peaks indicate the close proximity of an incommensurate phase with two strongly coupled parameters. The material studied was a mixture of $\mathrm{DB}_{5}$ with 22.88 molar $\% \mathrm{~T}_{8}$. The sample cell oven and scattering geometry were as described previously $^{5}$. X-ray diffraction data were taken at NSLS port $\mathrm{X} 9 \mathrm{a}$ utilizing a double crystal $\mathrm{Si}(111)$ monochromator and matching analyzing crystal, with a longitudinal resolution $\Delta q=0.00012 A^{-1}$ HWHM.

Figure 1 shows plots of scattering intensity as a function of $\mathrm{q}_{\|}$, the momentum transfer along the orienting magnetic field, at a variety of fixed temperatures. The solid lines are the results of least-squares fits to a sum of Lorentzians. With descending temperature, the following phases are seen: a nematic $(N)$ phase above $124.5 \mathrm{C}$, a partially bilayer $A_{d}$ phase between 120 and $124.5 \mathrm{C}$, a monolayer $A_{1}$ phase between 119 and $113.5 \mathrm{C}$, and a true bilayer $A_{2}$ phase below $110 \mathrm{C}$. The $A_{d}$ and $A_{1}$, and the $A_{1}$ and $A_{2}$ phases are separated by coexistence regions.

The $A_{d}$ phase displays two sharp scattering peaks at $\mathrm{q}_{0}{ }^{\prime}=0.131 \mathrm{~A}^{-1}$ and $2 \mathrm{q}_{0}{ }^{\prime}$, and two additional two diffuse maxima at 0.11 and $0.238 \AA^{-1}$, signaling fluctuations toward the $A_{1}$ phase. The $A_{1}$ phase, by contrast, has a sharp peak at $2 q_{0}=0.2380 A^{-1}$ and diffuse maxima at $q_{o}^{\prime}$ and $q_{-}=\left(2 q_{0}-q_{0}{ }^{\prime}\right)$. The widths of the $q_{0}^{\prime}$ and $q_{-}$peaks

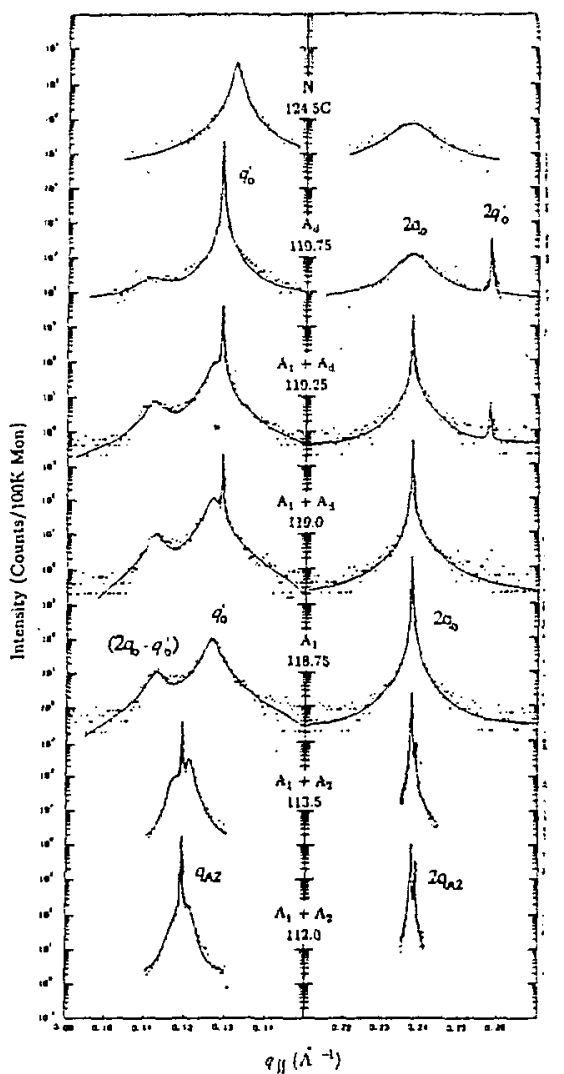

Fig. 1) Scattering intensity collected along $q_{\text {f }}$ (parallel tc the molecular long exis) at indicated temperatures (C) Note semilogarithmic axes.

are indicative of fluctuations into small smectic-like ordered regions with approximate size $\xi_{\|}=200-300 \AA-1$. These large fluctuations indicate the close proximity of an incommensurate smectic- $A_{i}$ phase, and the presence of the $q_{-}$"modulation" peak indicates that this must be a strongly coupled phase as discussed above. In a pure $\mathbf{A}_{\mathbf{i}}$ phase, of course, all peaks would be simultaneously resolution limited. Other peaks, $\left(2 \mathrm{q}_{0}+\mathrm{q}_{0}{ }^{\prime}\right)$ for instance, have not been seen and are probably too wealk to measure.

\section{Footnotes and References}

1. This work was supported by NSF-LRSM Grant No. DMR-85-19059. We thank the Institute for Structural and Functional Studies for their help at Brookhaven NSLS Port X9a, supported by NIH Grant No. RR-0163.

2. J. Prost, Proc. of the Conf. on Lig. Cryst. of One and Two Dimensional Order, Garmisch-Partenkirchen (1980), p. 125.

3. G.J. Brownsey and A.J. Leadbetter, Phys. Rev, Lett. 44, 1608 (1980); B.R. Ratna, R. Shashidhar, and V.N. Raja, Phys. Rev. Lett. 55, 1476 (1985).

4. A.M. Levelut, R.J. Tarento, F. Hardouin, M.F. Achard, and G. Sigaud, Phys. Rev. A24, 2180 (1981).

5. E. Fontes, P.A. Heiney, J.L. Haseltine, and A.B. Smith, III, J. Phys. (Paris) 47, 1533 (1986). 
S. Khalid(1), B. Chance(1,2)

(1) University City Science Center, Institute for Structural \& Functional Studies, Philadelphia, PA

(2) University of Pennsylvania, Department of Biochemistry/Biophysics, Philadelphia, PA 19104

\section{Introduction}

The beam size at Beam Line $\times 9-A$ is $0.5 \mathrm{~cm} \times 15 \mathrm{~cm}$. A total flux of $10^{12}-10^{13} \mathrm{photon} / \mathrm{sec} / \mathrm{eV}^{\mathrm{b}} \mathrm{b}$. pass at $16 \mathrm{~m}$ from the source can be obtained for $2.4 \mathrm{GeV}$ electron energy and $100 \mathrm{~mA}$ beam current. For this flux photon counting has its limitations. More so for the reason that in the future, some percentage of the NSLS $x$-ray operation will be in a single bunch mode. Large area sample holders are used for this beam size, and we use an array of 16 detectors for photon fluorescent signal collection in the integration mode. These detectors use zns(Ag) as scintillators mounted on a rectangular Hamamatsu Photomultiplier Tube (RMT).

\section{Experiment}

The R1612 rectangular PMT of area $88 \mathrm{~mm} \times 40 \mathrm{~mm}$ was used for these detectors. Four such PMTs were placed in a row, they were enclosed in a box to avoid light leak. A mozzle in front was attached for mounting filters and for minimizing the astray radiation (Fig.l).

$5 \mathrm{mM}$ of Fe-EDTA solution was used in the cell. An array of 4 detectors was placed on top and the same number at the bottoan of the sample in front, and the same arrangement of detectors was made at the back of the sample (Fig. 2). The detectors were so arranged that the direct $x$-rays were going between these detectors, and the detectors only see the scattered and fluorescent signal photons. To minimize the scattering we use $z_{-1}$ filters (Mn in this case) close to the sample.

\section{Results}

The counts were recorded below the edge at $7.080 \mathrm{KeV}$ and above the edge at $7.180 \mathrm{KeV}$. The beam current was $73 \mathrm{~mA}$ at $2.4 \mathrm{GeV}$. The average of the signal photons at the top and bottom at the front and at the back were recorded. It was found that as much as $2 \mathrm{~B}$ \& of the signal photons were present at the back of the $2 \mathrm{~mm}$ thick sample as compared to 100 at the front.

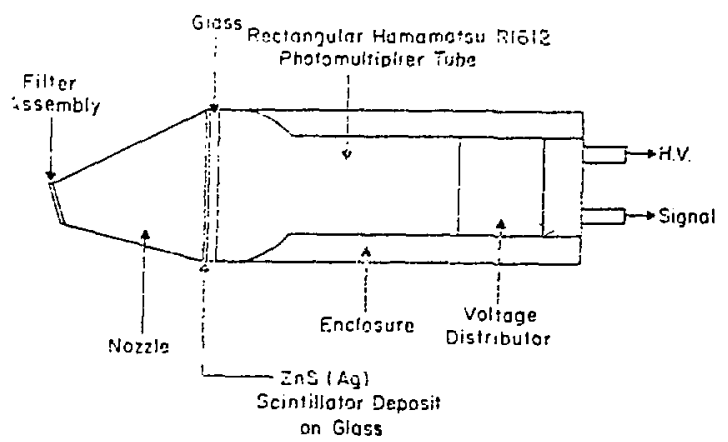

$5 \times 9$

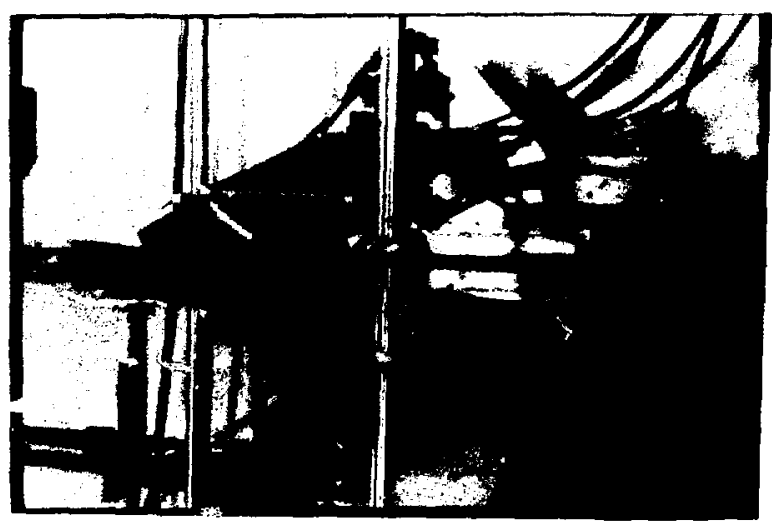

Fig. 2:

Fig. 1: 
S. Khalid(1), B. Chance(1,2), L. Thomas(1), M. Zhang(2)

(1) University City Science Center, Institute for Structural \& Functional Studies, Philadelphia, PA

(2) University of Pennsylvania, Department of Biochemistry/Biophysics, Philadelphia, PA

Int roduction

$X$-ray beam line fluctuation is a comon problem at almost all of the beam lines at different synchrotrons of the world. At NSIS the Pick-Up Electrodes (PUEs) correct the vertical and horizontal orbit of the electrons in the fing, and their sensitivity is not better than \pm 100 microns in both directions. We built a device to reduce these fluctuations to less than \pm 30 microns at the experimental station. This improves the data quality and saves the collection time.

Experiment

A wooden reed with $\mathrm{ZnS}$ (Ag) phosphor gives $120 \mathrm{~Hz}$ light spikes picked-up by a detector (R-signal). When the mean position of the reed is at the center of the $x$-ray beam, the spikes are equal in phase. A fluctuation in the beam gives a phase change and consequently a vertical track voltage, proportional to the phase change. This voltage drives a motor which brings the sample, the fluorescent detectors (giving M-signal) and the reed back to the central position of the beam (Fig. 1). The integrated measure of $R$ and $M$ gives the $x$-ray absorption spectrum.

Results

Fig. 2 shows the comparison of the feedback closed and opened. The plot was taken in a non-scan mode with a time constant of one second. The 6 minutes interval of 100 microns disappear in the closed loop. In average the sample was never deviated from the mean position of the $x-r a y s$ by more than \pm 30 microns, and for the pracicical beam fluctuations of a smaller amplitude, the time response was a fraction of a second.

POSITION FLUCTUATION COMPENSATION ANO OTNODE VOLTAGE FEEDBACK SYSTEM

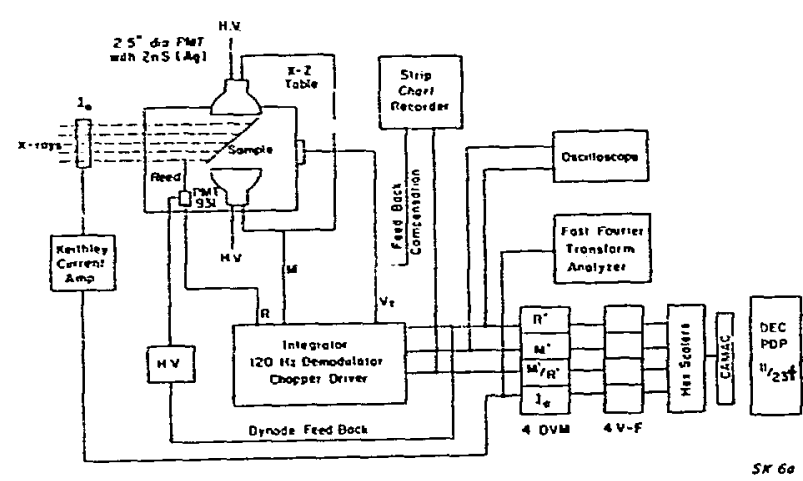

Fig. 1:

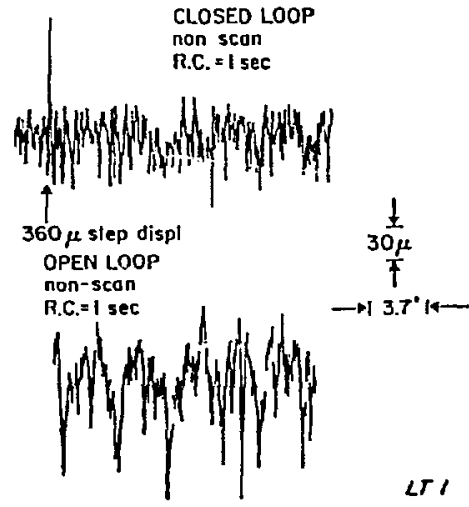

Fig. 2:

Beam Line X9-A is supported by NIH through the Blotechnology Resource Program of the Division of Research Resources under Grant RR-01633 and this work was also supported by Grant CA-41787. 
EXAFS STUDIES ON CARDIAC CYTOCHROME $c_{1}$

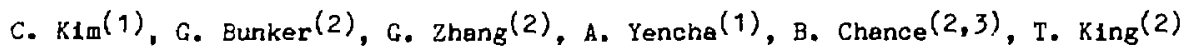

(1) State University of New York, Department of Cheristry, Albany, NY

(2)University City Science Center, Institute for Structural \& Functional Studies, Philadelphia, PA

(3)University of Pennsylvanie, Department of BlochemiatryfBlophysics, Philadelphie, PA

EXAFS experiments were performed on Beam Line X9-A at room temperature on 1-2 mil solutions of

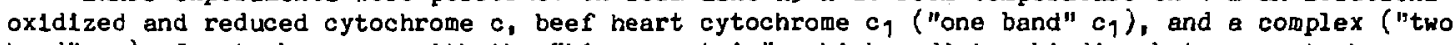
band" $c_{1}$ ) of cytochrome $c_{1}$ with the "hinge protein". which mediates binding between cytochrome c and cytochrome $c_{1}$ into the active electron trangfer complex in vivo. The cytochrome c spectra agree well with previous measurements made at SSRL and CHESS, the $c_{1}$ spectra were much better than those previously obtained at CHESS. Edge sh1fts upon reduction are consistent with those previously observed. The most interesting result of these experiments is that XANES and EXAFS spectra indicate that significant stereochemical changes occur upon binding of the hinge protein. An unusual double peak appears in the XANES of the two band $c_{1}$, which 18 reproducible between experiments and is not observed in one band $c_{1}$ or cytochrome $c$ spectra measured under the same conditions. Analysis is in progress to quantitatively determine the bond lengths and Debye Waller factors. Future experiments will be necessary to obtain spectra of improved signal-to-nolse ratio on frozen samples and to investigate the effects of possible radiation damage.

Beam Line X9-A is supported by NIH through the Blotechnology Resource Program of the DIvision of Research Resources under Grant RR-01633, and this work is supported by a grant from the Amerlcan Heart Assoclation/National Center and NIH Grant HL-31909. 
X-RAY ABSORPTION INVESTIGATION OF STEREOCHEMISTRY OF CYTOCHROME $c$ ' ON BEAM LINE X9-A

R. Korszun (1), G. Bunker (2), M. Cusanovich(3), R. Scheidt (4)

(1)University of Wisconsin-Parkside, Department of Chemistry, Kenosha, WI

(2)University City Science Center, Institute for Structural \& Functional Studies, Philadelphia, PA

(3)University of Arizona, Department of Blochemistry, Tucson, AZ

(4) Notre Dame, Department of Chemistry, South Bend, IN

EXAFS experiments were performed at room temperature on oxidized and reduced pH 7 samples of cytochrome c' from the bacteria Rhodospirillum Rubrum and Molischianum as well as appropriate model compounds and metazidohemoglobin. Unlike cytochrome c, Fe in cytochrome $c^{\prime}$ is known to have no sulfur 1igands. Cytochrome $c^{\prime}$ exhibits characteristic changes in spin state as a function of $\mathrm{pH}$, and under certain conditions an unusual "quantum admixed" intermediate spin state. The spectra on Beam Line X9-A were compared with data previously obtained at CHESS on frozen samples of the Rubrum protein at pH 7 , 10 and 12. No aignificant differences were observed between the proteins from the two species of bacteria. The first shell data have been thoroughly analyzed, and a chemically reasonable plcture of the heme environment ag a function of $\mathrm{pH}$ and redox state has emerged. A manuscript is in preparation.

Beam Line X9-A is supported by NIH through the Blotechnology Resource Program of the Diviston of Research Resources under Grant RI-01633, and this work was supported by GM-32692. 
David A. McKeown, Institute for Structural and Functional Studies, 3401 Market St., Su1te 320 , Philadelphia, PA 19104.

Glenn A. Waychunas, Center for Materlals Research, Stanford Univers1ty, Stanford, CA 94305.

\section{INTRODUCTION}

The focus of this experiment is to obtain Ti site information for acmite (NaFe( $\mathrm{S}_{10} \mathrm{O}_{3}$ ) and kaerautite $\left(\mathrm{Ca}_{2} \mathrm{Na}(\mathrm{Mg}, \mathrm{Fe})_{4}^{+}\left(\mathrm{Al}, \mathrm{Fe}^{+3}, \mathrm{TI}\right)(\mathrm{Al}, \mathrm{S1})_{8} \mathrm{O}_{22}(\mathrm{O}, \mathrm{OH})_{2}\right)$, which have 5 weight $\%$ and 7 weight $\% \mathrm{TIO}$, respectively. Titanite $\left(\mathrm{CaT1O}\left(\mathrm{SHO}_{4}\right)\right.$ ) was used as the model compound, where $\mathrm{TI}$ is in an octahedra1 site having $5 \mathrm{~T} 1-0$ distances ranging from 1.97 to $2.05 \AA$, and one shorter T1-0 distance at $1.77 \AA$. Considerable difficulty was encountered for the above samples at S.S.R.L., due to the low TiO, concentrations and significant alr absorption of X-rays with energies near the Ti K-absorption edge ${ }^{2}(4960 \mathrm{eV})$.

\section{EXPERDMENTAL}

The samples consisted of particles less than one absorption length (approximately $30 \mathrm{microns}$ ) in diameter, that were deposited as one layer on tape. The experiments were carrled out in fluorescence geometry, having ion chambers for the $I_{0}$ and $I_{f}$ detectors. A NaIO ${ }_{4}$ filter was placed between the sample and $I_{f}$ chamber to Improve signal-to-background levels for the Ti spectra. The Fe, and especially, the Ti data are surprisingly good, considering that no speclal provisions were made in the experimental set-up to reduce alr absorption of $\mathrm{X}$-rays.

\section{RESULTS}

Initial results indicate similar octahedral Fe environments for acmite and kaersutite. The Ti data were altered near the middle of the EXAFS range due to absorption of the coherent background from the $L_{I}$ edge of Iodine ( $5190 \mathrm{eV}$ ) from the filter. This effect is more pronounced for the samples having lower $I$ T concentrations (see Fig, 1). The resulzing cl.1 data extend out to only $7.5 \&-1$, However, some quantitative Interpretations can be made from tine raw daca ano chi data.

The general Erequency of the EXAFS oscillations are rough1y the same for all three Ti samples, indicating octahedral T1 for all three samples. The kaersutite data indicate Ti in a more distorted or disordered site than $\mathrm{T} 1$ in titanite or acmite, since the pre-edge feature is stronger in the kaersutite I1 edge (see FIg. 1). From using the ratto method, the kaersutite T1 site is considerably more disordered than the TI site in titanite, and is made up of two distributions of coordinating oxygens. One distribution accounts for approximately $30 \%$ of the oxygens surrounding the central T1 at $0.18 \&$ shorter distances than the average $T i-O$ distance for $T i$ in titanite; and the other distribution accounts for $70 \%$ of the oxygens in a much broader distribution of distances from the $\mathrm{T} i$.

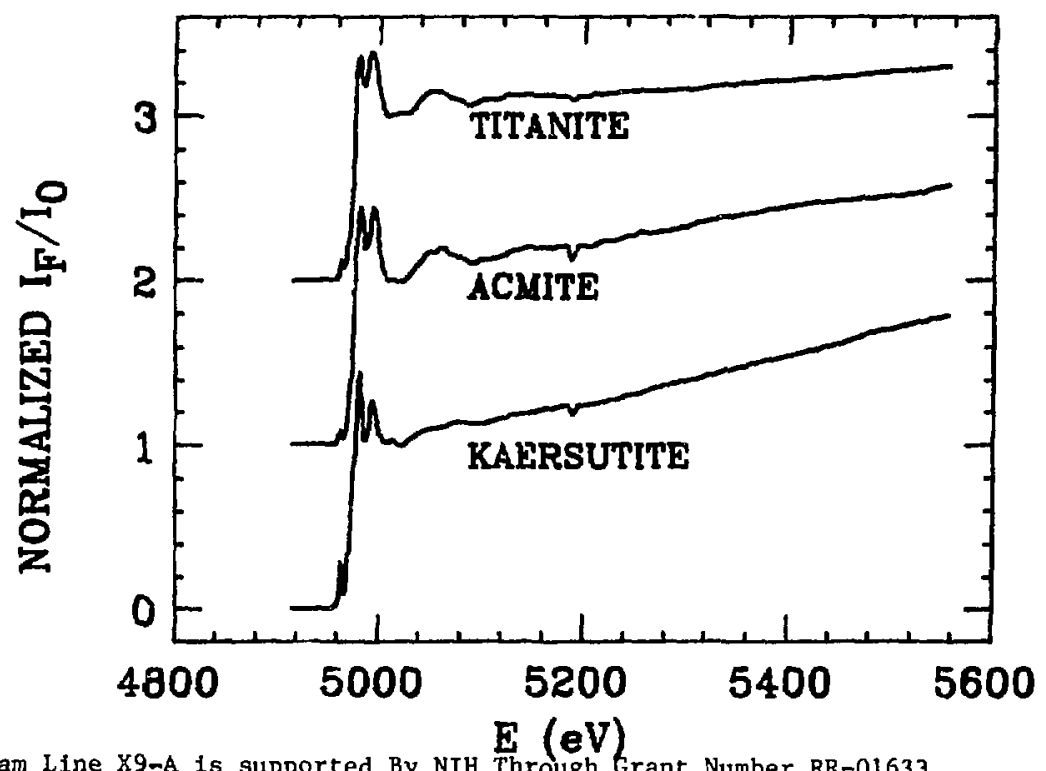

Fig. 1. Ti K-absorption edge and EXPFS; all data were pre-edge background subtracted; and the edge-steps were normalized to one. The spectra were then offset for the plot.

Beam Line X9-A is supported By NIH Through trant Number RR-01633. 
CONTINUOUS ENERGY SCAN OF THE DOUBLE CRYSTAL MONOCHROMATOR ON BEAM LINE X9-A

Gerd Rosenbaum, Syed Khalid, Michael Sullivan

University City Science Center, Institute for Structural \& Functional studies, Philadelphia, PA

The rotary table which serves as the Bragg-angle drive of the double crystal monochromator was originally driven by a stepper motor. We have replaced the stepper motor by a digitally controlled DCmotor. Position feedback to the control electronics is by an encoder mounted on the input shaft of a 200:1 gear reducer, the output of which drives the rotary table.

We have recorded EXAFS-spectra in step scan mode (Fig. 1), i.e. the DC-motor is driven to the next desired energy position and is then stopped. After the usual settling time, data accumulation is started. We have also recorded an edge spectrum in continuous scan mode (Eig. 2), i.e. the DC-motor is continuously running at a low speed. Data are accumulated for a certain time and are then read out together with the energy position at that moment. Immediately after readout, a new data accumulation cycle is started.

The removal of the vibration generating stepper motor has resulted in improved quality of the EXAFS-data in step scan mode (Fig. 1). The data in continuous scan mode are of at least as high quality. The elimination of the customary settling time of a few tenths of a second will greatly improve the duty cycle of data collection.

The resolution of the encoder is 4096 quadrature step per revolution which gives 409600 quad-steps per degree of Bragg-angle. In step scan mode, the DC-motor reached the desired position within 5-8 quad-steps corresponding to less than 0.1 arc sec at the monochromator crystal. This is a better resolution than the 400 half-steps of the stepping motor. Repeats of scans in continuous mode (Fig. 2) differed by less than $.02 \mathrm{eV}$ at $6.5 \mathrm{KeV}$ corresponding to 0.2 arc sec.

The improvement due to the "smooth running" DC-motor is demonsirated by the noise pattern of the monochromatic flux (Fig. 3). Besides the very small dip when the motor is turned on, there is no difference in the noise when the motor is at rest or running.

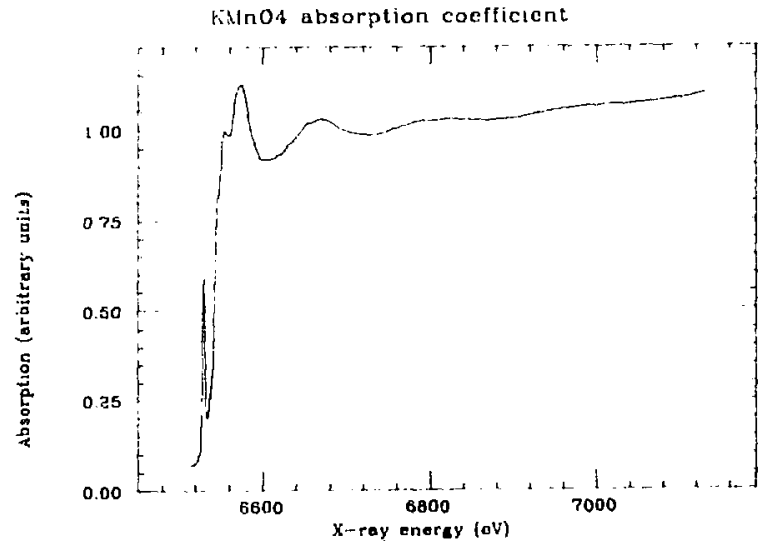

Eig. 1:

EXAFS-spectrum of $\mathrm{KMnO}_{4}$

Monochromator is driven by a digitally controlled DC-motor. The pattern was recorded in step scan mode.
KMnO4 edge spectrum in continuous scan mode

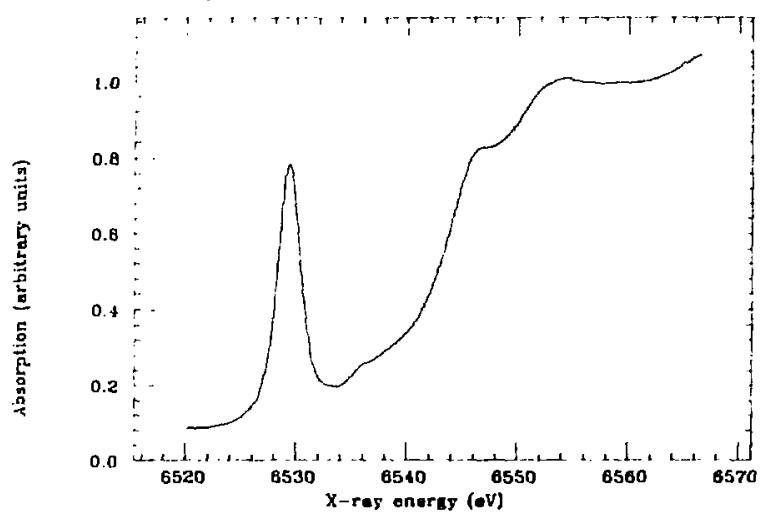

Fig. 2:

Edge spectrum of $\mathrm{KMnO}_{4}$ in continuous scan mode Same monochromator drive as in Fig. 1.

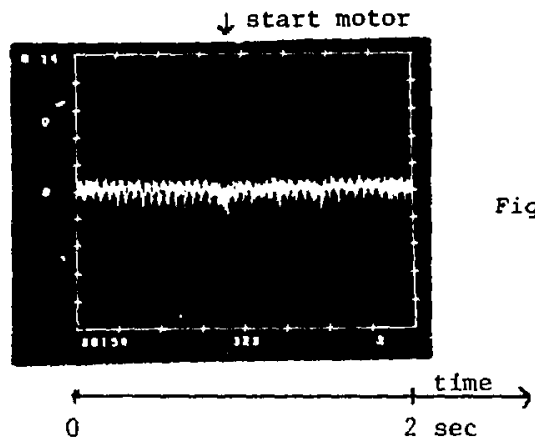

Supported by NIH through the Blotechnology Resource Program of the DIviston of Research Resources under Grant RR 01633 . 
Gerd Rosenbaum (1), George Reed (2)

(1)Univergity City Science Center, Institute for Structural \& Functional Studies, Philadelphia, PA

(2)University of Wisconsin, Institute for Enzyme Research, Madison, WI

3-Phosphoglycerate kinase catalyzes the following reaction in glycolysis:

$M($ II $)$ ATP + 3-phosphoglycerate $=====M($ II $) A D P+1,3$-diphosphoglycerate.

High resolution structures for the enzyme isolated from horse muscle (1) and from yeast (2) have been obtained from $x$-ray diffraction data. The enzyme crystallizes in an open conformation in which the two domains that make up the active center are too far apart to allow reaction $(1,2)$. The two domains are belleved to come together during catalysis. Like several other enzymes that catalyze phosphotransfer reactions, 3-phosphoglycerate kinase is inhibited by vanadate (3). The especially potent inhibition of vanadate with this group of enzymes is attributed to the ability of pentavalent vanadium to adopt a stable trigonal bipyramidal geometry that is analogous to the transition state geometry in phosphotransfer reactions $(4,5)$. Recent studies $(6$; have shown that vanadate forms a stahle complex with 3-phosphoglycerate kinase and a dead-end comblnation of substrate and product: M(II) ADP -3-phosphoglycerate. The apparent dissociation con-tant for vanadate from this complex is $0.1 \mathrm{ml}$ (6). EPR measurements show that addition of vanadate to the dead-end complex with Mn(II) changes the symmetry of the zero-field splitting tensor of Mn(II) from axial to rhombic, and the magnitude of the change indicates that a ligand exchange has occurred in the primary coordination sphere of the metal ion (6). EPR measurements with $[\alpha-17]$ ADP and $\left.e^{-17} 0\right]$ ADP show that ADP is bound to $\mathrm{Mn}(\mathrm{II})$ as an $\alpha, \beta$-bidentate complex before and after addition of vanadate. The geometry and position of vanadate in this complex is of considerable value in determining the structural basis for the potent inhibitory properties of vanadate.

The aim of this project is to determine the distance between the metal activator and Vanadium (as the vanadate anion) at the active site of the enzyme. If vanadate substitutes for the transfe rable phospho group, the Vanadium nucleus and the metal ion will be second-sphere neighbors. The EXAFS-spetra of $M n$ and of Vanadium will be used to determine the Mn-V distance.

So far the EXAFS-spectra of MnEDTA (whose 3-D crystal structure is known (7)), MnATP, MnADP and $\mathrm{V}_{2} \mathrm{O}_{5}$ have been recorded and $\mathrm{will}$ be used as reference. The data of MnATP and MnADP show structure beyond the nearest neighbor shell demonstrating that it oight be possible to determine the Mn-V distance which is estimated to be $3.5-4 \dot{A}$.

EXAFS-data of MnATP at a concentration to which the protein can be readily concentrated ( $5 \mathrm{mM}$ ) showed that a sufficiently large $\mathrm{S} / \mathrm{N}$-ratio can be achieved.

\section{References}

1. Benks, R.D., Blake, C.C.F., Evans, P.R., Haser, R., Rice, D.H., Hardy, G.W., Merrett, M., Ph1ll1ps, A.W. (1979) Nature (London) 279, 773-777.

2. Watson, H.C., Walker, N.P.C., Shaw, P.H., Bryant, T.N., Wendell, P.L., Fothergill, L.A., Perkins, R.E., Conroy, S.C., Dobson, J.J., Tuite, M.F., Kingsman, A.J., Kingsman, S.M. (1982) EMBO J. 1, 1635-1640.

3. Climent, F., Bartrons, R., Pons, G., Carreras, J. (1981) Blochem. Blophys. Res. Commun. 101, 570-576.

4. Macra, I.G. (1980) Trends B1ochem. Sc1. 5, 92-94.

5. Simons, T.J.B. (1979) Nature (London) 281, 337-338.

6. Moore, J.M., Reed, G.H. (1985) Blochemistry 24, 5328.

7. Richards, S., Pedersen, B., Silverton, J.V., Hoard, J.L. (1964) Inorg. Chem. 3.27.

This work has been carried out on Beam Line X9-A: The National Biostructures PRT is supported by NIH through the Biotechnology Resource Program of the Division of Research Resources under Grant RR-01633 and NSF under Grant DMR-85190959. 
PRECISION SUPPORT FRAME FOR FOUR-CIRCLE DIFFRACTOMETER ON BEAM LINE X9-A

G. Rosenbaum (1), L. Rock(2), J. Schultz(1), M. Sullivan(1)

(1) University City Science Center, Institute for Structural \& Functional Studies, Philadelphia, PA

(2) Automation Associates, Medford, NJ

A support and transport frame for the Four-Circle Diffractometer has been constructed. This allows one person to move the diffractometer in and out of the hutch (experimental area) and to position it precisely into the $x$-ray beam.

Vertical positioning of the $1000 \mathrm{lb}$ diffractometer is via four coupled lead screws driven by a remotely controlled $\mathrm{DC}$-motor. Ar encoder is used for feedback. Positioning accuracies of a few miccometers have been achieved.

During horizontal position and angle adjustment, the whole assembly is riding on four air bearings allowing smooth adjustment. Two remote-controlled positioning stages with a resolution of a few micrometers are used to control the position and angle of the diffractometer with respect to the beam in the horizontal plane.

The frame is also equipped with a w inch which will counter-balance heavy weight detectors mounted on the $2 \mathrm{~m}$ long two-theta arm of the diffractometer.

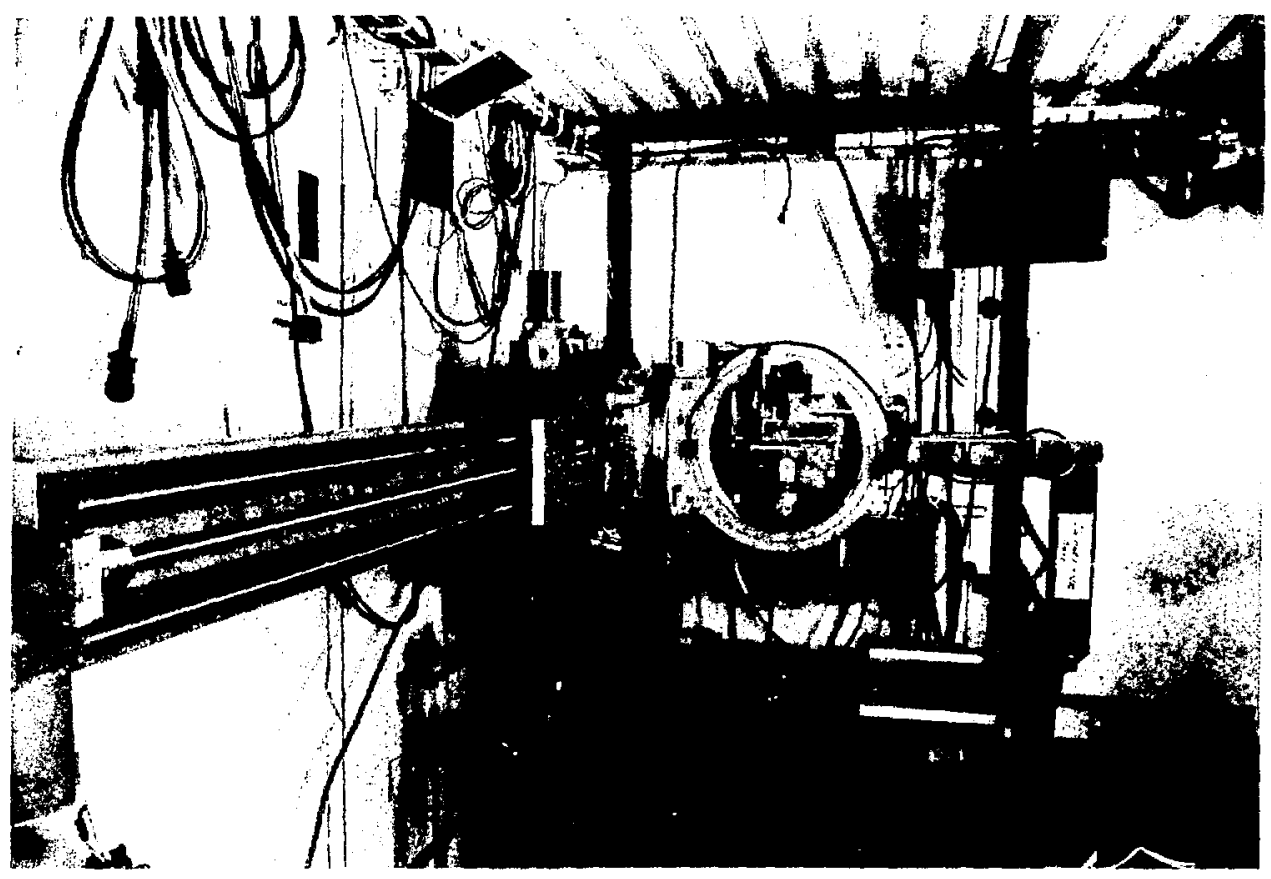

Four-Circle Diffractometer with 2 m-long Two-Theta Arm in Experimental Hutch

This work has been supported by NIH under Grants RR-01633 (Nat1onaI B1ostructures PRT) and GM-32692; and NSF under Grant DMR-8519059. 
Gerd Rosenbaum(1), Avril Somlyo(2), Andrew Somlyo(3)

(1)University City Science Center, Institute for Structural \& Functional Studies, Philadelphia, PA

(2) University of Pennsylvania, Department of Physiology, Philadelphia, PA

The equatorial and meridional small angle diffraction patterns of thin sheets of smooth muscle (taenia coll and portal vein, $0.15 \mathrm{~mm}$ thick) have been recorded using the line focused beam produced by the vertically deflecting mirror.

Smooth muscle has weak diffraction peaks on a high background. Using conventional Cu-radiation, the peaks are close to the center on a steep slope, are not well resolved and require exposure times of 3-5 hours even with a rotating anode $x$-ray tube and a point-focusing optic (1).

The alm of this study was threefold: (1) to see if the $115 \mathrm{~A}$ equatorial reflection can be resolved from the background (11) to measure the intensity of the reflection in order to predict the intensity with a point focused beam, and (111) to find out if using a longer wavelength gives better results.

The diffraction patterns have been recorded with a linear position sensitive detector (courtesy of Dr. J.K. Blasie) with $3 \mathrm{~mm}$ slit helght using both $1.74 \hat{A}$ and $3.1 \hat{A}$ radiation. W1th $3,1 \AA$ radiation, the patterns showed better resolved equatorial ( $F 1 g, 1$ ) and meridional peaks at $115 \mathrm{~A}$ and $145 \mathrm{~A}$ than patterns recorded with $1.74 \dot{A}$ radiation ( $F i g .2)$. With $1.74 \dot{A}$ radiation, the flux in both peaks (background subtracted) was about $10^{3}$ photons/sec at $100 \mathrm{~mA}$ beam current. With the point focused beam, we expect a $10 x$ higher flux into the peaks thus making possible recording times of a second or less.

(a)

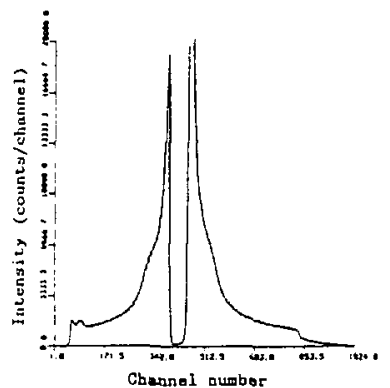

(b)

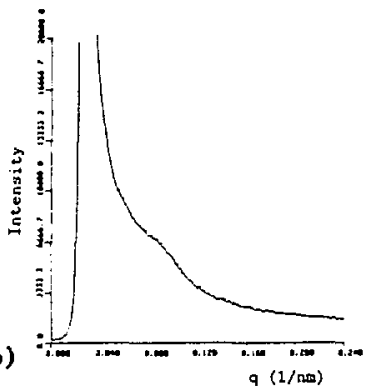

(c)

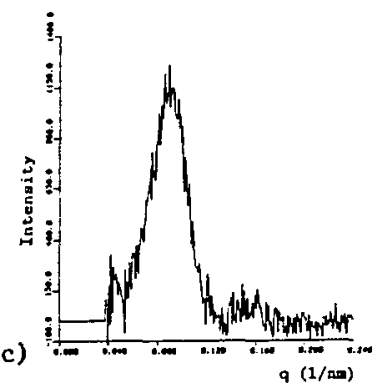

Fig. 1: Equatorial x-ray diffraction pattern from a thin sheet of smooth muscle (portal vein, appr. 0.15 mon thick)

Photon energy $=7.11 \mathrm{KeV}(1.74 \dot{A})$; exposure: $21 \mathrm{~min}$ at $48 \mathrm{~mA}$ beam current; an Al-f1lter with a transmission of $C .098$ has been used to prevent saturation of the PSD

(a) raw data, $x$-axis = detector channels

(b) $x$-axis converted into $q$-values $(q=2 \sin \theta / \lambda$ )

(c) background subtracted

(a)

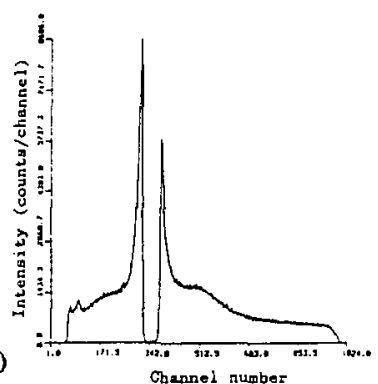

(b)

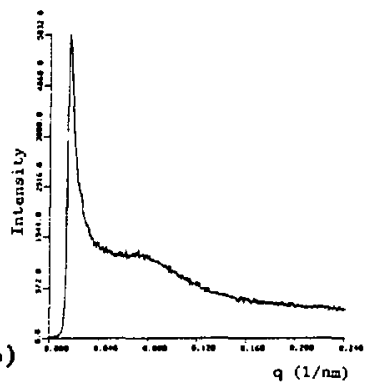

(c)

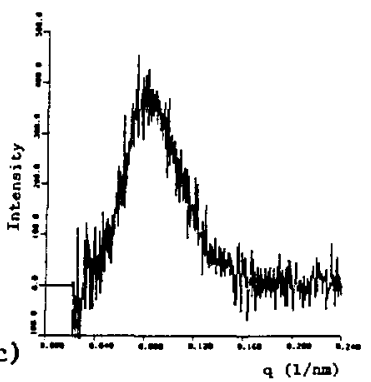

Fig. 2: Same as Fig. 1, but photon energy $=4.00 \mathrm{KeV}(3.10 \dot{A})$; exposure: $13 \mathrm{~min}$ at $72 \mathrm{~mA}$ beam current; no filter

(a), (b) and (c) same as in Fig. 1

Note that the strong scattering close to the beam center has about the same width in real space but not in q-space. It 1s, therfore, a background from the instrument and not scattering of the specimen.

Reference

1. Lowy, J., Foulsen, F.R., Vibert, P.J. (1970) Nature 225, 1053.

This work has been carried out on Beam Line X9-A: The National B1ostructures PRT 1s supported by NIH

through the Blotechnology Resource Program of the Division of Research Resources under Grant RR-01633

and NSF under frant NMR-8510no5a. 


\title{
DEVELOPMENT OF A FLOW FLASH APPARATUS FOR X-RAY ABSORPTION STUDIES OF CARBOXY HEMOGLOBIN PHOTOLYSIS
}

\author{
G. Zhang, K. Zhang, M. Z. Zhang, E. Gabiddon, and B. Chance \\ Institute for Structural and Functional Studies \\ University City Science Center \\ 3401 Market Street, Suite 320 \\ Philadelphia, PA 19104
}

The flow flash apparatus, which was designed for the time resoived $X$-ray absorption studies of the photoproducts of metalloproteins, was tested on National Biostructures PRT Beam Line X-9A.

The major components of this apparatus are xenon flash lamps, sample handling system and the equipments for $x$ ray absorption data collection. Figure 1 is a top view of the setup for the $X$-ray absorption data acquisition. The "dark" EXAFS, which denotes the EXAFS spectra collected with xenon lamps off, and the "light" EXAFS, which were collected during flashes of the xenon lamps, were acquired on a $19 \mathrm{mM}$ carboxy hemoglobin sample at room temperature from both the front and back side of the sample cells by means of plastic scintillation-PMT detectors. The detectors were in current integration mode and the fluorescence X-ray signals from the "light" and "dark" EXAFS were stored in separate channels by means of a dual signal switcher. The 8 millisecond duration of xenon light flash and $2 \mathrm{~Hz}$ repetition rate gave a duly ratio of 60 to 1 between the "dark" and "light" channels.

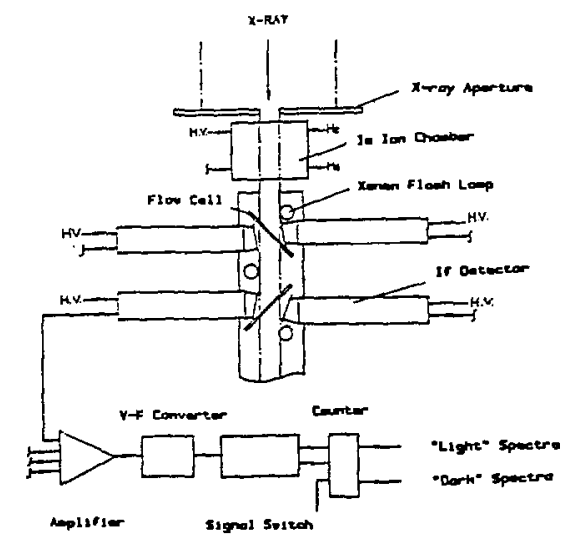

FIG.1. FLOW FLASH APPARATUS FOR ROOM TEMPERATUAE X-RAY ABSORPTION STUDIES OF HEMOGLOBIN-CO PHOTOLYSIS

The "light" and "dark" spectra were further processed by the conventional EXAFS data reduction procedure. Figure 2 shows a "light" spectrum (A) which is an average of twelve $0.16 \mathrm{~s} / \mathrm{pt}$ scans and a "dark" spectrum (B), which is an average of 12 corresponding scans. The signalto-noise ratio for this"light" EXAFS is approximately 200 or 40000 effective photons per second based on the comparison of this "light" spectrum with an EXAFS scan of $5 \mathrm{mM}$ myoglobin at $2 \mathrm{~s} / \mathrm{pl}$ using fluorescence ionization chamber as detector. A "MATCH" program was employed from -45 to $200 \mathrm{eV}$ relative to the midpoint of the absorption edge so that the "light" and "dark" spectra could be compared. These two spectra are almost identical if judged by eyes, as shown in Figure 3 , where the solid line is the "dark" spectrum while the dashed line is the "light" one. The deviation between these two spectra forms a Gaussian-shaped distribution which gives rise to a standard deviation of $7.4 \times 10^{-3}$ relative to the edge jump. In another words, no structural difference between the "light" and "dark" carboxy hemoglobin can be detected by EXAFS. This indicates the relaxation of quaternary structure does not significantly aflect the heme

environment in carboxy hemoglobin. Further improvement of this apparatus is under consideration.

In conclusion, this llow flash apparatus has shown the potential for the EXAFS structural studies of room temperature time-resolved photolysis of biological materials.

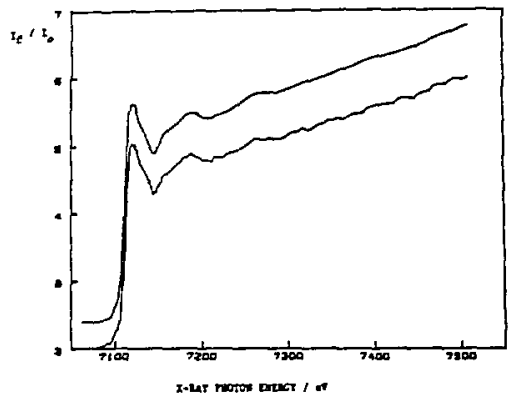

FIINURE 2. AVERAGED "LIEHT" ANO "OARK" SPECTRA DF HBCO USINC THE FLOY FLASH APPARATUS

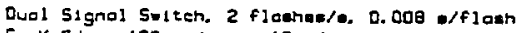

Fo K-Edge. 126 pt/acen. 10 $\bullet / p t$

A. Average of 12 "Itght" econe

B. Average of 12 "dork"

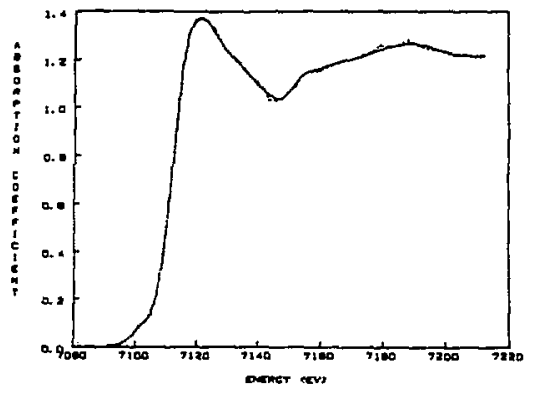

F JGURE 3. MATCH BETVEEN THE -LICHT" ANO "DARK" SPECTRA

Solid linas the normalizad "dark" upactrum Dasinad line, tho marmollzod "light" "pactrum

Beam Line X9-A: Supported by NIH Grant RR-01633, and this work was supported by Grants GM-31992 and HL-18708. 
K. L. D'Am1ro, H. W. Lerkman, and B. P. Flannery

Corporate Research Laboraturies, EXXOs Researrh and Englneering Cr., Annandale, iJ 088,1

We have developed the rapability to inage the 3-0 strurture of small (0.5-1.0) ma) sanples. It is based upon the X-ray tomography terhnique, whirh uses the measurement of the attenuation sf an $y-r a y$ bean by a material to mathenatically resonstrurt the incerior features ot the raterial. jur rapability is unique berause of the three-dimensional nature of the data obtalfied; we refer to $1 t$ as $3-1$ Mircotomography. D Typical mirrotomography terhniques have involved the use of either a pinhole aperture for the definition of the incident and transmitted beams, ${ }^{2}$ or a linear diode array to detert the transmitted beam. 3 Our technique improves on both of these.

The detector used for these measurenents is a novel, inaging area detertor developed at ExxoN. It allows for the simultaneous arquisition of approxinately 300 projertion ineasurenents through the sample, thus giving 300 starked planes in the reronstructed image. This compares with the single plane obtalned for the ronventional mediral CAT sran, as well as for the two mirotomography terhniques mentioned. With the use of a graphirs rapability, our terhririe allows the viewing of the romplete 3-D strurture of the sample.

An additional improvement over prevfous microtonography experiments has been made in spatial resolution. Systens which have employed a fixed aperture to perform the beam definition have been limited to approximately 5 mirro resolution. Diode arrays have a pixel size of approximately 25 inirrons. Our system is currently capable of about 1.0 micron resolution for a reronstrur.ted inage. Both of these figures can be improved, and efforts to do so are in progress.

Samples studled have included a variety of heterogenenus naterials with buth density and chenlral variations. Since the terhnique does not uniquely distingulsh between density and chemical differenres In a single measurenent, the ability to use two energies in two srans of a sample is $1 m p o r t a n t$. By tuning the $X-r a y$ energy it is posstble to distinguish between these two efferts and thus to quantitatively determine the rhemiral/density romposition of the sample. tie have surressfully done this to deternine the transftion metal content ir chenirally hererogeneous samples.

Plans for the future include the construction of a dedicated comography farflity. We have been given approval by the iSLS to build a beamline whtnh will be optinized for performing X-ray microtonography. The beamline will be ronstructed so as to allow photon energy, band pass, and beam size to earh be varied over a wide range. This will permit a wider variety of saiples to be rout inely studied.

We will also attempt higher resolution studies, as well as studies of dyamir proresses surh as flow behavior. Both of these will entail improvements on the existing system, but represent diert and trartable extensions of proven rapabilities.

B. P. Flannery, H. W. Derkinan, W. C. Roberge, and K. L. D'Araro, Srience 237, 439 (1987).

L. Grodzins, Nur.l. Instrum. Methods 206, 541 (1983).

K. lisani, et al., Proposal $186-005$, Photon Eartory Report. 


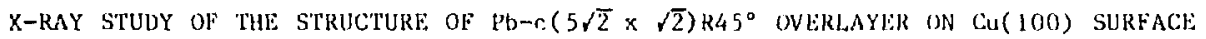

K. S. Liang, G. J. Hughes, E. B. Sirota, K. L. D'Amtro, J. M. Newsan, and P. Lisenberger EXXON Research and Englneering Co., Route 22 Last, Annandale, NJ $0880 \mathrm{~L}$

The study of structures and structural behaviors of metal overlayers is very celevant to many areas of research surh as epitaxial growth, surface modification, and ratalysis. Surh a study has been performed rerently on EXXON beamline (XIOA) on Pb-c $(5 \sqrt{2} \times \sqrt{2}) R 45^{\circ}$ overlayer on Cu(100) surface. We studied the strurture and the melting behavior of this overlayer using grazing incidence $x-r a y$ diffrartion terhnique.

The $c(n \sqrt{2} \times \sqrt{2}) R 45^{\circ}$ strurtures w1th centered rertangular untt rells are commonly observed on many metal overlayer systems on surfares whth four-fold symnetry. Previous LEED studies of pb on Cu(loo) showed a sertes of ordered strurtures at 1ncreased coverages. ${ }^{1-2}$ The $c(5 \sqrt{2} \times \sqrt{2}) R 45^{\circ}$ strurture is formed at about 0.6 monolayer. Using the htghly forused source from our beamline, $x$-ray measurements of this $\mathrm{Pb}$ overlayer revealed not only the superlattice reflertions assoriated with the (5 $\mathrm{x} 1$ ) modulation but also addftional satellites ( $F 1 g$. la). The integrated intensity observed at the strongest reflection at $(1.2,0)$ from the $\mathrm{Pb}$ overlayer was over $10 \mathrm{k} \mathrm{c} / \mathrm{s}$.

Structural analysis has been performed on the basis of the 20 fractional-order superlattire reflertions measured. ${ }^{3}$ The patterson map gives a f-atom unit cell with an antiphase-type atomte. arrangement in the cell. The result is qualitatively similar to that proposed by a rerent LEtil study. 2 However, the sateli1te reflections, as observed with $Q$ vertor nearly normal to the superlattice modulation, suggests the presence of coherent domaln walls. Based on this $x-r a y$ study, a tentative pirture of the overlayer structure is proposed, as shown in Fig. ib.

a

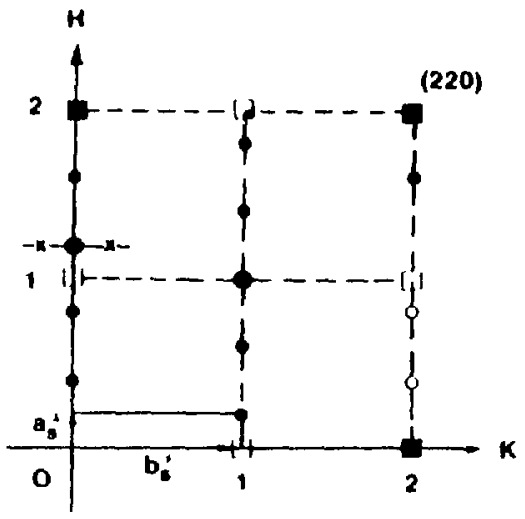

b

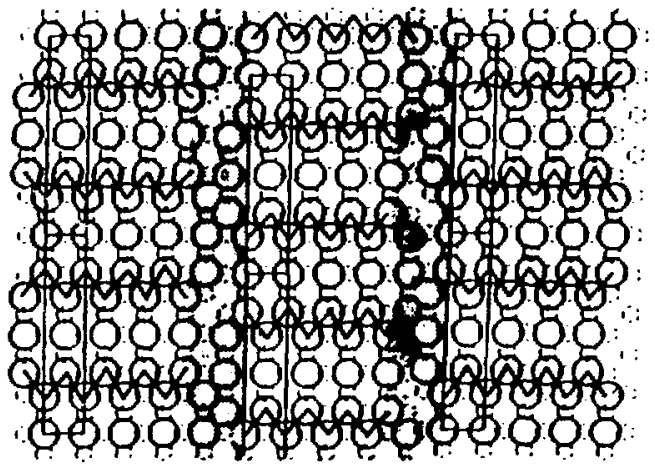

F1g. 1 (a) Part of the superlattice and satellite reflections measured on $\mathrm{Pb}-\mathrm{c}(5 \sqrt{2} \times \sqrt{2}) \mathrm{R} 45^{\circ} / \mathrm{Cu}(001)$ surface. Axes in unites of $2 \pi / 3.615 \AA^{-1}$. at $x$ bt represent the surfare unit rell. F11led squares: bulk forbtdden reflertion, rirles: superlattice reflections, crosses: satelilte. Pb coverage corresponds to an Auger ratio of 0.44 of $\mathrm{Pb}(93 \mathrm{eV}) / \mathrm{Cu}(60 \mathrm{eV})$. The reflert1ons from an equivalent domain rotated by $90^{\circ}$ are not shown.

(b) A schematic of the proposed structure of $\mathrm{Pb}-\mathrm{r}(5 \sqrt{2} \times \sqrt{2}) \mathrm{R} 45^{\circ}$ on Cu(100) surfare. Small circles: $\mathrm{Cu}$, large circles: $\mathrm{Pb}$, shaded area: domain walls. Note the antiphase-tyde atomir arrangement In the 6-atom unt cell and the presence of the domaln walls.

Preliminary study of the melting behaviors of this Pb overlayer was also performed. We observed large changes of the intensities of both superlattine and satelitte reflertions before melting of the overlayer at $=220^{\circ} \mathrm{C}$. Thts indirates that the domain walls probably play an important role in the melting. To understand the nature of the melting of this $\mathrm{Pb}$ overlayer will be a subjoril tor our future study.

1 J. Henrion and G. E. Rhead, Surf. Sri. 29, 20 (1972).

2 W. Hoesler and W. Morttz, Surf. Sr. $11 \overline{7}, 196(1982)$.

3 K. S. Liang, et a1., at Serond International Conferenre on the Strurture of Surfares, Amstesrdam, The Netherlands, June 22-25, 1987 (to be publtshed). 
K. S. Liang, E. B. Sirota, K. L. D'Am1r.o, G. J. Hughes, and S. K. Sinha EXXON Research and Engineering Co., Route 22 East, Annandale, NJ 08801

Since the first demonstration of monolayer sensitivity of $x$-ray diffraction from the surface, the grazing incidence $x$-ray scattering (CIXS) technique is quickly emerging as an important strurtural probe for surface and Interface studies. ${ }^{1}$ On EXXON beamline (X1OA), GIXS work has been performed usIng a z-axis type surface scattering spertrometer with integrated UHV and surface preparation capabil1t1es. In this report, we discuss the results of a GIXS study on a stepped surface, Cu(113), and the observed roughening transition on this surface.

The equilibrium roughening of a stepped surface can be described in terms of thermally created atom1r steps and kinks. 2 Experimentally, the thermal roughen1ng ("meander1ng") of the 11 nes of steps on surfaces at elevated temperatures has been observed in the He atom diffraction experiments on vicinal surfaces of $\mathrm{Cu}$ and $\mathrm{N1}$, but the interpretation of the results is complicated due to multiple and inelastic. scattering. 3

A typlcal x-ray 1n-plane scan in shown in Fig. la, which was measured in the direction normal to the steps on a $\mathrm{Cu}(113)$ surfare quenched from high temperature. We notice that the peak at wave-vertor transfer $Q=1$ ( 1 n unit of $2 \pi / 4.239 \mathrm{~A}^{-1}$, corresponding to the step-step distance of $4.24 \mathrm{~A}$ ) or $1 \mathrm{~g} 1 \mathrm{nates}$ from ordered steps and the satell1tes at $Q=0.85$ and 1.15 . Such a step superlatt1ce peak was observed only after rigorous surfare cleaning and annealing cycles. The width of the peak corresponds to a coherence length of -170 A. The satellite peaks were not observed when the sample was slowly cooled from high temperature, indicating that such a structural modulation is only metastable.
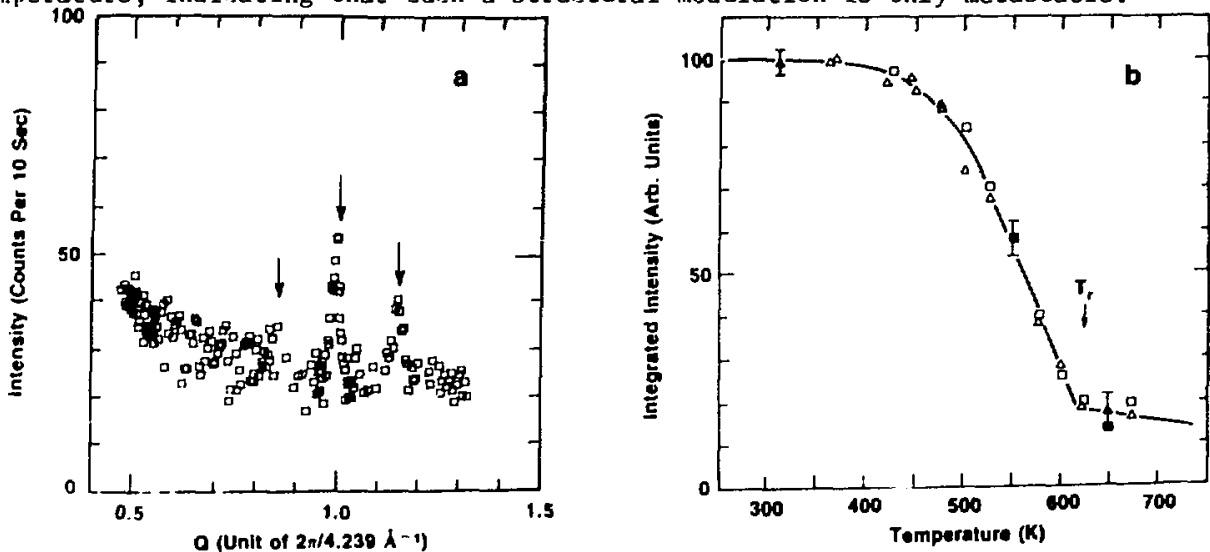

Fig. 1 (a) An In-plane longitudinal scan on a $\mathrm{Cu}(113)$ surface quenched from $710^{\circ} \mathrm{C}$. One notes that the step superlattice peak at $Q=1$, orlginating from the ordered steps, 1s accompanied by satellites. (b) The integrated intensity of the step superlattice peak as function of cemperature. Squares were taken on heating and triangles on cooling. The solid line is a fit to a form derived from Ref. 2 .

The reversible step roughening transition was observed when $x$-ray measurements were done by slow cool1ng. The 1ntegrated intensity of the step superlattice peak as a function of temperature obtained under such conditions is shown in Fig. 1b. By fitting the intensity curve so measured, we can compare our results with the theory of the step roughening given by Villain, et al. ${ }^{3}$ From the analysis we obta1n for $\mathrm{Cu}(113)$ surface, a kink energy of $2100 \pm 75 \mathrm{~K}$ and a step-step repuls1on energy $86 \pm 10 \mathrm{~K}$, with a roughening transition temperature of $620 \pm 10 \mathrm{~K}$. We note that the surface steps become "rough" at relatively low temperature with respert to the bulk melting temperature of Cu (Tm - $1356 \mathrm{~K}$ ).

In short, we have demonstrated that ordered surface steps can be observed using surface $x-r a y$ scatter1ng. The results on Cu(113) surface show directly the roughening transition.

1 P. Elsenberger and W. C. Marra, Phys. Rev. Letr. 46, 1081 (1981); For a review, Bee P. H. Fuoss, K. S. Liang, and P. E1senberger 1n Synchrotron Radiation Research: Advances In Surface Sclence, ed. by R. Z. Bachrach (Plenum, NY), to be published.

2 J. Villaln, D. R. Grempel, and J. Lapujoulade, J. Phys. F: Met. Phys. 15, 809 (1985).

3 F. Fabre, D. Gorse, J. Lapujoulade, and B. Salanon, Europhys. Lett. $3, \frac{15}{73}$ (1987). 


\section{X-RAY ABSORPTIONSTUDIES AT THE M-EDGE OF URANIUM AND NEPTUNIUM COMPOUNDS}

E.E. Alp, G.K. Shenoy, L. Soderholm, D.G. Hinks, Argonne National Laboratory, Argonne, Illinois 60439 J. Guo, and D.E. Ellis, Northwestern University, Evansion, Illinois 60201

A systematic study has been undertaken at the $M$ absorption edges of a series of Uranium and Neptunium compounds with $+3,+4$, and +5 valencies for $U$, and with $+3,+4,+5$, and +7 valencies for $N p$, to establish the $M$-edge XANES spectroscopy as an effective probe of unoccupied valence electronic states. The $M_{V}$ and $M_{I V}$ edges correspond to $3 d$ to $5 f$ transitions, while $M_{11}$ and $M_{I I I}$ correspond to $3 p$ to $6 d$, and $M_{I}$ correspond to $3 s$ to $7 p$ transitions. As a result, by complete analyses, one can probe the entire unoccupied valence electron bands. In the case of $U$ intermetallic compounds, the main interest is in $5 f$ electrons which are in an intermediate regime where the $5 f$ electron-electron correlation energy is comparable to $5 f$ bandwidth. This makes it possible to synthesize intermetallic systems with varying degrees of localization of $5 \mathrm{f}$ bands with proper doping. We have looked into compounds like URh ${ }_{3} \mathrm{~B}_{\mathrm{x}}(0<\mathrm{x}<0.8), \mathrm{URh}_{3-\mathrm{x}} \mathrm{Pd}_{\mathrm{x}}(0<\mathrm{x}<2.0)$, and UIr3-x $\mathrm{Pt}_{\mathrm{x}}(0.4<\mathrm{x}<2.6)$, in which the electronic character changes from localized to iunerant in each series. These samples were already characterized by electrical resistance, magnetic susceptibility, specific heat (1), and by X-Ray Photoemission Spectroscopy (2). For standard compounds, like $\mathrm{UO}_{2}$ and UCl4, relativistic first principal self-consistent molecular cluster calculations have been made to aid the interpretation of distinct features in the spectra. Similarly, $M$ edges of a series of $\mathrm{Np}$ compounds, like $\mathrm{NpP}, \mathrm{NpRu}_{2}, \mathrm{NpSn}_{3}$, and $\mathrm{Np}$-metal have been measured. The degeree of itineracy in these compounds is known to change from Mössbauer Spectroscopy measurements (3). A new data analysis package has been developed to normalize the spectra for proper comparison. The existing procedure of passing a polynomial spline through the smoothly varying hackeround to obtain a normalized step jump accross the absorption edge did not give reproducible results.

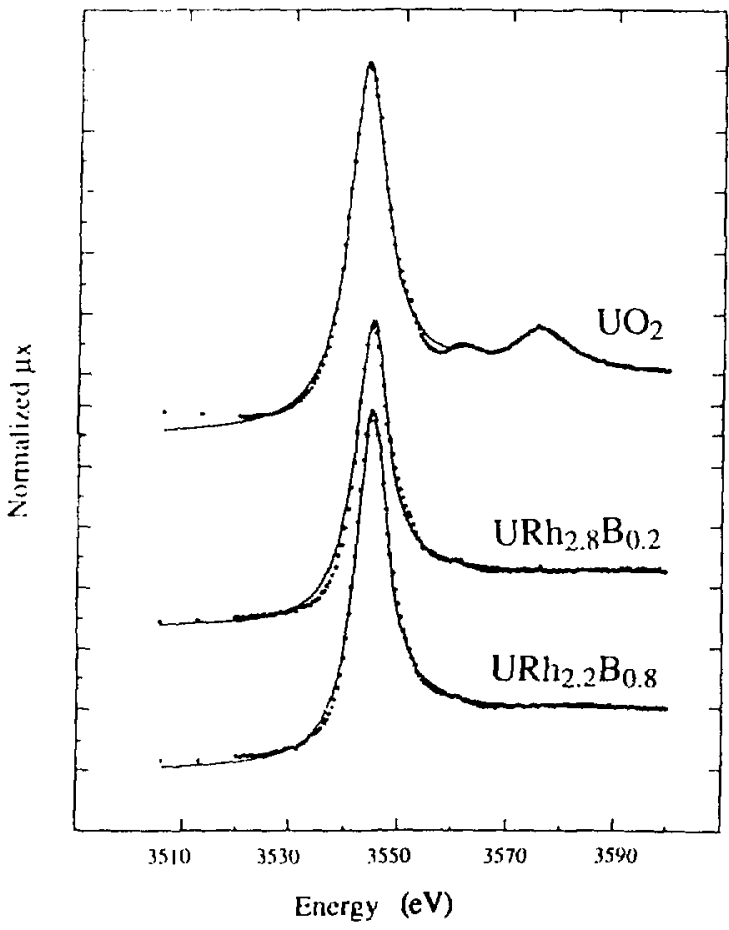

Fig.1 $\mathrm{U} \mathrm{M}_{\mathbf{v}}$-edge corresponding to $3 \mathrm{~d}_{3 / 2}$ to $5 \mathrm{f}$ transitions.

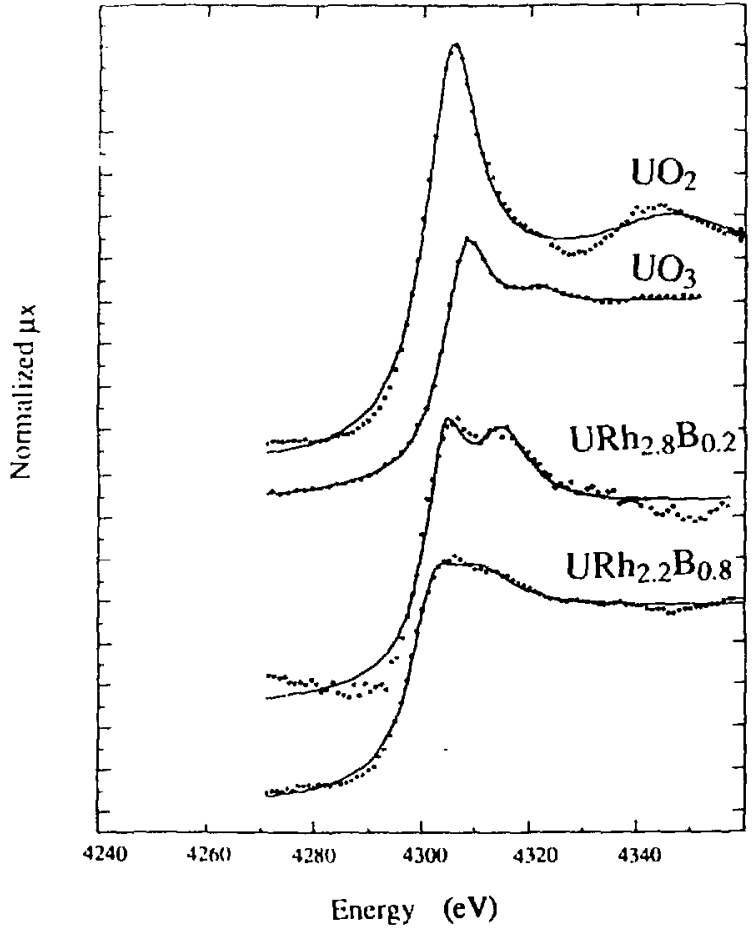

Fig 2. U MIII-edge corresponding to $3 p_{3 / 2}$ to $6 \mathrm{~d}$ transitions.

\section{References:}

1. B.D. Dunlap, F.J. Litterst, S.K. Malik, H.A. Kierstead, G.W. Crabtree, W. Kwok, D.J. Lam, A.W. Mitchell, "f-Band Narrowing in Uranium Intermetallics", Proc. of 5th Int. Conf.on Valence Fulctuations, Jan 5-9,1987, Bangaiore, India.

2. A. J. Arko, B. Yates, B.D. Dunlap, D.D. Koelling, A.W. Mitchell, D.J. Lam, "Understanding Photoemission Spectra in Uranium Based Heavy Fermion Systems", Proc. of 5th Int. Conf.on Valence Fulctuations, Jan 5-9,1987, Bangalore, India.

3. B.D. Dunlap, "Isomer Shifts in Actinides", Mossbauer Isomer Shifts, Eds. G.K. Shenoy, F.E. Wagner, North-Holland, Amsterdam (1978).

(*) Work suppsited by' US DOE, BES-Materials and Chemical Sciences, under contract \#W-31-109-ENG-38 
EXAFS STUDIES OP BURIED INTERFACES: Al ON GaAs

P. Bandyopadhyay and B. A. Bunker (Notre Dane)

When $x$-rays undergo total external reflection fron an interface, the $x$-ray bean penetrates the sample only a fen tei 8 of Angstrons. By combining this with $x$-ray pluorescence detection, EXAPS studies with high surface sensitivity are possible. Further, if a low-density naterial overlies a higher-density substrate, it is possible to tune the angle of incidence to penetrate the overlayer and reflect from the burfed interface.

An exanple of how this technique could be applied is to study metallization of seniconductor surfaces (e.g. Al on GaAs) and directly determine interdiffusion, compound formation, and phase segregation near the interface. Measurenents of Al on GaAs have been undertaken to study the feasibility of this technique. The experimental configuration is show in $P 1 g$. 1 . The two samples were MBE-grown GaAa with 500A of Al deposited in situ at (a) anbient growth tenperature, approxinately 500C, and (b) 90C. Our preliminary results show clear interdiffusion of Al into the GaAs, especially for the sample deposited at high temperature. Figure 2 shons EXAPS oscillations of for the two samples.

An Inportant advantage of the burled-interface work is that we soy study samples that have been prepared and well-characterlzed earlier. The measurements may also be made in open air. which significantly ginplifies the experiment.

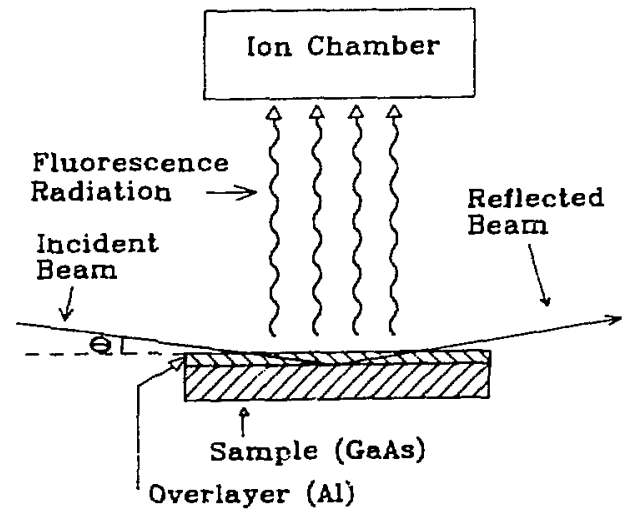

Pig. 1. Experimental contiguration for the EXAFS study of buried interfaces.

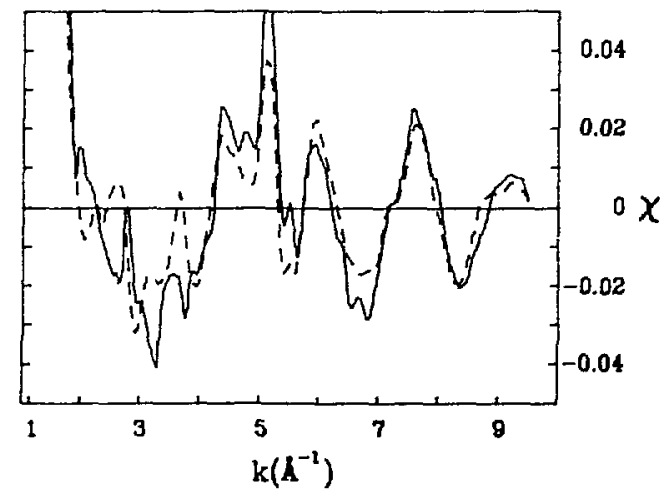

P1g. 2. As-edge EXAFS oscillations for 500A of Al on GaAs, for samples prepared at (a) $500 \mathrm{C}$, and (b) goc.

Supported by ONR NN00014-85-K-0614. The X11 beanline is supported by DOE 


\section{PREPARED BY HIGH DOSE ION INPLANTATION}

J. I. Budnick, Z. Tan, F. Sanchez (U. of CT)

Recent studies ' have shown that bigh dose ion 1mplantation of transition metals into single orystal silicon at elevated temperature (e.g. $350^{\circ} \mathrm{C}$ ) leads to silicide thin film formation at the surface. Inplantation at room temperature followed by chermal annealing also leads to the formation of silicides. Such thin film silicide systems are considered to be of great importance in VLSI technology. The compound formation mechanisms and their dependence on thermodynamics and kinetics are also of interest.

The EXAFS technique is well sulted to study the local transition metal atom environment in these implanted systems, and the compound formation sequence. The information on atomic bonding obtained from an EXAFS study may be helpful to the understanding of the silicide formation mechanism. We initiated such studies on copalt and nickel implanted into Si(100) wafers at an energy of $150 \mathrm{keV}$ and dose rate of $10-15 \mathrm{~A} / \mathrm{cm}^{2}$. Three samples were studied, samples A: Co-Si, Warer temperature $\mathrm{T}=$ $108 \mathrm{C}$, Dose $=7.5 \times 10^{17} \mathrm{Co}^{+} / \mathrm{cm}^{2}$; Sample B: $\mathrm{Co}-\mathrm{Si}, \mathrm{T}=350^{\circ} \mathrm{C}$, Dose $8.0 \times 10^{17} \mathrm{Co}^{+} / \mathrm{cm}^{2}$; Sample $\mathrm{C}:$ N1-S1, $T=350^{\circ} \mathrm{C}$, Dose $=8.0^{\circ} \times 10^{19} \mathrm{Ni}^{+} / \mathrm{cm}^{2}$. The EXAFS measurements were performed at beam 1 ine $X-11$, using a $45^{\circ}-45^{\circ}$ fluorescence detection method at near liquid nitrogen temperature (NT). Tne $X-r a y$ polarization forms a $45^{\circ}$ angle with the sample surface normal.

The Co K-edge EXAFS of samples $A$ and Sample $B$ are similar. The Fourier transform magnitude of a $k^{3}$ welghted EXAFS for Sample $A$ is shown for Fig. 1 with the backscattering atoms indicated at the corresponding peaks. Least square curve fltting using theoretical backscattering amplitude and phase was employed to extract the structural parameters including coordination number $N$, bond length $R$ and mean square relative displacement $\sigma^{2}$ about the Co atom. A typical fit is presented in Fig. 2. We combined the $l O B$ ratio method and curve fitting to minimize the effect of correlations among $N, \sigma^{2}$ and $E_{0}$ and correlation between $R$ and $E$. We estimate the uncertaint $y$ of $N$ and $\sigma{ }^{2}$ to be $15 \%$, and $R_{R}^{\prime}=0.03 \%$. Detalls of data analysis will appear elsewhere. Table 1 lists the results of fitting for sample $A$ and $B$. For Sample C; large Brags peaks made data analysis hard to proceed on the existing spectra. A rotating sample stage will be used for the future studies.

The Neff is the effective coordination number in EXAFS, it represents the real coordination number for nearest neighbor only if the sample is 1sotropic which is not the case for the samples under study. Since the near neighbor distances are determined up to 4.0 $\$$, a comparison with the known neighbor distances of $\mathrm{CoSI}_{1} \mathrm{Co}_{2} \mathrm{SI}_{\text {and }} \mathrm{CoSi}_{2}$ suggests that the phase in Samp..e $A$ and $B$ is dominantly (if not all) CoSi of cubic Fesi,type structure. Comparison of fitted $N$, R with the value of $\operatorname{CoS} 1$ (calculated from known structure ${ }^{3}$ ) in table 1 leads us to conclude that the silicide in both Sample A and B are highly oriented with respect to the surface, and might be single erystal. The rather peculiar behavior of Neff is due to the orientation and polarization of the $X-r a y s$. The orientations of CoSi in Sample $A$ and $B$ are different. Further EXAFS measurement should help to determine the precise orientation of the silfcide by changing the sample orientation with respect to $X$-ray polarization, $X$-ray diffraction vill also be utilized for such purpose. The complete suppression of the $S i$ shell at $2.47 \%$ aight be due to the orientation of the CoSi, but we should not exclude the possibility that these bonds are contracted to $\sim 2.3 \%$ such that ExAFs sees only a single shell at 2.318 . This will be clarifled by further EXAFS experiments. In fact, $X-r a y$ diffraction on Sample B annealed at $750^{\circ} \mathrm{C}$ for 1 hour showed a large line from Co $S 1$ ( 311 ) plane and two other much weaker lines. The latest work ${ }_{17}$ shows that nearly single crystal coSi can be formed by $\mathrm{Co}^{+}$implantation at dose as 1 ow as $2.5 \times 10^{17} \mathrm{Co}^{+} / \mathrm{cm}^{2}$ without post annealing.

A large $\sigma^{2}$ for Co-Co at $R=4.0 \&$ versus a small $\sigma^{2}$ at $R=2.7 \&$ suggests that the vibrations of nearest Co neighbors are highly correlated, since it is reasonable to believe that the far separated atom palr is less correlated. Such a small o at $R=2.7 \&$ indicates further that the nearest Co-Co atom pair tends to vibrate in phase.

References

1. F. Namavar, J. I. Budnick, H. C. Hayden, F. A. Otter and V. Patarint, Mater. Res. Soc. Symp. Proc. 27 (1984) 31;

F. H. Sanchez, F. Namavar, J. I. Budnick, A. Fasihuddin and H. C. Hayden, Aater. Res.

Soc. Symp. Proc. 51 (1986) 439;

F. Namavar, F. H. Sanchez, J. I. Budnick, A. Fasihuddin and H. C. Hayden, preprint.

2. B. K. Teo and F. A. Lee, J. Am. Chem. 101 (1979) 2815.

3. H. B. Pearson, "A Handbook of Lattice Spacings and Structures of Metals and Alloys", P. 37

Pergamon Press, 1958.

4. F. Namavar, unpublished. 
This work was performed at Beam Line $X-11$ at the NSLS and is supported by the Division of Materialg Science of DOE under contract No DE-AS05-80-ER10742.

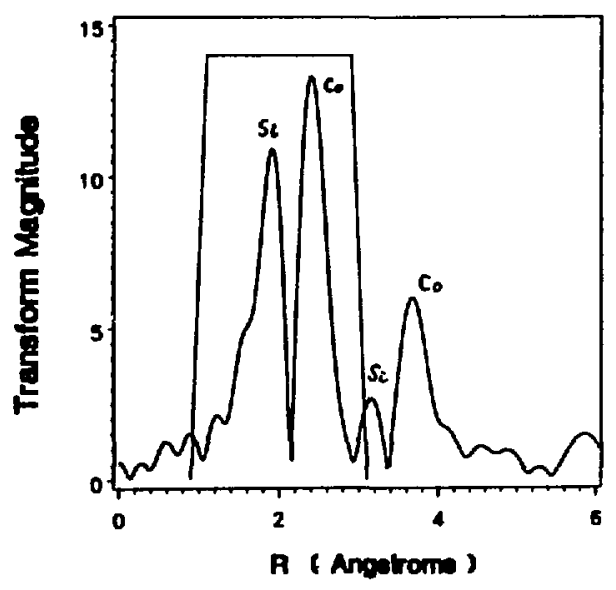

Fig. 1. Transform magnitude of $\mathbf{k}^{3} x$, Co K-edge fluorescence at NT of Co-Si ( $\mathrm{E}=150 \mathrm{keV},{ }_{1} \mathrm{~T}=100^{\circ} \mathrm{C}$, Dose $\left.7.5 \times 10^{17} \mathrm{Co}^{+} / \mathrm{cm}^{2}\right)$. The window for inverse transform is also shown.

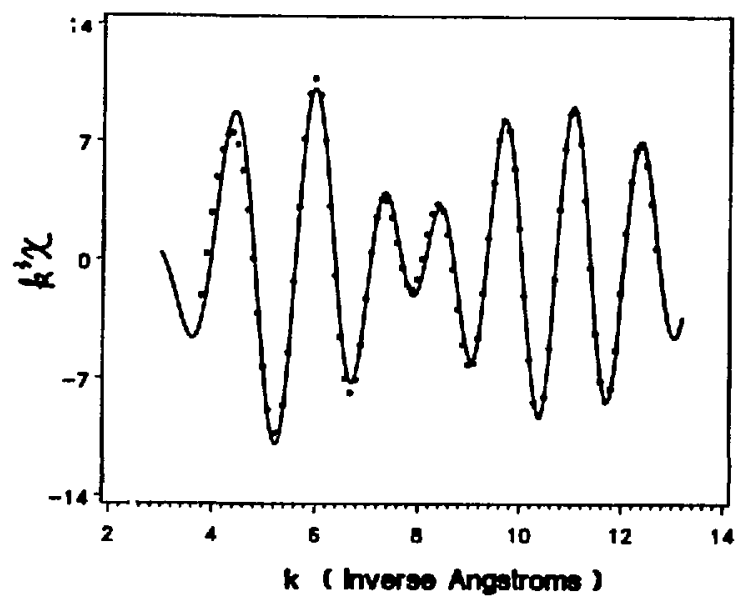

Fig. 2. Inverse transform $k^{3} \times$ from Fig. 1 ( 1 ine) and fit (dots). R: $1.0-3.0$ \&.

Table 1. Structural parameters obtained by fitting the Co K-edge EXAFS spectra at liquid nitrogen temperature. Sample $\mathrm{A}: \mathrm{Co}^{+} \rightarrow \mathrm{Si}(100), \mathrm{E}=1$ SOkev, $\mathrm{T}=100^{\circ} \mathrm{C}$, dose $=$ $7.5 \times 10^{1} \mathrm{Co}^{+} / \mathrm{cm}^{2} ;$ Sample B: $\mathrm{Co}^{+} \rightarrow \mathrm{Si}(100), \mathrm{E}=150 \mathrm{kev}, \mathrm{T}=350^{\circ} \mathrm{C}$, dose $=$ $8.0 \times 10^{17} \mathrm{Co}^{+} / \mathrm{cm}^{2}$.

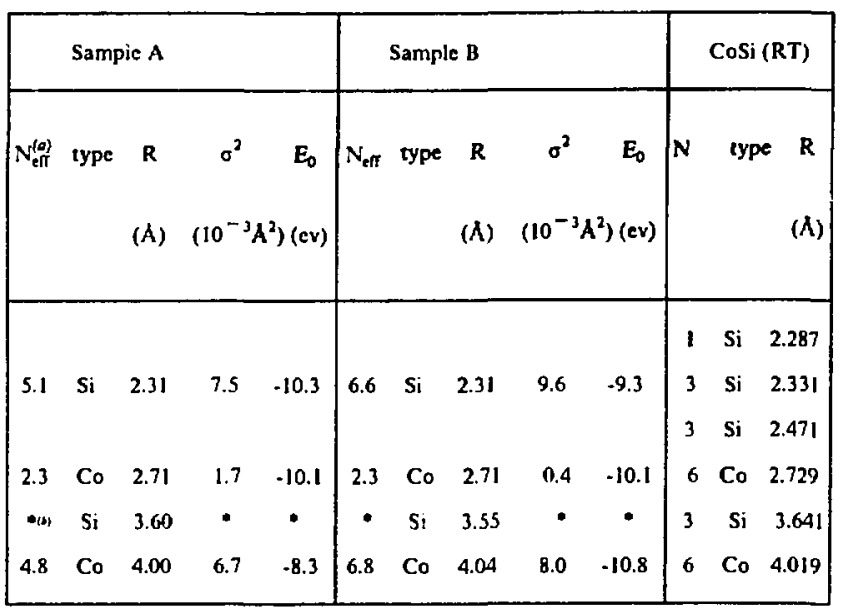

(a) A scaling factor of $S_{0}^{2}=0.70$ was used for $C o$ absorber.

(b) Reliable value not available for these parameters. 
D. C. Calabro (Mobtl Chemical, Edison), and G, L. Woolery (Mobil RED Corp., Paulsboro, NJ)

The oxidation state and local geometry of chromium on $\mathrm{CrO}_{\mathrm{x}} / \mathrm{SiO}_{2}$ catalysts and their synthetic intermedlates was studied using $x$-ray absorption spectroscopy. These catalysts, which are used comnercially for olefin polymerization, typically contain about 0.2 wt $C r$. Analysis of the chromium $K$ absorption edges provided much information on the stepwise changes in the metal oxidation state during catalyst preparation. In-situ exposure of the catalyst precursor to actual polymerization conditions enabled determination of final average chromium oxidation state of the activated catalyst. The effect of titanium modifiers on the Cr active site was also investigated.

The as-received catalyst contains $C r$ in a mixture of primarily +3 and +6 oxidation states. (The presence of $\mathrm{Cr}+6$ is primarily monitored by the intensity of the pre-edge absorption arising from a formally forbidden $1 s+3 d$ transition.) Activation of the as-recelved catalyst oxidizes all of the $\mathrm{Cr}$ to +6 . $\mathrm{A}$ number of different catalysts modiflers, added to primarily control polymer product properties, cause reduction of a significant fraction of $\mathrm{Cr}$, mostly to the +3 oxidation state. After initial polymerization reactions begin, the $\mathrm{Cr}$ is almost exclusively in an average oxidation state of +3 . Catalyst modiflers and initial polymerization, unlike the results found for $\mathrm{Cr}$, have little if any effect on $\mathrm{Ti}$ oxidation state. $T i$ remains in the +4 state in all samples examined. 
Hualyu Chen and Steve M. Heald (Brookhaven National Laboratory, Department of Applied Sclence)

Glancing angle reflectivity and EXAFs techniques provide the possibility of probing interfacial atomic structures without damaging samples. To demonstrate their sensitivity to interfaces, we have compared samples composed of 1000-Angstrom-Al/1000-Angstrom-Cu/glass prepared by evaporation and sputtering. Previous studies found dffferences between the two interfaces ( $H$. Chen et al. 273 , NSLS Annual Report, 1986). Intermixing was observed at the sputtered interface. This work follows the development of $\mathrm{CuAl}_{2}$ layer at both interfaces upon annealing. Each sample was annealed at temperatures ranging from $100^{\circ} \mathrm{C}$ to $200^{\circ} \mathrm{C}$ for 5 minutes at each step. Short annealing times were used so that the compound would not be too thick and the initial stages of compound formation could be studied.

The reflectivity as a function of $x$-ray incident angle probes the macroscopic structure of thin filns, e.g. thicknesses and roughnesses. A growth of an interface layer causes changes in the reflected signal. Figure 1 shows the reflectivity data taken from the two samples as deposited and after the final stage of annealing, $5 \mathrm{minutes}$ at $200^{\circ} \mathrm{C}$. One can notice the reduction of amplitudes on the evaporated one (curve Ea2, Eb2). More drastic change can be seen 1n the sputtered case (curve Sa2, Sb2). An extra peak shows up clearly in $\mathrm{Sb2}$. It is believed to be the reflection from the new CuAl 2 layer.

By choosing a reasonable incident angle, one can look at the atomic environment at a certain depth by collecting fluorescent signals, from which EXAFS can be extracted. EXAFS is very sensitive to nelghboring atom species and interatomic distances. Therefore it is able to show whether the sigal is from pure $\mathrm{Cu}$ or from a Cu-Al mixture. In F1g. 2 EXses from the two samples are compared to the standards, namely $\mathrm{Cu}$ and $\mathrm{CuAl}_{2}$. Despite minor differences, the two annealed ones (thlrd curves from top) have the main feature of $\mathrm{CuAl}_{2}$. It means that although the macroscopic qualities of the two films are different (which caused the difference in the reflectivities), the microscopic picture is probably very similar.

Difficulties were encountered when further analysis was attempted. Quantitative results can be obtained only when the distortion problem is solved. Corrections have been made on pure Au tinin film data and were quite successful. 1 Further efforts are needed for bilayer gituations.

\section{References}

1. S. M. Heald, H. Chen, J. M. Tranquada, to be published.

Acknowledgements

Th1s work was performed at Beam Line $X-11$, NSLS and is supported in part by U.S. Department of Energy, under Contract Nos. DE-ASO5-80-ER10742 and DE-ACO2-76CHOOOL.

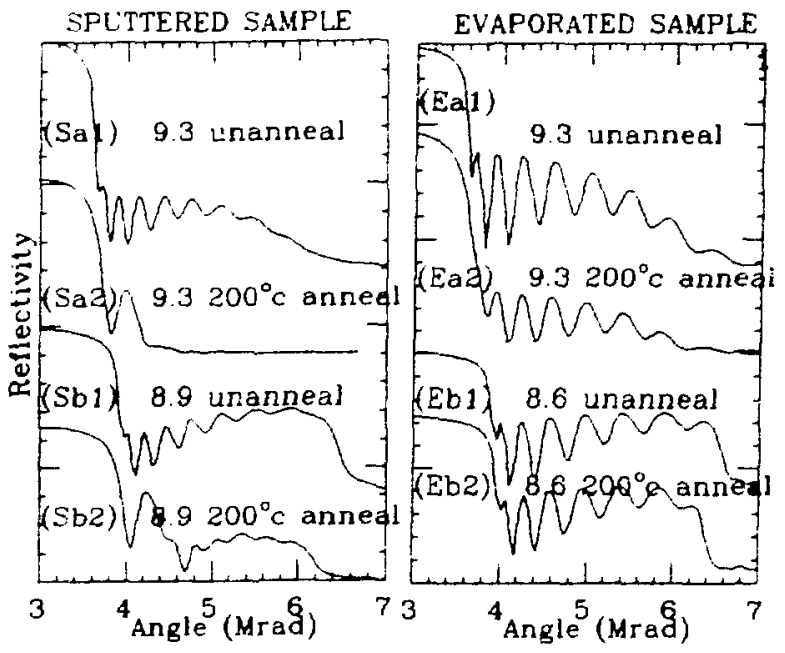

Fig. I Reflectivity data below and above the absorption edge of $\mathrm{Cu} f$ rom sputtered samples and evaporated samples, as deposited and annealed at $200^{\circ} \mathrm{C}$ for 5 minutes, respectively.

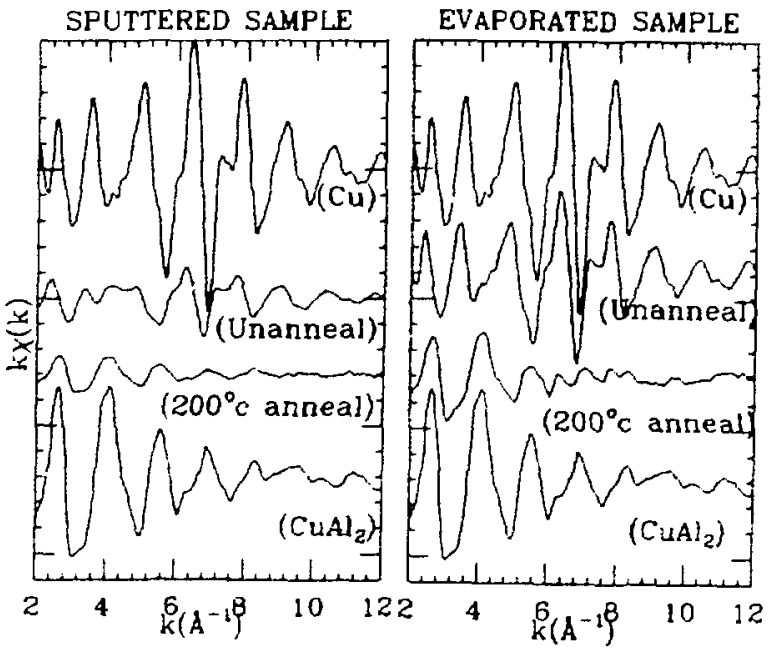

Fig. 2 EXAFS data taken at an inc1dent angle around $4.5 \mathrm{Mrad} f \mathrm{fom}$ sputtered samples and evaporated samples, as deposited and annealed at $200^{\circ} \mathrm{C}$ for 5 minutes, respectively. 


\section{STRUCTURB OF RHODTUY/CERIUY $\gamma-\mathrm{Al}_{2} \mathrm{O}_{3}$ CATALYST ITH BUASS}

T. W. Capehart and D. D. Beck (GM Research Labs)

K. I. Pandya and R. W. Hoffman (Case Western Reserve University)

\section{INTRODUCTION}

Noble metal catalysts dispersed on metal oxides are essential in meeting automotive emission standards. In particular, $\mathrm{Rh}$ is essential in these catalysts. Rhodium catalysts are durable under normal operating conditions but extended exposures to high temperature results in the loss of catalytic activity. The incorporation of Ce in the support permits the sample to maintain stoichiometry during brief excursions into reducing environments. Changes in $R h$ and Ce structure and chemistry afcompanying oxidation, reduction or deactivation are of interest. A number of previous studies on supported catalyst have demonstrated the capability of EXAFS to address these interests.

\section{RESULTS}

A $0.5 \pi \mathrm{tH} \mathrm{Rh}, 5 \mathrm{nt} \mathrm{Ce}, \gamma-\mathrm{Al} \mathrm{O}_{3}$ catalyst was treated at $1173^{\circ} \mathrm{K}$ in flowing $5 \% \mathrm{O}_{2} / \mathrm{N}_{2}$. A second pellet was treated at the same temperature in $5 \% \mathrm{H}_{2} / \mathrm{N}_{2}$. The samples were coolea to room temperature and then stored in $z^{i r}$ until the $x$-ray absorption measurements were made of the $R h$ $\mathrm{K}$-edge and $\mathrm{Ce} \mathrm{L}$-edge. The $\mathrm{k}^{2}$ weighted Fourier transforms of the $\mathrm{Rh} \mathrm{K}$-edge of the reduced catalyst are shown in Fig. 1. The oxidized catalyst shows no evidence of $\mathrm{Rh}-\mathrm{Rh}$ coordination. The $\mathrm{Rh}$ atoms are completely dispersed with only anion near neighbors. In contrast, standard analysis techniques show the reduced catalyst contains small $\mathrm{Rh}$ particles which have a $\mathrm{Rh}-\mathrm{Rh}$ coordination of $\cong 4.1$ at the bulk spacing. The persistence of this reduced state despite exposure to air is surprising.

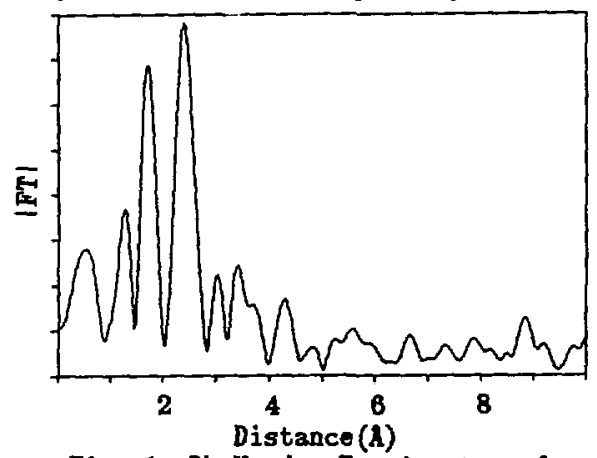

Fig. I Rh K-edge Pourier transforms.

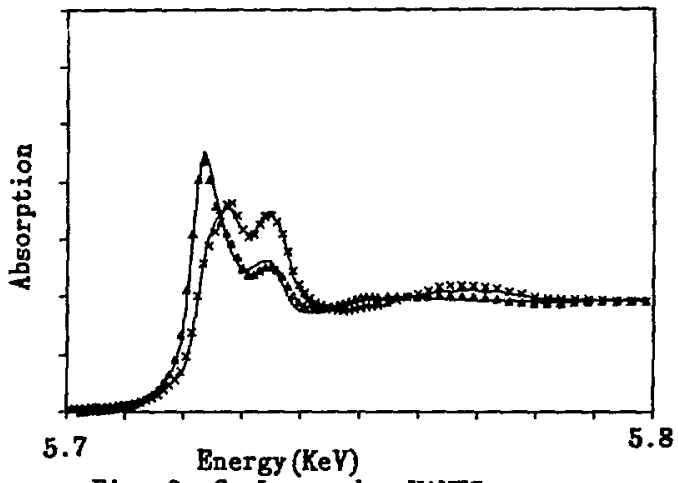

Fig. 2 Ce L III $^{- \text {edge XANES. }}$

The $\mathrm{L}_{\text {}}$ near edge structure of the oxidized and reduced catalyst were least squares fit to a weighted sum of the $\mathrm{CeO}_{2}, \mathrm{Ce}(+4)$, and cerrous acetate, Ce(+3) edges. The results, shown in Fig. 2, demonstrate that there is an appreciable change in the valence of Ce between oxidizing and reducing conditions. After normalizing the edge jumps to unity, the resulting fit for the reduced catalyst $(X)$ gives $0.5 \mathrm{Ce}(+4)+0.5 \mathrm{Ce}(+3)$, while for the oxidized catalyst $(\Delta)$ the result is $0.84 \mathrm{Ce}(+4)+0.06 \mathrm{Ce}(+3)$. This supports the vien of cerium's role as an oxygen reservoir which can buffer excursions into reducing conditions.

\section{REFBRBNCES}

1. K. C. Taylor, "Automobile Catalytic Converters", (Springer-Yerlag, Berlin, 1984).

2. J. B. A. D. van Zon, D. C. Koningsberger, B. F. J. van't Blik, and D. E. Sayers, J. Chem. Phys. 82, 5742 (1985).

3. B. M. Kincaid, $\mathrm{Ph}$. D. Thesis, Stanford University (1975).

This work was supported in part by the General Yotors Research Laboratories. 


\section{BUPS YBASURBYBNTS OP Ni(0H) 2 WTH COPRECIPITATED Co AND Fe}

D. A. Corrigan and T. W. Capehart (GY Research Labs)

K. I. Pandya and R. W. Hoffman (Case Western Reserve University)

\section{INTRODUCTION}

While previous BXAFS experiments have investigated the structure of pure nickel hydroxide ${ }^{1}$, the structural information obtained here by BXAFS should provide a better understanding of how foreign ions such as $\mathrm{Co}$ and $\mathrm{Fe}$ have beneficial and detrimental effects, respectively, on the charge storage efficiency of nickel battery electrodes .

\section{RESULTS}

Coprecipitation of $10 \%$ Co into $\mathrm{Ni}(\mathrm{OH})_{2}$ yielded a material with a Co K-edge EXAFS spectrum as shown in Fig. 1. Analysis results for this $\mathbf{k}^{2}$-weighted Fourier transform to obtain the coordination distances for the first two shells is summarized in Table I. The first coordination shell, thought to consist of 6 oxygen atoms, is contracted significantly in comparison to the Co-O shell of $\beta-\mathrm{Co}(\mathrm{OH})_{2}$ indicating $\mathrm{Co}_{\mathrm{O}}$ may be present in a higher oxidation state in the coprecipitated material. Further, the coordination distance of the second shell, thought to be 6 metal ions, is in close agreement with the $\mathrm{Ni}-\mathrm{Ni}$ distance in $\mathrm{Ni}(\mathrm{OH})$ providing evidence that the oxidized Co ions are incorporated into the Ni lattice. Finally, a third peak centered at $3.6 \mathrm{~A}$ in the Fourier transform may be indicative of the presence of Co sites in interlamellar octahedral holes in the brucite structure.

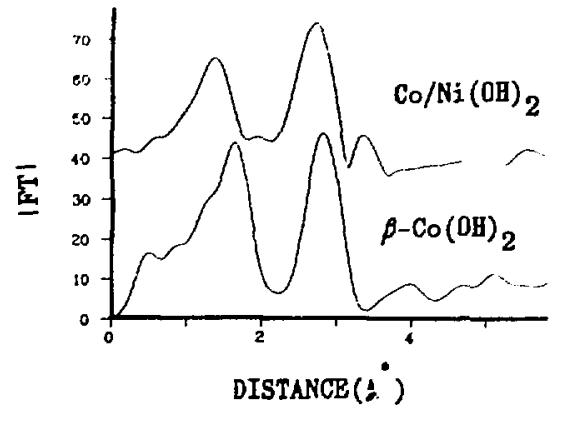

Fig. 1 Co K-edge Fourier transforms.

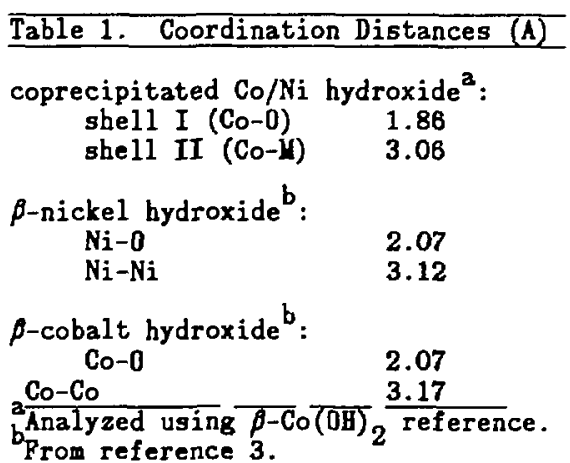

Coprecipitation of $10 \% \mathrm{Pe}$ into $\mathrm{Ni}(\mathrm{OH})_{2}$ produced a material with a $\mathrm{K}$-edge Fe EXAFS spectrum essentially identical to that of a-Pefoll which has a diaspore structure. Analysis also yielded identical coordination distances, within statistical uncertainty, indicating the Fe/Ni coprecipitate may actually consist of a wixture of the $\mathrm{Ni}(\mathrm{OH})_{2}$ and $a-\mathrm{PeOOH}$.

\section{REFBRBNCBS}

1. J. YcBreen, W. E. D'Grady, K. I. Pandya, R. M. Hoffman, and D. E. Sayers, Langmuir 3 , 428 (1887).

2. S. U. Palk and A. J. Salkind, "Alkaline Storage Batteries," John Wiley \& Sons, New York (1888).

3. B. W. G. Wyckoff, "Crystal Structures," John Wiley \& Sons, New York (1963).

This work was supported in part by NASA Grant NAG-3-694. 
EXAFS OF AN ENZYME TRANSIENT: ESO 2 OF PROTOCATEChUATE 3,4-DIOXYGENASE (PCD)

R.H. Felton, L.R. Furenlid, S.H. May, and J. Kalghobadi, School of Chemlstry, Georgla Institute of Technology

The iron-contalning dioxygenase, PCD, catalyzes intradiol cleavage of catechol derlvatives according to the minimal scheme:

$$
\mathrm{E}+\mathrm{S}=\mathrm{ES} \stackrel{\mathrm{O}_{2}}{\longrightarrow} \mathrm{ESO}_{2} \text { - } \longrightarrow \mathrm{ESO}_{2} \longrightarrow \mathrm{E}+\mathrm{P}
$$

where $E=P C D, S=$ protocatechuate or dihydroxyphenylpropionate (DHPP) to yleld a tricarboxylic acid. We have reported earlier on the EXAFS of $E$ and $E S$, as well as enyzme-1nhibitor complexes. In the present study, the catalytically competent intermediate, $\mathrm{ESO}_{2}$, was prepared by freeze-trapping at $-80^{\circ} \mathrm{C}$ and 1 t

To obtain sufficient $\mathrm{ESO}_{2}(2 \mathrm{mM}, 300 \mu 1)$, the enzyme was presaturated with 3 atm. oxygen at $5^{\circ} \mathrm{C}$. Addition of $30 \mu 1$ of concentrated DHPP solution, rapld transfer to the EXAFS cell, followed by quick freezing provided the sample. Total elapsed time of preparation was 90 sec. and, thus, the technique is not a rapid freeze-quench process. The use of excess oxygen (ca. $10 \mathrm{mM}$ ) caused $\mathrm{ESO}_{2}$ to be the majority species (99\%) during the preparation and transfer. Sample Integrity was verifled by use of a double-beam fiber optic spectrometer.

After twelve hours of beam exposure, the optical spectrum had changed. This alteration was asslgned to radiolytic products of oxygen in the mildly basic solution. That the 1 ron-site was not altered due to beam exposure was demonstrated by warming the solution, allowing oxygen to be consumed, and observing that the ES species is formed.

Figure 1 displays transforms of E, ES, and ESO ${ }_{2}$. The sharp peak at $R=2.5$ is indicative of chelation by substrate in ES, and its absence in ESO, clearly establishes loss of such chelation. The peak at $R=3.8 \mathrm{~A}$ is due to the presence of histidyl ligation. Likely structures of EsO have been modeled using spherical wave calculation of single and multiple-scattering EXAFS contributions. Data excludes a pseudoanhydride or peroxo complex, but the ring-opened and product-like structures of Fig. 2 are compatible with the EXAFS result.

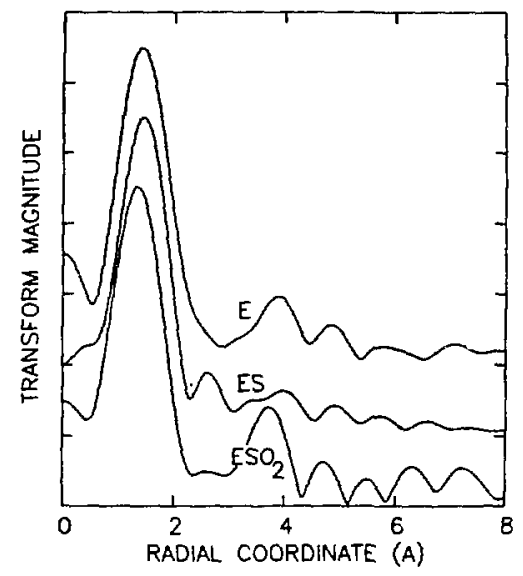

Fig. 1. Compartson of $\mathrm{E}$, ES, and $\mathrm{ESO}_{2}$

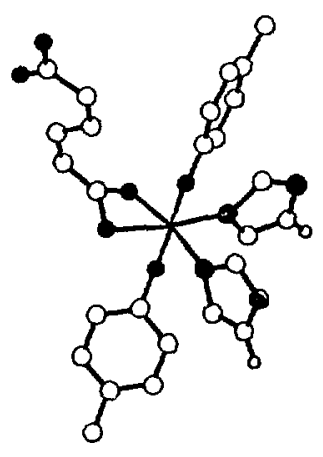

a) Single $\mathrm{COO}^{-}$binding

Fig. 2. Possible structures of $\mathrm{ESO}_{2}$.

Supported by NIH GM23474

1. R. H. Felton, L. R. Furenl1d, S. W. May, P. A. Morr1s, and E. Stern, NSLS Ann. Report 173 (1985). 
SPHERICAL WAVE EXAFS CALCULATIONS OF TRANSITION METAL COMPLEXES

L. R. Furenlid and R.H. Felton, School of Chemlstry, Georgia Institute of Technology

It has been recognized for sometime that spherical wave theorles of EXAFS are more accurate than those utilizing the planewave approximation. Recently, Rehr and co-workers, 1 employing a spherlcal wave (SW) theory, calculated $\mathrm{Br}_{2}$ and Cu EXAFS, and earlier others ${ }^{2-4}$ have examined ExAFS (in distinction to XANES) of $\mathrm{Cu}, \mathrm{NiO}$, and $\mathrm{Co}\left(\mathrm{H}_{2} \mathrm{O}\right) 6^{\circ}$. We extend the calculations to other transition metal complexes, and additionally examine 1midazole ( $\mathrm{Im}$ ) or catechol (Cat) complexes of $\mathrm{Mn}, \mathrm{Fe}, \mathrm{Co}, \mathrm{Ni}$, Cu, and $\mathrm{Zn}$, in which multiple scattering is clearly observed. Calculations employ the muffin-tin model with a potential modified by the energy-dependent Dirac exchange. The mean-free path term includes the "universal" photoelectron lifetime corrected for the core-hole lifetime. The energy zero is found from calculation of $\Delta E=E\left(1 s^{1} 3 d^{n}\right)-E\left(1 s^{l} 3 d^{n+l}\right)$ and the muffin-tin zero. In the instance of $N i(I m)$, a Debye-Waller factor is found from the temperature-dependent data. In other cases $\sigma^{2}$ is a parameter for the first-shell. Multiple-scattering calculations are 1 imited to three atoms and near-forward scattering paths. A spherfcal wave approximation (SWA) is used for multiple-scattering, while the SW is exact for single $\rightarrow$ scattering.

Figure 1 displays data, and planewave and SW calculations for a single-shell example, $\mathrm{Co}\left(\mathrm{NH}_{3}\right)$. The superiority of the $S W$ calculaticn is due in large part to the modification of the backscattering phase at low $k$. Examples of multishell calculations are shown in Figs. 2 and 3 , in which an $E_{0}$ shift of $5 \mathrm{eV}$ for the SWA contribution is necessary.

We conclude that the spherfcal wave computations are acceptable for $k>3 \mathrm{~A}^{-1}$, but are poor in the near edge regime. Extension of the calculations to biological systems is feasible and is in progress.

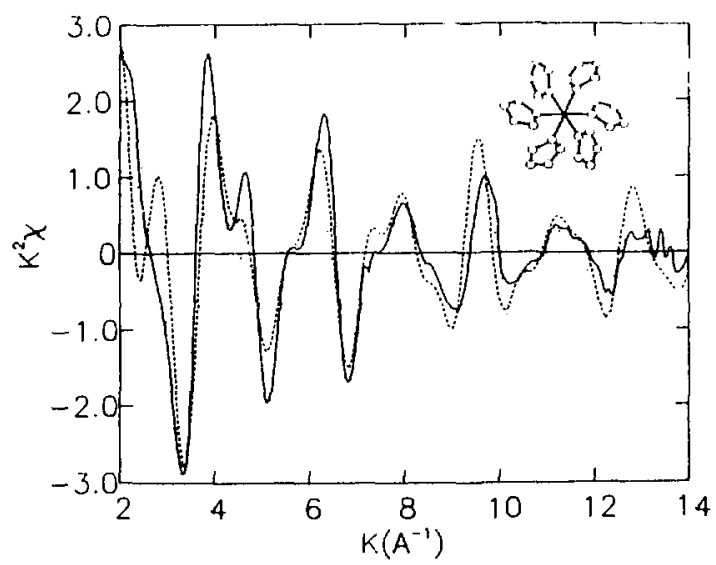

Fig. 2. $\mathrm{Ni}(\mathrm{Im})_{6}{ }^{3+}$. Data $(-)$, single-scattering SW $(\cdots)$, full calculation (--).

Supported by NIH GM23474.

1. J. I: Rehr, SPIE, 690, 2 (1986); J. J. Rehr, R. C. Albers, C. R. Natoli, E. A. Stern, Phys. Rev. B, 34, 4350 (1986).

2. S. J. Gurman, N. Binsted, I. Ross, J. Phys. C, 17, $143(1984)$.

3. A. G. Mckale, G. S. Krapp, S.-K. Chan, Phys. Rev. B, 33, 841 (1986).

4. J. E. Muller and W. L. Schaich, Phys. Rev. B., 27, 6489 (1983).

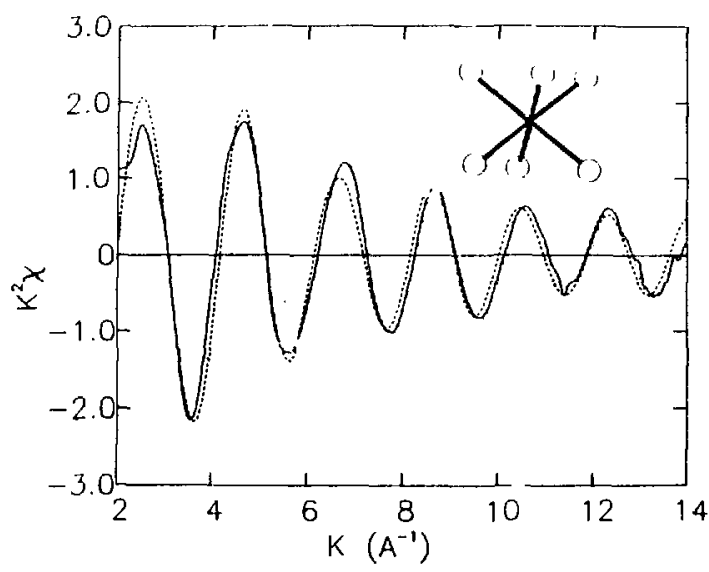

Fig. 1. $\mathrm{Co}\left(\mathrm{NH}_{3}\right)_{6}^{3+}$. Data $(-)$, SW (--), PWA (...).

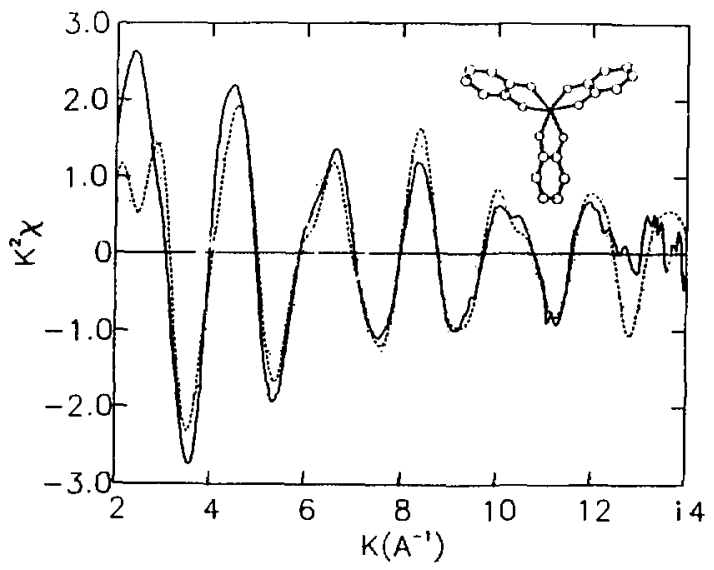

Fig. 3. $\mathrm{Fe}(\mathrm{cat})_{3}{ }^{3-}$. Legends as in Fig. 2 . 
EXAFS STUDIES OF HIGH $\mathrm{T}_{c}$ SUPERCONDUCTORS

S. M. Heald and J. M. Tranquada (Brookhaven National Laboratory)

Superconductors with the composition $\mathrm{La}_{2-x}(\mathrm{Ba}, \mathrm{S} \mathbf{r})_{\mathrm{x}} \mathrm{CuO}_{4-\mathrm{y}}$ and $\mathrm{X}=0.0$ to 0.3 have been studied through measurements of $x$-ray absorption near-edge structure at the Cu $K$ and La L edges. Contrary to recent band structure calculations, we find that the $C u 3 d$ electrons are localized with the copper ians having an integral $3 \mathrm{~d}^{9}$ configuration ( $2+$ valence) independent of dopant concentration (see Fig. 1 ). Variation in the area of the "white lines" at the La $\mathrm{L}_{2}, 3$ edges which increase with doping indicates that reduction of the valence charge results in an increasae in unoccupied states (probably consisting of holes in the $02 \mathrm{p}$ band) having d-symmetry relative to the La site. These 0 2p holes also appear to have d-symetry with respect to the cu sites.

From measurements of extended x-ray absorption fine structure (EXAFS) at the Cu $k$ edge between 10 and $300 \mathrm{~K}$, we have also determined the temperature dependence of the mean square relative displacements ${ }^{2}$ for $\mathrm{Cu}-\mathrm{O}, \mathrm{Cu}-\mathrm{La}$, and $\mathrm{Cu}-\mathrm{Cu}$ near neighbors in $\mathrm{La}_{2-\mathrm{x}} \mathrm{Sr}_{\mathrm{x}} \mathrm{CuO}_{4-\mathrm{y}}$ with $\mathrm{X}=0,0.15$, and 0.3 (see Flg. 2 ). It is found that $\sigma^{2}$ for $\mathrm{Cu}-\mathrm{O}$ and $\mathrm{Cu}-\mathrm{La}$ neighbors shows little varlation with $X$. Model calculations have been used to demonstrate that $\sigma^{2} \mathrm{Cu}-\mathrm{O}$ is sensitive to softening of the Cu-O breathing mode which has been predicted to be important for superconductivity in these materials. The Cu-0 bonding is observed to be quite strong and no evidence is found for any significant change in the breathing mode frequency with doping.

Acknowledgements

This work was performed at Beamline $X-11$ at the National Synchrotron Light Source and is supported in part by the U.S. Department of Energy under Contract Nos. DE-AS0580-ER10742 and DE-ACO2-76CH00016.

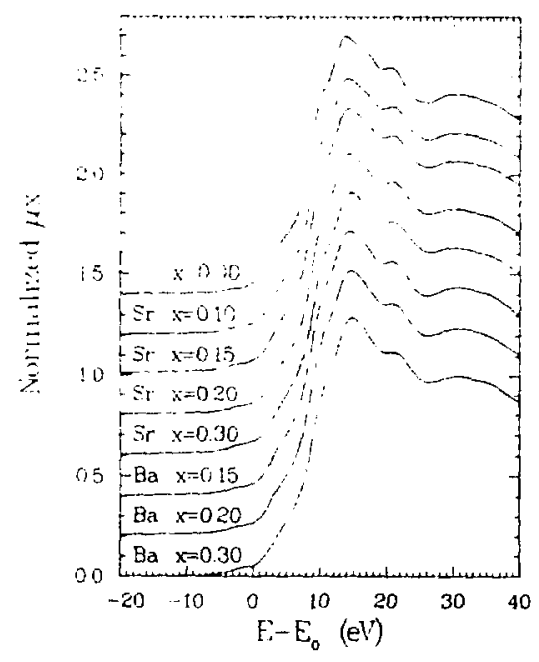

Fig. 1. Normalized XANES at the Cu $K$ edge in $\mathrm{La}_{2-\mathrm{X}}(\mathrm{Sr}, \mathrm{Ba})_{\mathrm{X}} \mathrm{CuO}_{4-y}$ as a function of doping.

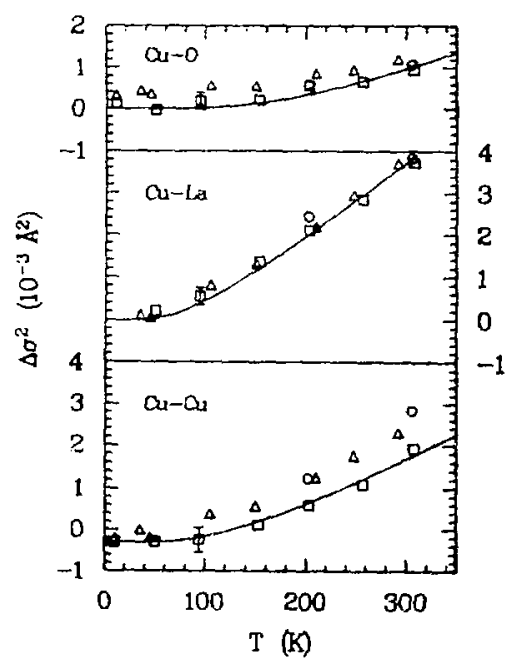

Fig. 2. Temperature dependence of $\sigma^{2}$ for $\mathrm{Cu}-\mathrm{O}$, $\mathrm{Cu}-\mathrm{La}$ and $\mathrm{Cu}-\mathrm{Cu}$ shells in La $2-x$ $\mathrm{Sr}_{\mathrm{x}} \mathrm{CuO}_{4-\mathrm{y}}$ : circles, $\mathrm{X}=0$; squares, $\mathrm{X}=0.15$; triangles, $\mathrm{X}=0.3$. 


\section{S. M. Heald and J. M. Tranquada (Brookhaven National Laboratory)}

EXAFS techniques have been shown to be valuable in studying multilayer structure, particularly in identifying and quantifying interface phasesl. In this work it is shown how standing wave effects can be used to permit EXAFS measurements to probe structure within the multilayer unit cell. When the multilayer 1: set to Bragg reflect $x$-rays, standing wave fields are set up which modulate the electric fleld Intensity within the multilayer period. By controlling the angle it 1s possible to control the phase of the standing wave, and the reglon within the multilayer contributing most strongly to the $x$-ray absorption. EXAFS measurements can then probe the local structure in this region. $A$ complication orlaes from the energy scans necessary for EXAFS measurements. Changing the energy necessitates an angle change in order to maintaln a fixed standing wave configuration. This is accomplished by using a precision angle stage capable of 0.3 arcsecond steps.

Measurements were made on a N1-T1 multilayer under study for neutron optics applications. Figure 1 shows the Fourler transforms of the N1 K-edge EXAFS for the multilayer compared to bulk H1. The signals are quite similar in shepe with the amplitude for the multilayer case showing a significant reduction and strong angle dependence. In Fig. 2 the first shell EXAFS amplitude 18 plotted as a function of angle and showa atrong modulation near the multilayer Bragg peak at $8.23 \mathrm{mrad}$. The amplitude reduction comes from the fact that the measurements were made using fluorescence detection and the NI concentration is high. As the standing wave fleld $1 \mathrm{~s}$ set up the Ni contrlbution to the absorption is modulated, changing the amplitude reduction. A calculation of chis effect assuming an Ideal multilayer gave the solid line 1n F1g. 2. Considering that the calculation had no adjustable parameters and ignored anomalous dispersion effects, the agreement is quite good, and clearly verifies the standing wave modulations.

For the NI layers there is little difference from bulk Ni Indicating 11tt!e intermixing with Ti. The TI EXAFS, however, Indicated the presence of significant low-z contatination determined to be $C$ and 0 impurities. Theae were undoubtedly picked up during deposition and atanding wave analysis found them to be uniformly distributed throughout the Ti layer. Including these impurities in the calculation in Flg. 2 gave the dashed curve which agrees slightly better with the measurements.

\section{References}

1. S. M. Heald, J. M. Tranquada, B. M. Clemens and J. P. Stec, J. de Phys1que 47, C8-1061 (1986).

Acknowledgements

We thank A. Saxena for providing the sample. This work was performed on Beamline X-11 at the National Synchrotron Light Source and is supported by the U.S. Department of Energy under Contract Nos. DE-AS0S$80-E R 10742$ and DE-ACO2-76CH0OOLI6.

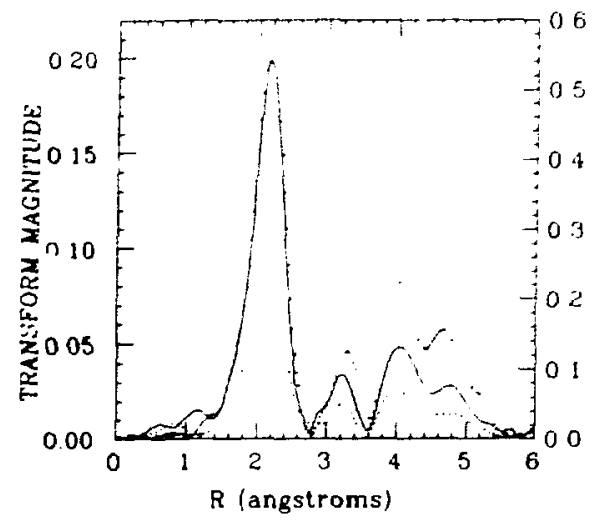

Fig. 1. Fourter transform of the NI EXAFS for the multilayer at $8.02 \mathrm{mrad}$ (solid line) and $9.41 \mathrm{mrad}$ (dashed line) compared to pure $\mathrm{N}$. The scale for the multilayer is on the left and for the foll on the right.

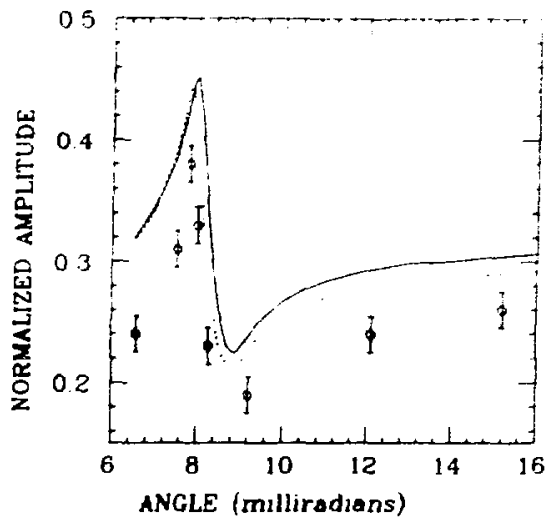

F1g. 2. Reduction in the EXAFS amplitude for the NI first neighbor shell. The polnts ace the data and the solid curve the calculated reduction factor for an ideal multilayer. The dashed curve includes the effect of the 0 and $C$ impurities observed by EXAFS. 

ABSORPTION

H. S. Isaacs, S. M. Heald, J. M. Tranquada (Brookhaven National Laboratory), J. K. Hawk1ns and G. E. Thompson (UMIST, Manchester)

Chromate species ate efficient inhibitors of the corrosion of aluminum in neutral aqueous environments, although the precise mechanism is far from clear. Presently, mechanisms 1nclude: (1) The reduction of $\mathrm{Cr}^{6+}$ or $\mathrm{Cr}^{3+}$ species, developing solid, hydrated $\mathrm{Cr}_{2} \mathrm{O}_{3}$. The location of $\mathrm{Cr}_{2} \mathrm{O}_{3}$ is the subject of discussinn, thought to develop generally over the alumina film surfacel, 2 or locally at flaws within the a lumina $f 1 \mathrm{~lm}^{3}$. (2) The gradual penetration of $\mathrm{Cr}^{6+}$ species through the outer alumina film regions. (3) The catalysis of $\mathrm{Al}(\mathrm{OH})_{3}$ precipitation at anodic sites.

Analysis of aluminum specimens was carried out using x-ray adsorption by fluorescence detection, with Incldent $x$-rays at a glancing angle to the specimen ${ }^{4}$. Shifts in the adsorption edge or changes in the preedge structure occurred with changes in valency, allowed determination of species. Two standards $\left(\mathrm{K}_{2} \mathrm{CrO}_{4}\right.$ and $\mathrm{Cr}_{2} \mathrm{O}_{3}$ ) were analyzed using transmission $\mathrm{x}$-ray absorption to characterize the $\mathrm{Cr}$ VI and $\mathrm{Cr}$ II states. Superpure aluminum (99.99\%) specimens were electropolished; barrier-type anodic films were formed by anodizing to selected voltages in borate electrolyte. The specimens were then immersed under open circult conditions for one hour in a $1 \mathrm{mM} \mathrm{NaCl}, 2 \mathrm{mM} \mathrm{K}_{2} \mathrm{CrO}_{4}$ ( $\mathrm{pH} 8$ ) electrolyte.

Analysis of the $\mathrm{K}_{2} \mathrm{CrO}_{4}$ standard showed a large pre-edge peak at the $\mathrm{K}$ adoorption edge. This was not observed for the $\mathrm{Cr}_{2} \mathrm{O}_{3}$ standard and, allowed ready differentiation between the Cr VI and $\mathrm{Cr}$ III states (Figs. 1 and 2). Comparison of the height of the pre-edge peak to the edge height were closely related to the ratio of $C r$ VI to $C r$ III present. After immersion, aluminum bearing the air-formed film 2 nm thick) showed no pre-edge peak, Indicating chromium was present predominantly as Cr III. this was reenforced by an edge position close to that of the $\mathrm{Cr}_{2} \mathrm{O}_{3}$ standard (Fig. 1). Aluminum, supporting anodic films (e.g. $36 \mathrm{~nm}$ ), showed a strong pre-edge peak and an edge position corresponding to that of the Cr VI standard, indicating that chromium was present primarily as Cr VI. An Intermediate situation was apparent for a specimen carrying an anodic film, which has been formed to a thickness of 6 nm. Here the pre-edge peak was less strong and the edge itself shifted towards the Cr III edge position, revealing that both $\mathrm{Cr}$ III and $\mathrm{Cr}$ VI were present (F1g. 2). Previous work has shown a declining population density of persistent flaws with increasing thickness of barrier anodic films ${ }^{3}$. Thus, less Cr III should be detected on specimens bearing thicker flims if reduction of Cr VI and Cr III is occurring within flaws, Thus, the results indicate that film thickening by anodizing corresponds to reduced detection of $C r$ III when the specimens are examined after immersion in a chromate containing electroly tes.

\section{Acknow ledgements}

This work was supported by the U.S. Department of Energy, Divisions of Materials Sclences and Chemical Sciences under Contract Nos. DE-ACO2-76CH00016 and DE-ASOS-80-ER/0742. The authors would also 11ke to thank the Sclence and Engineering Research Council for financlal support to J. Hawkins.

\section{References}

1. M. Koudelkova, J. Augustinsk1, and H. Berthou, J. Electrochem. Soc. 124, 1165 (1977).

2. A. Kh. Balramow, S. Zaklpour, and C. Leygraf, Corrosion Sc1. 25, 69 (1985).

3. G. E. Thompson and G. C. Wood, in Treatise on Materials Schence and Technology, Ed. Scully, Vol. $23,1983$.

4. S. M. Heald, E. Keller, and E. A. Stern, Phys. Lett. A103, 1553 (1984).

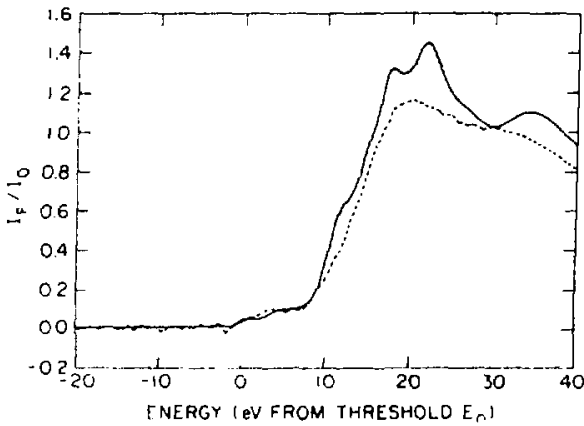

Fig. 1. Comparison of the absorption edges for chromium in the $\mathrm{Cr}_{2} \mathrm{O}_{3}$ standard with an alc formed film after immersion for $1 \mathrm{~h}$.

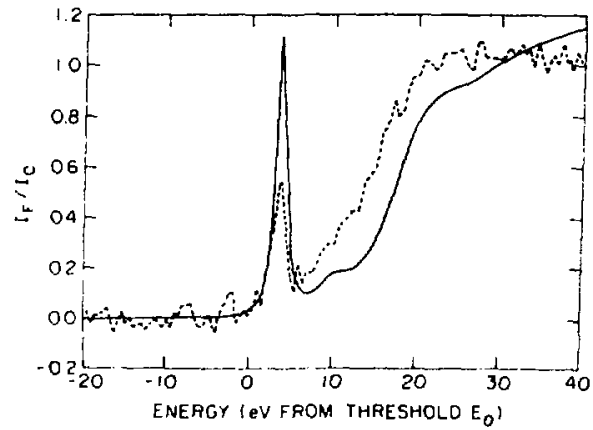

Fig. 2. Comparison of the absoprtion edge for chromlum in the $\mathrm{K}_{2} \mathrm{CrSO}_{4}$ standard $\mathrm{w} 1$ th a $5 V$ anodic film after immeraton for $1 \mathrm{~h}$. 
LOCAL STRUCTURE IN RERROELECTRIC $\mathrm{Pb}_{1-x e_{x} \mathrm{Te}}$

Q. T. Islan and B. A. Bunker (Notre Dane)

In this study. EXAFs has been used to study the local structure of the disordered alloy $\mathrm{Pb}_{1-x} \mathrm{Ge}_{\mathrm{X}} \mathrm{Te}$. These alloys undergo a ferroelectric phase transition fron the high-tenperature cubic phase of PbTe to the low-temperature trigonal phase of GeTe. The transition temperature 18 a strong, nonlinear function of Ge concentration. 1 suggesting that the Ge atos play an inportant role in the transition. EXAFs studies on the Ge site in these alloys have been performed above and below the transition temperatures for $x$ up to 0.3 . The Exaps results show that $G$ atons are displaced about 0.8 \& $i$ :on the cell center at all tenperatures and Ge concentrations in the both the low- and high-tenperature phases. 2 Because the lons are always off-center, this inplies that the ferroelectric transition involves long-range ordering of the dipoles, sinilar to that found in sone nolecular crystals. Pig. 1 shows a schenatic of the order-disorder noture of the transition. 3

In addition to the order-disorder character of the transition, there is also a displacive character: EXAFS measurements of the $\mathrm{Pb}$ alte clearly show that the entire anion sublattice ahifts relative to the cation aublattice below the transition tenperature. In the EXAFS neasurenents, this ohift 1 s nanifested as a splitting of the Pb-Te first-shell distances fron $81 x$ equal bonds to three short and three long bonda. The order paraneter of the transition is represented by this splitting, which 1s shown in P1g. 2. These neasurenents are the first direct evidence for a sinultaneous order-disorder and displacive ferroelectric transition in a seniconductor alloy.

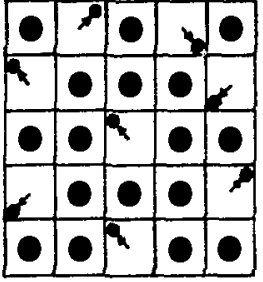

(a)

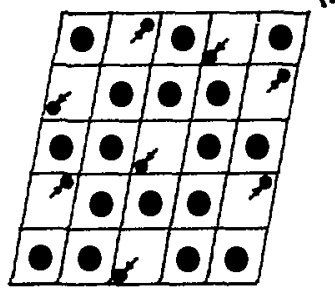

(b)
(111)

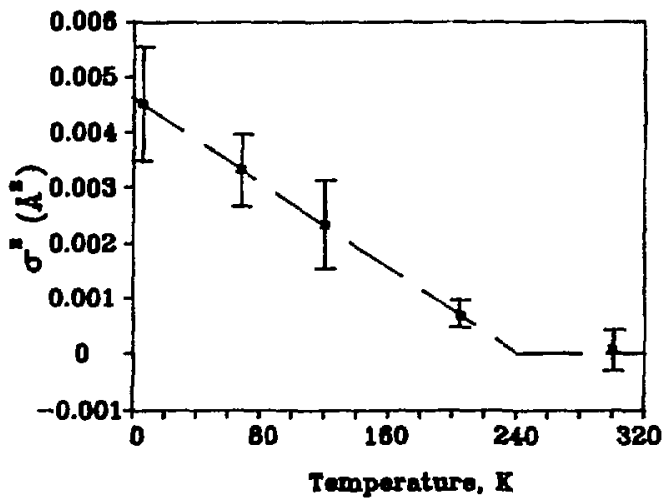

Fig. 1. Two-dimensional schenatic of the proposed alfenment of off-center Ge lons in (a) high tenperature cublc phese, and (b) low tenperature trigonal phese. Large c1rcles: Pb, sall circlea: Ge. The line Intersections represent $\mathrm{Te}$

P1g. 2. Mean-squere deviation in Pb-Te firstshell distances. The increased distance deviation at low tenperatures is due to the cation-anion sublattice shift in $\mathrm{Pb}_{0} .72^{\mathrm{Ge}_{0}} .18^{\mathrm{Te}}$ as a function of tenperature.

1 D. K. Hohnke, H. Holloway and S. Kaiser, J. Phys. Chen. Sol1ds, , 33, 2053 (1972).

2 Off-center fons also explain observed anomalies in electrical resistivity end opecific heat. See, for Instance, H. Yaraner1, A. D. C. Grassie, H. Yuaheng and J. U. Loran. J. Phys. C: Solld State Phya., 14, L411 (1881); T, Suski, S. Takaoka, R. Murase and S. Porowaki, Solid State Conmun., 45, 250 (1983); S. Katayana, S. Neekawe, and H. Fukuyana, J. Phys. Soc. Japan 56․, 687 (1987).

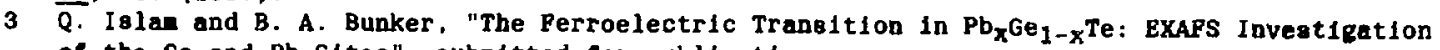
of the Ge and $\mathrm{Pb} S 1$ tes". subnitted for publication.

Supported by ONR *N00014-85-K-0614. The X11 beanl1ne is supported by DOE $\$ D M R-D E-A S 05-80 E R 10742$. 
SITE CORRELATIONS IN QUATERNARY III-V SEMICONDUCTOR ALLOYS

S. Islan and B. A. Bunker (Notre Dane)

It has becone increasingly apparent that the local structure of disordered allays 18 aore conplicated than previously belleved, with bond-length diatortions or even a tendency for long-range order under some conditions. 1

In this work, we are interested in local ordering: apecifically, correlated site occupation in disordered III-V quaternary alloys. Although nost electronic structure theorles of disordered alloys essune conplete randonness, there are alnost certainly deviations fron totally randon behavior. Por exanple, in the quaternary alloy $G a_{x} I n_{1}-x A s_{y} S b_{1-y}$, the "average" Ge aton will have sone Ixture of $A s$ and $S b$ neareat nelghbors. Because of differences In bonding energies and in atonic sizes, it is unlikely that the number of As atons as nearest neighbors to the Ga would siuply scale as the concentration $y$.

The saples were prepared by quenching fron the melt in evecuated quartz anpoules. The naterials were then repeatedly ground and annealed at 500C. Conpositional unifornity was monitored with $x$-ray diffraction line widths and electron nicroprobe analysis.

Our transaission EXAPS measurements for these alloys show large deviations fron randoness, with Ga-As palrs belng clearly preferred over In-As palrs. Por exanple, for the alloy geries $G a_{x} I n_{1}-x^{A s_{y} S b_{1} y}$, with $x=0,0.25,0.50,0.75$, and 1.0 , and $y$ fined at 0.1 , we nay 8 tudy the environment about an "average" As aton. The ExAFs results directly reveal the number of Ga atons neighboring the photoexcited As as a function of composition $x$. If the alloy were truly randon, the numer of Ga nelghbors would vary linearly with conposition. Our reauls, shown in Fig. 1 , show Ga-As pairs are nuch nore connon than expected. We have directly deternined that Ga-Aa pairs and In-Sb pairs are preferred over Ga-Sb and In-As pairs, and the "disordered" alloy is actually much nore ordered than earlier belfeved. Samples prepared at lower growth tenperatures with CVD or MBE technlques are expected to show even larger correlations. These results are expected to inpact calculations of energy levels, electron nobilities, phonon atates, and crystal growth.

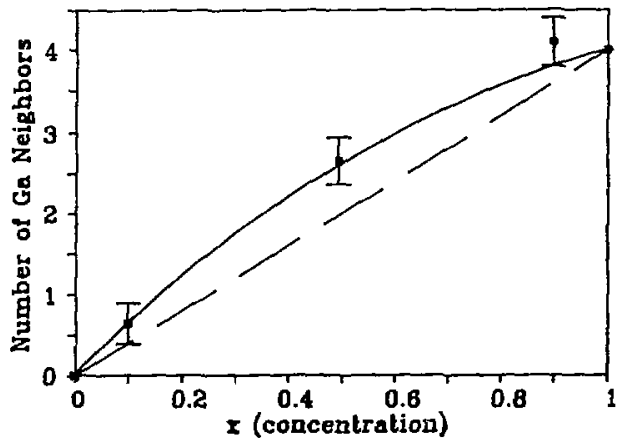

P1g. 1. The nunber of Ga neighbors surrounding the "average" As aton in GaxIn $1-\mathrm{x}_{\mathrm{A}} 0.1 \mathrm{Sb}_{0.9}$, as a function of $G a$ concentration $x$. The otraight dashed line is that expected if the alloy were truly randon. This deviation fron randonness ohow a tendency towards ordering, with Ga-As bonds being preferred over In-As.

1 T. S. Kuan, T. F, Kuech W. I, Wang and E. L. W1lk1e, Phys. Rev. Lett. 54, 201, (1985): T. Fukul and H. Saito, Jap. J. Appl. Phys, 23, L521, (1984).

Supported by ONR *N00014-85-K-0014. The X11 beanline 18 supported by DOE $\# D$ RR-DE-ASO5-80ER10742. 
$Y$. Ma and $E$ A. Stern

Physics Department, FM-15

University of Washington

Seattle, WA 98195

We have continued our work reported last year ${ }^{1}$ on identifying the structural unit in the icosahedral phase (i-phase) of AlMnSi. The position of the Al atoms in the structural unit is located. We also compared the Fe and $M n$ sites in the aperiodic $A l-(M n, F e)-(S i)$ alloys. We also investigated the strable icosahedral phase - T2 phase of AlCuLi.

We have developed a new method ${ }^{2}$ of analyzing non-gaussian distribution in EXAFS. This method is based on the cumulant expansion and yields the pair distribution function (PDF) by direct Fourier transform. The first shell PDF of $M_{n}$ in aperiodic $A l-M_{n}-(S i)$ was obtained using this method. 3 Combining these results with the focussing effect in the $a(A \mid M n S i)$, we aro able to locate the Al atoms in the Mackay Icosahedron (MI) which is the structural unit in the $i-A \mid M n S i$ and $i-A \mid M n$.

By a detailed comparison between a(AIMnSi) and $i-A \mid M n S i$, we find evidence that the cubic distortion of the MI in the a phase remains in the $i$-phase. ${ }^{4}$

The connection between the MI was also analyzed 3 and we found that the result gives a coordination number of about $7.2 \mathrm{MI}$ as opposed to the 8 in the a phase. This number is significantly higher than those predicted by the random accretion models of the $i$-phase (which is around four ${ }^{5}$ ) and the quasicrystalline model of Audier and Guyot 6 (which is around five).

bosed on these results we propose that the $i$-phase is composed of orientated fiMnSi a-phase microcrystals of size about $40 \mathrm{~A}$ interconnecticd by the individual, orientated MI units. 4

We also compared the Fe and $M n$ sites in the icosahedral Al-(MngeFegSi) and decagonal Al-(MnggFe2). ${ }^{7}$ While the $\mathrm{Fe}$ and $\mathrm{Mn}$ sites were found to be the same in the i-phase, we found that they are different in the decagonal phase. These results have implications on the Mossbauer and neutron scattering studies of the aperiodic alloys.

Finally, we investigated the $C u$ sites in the icosahedral T2-AICuLi and the bcc R-AICuLiB, we found that the $\mathrm{Cu}$ environments in the two phases are almost exactly the same. Based on this and the structure of the R-phase, we proposed a truncated icosahedron of about 160 atoms as the siructural unit in the T2 phase, playing a similar function as the MI in the i-AlMnSi. We also proposed that these II connect through their threo-fold axes, similar to the structure of the $i-A \mid M n s i$.

1 Y. Ma, E.A. Stern, and C.E. Bouldin, Phys. Rev. Lett. 67, 1611 (1986).

2 E. A. Stern, Y. Ma, D. Petitpierre, and C.E. Bouldin, submitted to Phys. Rev. B.

$3 Y$. Ma and E.A. Stern, submitted to Phys. Rev. B.

4 E. A. Stern and Y. Ma, Phil. Mag. Lett, 56, $x \times x$ (1987)

5 Y. Ma and E.A. Stern, unpublished; A.I. Goldman, private comn.

$6 \mathrm{P}$. Guyot, private communication; M. Audier and P. Guyot, Phil. Mag. B $52, \mathrm{~L} 15$ (1ng5).

7 Y. Ma and E.A. Stern, Phys. Rev. B 35, 2678 (1987).

8 Y. Ma, E.A. Stern, and F.W. Gayle, Phys. Rev. Lett. 58, 1956 (1987). 
AN EXAFS STUDY OF PYROLYZED METAL MACROCYCLIC ELECTROCATALYSTS

J. McBreen (BNL), W. O'Grady (BNL), D. Sayers (Nor. Car. U.), C. Yang (Nor. Car. U.), and K. Pandya (Case Hest. Reg. U.)

Absorbed $\mathrm{N}_{4}$-chelates of iron and cobalt are known to have electrocatalytic activity for oxygen reduction. However, these materials are unstable and decompose either via hydrolysis in the electrolyte or attack of the macrocycle ring by peroxide intermediates produced during oxygen reduction. Pyrolysis of these materials on carbon at temperatures between $300^{\circ} \mathrm{C}$ and $1200^{\circ} \mathrm{C} \mathrm{greatly}$ increases the activity and stablitty of these electrocatalysts.

Electrocatalysts were prepared as follows. The $\mathrm{N}_{4}$ metal macrocycle was absorbed on high surface area carbon from an organic solvent. The carbon was then dried and pyrolysis was done under an argon atmosphere. Best results have been obtained with cobalt and iron tetramethoxyphenylporphyrin. Previous structural studies on cobalt materials indicate the following. At temperatures of $800^{\circ} \mathrm{C}$ and above $x$-ray diffraction results Indicate the presence of cobalt metal. st temperatures below $350^{\circ} \mathrm{C}$ patterns that can be attributed to the original porphyrin material are present. At the intermediate temperatures where the catalytic activity is highest there is no $X$-ray diffraction pattern.

In the present study pyrolyzed tetramethoxyphenylporphyrins of iron (Fe-TMPP) and cobalt (Co-TMPP) on Vulcan XC-72 (a furnace black carbon) were Investigated by EXAFS.

Preliminary results revealed very complicated radial structure functions, indicating the presence of several compounds, including metal and oxides. Chemical leaching of the pyrolysis product removed the metal and oxides and revealed another material which is the electrocatalyst. Figure 1 shows the results for Co-TMPP at $800^{\circ} \mathrm{C}$. Also shown are radial structure functions for $7 \mu$ cobalt foll and the unpyrolyzed Co-TMPP on Vulcan XC-72. The results shows clearly the complexity of the radial structural function for the as-pyrolyzed material and the similarities between the electrocatalyst and the orlginal starting material. Figure 2 shows that gimilar results were obtained with the iron material after leaching with HC $f$ or oxalic acid.

Fitting parameters were determined for the first shell of the cobalt material leached with kOH. This ylelded values of $N=4.08, R=1.93 A$ and $\Delta \sigma^{2}=0.004 A^{2}$. Simllar results were obtained for Fe-TMPP pyrolyzed on carbon at temperatures between $600^{\circ} \mathrm{C}$ and $1000^{\circ} \mathrm{C}$.

The EXAFS results indicate that the electrocatalyst consists of the Co-N or Fe-N $\mathrm{N}_{4}$ core of the original macrocycle. The electrocatalytic sites appear to be monodispersed, nitrogen coordinated, Fe and Co aions.

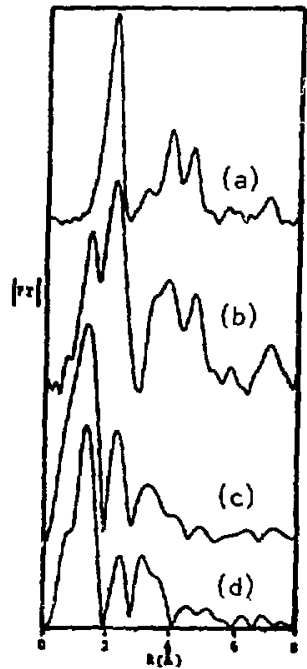

F1g. 1. Radial structure functions for (a) Co, (b) Co-TMPP pyralyzed at $800^{\circ} \mathrm{C}$, (c) after leaching with $\mathrm{KOH}$, and (d) Co-TMPP.

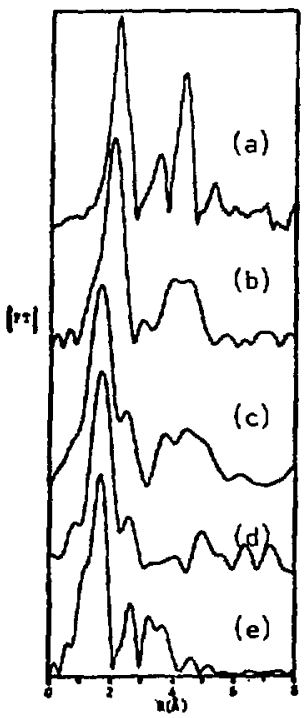

F1g. 2. Radial structure functions for (a) Fe, (b) Fe-TMPP pyrolyzed at $920^{\circ} \mathrm{C}$, (c) after leaching with oxalic ac1d, (d) after leaching with HCl, and (e) Fe-TMPP. 
METAL SUPPORT BONDS IN PLATINUM-CARBON CATALYSTS STUDIED BY EXAFS

W. E. D'Grady (BNL) and D. E. Koningsberger (E1ndhoven Univ. of Tech.)

Fuel cell electrocatalysts are based primarily on Pt supported on carbon. The catalytic activity of the electrodes is dependent on both the catalyst particle size and the type of support. In an effort to understand both the role of the catalyst structure and the influence of the carbon support on the catalytic activity, an EXAFS study of platinum supported on carbon has been initiated.

A sample containing 10 wt platinum was prepared on Vulcan XC-72. At present, Vulcan 1s the carbon used as the catalyst support in phosphoric acid fuel cells. The EXAFS data were recorded at beamline $\mathrm{X}-1 \mathrm{AA}$ on three samples: On the sample as prepared; after reduction in hydrogen at $20^{\circ} \mathrm{C}$ for 1 hour and after reduction in hydrogen at $250^{\circ} \mathrm{C}$ for 1 hour.

Analysis of the data from the as-prepared sample gave a Pt-Pt bond distance of $2.77 \mathrm{~A}$ as well as an oxfdic Pt-0 bond distance of $2.07 \mathrm{~A}$ Indicating a portial oxidation of the platinum particles. Also, a long bond of $-2.67 \AA$ was found. This long bond is attributed to the Interaction of the platinum with the carbon support.

The analysis of the data from the sample reduced 1 n hydrogen at $250^{\circ} \mathrm{C}$ for 1 hour gave a $\mathrm{Pt}-\mathrm{Pt}$ bond distance of $2.75 \mathrm{~A}$ and no $\mathrm{Pt}-\mathrm{O}$ bonds were observed. In this sample two long bonds were observed one at $2.58 \mathrm{~A}$ and one at $3.40 \mathrm{~A}$. The bond length of $2.58 \mathrm{~A}$ is $0.1 \mathrm{~A}$ shorter than that observed in e1ther of the other samples suggesting a tighter binding of the platinum particle to the carbon gurface. Since only platinum and carbon are present in the gas treatment cell the bond distance of $3.40 \mathrm{~A}$ must be 1 ndicative of the formation of an additional platinum carbon bond. Thls would suggest some change has occured in the relationship between the platinum particles and the carbon.

The as-prepared sample shows a Pt-Pt coordination number of 5 . When this (relative) coordinaticn number of 5 is corrected for the fact there are two types of platinum in the sample, a real coordination number between 5.5 and $6.51 \mathrm{~s}$ obtalned. The sample reduced at $250^{\circ} \mathrm{C}$ shows a coordination of 10.5. The treatment given to this sample was quite severe and led to a gignificant growth in the particle size as evidenced from the increased coordination number. The coordination number for the $20^{\circ} \mathrm{C}$ reduced sample was 6.5 . The increase $1 \mathrm{n}$ coordination number found here 18 due to the reduction of the surface oxide.

These reduced samples, whlle not characteristic of in altu fuel cell catalysts have allowed us, for the first time, to observe the interface between a metal and a carbon support.

Support for the development of beamline $X-11 \mathrm{~A}$ and partial oupport for this research was provided by the Department of Energy under contracts DE-AS05-80ER10742 and DE-AC02-76CH00016. 
EXAFS INVESTIGATIONS OF NICKEL HYOROXIDES

K. Pandya, R. Hoffman (Case West. Res. U.), W. O'Grady, J. MeBreen (BNL) and D. Corrigan, (GM)

Trangltion metal oxides and hydroxides are of great technological fmportance in many electrochemclal areas such as battertes, fuel cells, electrolyzers, photoelectrochemical devices and electrochromic devices. Even though transition metal oxides and hydroxides have been studied extenstvely the structure of many of these materials is pontly cliacacterized. One such example is nickel hydroxide, which employed in the nickel-zinc, nickel-cadium and niakel-1ron batterles. The structure of the nickel hydroxides depends upon the method of preparation. There are two maln classes of structure, the well crystallized B-Ni(OH) 2 phase and a poorly crystallized hydrated arNi(OH) 2 phase. The B-Ni(OH) 2 crystallizes in the C6-brucite type structure, whlch is a layered structure with each layer made up of a hexagonal arrangement of nickel atoms octahedrally coordinated by oxygen atoms. The layers are stacked along the c-axts and the $\mathrm{O}-\mathrm{H}$ bounds are parallel to the c-axis. B-Ni(OH) 2 is well characterlzed by $x-r a y$ and neutron diffraction. The $\alpha-N i(O H)_{2}$ on the other hand gives very diffuse and 111 defined diffraction patterns. The structure proposed for $\mathrm{a}-\mathrm{Ni}(\mathrm{OH})_{2}$ is of the brucite type with water and forelgn metal lons included in the structure. Hence, the stoichlometry of this hydrated nickelhydroxide depends on the experimental conditions and can be highly variable and is often denoted as $\mathrm{Ni}(\mathrm{OH})_{2} \cdot \mathrm{xH}_{2} \mathrm{O}$. The structures of $\alpha-\mathrm{N}(\mathrm{OH})_{2}$ and $\mathrm{\beta}-\mathrm{Ni}(\mathrm{OH})_{2}$ were invegtigated using EXAFS.

The $3-\mathrm{N} 1(\mathrm{OH})_{2}$ was obtalned as a reagent grade crystals from Alfa Products and the a-Ni(OH) 2 was preprepared by electroprecipitation from a $\left.0.1 M \mathrm{NI}_{(\mathrm{OH})}\right)_{2}$ solution. These materials were mixed with boron nitride and pressed to make self-supporting wafers for use in the EXAFs measurements. The EXAFs data were recorded on beam IIne X-1IA at the NSLS.

The radial structure function (RSF) for both the a and $B-N i(O H)_{2}$ consisted of three peaks arising the first peak frow the coplanar first $N$-O shell, the second peak frou the first $N 1-N i$ shell and the third peak from the third $\mathrm{Ni}-\mathrm{N} 1$ shel1, as shown in Figure $\mathrm{I}$. The data are sumartzed in Table I. The Ni-Ni peaks in $\mathrm{a}-\mathrm{Ni}(\mathrm{OH})_{2}$ are shifted to lower $\mathrm{R}$ values indicating a slight contraction of the lattice. However, there is no shift in the Ni-O distances. In the case of $B-N i(O H)_{2}$ the Interatomic distances $\mathrm{Ni}-\mathrm{O}$ and $\mathrm{N} 1-\mathrm{N} 1$ derived from $\mathrm{X}-\mathrm{ray}$ data are $2.14 \AA$ and $3.13 \AA$ respect 1 vely. The EXAFS data are $1 \mathrm{~A}$ excellent agreement with the $N A-N 1$ distance giving a value of $3.13 \pm 0.01 A$. However, the N1-0 distance found from the EXAFS data in $2.07 \pm 0.01 \AA$ shorter by about $0.08 \AA$. Also, a set of molecular force calculations have suggested a lower value for the $\mathrm{N1-O}$ distance of $2.09 \AA$. So there seems to be some question about the $2.14 \AA$ XRD value.

The third shell in the RSF of $B-N 1(O H)_{2}$ is unusually strong and colncides with the third coplanar Ni-Ni shell at $6.26 \mathrm{~A}$. This peak, which is unusual, probably arises from the multiple scattering focussing ef fect.

Support for the development of beamline $X-11 \mathrm{~A}$ and partial support for this rssearch was provided by the Department of Energy under contracts DE-ASOS-EOFR10742 and DE-ACO2-76CH00016. Part1al support for th1s work by NASA under Grant No. NAG-3-694 is also gratefully acknowledged.

Structural Parameters Obtained from the EXAPS Analys 1 s Uoing N1O as the Reference Compound

\begin{tabular}{|c|c|c|c|c|c|}
\hline Sauple & Temp. ${ }^{\circ} \mathrm{K}$ & Shell & $N$ & $R, A$ & $\Delta \sigma^{2}, A^{2}$ \\
\hline \multirow[t]{2}{*}{$\mathrm{B}-\mathrm{N} 1(\mathrm{OH})_{2}$} & 77 & $\begin{array}{l}N 1-N 1 \\
N 1-0 \\
N 1-N 1\end{array}$ & $\begin{array}{l}6.23 \\
5.96 \\
6.77\end{array}$ & $\begin{array}{l}3.30 \\
2.07 \\
6.26\end{array}$ & $\begin{array}{r}.0002 \\
-.0012 \\
.0018\end{array}$ \\
\hline & 297 & $\begin{array}{l}N 1-N 1 \\
N 1-0 \\
N 1-N 1\end{array}$ & $\begin{array}{l}6.00 \\
5.86 \\
6.02\end{array}$ & $\begin{array}{l}3.12 \\
2.07 \\
6.26\end{array}$ & $\begin{array}{l}.0026 \\
.00037 \\
.00539\end{array}$ \\
\hline$\alpha-N_{1}(\mathrm{OH})_{2}$ & $\begin{array}{r}77 \\
297\end{array}$ & $\begin{aligned} & N 1-N 1 \\
& N 1-0 \\
&- N 1-N 1 \\
& N 1-O\end{aligned}$ & $\begin{array}{l}5.68 \\
5.55 \\
5.30 \\
6.24 \\
\end{array}$ & $\begin{array}{l}3.08 \\
2.05 \\
3.08 \\
2.05 \\
\end{array}$ & $\begin{array}{l}.0024 \\
.0009 \\
.0049 \\
.002 \\
\end{array}$ \\
\hline
\end{tabular}

EBt loted Errors: $\Delta N= \pm 10 X, \hat{N} N^{2}= \pm 15 \pi, \Delta R= \pm .01 \mathrm{~A}$

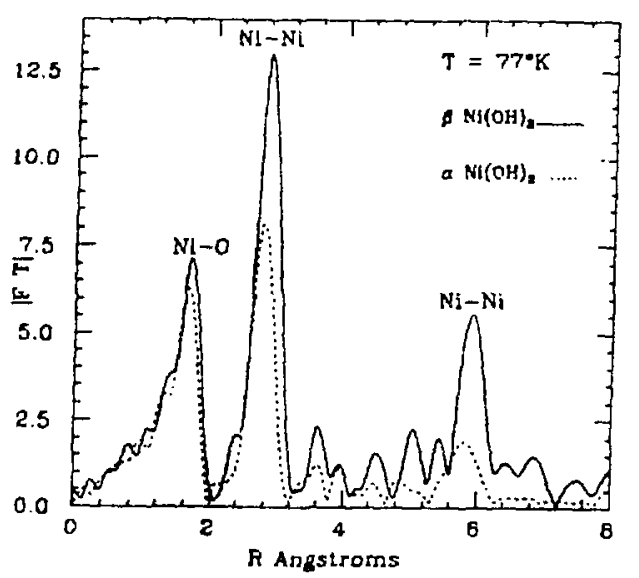

Hadlal strurture functions for $\alpha \rightarrow \mathrm{Ni}$ (oll) 2 and 8-Ni $(\mathrm{OH})_{2}$. For $\alpha-\mathrm{Ni}(\mathrm{OH})_{2}$, Ni-Ni peaks are shifted towards lower R-values Indlcating a contraction in borid distances. 
D. M. Pease, D. Brewe, 2. Tan, M. Cho1 and J. I. Budnick (U. of CT)

The Bphase transition metal aluminides are high temperature, light alloys which are, unfortunately, also brittle. In order to elucidate the bonding characteristics of these materials, transition metal $K$ edge EXaFS were obtained over a broad temperature range for $B$ phase, sto1chionetric N1Al, CoNl, and FeAl. We rind that the $\mathrm{K}-\mathrm{Al}$ and $\mathrm{Co}-\mathrm{Al}$ bonds have comparable vibrational anplitudes, but the TM-IM bonds in Co-Al are stiffer thar corresponding bonds in N1-Al. our analyses of Fe-Al is not yet complete, but the EXAFS results are intriguing in light of the metallurgical experience that Coll is decidediy the nost brittle alloy of this series.

Our EXAFS studies of the amorphous (H1 Pt 100$)^{\prime} P_{75}$ system allowed us to 1dent1fy three subshells 1n the Pt EXAFS corresponding to the Pt-Pt, ${ }^{100}-75$ ahd Pt-P coordinates. We find from a systenatic study of the temperature dependence that the structural disorder 1s less for Pt-Pt than for Pt-K1 pa1rs, though the thermal disorder is greater for Pt-Pt pairs. The Pt-Pt distance 1s close to that found for metall1c Pt. In th1s structure the $N 1$ atoms are found to have a larger basic disorder in their positions than the larger and more tightly packed Pt atons. This work will appear in Phys. Rey. B. Oct. 1987.

Acknowledgement

Th1s work was perforzed at Beam Line $X-11$ at the HSLS and is supported by the Division of Materials Science of DOE under Contract No. DE- ASO5-80-ER10742. 
BOND LENGTHS IN $Z_{1-X} \mathbf{M n}_{\mathbf{X}}$ Se

W.-F. Pong and B. A. Bunker (Notre Dame), U. Debska (Purdue), and J. K. Furdyna (Purdue and Notre Dane)

In this project, EXAFS has been uoed to determine bond lengths in the diluted aagnetic seniconductor $\mathrm{Zn}_{1-\mathrm{X}} \mathrm{Kn} \mathrm{Se}$. The magnet1c $\mathrm{Hn}$ jons in the alloys couple to one another through a super-exchange mechanian involving the Se lons, and also couple directly to the band electrons glving rise to unique electrical, magnet1c, and optical properties.1 The alloys change from a cublc (zincblende) crystal structure to a hexagonal (wirtzite) structure as a funstion of composition, with the transition at $x \sim 0.3 .^{2}$ Although $x$-ray diffraction measurents show the lattice paraneter to change by approxinately 0.2 A through the series, the neareet-neighbor bond diatances show no change within the experinental uncertainty of $0.01 \mathrm{~A}$,

The sanples used for this work were all grow using the Bridgenan growth technique using an rf-Induction-heated graphite cruclble. ${ }^{3}$ For these neasurenents, the samples were ground to a fine ponder sleved through 400 nesh. The EXAFS spectra were obtained in trananision mode at the National Synchrotron Light Source using the X11A bean line. Both the $Z$ n and lin edgee were neasured at roon tenperature for sapples of concentration $x=0.15,0.35,0.57$. As standards in tho analyeis, the $\mathrm{Zn}$ edge of pure $\mathrm{ZnSe}$ and the in edge of cublc linse were also measured.

The EXAFS results are sunarized In F1g. 1. These results shon that the local crystal atructure 18 highly distorted fron the average "virtual cryetal", and this diatortion Is insensitive to the differences between the cubic and hexagonal phases. The resultant dit ortion of the tetrahedral bond angles 1s aleo expected to strongly affect the super-exchange coupling between aagnet1c lons.

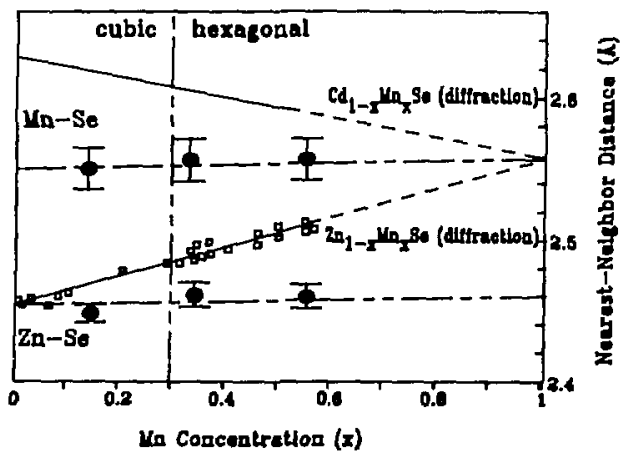

P1g. 1. EXAPS results for Zn-Se bond distance (lawer c1rcles); EXAPS reaulte for Mn-Se bond distance (upper circlea); $x$-ray diffraction deteraination of cation-cation distance. auliplied by $(3 / 8)^{2}$ (circles); and linear fit to diffractiol realte (dashed 11 ne).

J. K. Purdyna, J. Appl. Phys. 53, 7637 (1982).

D. R. Yoder-Short, U. Debska end J. K. Purdyna, J. Appl. Phys, 58, 4056 (1985).

3 U. Debska, W. G1riat, H.R. Harrison, and DR. Yoder-Short, J. Cryst. Growth 70,399 (1884).

Supported by ONR \$NO0014-85-K-0614. The X11 bealine 18 supported by DOE \#DMR-DE-ASO5-80ER10742. 
METAL IMPURITIES IN COAL AND ITS COHBUSTION PRODUCTS

C. L. Spiro (General Electric) and Joe Wong (Lawrence Livermore National Laboratory*)

As part of a major U.S. Department of Energy initiative to develop coal as an engine fuel, General Electric has contracted to examine both diesel and gas turbine engines fired on coal. A primary impediment to comercialization of ccal-fired engines is the indigenous coal minerals which may become corrosive, erosive, abrasive, adherent, or polluting as a result of combustion.

We have employed $x$-ray absorption spectroscopy to characterize the form and fate of coal-borne impurities from the mine, through beneficiation, and in samples taken at various engine locations and conditions. We have focussed on potassium 1 which is corrosive in some forms, icon which forms deposits and respirable vapors, and calcium which influences both deposition and gaseous sulfur emissions. Our major accomplishments have been to show that potassium occurs in an aluminagilicate clay, and fuses to a relatively benign, non-corrosive feldspathoid-like glass. Calcium was found to rapidly sorb sulfur in the engine, suggesting a meang to prevent acid-rain precursor formation. on the other hand, calcium was found to partition between sulfate and aluminosilicate moieties, and strict composition and thermal parameters must be adhered to in order to prevent catastrophic deposition. Iron participates through both stable hematite and a reactive aluminum spinel. The aluminum from the latter combines with calcium to form a tenacious anorthitic deposit when threshold temperatures are exceeded.

1 Forms of Potassium in Coal and Its Combustion Products, C. L. Spiro, J. Wong, F. W. Lytle, R. B. Gregor, D. H. Haylotte, and S. K. Lamson, Fuel 65, 327 (1986).

2 Combustion Products from Direct Coal-fired Turbine, C. L. Spiro, C. C. Chen, J. Wong. G. Kimura and R. B. Gregor, Fuel $\underline{66}, 563$ (1987).

*Work performed under the auspices of the U.S. Department of Energy by the Lawrence Livermore Vational Laboratory under contract number W-7405-ENG-48. 
E A Stern and Ke Zhang

Department of Physics, FM-15

University of Washington

Seattle, WA 98195

$X$-ray absorption fine structure (XAFS) measurements ${ }^{1}$ were made on pure $\mathrm{Pb}$ and a 5 at $\%$ solution of $\mathrm{Hg}$ in $\mathrm{Pb}$. Changes in the mean square displacement $\Lambda_{a}^{2}$ between both $\mathrm{Hc}$ and $\mathrm{Pb}$ atoms and their nearest neighbors were measured between low temperatures and bulk melting temperature. The results are shown in the Figure. The solid points are the temperature dependence of the measured values of $\Delta O^{2}$ for the $\mathrm{Pb}$ atoms relative to $10 \mathrm{~K}$. The solid curve is the variation expected for an Einstein oscillator of Einstein temperature $71 \mathrm{~K}$. The open points are the measured values of $\Lambda 0^{2}$ as a function of temperature for the $\mathrm{Hg}$ impurity atoms relative to $30 \mathrm{~K}$. The lower portion of the dashed curve is the variation expected for an Einstein oscillator of characteristic temperature 60K. Above $400 \mathrm{~K}$ the dashed curve is only to show the trend of the points. The top points with the symbol of an " $x$ " are the apparent coordination numbers about the $\mathrm{Hg}$ impurities versus temperature. The dashed curve through these points is only to show the trend of the points. The bulk melting temperatures for the two samples are indicated by the arrows.

Whereas the variation of $\Delta o^{2}$ for the $\mathrm{Pb}$ atoms is as expected for an atom in a solid, namely, a monotonic increase of $\Delta \sigma^{2}$ versus $T$, the variation for $\mathrm{Hg}$ atoms shows a non-crystalline behavior above $400 \mathrm{~K}$.

To interpret this non-crystalline behavior we note the following: Adding zero point motion to Lo 2 we find $a_{m}^{2} / d^{2}$, the mean square disorder at melting divided by the square of the nearest neighbor distance, equals 0.0045 (2) for $\mathrm{Pb}$ atoms, similar to the value around the Hg impurities of 0.0045 (2) at $400 \mathrm{~K}$. Thus the $\mathrm{Hg}$ impurities lose their non-crystalline behavior at the Lindemann critical value where $\mathrm{Pb}$ melts. The decrease in the apparent coordination and the leveling off of the $\Delta \sigma^{2}$ around the $\mathrm{Hg}$ impurities is similar to the local behavior around $\mathrm{Pb}$ atoms as pure lead melts. The decrease in apparent coordination number at melting occurs because diffusion increases by a factor of $10^{4}$ so that about $1 / 3$ of the time $\mathrm{Pb}$ atoms are diffusing and their XAFS during that time is invisible because of the large spread in nearest neighbor distances.

Since locally the $\mathrm{Hg}$ impurities above 400K show similar behavior to Pb atoms as bulk melting occurs, yet bulk melting hasn't occurred in the alloy, we interpret the results as a local melting about the $\mathrm{Hg}$ impurities starting at $400 \mathrm{~K}$, about $180^{\circ} \mathrm{C}$ below bulk melting.

The mechanism found for the $\mathrm{Pb}: \mathrm{Hg}$ solid solution may also be applicable to pure materials. Defects always occur in pure materials: thermally generated point defects such as vacancies; inherent ones in the sample such as dislocations, grain boundaries and surfaces. One expects, in general, that the atoms in the vicinity of such defects will have larger amplitudes of vibrations. Then the same mechanism of local melting is expected around these defects. Phenomena which can be interpreted as local melting have already been experimentally detected around surfaces 2,3 and grain boundaries 4 . It is of interest to note that Nachtrieb suggested a melted region around diffusing atoms in crystatline metals 5 .

The question remains, which defects dominate the nucleation of the bulk melting of pure materials. As the linear dimensions $L$ of the sample increases, the surface melting volume should grow as $L^{2}$ while the local melting volume around point defects should grow as $L 3$. Thus, in the thermodynamic limit, the melting process should be dominated by nucleation about point defects.

1 E. A. Stern and Ke Zhang, submitted to Phys. Rev. Lett.

2 J. M. Franken and J.F. van der Veen, Phys. Rev. Lett., 54, 134 (1985).

3 D. M. Zhu and J.G. Dash, Phys. Rev. Lett., 57, 2959 (1986).

4 G. Devaud and R.H. Willens, Phys, Rev. Lett., 57,2683 (1986).

5 N. H. Nachtrieb and G.S. Handler, Acta Metali, 2, 797 (1954). 


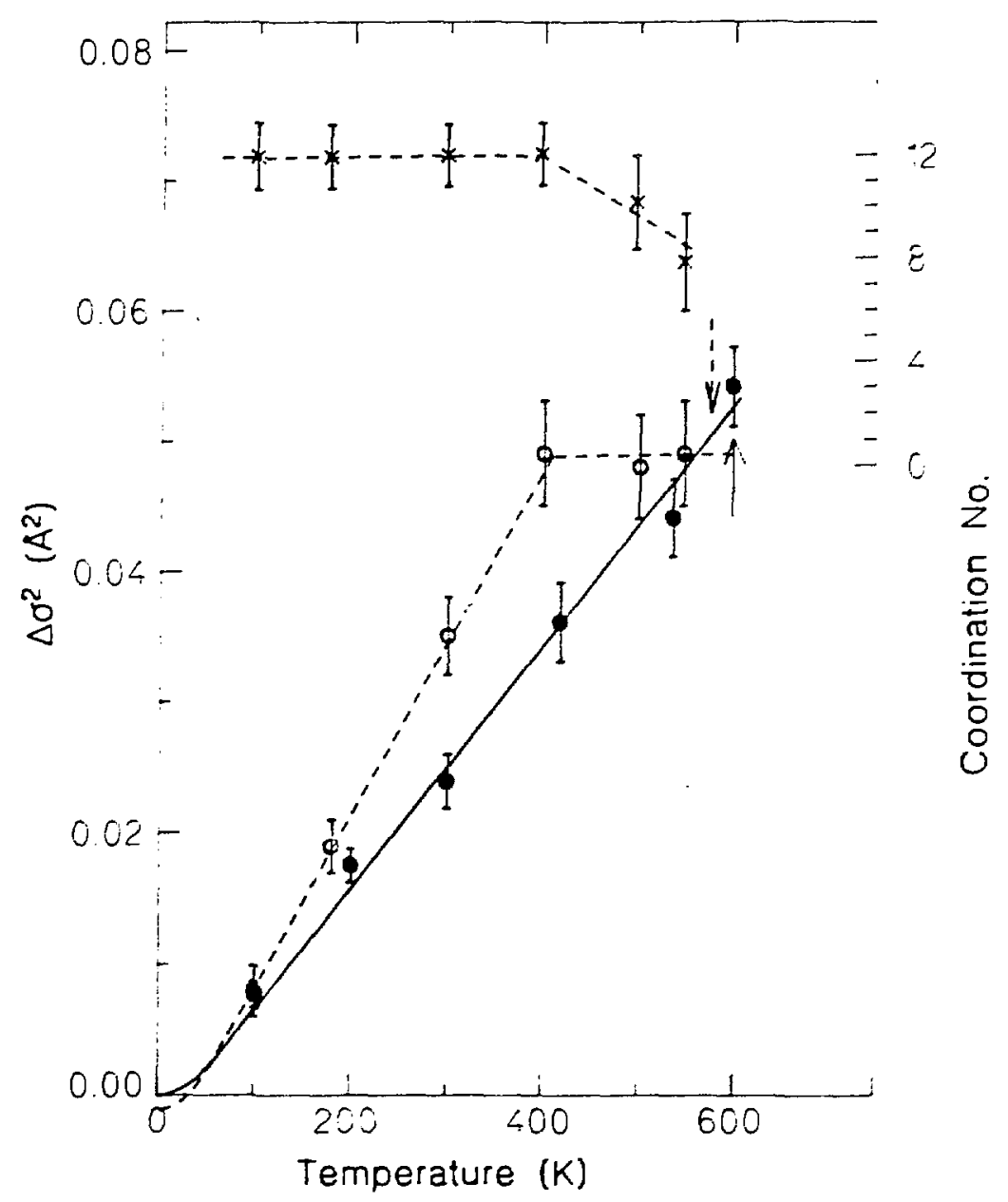

fut

The lower points associated with the left axis are plots of the change with temperature of mean square disorder $\triangle \sigma^{2}$ relative to $10 \mathrm{~K}$ for $\mathrm{Pb}$ atoms in pure lead (solid poirts) and relative to $30 \mathrm{~K}$ for $\mathrm{Hg}$ impurities in a lead host (open points). The curves are the calculations of Einstein oscillators of Einstein temperature 71K (solid) and 60K (dashed till 400K). The top points associated with the right axis are the apparent coordination numbers about the Hg impurities versus temperature. The dashed curve is only to show the trend of the points. The bulk melting temperature for the two samples are indicated by the arrows. 
2. Tan, J. I. Budntck, D. Pease (U. of CT), S. K. Heald, J. Tranquada (BNL)

Ye have applied both fluorescence and reflection EXAFs to study the interfacial reaction between niobium and aluminum thin films prepared by sequentially sputtering niobium and aluminum onto float glass in ultra-high vacuum. The $X$-rays were adjusted to be incident at angles greater than the critical angle of $\mathrm{Al}$ but less than that of $\mathrm{Nb}$, such that the interface region of the overlayer and nioblum is probed. In a narrow range of incident angles, both reflection and fluorescence signals yield EXAFS spectra of equal quality. Due to anomalous dispersion of the optical constants, the coordination number canngt be reliably obtained without properly correcting the distortion in the amplitudes our results indicate that this correction has to be carried out separately for reflection and fluorescence. The near neighbor distance (R) determined from reflection EXAFS and fluorescence EXAFS are the same within the expected error of the $R$ determination in standard EXAFS, but the value of $\sigma{ }^{2}$ extracted from the fluorescence EXafs tends to be smaller in most cases.

A comparison of the EXAFS functions and their Fourier transforms of the as sputtered Al/Nb/float glass sample to those of bulk niobium (measured by transmission) revealed no other phases except bce niobium in the interface region of $A l$ and $\mathrm{Nb}$. Therefore any compound formation during the sputtering and later thermal diffusion could not be detected and is expected to be small. part of the Al/ Nb/float glass sample was irradiateg at room, temperature with $\mathrm{Al}^{+}$lons of energy $50 \mathrm{keV}$ at a low dose rate to a total dose of $1 \times 10^{16} \mathrm{Al}^{+} / \mathrm{cm}^{2}$. A Rutherford backscattering measurement can barely see any composition change in the interface region. The EXAFS oscillation from the interface region dies out aboye $k=10 \%$. The Fourler transforms show very little contribution from near neighbors beyond $3.5 \%$. We believe that large disorder may be present in the ion beam mixed region, perhaps the phase formed is amorphous. We could tentatively assign the Al and Nb backscatter contribution to the Fourier transform magnitude in $\mathrm{B}$ space. From our data we estimated the near neighbor distances without taking into account any possible large disorder, using the Nb-Nb and NbAl phase shifts determined from model compounds. At extremely small penetration, the Nb nearest nelghbors are dominantly $A 1$ atoms at an average distance of 3.1\%. As the penetration increases, Nb atoms start to show yp at $3.0 \%$ from the Nb absorber. This Nb-Nb distance 1s close to that in

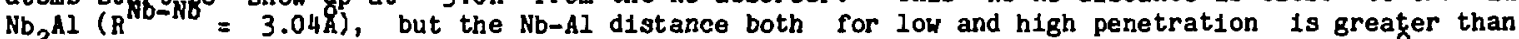
that in the $\mathrm{Nb}-\mathrm{Al}$ compounds ( $\mathrm{NbAl}_{13}, \mathrm{Nb}_{2} \mathrm{Al}$ and $\mathrm{Nb}_{3} \mathrm{Al}$. All have an Nb-Al bond length of $-2.89 \mathrm{R}$ ).

On a $\mathrm{Al} / \mathrm{Nb} /$ float glass sample irradiated to a dose of $1.5 \times 10^{17} \mathrm{Al}^{+} / \mathrm{cm}^{2}$, the Nb $\mathrm{K}$-edge EXaFS oscillations from the finterface persist into high $k$ region. However their Fourier transforms are damped out beyond $3.5 \%$, which suggests the lack of long range order in the ion mixed interface region. Analysis of the low $R$ part of Fourler transform is in progress. It is somewhat different frow that found in the low dose case.

\section{References}

1. H. Chen, S. M. Heald, J. M. Tranquada "NSLS" Annual Report 1987" P. 273; S.M. Heald, H. Chen and J. M. Tranquada, (to be published). 2. Z. Tan, J. I. Budnick et al. (in preparation).

\section{Acknowledgement}

Th1s work was performed at Beam Line X-11 at the NSLS and is supported by the Division of Materials Sclence of DOE under Contract NO. DE-ASO5-80-ERTO7 42. 
THE OXIDATIOH OF FE(II) DURLIG FERRITLH FORMATIOH: AH X-RAY AHSORPTIOH STUDY LEADLAC TO A REEVALUATION OF THE FUHCTION AHD THE EVOLUTLOHART AGE OF THE PHOTEIti

El 1 zabeth C. Thel 1 and Dale E. Sayers (N.C. State U.)

Ferritin is a protein found in plants, animals, and bacterla that stores iron in a soluble, non-toxic form. It conglsts of a protein coat surrounding a core of polynuclear hydrous ferric oxide of as many as $4500 \mathrm{ge}$ (III) atoms. At one tIme, ferritin was thought to be the response of organisms to the accumulation of dioxygen in the atmosphere starting ca. 2.5 billion years ago. However, experiments during the last year, using dispersive $x$-ray aboorption spectrobcopy at LuRE and conventional $x$-ray absorption spectroscopy at WSLS (Beam Line $\mathrm{x}-11$ ), have caubed a revaluation of the role of ferritin. The results, descrlbed in a preliminary fashion il], Buggest that ferritin way be a very old proteln associated with the most primitive living organiams.

Our experiments, based on earller concepts that the protein coat of ferritin catalyzed the conversion of Fe(II) to polynuclear Fe(III), were designed to meabure the rate of oxidation of Pe(II) in the presence of the protein using difference in the Xsiles between fe(II) and Fe(III) ae an assay. Becaure of the speed of the reaction predicted from indirect analyses of the pe environment, we performed our experiments on the dispersive line at LURE. However, we discovered that the previous 1 deas were incortect, and that the formation of the fertitin 1 ron ccre was very slow. The reaction was only $40 \%$ completed after 13 hours. We were able to finlsh the experimenta using conventional x-ray absorption on the $x-11$ Beam Line at liSLS. Up to 24 hours were required for oxidation and core formation to be complete, in contrast to the 1-2 hours prevlously deduced. The reaction conditions were comparable to those in living tissues in termb of the Fe/O2 ratio, and sugsest that, in vivo, the protein coat of ferritin way actually STABILIZE Fe(1I).

X-ray absorption spectroscopy of ferritin 1ron core formation, which allowed us to examine the pe environment in ferritin under conditions comparable to those in vivo, led to the following new ideas about ferritin function:

1. The role of ferritin in primitive organismb, even in the absence of dioxygen, way have been the sequestration of 1 ron to prevent promlscuous electron transfer to blologically important organic wolecules and the formation of free radicals in, e.g., lipid metobranes and nucleic acids.

2. The electron flux required for Fe metabolism through ferritin in cells which rapidly recycle iron In vivo may be greatly unimized if gote of the lron remains as Fe(1I) while in ferritin; the energy demand associated with pe metabolisw would thus be greatly reduced.

3. The formation of magnetite particles in organisms such as magnet1c bacterla and birds may proceed from the partial oxidation of $F e$ (II) In ferritin rather than the partial reduction of Fe(III) as $p r \in v 1$ ously belleved.

4. Ferritin can provide a toodel for studying the control of corrosion as hydrated Pe(II) and $\mathrm{Fe}(\mathrm{II})(\mathrm{OH})_{2}$ are converted to $\mathrm{Pe}(\mathrm{III}) \mathrm{O} \cdot \mathrm{OH}$ and $\mathrm{Pe}_{2} \mathrm{O}_{3}$.

Viext yeat the conditions whlch influence the oxidation of $\mathrm{Pe}(\mathrm{II})$ in ferritin, guch as pH, buffer anlons, and electron acceptors, w1l be examined using xalies of the Pe edge. In addition, the Influence of the ferritin protein coat will be Investigated using protelns from cloned Dis engineered for expression in E. col1. Preliminary experiments show that such proteins can form ferritin iron cores, but with Blightly altered properties.

References

1. The11, E. C., Sayers, D. E., Rohrer, J. S., Fontalne, A., and Dartyge, E. (1987) "The Ox1dat1on of Fe(II) Durlng Ferritin Pormation: An X-ray Absorption Study." Reculel des Travaux Chimigues des Pays-Bas 106: 267.

Supported $1 \mathrm{n}$ part by :iIH Grants DK20251 and 0.434675 . 
H. J. Weber and Joe Wong (Lawrence Iivermore National Laboratory*)

EXAF' was used to test computer simulations of the local structure of rare-earth-doped Be fluoride glasses of interest for laser applications. Simulations were performed using molecular dynamics and simple interionic pair potentials. Although the quenching rates in the simulations are extremely fast because of computer limitations, previous fXaFs studies of the $1 d^{3+}$ in simple BeF 2 showed that the general features of the local structure were correct. The simulations also predicted that for more complex glass compositions, the fluorine coordination number about the rare earth should increase. This was confirmed from $x$-ray fluorescence measurements of the ExAFS oscillations of the $L_{3}$ edge for Nd-doped $\mathrm{BeF}_{2} .55 \mathrm{BeF}_{2} \cdot \mathrm{RF}$ ( $R=\mathrm{Li}, K, \mathrm{Rb}$ ) and a multicomponent glass $34 \mathrm{BeF}_{2} \cdot 19 \mathrm{HgF}_{2} \cdot 10 \mathrm{CaF}_{2} \cdot 14 \mathrm{BaF}_{2}$ glasses. This feature can be used in tailoring the spectroscopic properties of laser glass.

Table I. White line analysis of the normalized Nd $L_{3}$ XANES.

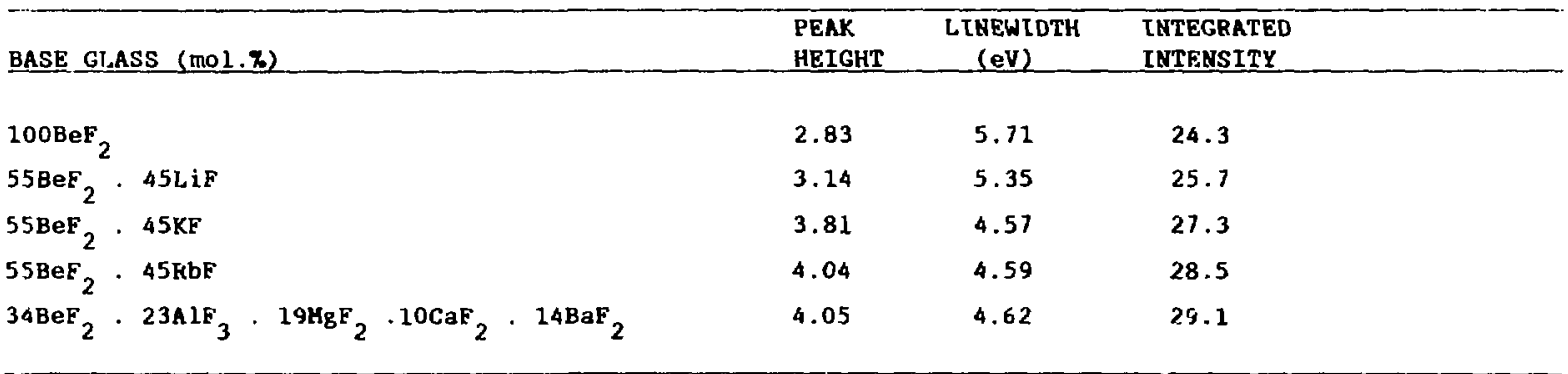

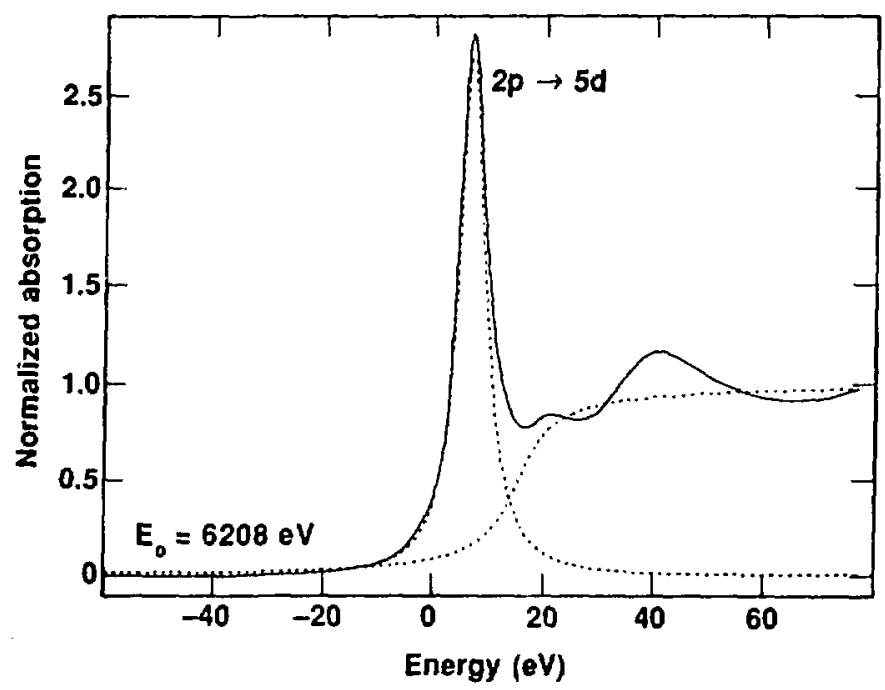

Fig. 1. Whiteline analysis of Nd L3 XANES

into a Lorentzian and an arctangent component.

*Work performed under the auspices of the U.S. Department of Energy by the Lawrence Livermore National Laboratory under contract number $W-7405-E N G-48$. 
Joe Wong (Lawrence Livermore National Laboratory*) and Glen A. Slack (General Electric)

Beta-boron is a semiconductor with a band gap of $-1.5 \mathrm{eV}$. It is hard and refractory with a very high melting point of $2300 \mathrm{~K}$. It satisfies the "small atom and large number of atoms per unit cell" criterion for potentially high thermoelectric efficiency. Grystallographically, beta-boron is made up of compact $B_{12}$ and $B_{10}$ polyhedral units and isolated $B$ atoms, all linked together by strong, directional covalent bonds. These structural and bonding features create a very open structure in beta-boron. With a boron radius estimated to be $0.88 \mathrm{~A}$, the degree of space filling is calculated to be only $36 \%$. Consequently, the stcucture contains many holes that can interstitially accomodate a variety of metal atoms in the Periodic Table. The doped bocon materials may be denoted by $B_{100-x}$ $H_{x}$. where $H$ may be a transition or non-transition metal and $x$ can vary from fraction of, to $a$ few atomic $h$ depending on solubility at the doping conditions at high temperature and pressure. We have undertaken a systematic xawes study of the $3 \mathrm{~d}$ metal sites and their concentration variation in beta-boron. The effect of double doping in two V/Cu-doped materials have also been examined. Chemical and atructural information of this kind are much needed to gain insight into the understanding of physico-chemical behavior that are relevant to improved and advanced radioisotope nuclear power thermoelectric applications.

In Fig. 1, the normalized KANES spectra are shown for a series of $3 d$ metals, 1 atomic $z$ in concentration, doped in beta-boron. The energy zero is taken with respect to the first inflection point of the corresponding pure pure metal in the respective derivative spectrum. For the early transition metals, $T i, y$ and $C r$ in particular a number of well-resolved features up to 24 eV are evident. The pre-edge features at 1-2 ev is a $1 \rightarrow 3 d$ transition, which normally is dipole forbidden, but is rather strong, indicative of appreciable $p$ overlap with the d states of the metal dopant. Two well defined bound states at 7 and $11 \mathrm{eV}$ are also evident. The principal maximum at $\sim 23 \mathrm{eV}$ is due to lattice scattering from the boron neighbors. As the d-states are progressively filled in going across the $3 d$ series from $T i$ to $\mathrm{Cu}$, the pre-edge feature at 1-2 eV becomes less well-defined as is seen from the XANBs of $\mathrm{kn}$ and Fe. The pre-edge feature almost disappear in the spectra of $\mathrm{Co}, \mathrm{Hi}$ and $\mathrm{Cu}$. At the same time the doublet feature below $10 \mathrm{ev}$ becomes less resolved and merges to a shoulder on the steeply rising edge. This is again evident from the spectra of $\mathrm{kn}$ through Cu. The principal absorption maximum decreases in energy from $\mathrm{Ti}$ to $\mathrm{Cu}$, implying an increase in the metal-boron separation.

The concentration dependence of the rawes spectra is also of interest, and may be correlated with the progressive occupancy of various interstitial sites, ie., the $\mathrm{a}$ site first, then $E$ and $D$ sites in that order with increasing concentration. This behavior is exhibited in $v, d i$ and $\mathrm{Cu}$. In the case of $\mathrm{Cu}$ changes in the xaves spectrum occur at above $1 \%$ doping. This is even more pronounced than that for $\mathrm{Ni}$ in that the $26.6 \mathrm{eV}$ feature disappears altogether at 37 doping, being replaced now by an absorption minimum. This correlates well with occupancy of a second $\mathrm{Cu}$ site as determined by $x$-ray crystallography.

*Work performed under the auspices of the U.S. Department of Energy by the Lawrence Livermore Uational Laboratory under contract number W-7405-EWG-48.

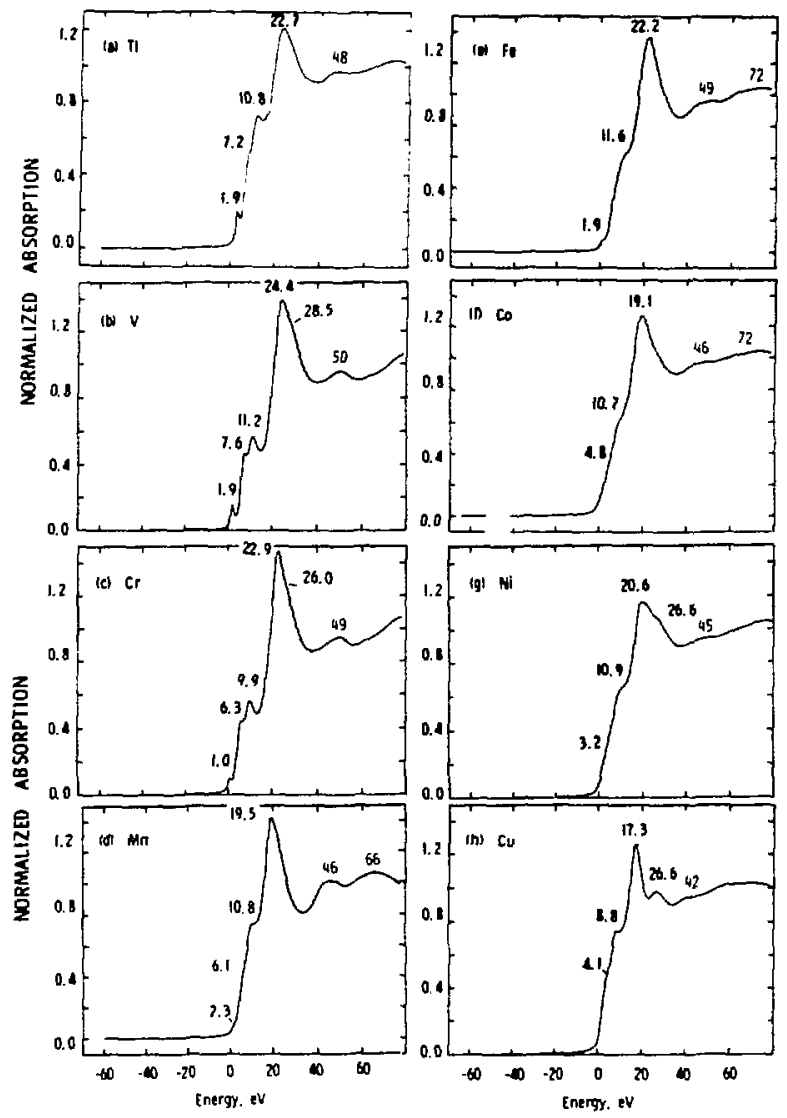

Fig. 1. Normalized K-edge xhNeS spectra of 1 at 7 3d metals doped in $\beta$-Bacon. 
G. L. Woolery, A. A. Chin, G. W. Kirker, A. Huss, Ir. (Mobil R\&D Corporation, Paulsboro, NJ)

$x$-ray Absorption Spectroscopy was used to investigate the oxidation state and local environment of vanadium in Fluid Catalytic cracking ( $F C C$ ) catalysts subjected to conditions simulating reaction and regeneration in an FCC unit. Vanadium and nickel, which deposit on catalyst during reaction, are detrimental to catalyst performance due to promotion of dehydrogenation reactions which increase coke make and light gas $y$ ield at the expense of gasoline production. Additionally, vanadium is known to cause zeolite structural degradation leading to irreversible loss of catalyst activity. Commercial FCC catalysts containing USY and REY were used in this study and vanadium near edge structure was monitored and compared with catalyst activity.

Microunit studies show that vanadium remains in the +4 oxidation state after cracking but converts to $\mathrm{v}^{+5}$ during catalyst regeneration. Identical v-edge data were observed using gas oil feeds doped with $v$ naphthenate, vanadyl porphyrin, or a high metals containing crude oll (Boscan), indicating insensitivity to vanadium source. V-doped catalysts deactivated over a wide range of conditions leads to chemically similar $\mathrm{v}+5$ species although cracking activity decreases with increasing severity. These results suggest that oxidation of vanadium is not solely responsible for catalyst deactivation but that other factors, such as $V$ location and mobility, play an important role in deactivation phenomenon. Basic alkaline earth oxide passivators such as Mgo, admixed to the catalyst, strongly interact with the vanadium during the regeneration period. Although the oxidation state of $V$ is essentially unaffected, Mgo structurally modifies $V$ as evidenced by a unique absorption spectrum. This species has been identified as a magnesium vanadate compound.

*This work was performed on beamline X-11A at the NSLS and is supported by the Division of Materials Science of DOE under Contract NO. DE-ASO5-80-ER10742. 
C. Y. Yang, J. M. Lee, M. A. Paeslex, and D. E. Sayers (NC State U.)

We report the first direct and quantitative structural information assoclated with the photo-structural change in $a-A_{2} S_{3}$. EXAFS experiments were performed on samples that had undergone three reversible and reproducible cycles of thermal annealing and light soaking. A reversible red-shift of the optical edge (1.e. photo-darkening) In light-soaked flims was confirmed by optical transmission measurements as shown in Flg. 1. Measured changes induced by light Include: 1) an increase in the atomic percentage of wrong (As-As) bonds from $1.5 \%$ to $2.0 \%, 11$ ) an enlargement of $\theta$, the mean As-S-As bond angle, from $99.5^{\circ}$ to $100.3^{\circ}$, 111) a $2^{\circ}$ incrase in the spread of the angle $\theta$; and $1 v$ ) an absence of any changes in the $3 \mathrm{rd}$ shell As-S distance. The $33 \%$ change in the number of wrong bonds alone would result in a fractional increase in volume $\Delta V / V=0.3 \times 10^{-3}$. In Fig. 2 , the first peak of the radial structural function for a-fllms arises from As scattering at $3.48 \AA$ for annealed films and $3.5 \AA$ for $11 \mathrm{ght}$ soaked fllms. The observed $2.0 \times 10^{-2} \AA$ Increase ta the As-As distance can be shown to result ln a fractional increase of $\Delta V / V=5.7 \times 10^{-3}$. The total increase in volume fraction from the EXAFS data is therefore $6.0 \times 10^{-3}$, which 18 exactly what has been measured. Although this precise agreement must certainly be considered somewhat fortuitous, we feel that these data provide the first quantitative correlation between microscoplc structural measurements and macroscopic measurements of the photoinduced effect. Because of an Interplay between the photo-structural changes and the photo-erpansion measurements, it is suggested ${ }^{2}$ that the dominant mechanism of the photo-induced changes involves a twisting of adjacent AsS 3 pyramids about their shared $S$ atoms as well as an expansion of the As-S-As angle at that shared atom.

References

1. C. Y. Yang, M. A. Paesler and D. E. Sayers, Phys. Rev. B, In press.

2. C. Y. Yang, J. M. Lee, M. A. Paesler and D. E. Sayers, J. Non-Crys, Solids, In press.

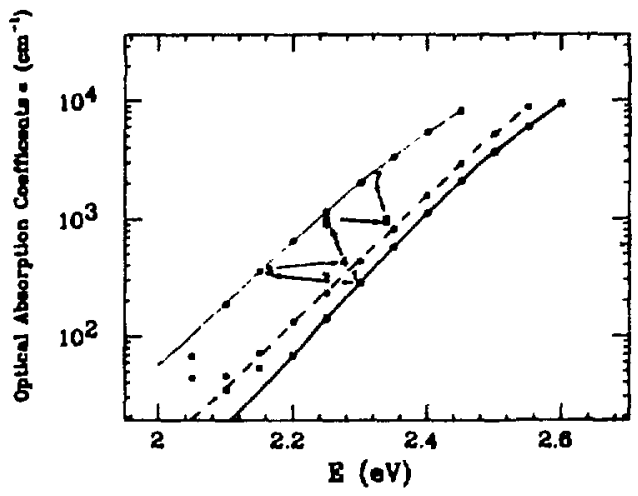

Fig. 1. Optical absorption edges of virgin (solid line), annealed (dashed line) and light-soaked (dotted line) a-As ${ }_{2} \mathrm{~S}_{3}$ films. The cycles are indicated by arrows. Photo-darkening and annerling cycles were reproductble and reversible for cycles 2 through 7 .

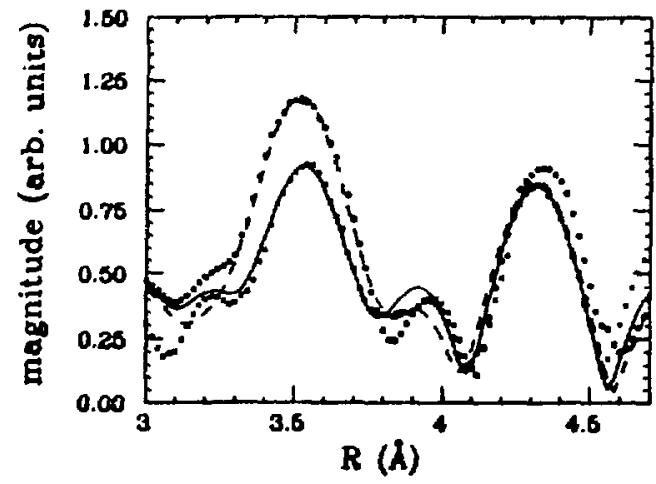

F1g. 2. Expended view of the As-S phase correciod Fourler transform for the second (opened circle) and third cycle (dashed line) of the annealed $f 1$ ins and the second (starred line) and the third cycle (solid line) the light-soaked films. This is to demonstrate the reproduclbility and reversibility of photo-structural changes in the second and third shell contributions.

ROTE: This research was supported by the U.S. DOE under Contract No. DE-ASOS-80-ER10742 and NSF Grant DHR-8407265. 


\section{THE USE OH AN ULTRA-HIGH RESOIUTION MONOCHROMATOR FOR NUCLEAP. BRAGG SCATTERING:}

\section{P. Siddons, J. B. Hastings, G. Faigel, P. E. Haustein, J. R. Grover, Brookhaven National Laboratory}

A new apparalus for the study of nuclear Bragg scaltering has been developed at beam line X 1 ?A. The system comprises an ultra-high resolution monochromator feeding a 2-circle daffactomeler. The $14.41 \mathrm{ktV}$ Mossbauer resonance of ${ }^{50} \mathrm{Fe}$ in an isotopically enriched and highly perfect $\mathrm{Fi}_{2} \mathrm{O}_{3}$ erystal was successiully exeited using the beam trom this monochromator as a probe.

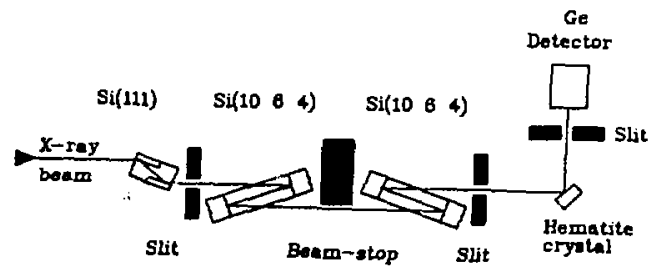

Fig. 1. Schematic arrangentent of the high-resolution monochromator and nuclear resonant sample.

Figure I shows the general arrangement of the apparatus. The first optical element is a silicon (111) monolithic double reflector (1) whose main function is to isolate the later high resolution ele ments from the thermal load of the synchrotron white beam. The second and third elenents are also silicon monoliths, but cut to provide very high order diffraction planes in order to maximize the resolution. The planes used were the $(10,6,4)$ planes, giving a resolution of $0.005 \mathrm{eV}$ at $14413 \mathrm{eV}$, with an angular divergente of the output beam of around 0.5 arc- seconds.

The requirement for such high resolution stems fron the extreme narrowness of thie Mossbauer line (of order ${ }^{10}-7$ ev). In order to detect resonant photons, the background of non-resonant photons must be as low as possible. If a conventional monochromator is used. (providing a bandwidth of a fiew $\mathrm{eV}$ ), the ratio of non-resonant to resonant photons incident on the nuclear scallering sample is around 8 . Much of this can be rejected by judicuous choice of the scattering sample. Our experiment used antiferronagnetic $F_{2} O_{3}$. [2] which has the property that cerain $B r a g g$ reflections have zero electronic scattering factor, but non-zero nuclear scattering. Such' reflections are termed 'pure-nuclear'. Incoherent processes still prevent one from reaching such good signal-to-noise ratios, and this is where a reduction in non-resonant input thux can be beneficial. It decreases the noise level (by a factor of 1000 or so) but only slightly reduces the signal level.

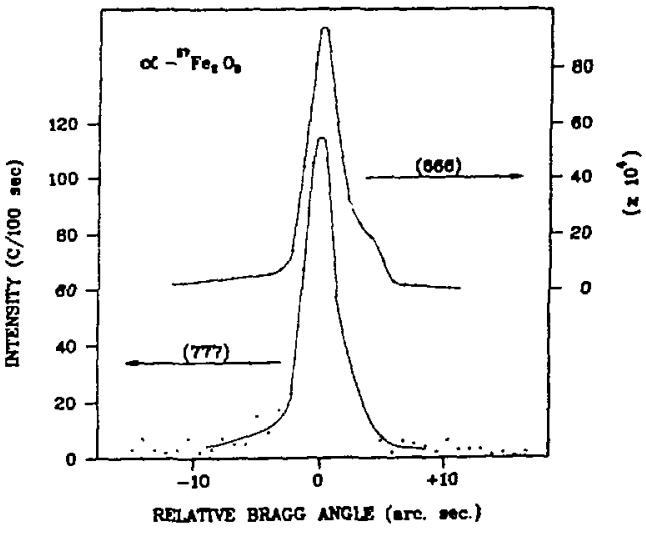

Fig. 2. Angle rocking curves of a nomal Bragg peak, the $(6,6,6)$, and nuclear resonant Bragg peak, the $(7,7,7)$. The angular widths are almost identical.

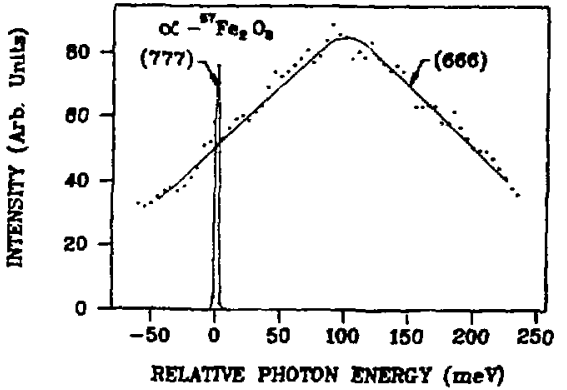

Fig. 3. Energy scans through the $(6,6,6)$ and $(7,7,7)$ peaks. Note the striking difference in widths, demonstrating the nuclear nature of the latter.

Using this apparatus, we were able to isolate a very pure beam of resonant plotions of intensity $>2$ photons per second and signal-to-noise ratio 100 : 1 , using the pure-nuclear $(7,7,7)$ reflection of $\mathrm{Fe}_{2} \mathrm{O}_{3}$ (rhombohedral indices). Figure 2 shows angle rocking curves of the Bragg peals found at the resonance energy for the pure-nuclear $(7,7,7)$ and the normal (electronically allowed) $(6,6,6)$ reflection. They are very similar in width, indicating that the width is dominated by crystal perfection. Figure 3 shows an energy scan through the pure nuclear reflection, contrasted with a similar energy scan for the electronically allowed reflection, the $(6,6,6)$. The energy width of the latter is doninated by the sample crystal reflection width, as dictated by Bragg's law. The energy width of the $(7,7,7)$ is dramatically different, and is in fact dominated by the monochromator resolution function. If this feature was of an electronic nature, if would show an energy width similar 10 that of the $(6,6,6)$, and so this data indicates that we are indeed observing nuclear Bragg scautering. A similar feature was also observed at the $(5,5,5)$ position, having identical energy and bandwidth.

\section{References}

1. J. N. Beaumont and M. Hart, J. Phys. E. 7 (1974) 823

2. S. L. Ruby, J. Phys. (Paris), Colloy. 35 (1974) C6-209 


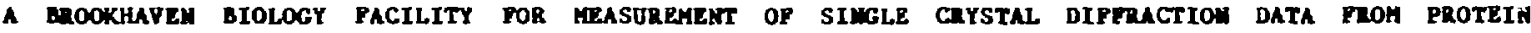 CRYstals,}

Robert M. Sweet and Donna M. Cyr (Biology Department, BNL)

Beamline $X-12 C$ has been developed by the Biology Department at BNL for measurement of diffraction data from crystals of biological macromolecules. It features a horizontally focused bean in the enerzy range $8-12 \mathrm{kv}$. The data-collection technique uged 13 rotation photography, and this is rery conveniently accomplished with the instrumentation and darkroom that have been provided.

The great majority of users of beamline $x-12 C$ are visitcts from other research institutions. The work done here represents a tiny fraction of the total effort required to obtain the three-dimensional structure of a biological macromolecule. For example, a trip to Brookhaven is rarely undertaken until substantial effort has been invested in specimen preparation, a process which could take a few years work. The data measured in 8 shifts of beam-line use could comprise over 300 individual $x$-ray films. It could easily take 2-3 man-months of work for digitization and primary data reduction to be performed on these films, and another 6-12 months could be required to interpret fully the results that follow from the data.

Although the $x$-ray beam was available for only 17 weeks during fiscal 1987, the facillty was in use for 125 shifts during this time. Heavy users were groups from NASA, oxford Univ., Univ. of Calif. San Francisco, MIT, UCLA, and Johns Hopkins. This represents a tremendous quantity of data collection. Many of these visitors were able to measure diffraction data for complete protein crystal structures in two days' work or less. Several, including members of the PRT, measured quite high-resolution data, say to 1.9 . $R$ resolution.

\section{Significant scientific results.}

1. The structure of a bacterial photosynthetfc reaction center has been deterained: data were measured at NSLS to $2.3 \&$ resolution and the structure has been refined to a crystallographic residual of $R=26 \%$ (Rees and co-authors). 1

2. The structure of the protein inhibitor from potatoes of the enzyme carboxyptidase has been refined to high resolution. Data were measured to $1.9 \%$ resolution and the refinement residual 1 s $R=19 \%$. Rees, UCLA.

3. The binding sites for phosphate ion alone and phosphate and glucose zogether have been found in phosphorylase a. Hajdu, oxford. This research was supported by the office of Health and Environsental 3esearch and by the U.S. Department of Energy.

\section{Publications}

1. Allen, J.P., Feher, G., Yeates, T.0., Komiya, H., and Rees, D.C. Structure of the reaction center from Rhodobacter sphaeroldes R-26: The cofactors. Proc. Nat. Acad. Sci. USA 84 5730-5734 (1987). See also Allen, Feher, Yeates, Komiya and Rees, ibid. $6162-6166$ for a report of the protein subunit struc ture. 
J. D. Buda1, J. 2. T1schler, A. Habenschuss, and G. E. Ice, (ORNL); and V. Elser (AT\&T Bell Labs)

A large number of studies have investigated the structure of 1cosahedral quasicrystals which were first discovered in rapidly cooled alloys ${ }^{1}$. Despite these studies, the atomic arrangements comprising a quasicrystal are not well understood. In our studies of alternative techniques for producing quasicrystals, we have found that the icosahedral grains formed by implanting Mn Ions directly into Al single crystals display a unique orientation with respect to the fcc matrix ${ }^{2}$. Since the quasicrystal grains are aligned, these ion-implanted samples are sultable for "single quasicrystal" $x$-ray diffraction studies.

High-resolution $x$-ray diffraction measurements obtained from these samples surprisingly show that the quasicrystal Bragg peaks do not lie at positions of exact 1cosahedral symetry. Recent theoretical treatments ${ }^{3}$ have shown that systematic peak shifts can be associated with the presence of a linear phason strain, a form of disorder not possible in ordinary crystals. An analysis of our data shows that, In one case, the observed positions of 37 different peaks can be quantitatively described by a diagonallzed linear phason strain matrix contalning only two independent parameters ${ }^{4}$. Figure 1 shows examples of the oscillatory peak shifts along particular symetry axes which result from a linear phason strain. Also plotted are the peak shifts predicted by Pauling's alcernative 1cosatwin model ${ }^{5}$. Clearly, the predictions of his model are inconsistent with our measurements. We find that the peak shifts observed in all Ion-implanted samples cannot be described by the same phason strain matrix. This observation is to be expected since the phason disorder should be correlated with the growth conditions for different quasicrystal grains.

In addition to providing the shifts, our $x$-ray diffraction measurements show that the quasicrystal Bragg peaks are falrly broad $\left(\geq .015 \AA^{-1}\right)$. However, the variation in width for different peaks does not simply increase with larger reciprocal lattice vector, $|G|$ as is expected for random strains in an ordinary crystal. Instead, the peaks al so show larger widths with increasing phason momentum, $\left|G_{\perp}\right|$. Th1s result is similar to the observations of Helney et al. ${ }^{6}$ in AlCuL1 quasicrystals and indicates the presence of either nonlinear components in the phason strain or the superposition of scattering from different grains with slightly different linear phason strain.

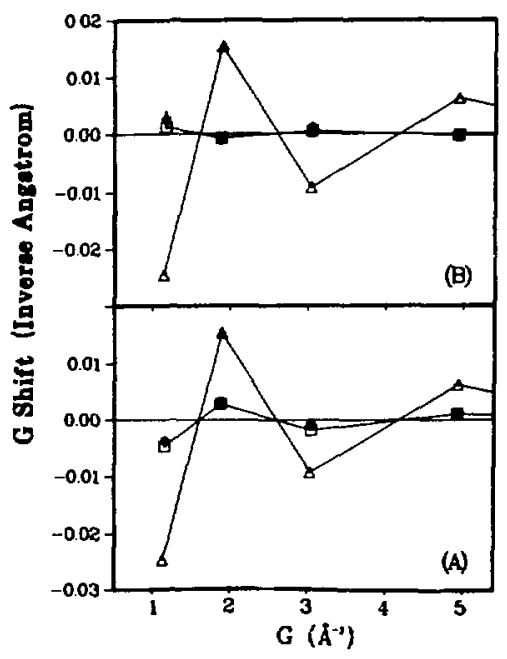

Fig. 1. Shift in peak position $|G|$ along twofold icosahedral axes (A) aligner with the sample surface normal and (B) $36^{\circ}$ from the normal. Experimental data (solid circles), phason strain model (open squares), and Pauling twinning model (open trlangles).

1. D. Shechtman, I. Blech, D. Gratlas, and J. W. Cahn, Phys. Rev. Lett. 53, 1951 (1984).

2. J. D. Budal and M. J. Az1z, Phys. Rev. B 33, 2876 (1986).

3. T. C. Lubensky, J. E. S. Socolar, P. J. Steinhardt, P. A. Bancel, and P. A. Heiney, Phys. Rev. Lett. $57,1440(1986)$.

4. J. D. Buda1, J. 2. Tischler, A. Habenschuss, G. Ice and V. Elser, Phys. Rev. Lett. 58,2304 (1987).

5. L. Pauling, Phys. Rev, Lett, 58, 365 (1987).

6. P. A. Heiney, P. A. Bancel, P. M. Horn, J. L. Jordan, S. Laplaca, J. Ang1lello, and F. W. Gayle, to be published in Science.

Research was sponsored by the Division of Materlals sciences, U.S. Department of Energy under Contract No. DE-ACO5-840R21400 with Martin Marietta Energy Systems, Inc. 
ORNL X-RAY DIFFRACTION BEAMLINE XI4A

G. E. Ice (ORNL), A. S. Bommannavar (ORNL), C. J. Sparks (ORNL), and A. Habenschuss (ORAU)

Beamline Overview

The Oak Ridge National Laboratory (ORNL) beamline incorporates several novel design features which simplifies the alignment and maximizes the flux avallable at the sample.l An 1mportant feature is a two-crystal monochromator which focuses the horizontal beam divergence with a dynamically bent Si( 111 ) crystal in the sagittal focusing geometry. ${ }^{2}$ Crystal focusing is attractive because it efficiently collects a much larger horlzontal divergence than focusing with an X-ray mirror. In additton, sagittal crystal focusing allows for much better energy and womentum resolution than with a doubly focused mirror placed upstream of the monochromator which mixes twenty times as much horizontal into the vertical divergence. The advantages of crystal focusing outwelgh the increase in operational complexity. We can cont1nuously change from one $X$-ray energy to another, over several kflovolts, under computer control and maintain a focused beam. Another novel feature of the ORNL beamline is the use of a thermally stable and wechanically simple cantilevered mirror for focusing the vertical beam divergence. ${ }^{3}$ Detalls of the beamline performance are contained in ref. 1 .

Experimental Program

During 1986 through March 1987, more than 25 experiments were performed on X14A. In general, these experiments were of materials science interest and suited to our beamline in terms of flux, energy resolution, and/or Q-space resolution. One of the b1g undertakings during the year was the measurement of the weak diffuse X-ray scattering from NiFe alloys. Although this data is still belng analyzed, obvious size differences were found between the $\mathrm{Ni}$ and $\mathrm{Fe}$ atoms in the lattice. By tuning the radiation near an absorption edge, we are able to determine the pair 1nteratomic vector. A measure of phason straln in $\mathrm{AL}_{4} \mathrm{Mn}$ quasi-crystals was undertaken. This measurement shows a linear phason strain and rules out the Pauling lcosotwin model. We undertook a study of the accomodation of strain at the nickel-sapphire interface and measurement of the surface roughness. The angular dependence of the real part of the anomalous scattering factors in a kinematically diffracting thin film of GaAs is under analysis. Further information can be obtalned by writing to the principle authors.

1 A. Habenschuss, G. E. Ice, C. J. Sparks, and R. A. Neiser, "The ORNL Beamline at the National Synchrotron Light Source," Synchrotron Radiation Instrumentation 5th National Conference, Madison, Wisconsin, June 21-25, 1987, to be published in Nuclear Instruments and Methods.

2 C. J. Sparks, G. E. Ice, J. Wong, and B. W. Bat Terman, "Sagittal Focusing of Synchrotron X-Radiation with Curved Crystals, Nucl. Instrum. Methods 194, 73-78 (1982).

3 G. E. Ice and C. J. Sparks, "A Simple Cantilevered Mirror for Focusing Synchrotron Radiation," Synchrotron Radiation Instrumentation 5th National Conference, Madison, Wisconsin, June 21-25, 1987, to be published in Nuclear Instruments and Methods.

Research performed in part at the Oak Ridge National Laboratory Beamline XI4 at the National Synchrotron Light Source, Brookhaven National Laboratory, supported by the U.S. Department of Energy, Division of Materials Sclences and Division of Chemical Sciences, and under contract AC05-840R21400 with Martin Marfetta Energy Systems, Inc. 
G. E. Ice (ORNL) and C. J. Sparks (ORNL)

A Large cantilevered mirror was constructed to focus the vertical divergence for the $\mathrm{Xl4A}$ beamine. The advantages of this mirror are its compactness, simple bending device, siaplicity of construction, and good thermal contact to structures outside the vacuum. Details of the mirror and its performance are given in ref. 1 .

The mirror figure was characterized prior to insertion into the beamline in June 1985, and its $X-r a y$ performance was carefully documented. It was then removed in March 1987, and the surface roughness and figure were measured. No degradation was found in mirror performance or surface aiter bean exposure.

The mirror reflectivity under various operating conditions was determined by monitoring the integrated flux through a $2.5 \mathrm{~cm}$ aperture sited 7 of from the aircor. The reflectivity at $8.333 \mathrm{keV}$ and $6 \mathrm{mrad}$ glancing angle was about $35 \%$. The reflectivity was improved to $67 \%$ by going to a glancing angle $0 i$ 3 mrad. This result is expected if surface roughress is responsible for the poor reflectivity. The estimated surface roughness from these measurements is from 21 to $26 \AA$.

A vertical focal spot size of $0.96 \mathrm{~mm}$ ( 40 ) was measured and compares to an ideal size of $0.61 \mathrm{~mm}$ based on our 1.5 magnification of the image of the electron beam. In the collimating mode a beam divergence of $1.8 \times 10^{-h}$ (Full-width, half maximum) was obtained. By comparison, the opening : igle of the source is about $4 \times 10^{-4}$ rad, and the source size-limited divergence for a perfect collimating mirror located 7 m from the source is $6 \times 10^{-5}$ rad.

Aiter exposure to the unartenuated whice radiation of the NSls x-ray ring for approximately 6000 h, the mirror surface was measured and inspected for overall flatness with standard interferometric techniques. The mirror figure showed a mean radius of $10 \mathrm{~km}$ in the meridional plane which is removed during focusing by the application of a slightly greater bending moment. The ígure error in the unbent mirror, however, may be responsible for the imperfect focusing properties. No degradation of the surface finish and no surface deposits were observed.

The rins roughness was measured by Takacs using a WYKO NCP $10005 \mathrm{~mm}$ profilometer. The surface roughness for spatial frequencies below $5 \mathrm{~mm}$ was found to range between 21 and $28 \mathrm{~A}$ with most regions having about $24 \mathrm{~A}$ rms roughness. This agrees well with the poor performance for the measured $\mathrm{X}-\mathrm{ray}$ reflectivity. The mirror is being repolished to improve the surface figure and roughness.

One of the chief advantages of the cantilevered mirror is its thermal stability. Desite the fact that water-cooling channels in the mirror weze not used, the mirror was found to be quite stable under varying beam currents. Figure 1 illustrates a long term stability of better than $0.38 \mathrm{eV}$ or about $15 \mathrm{\mu rad}$. The 1 ron $k$-edge was repeatedly scanned over a three-day interval with beam currents cycling between 50 and $200 \mathrm{~mA}$.

I G. E. Ice and C. J. Sparks, "A Simple Cantilevered Mirror for Focusing Synchrotron Radiation," to be published in Nuclear Instruments and Methods.

Research performed in part at the Oak Ridge National Laboratory Beamline X14 at the National Synchrotron Light Source, Brookhaven National Laboratory, supported by the U.S. Department of Energy, Division of Materials Sciences and Division of Cherical Sciences, and under contract AC05-840R21400 with Martin Marietta Energy Systems, Inc.

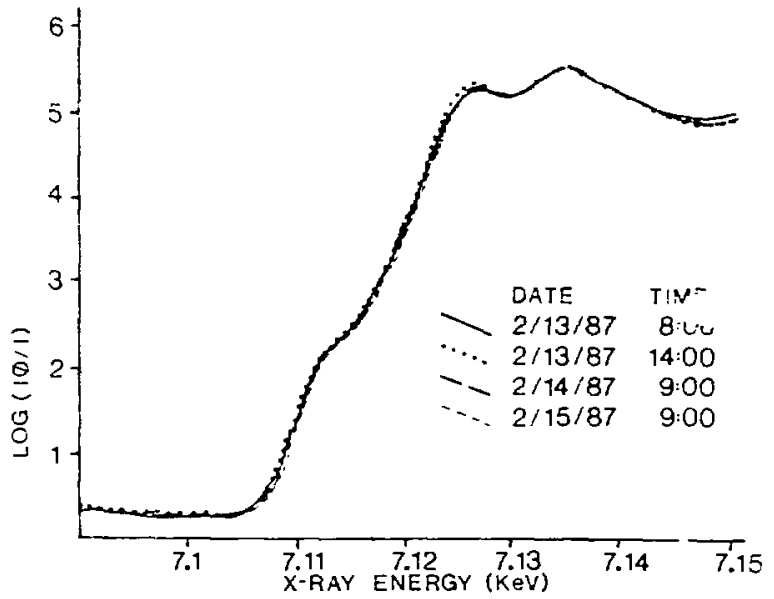

F 1. The iron K-edge was scanned in energy over a period of three days to test the mechanical and thermal stability of the $X$-ray optics and the reproducibility of the electron orbit. Energy changes less than $0.38 \mathrm{eV}$ were observed even though the beaw current cycled between 50 and $200 \mathrm{~mA}$. 
C. J. Sparks (ORNL), M. Hasaka (Nagasaki U., Japan), D. S. Easton (ORNL), S. BaIk (ORNL), T. Habenschuss (ORAU), and G. E. Ice (ORNL)

The structural perfection of epitaxial nickel films grown on the (00 $\ell$ ) or basal plane of heated sapphire $\left(\mathrm{Al}_{2} \mathrm{O}_{3}\right)$ single crystals was studied with $\mathrm{X}$-ray diffraction technlques. Nickel films approximately $700 \AA$ thick formed by vapor deposition increased in perfection as the temperature of the sapphire approached $1400^{\circ} \mathrm{C}$. Although the nearest nickel atom distances are $10.3 \%$ smaller than those of the closed-packed direction in sapphire, the strain was mostly accommodated at the interface rather than being distributed through the thickness of the nickel film. Diffuse rods of X-ray scattering which are assoclated with diffraction from the Interface gave information that the interface was comparatively rough.

The orfentation relationshlp between the nickel overlayers and the $00 . \ell$ deposition plane of sapphire was found to be $\mathrm{N1}(111) / / \mathrm{Al}_{2} \mathrm{O}_{3}(00-1)$ and $\mathrm{N1}\langle 110\rangle / / \mathrm{Al}_{2} \mathrm{O}_{3}\langle 11 \cdot 0\rangle$. The nickel close-packed directions are parallel in the plane of the substrate. The atom spacing of bulk nickel in the $\langle 110\rangle$ direction is $10.3 \%$ less than that of sapphire in the $\langle 11 \cdot 0\rangle$ direction.

The penetrating depth of $X$ rays permits studies of diffraction from interfaces buried even microns beneath the surface. Diffraction from mul-ilayers is such an example. Studies of a single interface such as a grain boundary are known to give rise to measurable diffraction effects. ${ }^{2}$ More recent work has shown that the abrupt termination of a crystal at a surface also glves rise to diffuse rods of $x$-ray scattering perpeadicular to the surface.3,4 Fot a filin thin enough to transmit the incident $X-r a y$ beam, the diffuse $x$-ray scattering from the nickel will include both the top surface and the interface with the substrate. The $\mathrm{Al}_{2} \mathrm{O}_{3}$ w1ll produce X-ray scattering from its interface with the nickel film. We can separate the scattering assoclated with the nickel surface and interface from that of the sapphire interface by measuring those truncation rods contalning either nickel- or sapphire-only reflections. Scans were made of the intensity distribution in the rods by making rocking curve measurements through them at various positions along their length. In particular, measurements were made near Bragg reflections where the interface scattering was most intense. Integrated intensities from such scans were corrected for background and for the Lorentz and polarization factors. These results for several truncation rods belonging to the $\mathrm{Al}_{2} \mathrm{O}_{3}$ and nickel reciprocal lattices are plotted in Fig. 1 . A least sqilares fit to the data shows that the intensity fall-off follows the relation given by Andrews and Cowl $\geq y:{ }^{3}$ Intensity $\propto q_{1}^{7}$, with $n$ ranging between 2.63 to 2.78 for the $\mathrm{Al}_{2} \mathrm{O}_{3}$ interface and 2.6 for the nickel tnterface. Both the sharp and diffuse truncation rods prodicted by Andrews and Cowley were observed for sapphire. 3 That the nickel truncation rods were, for the most part, associated with the nickel-substrate interface and not the nickel sutface was established by observing that roughening of the nickel surface with fine abrasive had no effect on the observed intensity. In addition, the known smoothness of properly prepared sapphire surfaces exceeds that expected for vapordeposited surfaces. Theory for a sharp interface (a crystal terminated with a single atom plane as its surface) gives $n=$ 2.0 [refs. 3 and 4]. Values of $n$ may range up to four with four befing associated with a very rough surface or interface.

1 Abstracted from article in Proc. MRS Interfaces, Superlattices, and Thin Films, Vol, 77, 1987 .

2 D. Y. Guan, B. W. Batterman, and S. L. Sass, Phil. Mag. 33, 199 (1976).

3 S. R. Andrews and R. A. Cowley, J. Phys. C 18, 6477 (1985).

4 I. K. Robinson, Phys. Kev. B $33(6), 3830(1986)$.

Research performed in part at the Oak RIdge National Laboratory Beamline $X 14$ at the National Synchrotron Light Soirce, Brookhaven National Laboratory, supported by the U.S. Department of Energy, Division of Materlals Sciences and Division of Chemical Sciences, and under contract AC05-840R21400 with Martin Marletta Energy Systems, Inc.

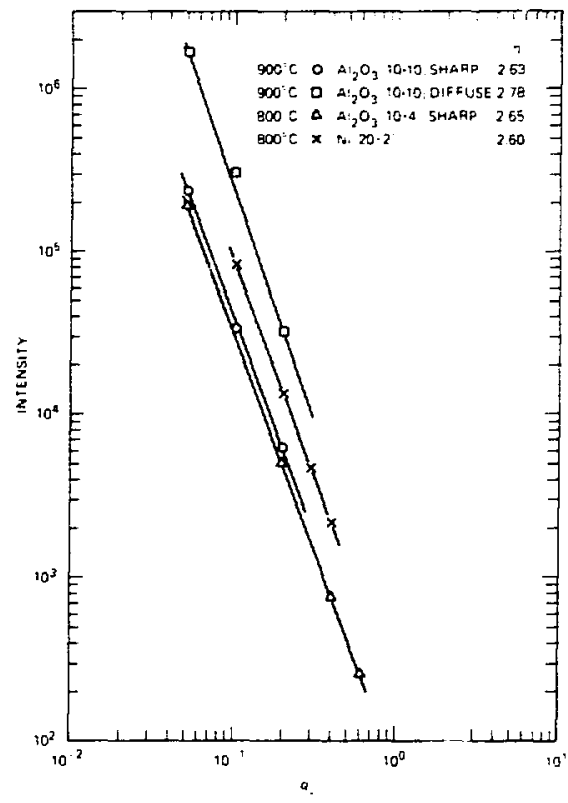

Fig. 1. X-Ray intensity from $\mathrm{Al}_{2} \mathrm{O}_{3}$ and nickel overlayer interface plotted against $\mathrm{q}_{\perp}$ is shown to vary as $q_{1} \pi$ where $n$ approaches a value for a very rough interface. 
J. 2. Tischler (ORNL), J. D. Budal (ORNL), G. E. Ice (ORNL), and A. Habenschuss (ORAU)

Recent indications of a possible nonzero structure factor for the silicon (200) reflection pose an interesting question since, due to symmetry, the (200) X-ray stcusture factor (F) in diamond structure materials should be exactly zero. ${ }^{3}$ To investigate this question, we have made measurements of the (200) reflection in silicon and germanium. These measurements were placed on an absolute scale by using a PIN diode, one of the few devices with sufficient dynamic range to measure both a diffracting beam $\left(10^{3}\right.$ counts $\left./ \mathrm{sec}\right)$ and the direct beam $\left(10^{10}\right.$ counts $\left./ \mathrm{sec}\right) .^{4}$ The diffraction measurements were made at various azlmuthal orientations. To properly determine $F(200)$, one must use dynamical theory and include the multiple scattering contributions of hundreds of nearby rectprocal lattice points. 5 To simplify the computation of multiple beam rocking curves, it is conventent to use an approximation described previously.5,6 By measuring the absolute integrated intensity at various $\phi$ angles and comparing with calculations of the integrated incensity, one may determine the exact magnitude and phase of $F(200)$. We find that the measirements may be completely explained by multiple scattering with a (200) structure factor, $F(200)$, less than $0.0004 \pm 0.00042$ electrons for silicon and less than $0.00083 \pm 0.00042$ electrons for germanium. We conclude that previously reported sharp rocking curves measured at the (200) reflection are explained as multiple reflections.

1 To be published in Acta Crystallography A43, (1987).

2 B. Post and J. Ladell, Acta Crystallogr. A43, 173-79 (1987).

3 P. 341 in International Table for $X$-Ray Crystallography, Vol. 1, eds. Norman Henry and Kathleen Lonsdale, Kynoch Press, Birmingham, England, 1952.

4 T. Jach, private communication.

5 J. Z. Tischler and B. W. Batterman, Acta Crystallogr. A42, 510-14 (1986).

6 Q. Shen, Acta Crystallogr. A42, 525-33 (1986).

Research performed in part at the oak Ridge National Laboracory Beamline $\mathrm{Xl4}$ at the National Synchrotron Light Source, Brookhaven National Laboratory, supported by the U.S. Department of Energy, Division of Materials Sclences and Division of Chemlcal Sciences, and under contract AC05-840R21400 w1th Martin Marietta Energy Systems, Inc.

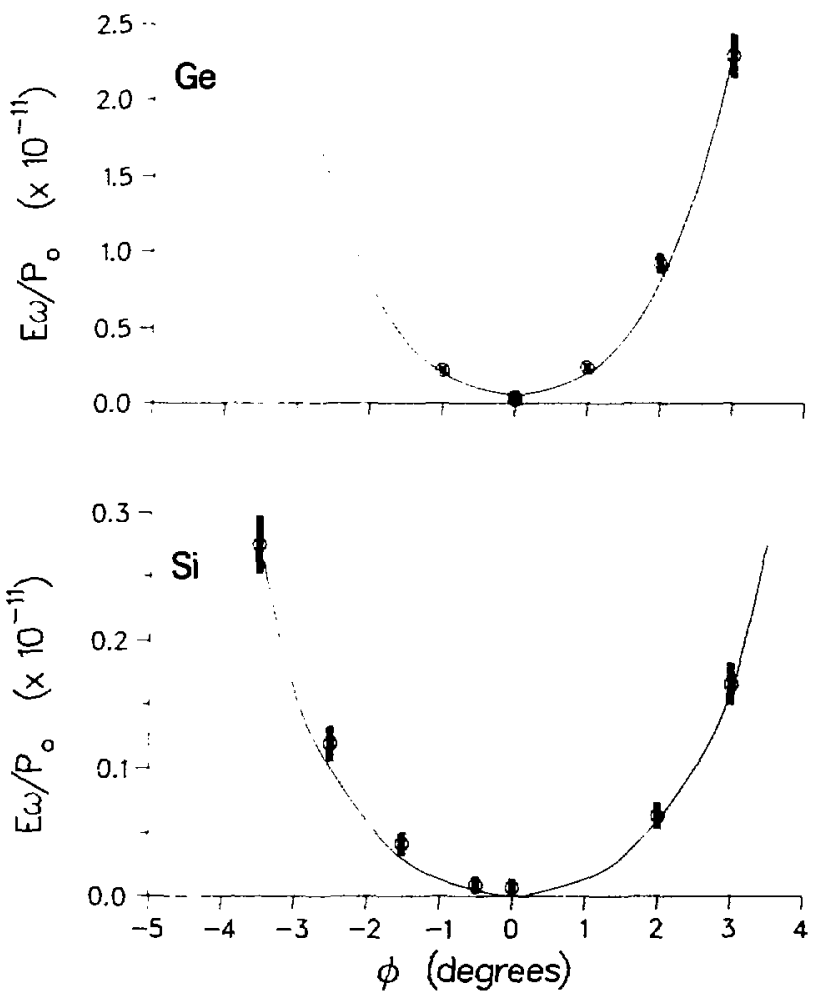

Fig. I Measured absolute integrated intensity shown as open circles with error bars from $\mathrm{Ge}(200)$ and $S i(200)$ as a function of rotation, $\phi$, about the $[100]$ surface normal. The solid line is a theoretical calculation of the multiple scattering contribution from 400 beams and explains the observed intensity. 


\section{DEVELOPMENT AND USE OF A SMPLE EXAFS SYSTEM ON A WHITE BEAMLINE (X-15A)}

M. Marcus, B. M. Kincaid, J. Mock

AT\&T Bell Labs Murray Hill, New Jersty 07974

\section{The System}

The EXAFS system consists of a channel-cut monochromator which accepts a white beam, an optical rail on which EXAFS accessories may be mounted, and a PC (ATT PC6300) and CAMA' crate to control the whole thing. The crystal is $220 \mathrm{Si}$, made from float-zoned, dislocation-free material. It is rotated by a Huber circle directly driven by a Compumotor inicrostepper. The optical elements currently used for EXAFS include a motorized slit, a PIN diode detector, an ion chanber. a photoelectron-yield chamber, and a fluorescence detector with shielding. The data are gathered by the PC via a CAMLAC crate. Counting and tining are done in CAMAC, thus allowing counting to continue while keyboard commands are processed The experiment-control program allows flexible control over the data-gathering process, as well as on-line data inspection during a scan. The output data format is that which feeds into the Bell I.abs EXAFS analysis package, as implemented on $\Gamma C$ s. This package is available on the PC.

\section{Results}

The above system produced Be!l Labs' first full-range EX.VFS spectra at NSLS, on Ni foil. After that, we then did EXAFS on quasicrystals, dilute solid solutions, and mechanical alloy systems.

$\mathrm{T}_{2} \mathrm{AJ}-\mathrm{Li}-\mathrm{Cu}$ is one of $\mathrm{t}$ wo known stable quasicrystals. It can be obtained as rapid-quenched ribbon or as large-grain polycrystal. Close to it in the ternary diagram is a Frank-Casper phase referred to as $R$. It has been speculated that the quasicrystal and $\mathrm{R}$ structures are related. We performed photoelectron and fluorescence EXAFS measurements about the Cu edge in $\mathrm{R}$ and $\mathrm{T}_{2}$ phases. We find that the Cu EXAFS from $\mathrm{T}_{2}$ and $\mathrm{R}$ are almost identical, indicating a close structural relation between the two compounds. The $R$ spectrum may be converted into the $T_{2}$ spectrum simply by attenuating the former by a factor of 0.88 .

The aloy $\mathrm{AJ}_{0} \mathrm{~V}$ may be quenched into a quasicrystal. In this system, there is no obvious model compound as there is in Al-Li-Cu or Al-Mn(-Si). The EXAFS pattern for this icosahedral phase is very different from that for Al-Mn. While the inferred RDF for $A l$ about $M$ is very broad, with two resolved peaks, that for $A l$ about $V$ is much narrower, again with two peaks. The EXAFS for $\mathrm{i}-\mathrm{Al} \mathrm{I}_{\mathrm{V}} \mathrm{V}$ is surprisingly close to that for $\mathrm{Al}_{3} \mathrm{~V}$, which is a simple tetragonal superstructure on fcc, with no obvious connection to anything icosahedral. The EXAFS evidence thus indicates that $\mathrm{N}_{0} \mathrm{~V}$ is in a different structural class than $\mathrm{Al}-\mathrm{Mn}(-\mathrm{Si})$.

Mechanical alloys are made by mixing powders of two or inore elements together in a high-energy ball mill. The resulting compaction, fracture, and recompaction causes a mixing action which may extend down to the atomic level. Novel materials may be made this way. We have studied a 50-50 mixture of $\mathrm{Cu}$ and $\mathrm{Fe}$ at both the $\mathrm{Cu}$ and $\mathrm{Fe}$ edges. The Cu EXAFS remains fcc-like for all mill times, and the interatomic distance stays at $2.55 \dot{A}$. The Cu seems to be surrounded mostly by $\mathrm{Cu}$ neighbors. The Fe pattern evolves from bec at the start to fec-like at longer times. There are two distances about the Fe atoms, separated by $0.07 \AA$. We conclude that the $50-50$ alloy is a clustered foc solid solution after long milling. Curiously, this alloy remains ferromagnetic, with a Curie point near $200^{\circ} \mathrm{C}$. We also milled a $50-50 \mathrm{Cu}-\mathrm{Nb}$ mixture, in which the Cu remained fec, while the $\mathrm{Nb}$ became disordered in a way we have not yet analyzed.

We have studied rapidly-quenched dilute alloys in which the solute atoms are much smaller than the solvent atoms. This mismatch induces insolubility in equilibrium, and interesting siting patterns when solubility is torced by rapid quenching. For instance, we find that $1 \%$ of $\mathrm{Cu}$ in $\mathrm{Y}$ yields an EXAFS pattern about $\mathrm{Cu}$ which shows two shells - disordered $\mathrm{Y}$ at $2.8 \dot{\mathrm{A}}$ and disordered $\mathrm{Cu}$ at $2.52 \dot{\mathrm{A}}$. We interpret this as due to disubstitutional siting of $\mathrm{Cu}$ in $\mathrm{Y}$. We rule out the possibility that $\mathrm{Cu}$ has precipitated in the form of $\mathrm{Cu}-\mathrm{Y}$ metallic glass (the most likely precipitate for this system) by comparing the spectrum for this glass with that of the dilute solution. 


\section{DEVELOPMENT AND USE OF A SMPLE SAXS SYSTEM ON A WHITE BEAMLINE (X-15A)}

M. Marcus, B. M. Kincaid, J. Mock

AT\&T Bell Labs Murray Hill, New Jersey 0797.4

The System

The SAXS system consists of the monochromator and optical rail used in the BL X-15A EXAFS system (see other report $j$, with a pinhole camera in place of the EXAFS equipment. The wavelength is set at CuK $\alpha$ using the EXAFS soltware. The pinhole camera consists of a collimator assembly and a He-filled flight path, which is about $25 \mathrm{~cm}$ long. The collimator is a pair of tube with brass plugs in the ends. The plugs have $1 / 2 \mathrm{~mm}$ holes drilled in them to form the pinholes. For ease of a)ignment, there is a pair of wires cemented into the tube just after the first pinhole. These wires straddle the beam path and form a prinitive ion chamber. The second plug has a heater and thermister in it, as well as a vertical hole for a $1 \mathrm{~mm}$ sample capillaries. Thus, the second plug is the sample holder as well as the guard pinhole. Detection is photographic, usiris a screen-intensified polaroid Laue camera. A movable lead strip forms the beam stop. The main virtue of this system is compactness, as it measures less than $1 \mathrm{~m}$ from beam port to camera.

The system easily resolves the scattering from Ludox, a suspension of $70 \AA$ silica spheres in water. Lines down to $160 \AA$ $d$-spacing should be visible. For typical liquid-crystal specimens, exposures of 5-30 min. are required.

\section{Results}

This system was intended for use with lyotropic and thermotropic phases, and has been used for such. For instance, we have measured the d-spacings for several alkylated subars, and shown that the molecular packing is probably bead-head interdigitated, as has been shown for other alkylated sugars. This result is relavant because it contradicts some work by others in which it was stated that the $\mathrm{N}$-alkyl gluconamides were monolayer smectics, unlike all the others, which are bilayers. The $\mathrm{N}$-alkyl gluconamides in their isotropic phases show fairly narrow rings of scattering, centered about the $q$ value for the smectics. We interprel this as being due to remnant smectic order in the isotropic phase.

The :urfactant AOT is known to show hexagonal, cubic, and lamellar phases when mixed with water. A commercial water solut: , of AOT is in the concentration range appropriate for the cubic phase, is optically isotropic as = cubic should be, but is muc: $r$, ?re fluid than a cubic made by adding water to purified AOT. We did SAXS on this preparation and find two diffuse rings $u$ icattering instead of the several sharp ones others have found for cubic surfactant phases. We interpret this phase as being a disordered cubic, the disorder probably coming from impurities such as salts (known to be present) or aydrolysis products.

We see that even as primitive a system as described above is capable of useful diagnostic functions in liquid-crystal physics. Obvious upgrades, such as a position-sensitive detector, should greatly enhance the physics output. 
INTERFACE STRUCTURE OF EPITAXIAL NiSi, ON Si(111)

J. Zegenhagena, K. $-G$. Huang and W.M. Gibson (SUNY Albany), B.D. Hunt (G.E. Schenectady), L.J. Schowalter(RPI Troy)

We invegtigated the interface structure of epitaxial layers of A-type and B-type $N i s i_{2}$ on $S i(111$ ) with $x$-ray standing waves (XSW). The XSW results show that the Ni atoms at the interface are sevenfold coordinated i.e. the si acoms of the silicide bond to the si(111) surface dangling bonds (compare figure la and b). Figure 2 shows the results of XSW measurements on four samples of different thickness.

a) 7-FOLD A-TYPE b) 7-FOLD B-TYPE
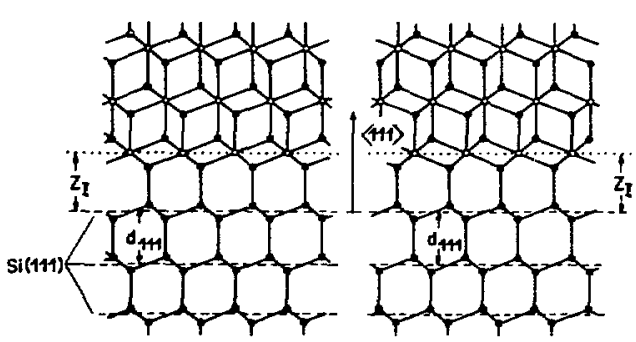

a) 5,8- FOLD B-TYPE

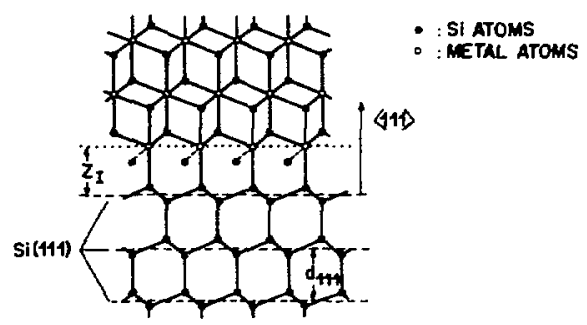

Fig. 1 For A-type(a)Nisi, on $\mathrm{si}(111)$ all cryotal axis align with the substrate whereas the cubic ( $\mathrm{CaF}_{2}-$ structure) epilayer is rotated by $180^{\circ}$ around $\langle 111\rangle$ in case of B-type(b). For Cosi, on Si(111) the co atoms of the epilayers are attached to the $S i(111)$ dangling bonds(c).

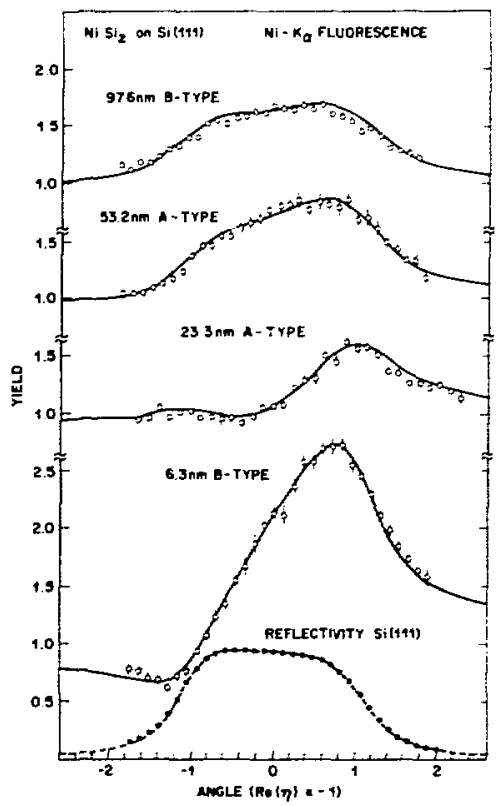

Fig. 2 Experimental results of the XSW measurements for four of the six investigated samples. Dots and circles represent the experimentally determined reflectivity and Co $k_{a}$ fluorescence yield respectively. The solid curves are calculated according to the dynamical theory of $x$-ray diffraction and fitted to the experimental data.

The excellent crystaline quality of the Nisiz epilayers is reflected in coherent fractions which are as high as theoretically expected for perfect overlayers even for the $97.6 \mathrm{~nm}$ thick sample. From our results the interface distance zi (compare figure 1) is deduced together with the amount of interface relaxation $\Delta z_{I}$. Both types of $\mathrm{NiSi}_{2}$ are relaxed inward, the A-type, however, more pronounced than the Btype.

\section{Acknowledgments}

We would like to thank B.M. Kincaid and J.B. Mock for valuable assistance at the AT\&T beamline and J.R. Patel and P.E. Freeland for kindly lending us XSW instrumentation. This work was oupported by the National Science Foundation under grant number DMR 8017 30303 .

a Now at ATET Bell Laboratories 
INTERFACE STRUCTURE AND LATtICE MISMATCh OF EPITAKIAL COSi 2 ON(111)

J. Zegenhagena, K.-G. Huang (SUNY Albany), B.D. Hunt (G.E. Schenectady),

L.J. Schowalter(RPI Troy)

We have used the $\mathrm{X}$-ray standing wave technique and bulk $\mathrm{x}$-ray diffraction to investigate the structural properties of thin Cosi ${ }_{2}$ layers grown epitaxially on si(lll). The perpendicular lateice mismatch with respect to the si substrate was found to be $-0.0152 \pm 0.0003$ and $-0.016 \pm 0.001$ for $6 \mathrm{~nm}$ and $16 \mathrm{~nm}$ thick layers respectively. The distance between $\mathrm{si}(111)$ and the first Co layer was measured to te (0.288 \pm 0.005$)$ nm and is thus stretched by $(0.014 \pm 0.005)$ nm compared with a value determined by silike bond length. The co atoms are attached to the si(111) dangling bonds in agreement with the model of fivefold coordinated metal atoms at the interface.
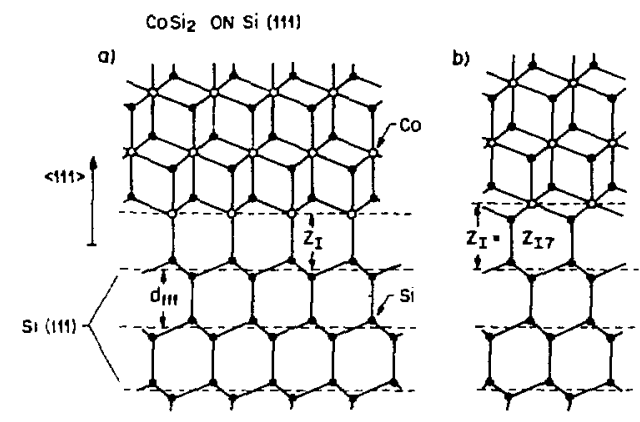

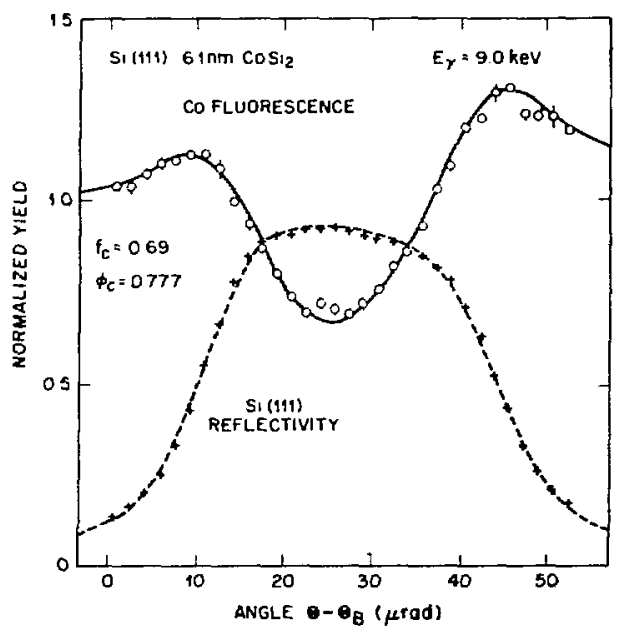

Fig. 2 Results of an XSW scan: + Experimental determined and --Eitted rocking curve, - experiment a 1 determined and fitted co $K$ fluorescence yield. FWHM of the rocking curve is $35 \mu \mathrm{rad}=7.2$ arcaec. The $X-r a y$ energy is EY.

Acknowledgments

We would like to thank B.M. Kincaid and J.B. Mock for valuable assistance at the ATsT beamline and J.R. Patel and P.E. Freeland for kindly lending us XSW instrumentation. K.-G. Huang would like to thank W.M. Gibson for encouragement and his continued interest during this work. This work was supported by the National science Foundation under grant number DMR 801730303.

a Now at AT\&T Bell Laboratories 
J. Zegenhagen, J.R. Patel, B. M. Kincaid, J.A. Golovchenko,a J. B. Mock, P.E. Ereeland and R.J. Malik (AT\&T Bell Labs)

R. - G. Huang (SUNY AIbany)

We used the $x-r a y$ standing wave ( $X S W$ ) technique with synchrotron Radiation to investigate the structure of monolayers of As on si(100). Samples prepared in uHV had been provided with a protective coating of amorphous si because the xsw measurements were performed outside of the UHV environment. The results of the measurements done at the $\mathrm{X}-15 \mathrm{~A}$ AT\& $\mathrm{T}$ Bel1 Labs beamline are in good agreement with the formation of As dimers. The model of As dimers as proposed recently by uhrberg et. a 1.1 is shown in Fig. 1. Each As bonds to two $S i$ atoms and to a neighboring As atom, is thus threefold coordinated and electronically left with a doubly occupied lone-pair state. This model was mainly supported by pseudopotential calculations and angular resolved photoemission. The present $x \mathrm{SW}$ study yields structural information by determining the distance $z_{I}$ between the As overlayer and the ideal si(100) surface (compare Fig. lb). The result of an XSW measurement is shown in Fig. 2 .

$10)$
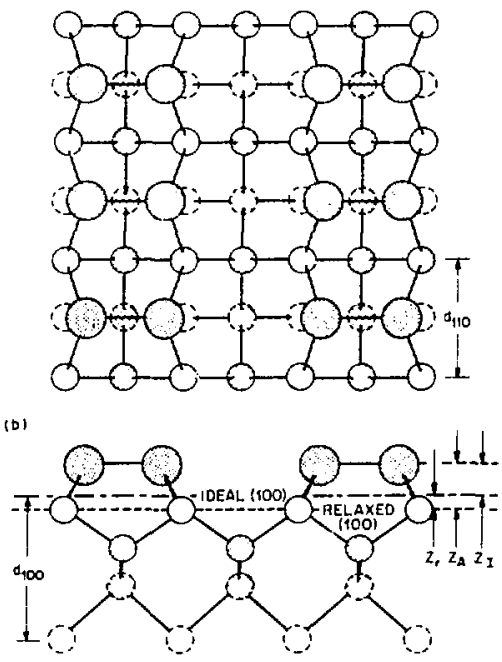

Fig. 1 As dimers on the si(100) surface in top view (a) and side view (b). The size of the $(100), 1 \times 1$ surface unit cell is $d_{110} \times d_{110}$. The size of the $2 \times 1$ surface unit cell of the dimers is $2 d_{110} \times d_{110}$. This simplified model shows only one type of domain of As on $\mathrm{si}(100),\left(d_{100}=a_{\mathrm{Si}}=0.543 \mathrm{~nm}\right.$, $\left.d_{110}=a_{S_{i}} / \sqrt{2}=0.384 \mathrm{~nm}\right)$. The As sat uration coverage is $1 \mathrm{ML}$.

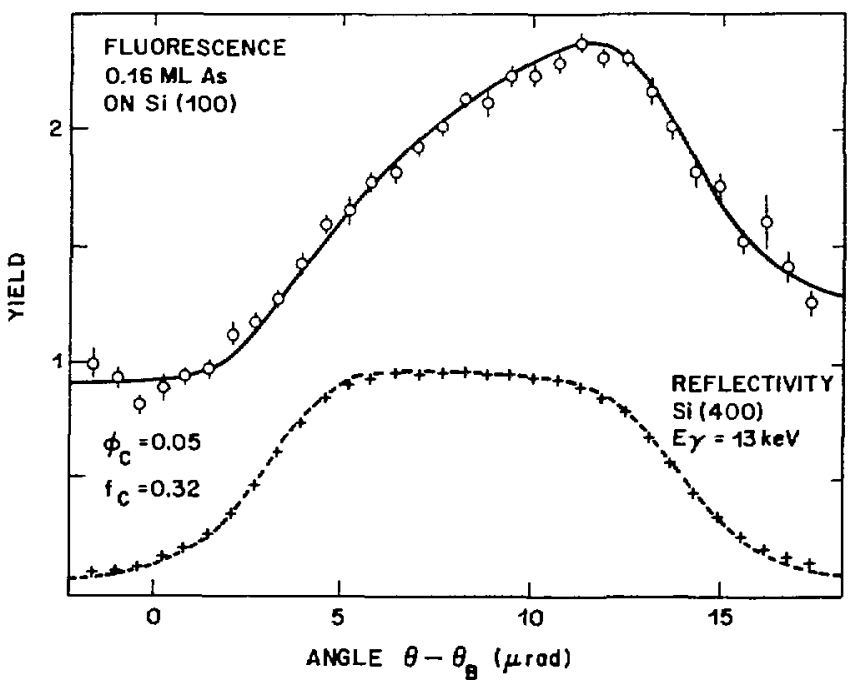

Fig. 2 Result of an XSW on an unprotected Si(100)-As sample. The experimentally determin ed $(+)$ and fitted $(--)$ reflectivity as well as the experimentally determined As $k_{\alpha}$ fluorescence $(0)$ and the fitted fluorescence yield (-) are plotted as a function of Bragg angle.

The distance of the As dimers normal to the ideal ( 100$)$ surface was found to be $(0.126 \pm 0.001) \mathrm{nm}$ which agrees well with the distance $Z_{I}=0.132$ nm deduced from the pseudopotential calculations. Without a protective coating the As position was influenced by the surrounding atmosphere. However, the As phase formed under thesa circumstances appeared to be surprisingly stable.

I R. I.G. Uhrberg, R.D. Bringans, R.Z. Bachrach, J.E. Norethrup, Phys. Rev. Lett. 56, $520(1986)$.

a Now at Harvard University 
A SOFT-HARD X-RAY BEAMLINE FOR PHOTOABSORPTION, PHOTOEMISSION, AND STANDING hAVE MEASUREMENTS IN THE ENERGY RANGE OF $0.5-15 \mathrm{keV}$

A. A. MacDowell, * T. Hashizume,t and P. H. Citrin

A.T.\&T. Bell Laboratories, turray Hill, NJ 07974

A versatile, forused, ultra-high vacuum beamline has been completed this year for performing combined electroric and geometric structural measurements of bulk, Interface, and surface spectes. The basic layout of the design is source $\rightarrow$ collimating premirror $\rightarrow$ monochromator + focusing mirror $\rightarrow$ experiment. A variety of problems inherent with previous designs have been minimized or eliminated and a number of desirable features have been expanded. The table below sumarizes these features.

Feature

1. High energy resolution

2. Wide energy range

3. High beam stability

4. High beam brightness

5. High bean purity

6. t'ltra-high vacuum

7. Variable focus at experiment
Achleved By

- variably bent collimating premirror

- post-monochromator location of focusing mirror

- rapid exchange of several different premounted crystal pairs (involves venting vacuum-isolated, differentially-pumped nonochromator; 30 min. total turnaround time).

- UHV beamline - no Be windows

- <7 mrad incident angle on focusing wirror

- air-cooled rotatable premirror (decreasing heat ioad on first monochromator crystal)

- water-cooled first monochromator srystal, thermally coupled with liquid gallium

- multi-feedback, position-sensitive Io system

- vibrational isolation of mirrors

- inproved, robust, flxed-exit monochroator design

- low surface roughness, excellent figures of Pt-coated electroless N1-on-Al mirrors (cylindrically bent flat " paraboloid; cylindrically bent cylinder * toroid)

- independent, variable vertical focusing of two mirrors

- rellable mirror bending mechanist

- low-pass filter: variable grazing incidence angle on premirror, 0-28 mrad, cutting out higher hamontcs (entire beamline rotates to follow reflected beam)

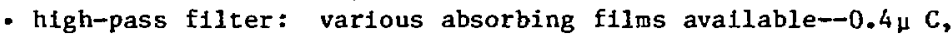
$1.6 \mu \mathrm{C}, 1.6 \mu \mathrm{Al}, 240 \mu \mathrm{Be}$

- differential pumping in long (9m) drift tube ensures true UHV $\left(<10^{-10}\right.$ Torr $)$ in experiment.

- easy to change incidence angle on post-monochromator focussing mirror

- two sequential in-line experimental stations planned, operating in either/or mode

* National Synchrotron Light Source, Brookhaven National Laboratory, Upton, NY 11973

†Institute for Solid State Physics, University of Tokyo, Roppong1, Mfnato-Ku, Tokyo 106, Japan 
P. H. Fuoss, L. J. Norton (AT\&T Bell Laboratorles, Holmde1), and S. Brennan (Stanford Synchrotron Radiation Laboratory)

of fundamental importance in understanding melting of three-dimensional crystals is the simple question: Do surfaces melt at a lower temperature than the bulk equilibrium melting temperature $\left(T_{m}\right)$ ? The presence of surface melting at low temperatures (premelting) has been invoked to explain the lack of supe neating during melting and is consistent with simple intuition regarding vibrations at surfaces. A wide range of theoretical and molecular dynamics simulations have predicted that surfaces do in fact melt below $\mathrm{T}_{\mathrm{T}}$. Experimentally, ion channeling results suggest that the $\mathrm{Pb}(110)$ surface melts at up to $50^{\circ} \mathrm{K}$ below the $\mathrm{Pb}$ melting temperature of $600^{\circ} \mathrm{K}$ and that up to 20 molten layers are present on the surface at temperatures very close to the melting temperature [1] [2]. However, these studies do not yield a direct measurement of liquid correlations on crystalline surfaces and are only indirect evidence for prenelting.

Figure 1 shows radial scans along the (110) azimuth from the $\mathrm{Pb}$ (110) surface for various temperatures. As is clearly seen, a strong diffuse component appears at momentum transfers of $2 \AA^{-1}$ and $4 \AA^{-1}$ as the temperature is increased from $380^{\circ} \mathrm{K}$ to $597^{\circ} \mathrm{K}$. Azimuthal scans (rotation about the surface normal at constant momentum transfer) are shown in the inset and demonstrate that these peaks in the diffuse spectrum are also rotationally diffuse. We emphasize that these are rings in reciprocal space and are not diffuse streaks connecting Bragg points.

Figure 2 shows the integrated intensity of the $2 \AA^{-1}$ peak as a function of temperature. The average scattering intensity from the $(110)$ surface (at $599^{\circ} \mathrm{K}$ ) is $\approx 100$ photons/sec and corresponds to $\approx 3$ layers of liquid on the surface. Figure 2 also shows the integrated intensity from the (111) surface as a

function of temperature. We calculate that there is $<\frac{1}{2}$ monolayer of liquid on the (111) surface at $1^{\circ}$ below $\mathrm{T}_{\mathrm{m}}$.

In sumary, we observe diffuse scattering from liquid layers on the $\mathrm{Pb}(110)$ and (111) surfaces at temperatures substantially below the bulk melting point of $\mathrm{Pb}$. Surprisingly, the initial liquid scattering appears at $\approx 230^{\circ} \mathrm{K}$ or $<\frac{1}{2} \mathrm{~T}_{\mathrm{m}}$ on both the $(110)$ and the (111) surfaces. On the (110) surface, analysis of the scattered intensity ylelds $2-3$ monolayers of liquid from $575^{\circ} \mathrm{K}$ to $599^{\circ} \mathrm{K}$ while substantially less than 1 monolayer of liquid is present on the (111) surface.

We would like to thank $W$. K. Waskiewicz for his extraordinary efforts in commissioning X16A and G. Wright for his assistance.

References

1. J. W. M. Frenken and J. F. van der Veen, Phys. Rev. Lett, 54, 134(1985).

2. J. W. M. Frenken, P. M. J. Maree and J. F. van der Veen, Phys. Rev. B, 34, 7506(1986).
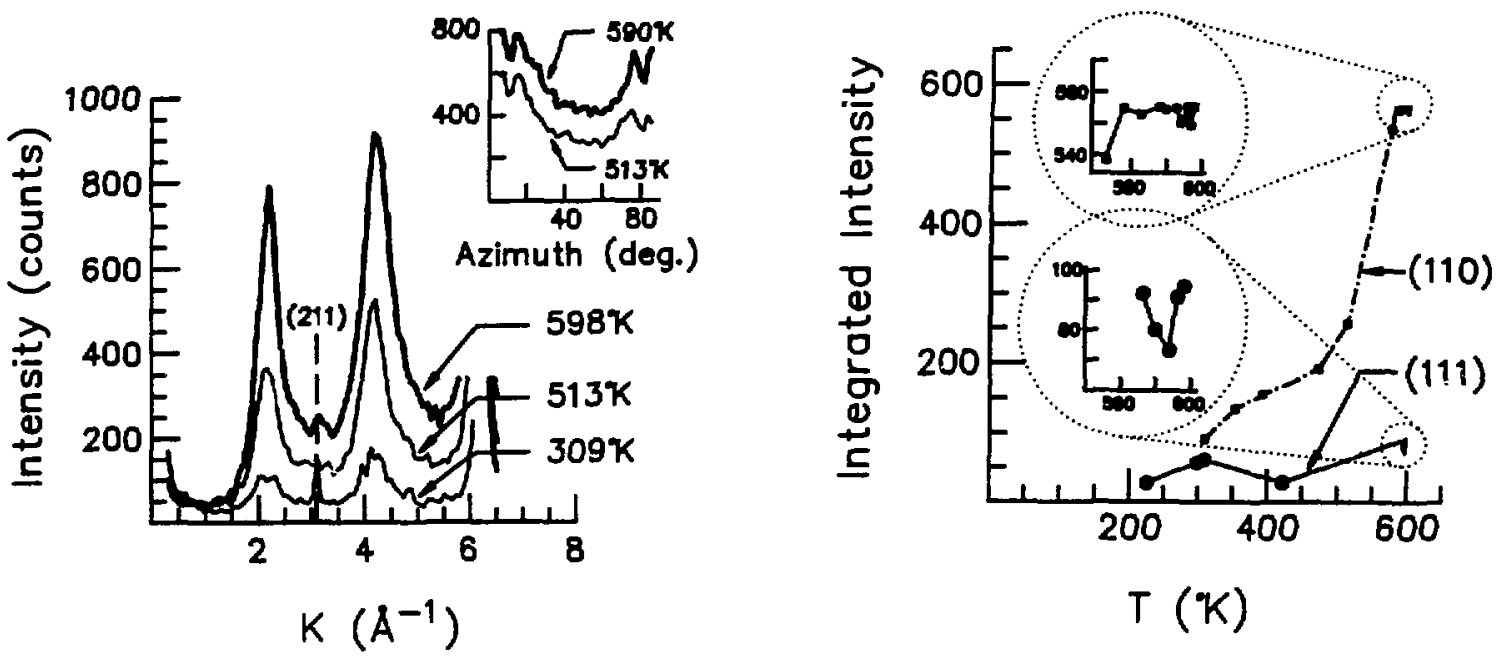
VERTICAL STRUCTURAL INVESTIGATION OF AU(110) $1 \times 2$

I. K. Robinson (ATET Bell Laboratories), R. Feidenhang'l (R18Ø National Lab. Denmark), and $M$. Sauvage (LURE)

There are two reasons for further work on this surface: unresolved questions about the out-of-plane structure, and 1ts interesting temperature dependence. Previous work using a rotating anode source demonstrated a missing row model of the reconstruction but with uniaxial disorder which was found to depend on annealing time and conditions. Roughening 1s also expected to take place on this surface at relatively low temperatures. We did a preliminary investigation of both aspects of the problem, which 18 well sulted to our in-situ UHV systerl.

We observed abrupt ordering of the $1 \times 2$ phase at $200^{\circ}$ and the gradual disappearance of the half-order intensity associated with the phase transition at $400^{\circ} \mathrm{C}$. Under no circumstances of preparation were we able to obtain coherence lengths better than $150 \hat{A}$ in the surface [100] direction corresponding to the disorder.

We measured the perpendicular momentum transfer dependence of the integrated diffraction intensity along several half-order rods. The figure below shows an example. In several cases we observed nodes in the curves and in general there was much more structure along the rods than we expected from a reconstruction involving just the three topmost layers. Furthermore the position of the nodes was found to change slightig with preparation conditions and was always different for the [100] and [100] directions. We know that our sample was miscut in this direction, and that there must be many steps within the coherence length. We expect that the curves can be explained as interference between ordered regions at different heights that arise from the steps.

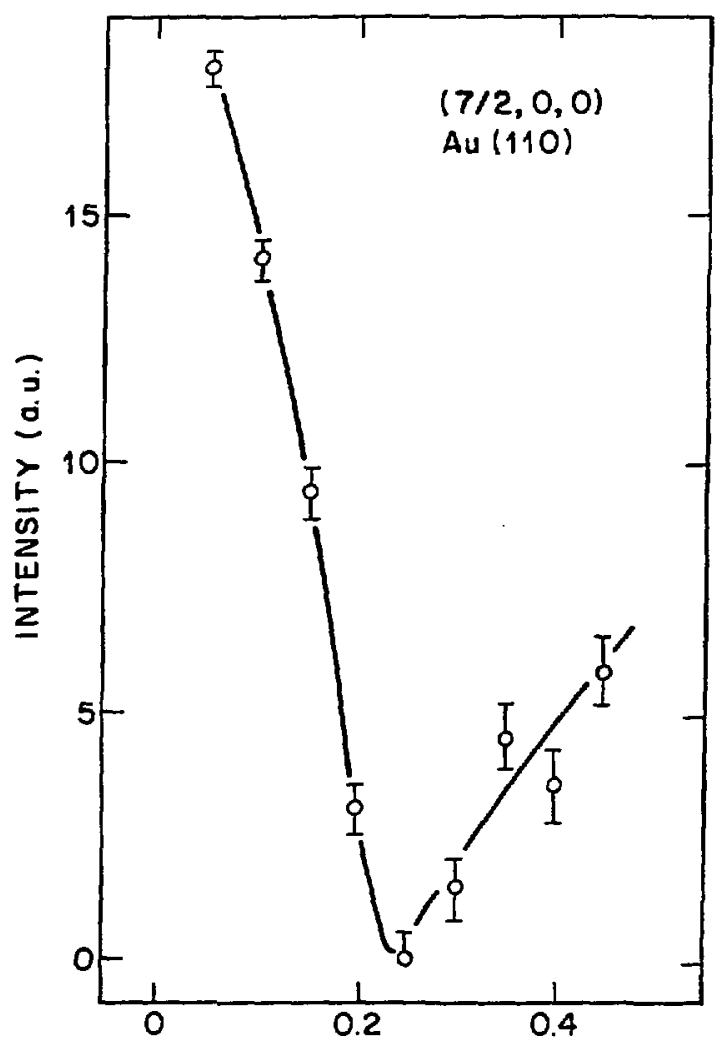

PERP. MTM. TRANSFER (RLU) 
I. K. Robinson, F. Sette, A. A. Macdowell (ATET Bell Laboratories), R. Feidenhans'l. (Risø National Lab. . Denmark)

We sought to 1nvestigate the ordering of fractional monolayers of a strongly bound element upon a simple substrate. We found an oraered $p 2 \times 2$ phase at around $1 / 4$ monolayer $\mathrm{Te}$ coverage which was stable up to about $200^{\circ} \mathrm{C}$. We obtained a surface $x$-ray diffraction signal of $3000 \mathrm{c} / \mathrm{B}$ in the $(1 / 2,1 / 2,0)$ peak and observed 1 ts temperature dependence as shown below. The phase transition 1s broad but has some hysteresis. We belleve the hysteresis to be a problem with the thermocouple.

We measured a full set of 17 surface diffraction intensities along with symmetry equivalents for the annealed p2×2 state at room temperaturo. Wo expected a trivial structure with one atom per unit cell. This would have a diffraction pattern with all intensities equal, except for smooth form- and Debyo-waller-factor effects, To our surprise we found a systematic pattern with half orders stronger than integer orders stronger than truncation rods. The indexing was the same as for bulk cu. The suppression of the truncation rods was expected because To 18 approximately twice as heavy $38 \mathrm{Cu}$. but the other difference was not. Subsequent analysis has shown that this is due to disorder in the overlayer, which glves rise to partial (20\%) occupation of secondary sites in the p2x2 unit cell. It 18 expected that this will correlate with the linewldths of the peaks whlch 1ndicate a doma1n-wall disorder.

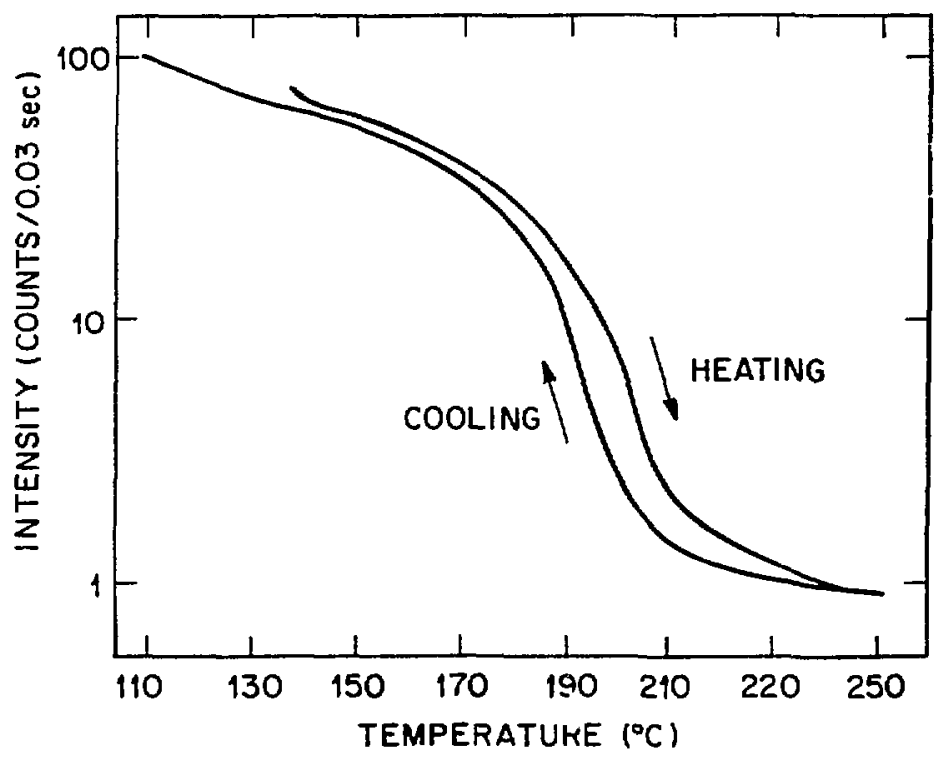


I. K. Robinson, W. K. Waskiewicz, P. H. Fuoss, and L. J. Norton (AT\&T Bell Laborator1es)

This was the first experiment performed on $X 16 \mathrm{~A}$ and so was intended as a benchmark of surface $x$-ray diffraction. We had run $51(111) 7 \times 7$ at SSRL and so could make a performance comparison.

X16A is customised for diffraction experiments in UHV. It has a toroldal quartz. Pt coated mirror which accepts 3.5 mrad of 11 ght at 5.67 mrad 1nc1dence angle. This $1 \mathrm{~s}$ monoch-omated by a double crystal si(111) monochromator bu1lt by Princeton Research Instruments. A UHV Bystem sits inside the nutch at the focal point. The sample 15 prepared by standard methods (here sputtering and annealing) and then transferred onto the centre of the 4 axes of an external Huber diffractometer which couples to the UHV system by bellow and rotary seal. A scintiliation detector sits behind the resolution-defining alit on the $2 \theta$ arm.

Intensity data were collected by $w$-scans of which a typical result 18 shown top left in the figure. The sample 18 inclined using the $x$-motion until the incident and diffracted beam Here around $0.5^{\circ}$ to the surface. By staying above the critical angle for total reflection, we avold refraction complications but can still take advantage of the improved signal to background and favourable resolution function of the grazing incldence geometry. We used a $2 \times 10 \mathrm{~mm}$ detector slit at 0.5 m which accepts a $1^{\circ}$ range of exit angles. Because of the smaller beam size we 1lluminated a quarter of the sample area compared with the equivalent setup at SSRL. yet we obta1ned $70 \%$ of the signal rate obtained on the wiggler beamilne VII-2 end station there.

\begin{tabular}{l|cc} 
Measurement on S1(111) $7 \times 7$ & SSRL & NSLS \\
VII-2 & X16A \\
\hline$(1,0,0.06)$ truncation rod & $1280 \mathrm{c} / \mathrm{s}$ & $733 \mathrm{c} / \mathrm{s}$ \\
$(1,3 / 7,0.12)$ surface peak & $218 \mathrm{c} / \mathrm{s}$ & $167 \mathrm{c} / \mathrm{s}$
\end{tabular}

The intensities of at least three symetry equivalents of each surface peak were measured and averaged together to obta1n error bars. The reproduc1b1l1ty of the data was $15 \%$ in intensity for strong reflection and greater (because of statistics) for weak ones; a compound error was thus derlved. The measured data are shown as the areas of the left half circles in the figuro. Tho right half circles were calculated for a model derived from that of Takayanagl after refinement of all the atomic coordinates. The result shows the presence of strain fields in the surface.

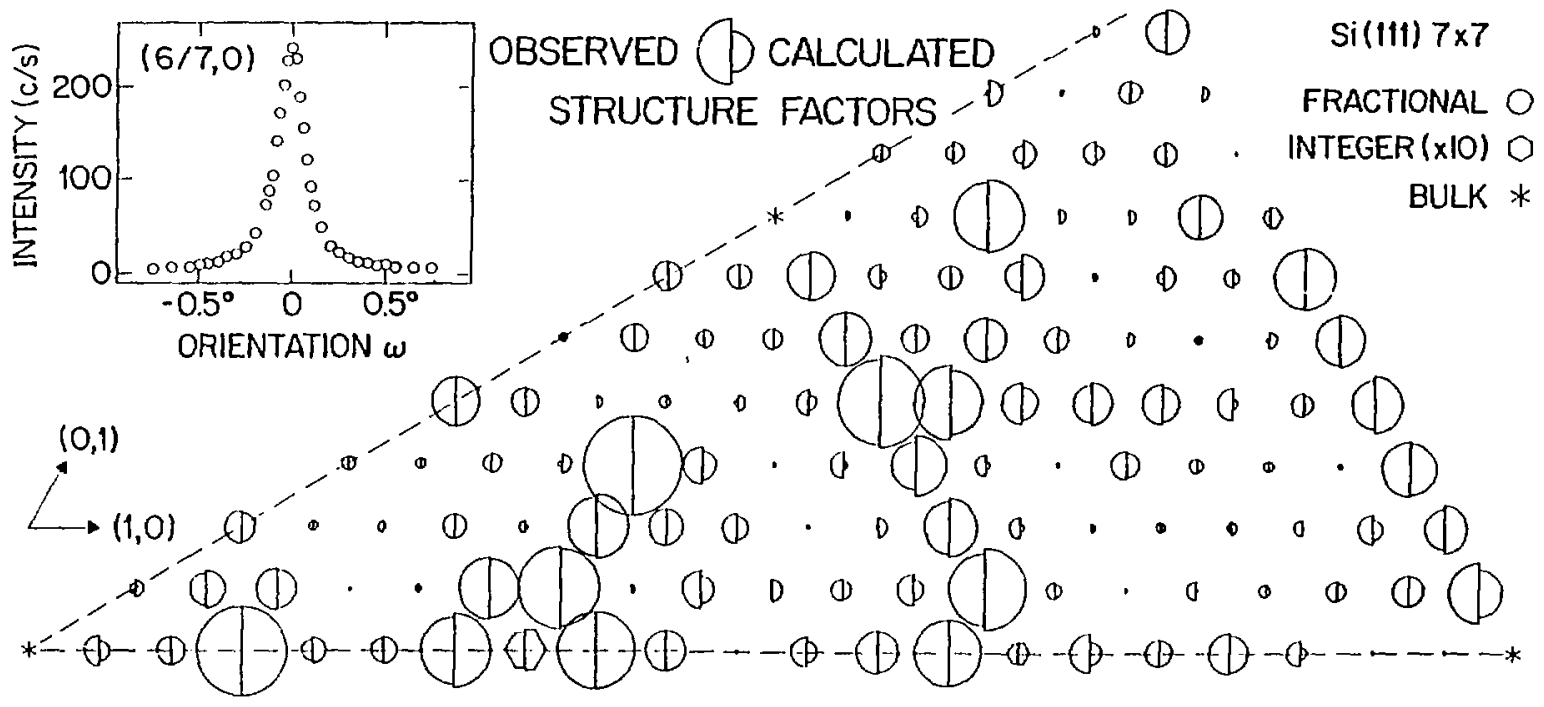


D. R. Harshman and D. B. McWhan (AT\&T Bell Labs) and D. Gibbs (BNL, Upton)

On beamline X16B the degree of circular polarization can be changed by translating the premonochromator slit normal to the plane of the synchrotron. The components of the linear polarization of the scattered beam are measured using an analyzer crystal with a scattering angle, two-theta, of 90 degrees. The $x$-ray energy was chosen so that two-theta for the graphite (006) was 90 degrees. A polarization analyzer has been built in which the graphite crystal can be rocked in both directions under stepping motor control and also rotated around the scattered beam. In this way integrated intensities for the two components of polardzation can be measured. The efficiency of the polarization analyzer is illustrated in fig. 1. This shows the intensity as a function of the angle of rotation of the analyzer.

The polarization of the $x$-ray beam from a bending magnet is strictly linear in the plane of the electron orbit and becomes increasingly right or left elliptically polarized above or below the plane. The degree of linear polarization, defined as ( (perp.)-I(parallel))/(I (perp.)+I(parallel)), versus the vertical displacement of the premonochromator slit on X16B are shown in $\mathrm{fig}$. 2 . The measurements were made on the (200) reflection from an iron film, and the component of polarization parallel to the scattering plane was corrected for the $\cos ^{2}(20)$ dependence of charge scattering. Similar measurements have been made at DESY (1) and LURE (2) with comparable results.

In magnetic $x$-ray scattering, the orbital and spin densities of a magnetically ordered materlal can be separated from an analysis of the polarization of the scattered beam $(3,4)$. For a simple basal plane spiral antiferromagnet the separation can be made using a Inearly polarized Incident beam. For a basal plane ferromagnet, it is necessary to compare the flipping ratios for both right and left circularly polarized incident beams (2). We have made preliminary measurements on the antiferromagnetic spiral structure of holmium metal. With an incident flux of $2 \times 10^{10}$ photons/sec on the sample the tntensity of the $(004)+$ pure magnetic peak was 400 counts/second before polarization analysis and $\sim^{4}$ and 220 counts/second after scattering from the analyzer in the directions perpendicular and parallel to the scattering plane respectively. These results show that polarization analysis of magnetic scattering is feasible on a bending magnetic source.

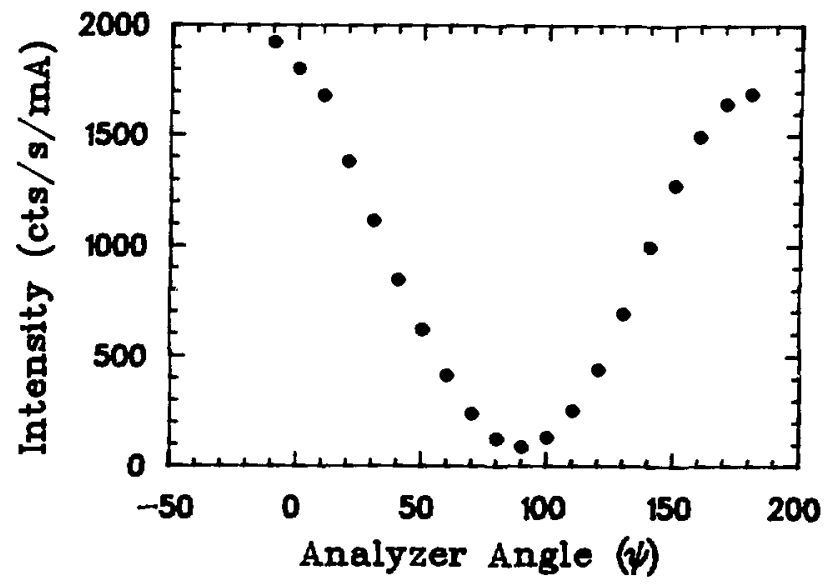

Fig. I Intensicy vs analyzer angle for the polarization analyzer with $0^{\circ}$ corresponding to polarization perpendicular to the scattering plane and $90^{\circ}$ in the scattering plane.

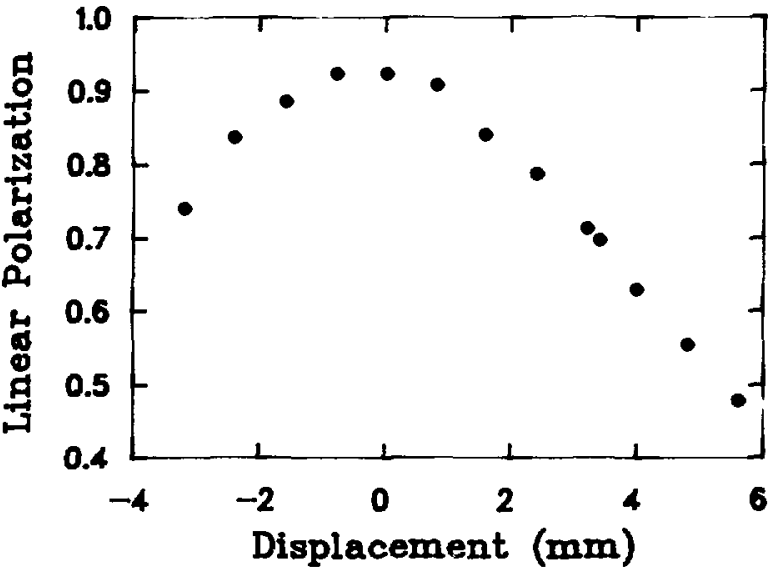

Fig. 2 Degree of IInear polarization vs vertical displacement from the orbit on $\mathrm{X} 16 \mathrm{~B}$.

References

1) G. Materlik and P. Sourtt1, DESY SR 83-13

2) M. Brune1, G. Patrat, F. deBergevin, F. Rousseaux and M. Lemonnier, Acta Cryst. A39, 84 (1983)

3) M. Blume, J. Appl. Phys, 57, 3615

4. M. Blume and D. Gibbs, Phys. Rev. B (1n press) 
S. G. J. MOCHRIE (AT\&T Bell Laboratories)

The simplest interface one can conceive is an atomically smooth facet, separating a crystalline element from its vapor. However, a recurrent idea of the last thirty years is that of a surface roughening transition ${ }^{1}$, which may occur at a much lower temperature than bulk melting. Below the roughentng temperature $\left(T_{R}\right)$, the interface corresponds to the ideal, but for $T>T_{R}$, its behavior is determined by surface stiffness. There have been few experimental studies of the microscopic aspects of interfactal roughening.

Here, I report the results of an $x$-ray diffraction study of the (110) face of copper, between $200^{\circ} C$ and $700^{\circ} \mathrm{C}$. A longer report of this work has previously appeared. 2 From the $\mathrm{T}$ dependence of the Bragg reflectivity, $T_{R} \simeq 600^{\circ} \mathrm{C}$ is deduced. This provides the first direct observation of a roughening transition of a low-index face of a metal crystal. The choice of copper was motivated in part by studies of the equilibrium crystal shape (ECS) of $5 \mu$ metal crystals 3,4 , close to their melting temperatures. Specifically, it is known that the (110) face of copper is absent from the ECS immediately below its melting temperature $\left(\mathrm{T}_{\mathrm{m}}=1083^{\circ} \mathrm{C}\right)^{4}$, implying that this facet has already roughened. In addition, He diffraction measurements of Lapoujoulade et al. suggest that the (113), (115) and (117) faces undergo roughening transitions. 5 One advantage of x-ray diffraction is that behavior on length scales between $1 \mathrm{~A}$ and $1 \mathrm{~km}$ is accessible.

These measurements were performed on X16B, using a $\mathrm{Ce}$ (111) monochromator, bent to focus 2 mrad. of synchrotron radiation into a spot $0.5 \mathrm{~mm} \times 5 \mathrm{~mm}$ at the sample position. A high resolution configuration utilized a Ge (111) analyzing crystal. The sample was cut to expose the (110) face and then Syton polished. Fig. 1 shows profiles at several temperatures near $(001)$. For an f.c.c. structure there is no Bragg peak at (001). These data correspond to scans transverse to the reflectivity which extends between the (11i) and the (111) Bragg peaks. ${ }^{6}$ The (001) position is particularly sensitive to surface roughness, because successive planes scatter out of phase. Importantly, the profiles are close to the resolution limit, with a FWHM of $0.0008 \AA^{-1}$, implying that the surface is well-defined over lengths of $>0.5 \mu \mathrm{m}$. Also, there is no increase in width with increasing temperature. However, diffuse scattering away from the Bragg reflectivity cannot be ruled out. The behavior is quite reversible - the intensity remains nearly constant betwe i $\mathrm{T}=200^{\circ} \mathrm{C}$ and $\mathrm{T}=350^{\circ} \mathrm{C}$, but decreases upon further heating. By nearly $T=600^{\circ} \mathrm{C}$, the inter ty has fallen to zero - much more rapidly than can be accounted for by a simple Debye-Waller factor. At this temperature, there are numerous atomic steps on the (110) facet. This is precisely the requirement for a roughening transition. Thus, I tentatively identify $T_{R} \simeq 600^{\circ} \mathrm{C}$. Strictly, this is a lower bound on $T_{R}$.

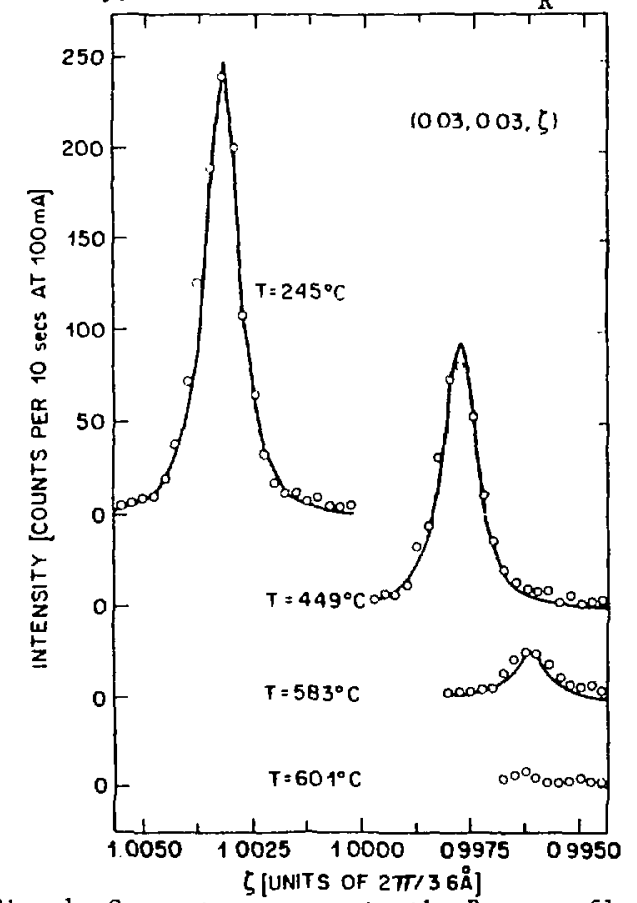

\section{References}

1. J. D. Weeks, p. 293 in Ordering in Strong1y Fluctuating Condensed Matter Systems, Plenum, New York $(1980)$.

2. S. G. J. Mochrie, Phys. Rev. Lett. 59, 304 (1987).

3. J. C. Heyraud and J. J. Metois, Acta. Met. 28, $1789(1980)$

4. K. D. Stock and E. Menzel, Surf. Sci, 61, 272 (1976).

5. J. Villain, D. R. Grempel and J. Lapoujoulade, J. Phys. F 15,809 (1985)

6. D. A. Bruce, J. Phys, c14, 5195 (1981).

I thank $B$. Larson and $J$. Budal for the sample and $B$. Flood for preparing it. G. Wright provided excellent technical assistance. I have enjoyed discussions of this work with D. Gibbs, D. McWhan, and I. Robinson. I am grateful to everyone involved in the development of the AT\&T beam lines, especially D. McWhan and $B$. Buntschuh for their collaboration on $X 16 B$.

Fig. 1 Scans transverse to the Bragg reflectivity at (001). The solid lines are all the same shape. The change in peak position is a result of thermal expansion. 
F. S. Bates, H. D. Keith, and D. B. McWhan (AT\&T Bell Labs)

The isomorphous monoclinic-(011) forms of "normal" (hydrogenated) and perdeuterated hexatriacontanes $\left(\mathrm{n}-\mathrm{C}_{36} \mathrm{H}_{74}\right.$ and $\left.\mathrm{n}-\mathrm{C}_{36} \mathrm{D}_{74}\right)$ have been examined by $\mathrm{x}$-ray diffraction at room temperature. Substitution of deuterlum for hydrogen results in slight reduction in the parameters $a_{s}=a$ sin $B$ and $b$ of the orthorhombic subcell by $0.33 \pm 0.02 \%$ and $0.19 \pm 0.02 \%$ respectively (within experimental error the $c$ parameter appears to be unaffected). This reduction in cross sectional area of the unit cell as seen in pro$j e c t i o n$ along the chain axis is primarily a consequence of $C-D$ bonds being slightly shorter than $C-H$ bonds. Based upon the change in molecular volume, and an associated change in molecular polarizabil1ty, a relationship is proposed to account for the difference in melting temperatures of normal and perdeuterated hexatriacontane. This relationship also predicts successfully corresponding differences in melting temperature occasloned by perdeuteration of polyethylene and isotactic polystyrene, but fails to do so in the case of 1sotactic polypropy?:a. We speculate that, in the latter case, isotope substitution influences rotational degrees of freedom of pendant methyl groups, leading to an isotope dependent entropy of melting not experienced in the other species cited. 


\section{IIOT PIIONONS IN QUARTZ}

\section{D. Chapman (NSLS), S. N. Ehrlich (Purdue University) and N. M. Lazarz (NSLS)}

We have performed a time-resolved $x$-ray diffraction study of non-equilibrium phonons in $\alpha$-quartz at low temperatures where the phonon generation mechanism is direct stimulation of TO phonons by infrared light excitation using a powerful $\mathrm{CO}_{2}$ laser. For the initial phonon generation we have used the fact that the intense $10.6 \mu \mathrm{m} \mathrm{CO}_{2}$ laser line very nearly matches the TO phonon induced infrared absorption in $\alpha$-quartz near $9.38 \mu \mathrm{m}$. The lifetime broadening of this TO mode excitation is so large that there is significant population of this mode even though there is a frequency mismatch. While there is no hope of observing the lifetimes $(t \sim 1$ fs $)$ of the optical phonons, we performed the experiment in a time-resolved manner in order to distinguish the resulting LA and TA modes arising from the initial laser pulse as these phonons propagate through the sample. This also allowed us to measure the steady state thermal diffuse scattering since scattering was measured prior to the firing of the laser.

The experimental setup is shown in Fig. 1. The sample material was synthetic quartz whose orientation was determined by Laue photographs. The $x$-rays used in this experiment were synchrotron radiation monochromatized to an energy of $15.08 \mathrm{KeV}$. The $x$-ray beam which struck the sample was about $0.5 \mathrm{~mm}$ high $\times 2 \mathrm{~mm}$ wide. The sample was mounted in a CTI refrigerator which was then mounted on the $\chi$ ring of a four circle Huber diffractometer. The $\mathrm{CO}_{2}$ laser was $Q$ switched by a mechanical chopper at a frequency of $10,000 \mathrm{~Hz}$, with a pulse width of $200 \mathrm{nsec}$ and a peak power of $10 \mathrm{KW}$.

A timing signal was derived from the laser pulse by collecting the outer ring from the laser TEM 01 mode onto a photon drag detector. This signal, which was delayed by $\sim 1 \mu \mathrm{sec}$ from the detector's output, was used to start 1 , time-resolving data acquisition system. The $x$-rays scattered by the sample were collected by a Harshaw NaI(TI) scintillation detector. The output of the scintillation detector was delayed by $4 \mu \sec$ to ensure that $x$-rays which were scattered by the sample before and during the laser pulse could be collected by the time-resolving module.

Typical experimental results are shown in Fig. 2. This figure shows the diffuse scattering at (0.0.1.9), near the Brillouin zone center. The x-rays strike a region of the sample approximately $2.0 \mathrm{~mm}$ from the top, where the laser impinges. The diffuse scattering has been normalized for monitor counts and laser pulses. The baseline approximates the thermal diffuse scattering with no laser striking the sample.

The laser pulse is indicated striking the sample at $t=0$. Shown are the calculated arrival times of (0)i) propagating TA and LA phonons at a point $2.0 \mathrm{~mm}$ from the top of the sample after being generated, presumably, by TO phonons created by the lasez at the top of the sample. Arrival times for phonons reflecting off the bottom of the sample are included. In this range of phonon wavevectors, the $x$-ray diffuse scattering will be sensitive to the nearly stationary optical phonons and the acoustic phonons propagating with the acoustic sound velocity.

There is consistently a peak at the time corresponding to the firing of the laser. This confirms the existence of non-equilibrium (hot) phonons in the quartz. The fact that they are non-equilibrium and not thermal was confirmed in another experiment. ${ }^{1}$ The first peak in the diffuse scattering data is consistent with the arrival times of acoustic phonons generated at or near the surface. Other peaks in the diffuse scattering data occurring somewhat later $(>2 \mu \mathrm{sec})$ do not seem to match transits of the acoustic phonons. These peaks could be due to the slowly propagating optic modes.

1) L. D. Chapman, S. M. Hsieh and R. Colella, Phys. Rev. B 30, 1094 (1984).

Research performed at MATRIX beamline X-18A and supported by DOE contracts DE-FG02-85ER45183 and DE-AC02-76CH00016.

Figure 1

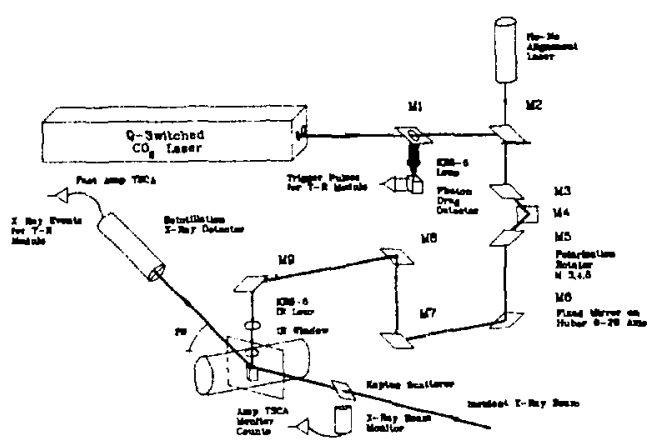

Figure 2

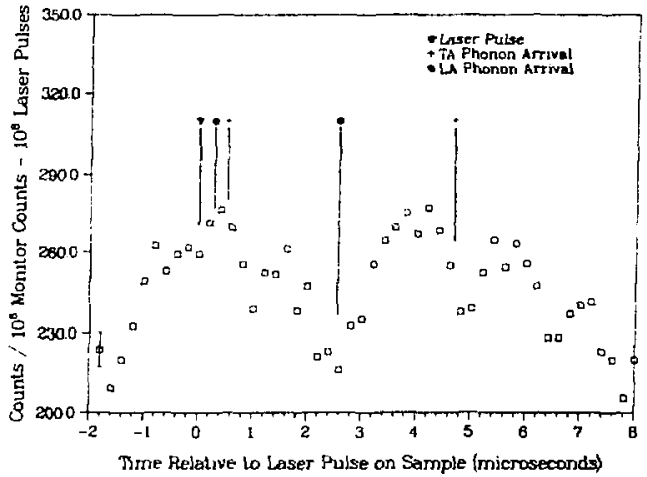


STRUCTURE AND PHASE TRANSITIONS OF HEXANE MONOLAYERS ADSORBED ON GRAPHITE

J.R. Dennison, S.-K. Wang, J.C. Hewtın, H. Taub, E. Conrad (U. of MO-Columbia), and H. Shechter (Technion, Israel)

Hexane monolayers adsorbed on a graphite basal plane surface exhibit interesting structures and phase transitions which we have been investigating by synchrotron $x$ ray diffraction. Our attention was drawn to this system by neutron scattering experiments at the University of Missouri Research Reactor which indicated unusual melting behavior of the commensurate monolayer to a highly-correlated fluid phase. The rod-like shape of the hexane molecule suggested to us that the monolayer fluid might be a liquid crystal.

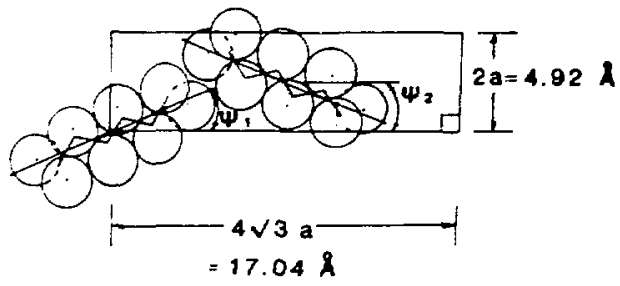

Fig. 1. Projection on the graphite (0001) surface of the unit cell for the commensurate monolayer phase of $\mathrm{C}_{6} \mathrm{D}_{14}$.

From our neutron and $x$ ray experiments, we infer the commensurate $(2 \times 4 \sqrt{3})$ herringbone structure shown in Fig. 1 for a complete monolayer of deuterated hexane $\left(C_{6} D_{14}\right)$ adsorbed on exfoliated graphite at $10 \mathrm{~K}$. The herringbone arrangement is similar to that found for other nonspherical molecules on the graphite (0001) surface.

In $z$ series of measurements at the MATRIX beam line $(x 18 \mathrm{~A})$ in December, 1986, we observed the temperature dependence of the $x$ ray diffraction patterns from a 1.5 -layer hexane sample shown in Fig. 2. The patterns at $5 \mathrm{~K}$ and $130 \mathrm{~K}$ can be explained by the coexistence of a complete commensurate monolayer with bulk hexane. The asymmetric peaks marked (!1) have the characteristic Warren lineshape expected for a polycrystalline monolayer. The broader, symmetric peaks marked (B) are at the positions predicter for the bulk solid, while the peak labeled (?) appears to be an artifact of imperfect background subtraction.

The bulk diffraction peaks in Fig. 2 disappear by $175 \mathrm{~K}$, i.e., below the melting point of bulk hexane at $178 \mathrm{~K}$. We are tentatively interpreting this behavior as evidence of a layering transition in which a second layer of film (possibly fluid or amorphous) forms at the expense of bulk. Above $175 \mathrm{~K}$, the Bragg peaks of the commensurate monolayer begin to broaden, disappearing near $190 \mathrm{~K}$. It $1 \mathrm{~s}$ quite unusual for the melting point of a physisorbed film to exceed tiat of bulk. In the case of hexane, we attribute it to steric hindrance of the rod-shaped molecule to rotational motion about a surface normal. A broad peak remains in the diffraction patterns above $190 \mathrm{~K}$, although it appears weaker than in the neutron experiments. Whether this results from a liquid-crystal-like phase will require further measurements of the peak lineshape as a function of temperatise. In conjunction with these experiments, molecular dynamics simulations of the melting of hexane monolayers on graphite are now in progress by $F . Y$. Hansen at The Technical University of Denmark.

IJ.C. Newton, J.R. Dennison, S. -K. Wang, R. Wang, H. Taub, E. Conrad, and H. Shechter, Bull. Am. Phys. Soc. 32, $467(1987)$.

2H. Taub, in The Tize Domain in Surface and Structural Dynamics, NATO ASI Series, edited by G.J. Long and $F$. Grand jear (Reidel, Dordricht, 1983).

This work was supported by NSF Grants DMR-8304366 and DHR-8704938, Israel-U.S. Binational Science Foundation Grants No. 2687 and 86-00294, and the MATRIX PRT by DOE Grant No. DE-FG02-85ER45183. 
SOLUTION OF THE PHASE PROBLEM IN CRYSTALLOGRAPHY BY MULTIPLE BRAGG SCATtERING. Q. Shen and R. Colella (Purdue L.). - Multi-beam diffraction, in conjunction with the notion of Virtual Bragg Scattering (VBS), has been proved to be a feasible method for determining phases of structure factors in diffraction txperiments. A VBS situation is one in which a weak "main" reflection (hkl) is fully excited, and another simultaneous strong reflection (HKL) is weakly excited by a suitable choice of the azimuthal angle $;$ around the scattering vertur $\vec{G}_{\text {hkl }}$. The asymetric pattern obtained as the crystal is rotated around $\vec{G}_{h k l}$ is used to extract phase information. While encouraging results were obtained on perfect (Ge, $\mathrm{Si}$ ) and mosaic inorganic crystals $\left(\mathrm{V}_{3} \mathrm{Si}\right.$ ), some problems and limitations of the method were encountered with molecular crystals, because their reciprocal space is densely populated, and their nodes (Bragg reflections) have very small sizes on account of the small values of the structure factors involved. We report here on a recent experiment performed at NSLS (Brookhaven National Laboratory) that successfully revealed the phase related asymmetry effect on the (202) reflection of a large, parallel sided, organic crystal (benzil: $\mathrm{C}_{14} \mathrm{H}_{10} \mathrm{O}_{2}$ ), by utilizing $3.5 \mathrm{keV}$ soft x-ray radiation. A multi-beam calculation with mosaic spread included shows good agreement with the experimental data. Further analysis indicates that it is possible to extract arbitrary values of the phase angle from an experiment, for a noncentrosymmetric crystal, by using an analytical formula derived from a perturbation theory of the asymmetry effects. The same experiment was repeated at SSRL using a small quasi spherical crystal (diameter $\simeq 0.3 \mathrm{~mm}$ ) and the same result was obtained. It is now clear that our method, based on the notion of Virtual Bragg Scattering, can be applied to any kind of crystal with arbitrary shape. This work was supported by NSF. 


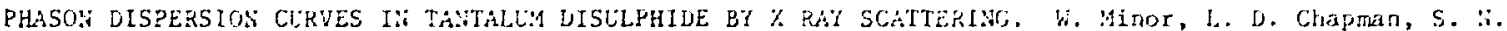
Ehrlicin and K. Colelia (Piysics Department, Purdue liniv.). -The thermal difeuse x-ray scattering in the neighborhnod of first order satellites has been measured with high resolution in 1.T. Tas; (incammensurate phase), using synchrotron x-rays at asLS $\left(j=0.711\right.$ h). A total of about $24000^{\circ}$ points in $j-5 p a c e$ have been measured at 363 and $423 K$ in small "boxes" surrounding twr, first arder satellites, onse close to (010) and the other one close to (030). Our analysis shows that Phason Diffuse Scattering (PDS) falls off like $q^{-2}$, and that the iso-diffusion surfaces surrounding a satellite reflection are ellipsoids, reflecting the anisotropy of pDS as predicted by theor;'. For a satellite whose projection on the bko plane is located along the $\vec{b}^{*}$ axis, the largest ellipsoidal axis is parallel to $\vec{c}^{*}$, and the shortest one is parallel to $\vec{b}^{*}$. The ratios of the three axes are 2.5 , 1.8 , 1 . absolute measurements of the scattered intensity have led to a quantitative determination of the pinason velocities (v, $s$ ) in various directions. The value of $\mathrm{v}_{;}$along $\mathrm{b}^{*}$ is about 1.3 , $10^{\mathrm{5}} \mathrm{cm} / \mathrm{sec}$, while along ctice velocity $v_{\text {; }}$ is about $1 / 3$ smaler $\left(4.7 \times 10^{\circ} \mathrm{cz} / \mathrm{sec}\right)$. As the temperature is increased from $363 \mathrm{to} 423 \mathrm{k}$, the velocity along $\vec{b}^{*}$ is essentially unchanged, but along $\vec{c}$ the value of $v$ is decreased by $13 \%$ approxinatel\%. This work is one of tie first examples of a fully deternined phason spertrum. This work was supported by MRL-YSF.

2. H. Overhauser. Pays. [ev. 83, 3173 (1971). 
P. Zschack, J.B. Cohen, and Y.W. Chung

MATRIX ard the Department of Materials Science \& Engineering

Northwestern University

Evanston, II

Introduction

The catalytic and chemisorption properties of metal catalysts supported on oxides such as $\mathrm{TiO}_{2}$ are to some extent affected by the nature and properties of the

substrate. ${ }^{2}$ Such is the behavior of the so called strong metal-support interaction, SMSI. The clean, ordered (100) surface of rutile $\mathrm{TiO}_{2}$ is known to reconstruct to form a $1 \times 3$, 1X5, or $1 \times 7$ LEED image, determined by the annealing temperature. The aim of this investigation is to locate the atomic coordinates of the $1 \times 3$ surface by using the glancing angle diffraction (GAD) technique. Additionally, complementary LEED data, taken at normal incidence, is collected from the same surface.

\section{Experimental Description}

The experiment was performed at beamline $\mathrm{X}-18 \mathrm{~A}$, operated by the MATRIX PRT, and used a transportable, ultra-high vacuum (UHV) chamber developed for surface and interfacial diffraction studies. This chamber mounts directly to a Huber 4-circle diffractometer, and permits glancing angle incidence through a $0.015^{\prime \prime}$ thick cylindrical Be window. In-situ preparation of the surface of interest is possible since a transfer cell is not used, and vacuum integrity can be maintained throughout the experiment. The preparation features prgvided include $\mathrm{Ar}^{+}$ion sputter cleaning, and annealing to temperatures in excess of $600 \mathrm{c}$. And diagnostic capabilities include retarding field Auger electron spectroscopy, as well as pulse counting LEED. The pulse counting IEED allows for quantitative data collection by storing LEED images in computer memory. A series of images is collected, and can be used to obtain comparisons with theoretical calculations for one or more LEED peaks. SO, IEED and GAD data are collected from the same structure.

\section{Results}

It has been verified that the surface diffraction chamber can be used successfully for GAD and LEED data collection from the same $1 \times 3$ surface reconstruction. In this study, 20 unique surface reflections were measured with GAD. Figure 1 shows the results of several scans of one such surface peak, taken over a period of several days.

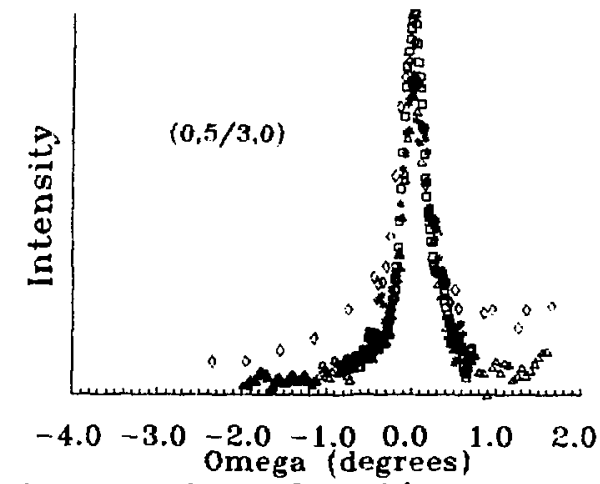

Figure 1: Several rocking curve scans of a surface peak.

The stability of the surface is seen to be good, and the peak intensity reliably reproducible. While at this time no conclusions can be stated with regard to the structural determination, analysis of the $x$-ray and LEED data is not complete. It is anticipated that upon completion of analysis and refinement, a structural determination will result.

This work was supported, through the MATRIX PRT, by the U.S. DOE under grant No. DE-FG02-85-ER45183. 

Ithaca, New York 14853

The preparation and characterization of well defined microstructures on electrode surfaces are areas of active research since such engineered strctures have been shown to exhibit novel and interesting properties.[I] A particularly exciting possibility would be the preparation of films that are ordered down to molecular or atomic dimensions since this would allow the development of molecularly organized devices. Given that electropolymerization of of transition metal complexes contairing vinyl-substituted ligands [2] (e.g. vinyl-bipyridine and related materials) is a very versatile lechnique for the depositio!, of very thin films of electrochemically active polymers, we have investigated the possibility of employing such a technique for the deposition of molecularly thin and ordered polymeric films of the monomer complexes. In order to ascenain the degree of order of such deposited films, we have employed the $x$-ray standing wave technique (XSW) since it represents an extremely sensitive tool for determining the pasition of impurity atoms within a crystal or adsorbed onto crystal surfaces.[3] One of the problems associated with the implementation of the standing wave technique is that it requires the use of perfect or nearly perfect crystals. An altemative is the use of synthetic layered microstructures (LSM) and we recently reported a study on th use of LSM in the investigation of electrochemical interfaces.[4] We r.ow present some preliminary results on the deposition of molecularly ordered films of $\left[R u(v-b p y)_{3}\right]^{+2}$ on a tungsten carbon LSM.

$\left[R u(v-b p y)_{3}\right]^{+2}$ was prepared and electropolymerized, as previously described,[3] on a W/C LSM (Energy Conversion Devices) employed as an electrode and consisting of 200 layer pairs ef tungsten and carbon of 6 and $24 \AA$ thick each, respectively and with tungsten as the outermost layer. Integration of the area under the voltammetric wave gave a coverage of about 5 monolayers. After deposition, the electrode (LSM) was rinsed with acetone and mounted on a Huber model 410 goniometer stage providing better than 10 microradian angular resolution. All experiments were performed at the $X-18 B$ beam line of the National Synchrotron Light Source at Brookhaven National Laboratory. Monochromatic radiation at $22.5 \mathrm{keV}$ was obtained with a Si(220) double crystal monochromator with 50 \% detuning to eliminate higher harmonics. Both the reflectivity and the $\mathrm{Ru}_{\mathrm{k}} \alpha$ fluorescence intensity curves were obtained simultaneously as the angle of incidence of the $x$-ray, relative to the electrode surface, was scanned across the first order Bragg reflection peak. A reflectivity scan of the unmodified LSM showed a well
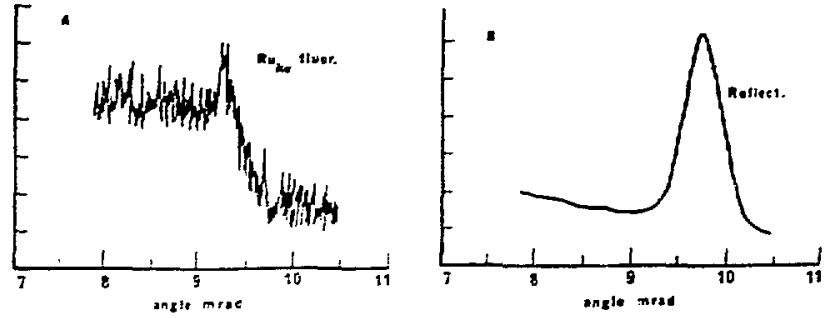

Figure :. Characteristic $R u_{K a}$ fuorescence at $19.3 \mathrm{keV}$ (A) and reflectivitv curve (B) for a W/C LSM modified with an electropolymerized film of $\left[R u(v-b p y)_{3}\right]^{+2}$. Incident $x$-ray energy was $22.5 \mathrm{keV}$.

developed first order Bragg reflection with a reflectivity maximum at about 9.7 milliradians which correlates well with the calculated value of 9.3 milliradians for an incident energy of $22.5 \mathrm{keV}$ and a $30 \AA \mathrm{d}$-spacing. The difference in the values more than likely arises from having a d-spacing slightly different from $30 \mathrm{~A}$.

The LSM was modified with a polymeric film of $\left[R u(v-b p y)_{3}\right]^{+2}$ as described above and again analyzed via the $X S W$ The incident energy $(22.5 \mathrm{keV})$ was such that characteristic $R u_{K a}$ (Ruk edge is at $22.1 \mathrm{keV}$ ) fuorescence at $19.3 \mathrm{keV}$ could be excited so that both the reflectivity and the fluorescence intensity could be simultaneously monitored. Figures $1 \mathrm{~A}$ and $\mathrm{B}$ show the angular dependences of the $R u_{K \alpha} \alpha$ fluorescence intensity and the reflectivity of the W/C LSM, respectively. The reflectivity curve (Fig. 1B) is essentially identical to that ootained prior to modification, indicating that the properties of the LSM were unaltered by the polymer electrodeposition. Figure $1 \mathrm{~A}$ shows the angular dependence of the RuKa fuorescnce and although the data is rather noisy, there is a well defined modulation. The fluorescence intensity peaks on the low angle side of the reflectivity curve and then decreases as the angle is advanced through the first order Bragg reflection. The sole fact that a modulation is observed is a clear indication that there is order, down to atomic dimensions, in the deposited layer. The general shape of the modulation indicates that on th: average, the ruthenium centers are closer to the midpoint between diffracting plases than to the diffracling planes themseives (actualty, the projection of these planes away from the interface).

In conlcusion, we have shown that simple electrochemical techniques can be employed in the preparation of moleculariy ordered layers and that these can be characterized with the $x$-ray standing wave technique. We are currently investigating the preparation of segregated layers of these polymers and preliminary results indicale that these also retain their order. In addition we are also investigating the diffracting properties of these films.

Literature Cited

1. R. W. Murray in Electroanalytical Chemistry, A. 1. Bard ed., Vol. 13, 191 (1984)

2. H. D. Abruña, P. Denisevich, M. Umaña, T. J. Meyer, R. W. Muray; J. Am. Chem. Soc. 103, 1 (198I)

3. B. W. Batterman, H. Cole; Rev. Mod. Phys. 36, 681 (1964)

4. M. J. Bedzyk, D. W. Bilderback, J. H. White, H. D. Abruña, G. M. Bommarto; J. Phys. Chem. 90,4926 (1986)

${ }^{1}$ This work was generously supposted by the Materials Science Center at Comell University, the National Science Foundation, and the Army Research Office. HDA is a recipient of a Presidential Young Investigator Award and an A. P. Sloan Fellow. 


\section{NEAR TOTAL EXTERNAL FLUORESCENCE FROM Mn-STEARATE MONOLAYER}

W. B. YUN and J. M. BLOCH

Argonne National Laboratory, 9700 S. Case Avenue,IL 60439

M. RAMANATHAN

Dept. of Phy., West Virginia University, morgantown, WV 26506

P. A. MONTANO

Dept. of Phy., Brooklyn College, NY 11210

C. CAPASSO

Dept. of Phy., University Of Minnesota, minneapolis, MN 55403

The adsorption of a metal ion from the subphase solution to the liquid-air interface, induced by a surfactant monolayer on that interface, has been measured by us quantitatively. We applied the Near Total External Fluorescence technique (NTEF) for this experiment. The surfacant materials used in our study was stearic acid and the substrate solution was a $1 * 10^{-2}$ Mole solution of $\mathrm{Mn}^{++} \mathrm{Cl}_{2}^{-}$. The fluorescence signal from the $\mathrm{Mn}^{++}$in the bulk as a function of the angle of incidence of the beam on the liquid surface is given in Fig.1a. This data is consistent with having the $\mathrm{Mn}^{++}$evenly spread in the solution. When a stearic acid monomer was spread on the surface and the experiment repeated (fig.1b) a large fluorescence signal appeared around the critical angle. It indicates that the $\mathrm{Mn}$ ion is strongly adsorbed now to the surface. The solid line in both figures is a fit with a theoretical curve calculated using the coupled Fresnel equations with the appropriate optical parameters for both cases. The ratio of $M_{n}$ ions segregated to the surface to the number of Stearate chains on the surface derived from this fit was $1.05 \pm 0.2$.
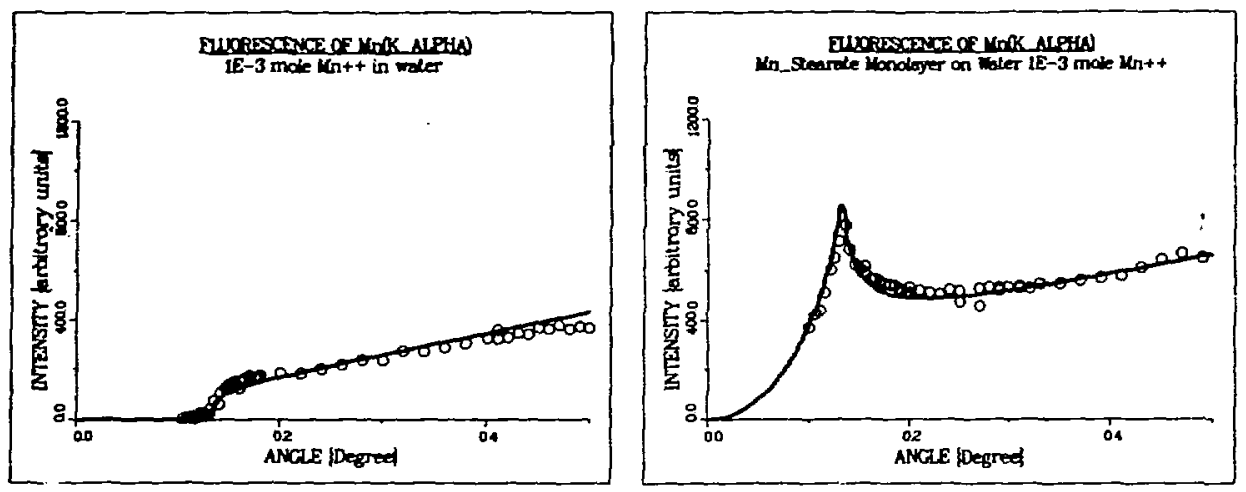

Figure 1. Measured fuorescence intensity (circle) and the fit (solid line) of $\mathrm{Mn}(\mathrm{K}$-alpha) from the Mn-stearate monolayer on the substrate (b) and from the substrate alone (a).

This work was partially supported by the department of energy ,BES-Materials Sciences, under contract W-31-109-ENG-38. 


\title{
FIRST SURFACE EXAFS FROM SURFACTANT MONOLAYER ON LIQUID
}

W. B. YUN and J. M. BLOCH

Argonne National Laboratory, 9700 S. Case Avenue,IL 60439

M. RAMÁNATHAN

Dept. of Phy., West Virginia University, morgantown, WV 26506

\author{
P. A. MONTANO
}

Dept. of Phy., Brooklyn College, NY 11210

C. Capasso

Dept. of Phy., University Of Minnesota, minneapolis, MN 55403

Surface Extended X-ray Absorption Fine Structure (SEXAFS) has been applied by us for the first time to investigate the local order acquired by a monomolecular Mn-Stearate film spread on the surface of water solution. In the experiment, $\mathrm{X}$-rays were incident on the sample at an angle smaller then the critical angle. Therefore only those $\mathrm{Mn}$ ions within a thin layer at the interface were excited and fluorescence from those ions was measured. SEXAFS in the condensed and the expanded phases of the Mn-Stearate monolayer was measured. The peak at around $1.5 \dot{A}$ (see Fig.1) was interpreted as the $\mathrm{Mn}-\mathrm{O}$ distance. In the condensed phase, an additional peak (see Fig.1a) appears at a distance of about $4.1 \dot{A}$ after phase correction and this was interpreted as the $\mathrm{Mn}-\mathrm{Mn}$ distance. This distance corresponds well with that measured previously in the Mn-stearate monolayer withdrawn to a solid substrate. The presence of the characteristic $\mathrm{Mn}$-Mn distance in the condensed phase and the absence of this distance in the expanded phase reveals a different ordering of the monolayer in the condensed and the expanded phases.
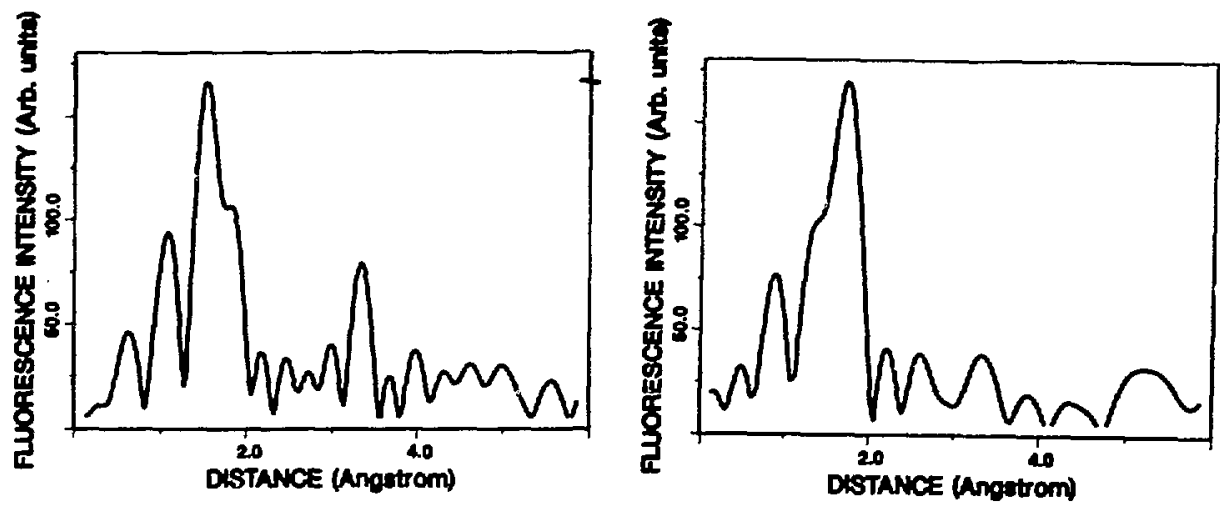

Fig.1 The fourier transformed spectra of the fluorescence EXAFS from the condensed phase (a) and the expanded phase (b).

This work was partially supported by the department of energy ,BES-Materials Sciences, under contract W-31-109-ENG-38. 
SCATTERING OF X-RAYS FROM SMOOTH SURFACE - THEORY VS, EXPERIMENT*

P. Z. Takacs (BNL), Hu-ming Liu (Inst. HEP, Be1j1ng/BNL ${ }^{1}$ ), and E. L. Church (BNL/USAARDEC)

The Optical Metrology Laboratory in the Instrumentation Division at BNL has been engaged In the development of metrology techniques to evaluate the surface finish quality of optical components to be used in NSLS beamlines. Our goal is to be able to predict the performance of x-ray opt1cs under actual operatIng conditions based on our laboratory metrology techniques. To this end we performed a set of experiments on a super-smooth Au-coated SiC plane mirror to compare the measured scatter to predictions based on measurement of the power spectral density (PSD) of the surface roughness.

The basic angle-resolved scatter equation in the grazing incidence approximation is: ${ }^{2}$

$$
\frac{1}{I_{1}}\left(\frac{i}{d \theta}\right)_{s}=(1-g) \cdot R\left(\theta_{1}\right) \cdot \delta\left(\theta_{s}-\theta_{1}\right)+16 \pi^{2}\left(\frac{s \ln \theta_{1}}{\lambda}\right)^{3} R\left(\theta_{1}\right) \cdot K \cdot S\left(f_{x}\right) \text { where } S\left(f_{x}\right) \text { Is the PSD curve as }
$$

measured by the WYKO profiler, and $\mathrm{K} 1 \mathrm{~s}$ the theory-dependent materials-obliquity factor, which for the Rayleigh-Rice theory 1s:

$$
K_{R R}=\left(\frac{\theta_{g}}{\theta_{1}}\right)^{2}\left(\frac{R\left(\theta_{s}\right)}{R\left(\theta_{1}\right)}\right)^{\frac{1}{2}} \text { where } R(\theta) \text { is the Fresnel intensity reflectivity of the 1deal surface. }
$$

Measurements of the angular distribution of scattered light were made at beamline XI9A with highly collimated monochromatic $8.9 \mathrm{keV}$ photons. The incident beam was $100 \mu \mathrm{m}$ high; a $20 \mu \mathrm{m}$ slit was placed in front of an open afr Ionization detector and was scanned through the reflected and scattered beam in the vertical direction over a distance of several millimeters. Results for three angles of Incidence are shown in Fig. I normalized to the direct beam intensity. These curves represent the left side of $\mathrm{Eq}$. (1) with the finite angular size of the detector slit included. The peak specular intensities are used to adjust the values of $n$ and $k$ and the critical angle, according to the results of Bllderback, ${ }^{3}$ and are used in the calculation of $R(\theta)$. Figure 2 shows the calculation of the right side of Eq. (1) for each of the angles of incidence superimposed on the measured scatter curves. The Rayleigh-Rice theory correctly predicts the shape and magnitude of the scattering based on measurements of the surface roughness of the surface. It successfully explains the "Yoneda effect" asymmetry in the $8.593 \mathrm{mrad}$ data and "ant 1 -Yoneda effect" In the 3.864 mrad data.

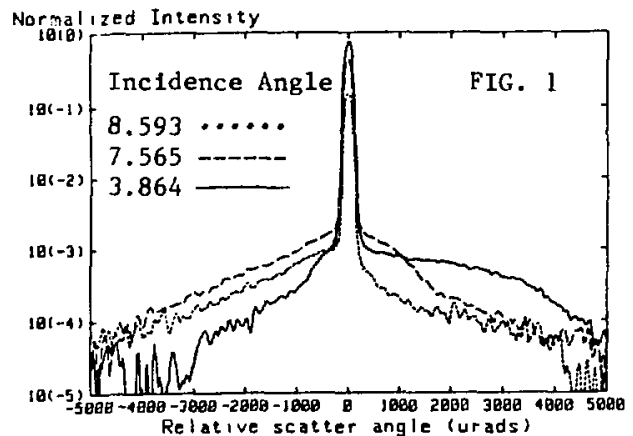

Acknowledgments

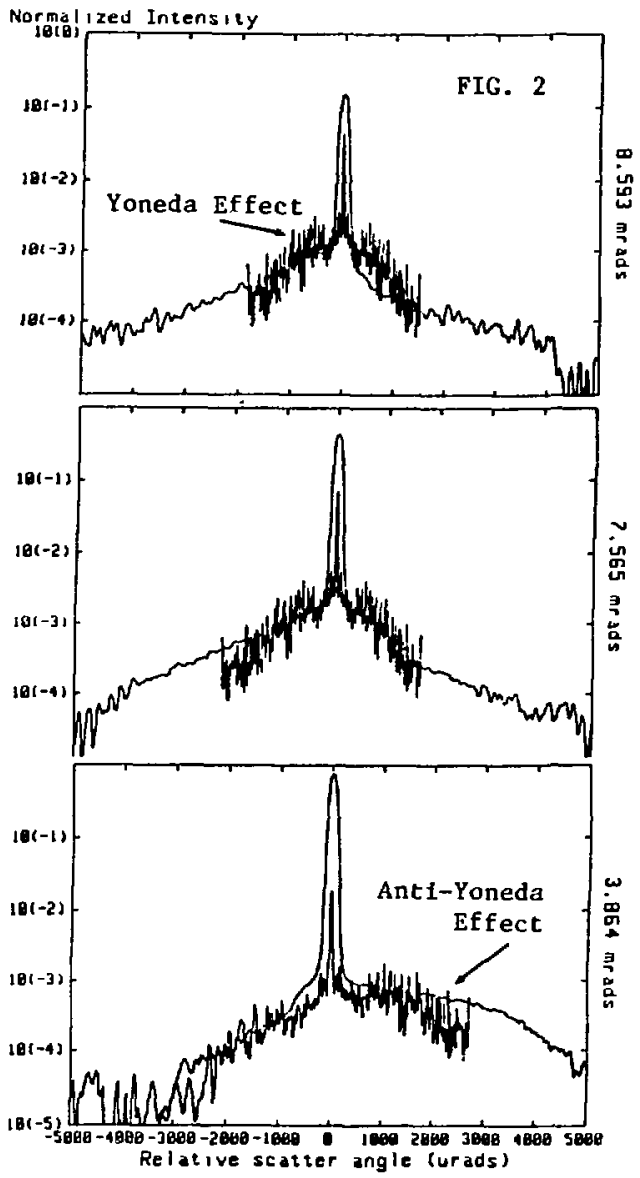

The authors acknowledge the assistance and support of Dr. Peter Stefan in allowing us to perform the first experiment on X19A.

\section{References}

1. Visiting scientist from the Institute of High Energy Physics, Beifing, China.

2. E. L. Church and P. 2. Takacs, Grazing Incidence Optics; BNL 38386; Proc. SPIE 640, 126 (1986).

3. D. H. Bllderback, Reflecting Optics for SR, Proc. SPIE 315, 90 (1981).

*Th1s research was supported by the U. S. Department of Energy: Contract No. DE-AC02-76CHO0016. 


\section{STUDIES AND COMMISSIONING ON X-19A}

\section{P. M. Stefan}

National Synchrotron Light Source

Brookhaven National Laboratory

Upton, NY 11973

In this fiscal year, studies of beamline optical components were continued and initial beamline commissioning work begun. $\mathrm{X}-19 \mathrm{~A}$ is an NSLS facility beamline, and negotiations for the formation of a special User Administration Group, to manage the beamline for general users, are underway.

Monochromator studies included testing of new first and second crystal holders. Modulation of the output $x$-ray beam through floor vibrations has been controlled in the new prototype second crystal holder. Use of Ga-In liquid metal in the first crystal holder now permits reduction of the clamping force required on the cooling blocks, and consequent reduction of strain in the crystal.

Commissioning of the beamline began with the testing of a VAX II-based data acquisition system developed by Mark Engbretson and Pedro Montano of X-18B. In addition to running the monochromator and accepting detector output, the system also controls 15 stepping motors which position various slits and a multi-axis table in the hutch. EXAFS analysis routines are also included in the package.

The monochromator was equipped with flat $\mathrm{Si}(220)$ crystals and covers an energy range of 3.5 to $12.5 \mathrm{keV}$. First EXAFS scans were made, but improvements in the main scan motor electronic drive and in the feedback stabilization systems are required. The re-focusing mirror was tested and produced a final focus of less than $1 \mathrm{~mm}$ in diameter in the hutch.

Plans for the User Administration Group are being finalized. This group, composed of members of the EXAFS general user community, will manage the majerity of the beamtime for general users, in exchange for a separate guaranteed fraction of the time. "Management" include: scheduling users and assisting general users in setting up experiments, becoming familiar with the computer sysiem, log stics, etc. 


\section{A STUDY OF CREEP DAMAGE USING MICRORADIOGRAPHY}

\section{J.E. Benc $i$ and D.P. Pope (U. of PA)}

We have shown, using the NSLS at Brookhaven National Lab., that cavitated grair bourdary facets in iron ard steel samples of about $100 \mu \mathrm{m}$ grain size and 1 to $2 \mathrm{~mm}$ thick can be easily observed using microradiography. The exposure times are approximately 10 mirutes using Kodak High Resolution Plates, ever though the sample (along with the film) is scanned through the $x$-ray beam in a periodic fashion through a rarge of several cms. to ircrease the exposed area. This is done because the beam size is smaller thar the area we wart to examire. We have also determired the minimum size defect that car be observed using this technique. The minimum dimension in the direction perpendicular to the beam is cortrolled by resolution. For beamlire $X-19 \mathrm{C}$ at the NSLS, a resolutior limit of approximately $14 \mathrm{~m}$ in the direction perpendicular to the beam is obtained. In the direction parallel to the beam the minimum size defect observable is determired by cortrast consideratiors. Assuming that a contrast of 10\% car be seer or the film, a void of dimersior 9 um parallel to the $x$-ray beam can be detected. Therefore, a sirgle cavity lum in diameter canrot be seen by this techrique, but ter such cavities aligned paralle? to the beam or a microcrack 10um lorg (parallel to the beam) can be detected. Figure 1 is ar area from a radiograph of a rotched iror. sample which was tested at $700^{\circ} \mathrm{C}$ for 68 hours at a displacement rate of $2.11 \times 10^{-5} \mathrm{~mm} / \mathrm{sec}$. The large white area is the macroscopic crack and the small white features are microcracks. It car be seer that the creep damage fans out from the crack tip.

The distribution of damage around creep cracks recorded on microradiographs has been analyzed using a microscope equipped with a digital aralyzirg system. Quantifyirg creep damage allows one to compare experimental results to theoretical predictions on the extert and distribution of creep damage around specific notch geometries. Figure 2 shows the results of the image aralysis from an area of the crack tip region from the radiograph in fig. 1 (rotated by $90^{\circ}$ ). The numbers represent the area fraction of damage ir units of $0.1 \%$. The macroscopic crack is showr by the solid black region with greater than $10 \%$ damage. The corcentration of damage can therefore be determined as a function of position, and cortours of corstant damage can be plotted.

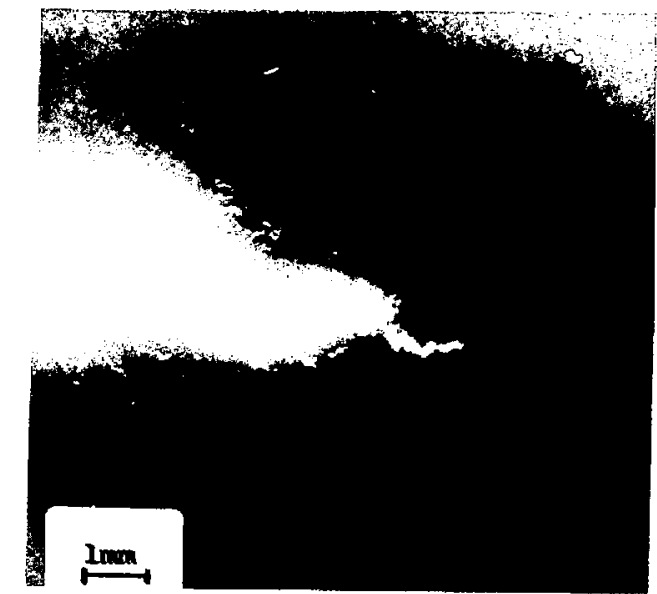

Fig. 1 Radiograph of a notched iron sample tested at $700^{\circ} \mathrm{C}$ for 68 hours. The damage extends down to the bottom right corner of the radiograph, several mms. from the crack tip.

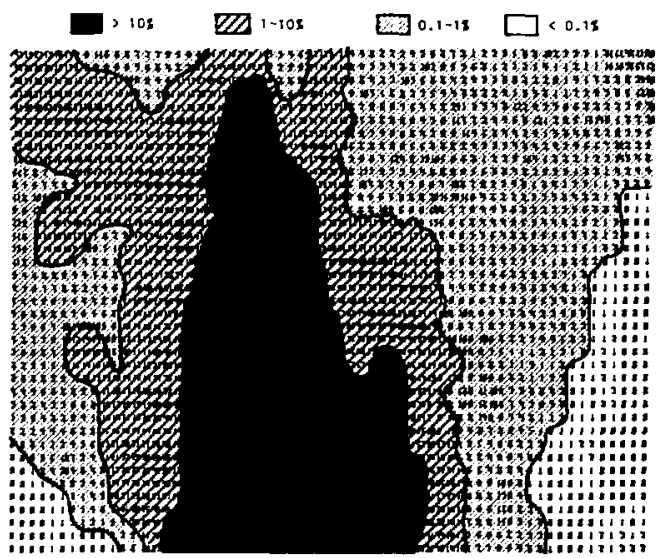

Fic. 2 Results from the image analysis of the crack tip region from the radiograph in fig. 1. The solid black region is the macroscopic crack.

Ir summary, we have developed a microradiographic technique using synchrotron radiation which can be used to quickly and reliably measure the amount and the distribution of creep damage in a sample. This technique is possible only because of the availability of a high intensity synchrotron source. The rext step is to use this technique to test models of damage accumulation in metallic materials. Towards this end we have choser a model material to study: high purity copper heavily doped with oxyger. Prelimirary tests on the high temperature ductility of this material have been performed. A ductility minimum was observed at about $500^{\circ} \mathrm{C}$, with a resultart reduction of area of about $3.1 \%$. The fracture at $500^{\circ} \mathrm{C}$ was totally intergranular due to cavity coalescence. Further mechanical testing is currertly underway at $500^{\circ} \mathrm{C}$ to determine the materials constarts of deformation and fracture necessary for the finite element modeling of the damage accumulation process in this material.

Acknowledgements: This work was performed on the Synchrotror. Topography Project beamline, $X-19 \mathrm{C}$, which is supported by the U.S. Department of Energy urder grant DE-FG02-84ER45098. The image analysis was performed at the National Bureau of Standards with the assistance of Dr. R.J. Fields. 
ANALYSIS OF X-RAY PENETRATION DEPTHS ON WHITE BEAM TOPOGRAPHS RECORDED IN GRAZING BRAGG-LAUE GEOMETRIES.

Michael Dudley, Jun Wu and Gong-Da Yao (SUNY SB - Dept. of Mat. Sci. \& Eng.)

It is well known that the projective properties of white beam topographs recorded in transmission Laue geometries can be exploited to determine the spatial distribution of defects in a single crystal.1,2 In this experiment the projective properties of white beam topographs recorded in grazing Bragg-Laue geometries, from a silicon crystal with a well defined spatial distribution of defects, were used to enable direct determination of the depth of penetration of the $X$-ray beam into the crystal. The particular set of defects chosen for study consisted of a set of parallel 60 degree dislocations, of line direction [101], and Burgers vector 1/2 [110]. The projected lengths of the direct, or kinematical images of these dislocations depend on the relative orientations of crystal and detector and also on the length of defect sampled by the $x-r a y$ beam, which is determined by the penetration depth. Suitable analysis of the measured projected lengths of dislocation images enables the penetration depth to be determined. Results obtained can then be compared to penetration depths calculated from the kinematical and dynamical theories of diffraction, respectively. Generally, dynamical effects concede to kinematical effects as crystal quality deteriorates from perfect. Therefore, from the measured lengths of dislocation images one can also determine the nature of the local diffraction process.

Figure 1 shows a White beam reflection topograph taken from the (111) crystal surface in the grazing Bragg-Laue geometry, with the detector normal to the incidene white beam. $(g=022, \lambda=0.4 \mathrm{~A},>99 \times$ fundamental). Note the very long projected dislocation lengths. Figure 2 shows a White beam reflection topograph taken from the same region of (111) crystal surface in a slightly different grazing Bragg-Laue geometry, with the detector no longer normal to the incident beam $(g=022, \lambda=0.7$ $A,>99 \%$ fundamental). Note the very short projected dislocation lengths. Analysis shows that the projected lengths of dislocation images measured from the topographs agree very closely with those predicted on the basis of kinematical diffraction theory. Results obtained convey two important points; (1) the assumption that in direct dislocation image formation, the regions iminediately surrounding the dislocation line behave like miniature mosaic crystals, is validated. (2) the assumption that adoption of grazing Bragg-Laue geometries yields very narrow penetration depths (according to dynamical theory) is shown not to be general, but rather depends on the distribution of localized distortion fields in the crystal. In the regions immediately surrounding dislocation lines in a silicon single crystal, kinematical effects clearly dominate, and thereby determine penetration depths. It is to be expected that dynamical effects may still be valid in crystals where the local distortion in the crystal leads to effective misorientations, $\delta(\Delta \theta)$, which are smaller than the perfect crystal rocking curve width.
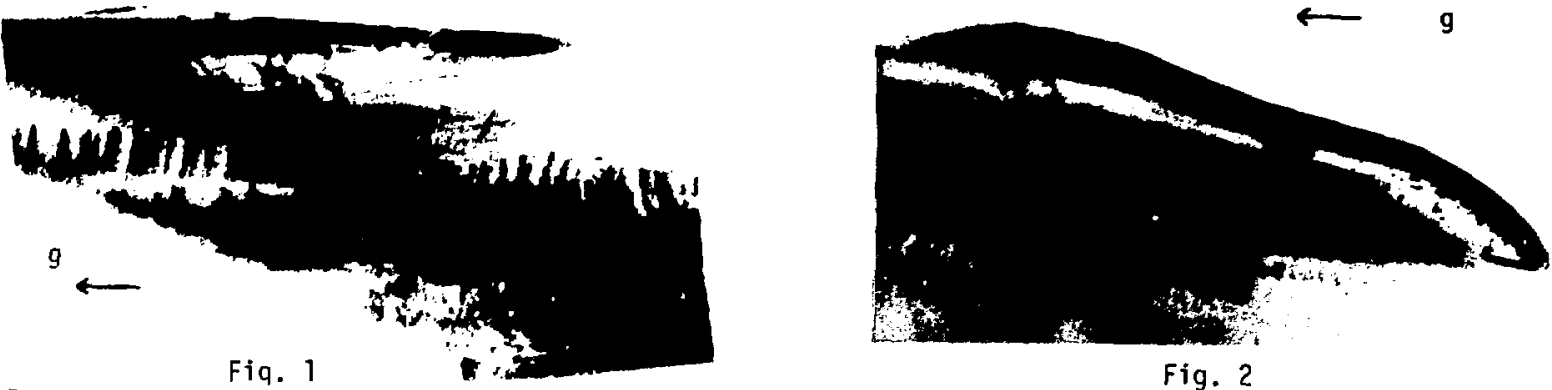

Fig. 2

References

(1) J. Miltat and M. Dudley, J. Appl. Cryst. 13, 555, (1980).

(2) M. Dudley, J. Miltat and D.K. Bowen, Phil. Mag. A50, 487, (1984).

(3) A.M. Afiansiev, P.A. Aleksandroy, R.M. Imamov, E.M. Pashaev and V.I. Polovinkina, Phys. Stat. Sol. (a) $90,419,(1985)$.

Acknowledgments

Research work was supported by the Division of Materials Research, National Science Foundation, under grant number DMR-8506948. The topographic work was performed on the Synchrotron Topography project, beamline $X-19 C$, which is supported by the U.S. Department of Energy under grant No. DE-FG02-84ER45098. 
CHARACTERIZATION OF CRACK-TIP MICROSTRUCTURES VIA SYMCHROTRON FRACTORGRAPHY IN MO AND MO-Nb ALLOY CRYSTALS

A. B. Hmelo (SUNY SB), J. C. Bilello (CSUF)

The nature of the plastic relaxation associated with the semi-brittle cleavage fracture of a series of pre-cracked Molybdenum-Niobium alloy single crystals has been investigated as a function of composition and temperature from $77^{\circ} \mathrm{K}$ to $298^{\circ} \mathrm{K}$. Conventional optical microscopy and white beam Synchrotron X-Ray Fractography (SXRF) were used to examine the structure of a thin layer a few microns thick at the remnant of the precursor crack plastic zone.

The plastic work of fracture has been evaluated by measuring the lattice curvature associated with networks of dislocations beneath the cleavage surface. Using SXRF, lattice curvature is detected as asterism on photographic plates, and is associated with an excess density of edge dislocations of one sign. The results are in qualitative agreement with a previous determination of the fracture toughness of these specimens. Excess edge dislocation density of one sign has been shown to vary as a function of temperature and composition, in a way which is consistent with previous studies of total dislocation content in these materials. Unlike the etch pit analysis which can reveal the total dislocation content only, the tensor based analysis described here allows the activity on individual slip systems to be distinguished.

White beam fractography has been shown to be a novel method capable of revealing the crack tip defect structures left behind in the wake of crack propagation in single crystal specimens. It can be used on specimens for which no etchant for lattice dislocations is available. It reveals distortions of the single crystal lattice in all orders of diffraction, simultaneously in a single exposure, in a thin layer adjacent to the cleavage surface, and is nondestructive.

As such, the technique is a new method of fractographic characterization which has been applied to the technically interesting case of the Molybdenum-Niobium solid solution series. Although the analysis described here provides some insight regarding the crack-tip defect structure, its applicability is limited by diffraction effects and details of the mechanism of image contrast which detect only pure bend components of the total lattice curvature.

Acknowledgement

This work was performed on the Synchrotron Topography Project Beamline $x-19 C$ which is supported by the $U$. S. Department of Energy under Grant No. DE-FG0284 ER45098. 
CRYSTALLINE IMPERFECTIONS AND THEIR ROLE IN THE REACTIVITY OF $\mathrm{NaNO}_{3}$ AND $\mathrm{NH}_{4} \mathrm{ClO}_{4}$ SINGLE CRYSTALS STUDIED BY X-RAY DIFFRACTION TOPOGRAPHY
J. R. Laia, Jr. (SUNY SB) and P. J. Herley (SUNY SB)

Sections of solution-grown $\mathrm{NaNO}_{3}$ and $\mathrm{NH}_{4} \mathrm{ClO} 4$ crystals were examined by both the Lang (sealed beam) and Synchrotron $X$-ray transmission topograph (XRT) methods and, both growth and post-growth line defects were characterized within the resolution limits of the techniques. The sections were sufficiently thick (up to $3 \mathrm{~mm}$ ) to be fully representative of the material's bulk structure. It was found that Burgers vectors 1 ie along the $[010]$ and $[001]$ directions in $\mathrm{NH}_{4} \mathrm{ClO} \mathrm{O}_{4}$ and the $\langle 1 \overline{1} \mathrm{i}\rangle$ and $\left.20 \mathrm{I}\right\rangle$ directions in $\mathrm{NaNO}_{3}$.

$x$-ray topographic observations of the changes in the microstructure of these crystals during $x$-ray radiolysis show that dislocations play no observable role in nucleating the chemical reaction for either material. In addition the dislocations were found to have no effect on the chemical processes induced in $\mathrm{NaNO}_{3}$ by gamma-rays, UV 7 ight or thermal treatment. For both materials observations of resolvable line defects were limited to the early stages of the reaction as considerable strain was induced in the crystal lattice resulting from trapped gaseous product. However dislocation motion and/or generation due to either the stimuli or pressures exerted by the internally trapped gas was not observed.

Three types of chemical etch pits were formed on the cleavage surfaces of $\mathrm{NaNO}_{3}$ crystals by glacial acetic acid. XRT showed that the large, (480-100 $\mu m$ ) asymmetrical, rhombic pits correlated well with dislocation outcrops of the type (110) $\langle 111\rangle$. No correlation with existing dislocations was found for the remaining two types. The $(110)<1 \bar{l} 1>$ slip system was observed directly in room temperature in-situ tensile tests and was also found to explain; - (i) the XRT observed strain distribution around an indentation, ( $i i)$ the measured variation in knoop hardness number as a function of position of the indenter's long diagonal, (iii) the observed etch pit alignments around indented and etched surfaces, and ( $i v$ ) the observed microcracking that accompanied particular indenter orientations.

In $\mathrm{NH}_{4} \mathrm{ClO} \mathrm{O}_{4}$ Knoop hardness anisotropy measurements showed the (102) [010] and $(001)$ [010] slip systems best described the data for the (001) face, while the (100) [010] slip system best described the data for the (210) face. Both the (001) [010] and (100) [010] slip systems were observed by XRT.

This work was performed on the Synchrotron Topography Project Beamline $X-19 \mathrm{C}$ which is supported by the U. 5. Department of Energy under Grant No. DE-FGO2$84 E R 45098$. 
YunJi Liu (SUSB SB) and A.H. King (SUSB (SB))

The stresses are of considerable importance in the use and application of silicide thin films in microcircuit technologies. Stresses can cause film rupture, loss of adhesion, and may introduce strain into the silicon substrates and cause dislocation generation or multiplication with its effects on the electric properties of some devices. In the present study, synchrotron topography was used to measure the stresses of nickel silicide thin films on $S i$ wafers.

4" silicon wafers, both (100) and (111) oriented, were used as substrates. Nickel was coated on these silicon wafers by using resistance evaporation at pressures of 10 torr. Thicknesses ranging from $500 \mathrm{~A}$ to $2000 \mathrm{~A}$ were obtained. Nickel silicides were formed by rapid thermal processing at $600 \mathrm{C}$ for 5 seconds.

The study included the use of a Golovchenko double crystal monochromator to make high resolution strain studies. 1A wavelength was used to obtain a glancing incidence beam on the sample with a large surface area imaged. A new sample holder was designed so there was no force on the samples examined. The Bragg contour mapping method was used to measure the radius of curvature of the wafers. From the measured radius of curvature the internal stress in the film can be calculated. The measurenent was performed before and after the rapid thermal process, so the stress changes in the formation of silicide films could be studied. No large stress changes were observed in our experiment. Phases identification and structure studies of the thin film-silicon systems were performed by using TEM, STEM, EDAX techniques.

\section{References}

1. C.L. Kuo, P.E. Vanier and J.C. Bilello, J. Appl. Phys. 55(2), 375, (1984).

\section{Acknowledgement}

This work was performed on the Synchrotron Topography Project Beamline $X-19 \mathrm{C}$ which is supported by the $U$. S. Department of Energy under Grant No. DE-FG0284ER45098. 
AN EXPERIMENTAL AND THEORETICAL STUDY OF THE CRITICAL FACTORS CONTROLLING THE MECHANICAL PROPERTIES OF MOLYBDENUM AND OF THE INTERACTIOH OF INTERSTITIALS WITH BODY-CENTERED-CUBIC TRANSITION METALS

R. Rebonato (SUNY SB), G. Ice (NSLS), A. Hadbenschuss (NSLS), J. C. B11e110 (CSUF)

The experimental part of this thesis presents a new high-sensitivity technique for the determination of the strain field in perfect-to-highly deformed crystals. A sensitivity of one part in $10^{4}$ has been attained, and the spatial resolution has been pushed down to 25 microns. This technique has been implemented at the Brookharen National Synchrotron Light Source (NSLS) for the study of the strain field in the proximity of a stress raiser in Mo single-crystals. Variations of lattice spacing as high as $300 \%$ and angular misalignments of $100 \%$ over 25 microns have been detected. Interesting features such as the change in sign in the variation of the lattice spacing of the diffracting planes above and below the tip of the notch have been revealed.

As for the theoretical part, the suitability of the recentiy introduced Finnis Sinclair potentials has been investigated for the study of highly defective systems. Equilibrium (phonon dispersion curves, phase stability) and non equilibrium (pressure versus volume behavior) properties have been calculated and compared with experimental data. A simple modification has been introduced to the Finnis-Sinclair potentials to extend their applicability to highly deformed systems. The availabie experimental evidence pertaining to several transition metal/octahedral interstitial systems has been critically analyzed, in the attempt to understand the features of an interaction potential capable of describing the host/impurity system. Angulardependent three-body potentials have been found necessary in order to account satisfactorily for the available experimental evidence. The displacement field out to very far neighbors of the impurity - at least ninth- has been found to show marked oscillatory behavior superimposed on generally expected decay.

Acknow ledgement

This work was performed on the Synchrotron Topography Projezt Beamline $X-19 C$ which is supported by the U.S. Departement of Energy under Grant No. DE-FGOZ84 ER45098. 
TRANSGRANULAR FRACTURE IN ZINC BICRYSTALS AS PROBED BY MONOCHROMATIC AND WHITE BEAM SYNCHROTRON X-RAYS

H. A. Schmitz (SUNY SB), J. C. Bilel10 (CSUF)

Crack propagation at $77^{\circ} \mathrm{K}$ and $298^{\circ} \mathrm{K}$ was studied for low cycle prefatigued zinc bicrystals. One grain was fixed so that the basal cleavage plane was always normal to the tensile axis while the orientation of the other grain varied. Cracks usually nucleated in the latter grajn after extensive plastic deformation. synchrotron $X-R a y$ Fractography (SXRF) and Monochromatic Bragg angle Strain Contour Mapping (SCM) was used to examine the strain field of the crack in relation to the bicrystal boundary plane. Lattice curvatures due to crack opening strains were accurately determined for several pure tilt boundaries. The behavior of twist boundaries and random boundaries was also characterized by $x-r a y$ and optical examinations.

The lattice curvatures were interpreted in terms of crack opening displacements. This data was then used to approximate the fracture toughness or penetration strength of the grain boundary. A boundary affected zone (BAZ), apparently a consequence of accommodation slip, was clearly discerned; the size of the BAZ was found to be strongly dependent on the test conditions. The penetration strength of the grain boundary was not strongly dependent on the size of the boundary affected zone; but earlier stages of crack nucleation and growth may be influenced by this deformed region due to the inhibition of basal slip.

Pure tilt boundaries were inexplicably found to be several times tougher than a single crystal. This high toughness was attributed to a grain boundary crack tip relaxation process.

Many interesting phenomena pertaining to nonbasal cleavage, incompatible bicrystals, and fatigue behavior were observed and documented so that a comprehensive understanding of the range of bicrystal orientations and fatigue properties could be approached.

Ack now ledgement

This work was performed on the Synchrotron Topography Project Beamline $X-19 \mathrm{C}$ which is supported by the U. S. Department of Energy under Grant No. DE-FGO2$84 E R 45098$. 

SYNCHROTRON X-RAY TOPOGRAPHY

\author{
V. S. Wakharkar (SUNY SB) and J. C. Bilello (CSUF)
}

In-situ deformation experiments provide a good basis for investigating the time dependent evolution of the microstructural features that exist in the deforming specimen under load and that do not lend themselves to observation using conventional techniques. Synchrotron X-ray Topography is being used as an in-situ probe to study these changes in 'bulk' Mo crystals under controlled conditions. The experimental set-up consists of a computer controlled miniature tensile stage mounted on the white beam camera assembly. The detector arm carries the microchannel plate image intensifier tube along with a solid state CID television camera for real-time detection, display and recording of Synchrotron X-ray Topographs; while high resolution topographs ( 5 microns) can be taken on Kodak SR5 film. Tensile specimens for the deformation experiments were made form large Mo single crystals prepared by the secondary recrystallization technique. The main metallographic feature of these crystals is the presence of 'island grains' which are embedded localized regions misoriented by about 10-15 degrees with respect to the single crystal matrix and about 50-300 microns in diameter. Room temperature tensile tests were carried out on the specimens at a low strain rate of the order of $10(-4) / 5 e c$. The experimental results have indicated the existenre of locallized plastic deformation below the yield point in these Mo crystals. Slip initiation at stress levels of about 0.3-0.7 of the macroscopic yield stress was observed in specimens which were continuously strained at a low strain rate. The presence of 'island grains' had a pronounced effect on the deformation characteristics of these crystals. It was observed that microcracks were initiated preferentially near the island grain - single crystal interface. Synchrotron X-ray Topography was used to follow the localized deformation processes which lead to the formation of microcracks at the interface.

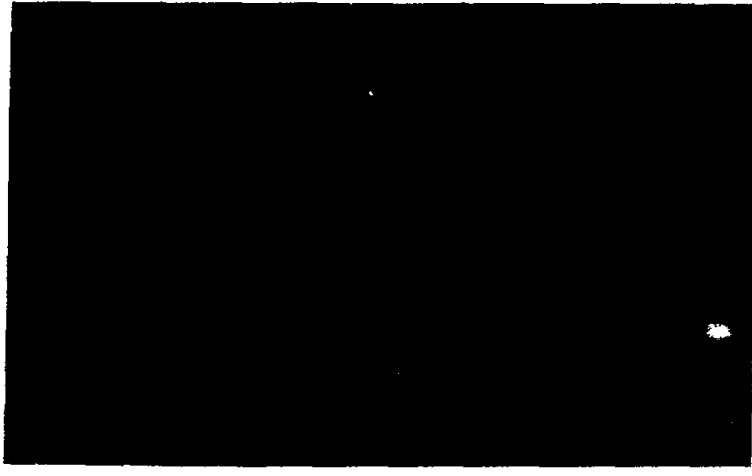

$1 \mathbf{a}$

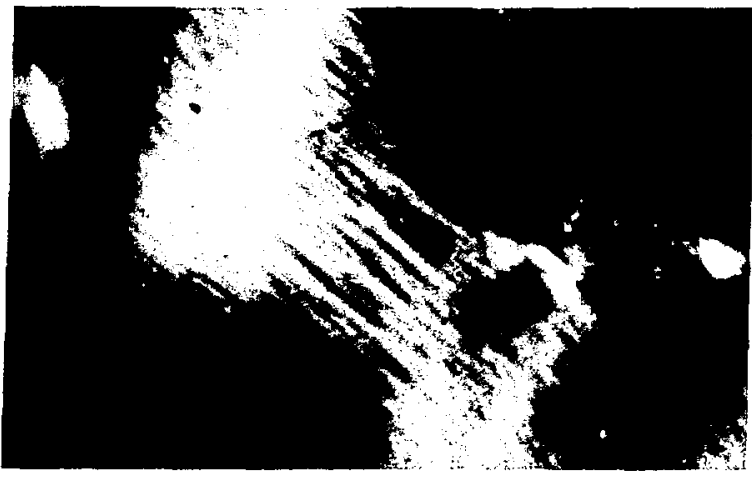

$1 b$

Figure $1 \mathrm{a}$ and $1 \mathrm{~b}$ show the changes occurring in the (111) reflection at increasing stress levels. Note the localized deformation near the isiand grains.

Acknow ledgement

This work was performed on the Synchrotron Topography Project Beamijne $X-19 C$ which is supported by the U. S. Department of Energy under Grant No. DE-FGOZ84ER45098. 


\section{GALLIUM ARSENIDE TOPOGRAPHY AT BEAMLINE X-19C}

J.M. Winter, Jr. (Johns Hopkins U.), R.E. Green, Jr. (Johns Hopkins U.), W.S. Corak (Westinghouse Advanced Tech.)

Genera1

The defect structure of gallium arsenide has been examined using white beam transmission topography as part of a contiruing program. The specimens examined were three inch diameter, single crystal substrates from various suppliers in the "as received" condition. Figure 1 shows an enlarged view of one topograph.

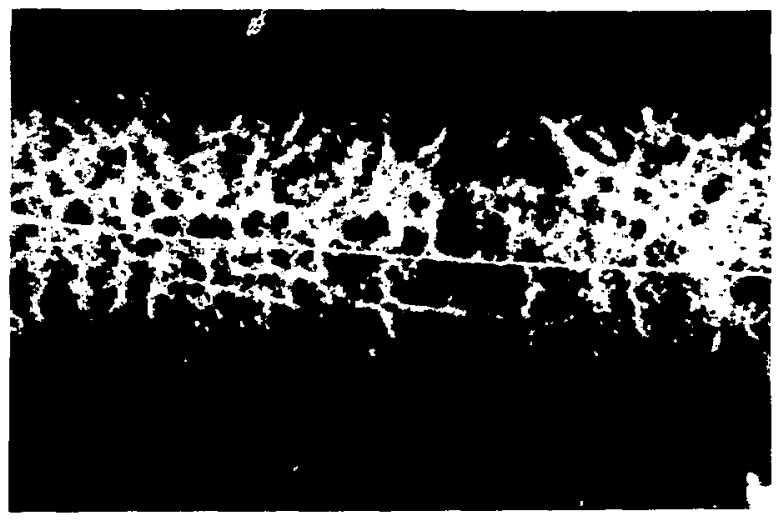

Fig. 1. Enlarged topograph of gallium arsenide.

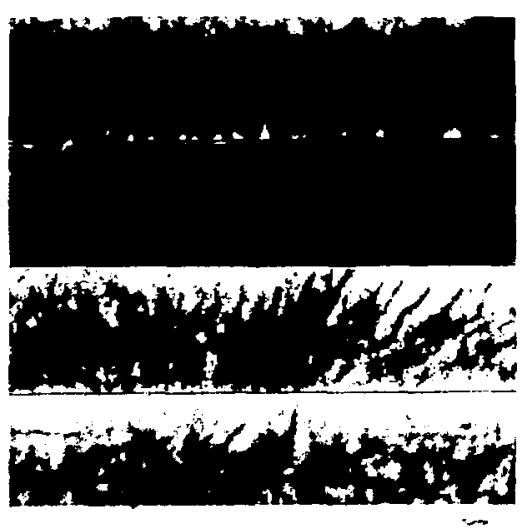

F1g. 2. Montage of topographs.

The wealth of information recorded in the topograph is apparent. There are two basically distinct defect structures which appear with variations in all the gallium arsenide topographs we have examined. They become most obvious if one assembles a photographic montage of topographs from adjacent locations on the specimen, as shown in Fig. 2. First is a falrly 1sotropic cellular network or mosaic-like structure which seems ubiquitous throughout the specimens. Second are the more striking highly linear arrays which are localized to a few areas, and generally appear to run radially.

Results and D1scussion

There are some complications in extracting all the information avallable from the topographs. First, the diffraction process is such that the images are formed in reciprocal space. Consequently, the reconstruction of defect structures from their apparent Images as diffracted from various sets of lattice planes is not simple. This problem is currently being addressed as an image processing problem in the authors' laboratory. The second complication is that only a part of the three inch diameter specimen is illuminated by the incident beam (because of the inherent. limitations on the beam dimensions available at the NSLS). As indicated above, this limitation has been clrcumvented by makfng montages of adjacent images. Future work will utilize a change in the experiment geometry to eliminate the need for photographic montages.

Acknowledgements

This effort was supported in part by Westinghouse Advanced Technology Division, which also supplied the experfmental samples. The work was performed at Beamline X-19C of the National Synchrotron Light Source, Brookhaven National Laboratory, which is supported by the U.S. Department of Energy under Grant No. DE-FG-02-84ER45098. 


\section{WITIAL STAGE ORDERING KINETICS IN $\mathrm{Cu}_{3} \mathrm{Au}$}

Karl F. Ludwig (IBM), G. Brian Stephenson (IBM), Jacques Mainville (McGill U.), Yong Yang (McGill U.), Mark Sutton* (McGill U.), and Jean L. Iordan-Sweet (IBM)

The kinetics of a first-order ordering transition is expected to be described by an initial stage of either nucleation and growth or spinodal ordering', followed by a later stage of domain-size coarsening. Because of the time resolution obtainable, previous scattering sturies ${ }^{2}$ of ordering kinetics have been limited to the later stage. Recently we performed a time-resolved x-ray scattering study of the initialstage ordering kinetics in $\mathrm{Cu}_{3} \mathrm{Au}$ at the IBM/MIT beamline X-20C. In order to obtain the best possible time resolution, the $\mathrm{x}$-ray flux on the sample was maximized by the installation into the beamline's monochromator of $\mathrm{W} / \mathrm{Si}$ multilayers having a $1.1 \%$ energy banapass ${ }^{3}$. At the $8.1 \mathrm{keV}$ x-ray energy used, a flux of $10^{13}$ photons per second was obtained in a $1 \mathrm{~mm}^{2}$ spot under typical NSLS operating conditions $(100 \mathrm{~mA}, 2.5 \mathrm{GeV})$. The samples studied were cut from melt-spun polycrystalline $\mathrm{Cu}_{3} \mathrm{Au}$ ribbon and were resistively heated in situ in a He atmosphere. The sample temperature was monitored using an optical pyrometer. The scattered x-ray intensity was measured in real time with a position-sensitive detector based on a linear photodjode array ${ }^{3}$. In the experimental geometry the detector accepted a line of scattering $0.9 \AA^{-1}$ long in $\mathrm{k}$-space, which allowed us to study the changes in the (100) or (110) superlattice peaks with millisecond time resolution as the sample ordered.

For a typical data set, a $\mathrm{Cu}_{3} \mathrm{Au}$ ribbon was initially annealed in situ at $450-500^{\circ} \mathrm{C}$, well above the first-order transition point $\left(T_{T R}=390^{\circ} \mathrm{C}\right)$. The sample was then rapidly quenched to a new temperature, $T_{2}$, below or just above the ordering point and held at constant temperature $\left( \pm 1^{\circ} \mathrm{C}\right)$. The $x$-ray scattering, sample temperature, and sample resistance were measured in real time as the sample was quenched and began to order. The sample temperature could be changed by $100^{\circ} \mathrm{C}$ and stabilized in approximately 200 ms. This was sufficiently fast that very little ordering took place during the quench (see Fig. 1). After each run, the sample was reannealed to restore the disordered state and then re-quenched, so that many data sets at various $T_{2}$ were obtained from each sample.

For $T_{Q}>T_{T R}$ the data show that the diffuse scattering from short-range order fluctuations equilibrates relatively quickly (in 5 seconds or less depending on $T_{Q}$ ). At progressively lower values of $T_{Q}$, the intensity of the diffuse scattering and the equilibration time increase. This trend continues urinterrupted as $T_{Q}$ passes :hrough $T_{T R}$. In addition to this process, a larger increase in intensity characteristic of nucleation and growth is observed on a much longer time scale (several minutes) for quenches to temperatures just below $T_{7 \mathrm{~A}}$. As $T_{Q}$ is lowered further, the time scales for the two processes merge so that they are no longer distinct. These results show directly and quantitatively how homogeneous nucleation and growth changes to spinodal ordering with decreasing temperature. Detailed analysis of the data is now underway. The measured superlattice peaks can be fit using a 3-dimensional Hendricks-Teller-type model based on the two common types of antiphase domain boundaries. ${ }^{4}$. Figure 2 shows typical fits of the theory function to our data for a quench to $362^{\circ} \mathrm{C}$. The densities of the two types of domain walls can be determined from the fits and the average domain size as a function of time and temperature can be calculated. This information will be compared with theories of ordering kinetics.

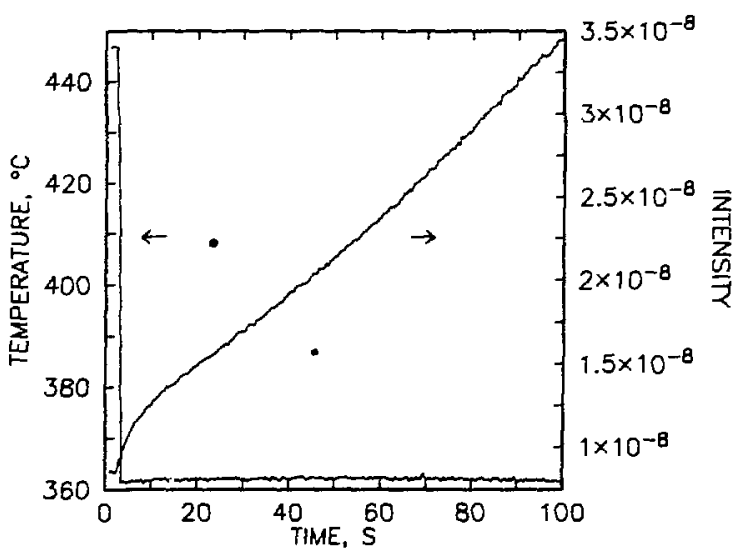

Fig. 1. Sample temperature and scattered intensity at wavenumber $1.58 \AA^{-1}$ as a function of time after a quench from $447^{\circ} \mathrm{C}$ to $362^{\circ} \mathrm{C}$.

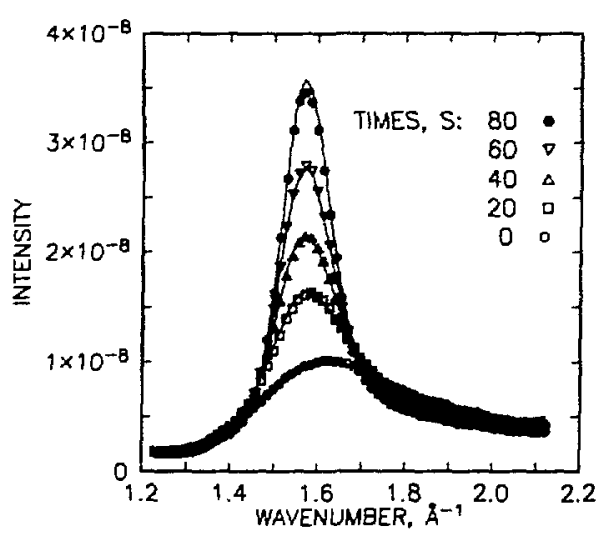

Fig. 2.Theoretical fits to the scattered intensity near (100) at five times after the quench shown in Fig. 1.

'D. de Fontaine, Acta metall. 23,553 (1975).

${ }^{2}$ Y. Noda, S. Nishihara, and Y. Yamada, J.Phys. Soc. Jap. 53,4241 (1984).

${ }^{3}$ G. B. Stephenson, to be published in the Proc. Sth Nat. Conf. on Synch. Rad. Instr., Madison, WI (1987).

${ }^{4}$ S.C. Moss, Local Arrangements Studied by X-ray Diffraction, edited by J.B. Cohen and J.E. Hilliard (Gordon and Breach Science Publishers, New York, 1966), pg. 95.

-This work supported in part by the National Science and Engineering Research Council of Canada. 
A. Braslau, B. Ocko, P.S. Pershan, D. Schwartz, and G. Swislow, Physics Department and Division of Applied Sciences, Harvard University, Cambridge, MA 02138

We have carried out $x$-ray reflectivity measurements from the free surface of mixtures of 4-cyano-4'-nnonyloxybiphenol $(9 \mathrm{CB})$ and $4-c y a n o-4^{\circ}-n-d e c y l o x y b i p h e n o l$ (10CB) at $X 22 B$. If the phase diagram for mixtures of $8 C B, 9 C B$ and $10 C B$ is plotted as though the concentration $n$, of $n C B$, is a cont inuous intensive variable, then for small concentrations of $10 \mathrm{CB}$, there is a first order nematic to smectic-A phase transition. The pure 9CB is near a tricritical point and for all mixtures that would have a value of ns9 the nematic to smectic-A transition is second order. I A1l previous measurements of nematic phases that undergo second order transitions to the smectic-A phase indicated that the surface induced smectic orter penetrates into the bulk exponentially with a penetration length that is equal to the bulk correlision length $\xi I(T)$. Our present measurenents show that for a system in which the transition is first order, the surface induced order penetrates into the bulk from two to four times further than the bulk correiation length. This is analogous to wetting phenonena and we are in the process of analyzing that data.

Partially supported by the National Science Foundation through Grants DMR-86-14003, DMR-85-13523

i. J. Thoen, H. Marynissen, and W. Van Dael, Phys. Rev. Lett. 52, 204 (1984). 
Doon Gibbs, K.M. Mohanty, Brookhaven National Labaratory, Upton, NY 11373

and Jakob Bohr, Riso National Laboratory, OK-4000 Roskilde, Denmark and Brookhaven Mational Laboratory. Upton, H.Y. 11973

During the last several years magnetic x-ray scattering experiments have been performed on a growing number of magnetic materials, which now include both bulk and thin film ferromagnets and antiferromagnets (1-4). For long-period modulated magnetic structures the high resolution available from synchrotron radiation and the sensitivity of x-rays to modulations of the charge density have particularly motivated the use of synchrotron techniques. In recent $x$-ray studies of rare earth metals, for example, new lock-in behavior and additional peaks, arising from lattice modulations accompanying magnetic ordering, were discovered (2). The explanation of these effects in terms of competing exchange and magnetoelastic interactions has led to a new description of the magnetic structure of rare earths based on the concept of spin discomensurations or spin slips. In contrast to the rare earth metals the magnetic structure of chromium lacks a wll localized moment and is described by an itinerant spin density wave (SDW). In addition to the magnetic scattering located at $Q, x$-ray and neutron scattering studies have estabijshed the existence of higher harmonics at 20 and 30 . The scattering at 20 is believed to arise from a charge density wave accompanying the spin density wave or to exchange striction.

We have performed a high resolution $x$-ray scattering study of the charge density wave modulation in chromium at the National Synchrotron Light Source on X22B, using 2 mrad unfocused radiation of wavelength 1.7A. A single bounce Ge(111) monochromator was employed with a standard six-circle spectrometer and Ge(ill) analyzing crystal, all diffracting within the horizontal plane. The crystal was an oriented $4 \times 4 \times 0.1(\mathrm{~m})^{3}$ square ((100) normal to large face) grom from the melt and strain annealed at $1700 \mathrm{C}$ for two days. The wave vector at 20 was found to vary continuously between $170 \mathrm{~K}$ and $10 \mathrm{~K}$, consistent with the results of earlier neutron diffraction studies of the magnetic wave vector at 0 .

Figure 1. Temperature dependence of the distinguish different cycles of the temperature taken with different thermometers. The dashed line is a horizontal reference. The arrow indicates the spin-flip temperature near 122K. scattering at 20 . Open and closed circles

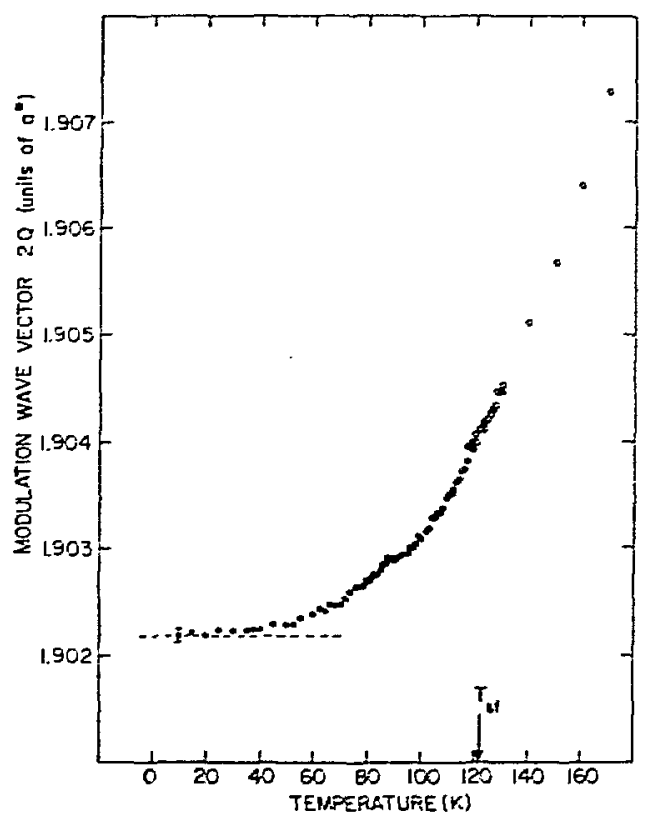

1. M. Brunel and F. de Bergevin, Acta Cryst. A37, 324 (1981); F, de Bergevin and M. Brunel, Acta Cryst. A37, 314 (1981).

2. D. Gibbs, D.E. Moncton, K.L. D'Amico, J. Bohr, and B. Grier, Phys. Rev. Lett. 55, 234 (19:35); 0. Gibbs, J. Bohr, J.D. Axe, D.E. Monctón, and K.L. D'Amico, Phys. Rev. B34, 8182 (1986); J. Bohr, 0. Gibbs, D.E. Moncton, and K.L. D.Amico, Physica 140A, 349 (1986).

3. C. Vettier, D.B. Mchan, E.M. Gyorgy, J. Kwo, B.M. Buntschuh, and B.W. Batterman, Phys. Rev. Lett. 56,757 (1986).

4. A. Goldman, K.L. Mohanty, G. Shirane, P. Horn, R.L. Greene, C. Peters, J. Thurston, and R.J. Birgeneau, (submitted to Phys. Rev. B). 
HIGH RESOLUTION SYNCHROTRON X-RAY STUDY OF THE STRUCTURE OF La ${ }_{1 .} \mathrm{Ba}_{\cdot 2} \mathrm{CuO}_{4-y}$

S.C. Moss, K. Forster, Department of Physics, University of Houston, Houston, TX 77004

J.D. Axe, H. You, D. Hohlwein*, D.E. Cox, Department of Physics, National Synchrotron Light Source, Brookhaven National Laboratory, Upton, New York 11973

P.H. Hor, R.L. Meng and C.W. Chu**, Department of Physics, Space Vacuum Epitaxy Center, University of Houston, Houston, TX 77004

$x$-ray diffraction of $\mathrm{La}_{1},{ }_{8} \mathrm{Ba} .{ }_{2} \mathrm{CuO}_{4-y}$ reveals two macroscopically segregated tetragonal ( $\mathrm{K}_{2} \mathrm{Ni}_{4}-t y p e$ ) phases of nearly identical lattice parameter $\left(\Delta a / a m \Delta C / C=10^{-4}\right)$. These peaks show additional broadening

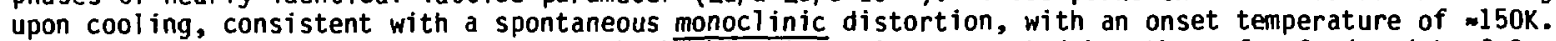
These data are inconsistent with the orthorhomic distortion resported by others for $\mathrm{Sr}_{-\mathrm{doped}} \mathrm{La}_{2} \mathrm{CuO}_{4} \cdot$ By carefully reducing the size of the highly collimated synchrotron $x$-ray beam we were able to isolate and study individual $-70 \mu m$ single cyrstals in the powder aggregate, using a novel high resolution Weissenberg camera that we have developed. These experiments confinn the interpretation of the powder data, and show that major and minor phases can coexist within a single macroscopic crysta). The brightness of a synchrotron $x$-ray source was essential for these high resolution powder and single crystal diffraction experiments. The observations of a minor phase in this sample, and al so in a series of Sr-substituted compounds, 1 suggest phase separation within a nominally single-phase field as a motif in these oxides. The form and extent of this phast separation may depend both upon elastic anisotropy and on therma? and/or oxygen treatment.

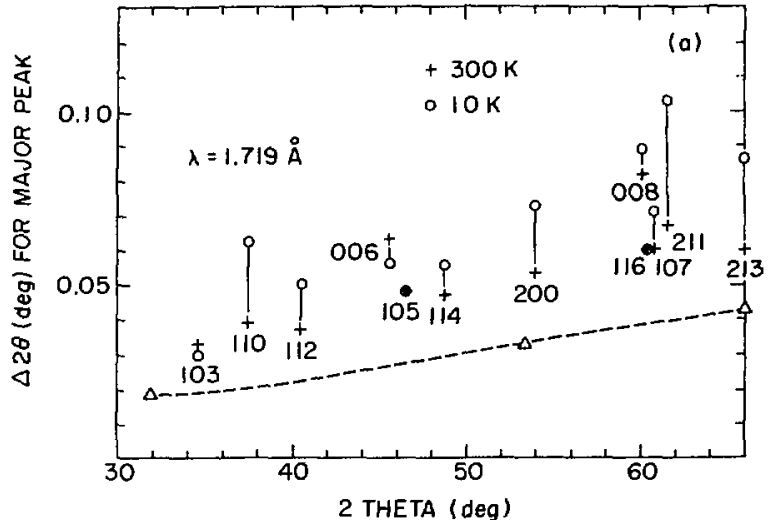

Fig. 1. FWHM $(\Delta 2 \theta)$ of all of the measured Bragg peaks at 300 and $10 \mathrm{~K}$; the dashed curve is the measured instrumental width. Many peaks show an unusual broadening as the temperature is lowered.

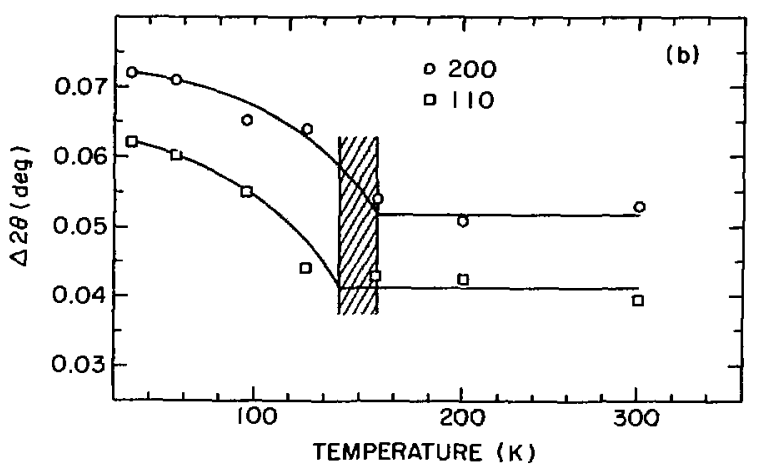

Fig. 2. The widths of the $(200)$ and (110) peaks vs. temperature, revealing a "transition region" at about 130-150K. Uncertainties in $\Delta 2 \theta$ are about $\pm 0.005^{\circ}$.

1. D.E. Cox, S.C. Moss, P.H. Hor, R.L. Meng, and C.W. Chu (unpublished). 
G. Swislow, A. Braslau, B. Ocko, P.S. Pershan, and D. Schwartz, Physics Department and Division of Applited Sctences, Harvard University, Cambridge, MA 02138

We have performed $x$-ray reflectivity measurements from the surface of the lyotropic liquid crystal formed from Cesium-perfluoro-octanoate (CSPFO) and water as a function of temperature for the surface of both the isotropic and nematic phases using the free surface liquid spectrometer at $\times 228.1$ Preliminary analysis indicates that the surface induced smectic order in the nematic phase penetrates into the bulk exponentially with a characteristic length that is equal to the longitudinal correlation length for critical fluctuations in the bulk. This is identical to the behavior of surface induced order that we have previously observed for thermotropic nematic surfaces when the nematic to smectic-A transition is 2nd order. On the other harld the angular dependence of the peak in the specular reflectivity has a dispersive type of line shape, in contrast to the absorptive shape that is typically observed at the surface of all thermotropic nematic phases. This data is currently being analyzed.

As demonstrated with the thermotropic samples, the critical scattering from the bulk phase below the surface can be measured using the free surface liquid spectrometer. The advantage, however, is that the presence of a free surface often results in considerably improved al ignment of the bulk phase. Measurements of the critical fluctuations in the bulk of CsPFO have a very different line shape than that of typical themotropic nematic phases, suggesting that $\xi$ may be larger than $\xi 1$. This is particular interesting since thermotropic liquid crystals always have $\xi 1$ longer than $\xi \downarrow$. In view of the fact that the nematic unit in the micelles formed by CSPFO are believed to be oblate, or disk shaped, while the molecules that form thermotropic nematic phases are prolate, or rod shaped, the difference in the ratio of the correlations lengths appears to be directly related to the shape of the nematic unit. This data is currently being analyzed.

Partially supported by the National Science Foundation through Grants DMR-86-14003, DMR-85-13523 and by the Joint Services Electronics Program (U.S. Army, Navy, and Air Force) through Grant JSEP No. No0014-84-K-0465.

1. B.D. Larson and J.D. Litster, Molecular Crystals and Liquid Crystals 113, 13 (1984); N. Boden, P.H. Jackson, K. M.Mullen and M.C. Holmes, Chem. Phys. Lett. 65, $476(1979)$; Charles Rosenblatt, Satyendra Kumar and J.D. Litster, Phys. Rev. A19, 1010 (1984). 
Hoydoo You and J.0. Axe, Physics Department, Brookhaven National Laboratory, Upton, New York 11973 Dietmar Hohlwein and J.B. Hastings, National Synchrotron Light Source, Brookhaven National Laboratory, Upton, New York 11973

In the conventional description of a metal, the conduction electrons are uniformly distributed in a background of ion cores and, to a good first order approximation, behave independently. Because this nearly free electron model has not explained certain properties of even the simplest metals, such as $K$, $\mathrm{Na}, \mathrm{Rb}$, and $\mathrm{Cs}$, an alternative model was suggested by $\mathrm{A} . \mathrm{W}$. Overhauser 25 years ago. One direct consequence of CDW phenomena is a periodic modulation of ion-core lattice to neutralize the CDW's which should produce a unique pattern of satellites around Bragg peaks in diffraction experiments. Despite several diffraction studies CDW satellites have not been found unt il recently Giebultowicz, overhauser, and Werner ${ }^{1}$ performed a key neutron diffraction experiment and reported the observation of cDW satellites in a single crystal of potassium. Since the discovery of cDW satellites have profound effect on the fundamental description of simple metals, we performed synchrotron x-ray diffraction study on single crystals of potassium to further explore satellites not accessible by the neutron study. The reported satellite intensity at A-D positions shown in Fig. 1 were $1.5 \times 10-5$ of (110) Bragg intensity and the other expected satellites were obscured by the nearby strong Bragg reflection in the neutron study. With high momentum-resolutions due to the extremely high collimation of synchrotron radiation, we were able to scan all the satellite positions (marked by letters) with a sensitivity of 10-7 (110) Bragg intensity. We have been unable to confirm the existence of any of the CDW satellites in spite of such high sensitivity. It is possible that the Cow satelitites are much broader than the Bragg peaks in potassium and thus escape detection in our high resolution experiment although they would appear sharp with the poorer resolution of neutron experiments. We therefore performed additional experiments with somewhat reduced sensitivity but with resolution comparable to that of the neutron study. These experiments al so failed to reveal COW satellites. Our results ${ }^{2}$ are summarized in Fig.2, which shows the range of CDW satellite integrated intensity (-COW strength) and width (-inverse CDW coherent length) which are compatible with our observations.

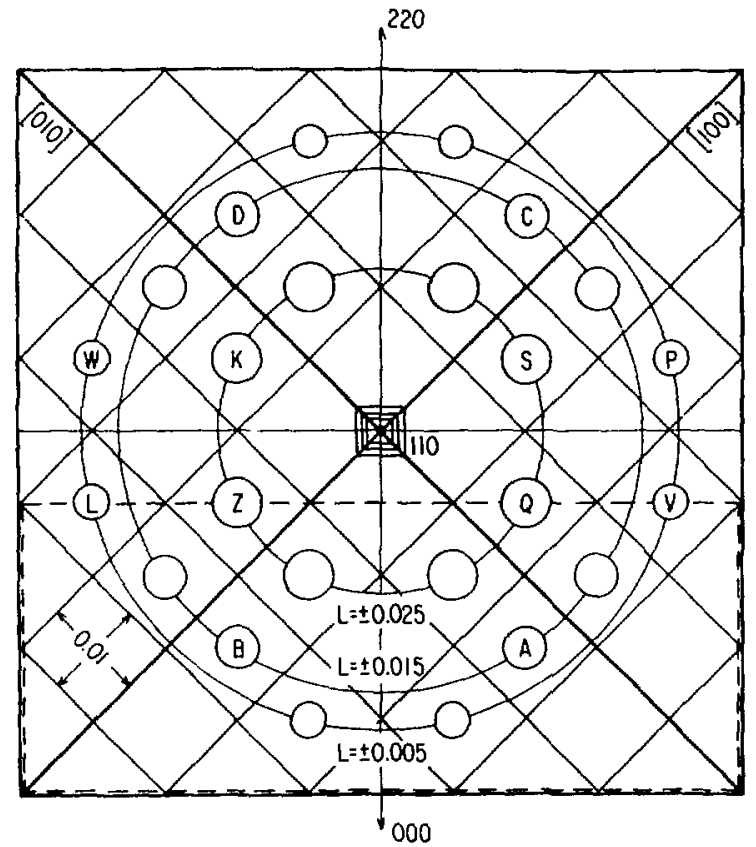

Fig. 1. (hk0) plane around (110). Twelve COW satellites positions with highest predicted intensities are marked by letters. All the CDW satellites (small circles) are located on the surface of a sphere (big circles) around $(110)$. The satellites on a same large circle have the same $L$ value as specified.

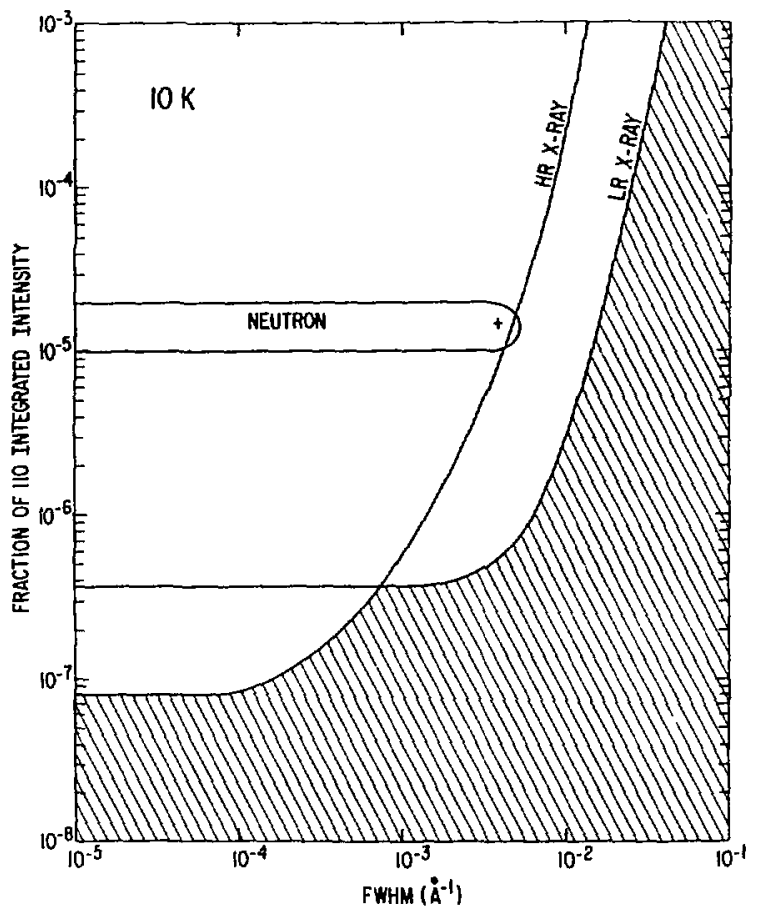

Fig. 2. Detectability diagram of our measurements The area MEUTRON is the assumed confidence region of the neutron study. The unshadowed region is rejected with the $99.5 \%$ significance test.

* Supported by Division of Materials Sciences, I.S. Department of Energy, under Contract No. DE-AC02-76CH0OO16.

1. T.M, Giebultowicz, A.W. Overhauser, and S.A. Werner, Phys, Rev. Lett. 56,1485 (1986).

2. H. You, J.D. Axe, D. Hohlwein, and J.B. Hastings, Phys. Rev. B35, 9333 (1987). 


\section{X-RAY REFLECTIVITY FROM SOLID SURFACES}

I. Tidswell, B. Ocko, and P.S. Pershan, Physics Department and Division of Applied Sciences*, $\star \star$ Harvard University, Cambridge, MA 02138, S. Wasseman and G. Whitesides, Chemistry Department*, Harvard University, Cambridge, MA 02138, J.D. Axe, Department of Physics, Brookhaven National Laboratory, Upton, NY 11973

We have continued our studies of the $X$-ray reflection from silicon surfaces using the Harvard MRL Rotation Anode X-ray Source (RAXS) and X22-B beam 1 ine at NSLS. We have investigated the structure of silicon surfaces coated with silanes of varying hydrocarbon length and terminations (straight chain hydrocarbons of the form $\left.\mathrm{SiO}_{3}-(\mathrm{CH} 2) n-X\right)$. The silicon is bonded to the surface silicon oxide layer and cross linked to other silane molecules. For normal alkanes the termination group $x$ is simply $\mathrm{CH}_{3}$ however we have studied samples where $X$ is $-\mathrm{COOH}$ and $\mathrm{CB}_{3}$. The layers were formed as self assembling monolayers from solution.

From analysis of the ratio of the measured reflectivity to the ideal reflection from a sharp, flat surface the electron density normal to the surface can be determined. Destructive interference between $x$-ray's reflected from the hydrocarbon-air and the hydrocarbon-silicon oxide interface determine both the thickness and homogeneity of the coating. The thickness of the coating agrees with the values inferred from optical ellipsometric measurements to within $10 \%$ of the molecular length. In addition, non-harmonic interference minima were found at larger angles suggesting other subtle aspects of the surface structure.

We have found previously unreported $x$-ray damage of the monolayers and XPS analysis of the damaged has identified the change to be the oxidation of carbon atoms in the silane chain. This damage affects the specular reflection at large angles and was detected through a large reduction in the contact angle with water where the $x$-rays had illuminated the surface.

The structure of the silanes have been analyzed by taking the Fourier transform of the normalized reflectivity to directly obtain the autocorrelation of the derivative of the surface density profile normal to the surface. Although the previous analysis technique, in which the reflectivity was calculated from hypothetical models of the surface density profile, was able to explain the observations it was not possible to prove uniqueness of the density profile.

The basic results from both analysis techniques is that the width of the interfaces between the vacuum/hydrocarbon and hydrocarbon/silicon oxide layers are both approximately 3 Angstroms when the coatings are fully formed. Partially fomed silane layers are shorter suggesting tilted molecules. addition the width of the vacuum/hydrocarbon interface in partially formed layers is larger (i.e. 5 Angstroms) than the corresponding interface with the fully coated layer.

There is a $\mathrm{SiO}_{2}$ layer on the surface of the bulk Si that is generally believed to be between $10 \mathrm{~A}$ and $20 \AA$ thick. We have found preliminary evidence of this layer but further experiments will be necessary to confim this interpretation. We have also investigated the use of $x$-ray scattering to study the physical effects of chemical changes in the silane monolayers through changes in the termination.

Partially supported by the National Science Foundation through Grants DMR-86-14003*, and by the Joint

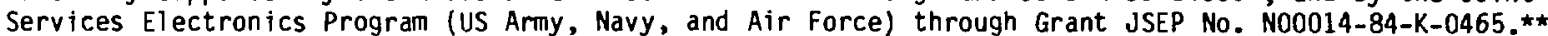




\section{X-RAY IMAGING FOR MICROTOMOGRAPHY AND MICRORADIOGRAPHY ${ }^{1}$}

Ronald C. Dobbyn (NBS), Hasao Kurlyama (NBS), and Shozo Takag1 (ADA)

Success in achieving one micrometer or better spatial resolution in two-dimensional $x$-ray imaging is dependent on three prime factors: (1) providing a sufficiently parallel incident beam (2) at sufficiently high flux levels and (3) providing two-dimensional imaging detection with sufficient spatial resolution and sensitivity. The highly-parallel, monochromatic, variable-area beam ( $5-30 \mathrm{keV}$ ) available at the X-23-A3 beamline and the use of two-dimensional diffraction image magnification ${ }^{1.2}$ before detection have been used to demonstrate a unique approach to achieving these goals.3,4,5

Progress toward providing a high-resolution microtomography capability at the X-23-A facility was made during this reporting perlod. Two-dimensional imaging of biomaterials, ceramics and alloys was continued. Radiographic images, magnified up to $120 \mathrm{X}$ (13.2 keV) before detection were obtained. At higher magnification levels evidence of polishing artifacts in the $x$-ray optics has become evident. However, one micrometer spatial resolution after image magnification, with existing image detector technology, has been achieved and flux levels have been sufficient for real-time video display. Scatter rejection, inherent in the $x$-ray image magnification process, is dramatic.

An AT/PC-based image processing computer and peripherals for use at the beamline have been received. This limited image analysis capability will provide the capacity for differential absorption microtomography, microradiography and depth-profiling in diffraction imaging as well as verification of successful data acquisition for complete tomosynthetic reconstruction on much larger computers. A complete implementation of this system awaits restoration of operations at the $x$-ray ring.

1. W. J. Boettinger, H. E. Burdette, M. Kuriyama, Rev. Sci. Instr. $\underline{50}$ (1979) 26 .

2. W. J. Boettinger, R. C. Dobbyn, H. E. Burdette, and M. Kuriyama, Nucl. Instr. and Meth. 195 (1982) 355 .

3. S. Takagi. L. C. Chow, W. E. Brown, R. C. Dobbyn and M. Kuriyama, Nucl. Instr. and Meth. $\underline{222}$ (1984) 256.

4. S. Takagi, L. C. Chow, W. E. Brown, R. C. Dobbyn and M. Kuriyama, J. Dent. Res. 64 (1985) 866 .

5. M. Kuriyama, R. C. Dobbyn, S. Takagi and I. C. Chow, Medical Physics 14 Nov-Dec 1987. To be published.

\footnotetext{
${ }^{1}$ Work supported by IMSE, NBS and USPHS Grant DE 05030
} 
TOTAL REFLECTION EDXRF USING MONOCHROMATIC SYNCHROTRON RADIATION: APPLICATION TO SELENIUY IN BLOOD SERUM ${ }^{1}$

Ronald C. Dobbyn (NBS), Peter A. Pella (NBS)

Several papers have recently appeared which describe the salient features of synchrotron $x$ radiation for the EDXRF analysis of metals at $\mathrm{ng} / \mathrm{g}$ (ppb) levels. Because of the small source size and natural collimation of synchrotron radiation exiting the storage ring, $x$-rays can be directed with high precision at small glancing angles to the specimen and are particularly effective for use in the total reflection geometry. In addition, the high degree of polarization, high intensity, and continuous tunability of the beam energy are contributing factors for obtaining good analytical sensitivity.

The motivation for this work stems from the need for a blood serum reference material in which the selenium content, present at natural levels (e.g., 30-100 ppb), is known. Selenium in pure solutions and in NBS-SRM 1643b (Trace Elements in Water) was also measured for comparison. Minimum detection and quantitation limits (mdl) were calculated to characterize instrumental performance with the intent of developing a sensitive analytical method for the certification of such elements at ppb levels in future NBS SRMs.

The instrumentation at the NBS beamlines (port $\mathrm{X}-23 \mathrm{~A}$ ) was designed at NBS for diffraction imaging, spectroscopy, small angle scattering and energy dispersive experiments and has been described elsewhere.[1] The $x$-ray beam energy is tunable from 5 to $30 \mathrm{keV}$ with a bandpass of 0.018 (at $8 \mathrm{keV}$ ), using a pair of asymetrically-cut, flat silicon (111) crystals. For the total reflection geometry experiment the X-23-A3 micropositioning facilities were easily adapted to the scheme shown in Figure 1. An mdl of $8 \mathrm{ppb}$ was determined for selenium in human blood serum and in proposed NBS-SRM 1598 bovine serum. The results show that this method is sufficiently sensitive for analysis of $\mathrm{Se}$ in blood serum. Se is present at about 30-100 ppb in human blood serum and about $40 \mathrm{ppb}$ in NBS-SRM 1598. The lowest concentration of senium measured was $9.7 \pm 0.5 \mathrm{ppb}$ in NBS-SRM 1643b-Trace Elements in Water where a mdl of $0.6 \mathrm{ppb} \mathrm{Se}$ was obtained. Spectra are shown in Figure 2. Mdl's were also calculated to compare relative sensitivities of tube-excited secondary target conventional sources when illuminating a large sample area with NSLS excitation when probing a much smaller sample area.

Although this technique was examined in light of possible applications to non-destructive analysis, one should not lose sight of the fact that with appropriate sample dissoiution, matrix separation and concentration of the analyte in small volumes, the sensitivity can be greatly increased and the analysis of samples containing trace elements at sub-ppb levels should be possible providing always, of course, that the blank is acceptable.

(1). R. Spal, R. C. Dobbyn, H. E. Burdette, G. G. Long, W. J. Boettinger and M. Kur1yama, Nucl. Instr. Meth. 221, 463 (1984).

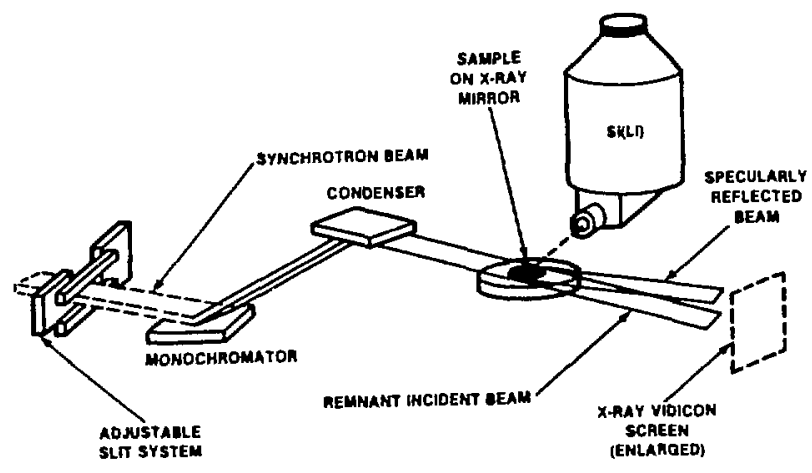

Figure 1 .
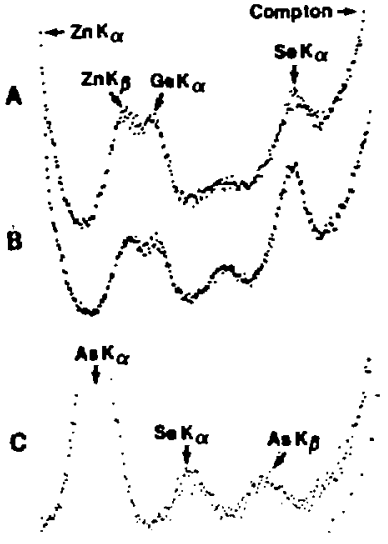

$\mathbf{0}$

Figure 2.

${ }^{1}$ Work sponsored by the Department of Commerce at the National Bureau of Standards 


\section{ANGLE-RESOLVED IMPERFECTION SCATTERING IN DIFFRACTION IMAGING ${ }^{1}$}

\section{Ronald G. Dobbyn (NBS), Bruce Steiner (NBS), and Masao Kurfyama (NBS)}

The quantitative analysis of the microstructure of materials revealed in diffraction images (topographs) requires a thorough analysis of the scattering of photons producing the images. The intensity distribution (contrast) observed in these complex tmages depends upon the glancing angle even at slight deviations from the Bragg condition, and arise from two basic phenomena, misorientation contrast and extinction contrast. Misorientation contrast is produced by dynamical diffraction from otherwise perfect crystal regions (mosaic blocks) which are separated by subgrain bounderies and are slightly misoriented with respect to one another or are misorlented in a continuous fashion as the result of homogeneous strain fields. Contrast occurs when beams diffracted from these regions separate or overlap. For a sufficiently parallel incident beam subtle contrast occurs when different blocks diffract from different parts of the rocking curve. In this case, there is no additional divergence introduced in the diffraction process $(\Delta k=0)$; such intensity distributions can be explained adequately by perfect crystal diffraction theory. Extinction contrast is the result of scattering of the dynamically propagating photon field within the crystal by imperfections (e.g. dislocations, voids, stacking faults, localized non-homogeneous strains, etc.). Therefore, additional divergence is imparted to the beams that make up the image ( $\Delta k \neq 0)$. This divergence mantfests itself in the blurring of these imperfection images when the detector is placed too far from the diffracting sample and also in the additional increase in the acceptance angle for diffraction from the sample (mistakenly called "larger rocking curve width" since rocking curve is an attribute of perfect crystal theory). Dynamical theories for a perfect crystal cannot describe this phenomenon. It is possible to describe this imperfection scattering analytically 1,2 ; the results of this analysis lead one to attempt a line-broadening analysis of the imperfection images. However, only recently have the means to carry out such experiments become available. Very bright $x$-ray sources of small emittance and high-quality $x$-ray optics are required to produce the very parallel incident beam and analyzer crystals needea for an unambiguous analysis. ${ }^{3}$

Preliminary experiments were conducted at the X-23-A3 beam line in February, 1987 for the purpose of determining flux levels and qualifying analyzer optics. The images shown below are of the (004) symmetric surface reflection from the central region of an In-doped GaAs wafer, viewed through an analyzer crystal set for (333) symmetric diffraction of $10 \mathrm{keV}$ photons. The object of the experiment is to accept or reject, at will, the misorientation (perfect crystal) contribution to the image. When successfully rejected, one is left with only that contribution to the image from imperfection scattering. Image (a) is that of the complex diffraction image (misorfentation contrast plus imperfection scattering); image (b) shows the imperfection scattering images only. A simple test for total rejection of the misorientation contrast can be made by checking for contrast reversal (black-to-white) as one rocks the specimen over its range of diffraction (acceptance angle) while viewing the image through the analyzer crystal. Contrast reversal will not be observed if the analyzer crystal is fully rejecting the mosaic contribution. This is easily observed in real time video at the X-23-A3 beamline.

1. M. Kuriyama, J. Phys. Soc. Japan 23, 1369 (1967).

2. M. Kuriyama and G. G. Long, in Application of X-Ray Methods to Materials Science, U.S.France Cooperative Science Seminar, edited by S. Weissman Plenum Press, New York, 97 (1985).

3. R. C. Dobbyn and K. C. Yoo, in Application of X-Ray Methods to Materials Science, U.S.France Cooperative Sclence Seminar, edited by S. Weissman Plenum Press, New York, 241 (1985).

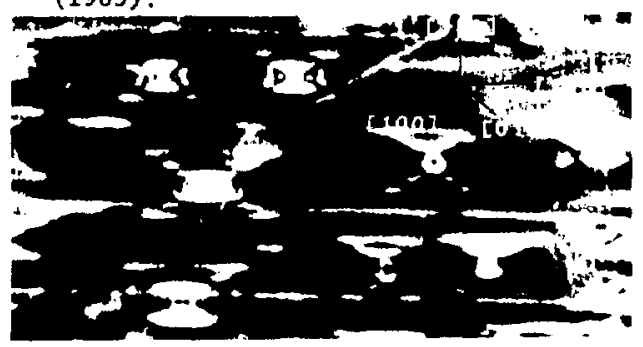

(a)

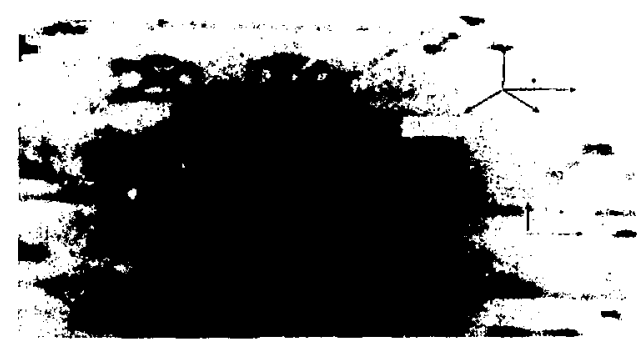

(b)

${ }^{1}$ Work sponsored by the Department of Commerce at the National Bureau, of Standards 
Masao Kurlyama (NBS), Bruce Stelner (NBS), and Ronald C. Dobbyn (NBS)

Orders of magnitude improvement in communication capacity and in the speed of the processing of information in recent years has resulted from major advances in the purity, crystal perfection, and yield of silica and silicon. Continuation of these advances in performance is promised by other materials such as gallium arsenide, especially in modulated structures. For these anticipated advances to be realized, improvement in crystal quality to approach that now achieved in silicon is an essential requirement. In addition, fundamental guidance on the materials structures producing specific properties will be of seminal importance., with the flexibility now promised by the growth of crystals under microgravity, progress in both areas can lead to early application of the results.

Diffraction imaging of high quality crystals will play a central role in addressing both sets of questions, that is both in uniformity and in the determination of superior structures. As an initial aspect of collaborative activity to achieve high quality crystals through their growth in space, we have surveyed the state of the art of crystal perfection of gallium arsenide, both doped and undoped; cadmium telluride; and mercuric iodide. This survey has been undertaken in order to determine the nature and extent of various defects, investigate their origins, and correlate these with their performance.

Each of three samples of undoped gallium arsenide observed displays complex sets of dislocitions, interacting to form a cellular structure, shown in Figure 1 . Linear subgrain boundaries appear and disappear in each of these samples, but not in the doped sample. The structure of an indium doped sample consists of a central faceted region, shown in Figure 2 , surrounded by a peripheral set of circular striations and separated from it by a region reflecting turbulence in the solidification process. Linear arrays of dislocations record slip planes in the outermost circumference.

Four samples of cadmium telluride are all more highly strained than are the gallium arsenide samples. All crystals display rectilinear features, suggesting that these are closely related to the growth process. The large number of mercuric iodide samples all surveyed all contained separate grains, differing in orientation with respect to one another by several degrees around a common crystallographic axis. Rectilinear features in this material, however, closely resembled similar structures in cadmium telluride.

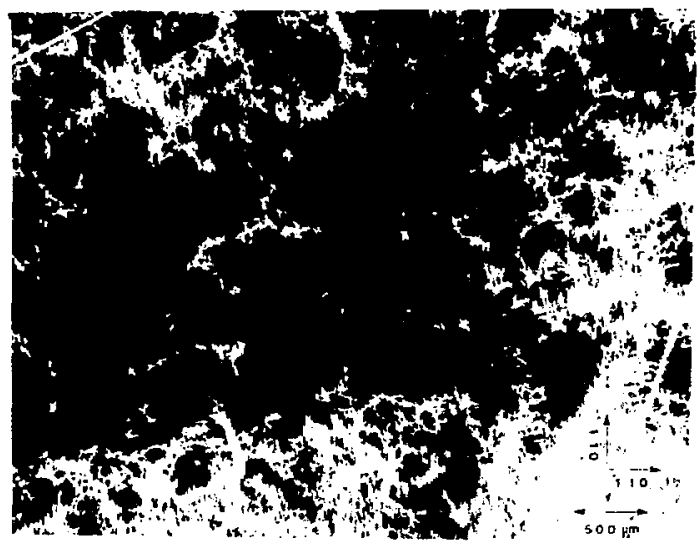

Figure 1. Enlarged portion of transmission (220) diffraction image through an approximately 700 micrometer thick undoped gallium arsenide wafer taken at $10 \mathrm{keV}$. Both Individual dislocations and their interaction, seen as cellular boundarles at lower resolution, are observed.

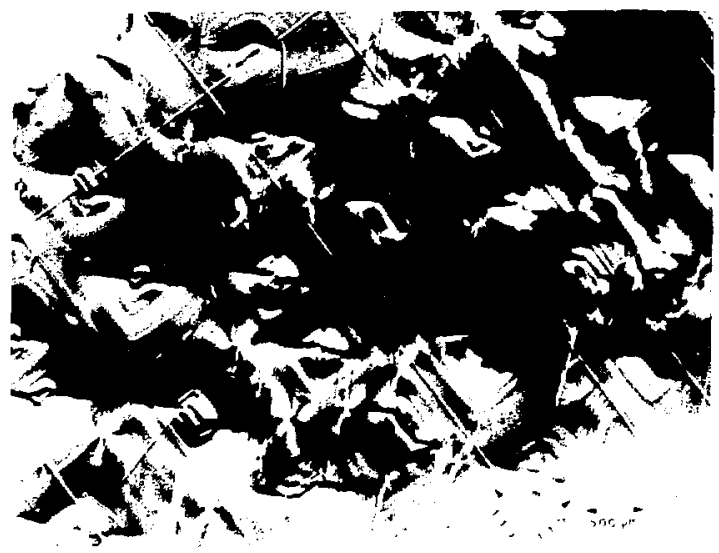

Figure 2. Enlarged central portion of transmission (040) diffraction Image of 800 micrometer thick Indium doped gallium arsenide wafer taken t $10 \mathrm{keV}$. The central, faceted region shown is surrounded by a peripheral region of growth striations.

\footnotetext{
${ }^{1}$ Work performed as a member of the Center for the Development of Crystal Growth in Space, sponsored by the NASA and industrial members of the Center, including Grumman Rockwell
} 
R. Spal (NBS), T. Jach (NBS), D. Novotny (NBS), G. Carver (NBS), and J. Gelst (NBS)

Alignment of a double crystal $x$-ray monochromator requires a method to determine when the second crystal satisfies the Bragg condition. In the past, an ionization chamber or photodiode situated in the exit beam has been used to measure the diffracted power from the second crystal. The detector unavoidably introduces absorption and scattering. This disadvantage would not be serious if the detector were only in the beam temporarily; however, it is desirable to keep it there permanently for rapid monitoring and correction of the alignment.

A new alignment method described in this report is to measure the power absorbed by the second crystal, using a photodfode fabricated directly on the diffracting surface of the crystal. The photodiode may cover the entire surface for maximum sensitivity. As the crystal is rotated through the Bragg condition, the $x$-ray penetration depth passes through a minimum due to extinction. Consequently, the absorption also passes through a minimum. If the pn junction depth is comparable to this minimum $x$-ray penetration depth, then the photocurrent should pass through a minimum at the Bragg condition. This method obviously avoids the disadvantage of the older method.

A photodiode has been fabricated on a silicon <l11> wafer (see Fig. 1). The thickness of the wafer is $2 \mathrm{~mm}$, and the diameter is $5 \mathrm{~cm}$. The starting material is n-type, with a resistivity of $4 \mathrm{ohm}-\mathrm{cm}$. A $2 \times 2 \mathrm{~cm}^{2}$ area is boron doped by thermal diffusion to yield a boron concentration of $1.8 \quad 10^{18} \mathrm{~cm}^{-3}$ at the surface, and a pn junction depth of .54 microns. Aluminum electrodes, .70 microns thick, are deposited along the perimeters of the $p$-type and $\mathrm{n}$-type regions.

The performance of the photodiode has been measured at $8 \mathrm{keV}$. The incident beam was prepared

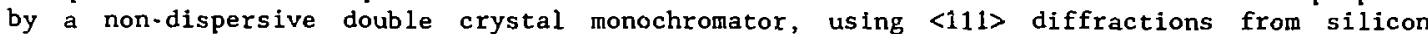
crystals. The diffraction from the first crystal was symmetric, while that from the second was asymmetric, with a magnification factor of eight. This arrangement provides a beam sufficiently parallel to study the rocking curve of the photodiode. Figure 2 shows the power absorbed and diffracted by the photodiode as a function of angular deviation from the Bragg condition. The "absorbed power" is actually just the photocurrent. The diffracted power was measured by another photodiode placed in the diffracted beam. The FWH of both curves is about 10 arcseconds, in agreement with the rocking curve width of 7 arcseconds for perfect single crystal silicon. Thus, the built-in photodiode does not degrade the $x$-ray optical properties of the crystal. Finally, the photocurrent signal is clearly suitable for precise alignment of the crystal.

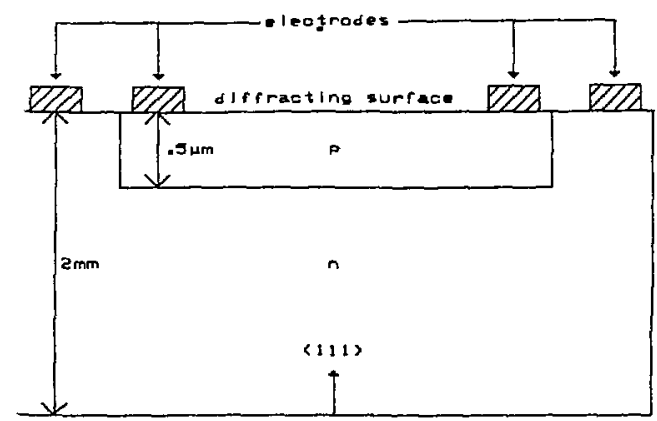

Fig. 1. Photodlode Cross Section

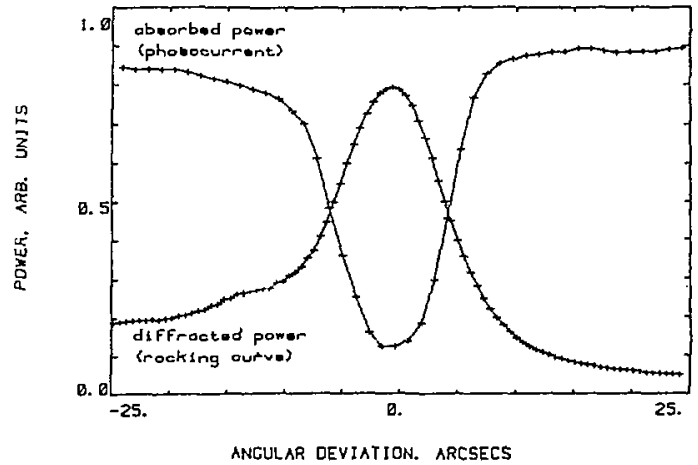

Fig. 2. Photodiode Performance

${ }^{1}$ Work sponsored by the Department of Commerce at the National Bureau of Standards 
Bruce Steiner (NBS), UrI Laor (NBS), Masao Kuriyama (NBS), and Ronald C. Dobbyn (NBS)

Bismuth silicon oxide (BSO) is of interest in advanced approaches to parallel reversible optical signal recording and real time optical signal processing because of its exceptionally large photorefractive and electrooptic response. For ultimate success with such technology, both optimization of these properties and a high degree of material uniformity will be required.

Examination of diffraction images of several slices from a high quality boule of BSo has enabled us to identify four types of microstrain patterns, growth striations, and interface boundaries, and to associate each with distinct aspects of the crystal growth. ${ }^{2}$ Analysis of these strains has led to a detailed understanding of the formation of this material. The model developed suggests ways to realize further improvement in the degree of crystal perfection.

Figure 1 shows a transmission diffraction image of one slice displaying each of the features observed: division into five principal regions common to all slices, a region of high strain observed in two of the three slices, striations in the four peripheral regions observed in all of the slices, and fringes in the central portion of all slices. Figure 2 shows an abstracted version of these regions for this crystal and for the other two.

The striations record growth of the peripheral regions in the $(101)$ directions at $45^{\circ}$ to the principal growth direction, while the fringes record growth of the central region on a surface oriented about $2^{\circ}$ from the crystallographic [001] direction. The regions of high strain are associated with the sudden cessation in the growth of one of the facets, followed by a gradual resumption. The Moiré effect in the central portion of Figure 1 results from strains caused by growth layering at the two faces of the crystal. Rotation in the orientation of the central fringes during crystal growth is correlated with changes in the growth rates of the various facets and thus with the temperature distribution and flow in the melt. The asymmetric growth patterns are associated with these changes in fiow and growth rates.

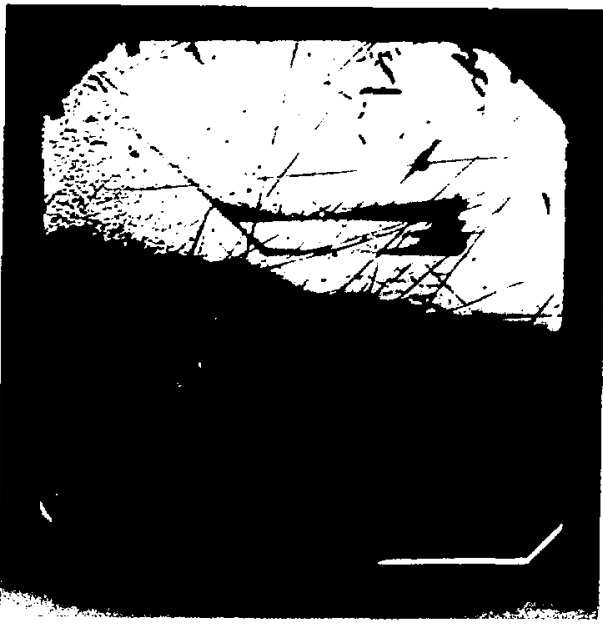

F18. 1. Trensmission (060) diffrection 1mage of slice of BSO crystal taken et $13.4 \mathrm{keV}$. Varlous types of strain are visible, each associeted with distinct espects of the faceted growth of the boule and with the intersection of these stralns with surfaces of the slice.

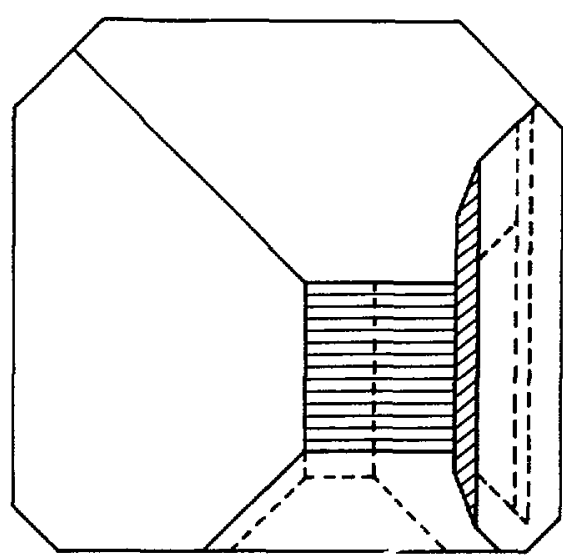

F1g. 2. Abstracted version of the diffraction Image hown in Plgure 1 , In solid lines, and of imilar images of two other crystals from the same boule, in dashed lines. From the changes in position from slice to slice, the faceted grouth of the boule can be declphered.

${ }^{1}$ Work sponsored by the Department of Commerce at the National Bureau of Standards

${ }^{2}$ Bruce Steiner, Uri Laor, Masao Kuriyama, Gabrielle G. Long, Ronald C. Dobbyn, and Armand Tanguay, Jr., "Diffraction Imaging of High Quality Bismuth Silicon Oxide with Monochromatic Synchrotron Radiation: Implications for Crystal Growth, " accepted J. Crystal Growth (1987) 
S. Shih, C. Hor, D. Mueller, a C. R. K. Marrian,

W. T. Elam, P. Wolf, a J. P. Kirkland, ${ }^{C}$ and R. A. Neiser, $c$

Condensed Matter Physics Branch

Naval Research Laboratory

Washington, DC 20375-5000

aNRL/NRC Postdoctorai Fellow

bCode 6831, Surface Physics Branch

CSachs/Freeman Associates, Inc., Landover, MO 20785-5396

Surface EXAFS (Extended $X$-ray Absorption Fine Structure) of near monolayer BaO films on polycrystalline $W$ surfaces has been measured above Ba $L 3$ edge $(\sim 5247 \mathrm{eV})$, with a total electron yield technique in a UHV system. Bond lengths and coordination numbers of the first two atom shells around the barium adatoms were analyzed using the ratio technique. We found that the first two strong features in the fourier transform of the EXAFS spectra, shown in the figure below, were from $\sim 3$ oxygen atoms and $\sim 6$ barium atoms, while no feature was observed attributable to the tungsten substrate atoms. A substantial Ba-0 bond length contraction was observed for the surface BaO species, which is about 2.3 $\mathrm{A}$, in contrast to the $2.76 \mathrm{~A}$ bulk BaO value.

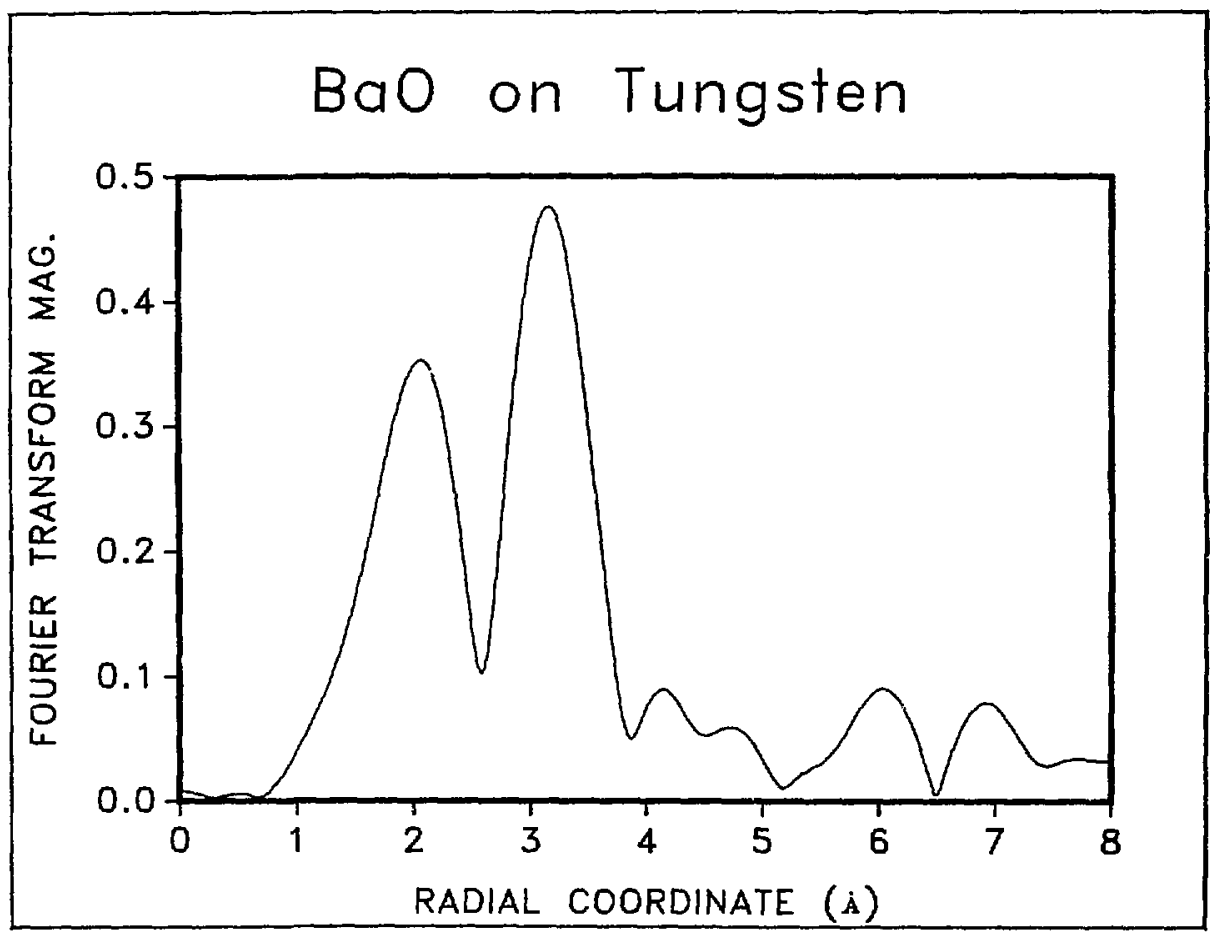




\title{
Escape Depth of Electron-Detection EXAFS
}

\author{
W. T. Elam, J. P. Kirkland, a R. A. Neiser, a \\ and P. A. Wolfb \\ Condensed Matter Physics Branch \\ Naval Research Laboratory \\ Washington, DC 20375-5000 \\ aSachs/Freeman Associates, Inc. \\ Landover, MD 20785-5396
bVirginia Polytechnic Institute and State University \\ B1 acksburg, VA 24061
}

The sensitivity vs. depth into the sample was measured for electron-detection EXAFS as described by Kordesch and Hoffman. Samples consisting of a $100 \mathrm{~A}$ iron $\mathrm{film}$ covered by various amounts of aluminum were used to compare electron yield as a function of aluminum thickness. Measurements made at the iron $K$ edge in vacuum $\left(-10^{-5}\right.$ torr) gave a yield of the order of one electron per photon absorbed in the iron layer (see table below). The depth dependence was exponential with a decay depth of $1500 \mathrm{~A}$. Identical measurements made after filling the detector with one atmosphere of He gas showed an increase in the raw signal of almost a factor of 100 , independent of depth (third column in table). Using a value of $30 \mathrm{eV}$ for the ion-pair production energy in helium, this implies an average electron energy of about $2500 \mathrm{eV}$.

$\begin{array}{rcc}\text { Thickness A } & e^{-} \text {per Photon Absorbed } \\ \text { (vacuum) } & \text { Ratio of He to } \\ \text { Vacuum }\end{array}$




\title{
STRUCTURAL STUDIES OF EPITAXIALLY GROWN POLYCRYSTALUNE DIAMOND
}

\author{
E. F. Skelton, W. T. ELAM, S. B. Qadri", and J. M. Pinneot \\ Naval Research Laboratory, Washington, DC 20375-5000 \\ 'Sachs/Freeman Associales, Inc., Bowie, MD 20715; †Crystallume, Palo Alto, CA 94304
}

The work described in this report was undertaken to examine the possibility of using standard diflraction techniques with both a conventional $x$-ray source and synchrotron radiation to determine the crystallinity of a thin synthetic diamond films. Diamond films were prepared at Crystallume using plasma-enhancad CVD techniques. The films were deposited on a polished (100)-face of a Si single crystal to thicknesses varying trom 0.2 to $0.5 \mu \mathrm{m}$. As a preliminary test of the epitaxial diamond surface effects, several Vickers hardness tests were run. The uncoated Si surface gave a Vickers hardness number of 900 . Sirnilar lests were made of the diamond coating; Vickers hardnesses neat the thinner and thicker regions gave values of 1450 and 1854, respectively. The hardness of $S i$ is in agreement with accepted values, whereas those of the diamond are slightly below that of bulk diamond.

The sample was then mounted on a computer controlled dilfractometer and illuminated with radiation from a $\mathrm{Cu} x$-ray tube operated at $30 \mathrm{kV}$ and $20 \cdot \mathrm{ma}$. A diffraction spectrum was obtained by step scanning from $40^{\circ} 1080^{\circ} 20$ at $0.0167^{\circ}$ intervals and counting for $25 \mathrm{~s}$. at each step. The resulting spectrum, which was collected over a period of $22 \mathrm{~h}$, revealed the presence of the diamond (113) and (220) peaks, but the peak to background ratio was too poor to allow any further characterization.

The sample was then mounted on a second diffractometer, controlled with the same soltware. and illuminated with monochromatized radiation on X23-B. The same $2 \theta$ range was scanned in steps of $0.25^{*}$ at a count duration of $1 \mathrm{~s}$ with the monochromator set at $1.5 \mathrm{~A}$. This spectrum, which was collected in only $10 \mathrm{~m}$. is shown below. From the recorded positions of the diamond (111) and (220) peaks a unit cell parameter of $3.562 \pm 0.005 \mathrm{~A}$ was determined; this is in agreement with the accepted latlice parameler for diamond. Using a calibration standard and assuming zero residual strains in the sample, the Scherrer equation was used in conjunction with the measured breaths of the diamond peaks to eslimate the mean crystallite dimension. A value of $110 \mathrm{~A}$ was determined. These measurements indicate that quality information can be obtained from thin films of low $Z$ materials in relatively short time periods using synchrotron radiation.

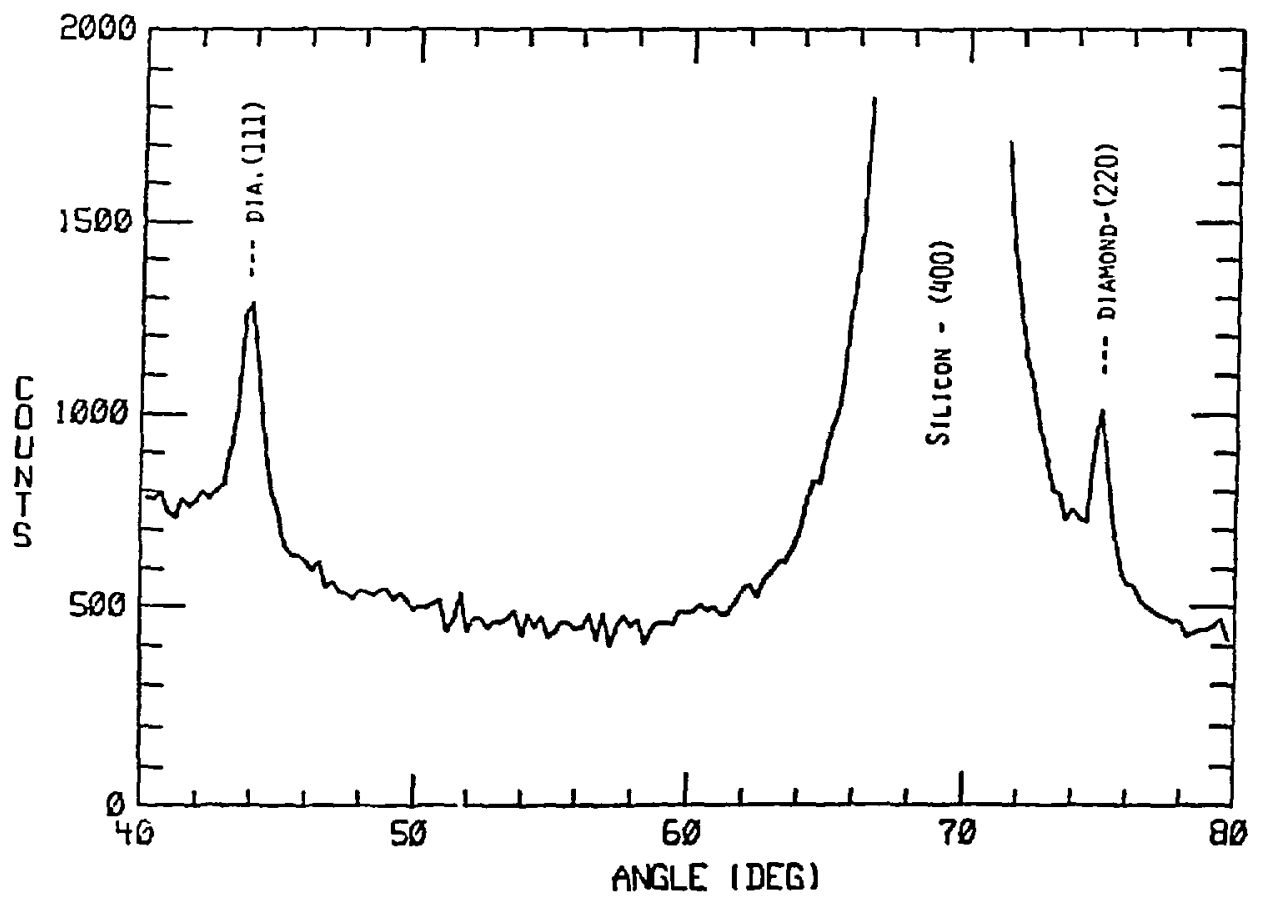


STRUCTURAL ANALYSIS OF PLASMA SPRAYED NICrAIY COATINGS

R.A. Nelser* (Sachs/Freeman), J.P. Kirkland* (Sachs/Ereeman), W.T. Elam (NRL), J. Cocking (NRL), J. Sprague (NRL), S. Sampath (SUNY-SB) and H. Herman (SUNY-SB).

The superalloy NiCrAlY (17\% $\mathrm{Cr}, 6 \% \mathrm{Al}, 0.5 \% \mathrm{Y}$, bal $\mathrm{N1}$ by weight) is commonly used in the aircraft industry as a bigh temperature oxidation resistant coating material. The purpose of this study was to use EXAFS to monitor structural changes in NiCrAlY coatings which were ion implanted with vanadium. The nickel, chromium and vanadium $\mathrm{K}$-edges were studies. Two doses of vanadium (2x10l6 and $2 \times 10^{17}$ ions $/ \mathrm{cm}^{2}$ ) were implanted at $85 \mathrm{keV}$. The vanadium was implanted to a depth of several hundred angstroms. Photoelectron EXAFS spectra were collected from 150 micron thick plasma sprayed coatings. The photoelectron escape depth is approximately $1000 \mathrm{~A}$, which was similar to the implantation depth.

A Fourier transform of the nickel edge EXAFS signal from an unimplanted NiCrAlY coating showed that the nickel matrix had an fcc crystal structure. The transform of the chromium edge data taken from the same coating showed that the chromium atoms also resided in the fcc lattice. Figure 1 gives the vanadium EXAFS transform from the low dose coating. Two coordination shells are clearly resolved. When compared to the nickel and chromium transforms, Fig. 1 indicates that the implanted vanadium had a near neighbor environment similar to nickel and chromium.

The Ion implantation increased the disorder in the NiCrAlY coating. Figure 2 shows the vanadium edge transform of the high dose coating. As compared to Fig. 1, the magnitude of the first shell at 2 A was considerably reduced. Also, note that the ratio of the amplitude of the second shell to the first shell is considerably smaller in the high dose coating than in the low dose coating. The nickel and chromfum transforms from the low dose implanted coating showed less disorder than the high dose, but more than the unimplanted coating.

The coatings were oxidized for 10 minutes at $900 \mathrm{C}$ in an $80 \% \mathrm{Ar}-20 \% \mathrm{O}_{2}$ atmosphere and reexamined using EXAFS, TEM and energy dispersive $x$-ray analysis (EDX). TEM and EDX revealed the presence of $\mathrm{NiO}, \mathrm{NLAl}_{2} \mathrm{O}_{4}$, and Possibly $\mathrm{NiCr}_{2} \mathrm{O}_{4}$ and $\mathrm{NiCrO}_{3}$. The EXAFS data showed that there were no significant changes in the chromium transforms as a function of vanadium dose, and only a small change in the nickel transforms. This result was surprising because it was expected that the vanadium would have a large effect on the oxidation beinavior of the coating.

*This work was performed under contract number No0014-85-C-2628 from the Naval Research Laboratory.

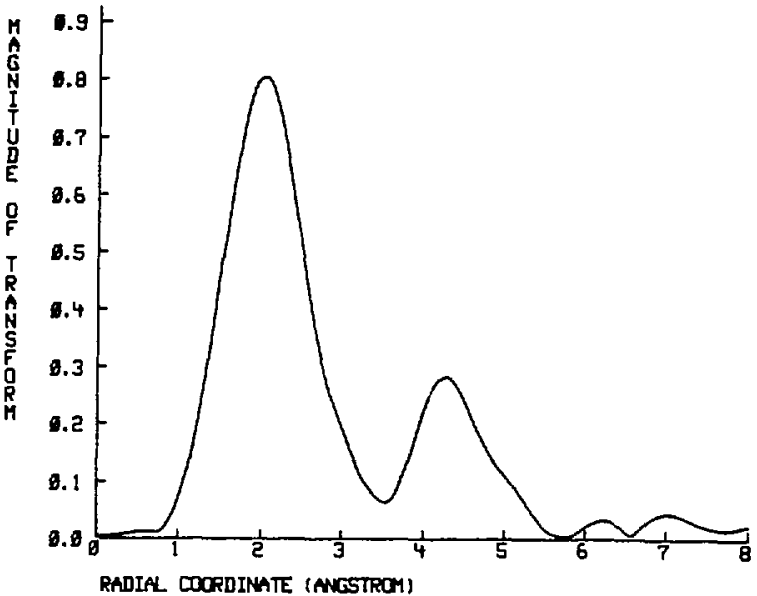

Fig. 1) Vanadium edge transform of low dose NiCrAlY coating.

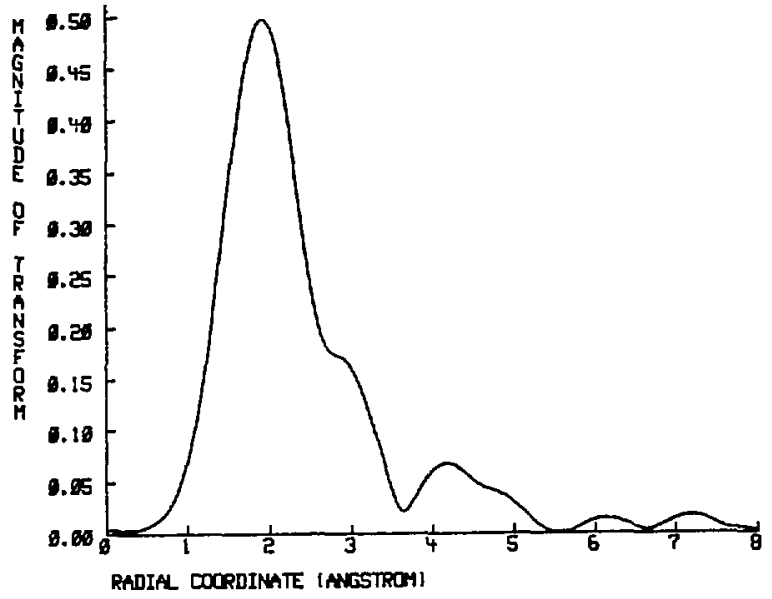

Fig. 2) Vanadium edge transform of high dose coating. 


\title{
RELATIONSHIP OF THE CONCENTRATION-DEPENDENT Ti CENTER
}

TO THE LINbO 3 ORDINARY OPTICAL INDEX

\author{
Perry Skeath, *, W. K. Burns, ${ }^{* *}$ and W. T. Elam \\ Condensed Matter Physics Branch \\ Naval Research Laboratery \\ Washington, DC 20375-5000 \\ *Sachs/Freeman Associates, Inc., \\ 1401 McCormick Drive, Landover, MD 20785-5396 \\ **Code 6571, Optical Sciences Division
}

Using $x$-ray absorption techniques, the $\mathrm{Ti}$ center in congruent $\mathrm{LiNbO}_{3}$ is shown to be concentrationlependent. The change in the Ti center takes place within the concentration range used for integrated optics and involves a displacement in the $x y$ plane of the $\mathrm{LiNbO}_{3}$ crystal lattice perpendicular to the polar axis. Reports in the literature indicate that as the ordinary optical index increases with increasing $T i$ concentration, an abrupt decrease in slope occurs at approximately the same concentration at which our data shows the Ti center itself changes. Simple theory based on a linear-combination-ofatomic-orbitals (LCAO) model suggests that the change in slope of the ordinary index vs. Ti concentration can be accounted for by the observed $x y$ displacement of the Ti.

The figure shows $\mathrm{Ti}$ is $x$-ray absorption data for two samples of $\mathrm{Ti}$-diffused $\mathrm{LiNbO}_{3}$. The curve labeled "diffused (1a)" corresponds to a sample with $5 \times 10^{20} / \mathrm{cm}^{3}$ near-surface Ti concentration. The curve labeled "diffused (hi)" corresponds to a sample with $2 \times 10^{21} / \mathrm{cm}^{3}$ near-surface $T i$ concentration.

\section{$X-R A Y$ ABSORPTION SPECTRA $\mathrm{Ti}: \mathrm{LNBO}_{3}$}

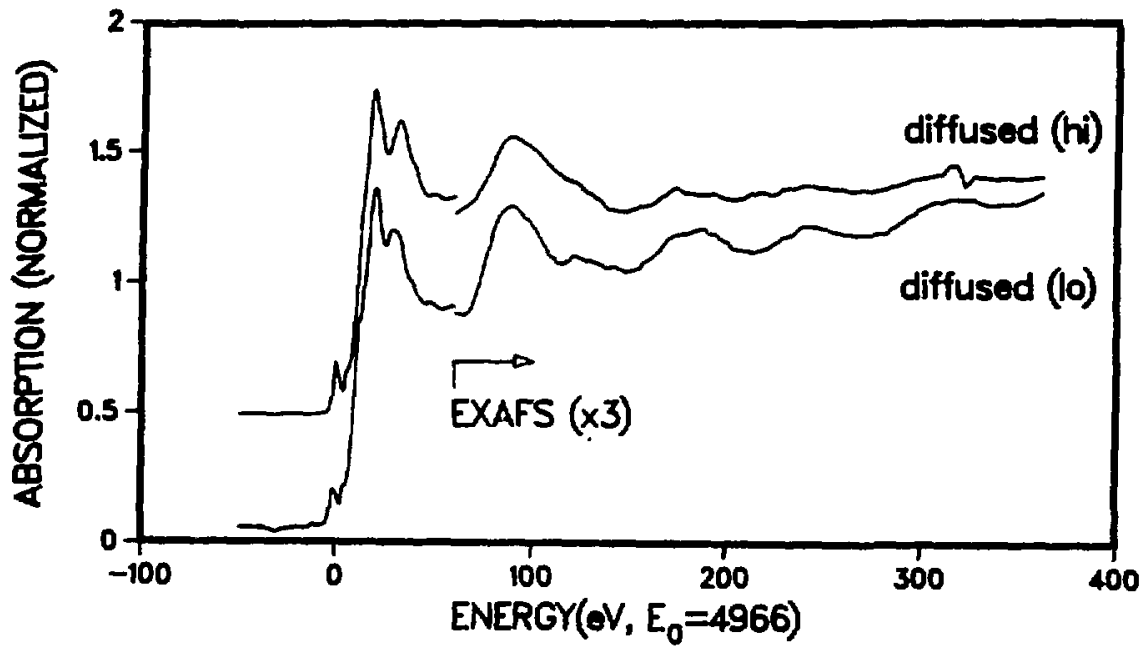


S. Sampath (SURY-SB), H. Herman (SUKY-SB), R.A. IieLsez (IRL), J.P. K1rkland (HRL), W.T. Elam (tiHL) and S. Rargaswanty (lietco).

It 1 a well known that the high velocity deposition of plasma melted particleg, jieldu highly disordered and metastable structures in many metal alloys and ceramics. A ia1-Cr-ko based alloy with a composition tallored to form an amorphous phase during rapld bolidification conditions, was plasma sprayed in alr and low pressure. Plasma spraying under atmsapher lc conditions (APS) generally provides a high rate of quench, due to cold alr cooling of substrate. In vacuum plasma spray ing (VPS) (usually a low presiure of 20-60 mbar), however, due to absence of convective cooling, the Bubstrate temperatures are in excess of $800 \mathrm{C}$.

Figure 1 shows the Fourier transform of EXAFS for the H1-edge in the APS coating. These results have been compared to that of a fully crystalline 11 foll standard. It 1s observed, that the higher order shells in the transform are suppressed with respect to that of a crjstaline materlal and in addition show significantly lower amplitudes. The results indicate absence of long range order in APS coating. Plgure 2 ghows the Pourier transform of the EJAFS for the Cr-edge in the coating. The data indlcates partial oxidation of the Cr during plasma spraying.

The transform for the M1-edge of VPS coating ( $P 1 g$. 3) shows significantly increased ordering as indicated by the increase in amplitudes of the transform. The Cr-edge data (71g. 4) shows that $\mathrm{Cr}$ is substitutional in the PCC lil-lattice in the VPS coating.

This work was supported by liational Sclence Poundation grant number MSM 8513038.

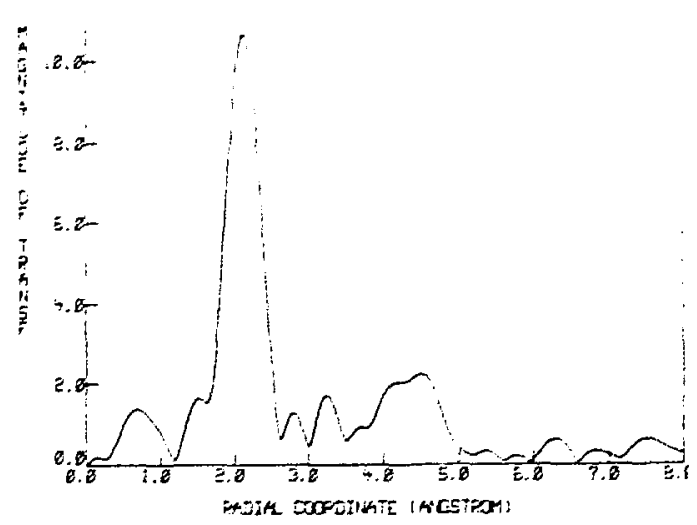

P1g.1 Ni-edge APS coat1ng.

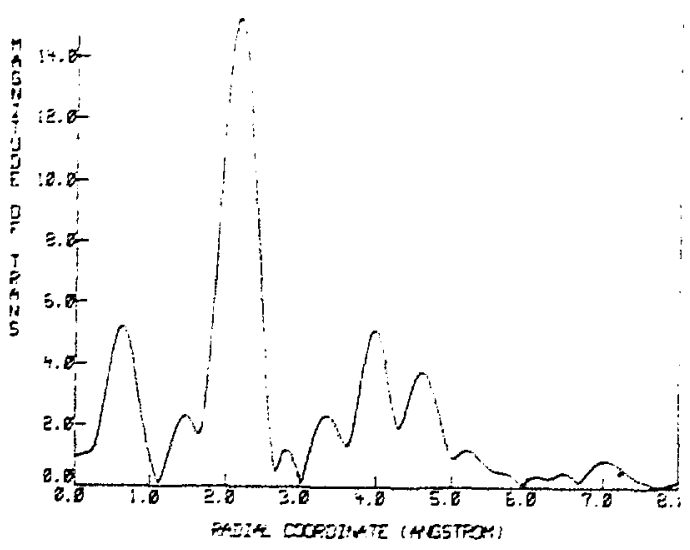

Pig. 3 lil-edge VPS coating.

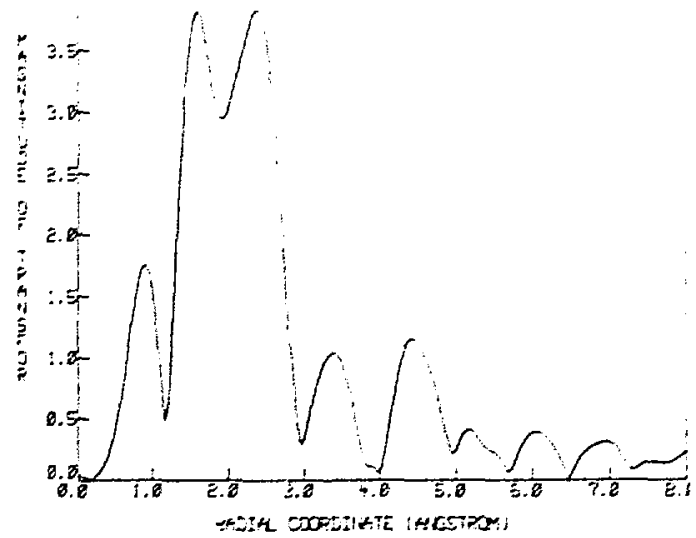

F1g. 2 Cr-edge APS coating.

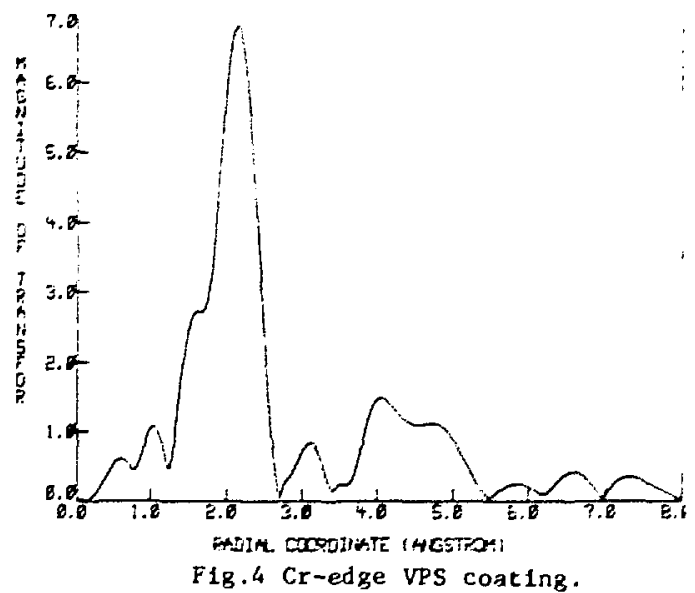


APPEARANCE FOTENTIAI X-TAY FIUORESCENCE SPEOTROSOOPY

J. P. Kirkland*, J. V. Gilfrich* and W. T. Elam

\author{
Condensed Matter Physics Branch \\ Naval Research Laboratory \\ Washington, DC 20375-5000 \\ *Also at \\ Sachs/Freeman Associates, Inc. \\ 1401 McCormick Drive \\ Landover, MD 20785-5396
}

Appearance potential spectroscopy has been practiced for many years. In essence, it simply involves ramping the energy of the exciting quanta across excitation edges and observing the onset of a signal. Because of the relative simplicity with which the energy can be controlled, electrons have been the conventional quanta employed. The signals which have "appeared", characteristic of the atoms being studied, have been either Auger electrons or x-rays. With the availability of variable $x$-ray energy from synchrotron beam lines, it becomes possible to use x-ray excitation to observe the appearance of the $x$-ray fluorescence signal. This technique is simply a variant of fluorescence EXAFS, where the magnitude of the absorption edge jump is a quantitative measure of the number of atoms present. In fact, a single measurement can provide information about the elemental concentration (from APXRF) and local atomic structure (from fluorescence EXAFS). The degree of EXAFS data available depends to some considerable degree on the resolution provided by the beam line monochromator; high resolution is required in many cases. APXRF, on the other hand, benefits from the increased intensity from a low resolution monochromator; a single $y s$ lovice is perhaps the more desirable. Some compromise is necessary when both types of information are required.

The figures illustrate the APXRF/fluorescence EXAFS spectrum of a $24 \mu \mathrm{g} / \mathrm{cm}^{2} \mathrm{film}$ of Fe, measured on beam line $X-23 B$, using two mirrors and a Si double crystal monochromator as the beam 1 ine optics.
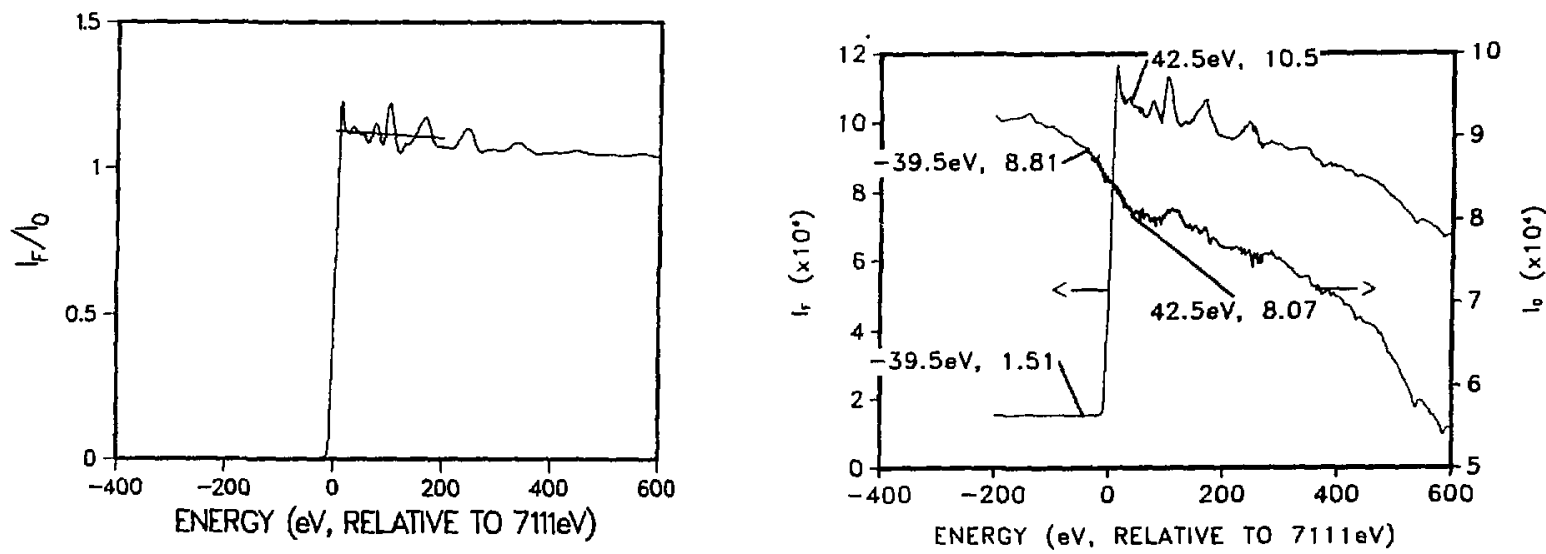
XANES STUDY OF IOR CONDUCTING POLYMERS

X. Q. Yang (BNL), M. denBoer (Hunter College/CUNY), T. A. Skothelm (BNL), P. Holf (VA Polytech. and Stace U.), and J. Kirkland (Naval Res. Lab. and SFA Assoc.)

X-ray absorption experiments at the potassium K-edge were performed on series of polymer-salt complexes of poly(ethylene oxide) and potansium lodide at different temperaturea and with varying alt conceatration. The purpose was to study the atructure of the polymer-1on complex through the transition from the room temperature phase with low lon mobility to the higher nobility phase at elevated tempereture $\left(\sim 100^{\circ} \mathrm{C}\right)$. The potassium $10 \mathrm{n}$ 1s complexed by the lone-palr electrons of the oxygen atome of the ether molety $\left(\mathrm{CH}_{2} \mathrm{CH}_{2} \mathrm{O}\right)_{\mathrm{n}}$, as in an oxygen cage. The near edge otructure of the potassiun $x$-ray aboorption spectra was compared with those of atandarda consisting of organlc salt conplexes where the potassium 1on 1s complexed by 1,2 , and 6 oxygen atoma As can be seen from F1gs. 1 and 2 , the change in the aear edge tructure with increasing temperature follows the sane pattern as decreasing the number of oxygen atons complexing the potassium lon. This indicates that, at elevated temperature, the Increased moblilty of the potasilum lon 1a correlated with a decreasing number of complexing oxygen atoms, 1.e. the potassiun lon 1s less tightly bound to the polymer backbone. This interpretetion is also supported by a more detalled analyals of the exars region of the spectra as well a independent thermodynamic experiments.

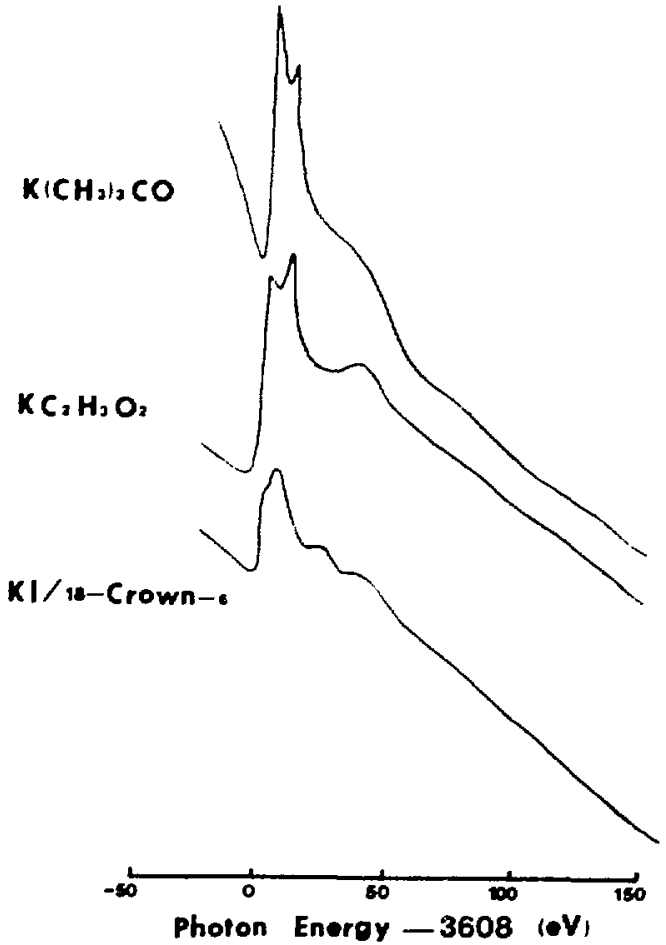

F1g. 1. X-ray absorption apectra of a series of organic potasilu salts with 1,2 and 6 oxygen atoms conplexing the potasalum lon. The sectra were taken at roon tenperature.
PEO/KI 4:1

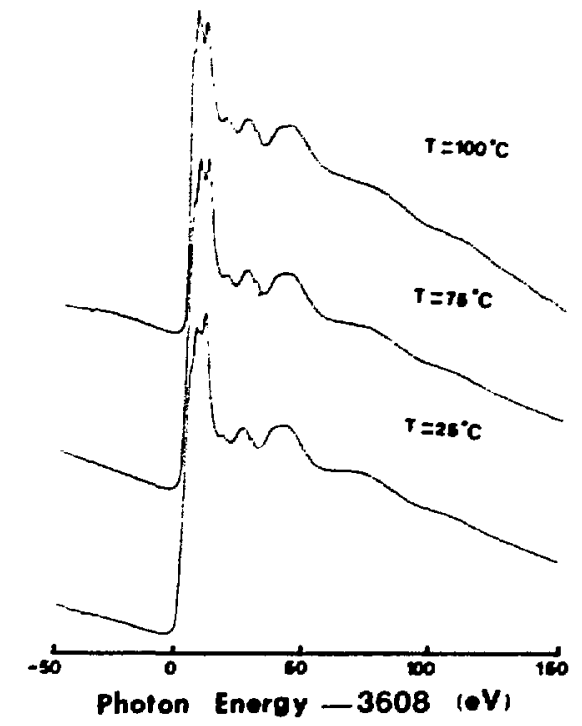

P18. 2. X-ray absorption spectra of poly(ethy 1ene oxide)-KI walt conplexes as a function of tenperature. The salt concentration correaponda to four oxygen atome of the polyner buckbone for each pocassiun ion.

NOTE: This research was supported by the DIyialon of Materials Science, U.S. Department of Energy under Contrect No. DE-ACO2-76CHOOO 16. 
X-24A INSTRUMENTATION: PERFORMANCE OF A HIGH ENERGY RESOLUTION, TENDER X-RAY SYNCHROTRON RADIATION BEAMLINE

P.L. Cowan (NBS), S. Brennan (SSRL), T. Jach, (NBS), D.H. Lindle (NBS), and B.A. Karlin (NSLS)

Design Goals

Beamline X24-A is designed for optimal performance in the tender $x$-ray (i.e., firmer than soft $x$-ray) spectral region from $800 \mathrm{eV}-5000 \mathrm{eV}$. This choice of energy range places a number of constraints on the beamline design, requiring a crystal monochromator and at the same time a windowless environment. Nevertheless, there are compelling scientific reasons for our desire to work in this range $[1,2]$. In addition to tunability over the selected energy range, a primary goal is to obtain the highest possible energy resolution in the primary beam as discussed below. Finally, it is important to focus as much flux as possible from the bending magnet source at $\times 24-\mathrm{A}$.

\section{Design Features}

A toroidal mirror was located downstream from the monochromator to enable full-aperture focussing without loss of energy resolution. Another mirror, which is effectively cylindrical in shape, was placed upstream of the monochromator to improve collimation of radiation incident on the monochromator crystals. The entire beamline was designed to rotate about the axis of upstream mirror to permit filtering of radiation prior to the monochromator. This feature is particularly important in allowing the use of multilayer coatings on the upstream mirror [2].

\section{Resolution Considerations}

The oft cited rule of thumb for synchrotron radiation beamlines is that the energy resolution need be no better than the core-level lifetime broadening for a given energy range. He have achieved energy resolution significantly better than the core-level lifetimes allow. This has permitted studies of processes that are not broadened by lifetimes, such as resonant scattering and back reflection $x$-ray standing wave effects [2].

Optimal resolution can be achíeved by an appropriate choice of monochromator crystals for the selected energy range of a given experiment [1]. It is also possible to sacrifice energy resolution in exchange for higher flux by crystal selection. The design of the monochromator mechanism [3] permits additional gains in energy resolution or flux through the use of asymnetric crystals, or additional (i.e., >2) Bragg reflections.

\section{Performance}

To date the performance of only si(111) crystals has been completely characterized. Measured energy resolution agrees with predictions but flux was initially $<20$ of prediction [1]. Subsequently, we have learned that a factor of 4 was lost due to problems with the NSLS apertures and orbit. Additional flux loss was due to excessive roughness of the toroidal mirror which has recently been repolished.

Initfal studfes of the performance of InSb monochromator crystals were thwarted when a shift in the storage ring orbit caused the white $x$-ray beam to miss our filtering multilayer and melt the first monochromator crystal. A direct beam block will be installed between the filtering mirror and the monochromator before testing of exotic monochromator crystals resumes.

\section{References}

1. P.L. Cowan, et al., Nucl. Instrum. \& Meth. A 246, 154 (1986).

2. See accompanying reports from beamline $X 24-A$

3. P.L. Cowan, et al., Nucl. Instrum, Meth. A 208, 349 (1983). 
X24A INSTRUMENTATION: PERFORMANCE OF A MULTILAYER MIRROR AS A PRE-FILTER FOR A SYNCIROTRON XRADIATION BEAMIINE.

J.B. Kortrlght, P. Plag, R.C.C. Perera (LBL); P.L. Cowan, D.W. Llndle (NBS); and B.A. Karlin (NSLS).

Mult1layer-coated mirrors, rather than conventional total-reflection mirrors, have been proposed as a means to reduce power incldent on the first optical element of high resolution monochromators. This work represents the first step toward implementing this concept in a syrchrotron radiation beam line. We have designed, Eabricated, Installed and characterized a multilayer coated pre-mirror specifically for the $800-4000 \mathrm{eV}$ range for the X24-A bending magnet beamline. The ultimate goal of this pre-mirror is to enable use of radiation sensitive crystals [1] in the 800-2000 eV range.

Many factors affecting the choice of the constituent multilayer materlals and operating energy and angular ranges were consldered in the design stages. We were lead to the relatively low-2 combination of amorphous SIC and $V$ in a relatively large period structure for this application [2]. Flgure 1 shows the calculated reflectivity of the SIC/N multilayer which was chosen to coat the premirror compared to that calculated for the Ni-coated mirror which it replaced. The area above the multilayer reflectivity and below the $\mathrm{NI}$ mirror reflectivity represents the additional power filtered out by the multilayer compared to the graing incidence mirror. In this case the multilayer decreases the reflected power by facior of 4 .

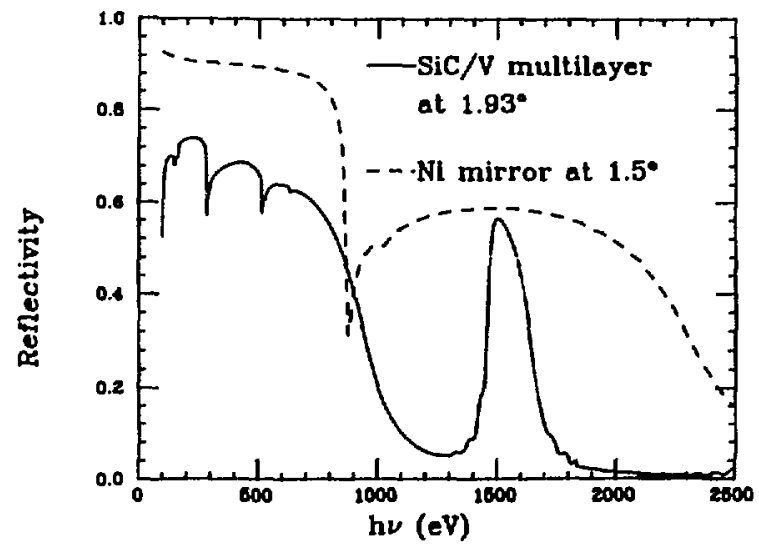

Fig. 1. Comparison of calculated reflectivity of the multilayer and Ni-coated mirror.

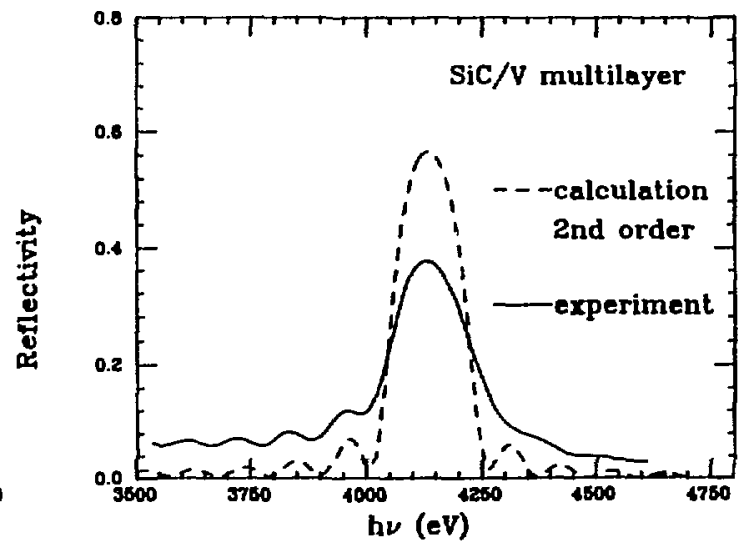

Fig. 2. Measured pre-mirror reflectivity compared to the calculated reflectivity of the miltilayer.

The multilayer pro-mirror was installed inmedlately prior to the 1987 shutdown. Characterization of the reflectivity as a function of energy at fixed angle was more easily accomplished than reflectivity as a function of angle at fixed energy. Figure 2 shows reflectivity data in a higher energy range than that intended for pre-mirror operation. Superimposed on Fig. 2 is the calculated reflectivity for the second order multilayer Bragg peak. The measured reflectivity has not been corrected for background or for varying detector efficiency with energy and is plotted on an arbitrary vertical scale. Since the second order peak is significantly narrower than the first order peak, this comparison strongly suggests that the multilayer on the pre-mirror was quite uniform, as the measured Bragg peak is not substantially broader than the calculated peak. Heating of the inililayer in the gynchrotron bean was not observed to cause any degradation with ring currents in excess of $100 \mathrm{~mA}$.

These results demonstrate the feasibility of utilizing multilayer pre-mirrors as power filters in synchrotron radiation beanlines. Calculations show that multilayers can reduce the power incident on a high resolution monochromator by as much as an order of magnitude corpared to conventional total reflection mirrors. These preltminary results encourage further development of this multilayer power filter concept to ascertain whether this device will pendt the use of nore radiation sensitive crystals in the monochromator.

\section{References}

1. Z. Hussain, E. Unbach, D.A. Shirley and J. Feldhaus, Kucl. Inst. and Meth. 195, 115 (1982). 2. J.B. Kortright and D.L. Windt, Appl. Optics (in press).

This work was supported by the U.S. Department of Energy under contract No. DE-ACO3-76SF00098. 


\section{X-24A INSTRUMENTATION: PERFORMANCE OF A TUNABLE SECONDARY $X$-RAY SPECTROMETER}

S. Brennan (NBS), P.L. Cowan (NBS), R.D. Deslattes (NBS), A. Henins (NBS), B.A. Karlin (NSLS), R.E. LaVilla (NBS), and D.W Lindle (NBS)

Introduction

An efficient high energy resolution secondary $x$-ray spectrometer is critical to studies of $x$-ray excited $x$-ray emission spectroscopy. Even with the highest available incident flux of $x$-rays the signal count rate can become unacceptably low when dispersed by an analyzing crystal. This can especially be a problem in studies of gas targets, or at low energies where fluorescent yields are low.

Design of Spectrometer

A Rowland circle geometry with a curved (Johann) analyzing crystal was chosen to increase efficiency while maintaining good (i.e., $<1 \mathrm{eV}$ ) energy resolution. A position sensitive proportional detector was used so that counts at different points of the Rowland circle corresponding to different wavelengths can be recorded in parallel. The source is positioned inside of the focus so that the source will subtend rays from a range of points on the Rowland circle.

By defocussing the source it is possible to collect data in parallel within a spectral window $15 \mathrm{eV}$ to $50 \mathrm{eV}$ wide. In most cases this is sufficient to record parent lines with all associated satellites or to observe the dispersion of resonant elastic or inelastic scatcering.

The instrument can be tuned over a Bragg angle range from $30^{\circ}$ to $60^{\circ}$. Since tuning is not required for data collection, this feature is primarily used to optimize the spectral window for the selected element and spectral feature(s) to be studied. Tuning is effected by a $\theta-2 \theta$ UHV compatible parallelogram linkage [1]. During tuning the cord of the Rowland circle between the crystal and detector is constant. This serves both to simplify the scanning mechanism and to minimize the change in energy resolution for a given detector position resolution. Maintaining a constant cord length for changing angle requixes an adjustable Rowland circle diameter and hence a variable crystal radius. This is accomplished by a novel crystal bender [2].

\section{Efficiency}

The expected efficiency for the spectrometer is on the order of one part per million. The high incident $x$-ray flux at $X-24 \mathrm{~A}$ compensates for this low efficiency to permit the observation of weak processes, such as sub-threshold elastic and inelastic $x$-ray scattering from gases with good resolution.

\section{Resolution Performance}

The spectrometer was designed with the assumption that the position sensitive detector resolution would be $120 \mathrm{\mu m}$ or better. To date the best resolution for our NBS built "Backgammon" detectors [3] was $200 \mu \mathrm{m}$ measured on a test stand with $8 \mathrm{keV} x-r a y s$. On-line at the NSLS the best measured resolution at $3 \mathrm{keV}$ was $400 \mu \mathrm{m}$. This spacial resolution limits the energy resolution of the spectrometer at all but the lowest energies. Performance at the low energies, where the analyzing crystal becomes highly dispersing, is excellent. Near $2310 \mathrm{eV}$, resolution better than $0.7 \mathrm{eV}$ has been obtained.

References

1. R.D. Deslattes and B. Simson, Unpublished.

2. A. Henins, Rev. Sci. Instrum. 58, 1173 (1987).

3. B. Duval et al., Nucl. Instrum \& Meth. 222, 274 (1984).

This research has been funded in its entirety by the National Bureau of Standards. 
X-24A Instrumentation: X-Ray Mirror Characterization for X-24A

P.L. Cowan (NBS), D.W. Lindle (NBS), B.A. Karlin, and P. Takacs (NSLS)

The NBS beamline $X-24 \mathrm{~A}$ was one of the first beamlines designed with two glancing Inctdence $x$-ray wirrors, and was the first such beamline to operate at a high brightness $x$-ray source. As such studies of the performance of the mirrors is critical in determining the advantages of such a design.

Pre-Monochromator Mirror

The first mirror is positioned upstream of the two-crystal monochromator and serves two functions. First it suppresses the high energy photon flux which reduces the power load on the first monochromator crystal and reduces problems with harmonics. Secondly, it is curved to improve upon the natural vertical collimation of the synchrotron radiation. This improved collimation is possible when the source size is sufficienty small.

For the initial 18 months of operations an electrodless nickel coated, aluminum substrate mirror was used. The reflecting surface had a concave, spherical curvature with a radius of $1.1 \mathrm{~km}$. Although provision was made for water cooling of this mirror, it was not used due to vibration problems with the HSLS water lines. Mirror temperatures as high as $100^{\circ} \mathrm{C}$ were observed, but no irreversible distortions of this mirror due to prolonged exposure to high power radiation were detected.

Tests of the effect of the mirror curvature on monochromator energy resolution have been performed. With low (i.e. $<50 \mathrm{~mA}$ ) storage ring current a 0.7 vertical aperture slit was positioned upstream of the mirror. Measurements of the narrow sub-threshold Ar absorption resonance were made for a variety of slit positions covering the full effective aperture of the mirror. The apparent energy of the resonance changed by $\leq 0.1 \mathrm{eV}$ which implies the effective figure erxor of the mirror is $s 12 \mu \mathrm{rad}$. However, at higher ring currents with larger aperture slits, noticeable degradation of monochromator resolution was observed. This degradation is believed to be due to temporary thermal distortions in the premirror caused by local beam heating of the mirror. A copper substrate mirror has been prepared and vibration-free water couling is being considered to improve high power performance when the $x$-ray ring resumes operation.

The surface roughness of the mirror and its effects on the $x$-ray beam have also been measured. Surface roughness tends to reduce specular reflectivity and increase scattered intensity which appears in the talls of the reflected beam profile. We have measured the monochromatic beam proffle at a number of photon energies and a number of incident angles and have observed only minor scattered intensity. This is consistent with profiloneter measurements [1] of the surface which indicate a roughness of $2.5 \mathrm{~nm}$.

Focussing Mirror

A second mirror is positioned downstream of the monochromator to collect the waximal horizontal divergence from the bending magnet source without degrading the monochromator energy resolution. The mirror is a torroid formed by bending [2] a cylindrically ground, fused quartz mirror with an evaporated nickel coating. Although beam profile measurements were not made for reflections from this wirror, noticeable scatter was apparent during observations made with a phosphor screen. Profilometer measurements indicated a surface roughness of 7 to $10 \mathrm{~nm}$. This mirror has been repolished to $<1.5$ non roughness and is awaiting resured operations.

\section{References}

1. P.Z. Takacs and J. Colbert, Nucl. Instrum. Meth. A 246, 233 (1986).

2. A. Henins, et al.. Nucl. Instrus. \& Meth. 208, 287 (1983).

This research has been funded in Its entirety by the National Bureau of Standards. 
$X$-24A NEW EXPERIMENTAL TECHNIQUES: ENERGY SELECTIVE EXCITATION OF X-RAY EMISSION SPECTROSCOPY

P.L. Cowan (NBS), S. Brennan (NBS\& SSRL), R.D. Deslattes (NBS), T. Jach (NBS), R.E. LaVilla (NBS), D.W. Lindle (NBS), and B.A. Karlin (NSLS)

Introduction

$\mathrm{X}$-Ray spectroscopy is one of the oldest experimental techniques for measuring the electronic structure of matter. Traditionally, $x$-ray absorption spectroscopy has been used for studying unoccupied states and high energy resolution $x$-ray emission spectroscopy has been used to study the occupied states. Activity in these areas has declined over the past few decades partially due to the availability of other techniques, such as photoelectron spectroscopy, and partially due to a number of fundamental problems with the $x$-ray spectroscopic techniques [1]. The availability of high fluxes of highly monochromatic, tunable $x$-rays from synchrotron radiation sources combined with efficient, high energy resolution $x$-ray emission spectrometers opens a number of possibilities for circurventing the debilitating difficulties. The past year at beamline X24-A we have made great progress both in demonstrating how "well known problems" can be overcome and in opening new areas of study for $x$-ray spectroscopy.

Multi-Vacancy Effects

When $x$-ray fluorescence is stimulated by high energy excitation (either charged particles or photons) the emitted spectra include components associated with the presence of multiple vacancies in the fluorescing atom. These multivacancy components can obscure single vacancy features of interest, and impede the interpretation of the emission spectrum. It has been shown [2] that the multivacancy components of fluorescent spectra can be selectively suppressed or even extinguished by tuning the energy of the excitation $x$-rays to near the single vacancy threshold. In the past year we have applied this effect for the first time to the study of molecules and solids.

The production of multiple vacancies is in itself an interesting subject of study. Measurements of multi-electron transitions potentially can yield information about electron correlation. Also the creation of multivacancy states is fundamentally linked to the detailed understanding of Auger electron spectroscopy. We have made extensive studies of multivacancy states in a closed shell atom (argon) and have initiated studies of such effects in several molecules and one solid ( $\mathrm{KCl}$ ).

\section{Lifetime Broadening}

$X$-Ray fluorescence requires the production of an inner shell vacancy. Normally, the width of the fluorescent spectral components is determined by the lifetime broadening due to the short inner shell lifetime. However, when highly monochromatic $x$-rays are used to excite fluorescence, study of the final (post emission) state structure is limited only by the instrumental resolution. This avoidance of lifetime broadening is particularly evident in our studies of resonant fluorescence from atoms, molecules and solids.

New Effects

In addition to solving the long-standing problems above, energy selective excitation opens new possibilities. For example the excitation energy can be tuned such that an inner shell electron is promoted to a selected unfilled orbital. This excited electron can differentially screen the subsequent decay of the core hole from electrons in the various outer levels and shift the fluorescent energy accordingly. Studies of such differential screening shifts can provide information about the spacial configuration of the various orbitals involved. Related information can be obtained from observations of the polarization of the fluorescence components under these conditions.

References

1. R.D. Deslattes, Aust. J. Phys, 39, 845 (1986).

2. R.D. Deslattes, R.E. LaVilla, P.L. Cowan, A. Henins, Phys. Rev. A 27, 923 (1983).

This research has been funded in its entirety by the National Bureau of Standards. 

(NBS), and B.A. Karlin (NSLS).

The $x$-ray emission spectrometer used at $X-24 A$ can also be used for polarization analysis of emitted $x$-rays. Maximum polarization sensitivity occurs when the Bragg angle of the analyzed radiation equals $45^{\circ}$, but significant polarization sensitivity can be obtained over a range of energies (see Fig. 1). The polarization of the emitted $x$-rays can be influenced by a number of factors including: orientation of incident beam wave vector, orientation of incident beam polarization vector, and orientation of the sample.

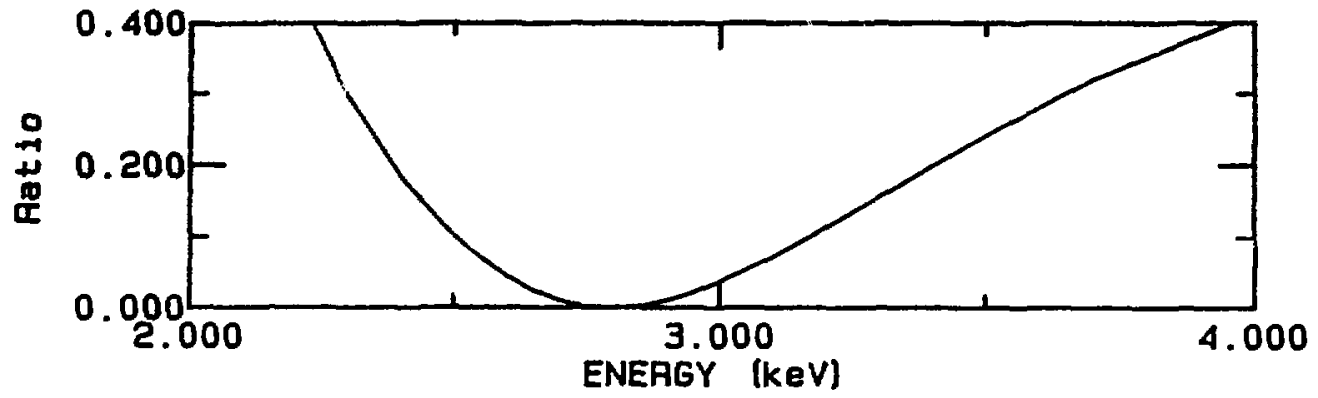

Figure 1 The ratio of Bragg reflectivity fron a $S 1(111)$ diffraction for $\pi$ and $\sigma$ polarized radiation vs. energy.

Wave Vector

To first approximation, the intensity of elastic scattered $x$-rays with polarization parallel to the incident wavevector should vanish. On resonance, however, this intensity can become measurable. This effect is termed resonant depolarization of elastic scattering. This effect could provide an additional method for studies of resonant structure, particularly if studied in combination with other influences on polarization. We have studied resonant depolarization of elastic $x$-ray scattering from Ar [1] and molecular gases.

Sample Orientation

Pronounced polarization-dependent effects have been reported for $x$-ray absorption which are a function of orientation for solid samples [2]. Similar effects have been predicted for $x$-ray emission [3]. Although we have not studied polarization of emission from solid samples we have seen polarization effects from gases which strongly imply the importance of sample orientation.

Incident Polarization

Synchrotron radiation tends to be polarized parallel to the plane of the electron orbit. This natural polarization can be further enhanced when the radiation is filtered by a twocrystal monochromator. When tuned to a sub-threshold resonance of a molecular gas, the polarized incident beam may excite only those molecules with particular orientations. The orientations which become excited depend upon the driven resonance and the symmetry of the unoccupled orbitals involved in the resonance. The resultant aligned, excited atoms can then emit $x$-rays which will be polarized depending on the molecular orientation and the electron orbitals involved in the $x$-ray emission. We have studied this affect for a number of molecular gases [1].

\section{References}

1. See accompanying reports from beamline $\mathrm{X}-24 \mathrm{~A}$.

2. D.H. Templeton and L.K. Templeton, Acta Cryst. A 38, 62 (1982).

3. A. Simunek, Czech. J. Phys. B 33,1413 (1983).

This research has been funded in its entirety by the National Bureau of Standards. 
X-24A NEW EXPERIMENTAL TECHNIQUES: DEVELOPMENTS IN BACK-REFLECTION X-RAY STANDING WAVE ANALYSIS

P.L. Cawan (NBS), T. Jach (NBS), F. Sette (Bell Labs), J. Rowe (Bell Labs), and B.A. Karlin (NSLS)

The X-Ray Standing Wave technique, which is based upon microscopic interference between incident and diffracted $x$-rays, has become a useful tool for precise determination of atomic structure. However, the application of the technique has largely been limited to those few materials which are readily available as highly perfect crystals. This is due to the fact that even a slight strain or mosaic spread in the sample crystal is enough to disrupt the $x$-ray interference.

It has long been realized that the crystal perfection constraint could be relaxed if the $x$-ray standing wave technique were established in a back-reflection (i.e. a Bragg angle of $\left.90^{\circ}\right)$ configuration. In this case the natural rocking curve width of Bragg diffraction can approach tens of milliradians. However, a number of technical obstacles had to be overcome to take advantage of this fact. First, the back-reflection condition constrains the energy of the $x$-rays at which diffraction occurs. For most crystals this energy lies roughly between $2 \mathrm{keV}$ to $4 \mathrm{keV}$ for the low index planes. Synchrotron radiation sources allow one to choose an appropriate energy and still retain high photon flux, but few beamlines are capable of working in this energy range. Secondly, although the angular width of the diffraction condition gets big in back-reflection, the energy width is relatively unchanged at about $1 \mathrm{eV}$ or less. Thus relatively high energy resolution must be achieved in the incident beam monochromator.

Demonstration experiments of the back-reflection $x$-ray standing wave effect have been independently reported from other synchrotron radiation facilities $[1,2]$. We have employed a number of features not included in the other work. We were able to directly detect the diffracted beam by using a transparent photodiode. We detected characteristic $x$-ray fluorescence in addition to Auger electrons. Also, we were able to observe the total or partial electron yield from the sample. We also had at our disposal the high $x-$ ray flux and high energy resolution available from beamline, X-24A. Finally, we were able to observe more than one diffraction from a single sample by simply tuning the monochromator to a new energy and rotating the sample crystal.

The importance of high energy resolution is illustrated below. Shown is the $\mathrm{Cl} x$-ray fluorescence vs. incident photon energy during diffraction from $\mathrm{Cu}(200)$ for $\mathrm{Cl}$ adsorbed on a $\mathrm{Cu}(100)$ surface. Note that the fluorescence varies from maximum to minimum with a change of $<1 \mathrm{eV}$ in the monochromator energy.

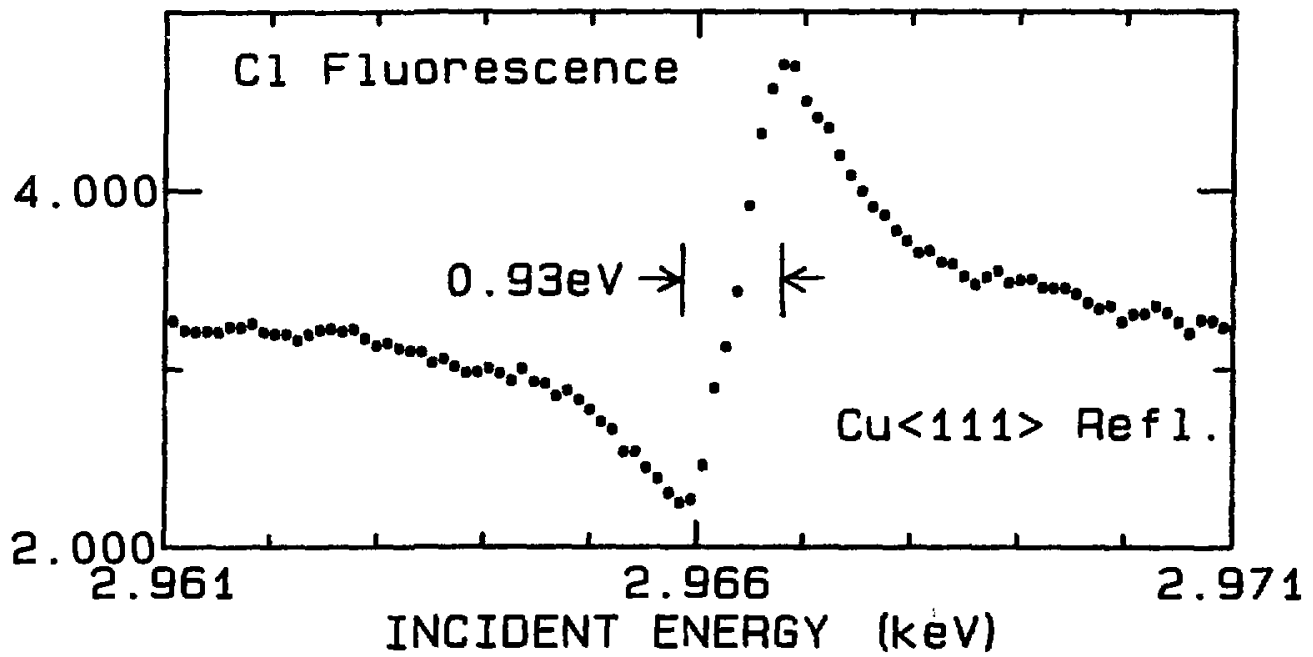

References

1. Ohta et al., Nucl. Instrum. and Meth. A 246, 760 (1986).

2. Woodruff et al. Phys. Rev, Lett. (1987). 
X-24A ATOMIC PHYSICS: STUDIES OF ARGON K-EDGE ABSORPTION

S. Brennan, J. Cooper, P.L. Cowan, R.D. Des!attes, T. Jach, F.E. LaVilla (NBS), and B.A. Karlin (NSLS)

Although argon is a mono-atomic gas, its $k$-edge absorption spectrum exhibits a wealth of detailed structure [1]. With the improved energy resolution available from beamine $X$ $24 \mathrm{~A}$, we have extensively remeasured this structure. Furthermore, recent calculations by Cooper [2] are being compared with our improved measurements.

Features of interest in the argon absorption spectrum can be divided into tinree classifications: the sub-threshold Rydberg series, the single vacancy threshold region, and the multivacancy resonance and threshold region. Modeling of the Rydberg series can determine parameters used for calculations of inelastic scattering [3]. The steep fall off of the near threshold single vacancy cross section has not previously been matched by theory [1]. However, recent calculations by Cooper [2] agree with preliminary analysis of our data to within experimental error. Additional calculations by Cooper [2] suggest a revision of the previous assignment [1] for the largest multivacancy absorption resonance.

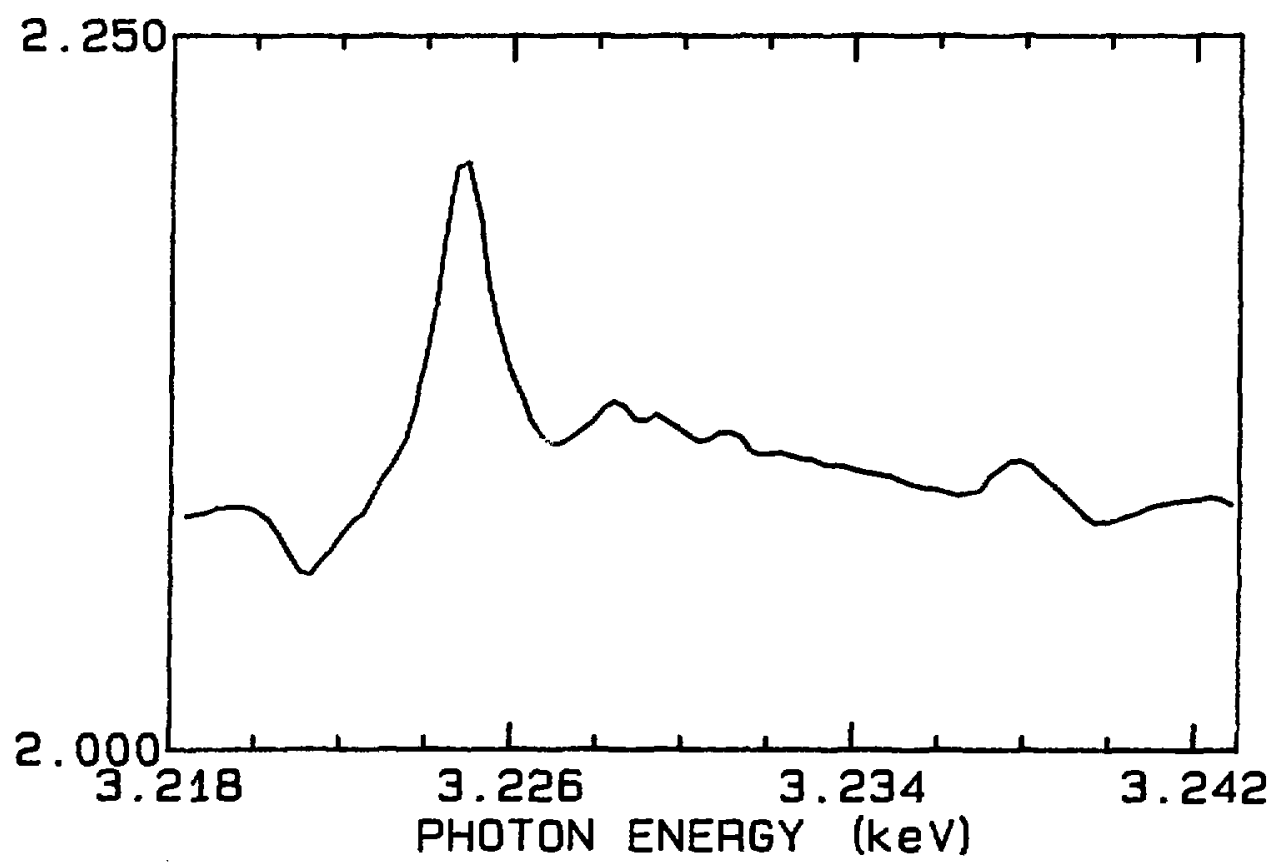

Figure 1. Measurement of multivacancy absorption structure for argon.

References

1. R.D. Deslattes, et al., Phys. Rev. A 27, 923 (1983).

2. J. Cooper, unpublished.

3. See accompanying reports from beamline $\mathrm{X}-24 \mathrm{~A}$.

This research has been funded in its entirety by the National Bureau of standards. 


\section{X-24A ATOMIC PHYSICS: RESONANT INELASTIC X-RAY SCATTERING FROM ARGON GAS}

P.L. Cowan, S. Brennan, T. Jach, R.E. LaVilla (NBS), and B.A. Karlin (NSLS)

We have conducted a detailed study of inelastic $x$-ray scattering from an atomic gas (argon) for incident photon energies near the $1 \mathrm{~s}$ threshold. Studies of the inelastic scattering process from a losed shell atom provide an ideal test for of the current understanding of this phenomenon. This understanding is basic to our studies of molecular and solid samples [1] which have indicated important potential appl'sations of inelastic $\mathrm{x}$-ray scattering involving sub-threshold resonances.

Theoretical analysis by Tulkki (2) has provided a simple model for understanding resonant inelastic scattering. This model describes the relationship between sub-threshold phenomena such as resonant Raman $x$-ray scattering to super-thresiold emission in the form of $x$-ray fluorescence. We have compared this iodel to our data and have found that quantitative agreement is achieved with no adjustable parameters.

Particularly striking is the sub-threshold narrowing of emission features which occurs both in the theory and experiment (see Fig. 1). Comparison shows that resonant emission

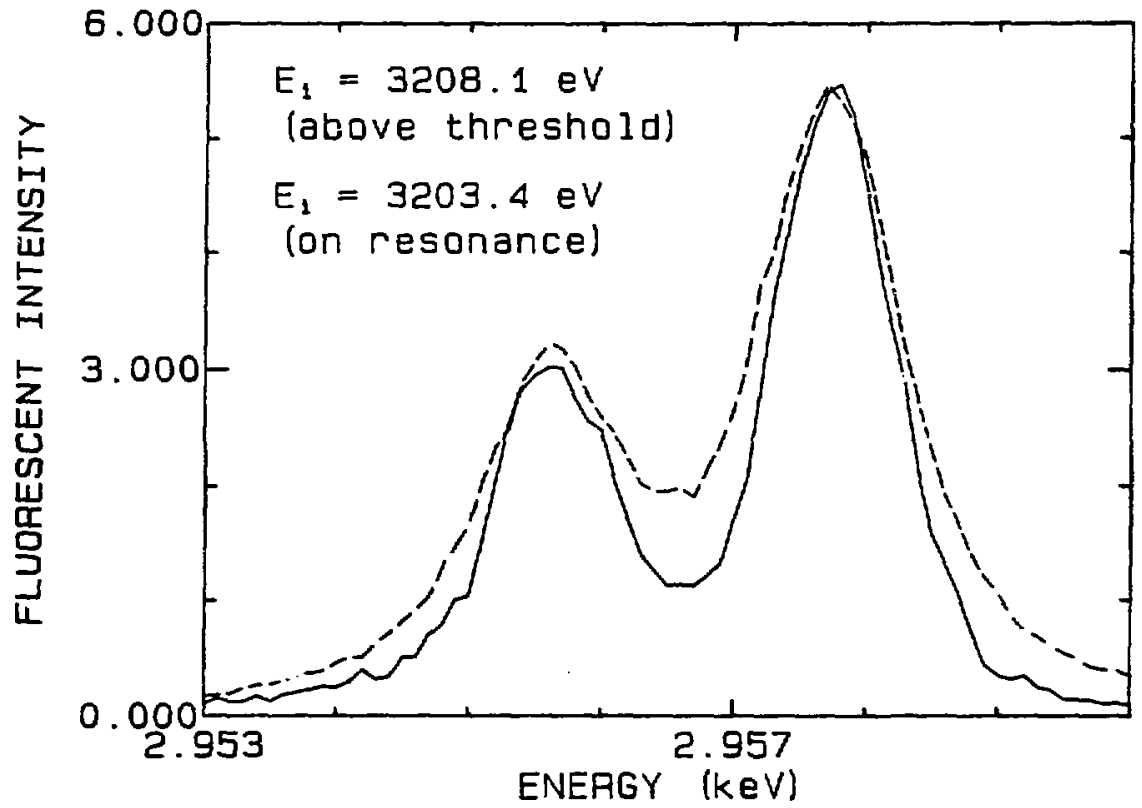

Figure 1. Emission spectra in the Ar $K$ region stimulated by resonant (solid) and superthreshold (dashed) incident $x$-rays.

is obviously narrower than fluorescence excited above threshold, but perhaps more significant is the shape change of the emitted peaks. Non-linear least squares fits of the data indicate that while the super-threshold excited emission peaks exhibit Lorentzian tails characteristic of is lifetime broadening, the resonant peaks are fit by a Gaussian shape. The Gaussian peak shape is characteristic of the measured instrumental response of the secondary spectrometer, indicating that additional sub-threshold narrowing may be observable with improved spectrometer performance. This opens the possibility of high resolution studies of electronic structure which circunvent inner-shell lifetime broadening limitations.

References

1. See accompanying reports from beamline $\mathrm{X}-24 \mathrm{~A}$,

2. J. Tulkki, Phys. Rev. A 27, 3375 (1983).

This research lias been funded in its entirety by the National Bureau of Standards. 
$X$-24A ATOMIC PHYSICS: THE ORIGIN OF THE ARGON $K \beta^{\prime \prime}$ SATELLITE IN THE K $\beta$ EMISSION SPECTRUM

R.E. LaVilla, S. Brennan, P.L. Cowan, T. Jach (NBS), and B. Karlin (NSLS)

The main features [1] of the argon $K \beta$ emission spectrum consists of the main line $\beta_{1,3}$ and Its satellite complexes $\beta^{V}$ and $\beta^{\prime \prime}$ positioned $3 \mathrm{eV}$ and $7 \mathrm{eV}$ respectively on the high energy side of the parent $\beta_{1,3}$ line. We had demonstrated earlier in a double differential experiment [2] that the $\beta_{1,3}$ line is due to the single vacancy transition $3 \mathrm{p}-1 \mathrm{~s}$ and that the satellites are multivacancy transitions. In particular the $\beta^{v}$ satellite was shown to be primarily transitions based on the $1 \mathrm{~s} 3 \mathrm{p}$ configuration with contributions from double and single ions and excited neutrals. The satellite $\beta^{\prime \prime}$ has been suggested to originate from $1 s 3 s$ double vacancy [2] or $1 s \mathrm{~s}^{2}$ triple vacancy [3] initial states. An accurate measure of the energy threshold of the $\beta^{\prime \prime}$ emission feature should help clarify the origin of this satellite feature.

The argon $K \beta$ spectrum in fluorescence was obtained with a secondary spectrometer as a function of incident excitation by $x$-rays from the primary monochrometer on beamline $\mathrm{X} 24$ $A$. The energy of the incident exciting $x$-rays was monttored by repeated measurement of

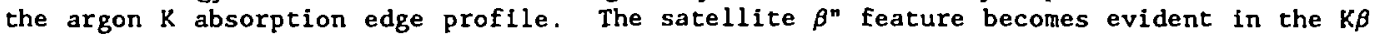
emission spectrum when the incident excitation is $46 \mathrm{eV}$ above the argon $K$ threshold $(3206.0 \mathrm{eV})$ in good agreement with our previous determination.

The 1s3snsnp channel opens at about $32 \mathrm{eV}$ above the $1 \mathrm{~s}$ threshold with the double ionization threshold at about $48 \mathrm{eV}$. The neutral and single ionized is 3 s Rydberg states can decay by Coster-Kronig transitions to $\underline{15} 3 \mathrm{p}$ based states to radiatively contribute to the $\beta^{v}$ feature. The $1 \mathrm{~s} 3 \mathrm{~s}$ double ion and Rydberg states also contribute to the $\beta^{v}$ complex.

The first triple excited neutral $1 \mathrm{~s} 3 \mathrm{p}^{2} 3 \mathrm{~d} 4 \mathrm{~s} 4 \mathrm{p}$ channel opens at about 46 eV above the $\underline{1 \mathrm{~s}}$ threshold. States based on the $1 \mathrm{~s}^{2} \mathrm{p}^{2}$ configuration with two or three Rydberg electrons can also autoionize to states based on the $1 \mathrm{~s} 3 \mathrm{p}$ configuration.

A prominant absorption feature approximately $44 \mathrm{eV}$ above threshold (labeled "G" In ref. 2 \& 3) is in reasonable proximity to the calculated energies for $1 s 3 p^{2} 4 p^{3}$ and $1 s \quad 3 p^{2} 4 s^{2} 4 p$ neutrals with multiplet spreads of about $7.5 \mathrm{eV}$. Since it is in this energy region that the $\beta^{\prime \prime}$ feature begins to be evident, it is suggested that the correct origin of $\beta^{\prime \prime}$ is due to these triple vacancy states. This is supported by the observation that the $1 \mathrm{~s} 3 \mathrm{~s}$ states which opened much less than $46 \mathrm{eV}$ above threshold did not give rise to any $\beta^{\prime \prime}$ intensity. In addition these results support some preliminary theoretical predictions [4]. Additional theoretical work would be welcomed to give a more detailed description of the competing processes in these interesting spectra.

\section{References}

1. R.D. Deslattes, Phys. Rev. 133, A390 (1964).

2. R.D. Deslattes, R.E. Lavilla, P.L. Cowan, and A. Henins, Phys. Rev. A 27, 923 (1982).

3. K.G. Dyall and R.E. LaVilla, Phys. Rev. A 34,5123 (1986).

4. K.G. Dyail and I.P. Grant, J. Phys. B 17, 1281 (1984).

This research has been funded in its entirety by the National Bureau of Standards. 
$\mathrm{X}$-24A ATOMIC PHYSICS: ENERGY DEPENDENCE OF THE $K \beta^{v}$ SATELLITE IN AT GAS

T. Jach (NBS), P. L. Cowan (NBS), S. Bremnan (SSRL), R.E. LaVilla (NBS), and R.D. Deslattes (NBS)

We have taken advantage of the high $x$-ray flux delivered by the $X-24 \mathrm{~A}$ beamline to measure the excitation energy dependence of the Ar $K \beta$ fluorescent line ( $3190 \mathrm{eV})$ and 1 ts two satellites. Previous work in this area [1] has called attention to the satellites of the Ar $K \beta_{1,3}$ line, which are designated $K \beta^{v}$ and $K \beta^{\prime \prime}$. These satellite lines, occurring about 3.1 and $7.0 \mathrm{eV}$, respectively, above the $K \beta_{1,3}$ line, have been attributed to multiple vacancy states excited we $i 1$ above the $\operatorname{Ar} K$ edge $[1,2]$.

We have taken extensive data on the intensities of the $K \beta^{v}$ satellites relative to the $K \beta_{1,3}$ line itself over an energy range of $0-200 \mathrm{eV}$ above the $K$ edge. $A r$ gas near atmospheric pressure was excited by the highly focussed $x$-ray beam produced at beamline $X$ 24A. A combination of $x$-ray optics and a double crystal monochromator produced a beam with a bandwidth of $0.4 \mathrm{eV}$, tunable in energy about the Ar K-edge (3203 eV). Fluorescent radiation from the decay of the Ar excited states was analyzed by a bent-crystal focussing spectrometer of the Johann geometry and detected by a position-sensitive proportional counter of the backgammon type. The combination allowed us to record a spectral window 50 $\mathrm{eV}$ wide, including the $\mathrm{K} \beta$ line and both of its satellites. We were able to monitor the absorption spectrum of argon as well, thus relating the turn-on of satellites in the fluorescence to various features associated with excited state series in the absorption. The figure below shows the behavior of the $K \beta^{V}$ satellite as a function of energy above the threshold.

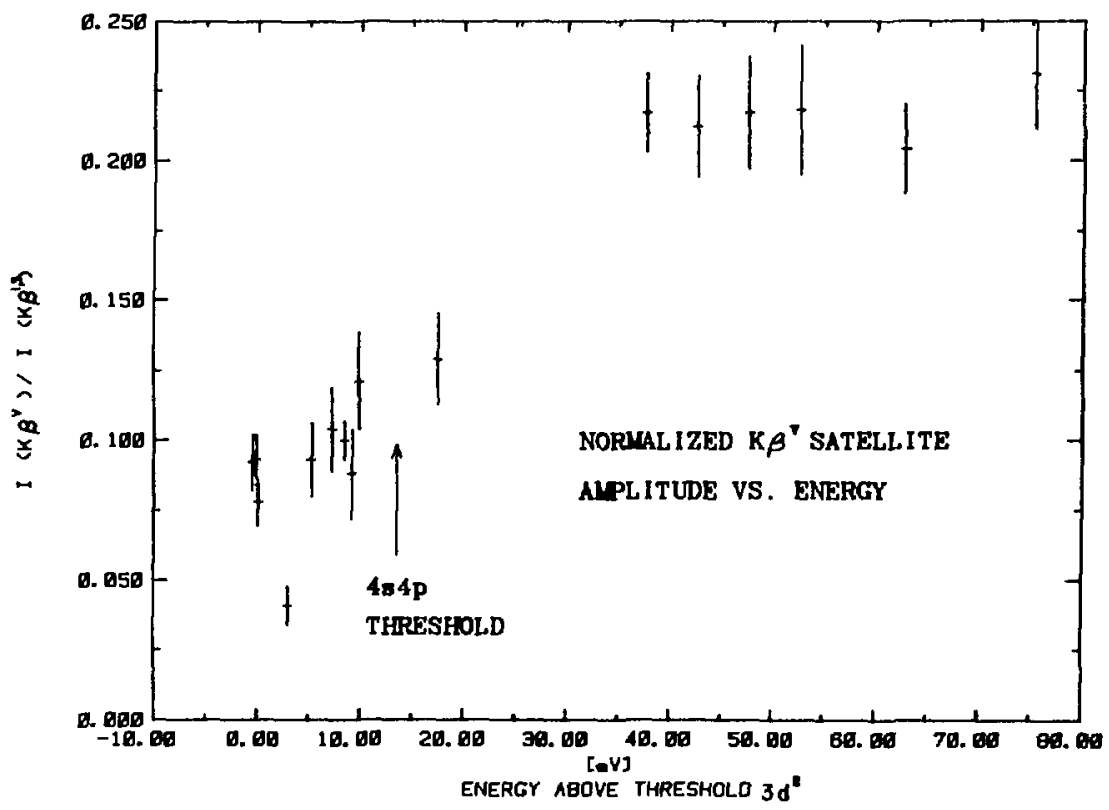

References

1. R.D. Deslattes, R.E. LaVilla, P.L. Gowan, and A. Henins, Phys. Rev. A 27, 923 (1983) and references therein.

2. K.G. Dyall and R.E. Lavilla, Phys. Rev. A 34, 5123 (1986).

This research has been funded in its entirety by the National Bureau of standards 
X-24A ATOMIC PHYSICS: UNUSUAL THRESHOLD BEHAVIOR OF THE K $\beta^{v}$ FLUORESCENCE SATELLITE IN Ar GAS

T. Jach (NBS), P.L. Cowan (NBS), S. Brennan (SSRL), R.E. LaVilla (NBS), and R.D. Deslattes (NBS)

We have observed unusual threshold behavior in the $K \beta^{v}$ satellite of the $k \beta$ enission in fluorescence ( $3190 \mathrm{eV}$ ) from Ar gas, using the $\mathrm{X}-24 \mathrm{~A}$ beamine. Previous work suggested that the $K \beta^{V}$ satellite originated from a shakeup transition to ([1s3p]4pnp) [1,2]. Recent calculations indicate [3] that the more likely assignnent of this suprathreshold feature is the transition to $\left([1 \mathrm{~s}] 3 \mathrm{p}^{5} 3 \mathrm{~d}^{2}\right)$. We have observed the amplitude and shape of this satellite as it is turned on at increasing energy. A series of spectra showing the $K \beta_{1}$, line and its $K \beta^{\psi}$ satellite for various incident energies above the threshold reveals a shoulder developing on the main line which then moves up in energy relative to the main line before becoming fixed and growing into a separate peak. In spectra taken over extended periods of time to obtain better statistics, the $K \beta^{V}$ satellite appears to have two components which may have different thresholds.

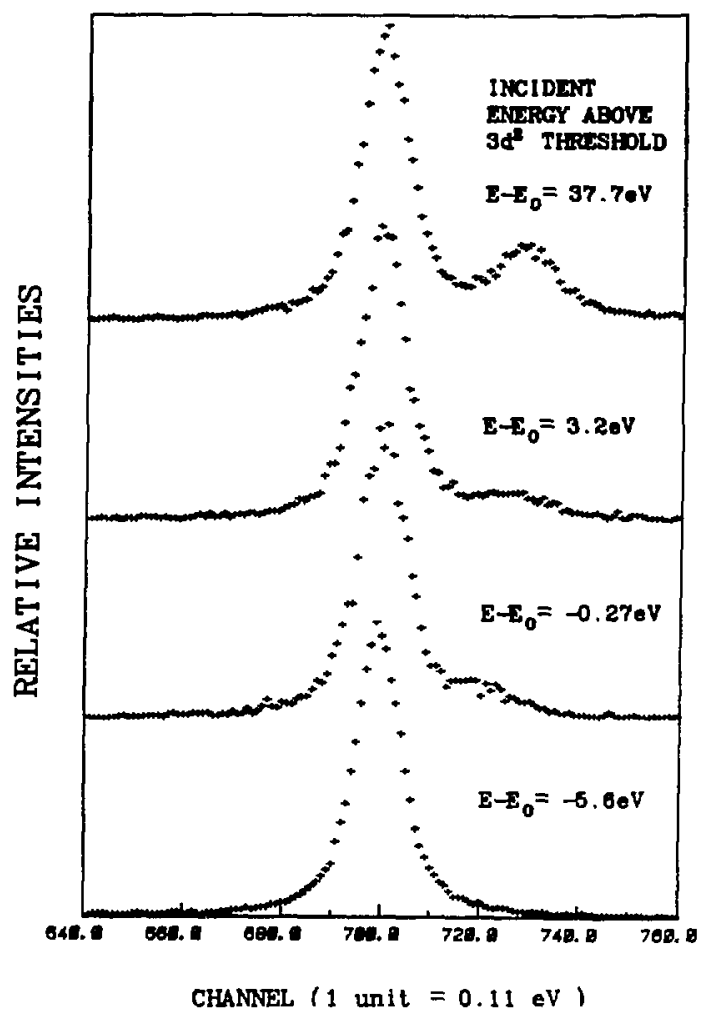

References

1. R.D. Deslattes, R.E. Lavilla, P.L. Cowan, and A. Henins, Phys. Rev. A 27, 923 (1983) and references therein.

2. K.G. Dyall and R.E. Lavilla, Phys. Rev, A 34,5123 (1986).

3. J. Cooper, private communication.

This research has been funded in its entirety by the National Bureau of standards. 
B.H. McQuaide, D.E. Jenkins, M.D. Hawkins, M.S. Banna (Vanderbilt U.), P.L. Cowan (NBS), and B.A. Karlin (NSLS)

The is photoionization of argon has been studied with synchrotron radiation using beamline $\mathrm{X}-24 \mathrm{~A}$. At hv=3600 eV, the main shake up peak, which is probably due to $3 p \rightarrow 4 p$ excitation accompanying $1 \mathrm{~s}$ ionization was found to be $10.8 \pm 18$ of the main peak (see Fig. 1). This result has been shown to be close to the sudden limit value using the theory developed by Thomas [1]. It is somewhat higher than the ratios obtained by other workers, most of whom, however, used lower-energy photons. The multiconfiguration calculations of Dyall [2] also yield a smaller ration of $7.1 \%$.

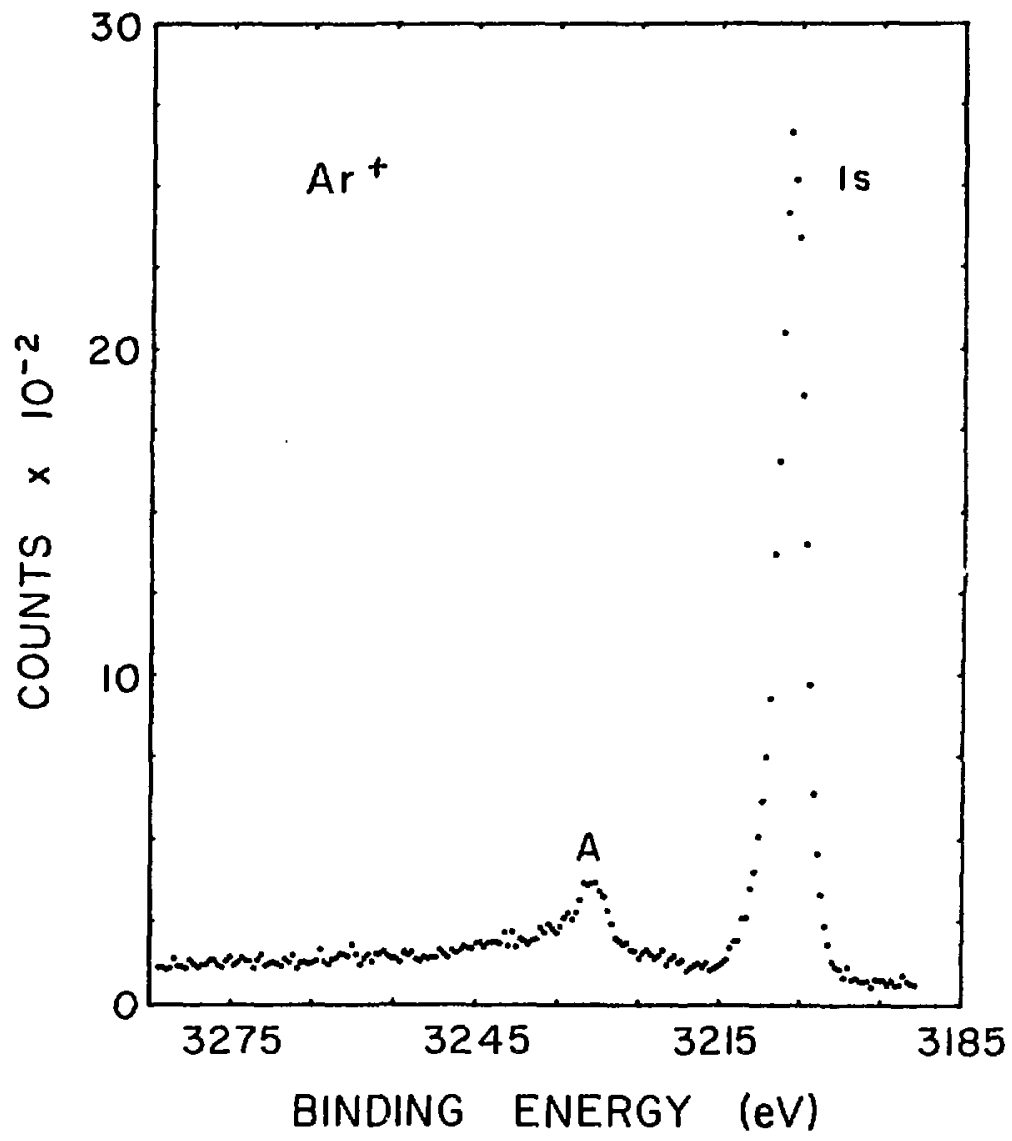

Figure 1. The argon 1s spectrum obtained with $3600 \mathrm{eV}$ photons at the magic angle.

Additional, higher resolution work is clearly needed on this system. It would then be possible to carry out a detailed comparison with theory.

References

1. T.D. Thomas, Phys. Rev. Lett. 52, 417 (1984); T.D. Thomas, J. Electron Spectrosc. 40 , 259 (1986).

2. K.G. Dyall, J. Phys. B 16, 3137 (1983).

This work has been supported in part by the National Science Foundation (grant No. CHE8319476 ) and by the National Bureau of Standards. 
X24A CHEMICAL IHYSICS: SUB-THRESHOLD EXCITATION OF C1 FLUORESENCE FROM CHLORO-FLUORO-METIANES

R.C.C. Perera (LBL); P.L. Cowan, T. Jach, R.E. Lavilla and D.W. Lindle (NBS); and B.A. Karlin (NSLS).

The $C l K$ absorption spectrum and $C l K \beta(K-V)$ fluorescent spectra of chloro-fluoro methanes were measured. The unoccupied molecular orbitals were selectively populated producing highly excited neutral molecules (i.e., excicon states), resulting in x-ray emission spectra from photon excitation below the ionization threshold [1]. As an example, results from $\mathrm{CF}_{3} \mathrm{Cl}$ molecule are presented.

The $\mathrm{Cl} \mathrm{K}$ absorption spectrum $\mathrm{CF}_{3} \mathrm{Cl}$ (gas) is shown in Fig. 1. The lowest unoccupied valence molecular orbitals (MOs) of $\mathrm{CF}_{3} \mathrm{Cl}$ are $6 \mathrm{a}_{1}, 7 \mathrm{a}_{1}$ and $6 \mathrm{e}$ in the order of decreasing binding energy (BE). The first discrete absorption maximum at $2823.1 \mathrm{eV}$ results from transition of a chlorine $1 \mathrm{~s}$ electron to the unoccupied $6 a_{1}$ orbital.

The $C l K \beta(K-V)$ emission spectrum presented in $F i g .2$ was excited at $2832.5 \mathrm{eV}$ energy, which is about $3 \mathrm{eV}$ above the $\mathrm{cl}$ is ionization threshold energy $(K+3 \mathrm{ev})$, but below the double vacancy threshold energy. It was shown before $[1,2]$ that such excitation produces no multiple vacancy satellite contributions in this spectral region. Peaks $A$ and $B$ in Fig. 2 are assigned as dipole-allowed transitions from electrons in $5 \mathrm{e}$ and $5 \mathrm{a}_{1}$ valence Mos, whereas peak $C$ is attributed to the overlapping transitions from the $3 e+2 e+4 a_{1}$ valence MOs.

In Fig. 3, the $c 1 \mathrm{~K} \beta(\mathrm{K}-\mathrm{V})$ spectrum excited with $2823.1 \mathrm{eV}(\mathrm{K}-6.5 \mathrm{eV}$ ) photon energy is presented, along with the deconvolved spectral components. As seen in Fig. 1 , the $2823.1 \mathrm{eV}$ energy corresponds to the first maximum in the absorption spectrum. Comparing the $C l K \beta$ (K-V) spectral components for (K - 6.5eV) excitation with the spectral components for $(K+3$ eV) excitation, large differences in energy positions, relative intensities and line widths are observed. The relative energy-position shifts and the significant intensity changes can be understood in terms of perturbation effects due to the presence of an electron in the first unoccupied Mo [1].

When a core electron is excited to an unoccupied orbital below the vacuum level, the "effective" hole production region in the core state [3] is limited by convolution of the the broadening of the unoccupied level and the band pass of the monochromator (neglecting the core hole reorganization effects). Since this "effective" core hole region is a fraction of the total is lifetime broadening, the line width of $x$-ray emission components from the exciton state will be smaller than the line widths of the above-threshold excited spectrum.

\section{References}

1. R.C.C. Perera, R.E. Lavilla, P.L. Cowan, T. Jach, and B. Karlin, Physica Scripta, 36, 132 (1987).

2. R.D. Deslattes, Aust. J. Phys. 39, 845 (1986).

3. T. Aberg and J. Tulkki, Atomic and Inner-shell Physics, ed. B, Crasemann (Plenum: New York, 1985), p. 419.

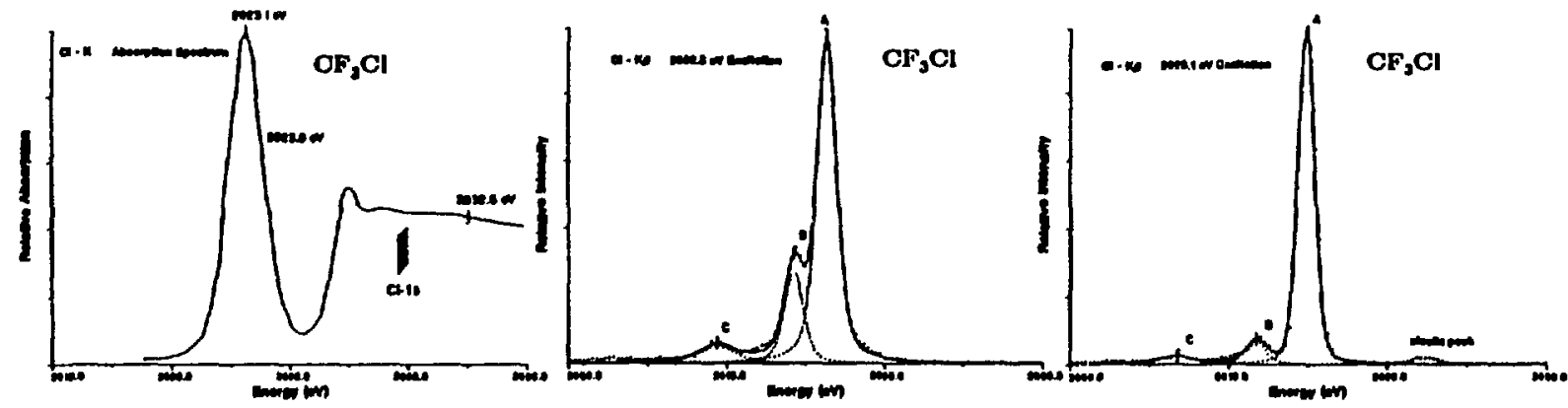

F1E. 1. Experiantal Cl $\mathrm{K}$ beorption epectrue of $\mathrm{CF}_{3} \mathrm{Cl}$. The position of Cl la lonlzation threshold energy le indicated.
F1․ 2. The Cl Ka $(K-V)$ epoctrun of CFjCl axclted usth 2832.3 . $v$ photon energy long with the deconvolved Volet epectral component.
F15. 3. The C2 KL (K-V) apectue of $\mathrm{Cr}_{3} \mathrm{Cl}$ oxeleed vith 2823.1.v photon enerey.

One of the authors (R.C.C.P.) acknowledges the support by the U.S. Department of Energy under contract No. DE-AC03-76SF00098. 
X-24A CHEMICAL PHYSICS: POLARIZATION OF X-RAY FLUORESCENCE FROM $\mathrm{CH}_{3} \mathrm{Cl}$.

D.W. Lindle, P.L. Cowan, R.E. LaVilla, T. Jach (NBS); B. Karlin (NSLS); and R.D. Deslattes (NBS)

Monochromatic synchrotron radiation (SR) with a high degree of linear polarization from beamline $\mathrm{X}-24 \mathrm{~A}$ was used to resonantly excite $\mathrm{Cl} \mathrm{K}$-shell electrons in $\mathrm{CH}_{3} \mathrm{Cl}$ to the unoccupied $8 a_{1}$ antibonding molecular orbital. The subsequent $C 1$ K $\beta$ fluorescence was energy- and polarization-analyzed by a curved-crystal secondary spectrometer with excellent polarization selectivity. Two $\mathrm{Cl} \mathrm{K} \beta$ spectra for orthogonal Eluorescence polarizations are shown in the figure, where peak $C$ in each spectrum has been scaled to the same relative intensity. We observe that the $k \beta$ fluorescence is strongly polarized.

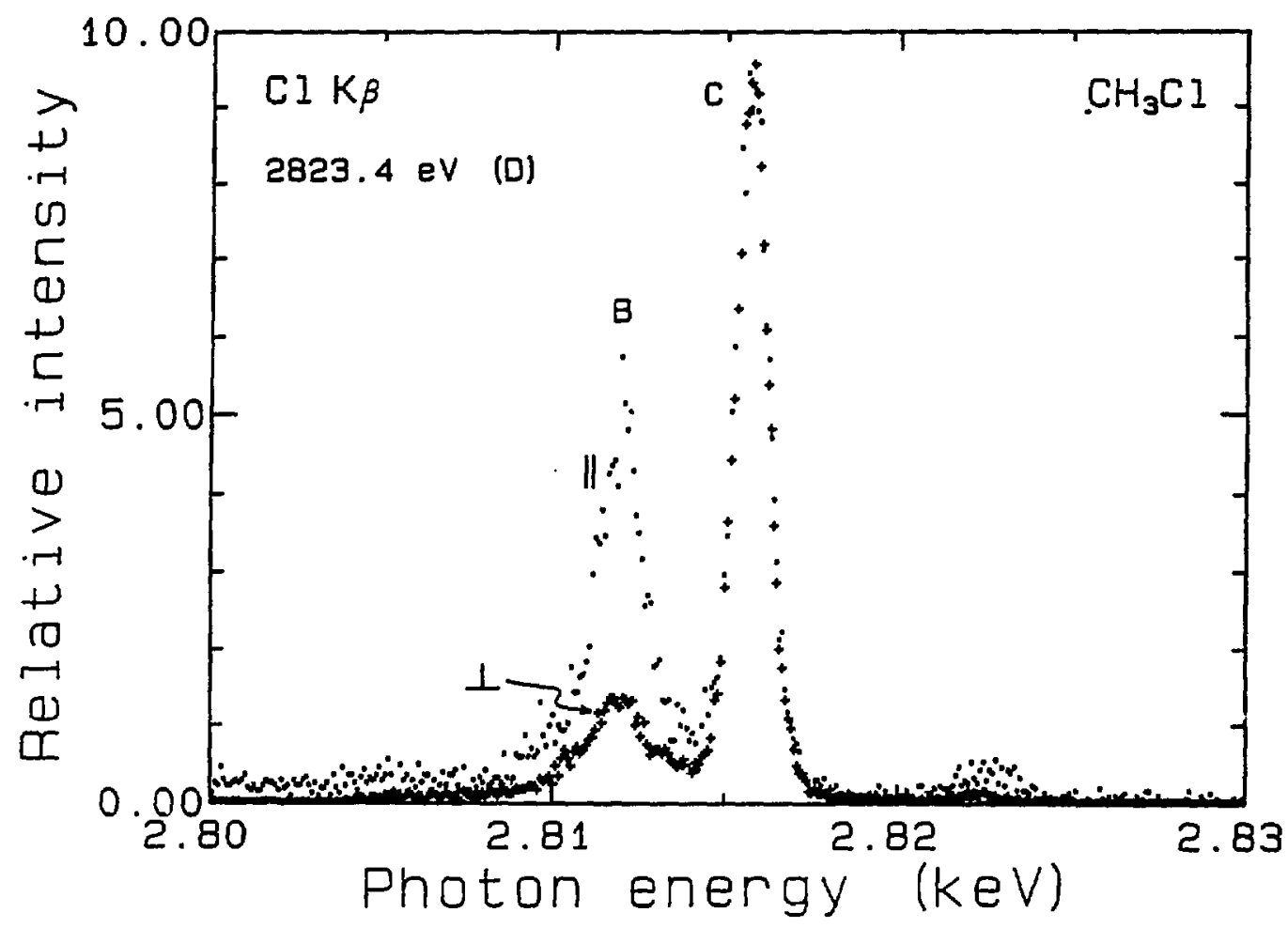

The direction of polarization is determined by the symmetry of the valence orbital involved in the fluorescence decay which fills the $\mathrm{Cl}$ is hole; valence orbitals of $a$ symmetry produce fluorescence $x$-rays polarized parallel to the SR polarization, whereas fluorescence from $\pi$-symmetry orbitals is polarized perpendicular to the SR polarization. Calculations [1] agree well with these observations, and indicate that, in $\mathrm{CH}_{3} \mathrm{Cl}$, the resonance lifetime is short enough to preclude substantial disorientation of the molecule prior to fluorescence decay. Measurements of this type may prove to be a sensitive probe of molecular-orbital symmetry in more complicated systems.

References

1. J.A. Sheehy, T.J. Gil, and P.W. Langhoff (private communication).

This research has been funded in its entirety by the National Bureau of standards. 
X-24A CHEMICAL PHYSICS: POLARIZATION OF X-RAY FLUORESCENCE FROM CHLORO-FLUORO-METHANES

D.W. Lindle, P.L. Cowan, T. Jach, R.E. LaVilla (NBS), B.A. Karlin, (NSLS), and R.C.C. Perera (LBL)

Highly polarized $x$-ray fluorescence has been observed following $K$-shell excitation of several chloro-fluoro-methanes. Monochromatic synchrotron radiation (SR) with a high degree of linear polarization was used to resonantly excite $\mathrm{Cl}$ is electrons in $\mathrm{CF}_{3} \mathrm{Cl}$, $\mathrm{CF}_{2} \mathrm{Cl}_{2}$, and $\mathrm{CF}_{3} \mathrm{Cl}$. The subsequent $\mathrm{Cl} \mathrm{K} \beta$ fluorescence was found to be strongly linearly polarized (see figures).

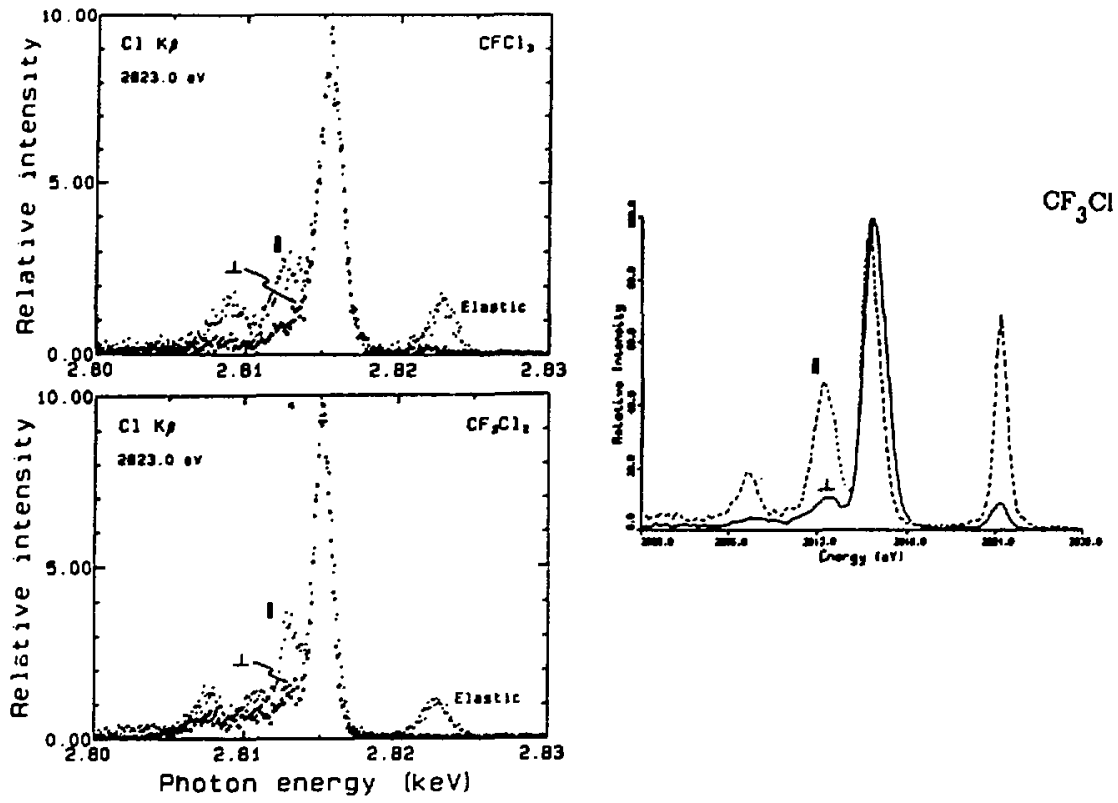

The direction of polarization of the $K \beta$ fluorescence is determined in part by the symmetry of the valence-orbital electron involved in the fluorescence decay which fills the $\mathrm{Cl}$ is hole. Our results illustrate that the core-level resonance lifetimes are short enough to preclude substantial disorientation of the molecule prior to fluorescence decay. Measurements of this type may prove to be a sensitive probe of orbital symmetry in more complicated molecular systems, condensed matter, and adsorbates.

The present measurements were performed at beamline X24-A at the National Synchrotron Light Source at Brookhaven. A high-energy-resolution primary monochromator focuses the incident beam into a cell containing the sample gas. The molecular $x$-ray fluorescence emitted upward from the gas cell is collected by a curved-crystal secondary spectrometer with position-sensitive detection. Polarization sensitivity is accomplished by using a Si(1ii) crystal in the spectrometer (and in the primary monochromator), for which the Bragg angle $1 \mathrm{~s} 44.6^{\circ}$ for $\mathrm{Cl} \mathrm{K} \beta$ fluorescence. Rotation of the secondary spectrometer, and hence the crystal dispersion plane, by $90^{\circ}$ suffices to detect orthogonal fluorescencepolarization components.

These preliminary results suggest the usefulness of fluorescence polarization to the assignment of resonant features both below and above threshold, and of the final valencehole-state symmetry. Beyond this straightforward spectroscopic utility, more general applications might include the study of molecules, lons, or molecular fragments in different environments and phases to determine spectroscopic or geometrical parameters. Furthermore, we suspect that the atomic specificity of this phenomenon may permit its use to study adsorbate orientations on surfaces.

One of the authors (RCCP) acknowledges support by the U.S. Department of Energy (contract no. DE-AC03-76SF0009B) 

HEXAFLUORIDE

P.L. Cowan, R.D. Deslattes, T. Jach, R.E. Lavilla, D.W. Lindle (NBS), and B.A. Karlin (NSLS).

Sulfur hexafluoride has long challenged the understanding of practitioners of core-level spectroscopies. The $x$-ray absorption spectrum is particularly rich in surprises and detailed structure $[1,2]$. Recently, photoionization spectroscopy has yielded some clues to the origin of several of the supra-threshold absorption features [3]. We have initiated studies of the molecule using energy selective excitation of $x$-ray emission spectra, partially to check the assignment of the supra-threshold resonances and partially to study the subthreshold region. Preliminary analysis of our data appears to add to the mysteries of this molecule.

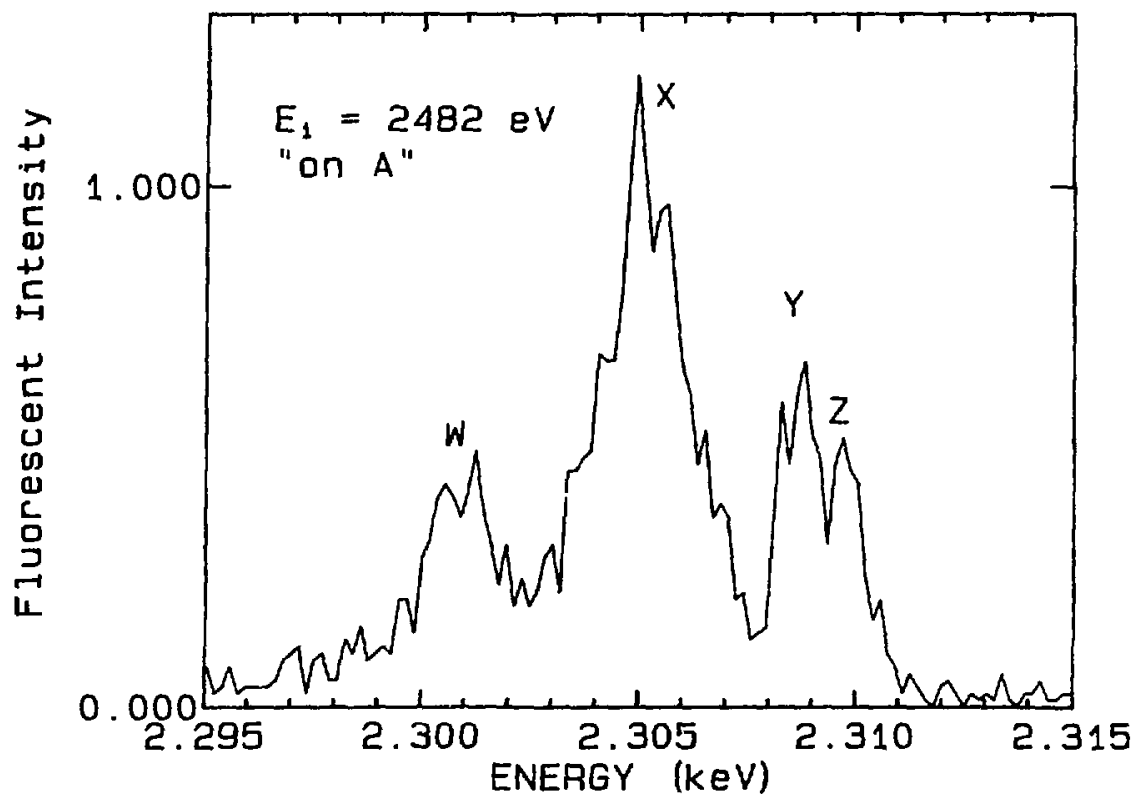

An example of the striking complexity observed by $x$-ray emission is presented in Fig. 1 . When the incident $x$-ray energy is tuned to the lowest sub-threshold absorption resonance, four emission peaks are resolved near the $\mathrm{S}$ Ka fluorescence energy. The two low energy peaks, labeled $W \& X$, are anomalously broad $(2.5 \mathrm{eV})$ while the higher energy doublet peaks, $Y$ \& $\mathrm{Z}$, are significantly narrower $(0.7 \mathrm{eV})$ than the observed supra-threshold Ka fluorescence peak widths $(1.0 \mathrm{eV})$. The positions of peaks $W \& X$ change linearally with changing excitation energy. Furthermore, comparison of polarization analyzed spectra indicates the peak $W$ is strongly polarized. Finally, although the $Y-Z$ doublet appears at the same emission energy as supra-threshold excited $K a_{1}$, fluorescence, the relative amplitudes are reversed ( $1 . e ., Z$ is less intense than $Y$ whereas normally the higher energy $\mathrm{Ka}_{1}$ line is stronger).

Although this molecule may be somewhat "pathological" (i.e., atypical of molecular spectroscopy in general) it is Important to accept the challenge of interpreting these results before one can have complete confidence in the use of core-level spectroscopies for studies of less exotfc molecules.

References

1. R.E. Lavilla, R.D. Deslattes, J. Chem. Phys. 44,4399 (1966).

2. R.E. Lavilla, J. Chem. Phys. 57,899 (1972).

3. T.A. Ferrett, et al., Phys. Rev. A 34,1916 (1986).

This research has been funded in fts entirety by the National Bureau of Standards. 
X-24A SOLID STATE SCIENCE: POTASSIUM AND CHLORINE K-ABSORPTION AND $\mathrm{K}$ FLUORESCENCE OF KCL

R.E. LaVilla, P.L. Cowan, D.W. Lindle (NBS); S. Brennan (SSRL); B. Karlin (NSLS); and R.D. Deslattes (NBS)

As a continuing part of our study of inner shell excitation phenomena, we measured the $K$ absorption and $K \beta$ emission from the $\mathrm{KCl}$ system, whose ions are isoelectronic with argon. The $\mathrm{K}$ and $\mathrm{Cl} \mathrm{K} \beta$ emission from a single crystal of $\mathrm{KCl}$ was obtained as a function of incident photon excitation through their respective 1 s thresholds and extending to about $100 \mathrm{eV}$ above the is edges.

These data provide information on the origin of the different features of the emission spectrum. Thus $K K \beta^{n}$ and $C l K \beta_{x}$ are due to the decay of a complex of initial doublevacancy states because they are absent within $10-15 \mathrm{eV}$ above the is edge. However, near threshold the $K \beta_{5}$ feature persists. This observation supports the view of $K K \beta_{5}$ as a single- vacancy transition. Further, the alignment of the $K \mathrm{~K} \beta_{5}$ with $\mathrm{Cl} K \beta_{1,3}$ relative to the respective $K$ and $C l$ absorption features supports the designation of $K \dot{K}_{5}$ as a cross transition.

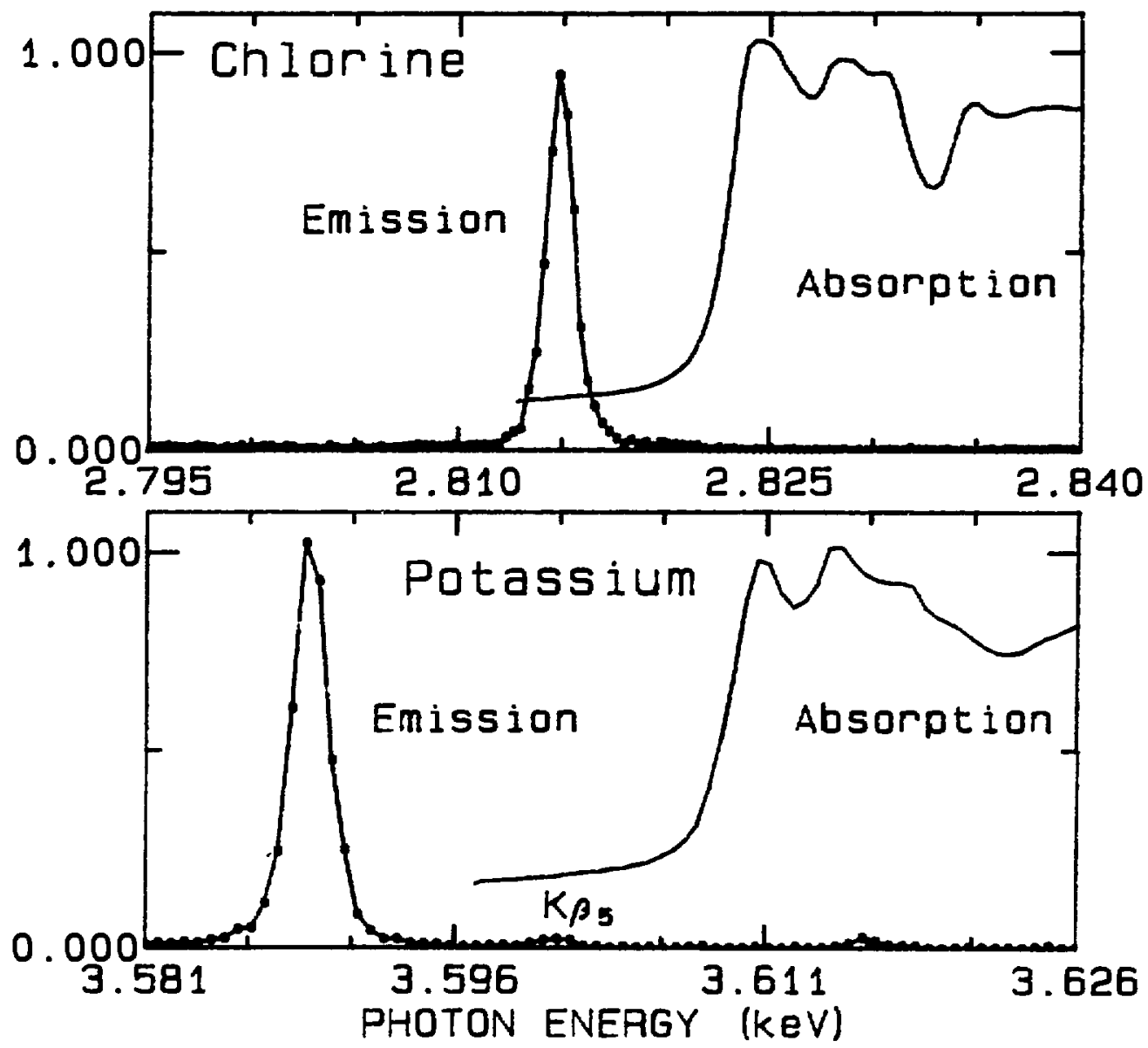

This research has been funded in its entirety by the National Bureau of Standards. 
$X$-24A SURFACE SCIENCE: STRUCTURE OF Cl ADSORBED ON Cu(100) DETERMINED BY BACK-REFLECTION $X$-RAY STANDING WAVES

J, Rowe (Bell Labs), F. Sette (Bell labs), P.L. Cowan (NBS), T. Jach (NBS), and B.A. Karlin (NSLS).

The $\mathrm{Cl} / \mathrm{Cu}(100)$ adsorbate system was studied as a test for the new back reflection $x$-ray standing wave technique. This system has been carefully studied by established techniques [1]. It also presents a challenge to the $x$-ray standing wave method in that previously $x-$ ray standing wave studies of metal crystals was all but impossible.

The sample crystal was known to have a mosaic spread of $\approx 1 / 4^{\circ}$. Despite this a clear $x$-ray standing wave effect is observed in the back reflection geometry. The $C l$ adsorption site was $1.7 \mathrm{~A}$ above the $\mathrm{Cu}(200)$ plane at the surface. Plots of the $\mathrm{Cl} \mathrm{K-fluorescence,} \mathrm{the} \mathrm{Cu}$ LMM Auger and the diffracted beam intensicy vs. incident $x$-ray energy are shown.

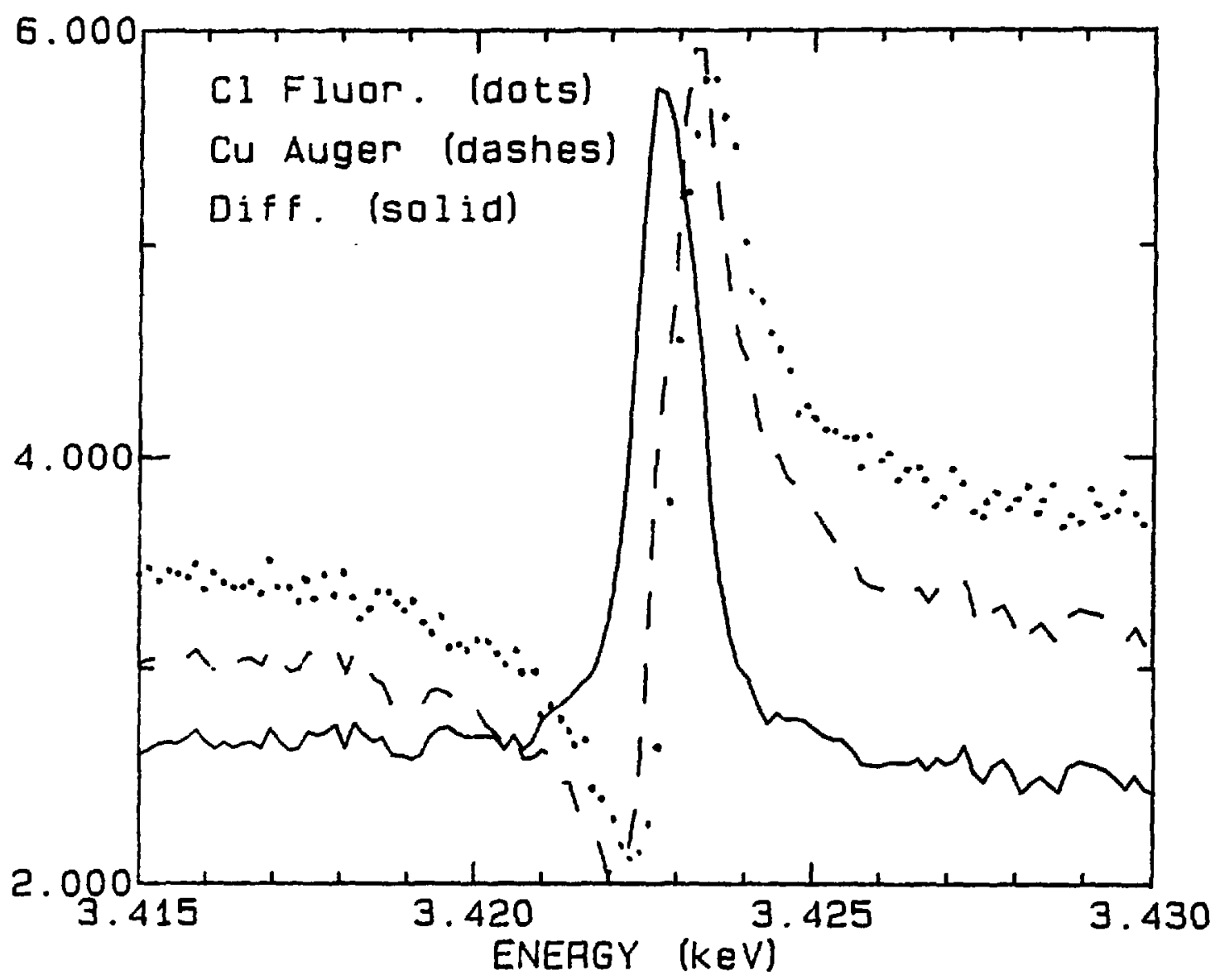

References

1. F. Sette, 1. Rowe, to be published. 
X-24A SURFACE SCIENCE: STRUCTURE OF S ADSORBED ON CU(100) DETERMINED BY SEXAFS AND BACKREFLECTION X-RAY STANDING WAVES

F. Sette (Bell Labs), J. Rowe (Bell Labs), P.L. Cowan (NBS), T. Jach (NBS), and B.A. Karlin (NSLS).

We have studied the structure of sulfur adsorbed on a Cu(100) surface using a variety of techniques. In addition to conventional laboratory analysis techniques such as LEED and electrcn beam stimulated Auger analysis, we examined the structure with SEXAFS and the nove $l$ back-reflection $x$-ray standing wave method.

A $\mathrm{Cu}(100)$ surface was sputter cleaned and annealed to $450^{\circ} \mathrm{C}$ for $5 \mathrm{~min}$. The sample was then exposed to $\mathrm{H}_{2} \mathrm{~S}$ and was annealed further at $200^{\circ} \mathrm{C}$ until a $\mathrm{p}(2 \times 2) \mathrm{S} / \mathrm{Cu}(100)$ LEED pattern was observed. Sulfur coverage was approximately $1 / 2$ monolayer.

SEXAFS was recorded by observing the S-fluorescence as a function of incident $x$-ray energy. The absorption spectrum and the derived pair distribution function are shown. Results indicate that the sulfur atoms sit at a 4-fold hollow site with a nearest neighbor (S-Cu) bond length of $2.24 \AA$. We believe that this is the first and only SEXAFS spectrum taken at the NSLS $x$-ray ring to date.
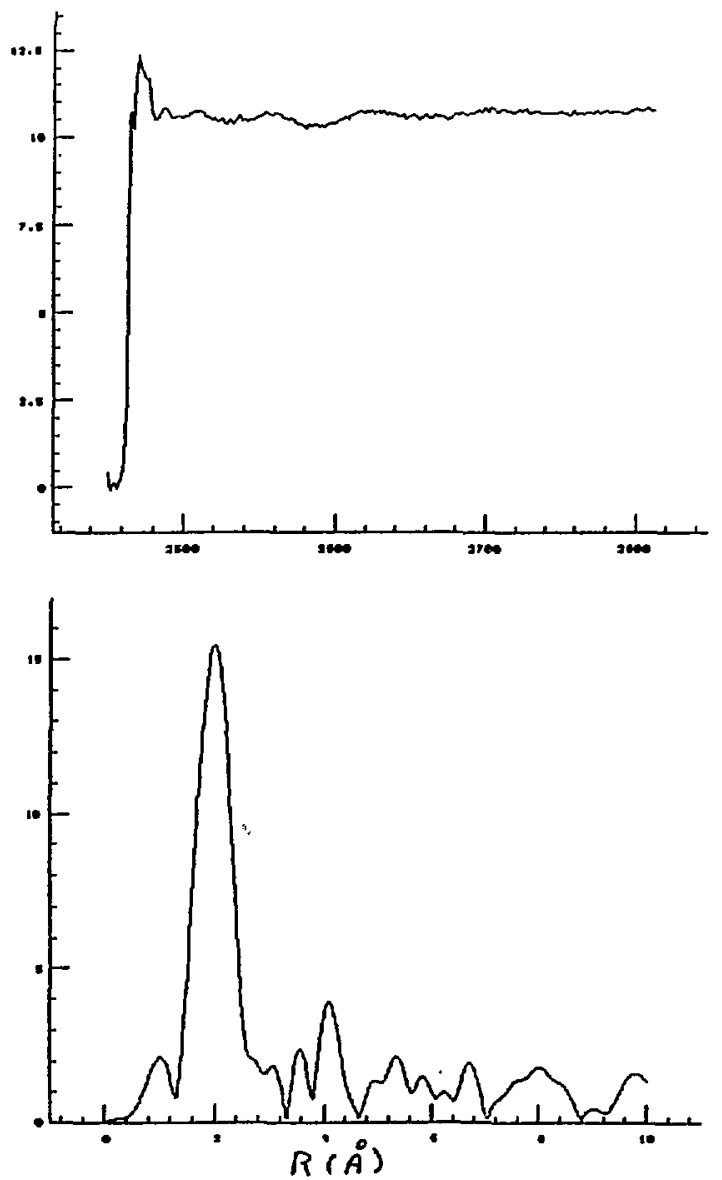

The sulfur adsorption site was also located by the back-reflection $x$-ray standing wave method. Both the $\mathrm{Cu}(200)$ reflection, normal to the surface, and a Cu<111> reflection were used. Preliminary analysis of the $x$-ray standing wave results indicate the sulfur atoms sit $1.6 \AA$ above the $C u(200)$ plane at the surface. 
X-24A SURFACE SCIENCE: TEMPERATURE DEPENDANCE OF SULFUR ADSORPTION SITE ON Cu(100) STUDIED BY BACK-REFLEOTION X-RAY STANDING WAVES

T. Jach (NBS), P.L. Cowan (NBS), F. Sette (Bell labs), J. Rowe (Bell Labs) and B.A. Karlin (NSLS).

The back-reflection $x$-ray standing wave technique was used to observe the structure of sulfur adsorbed on $a(u(100)$ surface as a function of crystal temperature. For this system a reversible phase change has been observed with LEED. At room temperature a $\mathrm{p}(2 \times 2)$ LEED pattern is observed, but at $250^{\circ} \mathrm{C}$ the pattern changes to (1x1).

The thermal expansion of the $C u$ substrate causes the energy where the back-reflection diffraction condition occurs to decrease. The figures compare the $x$-ray standing wave results obtained by observing the standing wave dependance of the $\mathrm{S} K$-fluorescence at room temperature and at $400^{\circ} \mathrm{C}$.
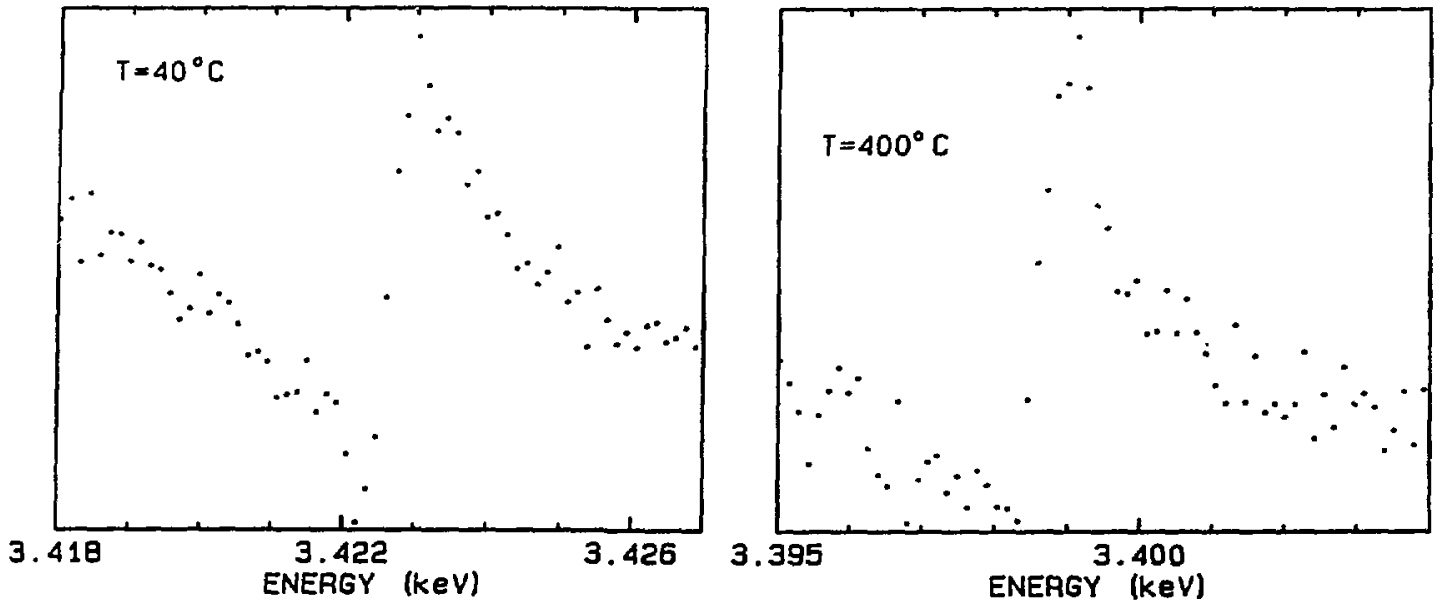

It is apparent, that although the $\mathrm{Cu}-\mathrm{Cu}$ bond-lengths are expanding, the S-Cu bond-lengths at the surface expand much faster with temperature. Preliminary analysis indicates that while the $\mathrm{Cu}-\mathrm{Cu}$ bonds expand by about it the $\mathrm{S}-\mathrm{Cu}$ bond-length increases by $\approx 25 \%$. Measurements were also taken at 7 intermediate temperatures.

It is important to note that our results indicate the $x$-ray standing wave technique is capable of determining atomic structure at elevated temperatures where other structure techniques such as SEXAFS and LEED cease to yield meaningful results.

This research has been funded in its entirety by the National Bureau of standards. 


\section{COMBINED LASER-SYNCHROTRON PHOTOEMISSION EXPERIMENTS ON X-24C}

J.P. Long, J.C. Rife, H.R. Sadeghi*, M.N. Kabler

Naval Research Laboratory, Code 4606, Washington D.C. 20375

The extension of photoelectron spectroscopy to the study of laser excited materials has begun on the NRL soft $x$-ray beam line with the installation of a copper vapor laser and time-resolved detection capability. Laser induced, pulsed photovoltages on clean silicon surfaces have been measured with 2 to 15 ns resolution by recording the transient si $2 p$ core level shifts. Such experiments yield information on the dynamics of the laser excited electronhole plasma and its interaction with the surface.

The beam line terminates in a conventional ultra-high-vacuum surface science chamber equipped with a cylindrical mirror analyzer (CMA) for phototelectron detection. The copper vapor laser provides 20 ns pulses with a wavelength of $510 \mathrm{~nm}$ at a repetition rate of $6 \mathrm{kHz}$. Photoelectron arrival times, relative to the laser pulse, are recorded by a time-to-digital converter capable of processsing up to eight events.

The measurements were taken in two modes. For time-resolved energy distribution curves, signal-to-noise considerations demanded that the ring operate in single bunch mode. In this mode, the copper vapor laser was synchronized to the $x-r a y$ pulse, and the best time resolution was realized. In the second mode, used for recording the photovoltage decay, the ring was operated in multibunch mode and the laser free-ran relative to the $x$-ray pulses. Here, the cMA was set to a kinetic energy near an inflection point on the core level line shape, and the count rate recorded as a function of time as the line edge shifted in response to the photovoltage. In this mode, tine resolution was measured to be - $15 \mathrm{~ns}$, limited by spread in photoelectron transit times through the CMA.

Si (111) n- and p-type samples were prepared by thermal desorption cleaning, by sputtering, or by sputtering and annealing. Several surfaces were also studied as a function of dosing with dissociated hydrogen. Spectra were recorded with

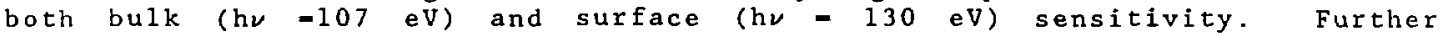
experimental details are contained in reference 1 .

Except for those from sputtered-only surfaces, photovoltage decays compare qualitatively with a prediction, based on Johnson's treatment ${ }^{2}$ in which surface state charge redistribution is neglected and the bulk electron-hole pair density is given by an analytic solution to the diffusion equation. In general, a large surface recombination ls found, characterized by recombination velocities up to $10^{6} \mathrm{~cm} / \mathrm{s}$. Photovoltages from hydrogen dosed surfaces match most closly the predicted decay. It is possible that the metallic surface state on the Si (111) $7 \times 7$ surface, which is severly attenuated with hydrogen dosing, plays a role in non-equilibrium surface charge redistribution which may account for the deviations from the predicted decay seen on clean surfaces. However, since large surface recombination is for the most part sustained on the hydrogen dosed surfaces, the metallic surface stace is not primarily responsible for the large surface recombination. The long ( $>60 \mu s$ ) photovoltage decays observed on sputtered-only surfaces are presumably caused by long-lived traps related to disorder.

1 James $P$. Long, to appear in Nucl. Instr, and Meth.

2 E. O. Johnson, Phys. Rev. 111, 153 (1958).

* Sachs/Freeman Associatea, Inc., Landover Md. 
SYNCHROTRON MICROPROBE AND MICRO-OPTICAL STUDY OF GOLD IN CARLIN-TYPE ORES

J. Chen (SUNY), E.C.T. Chao (USGS), J. Minkin (USGS), J. Back (USGS), W. Bagby (USGS), A. Hanson (BNL), K. Jones (BNL), M. Rivers (BNL), and $S$. Sutton (BNL)

Site specific occurrences of gold in unoxidized Carlin-type ores [1] have been determined using combined micromoptical and synchrotron $x$-ray fluorescence (SXRF) microprobe techniques [2]. Knowledge of the gold sites and their mineral associations is important for understanding the genesis of these disseminated Carlin-type deposits, and in the exploration and recovery of gold from such deposits, currently the major commercial source of gold in the United States.

To date three unoxidized and two oxidized samples from the Carlin and Horse Canyon nines have been studied. Beamline $X 26$ at the NSLS was used to achieve beam sizes down to 20 micrometers and SXRF minimum detection limits for Au from 3 ppm (in pyrite) to less than $1 \mathrm{ppm}$ (In siliceous matrix) [3]. Following the location of Au-enriched areas in the samples using SXRF, high resolution SEM augmented with EDX analysis was used to identify and study the mineral components in the samples. EPMA was also used to analyze various mineral phases.

Initial results indicate that: 1) gold is not associated with pyrite of any size, contrary to earlier reports [4]; 2) gold is not associeted with carbonaceous matter; 3) gold occurs sporadically in reticulated replacement quartz and secondary chert-like patchy quartz of early stages of silicification; and 4) gold is concentrated in matrix areas of pre-existing illite. Further studies are underway.

References

[1; W. C. Bagby and B. R. Berger, Reviews in Economic Geology Vol. 2, 169-202 (1986).

[2] E. C. T. Chao, J.R. Chen, J. A. Minkin, and J. M. Back, Process Mineralogy VII, TMS/AIME, in press.

[3] J. R. Chen, E. C. T. Chao, J. A. Minkin, J. M. Back, W. C. Bagby, M. L. Rivers, S. R. Sutton, B. M. Gordon, A. L. Hanson, and $K$. W. Jones, Nuc1. Instrum \& Meth. Vol. B22, $394-400$ (1987).

[4] J. D. Welis and T. E. Mullens, Econ. Geol. Vol, 68, $187-201$ (1973).

Acknowledgements

Research supported in part by the NSLS/HFBR Faculty Student Support Program funded by DOE, and in part by DOE, Division of Chemical Sciences (Contract No. DE-ACO2-76CH00016). 
K. W. Jones, B. M. Gotdon, A. L. Hanson, B. M, Johnson, M. Meron, J. G. Pounds (BNL), J. V. Smith, M. L. Rivers, S. R. Sutton (U. of Chicago)

\section{Introduction}

The activities at the X-26 bean port center on two main ereas of research. First, new analytical technlques are developed and used for experiments in geochemiatry, 2 coamochemistry and biomedical sciences, 4 Second, the properties of very low-energy multiply-charged atoms are investigated in several ways. 5 The activity at the $X-26$ bean line sumarized here includes work done by the main BNL and Chicago groups as well as collaborators and users.

\section{Bean Liae Development}

The configuration of the $X-26 C$ beem line is being changed during the shutdown of the $x-r a y$ ring. $A$ completely new beem line is being edded at the $X-26 \wedge$ position.

On the $\mathrm{X}-26 \mathrm{C}$ line a $1: 1$ focussing mirror is being installed to lncrease the flux of the white-11ght beam. A monochromator is being added so that monoenergetic photons can be used. Changes in the bean Iine vacuum system are being made so that it can be operated in the windowless mode. This change will eliminate the low-energy cut-off in the energy spectrum caused by the beryllium window previously used to isolate the beam line from the ring vacuum system. The $X-26 A$ line will be equipped with focussing mirror designed to produce a demagnification of the source by a factor of eight. The intent is to provide a maximum flux of photons in the hutch to be used for x-ray microscopy exferiments.

\section{Anelytical Technique Detelopent}

Application of the $x$-ray fluorescence technique to trace element detection was pursued with the objectives of developing maximum sensitivity and lateral spatial resolution. Two types of instruments were used to produce a photon beam with dimensions of about $10 \mu \mathrm{m}$. One instrument used a collimated beam and the other a focussed beam. Lateral resolutions of 10 micrometers and minimum detection limits close to one femtogram were obtalned.

Work on the development of mlcro-computed tomography methods was successful in obtaining apatial resolution of 30 micrometers. One alm of the project is to use the technique for in-vivo diagnostics on experimental animals. This was accomplished for the first time during the last year when the head of an anesthetized mouse was successfully lmaged.

\section{Atoofic Physice}

An extensive study of multiply-charged argon lons produced by photolonization was carried out. Measurements were made of fluorescent radiation enitted in the process, argon lons with a charge up to $8+$ were trapped at an energy of $40 \mathrm{meV}$ and used for rate coefficient determinations, and molecular effects were demongtrated in the energy spectrum of the lons extracted from the production reglon.

\section{Geochentetry and Cosnochenistry}

The results of experiments done during the past year show that the synchrotron x-ray microscope 1s a unique tool for the characterization of the elemental content of the materials encountered in cosmochemistry and geochemistry. They demonstrate that the combination of good spatial resolution, low values for the minimum detection limits, and ease of quantitation give the synchrotron instrument special propertles when compared to electron or ion probes.

\section{Bionedical}

Experiments were done that evaluated the distribution of essential trace elements in cerebrum, cerebellum, kldney and liver, of a toxic element (lead) in bone and cerebrum, and of metal contalning drugs in normal and tumorous tissue.

\footnotetext{
TProcesses and Technlques Branch, Division of Chemical Sclences, office of Baslc Energy Sciences, U.S. Department of Energy under Contract No. DE-ACO2-76CH00016.

2 National Sclence Foundation Grant No. EAR8313682 to the University of Chicago.

3 Grant No. NAG 9-106 to the Unlversity of Chicago.

4 The beam line operates as a NIH Biotechnology Research Resource under Grant No. P41RR01838.

5 Fundamental Interactions Branch, Division of Chemical Sciences, office of Basic Energy Sciences, U.S. Department of Energy under Contract No. DE-ACO2-76CH00016.
} 
REGIONAL ALTERATIONS IN TRACE ELEMENT CONTENT IN BRAINS OF LEAD-EXPOSED RATS ${ }^{1}$

S. M. Lasley (U. of IL Coll. of Med.) and J. G. Pounds (BNL)

Animal models of chronic lead exposure have been employed to produce environmentally relevant levels of the metal in blood $(30-40 \mu \mathrm{g} / 100 \mathrm{ml})$ in order to study 1 ts actions on CNS function. A few such studies have also measured lead content either in whole brain (1,2) or brain regions (3) to correlate with blood lead levels and length of exposure. No attempts have been made however to examine the effects of chronic lead exposure on brain content of other trace elements that play important roles in neuronal function such as calcium, iron, and zinc. Therefore, this study was performed to investigate tise effects of chronic lead exposure on content of trace elements in specific brain regions.

Long-Evans hooded rats were mated and on day 14 of gestation switched to NIH-07 diet to maintain a more consistent mineral intake. At parturition dams recelved $0.2 \%$ lead acetate in their drinking water, thus exposing the suckling pups to lead via the maternal milk. Control dams were maintained on distilled water. Offspring were weaned to and maintained on the same solution given their dam until sacrifice at 90 days. Brains from five exposed and five control rats were sliced by microtome in coronal sections $20 \mathrm{um}$ thick in a cryostat at $-15^{\circ} \mathrm{C}$, and slices appropriate for the risualization of nucleus accumbens, caudate-putamen, substantla nigra, ventral tegmental area and hippocampus were placed on Kapton film. Adjacent sections were placed on glass slides and treated with a hemotoxylin and eosin staln to aid in anatomical identification. Samples were analyzed using synchrotron microprobe radiation from the $2.5 \mathrm{GeV}$ light source. Sections were placed at $45^{\circ}$ to the beam (200 um square spot) and the resulting $x$-ray spectra collected at $90^{\circ}$ by a $S 1(L 1)$ detector using a 150 um aluminum filter on the primary beam and a 100 um Kapton filter on the detector. Spectra were fitted using a modified version of HEX, a curve-fitting program, on a MicrovAX II computer. Elemental concentrations are calculated from a detector efficlency curve obtained from gelatin standards spiked with selected trace elements and mounted on Kapton. Multiple point measurements were also taken to characterize the five brain areas of interest.

Initial data analysis indicated that manganese and iron were significantly decreased in ventral tegmental area of rats chronically exposed to lead $(p<0.05)$. Iron is an important cofactor for enzymes involved neurotransmitter synthesis, but it is not known what proportion of the decrease in content is due to iron of heme origin. Previous studies have shown that this exposure protocol does not alter hemoglobin or serum iron. Irrespective of treatment, calcium and manganese (both $p<0.01$ ) as well as copper and zinc (both $p<0.05$ ) differed significantly across brain regions. Lastly, the method did not have sufficient sensitivity to quantify lead content, which previously has been determined in whole brain analyses with this exposure model to be about $400 \mathrm{ng} / \mathrm{g}$ tissue in exposed animals (1). Further data analysis is currently being conducted.

1. Lasley, S.M., Wimbish, G.H. and Lane, J.D. NeuroToxicology 7:527 (1986).

2. Rader, J.I., Celesk, E.M., Peeler, J.T. and Mahaffey, K.R. Toxico1. App1. Pharmaco1. 67:100 (1983)

3. Collins, M.F., Hrdina, P.D., Whittle, E. and S1nghal, R.L. Toxico1. App1. Pharmaco1. 65:314 (1982)

${ }^{1}$ Th1s work was supported by NIH grant ESO4359 and the NSLS. 


\section{SECTION A}

\section{USER PUBLICATIONS BASED ON WORK AT THE NSLS DURING FISCAL YEAR 1987*}

Beam Line U1

B. Abeles, L. Yang, W. Eberhardt, and L. Roxlo, Structure of Hydrogenated Amorphous Silicon/Silicon Oxide Superlattices, 18th Int. Conf. on the Physics of Semiconductors, Stockholm, Sweden 1986.

B. Abeles, L. Yang, and W. Eberhardt, Growth and Electronic Structure of Amorphous Hydrogenated Silicon/Silicon Oxide Heterojunctions, Int. Workshop on Amorphous Semiconductors, Beijing, China, 1986.

W. Eberhardt, B. Abeles, L. Yang, H. Stasiewski, and D. Sondericker, Photoemission Study of the a-Si:H/a-SiO $: \mathrm{H}$ and a-Si:H/a- SiN:H Interface Formation, Mat. Res. Soc. Proc., Vol. 77.

D. Fischer and J. Gland, Soft X-ray Fluorescence (UHV Compatible) Proportional Counters for NEXAFS and SEXAFS above the C,N,O and S K edges, Int. Conf. on Soft X-ray Optics and Technology, Berlin, W. Germany, 1986.

\section{Beam Line U2}

F. Boscherini, Y. Shapira, C. Capasso, and J. H. Weaver, Synchrotron Radiation Photoemission Studies of Cu/ InSb(110) Interface Evolution and Modification by Al Interlayers, Phys. Rev. B (submitted).

M. DelGiudice, J. J. Joyce, F. Boscherini, C. Capasso, and J. H. Weaver, High Resolution Core Level Studies of Interdiffusion and Reaction at Metal-Semiconductor Interfaces, Proc. Mat. Res. Soc. Meeting, (in press).

\section{Beam Line U5U}

P. D. Johnson, S. L. Hulbert, and M. R. Howells, The Use of a Miniature Toroidal Grating Monochromator on the FEL Undulator at the NSLS, BNL 37242, 1986.

P. D. Johnson, S. L. Qui, L. Jiang, M. W. Ruckman, M. Strongin, S. L. Hulbert, R. F. Garrett, B. Sinkovic, N. V. Smith, R. J. Cava, C. S. Jee, D. Nichols, E. Kaczanowicz, R. E. Salamon, and J. E. Crow, Photoemission Studies of High $\mathrm{T}_{c}$ Superconductor $\mathrm{Ba}_{2} \mathrm{YCu}_{3} 09-{ }_{-}$. Phys. Rev. B35, 8811 (1987).

\section{Beam Line U7}

M. Rockman, V. Murgai, and M. Strongin, Morphology and Structural Phase Transitions of Pd Monolayers on Ta(110), Phys. Rev. B34, 6759 (1986).

M. W. Ruckman, M. Strongin, and X. Pan, Synchrotron Radiation Photoemission Studies of CO Chemisorption on Pt/ $\mathrm{Ta}(110)$ and $\mathrm{Ni} / \mathrm{Ta}(110)$, J. Vac. Sci. Technol. A5 (4), 805 (1987).

M. L. Shek, X. Pan, and M. Strongin, The Effects of Na on the Interaction of CO with Ta(110), J. Vac. Sci. Technol. A5 (4), 1057 (1987).

M. W. Ruckman and M. Strongin, Estimates of the Heats of Adsorption for Pt and Pd Monolayers on Ta(110), Phys. Rev. B35, 2487 (1987).

X. Pan, M. L. Shek, S. Paaen, M. 1. Florit, S. L. Qui, and M. Strongin, Observation of Bulk Ta Oxide Formation Below 30K, Phys. Rev. B35, 3740 (1987).

S. L. Qui, X. Pan, M. Strongin, and P. H. Citrin, Photoemission from Supported Metal Clusters; the Problem of the Support, Phys. Rev. B36, 1292 (1987).

\section{Beam Line U8}

R. Ludeke, G. Hughes, F. Schaffler, F. J. Himpsel, D. Rieger, D. Straub, ano G. Landgren, An Impurity Model for the Schottky Barrier: Transition Metals on III-V Compound Semiconductors, Proc. 18th Int'l Conf. on Physics of Semiconductors, Stockholm 1986. O. Engstrom, ed., World Scientific Publishing Co., Singapore, p. 287 (1987).

-Publicition list was compiled from PRT/IDT Progress Reports for the periods 8/86 - 1/87 and 2/87 - 9/87. It contains only published anicles, no abstracts, and does not represent a complete listing for the facility. 
F. Schaffler, W. Drube, G. Hughes, R. Ludeke, D. Rieger, and F. J. Himpsel, Metal-Induced Impurity States at the InP/ Transition Metal Interface, J. Vac. Sci. Techn. A5, 1528 (1987).

F. Schaffler, W. Drube, G. Hughes, R. Ludeke, and F. J. Himpsel, A Comparative Study of Y and Other Transition Metals on GaAs, Phys. Rev. B35 6328 (1987).

F. Schaffler, R. Ludeke, A. Taleb-Ibrahimi, and G. Hughes, The Sb/GaAs Interface: A Re-evaluation, Phys. Rev. Rapid Comm., (1987).

F. Schaffler, R. Ludeke, A. Taleb-Ibrahimi, G. Hughes, and D. Rieger, The Role of Order on the Interface Properties of Sb/GaAs (110), J. Vac. Sci. Tech. B5, 1048 (1987).

D. Risger, F. J. Himpsel, U. O. Karlsson, F. R. McFeely, J. F. Morar, and J. A. Yarmoff, Electronic Structure of the CaF2/Si(111) Interface, Phys. Rev. B34, 7295 (1986).

F. R. McFeely and J. A. Yarmoff, Mechanisms of the Ion Enhanced Etching of Silicon, Proc. of the ICPS I8 Conference in Srockholm (1986).

U. O. Karlsson, D. Rieger, J. A. Yamoff, F. R. McFeely, J. F. Morar, and F. J. Himpsel, CaF2/Si(111): Electronic Structure of the Interface. Proc. of the ICPS 18 Conference in Stockholm (1986).

J. A. Yarmoff and F. R. McFeely, Mechanism of lon-Assisted Etching of Silicon by Fluorine Atoms, Surf. Sci. 184, 389 (1987).

J. F. Morar, B. S. Meyerson, U. O. Karlsson, F. J. Himpsel, F. R. McFeely, D. Rieger, A. Ta ,-lbrahimi, and J. A. Yarmoff, Oxygen Removal from Si via Reaction with Absorbed Ge, Appl. Phys. Lett. 50, 463 (1987).

J. A. Yamoff and F. R. McFeely, Constant Final-State Photoemission Study of Silicon Fluoride Reaction Layer Created During Etching: Morphology of the Reaction Layer, Proc. of Fall 1986 MRS meeting, Boston, MA (1986).

F. J. Himpsel, U. O. Karlsson, J. F. Morar, D. Rieger, and J. A. Yarmoff, Microscopic Model for the Epitaxy of C F 2 on Si (11), Proc. of 1987 Spring MRS Meeting, Anaheim, CA (1987).

J. A. Yarmoff, D. R. Clarke, W. Drube, U. O. Karlsson, A. Taleb-Ibrahimi, and F. J. Himpsel, Valence Electronic Structure of $\mathrm{YBa}_{2} \mathrm{Cu}_{3} \mathrm{O}_{7}$, Phys. Rev. B36, 3967 (1987).

F. R. McFeely, B. D. Silverman, J. A. Yarmoff, and U. O. Karlsson, The Structure of the Reaction Layer in the XeF ${ }_{2}^{-}$ Si(111) System, Proc. of Eighth Inter. Conf. on Plasma Chemisiry. Tokyo (1987).

\section{Beam Line U9A}

M. A. Wickramaaratchi, J. M. Preses, and R. E. Weston, Jँ., Fluorescence of Cyclohexane Vapor: Pressure Dependence and Quenching Studies, J. Chem. Phys. 85, 2445 (1986).

\section{Beam Line U9B}

B. M. Sutherland, G. Ciarrocchi, M. Ciomei, and J. C. Sutherland, Quantitation of DNA Damage in Non-Radioactive DNA, Photochem. Photobiol. 44, 343, (1986).

W. R. Laws and J. C. Sutherland, The Time-Resolved Photon-Counting Fluorometer at the National Synchrotron Light Source, Photochem. Photobiol. 44, 343, (1986).

J. C. Sutherland, B. Lin, J. Mugavero, J. Trunk, M. Tomasz, R. Santella, L. Marley, and K. Breslauer, Vacuum Ultraviolet Circular Dichroism of Double Stranded Nucleic Acids. Photochem. Photobiol. 44, 295, (1986).

J. B. A. Ross, W. R. Laws, J. C. Sutherland, A. Buku, P. G. Katsoyannis, I. L. Schwartz, and H. R. Wyssbrod, LinkedFunction Analysis of Fluorescence Decay Kinetics: Resolution of Side-Chain Rotamer Populations of a Single Aromatic Amino Acid in Small Polypeptides. Photochem. Photobiol. 44, 365, (1986).

N. E. Geacintov, D. Zinger, V. Ibanez, R. Santella, D. Grunberger, and R. G. Harvey, Properties of Covalent Benzo[a]pyrene diol epoxide - DNA Adducts Investigated by Fluorescence Techniques; Carcinogenesis 8, 925 (1987). 
E. S. Stevens and B. Lin, Vacuum Ultraviolet Circular Dichroism of Keratan Sulphate, Biochimica et Biophysica Acta 924, 99 (1987).

\section{Beam Line U10}

K. L. Tsang, C. H. Zhang, T. A. Callcott, E. T. Arakawa, and D. L. Ederer, Fluorescent Emission Spectra of Lithium Fluoride Using Synchrotron Radiation, Phys. Rev. B35, 8374 (1987).

T. A. Callcott, K. L. Tsang, C. H. Zhang, D. L. Ederer, and E. T. Arakawa, High-efficiency Soft X-ray Spectrometer for Use with Synchrotron Radiation Excitation, Rev. Sci. Instrum. 57, 2680 (1986).

\section{Beam Line UII}

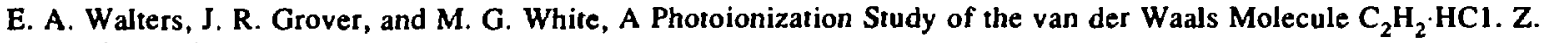
Hys, D4, 103 (1986).

E. D. Poliakoff, M.-H. Ho, M. G. White, and G. E. Le Roi, Chem.. Phys. Lett. 130, 91 (1986).

E. D. Poliakoff, J. C. K. Chan, and M. G. White, J. Chem. Phys. 85, 6232 (1986).

E. D. Poliakoff, M.-H. Ho, G. E. Le Roi, and M. G. White, J. Chem. Phys. 85, 5529 (1986).

G. R. Grover, E. A. Walters, and E. T. Hui, Dissociation Energies of the Benzene Dimer and Dimer Cation, J. Phys. Chem. 91, 3233 (1987).

M. G. White, G. E. LeRoi, M.-H. Ho, and E. D. Poliakoff, Multichannel Interactions in the Resonant Photoionization of Hel, J. Chem. Phys., 1987).

\section{Beam Line UI4A}

A. Tourillon, A. Fontaine, R. Garrett, M. Sagurton, P. Xu, and G. Williams, Near Edge X-ray Absorption Fine Structure Obervations of Ordering and Metallic like Behavior in Inorganic Conducting Polymers Grafted on a Pt Surface, Phys. Rev. B35, 9863 (1987).

G. Tourillon. S. Raaen, T. Skotheim, M. Sagurton, R. Garretı, and G. Williams, A Near Edge X-ray Absorption Fine Structure Study of the Adsorption of Pyrrole and $\mathrm{N}$-Methylprrole on $\mathrm{Pt}(111)$ : Orientation and Dissociation of the Adsorbed Molecules. Surface Sci. 184, L345 (1987).

E. Johnson, S. Hulbert, R. Garrett, G. Williams, and M. Knotek, In-Situ Reactive Glow Discharge Cleaning of X-ray Optical Surfaces, Rev. Sci. Inst. 58, 1042 (1987).

J. McKay, M. Mohamed, and V. Henrich, Localized 3p excitations in 3d Transition-metal-series Spectroscopy, Phys. Rev. B35, 4304 (1987).

\section{Beam Line U15}

B. X. Yang, J. Kirz, and S. Xu, Characterization of Phosphors in the Soft X-ray Region, Nucl. Inst. and Methods in Phys. Res., A258 141 (1987).

B. X. Yang and J. Kirz, Extended X-ray-absorption Fine Structure of Liquid Water, Phys. Rev. B, 36 (2) 1361 (1987).

B. X. Yang and J. Kirz, Extended X-ray-absorption Fine Structure of $\mathrm{CO}_{2}$ Analyzed by a New Algorithm, Phys. Rev. B. 35 (12), 6100 (1987).

C. K. Williams, A. Reisman, P. Bhattacharya, and W. Ng. Defect Generation in Silicon Dioxide from Soft X-ray Synchrotron Radiation, Proc. of the Workshop on Process-related Electrically Active Defects in Semiconductor-Insulator Systems, Sept. 1987.

M. C. Nelson, J. Murakami, S. L. Anderson, and D. M. Hanson, Fragmentation of Acetone Following Excitation in the Region of the Oxygen K Edge, J. Chem. Phys. 86 (8), (1987). 
D. M. Shinozoki, P. C. Chen, and R. Feder, Soft X-ray Induced Surface Roughness in PMMA, Proc. XIth Int. Cong. on Electron Microscopy, Kyoto, Japan, 1986.

C. Jacobson, J. M. Kenny, J. Kirz, l. McNulty, R. J. Rosser, F. Cinotti, H. Rarback, and D. Shu, Soft X-ray Scanning Microscopy: Its Practical Use for Elemental Mapping at the NSLS U-15 Beam Line, Photochemistry and Photobiology, 44 No. 3, 421, (1986).

M. R. Howells, M. A. Iarocci, and J. Kirz, Experiments in X-ray Holograph:? Using Synchrotron Radiation, J. of Optical of America A, 3, 2171, (1986).

B. X. Yang, J. Kirz, and I. McNulty, Proc. Int. Soc. of Optical Engineering. 689, 34, August 1986.

C. Jacobsen, J. M. Kenney, J. Kirz, I. McNulty, R. J. Rosser, F. Cinotti, H. Rarback, and D. Shu, Microanalysis with a Soft X-ray Scanning Microprobe, Ann. N.Y. Acad. Sci., 483, 463 (1986).

W.-B. Yun, J. Kirz, and D. Sayre, Observation of the Soft X-ray Diffraction Pattern of a Single Diatom, Acta Crystallographica A. 131 (1987).

Beam Line X3 (Previously X21)

J. C. Phillips, K. J. Baldwin, W. F. Lehner, A. D. LeGrand, and C. T. Prewitr, The SUNY X21 Beam Line at NSLS: A Multi-use Port on a Dedicated High Brightness Synchrotron Radiation Source, Nucl. Instrum. and Meth. in Phys. Res. A246, 182 (1986).

R. Wong, W. L. Roth, B. Dunn, and D. L. Yang, EXAFS Study of Nd-Exchanged Na $\beta$-Alumina Crystal and Powder. Sol. State Ionics 18,19, 599-602 (1986).

L. Mihaly, K. B. Lee, and P. W. Stephens, X-ray Diffraction Study of the Metastable Charge-Density-Wave State of $\mathrm{K}_{0.3} \mathrm{MO} \mathrm{O}_{3}$, Phys. Rev. B, Rapid Com. (1987).

B. N. Dev, S. M. Mohpatra, D. C. Mishra, W. M. Gibson, and T. P. Das, First-Principles Investigation of Geometric and Electron Structures of Aluminum Adsorbed on Silicon Surfaces, Phys. Rev. B., (1987).

Y. H. Kao, EXAFS Studies of Semiconductor Heterostructures, Phys 61, 2836 (1987).

Beam Line X7A (Previously X13A)

A. K. Cheetham, First Success of Powder Methods, Nature 325, 109 (1987).

W. Dmowski, T. Egami, Y Shen, S. J. Poon, and G. J. Shiflet, Structural Relationship between Icosohedral and FrankKasper Phases of Al-Li-Cu, Phil. Mag. Lett. 56, 63 (1987).

S. J. Hibble, A. K. Cheetham, and D. E. Cox, $\mathrm{Ca}_{0.75} \mathrm{Nb}_{3} \mathrm{O}_{6}$ : A Novel Metal Oxide Containing Niobium-Niobium Bonds. Characterization and Structure Refinement from Synchrotron Powder X-ray Data, Inorg. Chem. 25, 2389 (1987).

D. D. Kofalt, I. A. Morrison, T. Egami, S. Preische, S. J. Poon, and P. J. Steinhardt, Quasicrystallinity of Icosahedral $\mathrm{Pd}_{58.8} \mathrm{U}_{20.6}$, Phys. Rev. B35, 4489 (1987).

S. B. Qadri, E. F. Skelton, A. W. Webb, E. R. Carpenter, Jr., M. W. Schaefer, and J. Furdyna, Investigation of the Pressure-Induced B3-B 1 Phase Transition in $\mathrm{Cd}_{1-\mathrm{x}} \mathrm{Mn}_{\mathrm{x}} \mathrm{Te}(0 \leq \mathrm{t} 296 ; \leq 0.70)$, Phys. Rev. B35, 6868 (1987).

S. B. Qadri, E. F. Skelton, A. W. Webb, M. W. Schaefer, J. Dinan, D. Chandra, and L. Colombo, Investigation of Structural Properties of Epitaxially Grown $\mathrm{Hg}_{0.84} \mathrm{Zn}_{0.16}$ Te under Application of Hydrostatic Pressure, J. Vac. Sci. Tech. A5, 3024 (1987).

Y. Shen, S. J. Poon, W. Dmowski, T. Egami, and G. J. Shiflet, Structure of Al-Li-Cu Icosahedral Crystals and Penrose Filing, Phys. Rev. Lett. 58, 1440 (1987).

J. P. Attfeld, A. W. Sleight, and A. K. Cheetham, Structure Determination $\alpha-\mathrm{CrPO}_{4}$ from Powder Synchrotron X-ray Data, Nature 322, 620 (1986). 
D. E. Cox, J. B. Hastings, L. P. Cardoso, and L. W. Finger, Synchrotron X-ray Powder Diffraction at X13A: A Dedicated Powder Diffractometer at the National Synchrotron Light Source, Materials Science Forum, Vol. 9, pp. 1-20, edited by C.R.A. Catlow, Trans Tech. Publications, Switzerland (1986).

D. E. Cox, Synchrotron X-ray Powder Diffraction, Materials Res. Soc. Bull. 12, 16 (1987).

G. Gottstein, Orientation Determination in Very Small Volumes Using Synchrotron Radiation, Scripta Met. 20, 1791 (1986).

D. D. Kofalt, S. Nanao, T. Egami, K. M. Wong, and S. J. Poon, Differential Anomalous X-ray Scattering Studies of Icosahedral and Amorphous $\mathrm{Pd}_{58.8} \mathrm{U}_{20.6} \mathrm{Si}_{20.6}$, Phys. Rev. Lett. 57, 114 (1986).

A. W. Sleight and D. E. Cox, Symmetry of Superconducting Compositions in the $\mathrm{Ba} \mathrm{Pb}_{1-\mathbf{x}} \mathrm{Bi}_{\mathbf{x}} \mathrm{O}_{3} \mathrm{System}_{\mathrm{S}} \mathrm{Solid} \mathrm{State}$ Comm. 58, 347 (1986).

\section{Beam Line X9A}

B. Chance, Z. R. Korszun, and S. Khalid, Time Resolved Studies of Active Site Structural Changes in Solution, in Structural Biological Application of X-ray Absorption, Scattering and Diffraction (H. B. Bartunik and B. Chance eds) Academic Press, p. $49-69$ (1986).

G. Bunker, L. Petersson, B. M. Sjoberg, M. Chance, B. Chance, and A. Ehrenberg, Extendid X-ray Absorption Fine Structures Studies on the Iron-containing Subunit of Ribonucleotide Reductase from Escherichia Coli, Biochem. 26, 4708 (1987). (1987).

B. Chance, Combined Track and Measurement Circuit: Single Detector System, ISFS Report \#X9-A487BC-002

S. Khalid, Vertical Track Voltage as Feedback to Bring the Sample in the Beam, ISFS Report \#X9-A487SK-003 (1987).

S. M. Guner, Materials Properties of Liposomal Bilayers, in Liposomes, Vol. 2, (Ostro, M. ed) Marcel Kekker, NY (1987).

Y. Li, A. Naqui, T. G. Frey, and B. Chance, A New Procedure for the Purification of Monodispersed Highly Active Cytochrome-c Oxidase from Bovine Heart, Biochem. J. 242, 417 (1987).

M. Lundeen, B. Chance, and L. Powers, The Transmembrane Helices of Beef Heart Cytochrome Oxidase, Biophys. J. 51, 693 (1987).

L. Powers, B. Chance, I.-Y. Ching, and C. P. Lee, Structure of Copper Site in Membrane-bound Cytochrome-o Oxidase, J. Biol. Chem. 262, 3160 (1987).

\section{Beam Line X10}

J. M. Drake, P. Levitz, and S. Sinha, General Scaling, Phenomena in Porous Silica Gels as Probed by SAXS and Molecular Adsorption (Tiling), Mat. Res. Soc. Symp. Proc., Vol. 73, 1986.

\section{Beam Line XII}

T. Bein, S. McLain, G. Stucky, G. Woolery, D. Sayers, and K. Moller, EXAFS Study of Nickel Tetracarbonyl and NiClusters in Zeolite Y, J. de Physique 47, 277 (1986).

J. Budnick, M. Choi, G. Hayes, D. Pease, Z. Tan, E. Klein, and B. Illerhaus, Difference in Fe Atom Environments Between CuFe (2\% Fe) and CuAuFe ( 1 and $3 \% \mathrm{Fe}$ ) Alloys, J. de Physique 47,1037 (1986).

J. Budnick, M. Choi, D. Pease, Z. Tan, and G. Hayes, Local Structure and Magnetic Environments of Iron in Dilute Alloys, SPIE Proceedings 690, 52 (1986).

J. Budnick, D. Pease, M. Choi, Z. Tan, G. Hayes, F. Namavar, and H. Hayden, Krypton XANES Studies in Implanted Systems, J. de Physique 47, 1053 (1986). 
L. Ferunlid, D. Van Derveer, and R. Felton, Structure and EXAFS of Diaquatetrakis (imidazole) Cobalt(III) Dichloride, Acta. Cryst. C42, 806 (1986).

J. Hawkins, H. Isaacs, S. Heald, J. Tranquada, G. Thompson, and G. Wood, Study of the Inhibition of Corrosion of Aluminium by Chromates Using Fluorescence Detection of X-ray Absorption, Aluminium Surface Treatment Technology, ed. R. Alwitt and G. Thompson (1986).

S. Heald, H. Chen, and J. Tranquada, A Grazing Incidence X-ray Study of Interfacial Reactions in Al-Cu, Mat. Res. Soc. Symp. Proc. 54, Ed. R. J. Neemanich (1986).

S. Heald, H. Chen, and J. Tranquada, EXAFS and Reflecting Studies of Surfaces and Interfaces Using Glancing Angle $\mathrm{X}$-rays, SPIE Proceedings 690, 32-37 (1986).

S. Heald, M. Pick, J. Tranquada, D. Sayers, J. Budnick, E. Stern, J. Wong, G. Stuckey, A. Chester, G. Woolery, and T. Morrison, Materials Science EXAFS Line at the NSLS: Characterization and Initial Operations, Nucl. Inst. and Methods A246, 120 (1986).

S. Heald, A Simple Photoelectron X-ray Beam Position Monitor for Synchrotron Radiation, Nucl. Inst. and Methods A246, 411 (1986).

S. Heald and J. Tranquada, The Characterization of Cryogenic Materials by X-ray Absorption Methods, Advances in Cryogenic Materials 32, Ed. R. Reed and A Clark (1986).

S. Heald, J. Tranquada, and H. Chan, Interface EXAFS Using Glancing Angles, J. de Physique 47, 825 (1986).

S. Heald, J. Tranquada, B. Clemens, and J. Stec, EXAFS Study of Copper-Hafnium Multilayers, J. de Physique 47. 1061 (1986).

D. Koningsberger, F. Duivenvoorden, B. Kip, and D. Sayers, The Effect of Gas Environment $\left(\mathrm{H}_{2}, \mathrm{O}_{2}\right)$ on the Structural Properties of Small Iridium Metal Particles Supported on $\gamma-\mathrm{Al}_{2} \mathrm{O}_{3}$ as Determined by EXAFS, J. de Physique 47, 255 (1986).

Y. Ma and E. Stern, EXAFS Studies of AlMnSi and AlMn Periodic and Aperiodic Alloys, J. de Physique 47, 1025 (1986). (1986)

Y. Ma and E. Stern, Structure of Icosahedral AlMnSi and AlMn as Determined by EXAFS, SPIE Proceedings 690,52

K. Moller and T. Bein, EXAFS Studies on the Reduction of Pd(II) in X Zeolites, J. de Physique 47, 231 (1986).

L. Moroney and D. Sayers, The Defect Structure of Calcia Stabilized Zirconia, J. de Physique 47, 725 (1986).

T. Morrison, M. Brodsky, and N. Zaluec, Electron Energy Loss Spectroscopy: Probe of d-Band Occupancy in Amorphous Magnetic Alloys, J. de Physique 47, 159 (1986).

K. Pandy, K. Yang, R. Hoffman, W. O'Grady, and D. Sayers, Electron Yield Detectors for Near Surface EXAFS at Atmospheric Pressure, J. de Physique 47, 159 (1986).

D. Sayers and M. Paesler, X-ray Absorption Studies of Amorphous Semiconductors, J. de Physique 47, 349 (1986).

C. Spiro, J. Wong, F. Lytle, R. Greegor, D. Maylotte, and S. Lansan, Forms of Potassium in Coal and its Combustion Products, Fuel 65, 327 (1986).

E. Stern, Other EXAFS-Like Phenomena, J. de Physique 47, 3-10 (1986).

E. Theil, D. Sayers, C. Yang, A. Fontaine, and E. Dartyge, The Formation, Structure, and Dissolution of the Ferritin Iron Core Studied by X-ray Absorption Spectroscopy, J. de Physique 47, 1155 (1986).

J. Tranquada, S. Heald, M. Pick, Z. Fisk, and J. Smith, Lattice Dynamics of the Heavy Fermion Compound UBe $\mathbf{U B}_{13}, \mathrm{~J}$. de Physique 47, 937 (1986).

J. Tranquada and R. Ingalls, X-ray Absorption Study of CuBr at High Pressure, Phys. Rev. B34, 42 (1986). 
J. Wong, Extended X-ray Absorption Fine Structure: AS Modern Structural Tool in Materials Science, Mat. Sci. Eng. 80, 107 (1986).

J. Wong and G. Slack, EXAFS and XANES Study of Vanadium in $\beta$-Rhombohedral Boron, J. Solid State Chem. 6I, 203 (1986).

G. Woolery, G. Kuehl, A. Chester, T. Bein, G. Stucky, and D. Sayers, EXAFS Study of Ni Exchanged into Zeolite Y, J. de Physique 47, 281 (1986).

C. Yang, A. Bryan, E. Theil, D. Sayers, and L. Bowen, Structural Variation in Soluble Iron Complexes of Models for Ferritin; An X-ray Absorption and Mossbauer Spectroscopy Comparison of Horse Spleen Ferritin to Blutal (IronChondroitin Sulfate) and Imferon (Iron-Dextran), J. Inorganic Biochemistry 28, 393 (1986).

C. Yang, J. Lee, M. Paesler, and D. Sayers, EXAFS Studies of Thermostructural and Photostructural Changes of Vapor-deposited Amorphous $\mathrm{As}_{2} \mathrm{~S}_{3}$ Films, J. de Physique 47, 387 (1986).

C. Yang, A. Meagher, B. Huynh, D. Sayers, and E. Theil, Iron(III) Clusters Bond to Horse Spleen Apoferritin: An Xray Absorption and Mossbauer Spectroscopy Study that Shows that Iron Nuclei Can Form on the Protein, Biochemistry 26, 497 (1987).

C. Yang, M. Paesler, and D. Sayers, Analysis of Bond Strengths of Arseric and Arsenic Chalcogen Compounds Using the Temperature Dependence of the EXAFS, J. de Physique 47, 392 (1986).

K. I. Pandya, EXAFS Investigation of Nickel Hydroxides and Nickel Oxide Electrodes, Degree of Doctor of Philosophy for Case Western Reserve University, Advisor: R. W. Hoffman, Physics, (1987).

C. Yang, An X-ray Absorption Study of Amorphous Arsenic and Arsenic Chalcogenide Semiconductors, Degree of Doctor of Philosophy from North Carolina State University, Advisor: D. E. Sayers, Physics, (1987).

H. Chen, S. Heald, and J. Tranquada, Anomalous Dispersion Corrections to Surface and Interface EXAFS Measurements Made Using Glancing Angles, MRS Conf. Pro. (1987).

B. Clemens, J. Stec, S. Heald, and J. Tranquada, Structure of Copper-Hafnium Multilayers, MRS Conf. Pro. (1987).

J. McBreen, W. O'Grady, K. Pandya, R. Horman, and D. Sayers, EXAFS Study of the Nickel Oxide Electrode, Langmuir 3, 428 (1987).

C. Spiro, C. Chen, J. Wong, S. Kimura, and R. Greegor, Characterization of Products from a Gas Turbine Combuster Fired Directly with Coal-water Mixture, Fuel 66, 563 (1987).

J. Tranquada, S. Heald, A. Moodenbough, and $\mathrm{M}$. Suenaga, $\mathrm{X}$-ray Absorption Studies of $\mathrm{La}_{2-\mathrm{x}}(\mathrm{Ba}, \mathrm{Sr})_{\mathbf{x}} \mathrm{CuO}_{4}$ Superconductors, Phys. Rev. B, 35, 7187 (1987). (1987).

J. Tranquada, C. Trautmann, and S. Heald, X-ray Diffraction Study of Anharmonicity in V 3 Si Phys. Rev. B, 35, 4193

J. Tranquada and C. Yang, EXAFS Measurements of Bond-Stretching Force Constants in Arsenic and Arsenic Compounds, Solid State Comm. 63, 211 (1987).

\section{Beam Line X12C}

J. P. Allen, G. Feher, T. O. Yeates, H. Komiya, and D. C. Rees, Structure of the Reaction Center from Rhodobacter Sphaeroides R-26: The Cofactors. Proc. Nat. Acad. Sci. USA 845730 (1987). See also Allen, Feher, Yeates, Komiya, and Rees, ib. 6162 for a report on the protein subunit structure.

\section{Beam Line X14}

B. C. Larson, S. Iida, J. Z. Tischler, J. D. Lewis, G. E. Ice, and A. Habenschuss, X-ray Diffuse Scattering from Cobalt Precipitates in Copper, Proc. MRS Characterizasion of Defects in Materials, 82, 73 (1987). 
J. D. Budai, J. Z. Tischler, A. Habenschuss, and G. E. Ice, X-ray Diffraction Study of Phason Strain Field in Oriented Ocosahedral Al-Mn, Phys. Rev. Lett. 58, 2304 (1987).

G. E. Ice, Microdiffraction with Synchrotron Radiation, Nucl. Instrum. Methods B24/25, 397 (1987).

R. J. DeAngelis, A. G. Dhere, M. A. Maginnis, P. J. Reucroft, G. E. Ice, and A. Habenschuss, Synchrotron X-ray Scattering for the Structural Characterization of Catalysts, Advances in X-ray Analysis, Vol. 30 (1986).

B. C. Larson, S. Iida, J. Z. Tischler, J. D. Lewis, G. E. Ice, and A. Habenschuss, X-ray Diffuse Scattering from Cobalt Precipitates in Copper, Proceedings of the Mat. Res. Soc. Symp. on Characterization of Defects in Materials, Vol. 82 $(1987)$.

C. J. Sparks, M. Hasaka, D. S. Easton, S. Baik, A. Habenschuss, and G. E. Ice, Structural Studies of Nickel Films and Their Interfaces with Sapphire Substates, Proc. of the Mat. Res. Soc. Symp. on Interfaces Superlattices and Thin Films, Vol. 77 (1987).

J. D. Budai, Structural Studies of Oriented lcosahedral Al(Mn), Invited Paper, Proc. of the March APS meeting 1987 Session FL: Materials Physics Icosahedral Phase $N$.

A. G. Dhere, R. J. DeAngelis, P. J. Reucroft, G. E. Ice, and A. Habenschuss, Application of Synchrotron X-ray Radiation for the Study of Catalysts, presented at the 35th Annual Denver X-ray Conference on Applications of X-ray Analysis, August 4-8, 1986, Denver, Colorado.

P. Lamparter, A. Habenschuss, and A. H. Narten, Neutron and X-ray Diffraction Study of the $\mathrm{Ti}_{84} \mathrm{Si}_{16} \mathrm{Metallic}_{\mathrm{Glass}}$ J. Non-Cryst. Solids 86, 109 (1986).

A. G. Dhere, R. J. DeAngelis, G. E. Ice, and A. Habenschuss, Morphological Developments of Nickel Particles in Supported Metal Catalysis, Proc. of the Mat. Res. Soc. Symp. on Materials Problems Solving with the Transmission Electron Microscopy, Vol. 62 (1986).

\section{Beam Line $\times 16 B$} (1987).

S. G. J. Mochrie, Thermal Roughening of the Copper (110) Surface; An X-ray Experiment, Phy. Rev. Lett. 59, 304

\section{Beam Line X18A}

P. Dutta. J. B. Peng, B. Lin, J. B. Ketterson, M. Prakash, P. Georgopoulos, and S. Ehrlich, X-ray Diffraction Studies of Organic Monolayers on the Surface of Water, Phys. Rev. Let., 58 No. 21, 2228 (1987).

J. L. Staudenmann and G. L. Liedl, Monochromator for Continuous Spectrum X-ray Radiation, U.S. Statutory Invention Registration H313 (1987).

K. Mahalingam, B. P. Gu, G. L. Liedl, and T. H. Sanders, Jr., Coarsening of $\delta^{\prime}\left(\mathrm{Al}_{3} \mathrm{Li}_{\mathrm{i}}\right.$ Precipitates in Binary Al-Li Alloys, Acta Metall., 35 No. 2, $483-498$ (1987).

S. Polat, C. Marsh, T. Lïtle, C. P. Ju, J. E. Epperson, and H. Chen, Spatial Correlation of Gamma-Prime Precipitates in a Ni-Si Alloy, Scripta Met, 20, 1739 (1986).

K. J. Rutsky and P. Georgopoulos, EXAFS Studies of the Martensitic Transformation in Fe-Ni Alloys, Scripta Metall., 20, 419 (1986).

K. Ohshima, J. Harvda, M. Morenaja, P. Georgopoulos, and J. B. Cohen, Report on a Round-Robin Study of Diffuse X-ray Scattering, J. Appl. Cryst., 19, 188 (1986).

J. L. Staudenmann, R. D. Horning, R. D. Knox, J. Reno, I. K. Sou, J. P. Faurie, and D. K. Arch, In Situ Interdiffusion Measurements in HgTe-CdTe Superlattices, Semiconductor-Based Heterostructures: Interfacial Structure and Stability, M. L. Green, et al. eds., TMS-AIME, New York (1986).

S. Polat, C. Marsh, T. Little, C. P. Ju, J. E. Epperson, and Haydn Chen, Spatial Correlation of Gamma-Prime Precipitates in a Ni-Si Alloy, Scripta Met., 20, 1739 (1986). 


\section{Beam Line X18B}

E. E. Alp, G. K. Shenoy, D. G. Hinks, D. W. Capone II, L. Soderholm, H. B. Schwittler, J. Guo, D. E. Ellis, P. A. Montano, and M. Ramanathan, Determination of Valence of $\mathrm{Cu}$ in Superconducting $\mathrm{La}_{2-\mathrm{x}}(\mathrm{SrBa})_{x} \mathrm{CuO}_{4}$, Phys. Rev. B Rap. Comm. 35, 7199 (1987).

E. E. Alp, L. Soderholm, G. K. Shenoy, D. G. Hinks, B. W. Veal, and P. A. Montano, Valence Determination in High $T_{c}$ Oxide Superconductors by XANES and Mossbauer Spectroscopy, Proceedings of the International Conference on Electronic Structure and Phase Stability in Advanced Ceramics, Physica (1987).

H. Abrevaya, W. M. Targos, H. J. Robota, and M. J. Cohn, Metal Particle Size Effects in Fischer-Tropsch Synthesis with Supported Ruthenium Catalysts, Proceedings of the 10th North American Meeting of the Catalysts Society, Elsevier Publ. (1987).

\section{Beam Line X19C}

H. Chen, Observation of Pendellosung Fringes in Reflection-Section Topographs of Bent Silicon Crystals, Mat. Lett., $4(2), 65,(1986)$.

H. Chen, Measurement of Thermal Stress in $\mathrm{PD}_{2} \mathrm{Si}$ Film on Si(111) by Absorption Edge Contour Mapping, Mat. Lett., $4,(2), 61,(1986)$.

H. Chen, Diffusivity Measured by X-ray Diffraction, J. of Metals, 36, (1986).

J. C. Bilello, Synchrotron Radiation and X-ray Topography; 1: Techniques and Facilities, Mechanical Properties and Behavior of Solids: Plastic Instabilities, Editor, V. Balakrishnan and C. E. Bottani, World Scientific Publisher, 1986.

H. A. Schmitz, J. C. Bilello, and Z. Rek, Energetics of Dislocation Relaxation Associated with Cleavage in Cadmiumdoped Zinc Crystais as Probed by Synchrotron Topography, Materials Science and Eng., 81, 293 (1986).

M. Starke, D. Corcoran, and J. C. Bilello, Motor Control and Data-Acqquisition System: Automatic Control of X-ray Cameras, Rev. Sci. Instrum, 57, (5) (1986).

J. C. Bilello, Synchrotron X-ray Topography of Dislocation Arrays, MRS, December 1986.

J. E. Benci and D. P. Pope, Measuring Creep Damage Using Microradiography, Met. Trans. A. (1987).

G. E. White and H. Chen, In-Situ Study of Stresses in Metal Silicides Using Absorption Edge Contour (AEC) Mapping, Mat. Let. 4, (2), 61 (1987).

M. Dudley, Applications of Synchrotron Radiation Topography to Dynamic Processes in Single Crystal Materials, Nucl. Inst. and Meth. in Phys. Res., B24/25, 1068 (1987).

J. Bilello and C. L. Kuo, Depth Profising of Defects in Epilayer Semiconductor Materials by Using Synchrotron Xradiation Topography, J. Appl. Phys., 62, (1), 137 (1987).

A. B. Hmelo, Characterization of Crack-Tip Microstructures Using Synchrotron X-ray Fractography in Mo and Mo-Nb Alloy Crystals, Ph.D. Thesis, SUNY at Stony Brook (1987).

R. Rebonato, An Experimental and Theoretical Study of the Mechanical Properties of Mo and of the Interaction of Interstitials with BCC Transition Metals, Ph.D. Thesis, SUNY at Stony Brook (1987).

H. A. Schmitz, Synchrotron X-ray Topography Observations on Fatigue and Fracture Behavior in Zinc Bicrystals, Ph. D. Thesis, SUNY at Stony Brook (1987).

Beam Line X20

J. D. Brock, A. Aharony, R. J. Birgeneau, J. W. Evans-Lutterodt, J. D. Litser, P. M. Hom, G. B. Stephenson, and A. R. Tajbakhsh, Orientational and Positional Order in a Titled Hexatic Liquid-Crystal Phase, Phys. Rev. Lett. 57 , (1) 98 (1986).

A. Aharony, R. J. Birgeneau, J. D. Brock, and J. D. Litster, Multicriticality in Hexatic Liquid Crystals, Phys. Rev. Lett. 57, (8) 1012 (1986). 
E. Specht, Synchrotron X-ray Diffraction Studies of Translational and Orientational Order in Monolayer Krypton on Graphite, thesis, Massachusetts Institute of Technology, 1987.

\section{Beam Line X22B}

H. You, J. D. Axe, D. Hohlwein, and J. B. Hastings, Search for Charge-density waves in a Single Crystal of Potassium, Phys. Rev. B35, 9333 (1987).

S. C. Moss, K. Rorster, J. D. Axe, H. You, D. Hohlwein, D. E. Cox, P. H. Hor, R. L. Meng, and C. W. Chu, Highresolution Synchrotron X-ray Study of the Structure of $\mathrm{La}_{1.8} \mathrm{Ba}_{0.2} \mathrm{CuO}_{4-\mathrm{y}}$, Phys. Rev. B35, 7195 (1987).

J. Bohr. D. Gibbs, D. E. Moncton, and K. L. D'Amico, Spin Slips and Lattice Medulations in Holmium: A Magnetic X-ray Scattering Study, Physica 140A, 349 (1986).

D. Gibbs, J. Bohr, J. D. Axe, D. E. Moncton, and K. L. D'Amico, Magnetic Structure of Erbium, Phys. Rev. Rapid Comm. B34, 8182 (1986).

\section{Beam Line $\mathbf{X 2 3}$}

W. J. Boettinger, P. W. Voorhees, R. C Dobbyn, and H. E Burdette, A Study of the Coarsening of Liquid-Solid Mixtures Using Synchrotron Radiation Microradiography, Metal. Tans. 18A, 487 (1987)

M. Kuriyama, R. C. Dobbyn, S. Takagi, and L. C. Chow, Microradiograpy with an X-ray Image Magnifier: Application to Dental Hard Tissue, Biophysics (Japan), 27 April (1987)

L. H. Bennett, G. G. Long, M. Kuriyama, and A. I. Goldman, Local Atomic Structure in Transition Metal/Metaloid Glasses: Ni-P, in Structure and Bonding in Noncrystalline Solids ed. by E. G. Walrafen and A. K. Revez, Plenum, NY $385-$ 409 (1986).

W. J. Boettinger, P. W. Voorhees, R. C. Dobbyn, and H. E. Burdette, A Study of the Coarsening of Liquic-Solid Mixtures Using Synchrotron Radiation Microradiography, Met. Trans. A 18A, 487 (1987).

M. Kuriyama, R. C. Dobbyn, S. Takagi, and L. C. Chow, Microradiograph with an X-ray Image Magnifier (translated in Japanese), (Invited Article) SEIBUTSU-BUTSURI (Biophysics) 27, 5 (1987).

M. Kuriyama, Application of Synchrotron Radiation to Atomistic and Microstructure Characterization of Materials, J. Mat. Sci. and Eng. (1987).

R. C. Dobbyn, M. Kuriyama, S. Takagi, and L. C. Chow, High Resolution Radiography: Applications to Biomedical Imaging, in Biomedical Engineering VI: Recent Developmenteds R. C. Eberhardt and L. Howard, McGregor and Werner Pub. (1987).

\section{Beam Line X23B}

T. P. Thorpe, W. T. Elam, and A. Morrish, Correlation of Microstructure and Composition of Sputtered Titanium Nitride Films with Electrical and Optical Properties, J. Vac. Sci. Tech.

J. P. Kirkland, R. A. Neiser, W. T. Elam, J. C. Rife, and W. R. Hunter, Synchrotron Radiation Beamlines as X-ray Calibration Sources, Proceedings of SPIE, 689, 188-197, 1986.

C. M. Dozier, R. K. Freitag, and D. W. Fehl, Characterization of the Absolute Photon Sensitivity of Gold Cathode Photoelectric Detectors, Proceedings SPIE, 689, 87-92. 1986.

J. P. Kirkland, R. A. Neiser, and W. T. Elam, A Compacr, Modular, Mirror Bending and Positioning System, Nuclear Instruments and Methods, A246, 203-206, 1986.

\section{Beam Line X24A}

R. C. C. Pe ra, R. E. LaVilla, P. L. Cowan, T. Jach, and B. Karlin, $\mathrm{Cl} \mathrm{K} \alpha(\mathrm{K}-\mathrm{V})$ Emission of $\mathrm{CFCl}_{3}$ Excited by Synchrotron Raulation Below and Above Cl-1s Binding Energy: Perurbation Effects in a Highly Excited Neutral Molecular, Physica Scripta 36, 132 (1987). 
V. M. Bermudez, R. T. Williams, J. P. Long, J. C. Rife, R. M. Wiison, A. E. Tuttle, and G. P. Willians, Jr., Photoemission Study of Nitric Oxide Adsorption on (110) Gallium Arsenide, J. Vac. Sci. Technol. A5, 544 (1987).

J. C. Rife, W. R. Hunter, and R. T. Williams, Features and Initial Performance Tests of the Grating/Crystal Monochromator, Nucl. Instr. and Meth. A246, 252 (1986).

W. R. Hunter and J. C. Rife, An Ultrahigh Vacuum Reflectometer/Goniometer for Use with Synchrotron Radiation, Nucl. Instr. and Meth. A246, 465 (1986).

J. P. Long, M. N. Kabler, J. C. Rife, and R. T. Williams, Dynamics of Eletron-Hole Plasma in Laser Excited Silicon, in Proc, of 18th Intl. Conf. on the Physics of Semiconductors, Vol. 2 ed. O. Engstrom (World Scientific, 1986 ), p. 1469.

Beam Line $\times 26$

J. R. Chen, E. C. T. Chao, J. A. Minkin, J. M. Back, W. C. Bagby, M. L. Rivers, S. R. Sutton, B. M. Gordon, A. L. Hanson, and K. W. Jones, Determination of the Occurrence of Gold in an Unoxidized Carlin-type Ore Sample Using Synchrotron Radiation, Nucl. Inst. Meth. B22, 394 (1987).

M. Cholewa, A. L. Hanson, K. W. Jones, W. P. McNally, and I. Fand, Some Uncertainties Associated with Preparation of Standards in Organic Matrix, Fresenius Z. Anal. Chem. 326, 742 (1987).

M. Cholewa, W. M. Kwiatek, K. W. Jones, G. Schidlowsky, A. S. Paschoa, S.C. Miller, and J. Pecotte, Elemental Concentrations in Bones from an Ancient Egyptian Mummy and From a Contemporary Man, Nucl. Inst. Meth. B22, 423 (1987).

D. A. Church, S. D. Kravis, I. A. Sellin, C.-S. O, J. C. Levin, R. T. Short, M. Meron, B. M. Johnson, and K. W. Jones, Confined Thermal Multicharged Ions Produced by Synchrotron Radiation, Phys. Rev. A36, 2487 (1987).

B. M. Gordon, Survey of Chemical Speciation of Trace Elements Using Synchrotron Radiation, Biol. Trace Elem. Res. 12, 153 (1987).

B. M. Gordon, K. W. Jones, and A. L. Hanson, Application of Synchrotron Radiation to X-ray Fluorescence Analysis of Trace Elements, Proc. SPIE, Yol. 681, Laser and Nonlinear Optical Materials, L. G. DeShazer, Editor, pp. IO2, SPIE, (1987).

B. M. Johnson, M. Meron, A. Agagu, and K. W. Jones, Atomic Physics and Synchrotron Radiation: The Production and Accumulation of Highly-charged Ions, Nucl. Inst. Meth. B24/25, 391 (1987).

K. W. Jones and J. G. Pounds, Role of Nuclear Analytical Probe Techniques in Biological Trace Element Research. Biol. Trace Elem. Research, 12, 3 (1987).

K. W. Jones, B. M. Johnson, and M. Meron, Design Considerations for a Combined Synchrotron-light Source and Heavy-ion Storage Ring Atomic Physics Facility, Nucl. Inst. Meth. B24/25, 381 (1987).

K. W. Jones, B. M. Johnson, M. Meron, and V. O Kostroun,.APIPIS: The Atomic Physics Ion-photon Interaction System, Proc. Third Intern, EBIS Workshop, Cornell University, May 1985, V. O. Kostroun, R. W. Schmieder, Editors, pp. 221-6, Cornell University, Ithaca (1987).

K. W. Jones, B. M. Johnson, M. Meron, and P. Thieberger, Science with Multiply-charged Ions at Brookhaven National Laboratory, Proc. Workshop on Opportunities for Atomic Physics Using Slow, Highly-charged lons, Argonne, IL, Jan. 1987, ANL-PHY-87-1, pp. 183

K. W. Jones, B. M. Johnson, M. Meron, B. Crasemann, Y. Hahn, V. O. Kostroun, S. T. Manson, and S. M. Younger, Science with Synchrotron Radiation and a Heavy-ion Storage Ring, Comments At. Mol. Phys., 20, (1), 1 (1987).

J. Kajfosz and W. M. Kwiatek, Nonpolynomial Approximation of Background in X-ray Spectra, Nucl. Inst. Meth. B22, 78 (1987). 
R. T. Short, C.-S. O, J. C. Levin, I. A. Sellin, B. M. Johnson, M. Meron, K. W. Jones, and D. A. Church, Synchrotron Radiation Inner-shell Photoionization of Atomic and Molecular Gases, Nucl. Inst. Meth. B24/25, 417 (1987).

P. Spanne and M. L. Rivers, Computerized Microtomography Using Synchro:ron X-rays, Nucl. Inst. Meth. B24/25, 1063 (1987).

S. R. Sutton, M. L. Rivers, and J. V. Smith, Applications of Synchrotron X-ray Fluorescence to Extraterrestrial Materials. Nucl. Inst. Meth. B24/25, 405 (1987).

B. M. Gordon, K. W. Jones, and A. L. Hanson, Application of Synchrotron Radiation to X-ray Fluorescence Analysis of Trace Elements, Proc. SPIE, Vol. 681, Laser and Nonlinear Optical Materials, L. G. DeShazer, Editor, Pp. 102-8, SPIE, 1987.

A. L. Hanson, The Calculation of Scattering Cross Sections for Polarized X-rays, Nucl. Instrum. Methods A243, 58398 (1986).

A. L. Hanson, Further Comments on the Integrated Incoherent Scattering Cross Sections for Polarized X-rays, Nucl. Instrum. Methods A249, S22-9 (1986).

A. L. Hanson, The Polarization of X-rays Scattered into $90^{\circ}$. Nucl. Instrum. Methods A249, 515-21 (1986).

G. Harbottle, B. M. Gordon, and K. W. Jones, Use of Synchrotron Radiation in Archaeometry, Nucl. Instrum. Methods B14, $116-22$ (1986).

K. W. Jones, B. M. Gordon, A. L. Hanson, J. G. Pounds, and G. Schidlovsky, X-ray Fluorescence with Synchrotron Radiation, Microbeam Analysis-1986, A. D. Romig, Jr. and W. F. Chambers, Editors, pp. 175-6, San Francisco Press, Inc., San Francisco, 1986.

K. W. Jones, B. M. Johnson, and M. Meron, Informal Proposal for an Atomic Physics Facility at the National Synchrotron Light Source, Proc. Workshop on Aromic Physics with Stored Cooled Heavy Ion Beams, Oak Ridge, Jan. 1986, CONF-860144, p. D-1.

R. T. Short, C.-S. O, J. C. Levin, I. A. Sellin, B. M. Johnson, M. Meron, K. W. Jones, and D. A. Church, Configuration of Free Molecules and Orientation of Surface Adsorbed Molecules Studies by Synchrotron Radiation Inner Shell Photoionization, Bull. Am. Phy. Soc. 31, 1307 (1986).

J. V. Smith, C. M. Skirius, M. L. Rivers, and K. W. Jones, Optical and Trace-element Signatures of Quartz as Indicators of Crystallization Conditions, EOS, Trans. Am. Geophys. Union 66, No. 46, 1117 (1985).

S. R. Sutton, M. L. Rivers, and J. V. Smith, Synchrotron X-ray Fluorescence: the Diffraction Interference. Anal. Chem. 58, 2167-71 (1986). 


\section{PUBLICATIONS OF THE NSLS STAFF DURING FISCAL YEAR 1987}

Barton, M.Q., Craft, B., and Williams, G.P. Report of the Second Workshop in Synchrotron Radiation Sources for Xray Lithography. BNL 38789 Inf. Report, October 1986.

Barton, M.Q. Interactive Design of Accelerators - IDA. BNL 40011 lnf. Report, June 1987.

Bassetti, M., Batchelor, K., Galayda, J. Halama, H., Heese, R., Hsieh, H., Krinsky, S., Murphy, J., van Steenbergen, A., and Vignola, G. Conventional Magnet Storage Rings for X-ray Lithography. BNL 38764 Inf. Report, October 1986.

Brauer, E. and Thomlinson, W. Experimental Verification of "PHOTON", A Computer Program for Use in X-ray Shielding Calculations. BNL 39541 Inf. Report, March 1987.

Chou, T.S. and Halama, H.J. Trapped Ions and Beam Lifetime in NSLS Storage Rings. IEEE Trans. Nucl. Sci. NS34 (1987) in press.

Choudhary, K.M., Kim, S.T., Lee, J.H., Shah, S.N., denBoer, M.L., Williams, G.P., and Rothberg, G.M. Photoemission EXAFS Measurements of Al-O Bond Lengths in Al Films. Journal de Physique C8 203 (1986).

Dickinson, T. Radiation Safety Systems at the NSLS. BNL 39674 Inf. Report, April 1987.

Foerster, C.L., Halama, H., and Thomlinson, W. Requirements and Guidelines for NSLS Experimental Beamline Vacuum Systems - Revision A. BNL 28073 Inf. Report, October 1986.

Galayda, J. and Decker, G. Magnetic Measurements on the X-17 Superconducting Wiggler. BNL 4003I Inf. Report, July 1987. 1987.

Gjaja, I. On the Collective Variables Description of a High Gain Free Electron Laser. BNL 3997 I Inf. Report, June

Gmur, N. Analysis of Surface Contaminants on Beryllium Windows. BNL 39091 Inf. Report, December 1986.

Gmur, N. and White-DePace, S.M. Users Manual: Guide to the VUV and X-Ray Beam Lines. BNL 40156 Inf. Report, August 1987.

Godel, J.B., Marcuse, W., and Williams, G.P. Report of the Third Workshop; Program for X-Ray Lithography Development. BNL 52046 Inf. Report, December 1986.

Halama, H.J., Foerster, C.L., and Kobari, T. Vacuum Performance of the UV and X-Ray Rings at the National Synchrotron Light. J. Vac. Sci. Technol. A5 (4), 2342 (1987).

Halama, H.J. Summary of X-Ray Ring Performance Before the 1987 Shutdown. BNL 39768 Inf. Repon, May 1987.

Heese, R. Status of the National Synchrotron Light Source. BNL 39670 Inf. Report, April 1987.

Hulbert, S.L., Xiaohe, P., and Johnson, P.D. Inverse-photoemission Observation of the Shape Resonance. Phys. Rev. B35 7710 (1987).

Hulbert, S.L., Johnson, P.D., and Garrett, R.F. Intensity Oscillations in the Inverse Photoemission Cross Section of an Unoccupied Surface State on Cu(001). Physical Rev. 337326 (1986).

Hulbert, S.L., Johnson, P.D., and Weinert, M. High-resolution Inverse-photoemission Study of the Pd(111) Surface. Phys. Rev. B34, 3670 (1986).

Johnson, E.D., Hulbert, S.L., Garrett, R.F., Williams, G.P., and Knotek, M.L. In-situ Reactive Glow Discharge Cleaning of X-ray Optical Surfaces. Review of Scientific lnstruments 581042 (1987). (1987)

Johnson, P.D. and Hulbert, S.L. Inverse-photoemission studies of adsorbed diatomic nolecules. Phys. Rev. B35 9427 
Johnson, P.D., Qiu, S.L., Jiang, L., Ruckman, W., Strongin, M., Hulben, S.L., Garren, R.F., Sinkovic, B., Smith, N.V., and Cava, R.J. Photoemission Studies of the High-Tc Superconductor $\mathrm{Ba}_{2} \mathrm{YC}_{3} \mathrm{O}_{4.8}$. Amer. Phys. Society 358811 (1987).

Jones, K.W., Johnson, B.M., Meron, M., Lee, Y.Y., Thieberger, P., and Thomlinson, W.C. Design Considerations for a Combined Synchrotron Light Source and Heavy-Ion Storage Ring Atomic Physics Facility. Nucl. Instr. and Meth. in Phys. Res. B24/25 $381-390$ (1987).

Kobari, T. and Halama, H. Photon Stimulated Desorption From Vacuum Chamber at the National Synchrotron Light Source. J. Vac. Sci. Technol. A5 (4) 2355 (1987).

Krinsky, S. and Yu, L.H. Output Power in Guided Modes for Amplified Spontaneous Emission in a Single-pass Freeelectron Laser. Physical Review A35, 3406 April 15, 1987.

Klaffky, R. Construction and Commissioning of Dedicated Synchrotron Radiation Facilities. BNL 51959 Report, January 1987.

Marcuse,W. Report of the Workshop on Transferring X-Ray Lithography Synchrotron (XLS) Technology to Industry. BNL 52096 Report, July 1987.

Murphy, J.B. and Pellegrini, C. Proceedings of the ICFA Wortsshop on Low Emittance $e^{-}-e^{+}$Beams. BNL 52090 Report, March 1987.

Olsen, R. and Langenbach, H. High Precision Power Supplies for the National Synchrotron Light Source. BNL 39673 Inf. Report, April 1987.

Rubenstein, E., Hofstadter, R., Zeman, H.D., Thompson, A.C., Otis, J.N., Brown, G.S., Giacomini, J.C., Gordon, H.J., Kernoff, R.S., Harrison, D.C., and Thomlinson, W. Transvernous Coronary Angiography in Humans Using Synchrotron Radiation. Proc. Nat'l. Acad. Sci. USA 839724 (1986)

Somers, J.S., Th. Lindner, Surman, M., Bradshaw, A.M., Williams, G.P., McConville, C.F., and Woodruff, D.P. NEXAFS Determination of CO Orientation on a Stepped Platinum Surface. Surface Science 183576 (1987).

Stefan, P.M., Siddons, D.P., and Hastings, J.B. A New Beam Position Monitor for X-ray Synchrotron Radiation Facilities. Nuclear Instruments and Methods, A255 598 (1987).

Thompson, A.C., Zeman, H.D., Otis, J.N., Hofstadter, R., Rubenstein, E., Harrison, D.C., Kemoff, R.S., Giacomini, J. C., Gordon, H.J., Brown, G.S., and Thomlinson, W. Transvenous Coronary Angiography in Dogs Using Synchrotron Radiation. International Journal of Cardiac Imaging, 253 (1987).

Tourillon, G., Fontaine, A., Garrett, R., Sagurton, M., Xu, P., and Williams, G.P. NEXAFS Observations of Ordering and Metallic Like Behavior in Organic Conducting Polymers Grafted on a Pt Surface. Physical Review B35 9863 (1987).

Tourillon, G., Raaen, S., Skotheim, T., Sagurton, M., Garrett, R., and Williams, G.P. A Near Edge X-Ray Absorption Fine Structure Study of the Adsorption of Pyrrole and N-Methylpyrrole on Pr(111). Surface Science 184 L345 (1987).

Wang, Y., Keane, J., and Batchelor, K. Tuning of an RF Cavity With a Loop Inside the Cavity. BNL 39543 Inf. Report, February 1987.

Weilandics, C., Rohrig, N., and Gmur, N.F. Ozone Production at the National Synchrotron Light Source. BNL 39351 Inf. Report, January 1987.

White-DePace, S. and Gmur, N. National Synchrotron Light Source Annual Report 1986. BNL 52045, October 1986.

Williams, G.P. Monochromator Systems, Chapter 19 in Synchrotron Radiation Research: Advances in Surface Science, ed. R. Bachrach Plenum Press (in press).

Williams, G.P. Electron Binding Energies of the Elements, CRC Handbook of Chemistry and Physics, 67th Edition F170 (1987). 